\title{
Trends in Public Perceptions and Preferences on Energy and Environmental Policy
}

Barbara C. Farhar

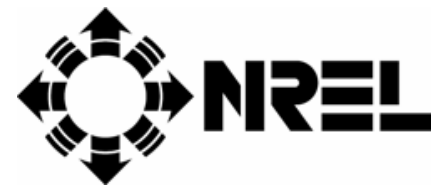

National Renewable Energy Laboratory 1617 Cole Boulevard

Golden, Colorado 80401-3393

Operated by Midwest Research Institute for the U.S. Department of Energy under contract No. DE-AC02-83CH10093 


\section{Trends in Public Perceptions and Preferences on Energy and Environmental Policy}

Barbara C. Farhar

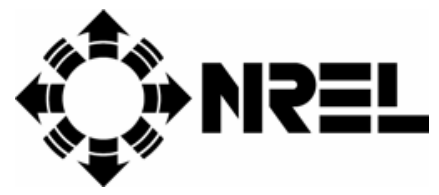

National Renewable Energy Laboratory (formerly the Solar Energy Research Institute) 1617 Cole Boulevard Golden, Colorado 80401-3393

A Division of Midwest Research Institute Operated for the U.S. Department of Energy under contract No. DE-AC02-83CH10093

Prepared under Task No. AS026105

February 1993 


\section{NOTICE}

This report was prepared as an account of work sponsored by an agency of the United States government. Neither the United States government nor any agency thereof, nor any of their employees, makes any warranty, express or implied, or assumes any legal liability or responsibility for the accuracy, completeness, or usefulness of any information, apparatus, product, or process disclosed, or represents that its use would not infringe privately owned rights. Reference herein to any specific commercial product, process, or service by trade name, trademark, manufacturer, or otherwise does not necessarily constitute or imply its endorsement, recommendation, or favoring by the United States government or any agency thereof. The views and opinions of authors expressed herein do not necessarily state or reflect those of the United States government or any agency thereof. 


\section{Acknowledgments}

This study was conducted in the Analytic Studies Division of the National Renewable Energy Laboratory (NREL). It was sponsored by the Office of Planning and Assessment, Office of Conservation and Renewable Energy, U.S. Department of Energy (DOE).

This study would not have happened without the support of numerous staff at the DOE and NREL. These include at DOE-Kenneth G. Moore, Fred Abel, Eric Petersen; at NREL-Walter Short, Tom Bath, Alyssa Tonelli, Kay Vernon, Noni Strawn, Becky Baldwin, Vickie Laus, Page Parker, Mary-Margaret Coates, DeLynn Anderson, Janet Fried, Pat Haefele, Ann Hanson, Stacy Lyon, Lisa Shertz, Tom Skubal, and Joe Woodburn. Others who supported the work in a variety of ways include, in addition to many members of the author's family, Mary Alice Campbell, Joseph E. Cater, III, Sarah Kirchen, Binny Martinson, Sherrie Peale, and Rebecca Vories.

Special thanks are expressed to the central members of the project team-Mary Anne Dunlap, Nancy Greer, Irene Medina, and Catriona MacKirnan, for their patient, dedicated, and professional support of the project. Special thanks are also given to Fred Abel, the Project's Program Manager at DOE, for his unfailing encouragement and support.

The following individuals reviewed the entire manuscript, or portions of it, and offered numerous helpful suggestions and comments: Tom Bath, NREL; William Babiuch, NREL; Stan Bull, NREL; Nancy Carlisle, NREL; Ken Friedman, Office of Industrial Technologies, DOE; Mark Friedrichs, Office of Domestic and International Energy Policy, DOE; Howard Geller, American Council for an EnergyEfficient Economy; Richard Jones, Office of Building Technologies, DOE; John Maples, Oak Ridge National Laboratory; Bonnie Maas Morrison, University of Minnesota; Dan Packey, NREL; Phil Patterson, Office of Transportation Technologies, DOE; Elizabeth Peelle, Oak Ridge National Laboratory; Kevin Porter, NREL; and Griffin Thompson, NREL. They contributed substantially to the report. Any inaccuracies are the responsibility of the author.

This work is dedicated to energy and environmental policymakers and analysts everywhere. 


\begin{abstract}
This report presents selected results from a secondary analysis of public opinion surveys, taken at the national and state/local levels, relevant to energy and environmental policy choices. The data base used in the analysis includes some 2000 items from nearly 600 separate surveys conducted between 1979 and 1992. Answers to word-for-word questions were traced over time, permitting trend analysis. Patterns of response were also identified for findings from similarly worded survey items. The analysis identifies changes in public opinion concerning energy during the past 10 to 15 years.
\end{abstract}

Among the many questions the report addresses are the following:

1. What are the public's perceptions about the link between energy consumption and environmental problems such as global climate change?

2. How much is the public willing to pay to protect and improve the environment? To change the energy production infrastructure? To change patterns of energy consumption in buildings and in transportation? Under what circumstances are they willing to pay it?

3. Does the public link externalities such as environmental damage and the Gulf war with energy policy?

4. How actively involved in recycling is the public? What are their preferences regarding municipal solid waste facilities?

5. How has the public's definition of the energy situation changed over the last 15 years? "Energy situation" includes perceived severity of the energy problem, its salience, future expectations, and perceived impacts.

6. What is the reputation of the major energy institutions in the United States-oil companies, utility companies, automobile manufacturers, and the U.S. Department of Energy? How credible are they?

7. What are the public's preferences about energy supply and demand alternatives? Does the public prefer policies that emphasize reducing demand or increasing supply?

8. What are public preferences regarding electricity generation, particularly using coal and nuclear energy?

9. What has the public reported doing to increase residential and transportation efficiency and the use of renewables?

10. What are the public's policy preferences about energy use in buildings? In transportation?

These and other questions are answered insofar as available public opinion data can shed light on them. Changes in perspective over the last 10 to 15 years are presented. 


\section{Contents}

Page

Executive Summary $\ldots \ldots \ldots \ldots \ldots \ldots \ldots \ldots \ldots \ldots \ldots \ldots \ldots \ldots \ldots$

Chapter 1. Introduction $\ldots \ldots \ldots \ldots \ldots \ldots \ldots \ldots \ldots \ldots \ldots \ldots \ldots \ldots \ldots \ldots$

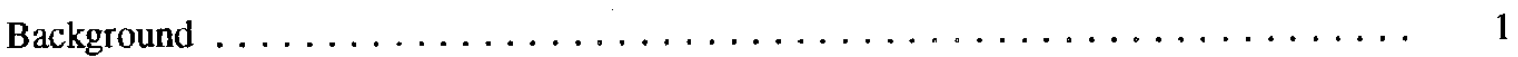

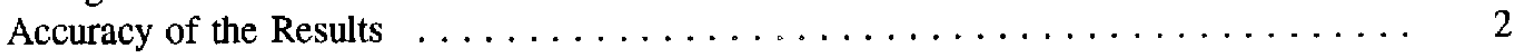

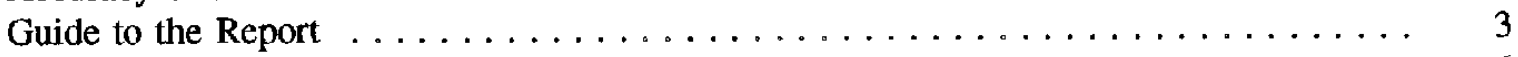

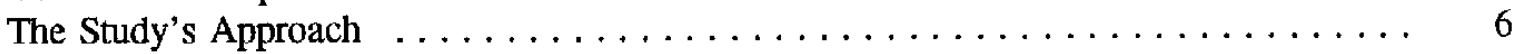

Chapter 2. Energy and Environment $\ldots \ldots \ldots \ldots \ldots \ldots \ldots \ldots \ldots \ldots \ldots \ldots \ldots$

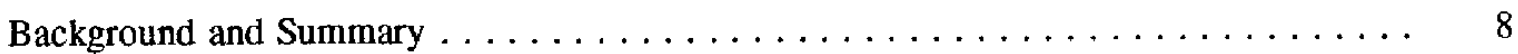

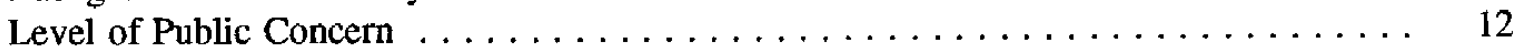

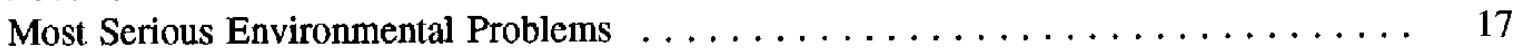

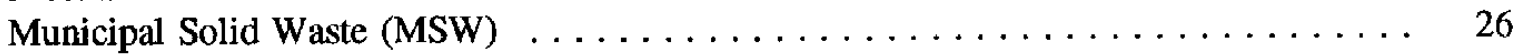

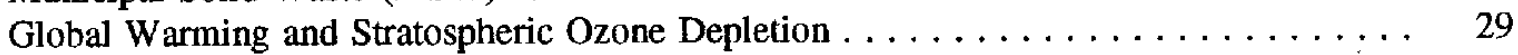

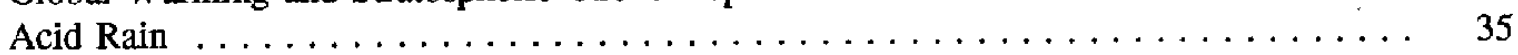

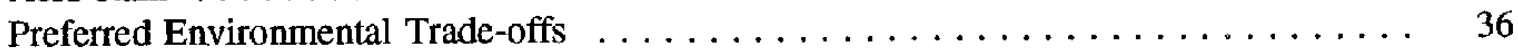

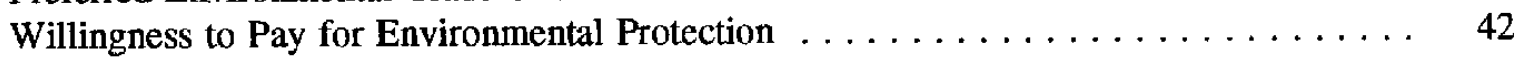

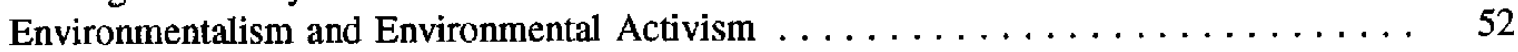

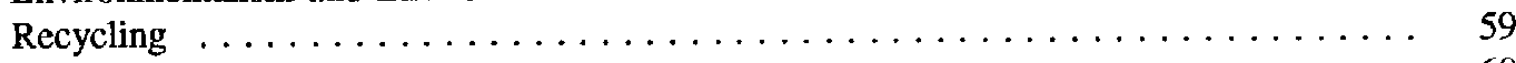

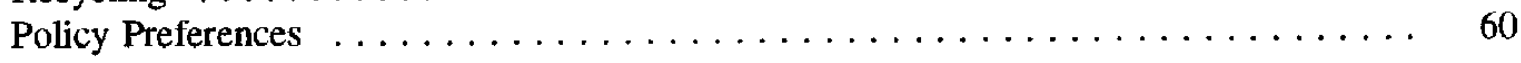

Chapter 3. The 1991 Gulf $\operatorname{War} \ldots \ldots \ldots \ldots \ldots \ldots \ldots \ldots \ldots \ldots \ldots \ldots \ldots \ldots \ldots$

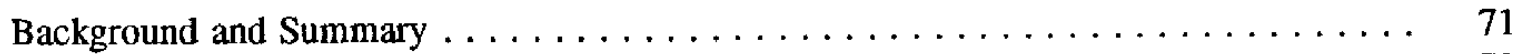

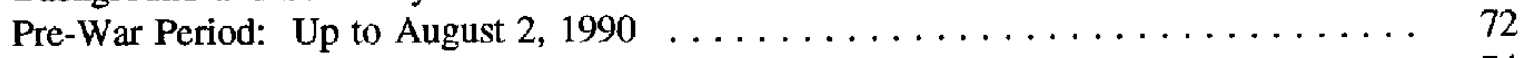

Interim Period: August 2, 1990 , to January $16,1991 \ldots \ldots \ldots \ldots \ldots \ldots \ldots \ldots$

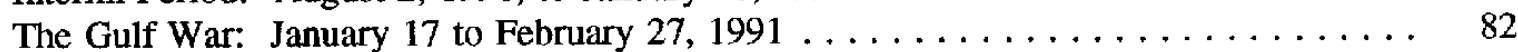

Post-War Period: After February $27,1991 \ldots \ldots \ldots \ldots \ldots \ldots \ldots$

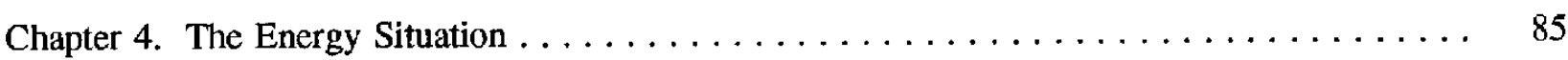

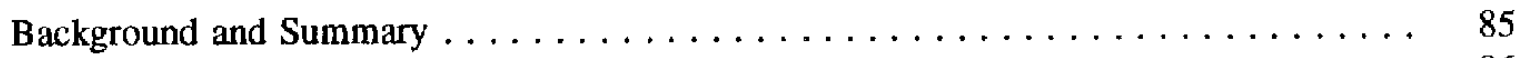

Perceived Severity of the Energy Situation $\ldots \ldots \ldots \ldots \ldots \ldots \ldots \ldots \ldots \ldots$

Perceptions about the Future Energy Situation: National Security $\ldots \ldots \ldots \ldots \ldots \ldots$

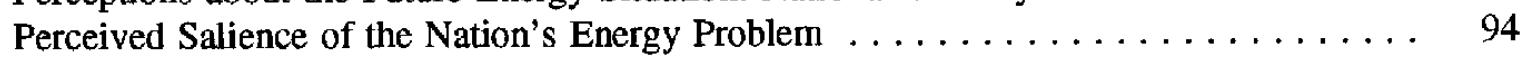

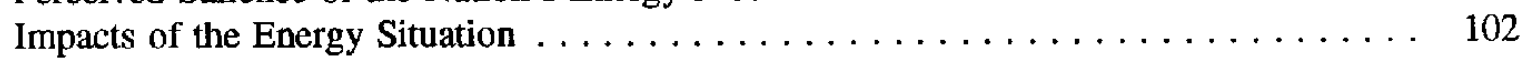

Chapter 5. Energy Institutions $\ldots \ldots \ldots \ldots \ldots \ldots \ldots \ldots \ldots \ldots \ldots \ldots \ldots \ldots \ldots$

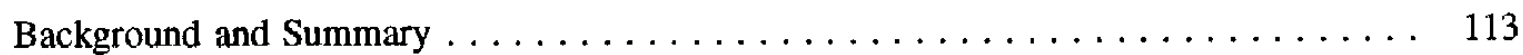

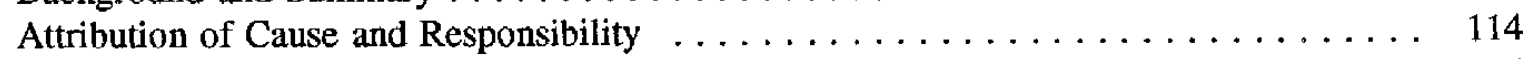

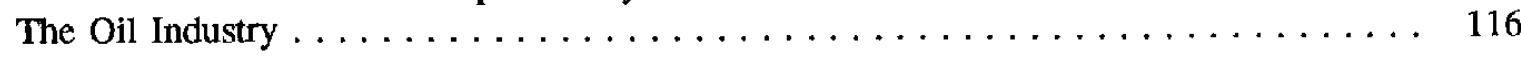




\section{Contents (Continued)}

$\underline{\text { Page }}$

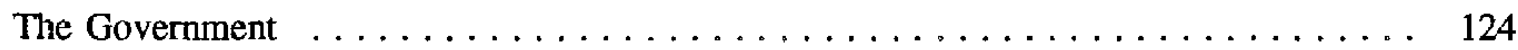

Electric Utility Companies . . . . . . . . . . . . . . . . . . . . . 127

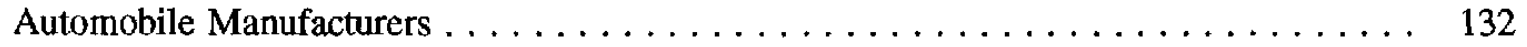

Chapter 6. Energy Alternatives $\ldots \ldots \ldots \ldots \ldots \ldots \ldots \ldots \ldots \ldots \ldots \ldots \ldots$

Background and Summary $\ldots \ldots \ldots \ldots \ldots \ldots \ldots \ldots \ldots \ldots \ldots \ldots \ldots$

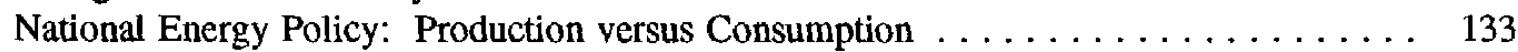

Comparisons among Energy Alternatives $\ldots \ldots \ldots \ldots \ldots \ldots \ldots \ldots \ldots \ldots \ldots \ldots$

Chapter 7. The Utility Sector $\ldots \ldots \ldots \ldots \ldots \ldots \ldots \ldots \ldots \ldots \ldots \ldots \ldots \ldots$

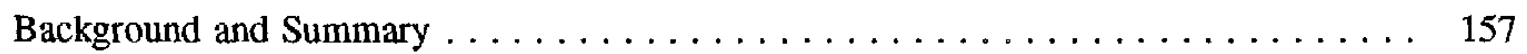

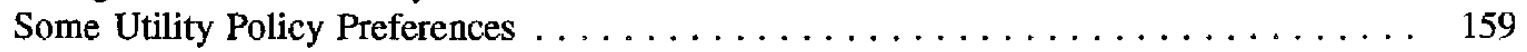

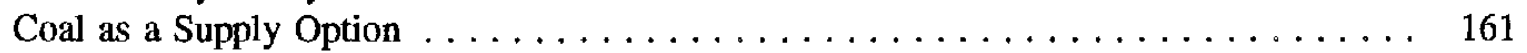

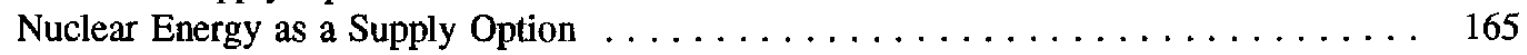

Chapter 8. Efficiency and Renewables in Buildings $\ldots \ldots \ldots \ldots \ldots \ldots \ldots \ldots \ldots$

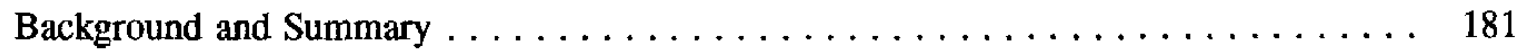

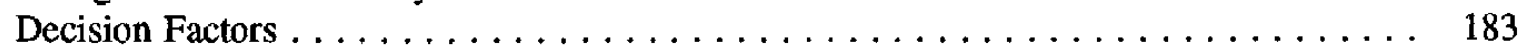

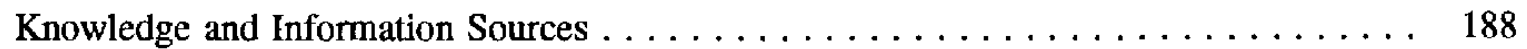

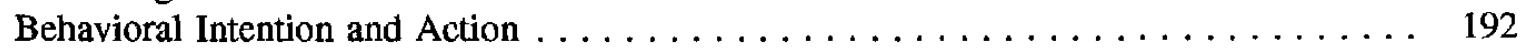

Policy Preferences $\ldots \ldots \ldots \ldots \ldots \ldots \ldots \ldots \ldots \ldots \ldots \ldots \ldots$

Chapter 9. Efficiency and Renewables in Transportation . . . . . . . . . . . . . . . . 202

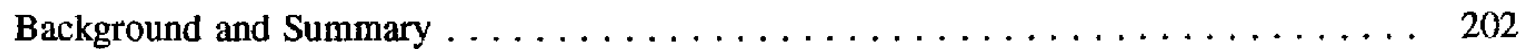

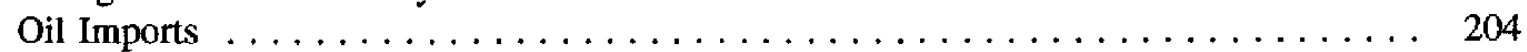

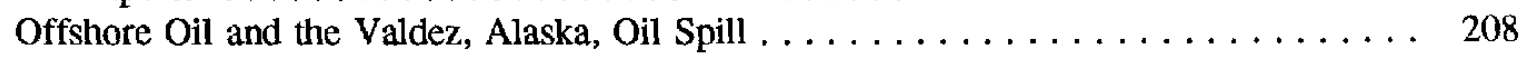

Gasoline Conservation ................................ 210

Alternative Fuels and Vehicles . . . . . . . . . . . . . . . . . . . 219

Chapter 10. Transportation Efficiency Policy Preferences . . . . . . . . . . . . . . . 229

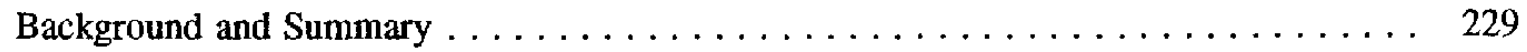

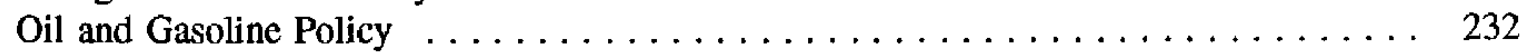

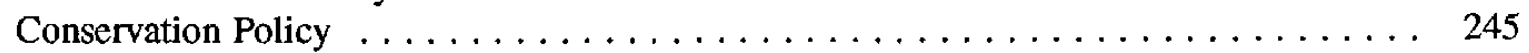

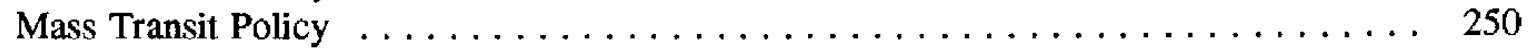

Alternative Fuels and Alternative Fuel Vehicle Policy $\ldots \ldots \ldots \ldots \ldots \ldots \ldots \ldots 2$

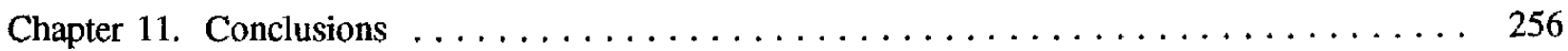

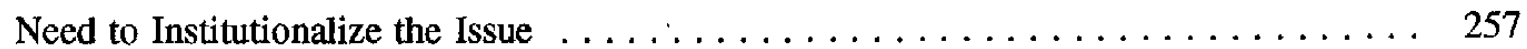

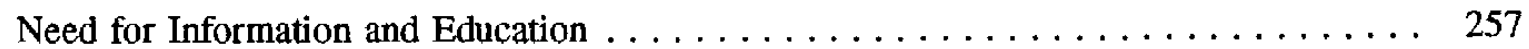

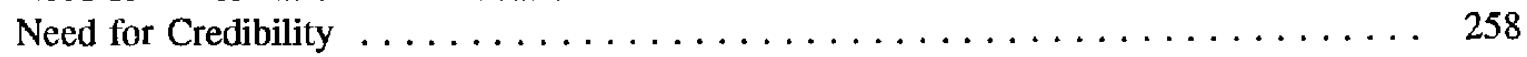




\section{Contents (Continued)}

Bibliography $\ldots \ldots \ldots \ldots \ldots \ldots \ldots \ldots \ldots \ldots \ldots \ldots \ldots \ldots \ldots \ldots \ldots \ldots$

Appendix A: Methodology . . . . . . . . . . . . . . . . . . . . . . 295

Appendix B: Public Opinion Surveys Included in the Study $\ldots \ldots \ldots \ldots \ldots \ldots \ldots \ldots \ldots$

Appendix C: State Financial Incentives for Renewable Energy Systems . . . . . . . . . . . . 329

Appendix D: Wording for Items that Asked about Increasing the Gasoline

Tax (Table 10-1) . . . . . . . . . . . . . . . . . . . 333

Appendix E: Item Wording for Table $7-2 \ldots \ldots \ldots \ldots \ldots \ldots \ldots \ldots \ldots \ldots \ldots \ldots \ldots$

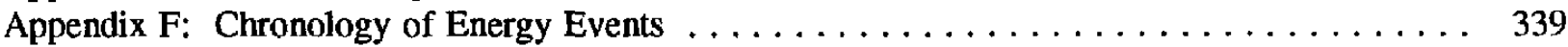

Appendix G: Item Wording for Table 2-4 Response Categories $\ldots \ldots \ldots \ldots \ldots \ldots \ldots \ldots \ldots$

Appendix $\mathrm{H}$ : Miscellaneous Policy Preference Items $\ldots \ldots \ldots \ldots \ldots \ldots \ldots \ldots$

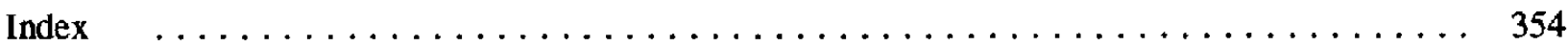




\section{List of Figures}

$\underline{\text { Page }}$

1. Trends in perceived environmental quality $\ldots \ldots \ldots \ldots \ldots \ldots \ldots \ldots \ldots \ldots$ xvii

2. Trends in preferences for environmental protection versus adequate

energy . . . . . . . . . . . . . . . . . . . . . . . . . . xviii

3. Preferred balance between economic growth and preserving nature, $1990 \ldots \ldots \ldots$ xix

4. Trends in preferences for amount of environmental regulation, $1973-1990 \ldots \ldots \ldots \ldots \ldots \ldots$. . . . . . . . . . . . . . . . . . . . . . . . . .

5. Comparison of general public and public interest and energy industry leader preferences on environmental trade-offs . . . . . . . . . . . . .

6. Trends in perceived severity of the U.S. energy situation, $1979-1991 \ldots \ldots \ldots \ldots$. . . . . . . .

7. Trends in anticipated near-term energy shortages $\ldots \ldots \ldots \ldots \ldots \ldots \ldots \ldots \ldots$

8. Trends in public preferences on regulating oil and gas prices of gasoline,

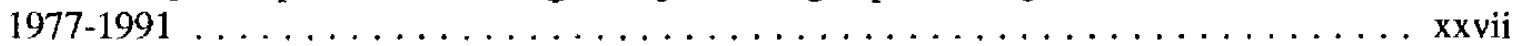

9. Preferences for efficiency or more power plants $\ldots \ldots \ldots \ldots \ldots \ldots \ldots \ldots \ldots$ xix

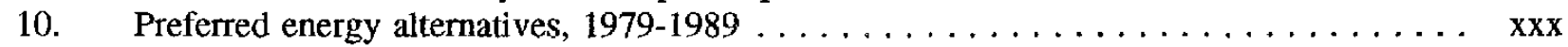

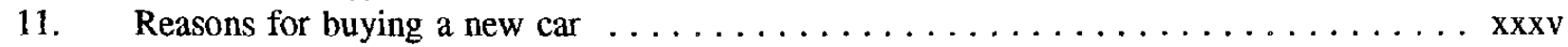

2-A. Trends in perceived environmental quality $\ldots \ldots \ldots \ldots \ldots \ldots \ldots \ldots \ldots \ldots \ldots$

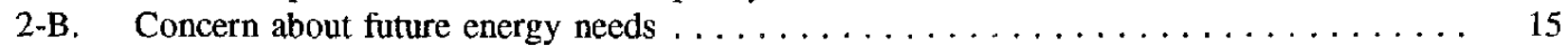

2-C. Environmental concerns viewed as important, $1989 \ldots \ldots \ldots \ldots \ldots \ldots \ldots \ldots$

2-D. Composition of U.S. municipal solid waste, $1988 \ldots \ldots \ldots \ldots \ldots \ldots \ldots \ldots \ldots$

2-E. Trends in preferences for environmental protection versus adequate

2-F. Comparison of general public and public interest and energy industry leader preferences on environmental trade-offs . . . . . . . . . . . . . . . 41

2-G. Preferred balance between economic growth and preserving nature, $1990 \ldots \ldots \ldots \ldots$

2-H. Preferred energy/environment trade-offs, $1991 \ldots \ldots \ldots \ldots \ldots \ldots \ldots \ldots \ldots \ldots$

2-I. Trends in preferences for amount of envirnomental regulation,

4-A. Trends in perceived severity of the U.S. energy situation,

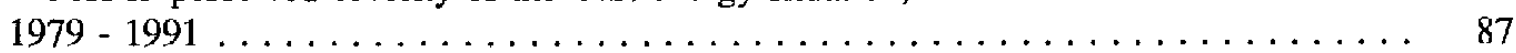

4-B. Trends in anticipated near-term energy shortages $\ldots \ldots \ldots \ldots \ldots \ldots \ldots \ldots$

4-C. Trends in perceived dependence on foreign oil $\ldots \ldots \ldots \ldots \ldots \ldots \ldots \ldots \ldots \ldots$

4-D. Trends in anticipated future energy crises $\ldots \ldots \ldots \ldots \ldots \ldots \ldots \ldots \ldots \ldots$

5-A. Trends in favorability toward the U.S. oil industry by gasoline prices,

6-A. Preferences for efficiency or more power plants $\ldots \ldots \ldots \ldots \ldots \ldots \ldots \ldots$

6-B. Preferred energy alternatives, $1979-1989 \ldots \ldots \ldots \ldots \ldots \ldots \ldots \ldots \ldots \ldots \ldots$

6-C. Funding priority of energy resources $\ldots \ldots \ldots \ldots \ldots \ldots \ldots \ldots \ldots \ldots \ldots$

6-D. Preferred energy alternatives, $1990 \ldots \ldots \ldots \ldots \ldots \ldots \ldots \ldots \ldots$

6-E. Electricity supply alternatives by level of perceived environmental ${ }_{\text {threat } \ldots \ldots \ldots \ldots \ldots \ldots \ldots \ldots \ldots \ldots \ldots \ldots \ldots \ldots \ldots \ldots \ldots \ldots \ldots \ldots \ldots \ldots \ldots \ldots}$

7-A. Percentages of fuels used to generate electricity in $1990 \ldots \ldots \ldots \ldots \ldots \ldots$

7-B. Trends in preferences for burning of coal to generate additional

7-C. Trends in favorability to increased coal burning, $1978-1991 \ldots \ldots \ldots \ldots \ldots \ldots$

7-D. Trends in favorability and opposition toward nuclear energy $\ldots \ldots \ldots \ldots \ldots$ 


\section{List of Figures (Continued)}

$\underline{\text { Page }}$

7-E. Trends in preferences concerning continuing to build nuclear power plants, $1979-1986 \ldots \ldots \ldots \ldots \ldots \ldots \ldots$. . . . . . . . . . . . . . . . . 173

7-F. Trends in perceived risk of nearby nuclear power facility, $1973-1990 \ldots \ldots \ldots \ldots 174$

7-G. Perceived right of the federal government to establish nuclear waste sites . . . . . . . . . . . . . . . . . . . . . . . . . . 176

7-H. Preference on the number of safety hearings required before nuclear power plant construction is allowed $\ldots \ldots \ldots \ldots \ldots \ldots \ldots \ldots \ldots \ldots \ldots \ldots \ldots$

9-A. Preferences for new oil drilling in California, Florida, and the Alaska National Wildlife Refuge, $1990 \ldots \ldots \ldots \ldots \ldots \ldots \ldots \ldots \ldots \ldots \ldots$

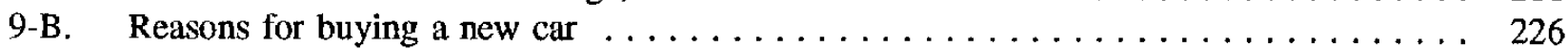

10-A. Trends in public preferences on regulating oil and gas prices of gasoline, 1977-1991 


\section{List of Tables}

Page

2-1. Trends in Perceived Environmental Quality, $1983-1990 \ldots \ldots \ldots \ldots \ldots \ldots \ldots$

2-2. Concern about Future Energy Needs by Region $\ldots \ldots \ldots \ldots \ldots \ldots \ldots \ldots$

2-3. Perceived Severity of Environmental Problems, U.S. and World

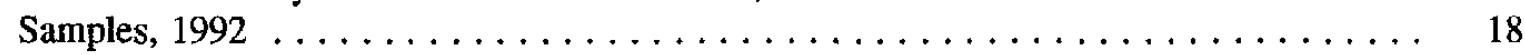

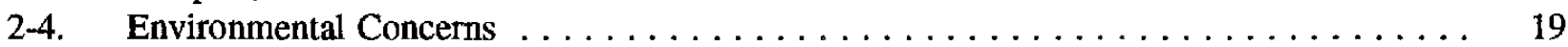

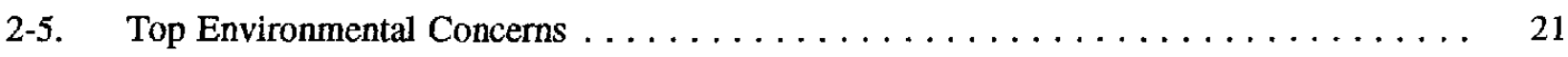

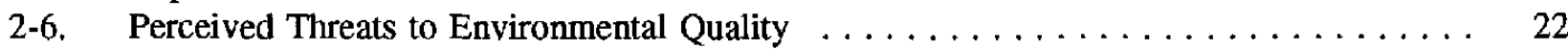

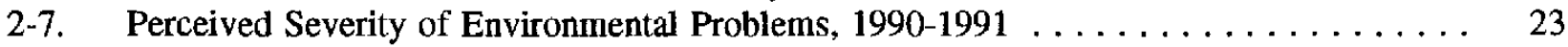

2-8. Trends in Perceived Resource Depletion, 1981-1991 . . . . . . . . . . . . . . 25

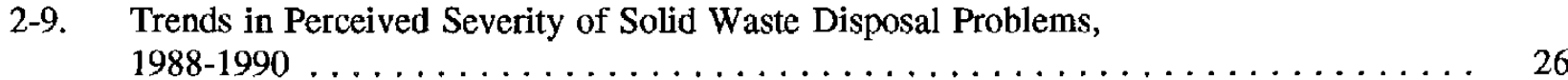

2-10. Trends in Concern about the Greenhouse Effect, $1989-1991 \ldots \ldots \ldots \ldots \ldots \ldots$

2-11. Trends in Preference for Environmental Protection versus Adequate

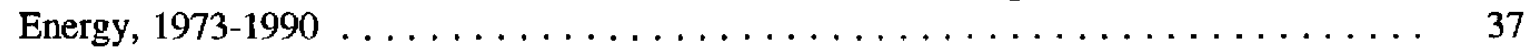

2-12. Trends in Preferred Spending on the Environment and Energy . . . . . . . . . 38

2-13. Trends in Preferred Policies to Protect the Environment Despite Economic Costs . . . . . . . . . . . . . . . . . . . . . . . . . . . 40

2-14. Dependence on Foreign Oil versus Environment Trade-Offs $\ldots \ldots \ldots \ldots \ldots$

2-15. Willingness to Pay More Taxes for Solving Major Environmental Problems . . . . . . . . . . . . . . . . . . . . . . . . . . 44

2-16. Additional Amount Willing to Pay for Fuel That Significantly

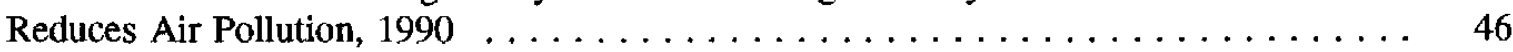

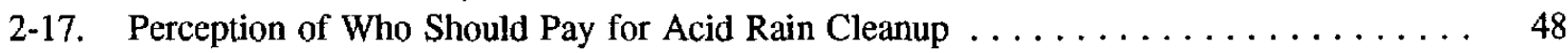

2-18. Trends in Preferred Trade-offs for Air Pollution Regulation . . . . . . . . . . . . 49

2-19. Additional Amount Willing to Pay for a Car That Significantly

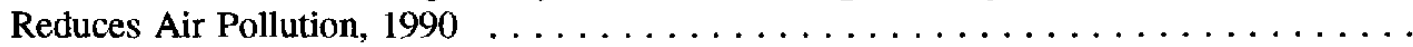

2-20. Founding Date, Membership, and Budget of Major U.S. Environmental

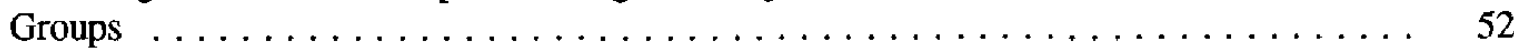

2-21. Perception of Efforts to Protect the Environment, $1990 \ldots \ldots \ldots \ldots \ldots \ldots \ldots \ldots$

2-22. Perceived Reasons for Protecting the Environment, $1990 \ldots \ldots \ldots \ldots \ldots$

2-23. Attitudes toward Technology and Environmental Protection $\ldots \ldots \ldots \ldots \ldots \ldots$

2-24. Trends in Reported Recycling Behavior, 1989-1990 . . . . . . . . . . . . . . 61

2-25. Self-Reported Recycling Behavior in New Mexico, $1990 \ldots \ldots \ldots \ldots \ldots \ldots$

2-26. Trends in Preferences for Amount of Environmental Regulation . . . . . . . . . 63

2-27. Preferred Policy Trade-offs in Environmental Protection Policies . . . . . . . . . . 65

2-28. Preferences in Dealing with Municipal Solid Waste, $1988-1990 \ldots \ldots \ldots \ldots \ldots 6$

2-29. Trends in Preferences for Community Approaches to Solid Waste,

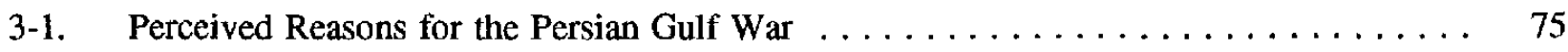

3-2. Evaluation of Reasons for Going to War in the Persian Gulf . . . . . . . . . . 77

3-3. Actions That People Believe Could Have Avoided the Gulf War . . . . . . . . . . 81

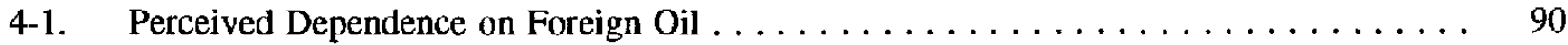

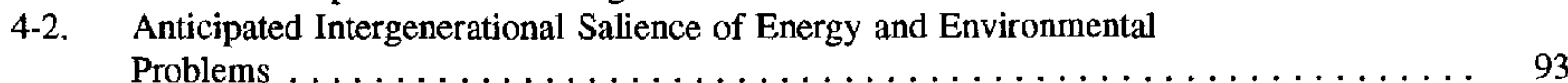

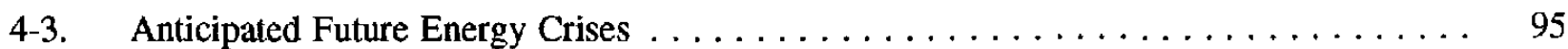

4-4. Perceived Salience of Domestic Goals $\ldots \ldots \ldots \ldots \ldots \ldots \ldots \ldots \ldots \ldots$

4-5. Perceptions of Society's Problems $\ldots \ldots \ldots \ldots \ldots \ldots \ldots \ldots \ldots \ldots$ 


\section{List of Tables (Continued)}

$\underline{\text { Page }}$

4-6. Perceptions of Money Spent on Increasing the Nation's Energy Supply . . . . . . . . 99

4-7. Preference for Levels of Federal Funding on National Problems $\ldots \ldots \ldots \ldots \ldots$

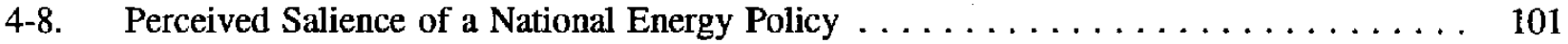

4-9. Percentages Perceiving Gasoline Price Increases, $1987-1990 \ldots \ldots \ldots \ldots \ldots 2$

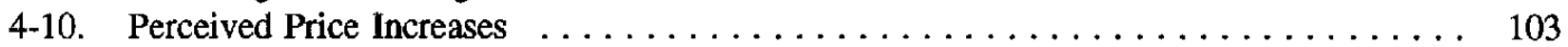

4-11. Perceived Impacts of Oil Price Declines on the Economy . . . . . . . . . . . . . . . . 104

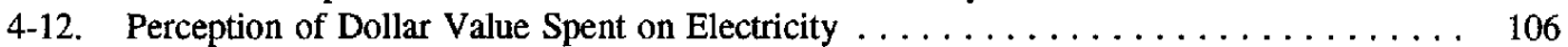

4-13. Expectations for Future Gasoline Prices $\ldots \ldots \ldots \ldots \ldots \ldots \ldots \ldots \ldots \ldots$

4-14. Perceived Impacts of 1986 Oil Price Decreases $\ldots \ldots \ldots \ldots \ldots \ldots \ldots \ldots \ldots$

4-15. Perception of the Cost of Utilities $\ldots \ldots \ldots \ldots \ldots \ldots \ldots \ldots \ldots$

4-16. Consumer Price Expectations, $1981 \ldots \ldots \ldots \ldots \ldots \ldots \ldots \ldots \ldots \ldots \ldots \ldots$

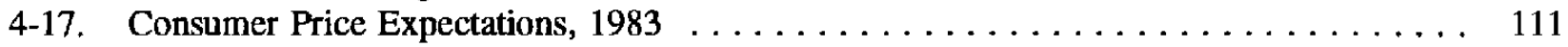

4-18. Consumer Price Expectations, $1984 \ldots \ldots \ldots \ldots \ldots \ldots \ldots \ldots \ldots \ldots \ldots \ldots \ldots \ldots$

5-1. Trends in Attribution of Responsibility for the Energy Situation, 1974-1990 . . . . . . . . . . . . . . . . . . . . . . . . . . . . . . . . . . .

5-2. Perception of Effectiveness of Various Groups in Causing or Avoiding

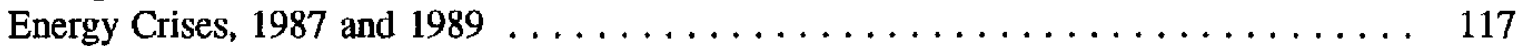

5-3. Trends in Favorability toward Automobile and Oil Industries . . . . . . . . . . . . . 119

5-4. Perception of Quality, Innovation, and Value of Oil Industry and Automobile Industry Products and Services . . . . . . . . . . . . . . . .

5-5. Perception of the Oil and Electric Utility Industries' Interest in the

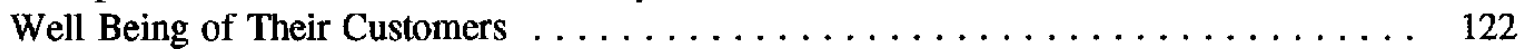

5-6. Perceptions of Oil Company Profits $\ldots \ldots \ldots \ldots \ldots \ldots \ldots \ldots \ldots \ldots \ldots$

5-7. Perceptions of Oil Industry Exploitation of the Persian Gulf

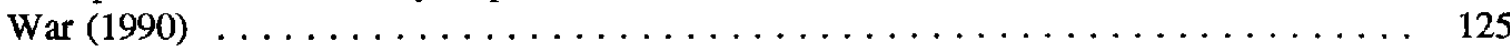

5-8. Trends in Favorability toward Federal Agencies, Including the

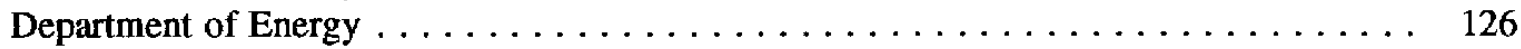

5-9. Favorability toward Energy Industries, $1979-1983 \ldots \ldots \ldots \ldots \ldots \ldots \ldots \ldots$

6-1a. Most Preferred Energy Policies to Decrease Demand and Increase Production . . . . . . . . . . . . . . . . . . . . . . . . . . 136

6-1b. Least Preferred Energy Policies to Decrease Demand and Increase Production . . . . . . . . . . . . . . . . . . . . . . . . . . 137

6-2. Policy Preferences: Increase Supplies or Decrease Demand . . . . . . . . . . . . . 139

6-3. Preferences for Energy Production and Demand Reduction by Region . . . . . . . . 140

6-4. Public and Leader Preferences on Energy Efficiency versus Energy Production . . . . . . . . . . . . . . . . . . . . . . . . . . . . . 141

6-5. Perceptions of U.S. Foreign Policy Goals, 1982 and $1986 \ldots \ldots \ldots \ldots \ldots \ldots$. . . . . . 142

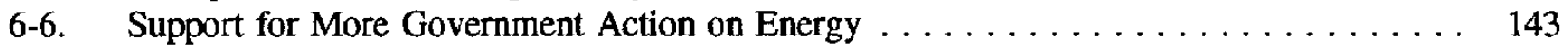

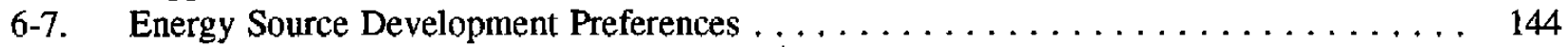

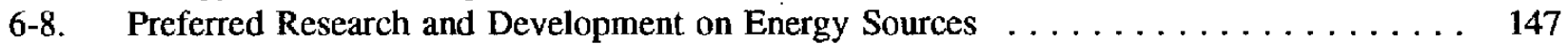

6-9. Preferred Energy Alternatives by Region . . . . . . . . . . . . . . . . . . . . . . 149

6-10. Public Interest and Energy Industry Leaders' Preferences for Future

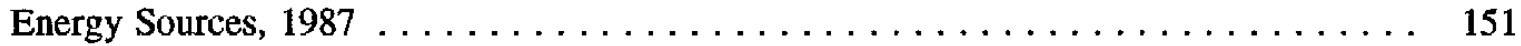

6-11. Perceptions on Future Energy Reliance $\ldots \ldots \ldots \ldots \ldots \ldots \ldots \ldots \ldots \ldots \ldots \ldots \ldots$

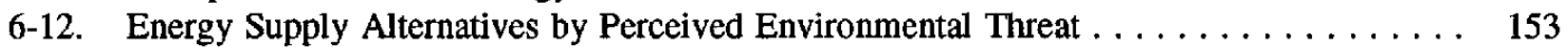

6-13. Levels of Perceived Risks of Nuclear Energy, Natural Gas, Coal, and Oil over Time 


\section{List of Tables (Continued)}

$\underline{\text { Page }}$

7-1. Leaders' Risk-Benefit Assessment of Nuclear Power, $1986 \ldots \ldots \ldots$. . . . . . . . . . 168

7-2. Trends in Favorability toward Nuclear Energy, $1986-1991 \ldots \ldots \ldots \ldots \ldots \ldots \ldots$

7-3. Trends in Perceived Degree of Risk of Living near a Nuclear Power

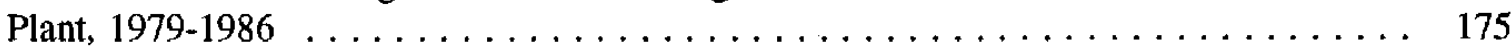

8-1. Perceived Benefits of Residential Solar Use, $1980 \ldots \ldots \ldots \ldots \ldots$. . . . . . . . . 187

8-2. Trends in Perceived Credibility of Energy Information Sources

(West Virginia) . . . . . . . . . . . . . . . . . . . . . . 190

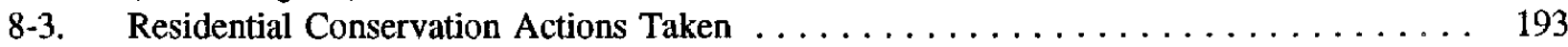

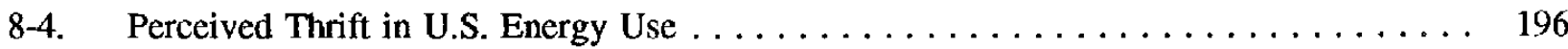

8-5. National Energy Strategy Policy Preferences for Buildings . . . . . . . . . . . . . 198

8-6. Preferred Buildings Policy Options to Protect the Environment . . . . . . . . . . . 200

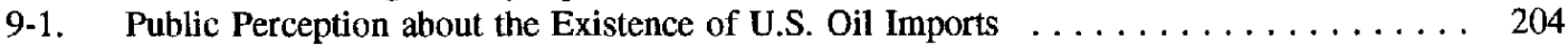

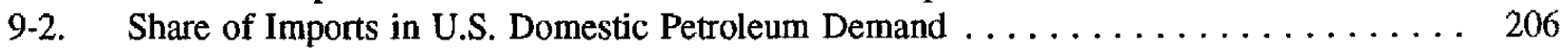

9-3. Public Estimates of Oil Imports to the United States . . . . . . . . . . . . . . . . 207

9-4. Preferences for New Oil Drilling in California, Florida, and the

Alaska National Wildlife Refuge, $1990 \ldots \ldots \ldots \ldots \ldots \ldots \ldots \ldots \ldots \ldots$

9-5. Trends in Reported Changes in Transportation Behavior to Conserve

Fuel (West Virginia Households) . . . . . . . . . . . . . . . . . . . . . 215

9-6. Means of Transportation to Work in the United States, 1980 and $1990 \ldots \ldots \ldots \ldots$

9-7. Awareness of Alternative Fuels by Educational Level, $1990 \ldots \ldots \ldots \ldots$

9-8. Preferences for Alternative Fuels by Gender, $1990 \ldots \ldots \ldots \ldots \ldots \ldots$

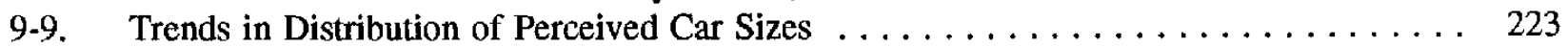

9-10. Trends in Size of Next Car to be Purchased $\ldots \ldots \ldots \ldots \ldots \ldots \ldots \ldots \ldots \ldots$

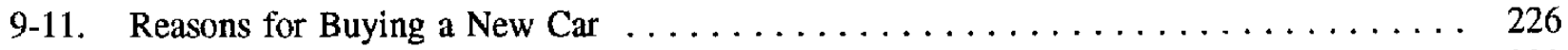

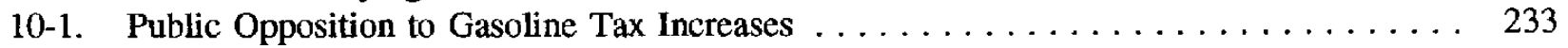

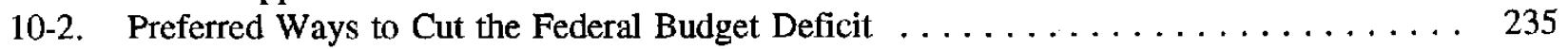

10-3. Trends in Public Preferences on Regulating Oil and Gasoline Prices . . . . . . . . 238

10-4. Preferences for Regulations to Improve Air Quality . . . . . . . . . . . . . . . 244

10-5. Trends in Preferences on Spending for Mass Transit, 1987-1991 . . . . . . . . . . 251

10-6. Preferences for Requiring the Manufacture of Alternative Fuel

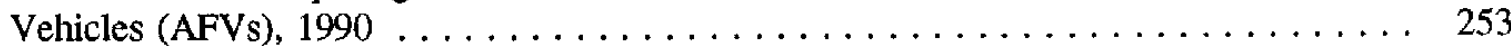


Public sentiment is everything. With public sentiment, nothing can fail; without it, nothing can succeed.

_Abraham Lincoln 
Polling is a form of listening. 


\section{Executive Summary}

\section{Introduction}

In the years since the Arab oil embargo (1973-1974), the public has been on a roller-coaster ride of energy events. On the upside, after the 1973-1980 energy crisis, much of the public seemed reassured by federal policy emphasis on free markets, falling oil and gasoline prices coupled with plentiful supplies, and stabilizing utility bills following deregulation of natural gas prices. The downside of the ride, however, has included events such as Three Mile Island (March 28, 1979), Chernobyl (April 26, 1986), the Valdez oil spill (March 24, 1989), the onset of Operation Desert Shield (August 6, 1990), and the Persian Gulf war (January-February 1991).

Policymakers and economists have long argued that the public would lose interest in energy efficiency and the use of renewable energy technologies as the price of oil stabilized at record low levels (in real dollars) and as utility costs leveled out after dramatic increases in the late 1970s. And some evidence exists that earlier gains in energy conservation in buildings and transportation are being eroded as consumers seem to relax their vigilance toward the energy situation. In the past few years, scientists have stressed the relationship between energy production (particularly the burning of fossil fuels) and potentially serious global climate change resulting from acid rain, stratospheric ozone depletion, and the greenhouse effect. And although the National Energy Strategy, released in February 1991, called for both energy supply- and demand-side actions, the extent to which the public makes any connection between its own and its leaders' energy decisions and actions on the one hand, and environmental degradation on the other hand, remains unclear.

\section{Purposes of the Study}

This review of opinion surveys provides information to help policymakers assess the congruence of energy and environmental policy options with public preferences. It updates an earlier study, published by the National Renewable Energy Laboratory (NREL/formerly the Solar Energy Research Institute), that identified patterns of public opinion about energy published in 1979 (updated in 1980). This new study provides a framework for evaluating public acceptance of policy options such as energy price increases. It helps policymakers to design policies that have a greater potential for public acceptance. The study also provides a comprehensive body of information on public opinion polls in the light of which policymakers can assess the results from any one survey question they encounter in the future. In addition, analysts can use this information to support a variety of projects, such as market assessments.

Understanding perceptions about energy and environmental technologies, policies, and programs forms a framework against which policies that encourage the use of new technologies or pursue other government agendas can be evaluated. Information on the perceived risks of energy-supply alternatives is pertinent to fuel-cycle thinking. Knowing factors that affect consumer decisions on energy-related purchases and lifestyle behaviors can increase the accuracy of market-penetration estimates and aid in modeling the potential for energy technologies. And whether the nation's energy institutions are linked in the public's mind with environmental problems is important information for policymakers seeking to make decisions that accurately reflect the public will. 


\section{The Study's Approach}

This updated secondary analysis of public opinion on energy and environmental policy relies on more data than had been available earlier. Researchers searched the Public Opinion On-Line data base on the DIALOG Information Retrieval Service for items relating to energy, environment, transportation, buildings, and alternative fuels, as well as for specific policy alternatives, such as energy-efficient mortgages. Searches focused on the period 1979 through 1991. Simultaneously, researchers obtained some studies by contacting the 50 state energy offices for energy-related surveys conducted over the past decade. In addition, colleagues at the U.S. Department of Energy (DOE) and NREL supplied studies of which they were aware. Most of the data base of nearly 600 surveys is composed of national probability samples of adults in the United States conducted by major polling organizations. Forty of the surveys involved samplings of adults and other demographic groups or samples at the state or local levels. Some gaps in secondary analysis of survey data exist because key questions simply were not asked. Relevant survey items probably exist that were not located and included in the analysis. Nevertheless, where trends and patterns of findings were established, these would be unlikely to change, even if other data were added.

The balance of this summary, save for the last section, summarizes the results of the empirical analysis. The interpretive conclusions are summarized in the last section.

\section{Energy and the Environment}

Public opinion data linking energy and the environment addressed the following topics: degree of concern people felt, most serious environmental problems perceived, municipal solid waste and waste-to-energy conversion, global warming and stratospheric ozone depletion, acid rain, preferred environmental tradeoffs, willingness to pay for environmental protection, environmentalism and environmental activism, recycling, and general policy preferences.

Level of environmental concern. Environmental concern is on the rise. The number of people believing environmental problems are getting worse has increased substantially in the past 9 years (Figure 1), although one survey reported some recent increased optimism. Opinion is that everyone should be more concerned-the federal government, business and industry, and the public. While still not one of the top three national concerns, the environment appears to be moving in that direction.

Recently, the public has begun to link energy and environmental concerns. According to survey results, environmental harm from energy production is a concern that people are beginning to feel will hurt them personally within 5 years. There is more widespread concern that individuals will be harmed by environmental problems from burning coal and oil than from nuclear power, and from war and strife over energy supplies than from environmental problems caused by the search for new sources of energy.

Most serious environmental problems. The U.S. Environmental Protection Agency lists stratospheric ozone depletion, air pollution from vehicles and industrial plants, and the greenhouse effect and global warming as some of the worst environmental problems. The concerns of the U.S. public mirror this list, although the ranking of importance varies by survey, probably because of differences in item wording. The most important concerns are: air pollution, water pollution, ozone depletion, waste disposal, hazardous waste sites, exposure to toxic chemicals, oil spills, and global climate change. Public concern about oil spills, the greenhouse effect, and ozone depletion increased dramatically between 1988 and 1990 .

Municipal solid waste. Most of the public is aware of waste disposal problems, and a rapidly increasing proportion believes that the problems are "very serious." Many people believe that disposable diapers, plastic packaging, styrofoam, aerosol containers, and plastic bottles constitute disposal problems, although 
"How would you rate the overall quality of the environment compared to how it was 5 years ago?" [1425]

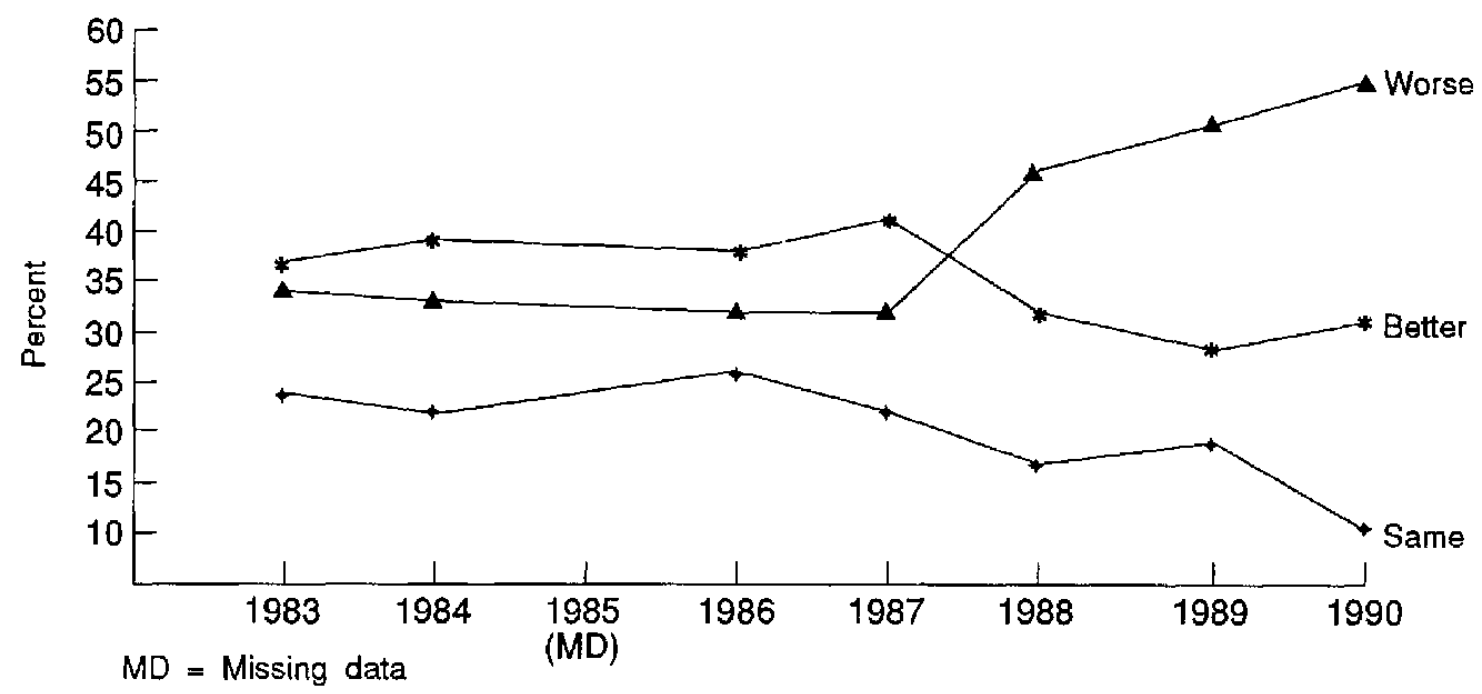

Source: Constructed by author using data from Cambridge Reports/Research International.

Figure 1. Trends in perceived environmental quality

paper products are the most ubiquitous form of solid waste. Disposition of waste through recycling and through waste-to-energy facilities are both favored options, although recycling is the option of choice.

Waste-to-energy. Although majorities of the public favor burning solid waste to produce electricity, the NIMBY ${ }^{1}$ syndrome could be an impediment to siting waste-to-energy conversion facilities. Despite offers to lower property taxes if a waste-to-energy plant were sited within 10 miles, opinion is still divided about it. Concerns about aesthetics, odors, increased truck traffic and noise, a decline in property values, and negative health effects (in this order) were paramount.

Global warming. Most people have heard about global warming, and awareness is increasing. However, understanding of its causes and effects is limited; misconceptions are apparent. The public also does not have a solid understanding of the chlorofluorocarbon problem. The public believes that global warming is a serious environmental threat, and many believe that the ozone hole over the North American continent is certain or very likely to cause skin cancer and other health problems.

Acid rain. A majority of the public appears to be aware of the problem; however, global warming seems to have superseded acid rain as a more pressing environmental concern.

\footnotetext{
${ }^{1}$ NIMBY = the "not-in-my-backyard" syndrome of resistance to local siting of many types of facilities.
} 
Environmental trade-offs. In the late seventies, questions about environmental trade-offs were posed. Currently, the trade-offs seem to be taking three major forms:

1. Environment versus economic development or protection against economic losses

2. Environment versus adequate energy supplies

3. Environment versus national security concerns (dependence on foreign oil).

The proportion favoring environmental protection over adequate energy supplies has been increasing over time; definite majorities now say they favor environmental protection (Figure 2). Majorities in 20 of 22 countries polled, including the United States, now choose protecting the environment over economic growth, although a few of the U.S. respondents stated that such a trade-off is unnecessary. This minority believes that environmental protection and economic development go together-the concept of "sustainable development" (although this term itself has not yet appeared in poil questions). Also, majorities indicate that they would like to see a balance between economic growth and preserving nature, with the emphasis on environmental protection (Figure 3).

Even though majorities now select environmental protection over adequate energy supplies, opinion is more divided on the question of environmental protection versus national security-pluralities tend to favor each side. The pattern of evidence indicates that slightly larger percentages favor environmental protection and see global environmental problems themselves as a security threat.

"Some people say that the progress of this nation depends on an adequate supply of energy and that we have to have it even though it means taking some risks with the environment. Others say the important thing is the environment, and that it is better to risk not having enough energy than to risk spoiling our environment. Are you more on the side of adequate energy or more on the side of protecting the environment?" [1554]

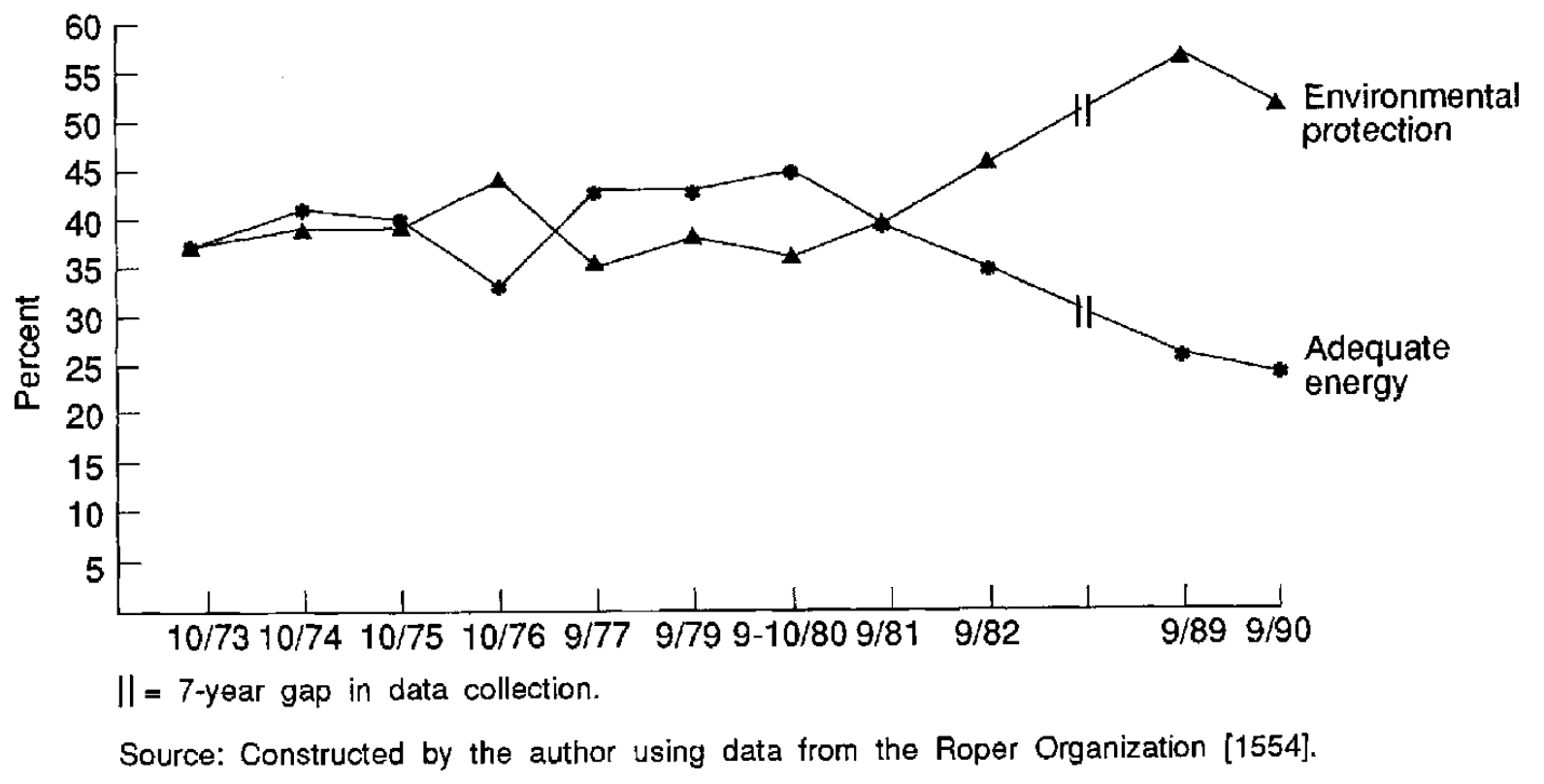

Figure 2. Trends in preferences for environmental protection versus adequate energy 
"Sometimes there is a conflict between economic growth and preserving nature. (Card shown). Here is a list of different views about these two things-economic growth on the one hand and presenving nature on the other. Would you please tell me which one comes closest to your own opinion?"[1552]

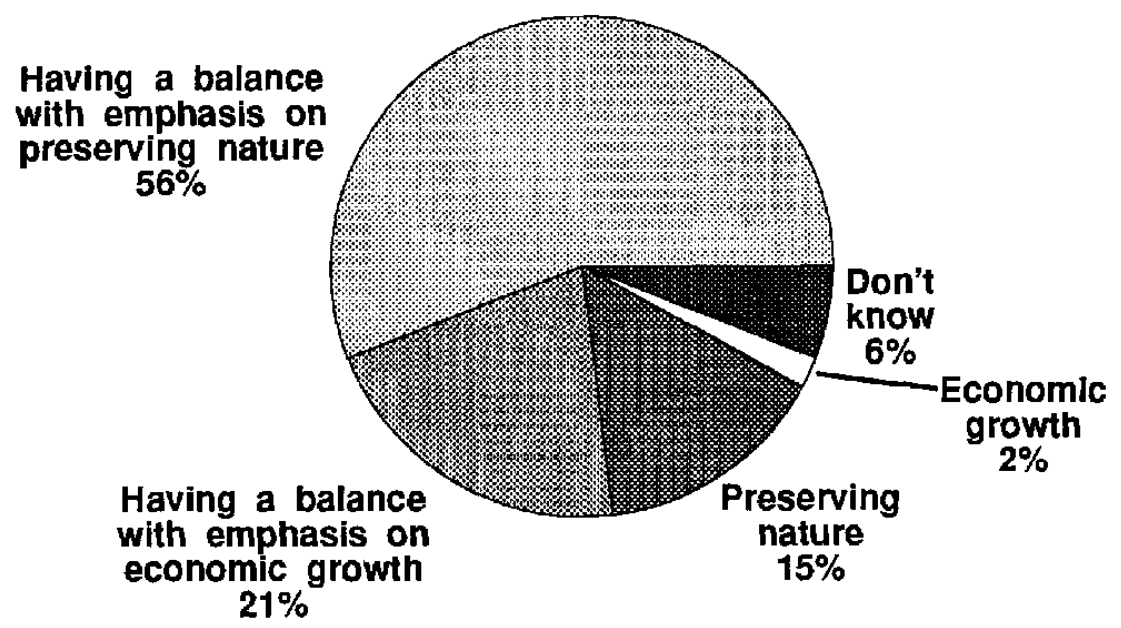

Source: Constructed by author using data from the Roper Organization.

Figure 3. Preferred balance between economic growth and preserving nature, 1990

Willingness to pay for environmental protection. Many survey items asked about people's willingness to pay more for goods and service to protect and improve the environment. The public says that it is willing to pay more-more for oil and gasoline, more for electricity, and more for automobiles to protect the environment-up to a point. People may want to believe that any extra costs they incur are actually used for environmental cleanup and protection. The low levels of credibility of today's energy institutions on environmental issues could, in practice, constitute a major barrier to the public's willingness to pay more.

However, when viewed strictly from people's point of view who say they would be willing to pay, the findings consistently support the environment. Majorities have stated they are willing to pay $15 \%$ more taxes (type unspecified) or $\$ 50$ in more taxes (type and length of time unspecified); proportions of those saying they are willing to pay more are increasing.

Increasing percentages state that they are willing to pay more for electricity if it is produced in a cleaner way that reduces air pollution ("green pricing"). Majorities are willing to pay amounts on the order of $\$ 6$ to $\$ 25$ more per month. When the suggested price increase reaches $\$ 50$ per month, majorities state they are unwilling to pay that much, but around $40 \%$ say that are willing to pay even that much more. Majorities are willing to pay for "stricter air quality regulations" or to "require electrical companies to cut back drastically on sulphur dioxide emissions." And most are also willing to pay more for "the things you buy" if business and industry increased its efforts to improve environmental quality. 
Other trade-offs the public are willing to make to protect the environment include accepting a lower standard of living; almost two-thirds responded positively to this idea. Protecting wilderness areas from energy development is another accepted trade-off. Most believe that environmental cleanup will not harm, or will benefit, the economy.

Environmentalism and activism. Majorities report that they are sympathetic to the environmental movement; about 1 in 10 reports being active in an environmental group. And most of those polled believe that, while regulation is necessary, environmental protection means lifestyle changes and changes in household spending patterns.

Perceived health effects of environmental degradation are a motivating factor in the swing toward environmental awareness. To protect the environment, majorities report that they recycle, buy "green products," avoid products that they believe are harmful to the environment, and conserve their use of energy. The public strongly supports recycling efforts and policies; large majorities favor recycling programs and strict regulations on recycling cans, glass, and newspapers. This is evidenced by the increasing proportions of the public who have recycled and are recycling.

Government is secn has having the most responsibility for environmental protection in the United States; also, citizens' groups and business and industry are seen as having roles to play. However, only about 1 in 10 of those polled believes that the federal government is doing its job as well as it should in environmental protection and pollution cleanup. Two-thirds believe more regulation will be required (Figure 4).

". . At the present time, do you think environmental protection laws and regulations have gone too far, or not far enough, or have struck the right balance?" [1554]

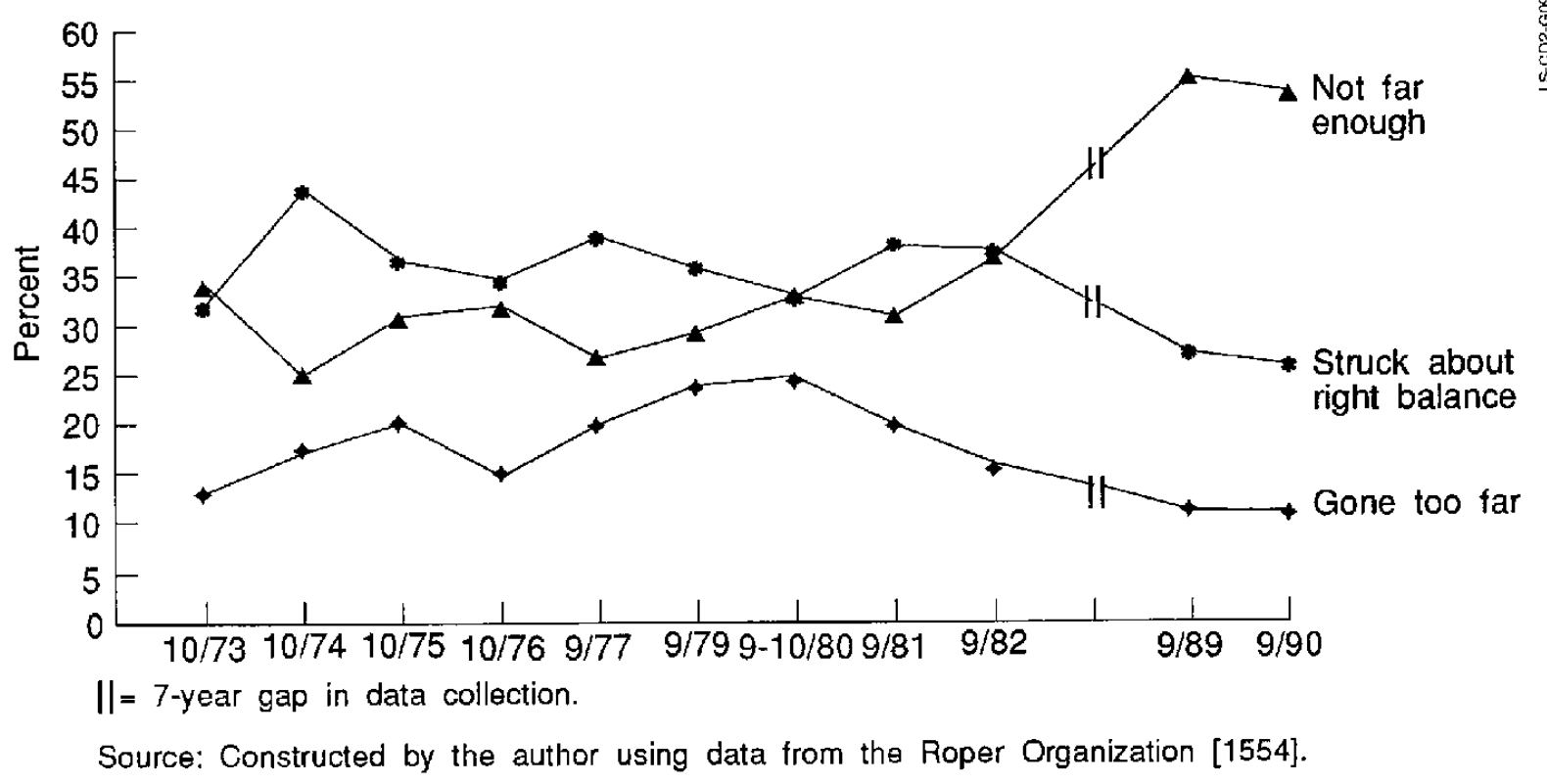

Figure 4. Trends in preferences for amount of environmental regulation, 1973-1990 
Belief that technology will solve environmental problems has declined over the past 10 years. Indeed, approximately one-third believe future scientific research is more likely to cause than to solve environmental problems.

Recycling. Public opinion and action support recycling of an array of materials, including aluminum, glass, plastic, and oil, as an effective means of dealing with solid waste disposal problems. Majorities favor mandatory recycling of certain materials. Recycling generally prevents facility-siting problems (by reducing the need for landfills). Waste-to-energy facilities are also favored and could possibly enjoy even greater public acceptance if coupled with recycling programs. Facility-siting issues would need to be sensitively dealt with to realize the full potential of municipal solid waste (MSW) in dealing with both solid waste disposal and energy needs.

Summary. Despite the public's favorable attitudes toward environmental protection, it has reported relatively little direct action to protect and improve the environment. However, the public is beginning to connect energy use and environmental concern. The problem of energy and the environment is better defined; the public is still working out its thinking on how to approach the solution.

Many say that the United States has spent too little on environmental protection. Some evidence shows that, as late as 1988, public interest and energy industry leaders opposed each others' views on environmental controls to foster energy development. Public interest leaders opposed relaxing such controls; industry leaders were divided, but a majority favored relaxing controls. A majority of the public opposed relaxing environmental controls in favor of energy production (Figure 5).

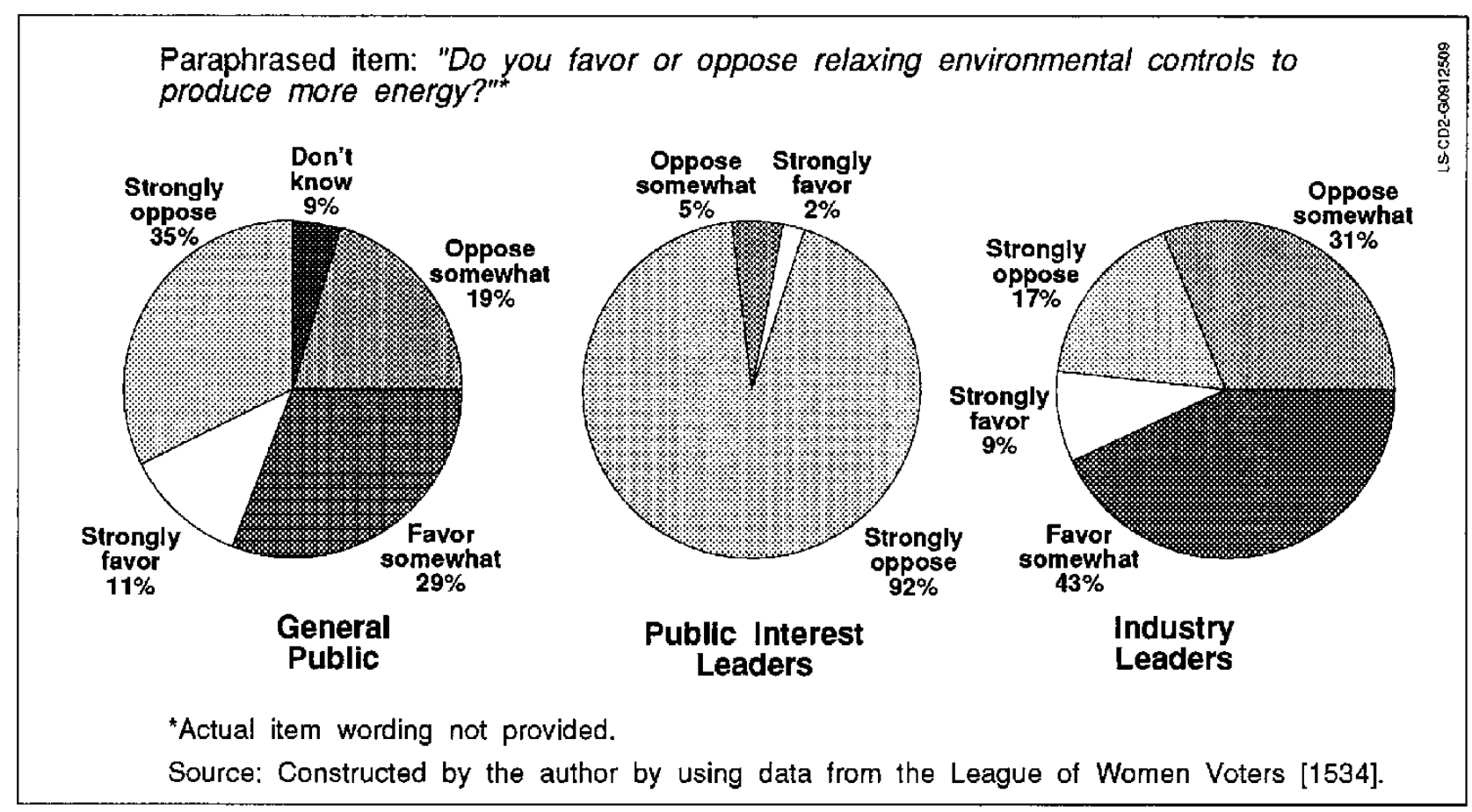

Figure 5. Comparison of general public and public interest and energy industry leader preferences on environmental trade-offs 
The polls asked about numerous policy actions that could be taken to protect and improve the environment. The types of actions that would receive the most public support are:

- $\quad$ Reforestation (a very popular option)

- $\quad$ Recycling programs and policies (these receive broad support)

- Power plant emissions controls and enforcement

- $\quad$ Reduced pollution from automobile emissions even if automobile costs rise

- $\quad$ New safety rules and emergency cleanup teams at oil facilities

- Development of new energy-efficiency measures and solar and wind energy resources

- No drilling in the Alaska National Wildlife Refuge

- Strict controls or limits on nuclear power

- A number of actions on the part of utility companies to protect and improve the environment.

Some environmental protection proposals are less popular. Creating more subcompact cars was not widely favored. Closing polluting factories resulting in job losses was not desired. Emissions trading was probably not well understood, and it was not particularly well liked. ${ }^{2}$ Although a majority in one study favored a "special tax on carbon dioxide" (or a carbon tax), increased gasoline taxes have consistently been opposed. People might oppose paying a carbon tax if they understood that it meant higher gasoline costs; or they might be willing to pay the higher cost if they believed the extra money would be used directly for environmental protection. The U.S. public also opposes the idea of international law overriding U.S. domestic law in dealing with global environmental problems.

\section{The Persian Gulf War}

Relations between the United States and some Middle Eastern countries became tense through problems with Libya, the Iran-U.S. hostage situation, and the Iran-Iraq war. When Iraq invaded Kuwait on August 2, 1990, the U.S. public feared a repeat of the oil shortages of 1973-1974. Many polls monitored public opinion about the Persian Gulf war.

Prior to the war. Before the war, extensive support existed for protecting an uninterrupted supply of oil to the United States and the world, even if military action was required. However, prior to the conflict starting, opinion was divided on the necessity of actually going to war.

After the Iraqi invasion, the primary reasons majorities saw for our troops' presence in the Middle East was to protect U.S. oil sources and to deter Iraqi aggression. Other reasons mentioned during this time were neutralizing Iraq's chemical and nuclear weapons capabilities, overthrowing Saddam Hussein (the Iraqi dictator), and protecting Israel. By and large, the public judged protecting oil supplies as a "good reason" for U.S. military involvement.

Before the war began, although the public feared another gasoline shortage, opinion was somewhat divided on how serious a threat to the nation's oil supply the situation in Kuwait actually was. Majorities expected, and saw, gasoline price increases, which it blamed on oil company greed. Most were also concerned or "upset" about environmental impacts from oil spills and refinery fires set by Iraq in Kuwait. During the war itself, primary justification for the military action shifted toward the moral principle of stopping Iraqi aggression; protecting oil supplies became secondary.

\footnotetext{
${ }^{2}$ Under the Clean Air Act, a utility can emit an amount of pollutants, such as sulfur dioxide, as long as another utility has decreased its sulfur dioxide pollution by the same amount. These "rights to pollute" or allowances can be bought and sold on the open market.
} 
Avoiding the war. When asked how the nation could have avoided going to war, the majority agreed that increased research and development (R\&D) on energy sources other than oil and waging a campaign for energy efficiency and conservation "in autos, homes, offices, and factories" would have helped avoid the war. During the war, $60 \%$ attributed U.S. involvement in the war to "not having a conservation or alternative energy policy in the United States" [1502]. The war polarized those who favored and opposed drilling for oil in protected wilderness areas, even when environmental risks were considered. Many called for peacemaking efforts, but a majority agreed that the United States should not settle for a compromise that would give Iraq any concessions on disputed oil fields.

After the war. After the war, opinion was divided on whether the war made the world's access to Middle East oil more secure. Opinion was also divided on whether the nation should maintain a military presence in the Middle East. Most were aware that the nation's dependence on foreign oil resulted in a military conflict costly in both human lives and monetary resources. Whether the public factors this awareness into its thinking about domestic energy policies, and its energy-use behavior, remains to be seen.

\section{The Energy Situation}

Most people in the late 1970s did not believe there was an energy "crisis," but instead perceived a serious national energy problem. Inflation, unemployment, and crime were the primary public concerns at that time. The nation's energy problem was considered of middling importance, although majorities foresaw future energy shortages and rising energy costs. In fact, many consumers believed the energy situation had been contrived by oil companies for their own benefit.

Perceived severity. Several surveys asked respondents to gauge the seriousness of the nation's energy situation, although there was a gap in the data between 1980 and 1986 . The surprising feature of the data on this question is its consistency. Although the perception of seriousness declined somewhat between 1979 and 1991, it appears to have increased during 1990 and 1991, the period leading up to the Persian Gulf war (Figure 6). In 1991, Gallup reported that $84 \%$ judged the energy situation as "very" or "fairly serious." The energy "roller coaster" seems to have caused people to remain cautious in their assessment of the seriousness of the energy situation. This caution is in evidence despite low gasoline and oil prices, stable utility costs, and plentiful supplies. It may be related to the perception of difficulties that could ensue from heavy U.S. reliance on imported oil.

Energy security. How confident is the public about future energy security? The pattern that emerged from the data was that people were more confident about the adequacy of energy supplies in the relatively short term and less confident about energy security 20 to 50 years out (Figure 7). Confidence in near-term energy security has been increasing. While half of the respondents in 1979 thought that a severe energy shortage was "very likely" within a year, the number dropped from 79\% to 51\% between 1979 and 1989. The proportion increased 17 percentage points, however, between March 1989 and September 1990, probably because of activities in the Persian Gulf at the time.

Conviction that energy will continue to be a long-range problem appears to be increasing. When Research/Strategy/Management (RSM) asked: "Some people say the 'energy crisis' like the United States experienced in the $1970 \mathrm{~s}-$ things like gasoline shortages, sharply higher prices, and oil supply disruptions-will not happen again. Other people say we will once again have periods of energy crisis, just as we did in the 1970s. Which view is closer to your own?" In 1981, 60\% said it will happen again; in 1988 and in 1990, two-thirds said it will happen again. The likelihood that the public will perceive a serious future energy problem seems to increase as the time lengthens.

Salience. The public's ranking in importance of national problems has changed somewhat in the last decade. Currently emerging as the most significant problems are: (1) the state of the U.S. and local 
Prototypical item wording: "How serious would you say the energy situation is in the United States - very serious, fairly serious, or not at all serious?"

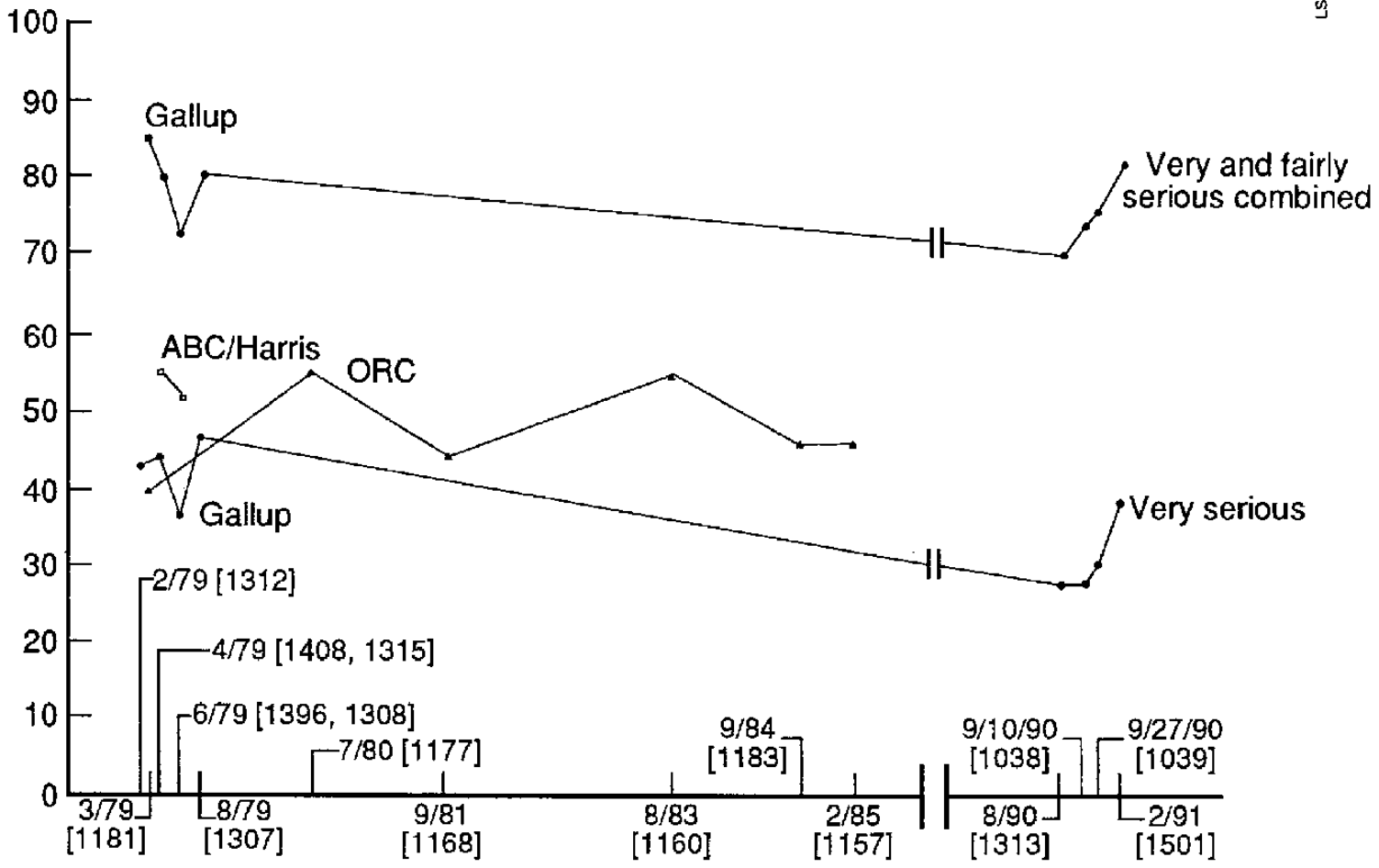

Source: Constructed by author using data from Gallup, Opinion Research Corporation, and $A B C$ News/Harris.

Notes: $-1 \models$ represents a significant break in time.

Study numbers are in brackets.

Gallup: "How serious would you say the energy situation is in the United States - very serious, fairly serious, or not at all serious?" [1312;1315; 1308; 1307; 1313; 1038; 1039; 1501]

Opinion Research Company: "From what you have heard or read, how serious would you say the need is to save energy - would you say it was very serious, somewhat serious, or not serious at all?" $[1157 ; 1160 ; 1168 ; 1177 ; 1181 ; 1183]$

ABC News/Harris: "How serious do you think the basic energy problem is in the county today - very serious, only somewhat serious, or hardly serious at all?" [1396; 1408]

Figure 6. Trends in perceived severity of the U.S. energy situation, 1979-1991 
"A few years ago, there was an energy shortage in this country, with gasoline, oil, and electricity in short supply. What do you think the chances are that in the next year this country will have another severe energy shortage like the one a few years ago-very likely, somewhat likely, somewhat unlikely, or very unlikely?" [1554]

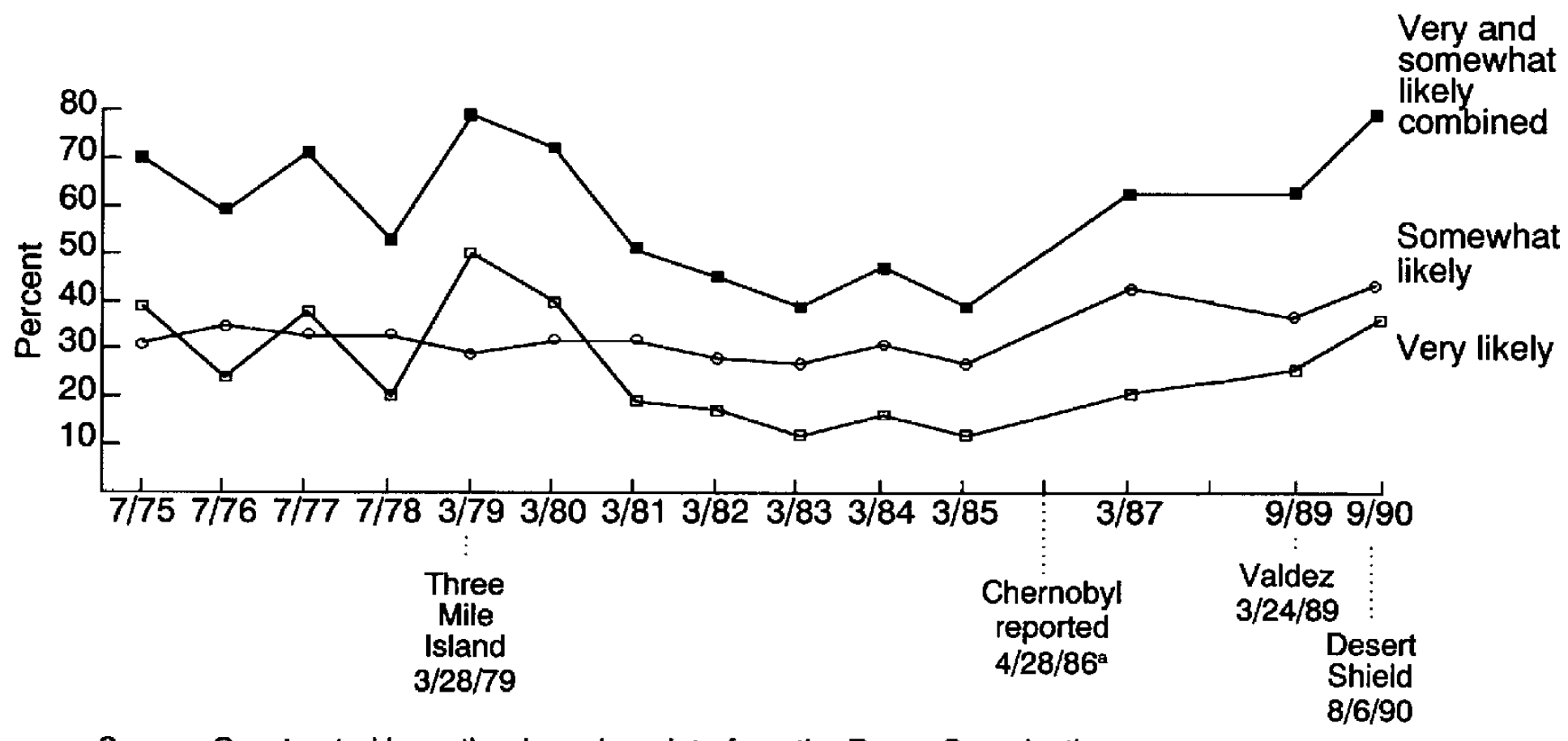

Source: Constructed by author based on data from the Roper Organization.

accident occurred 4/26/86.

Figure 7. Trends in anticipated near-term energy shortages 
economies (including the federal deficit, government spending, unemployment, poverty, and homelessness); (2) the state of education in the country, particularly at the primary and secondary levels; (3) crime, drugs, and their interrelationships; (4) health care and health care costs; and (5) the environment. Energy problems have declined in significance. However, since evidence shows that the environment is an increasingly prominent national concern, it would appear that most of the public has yet to fully link energy production and consumption with their environmental impacts. Energy choices seem to be increasingly environmentally driven.

\section{$\underline{\text { Energy Institutions }}$}

In general, energy institutions do not enjoy high levels of public trust. The seeds for this mistrust seem to have been planted during the mid- to late-1970s when the Arab oil embargo strained the adaptive capacity of the nation's oil production and delivery infrastructure. The legacy of that period seems to be an ongoing distrust. The oil industry is one of the least-favored industries in the United States. Nevertheless, a majority views the oil industry as essential to the nation.

Attribution of responsibility. During the late 1970s, the oil companies and the federal government were viewed as most responsible for the energy situation. The most recent data show that oil companies and Iraq were most blamed for energy difficulties; also blamed by some were Congress, any administration then in office, American consumers, utilities, and environmentalists.

The oil industry. Securing adequate energy supplies is seen as the central responsibility of oil companies, almost regardless of the cost. While 8.5 out of 10 want oil companies to search for new oil, only 6 out of 10 believe oil companies are actually doing this. Two-thirds want oil companies to develop new products, but only about half think oil companies actually do so. Eight out of ten want oil companies to develop alternative fuels; only one in three thinks they are.

A major reason for the oil industry's lack of popularity is public perception of oil-company profiteering. Virtually everyone blamed the oil companies for unfairly taking excess profits during the 1990 Iraqi invasion of Kuwait and the ensuing crisis in the Middle East. However, the public incorrectly estimates oil company profits at 10 to 20 times their actual amounts, according to the most recent data available. Thus believing profits are too high, many think the oil industry is inadequately regulated. The proportions of those calling for more oil industry regulation appear to rise and fall with the price of gasoline (Figure 8).

Other reasons for the lack of confidence in the nation's oil companies are a perception that product quality needs to be improved, service is declining, innovation is lacking, and the industry is not interested in the well-being of its customers. A very small amount of evidence suggests that oil companies may also be viewed as "environmentally incorrect." Taken one by one, individual oil company reputations tend to fare better with the public than the industry as a whole.

Government. In 1981, opinion was divided about President Reagan's proposal to close down the U.S. Department of Energy (DOE); pluralities both favored and opposed the idea. In 1990, however, a majority of 55\% held highly or moderately favorable opinions of DOE. The public tended to see Congress and the Bush Administration as more likely to help avoid than cause an energy crisis. The preferred governmental roles appeared to be deciding which energy resources are developed and encouraging private investment. Public preferences leaned toward private industry development of alternative fuels. Most seemed to want government to avoid crises and maintain stability, and to promote and encourage private industry rather than supplant or restrict it severely. 
"Now I'm going to name some things, and for each one tell me whether you think there is too much government regulation of it now, or not enough government regulation now, or about the right amount of government regulation now?" "The price of oil and gas" (February of each year) [1557].

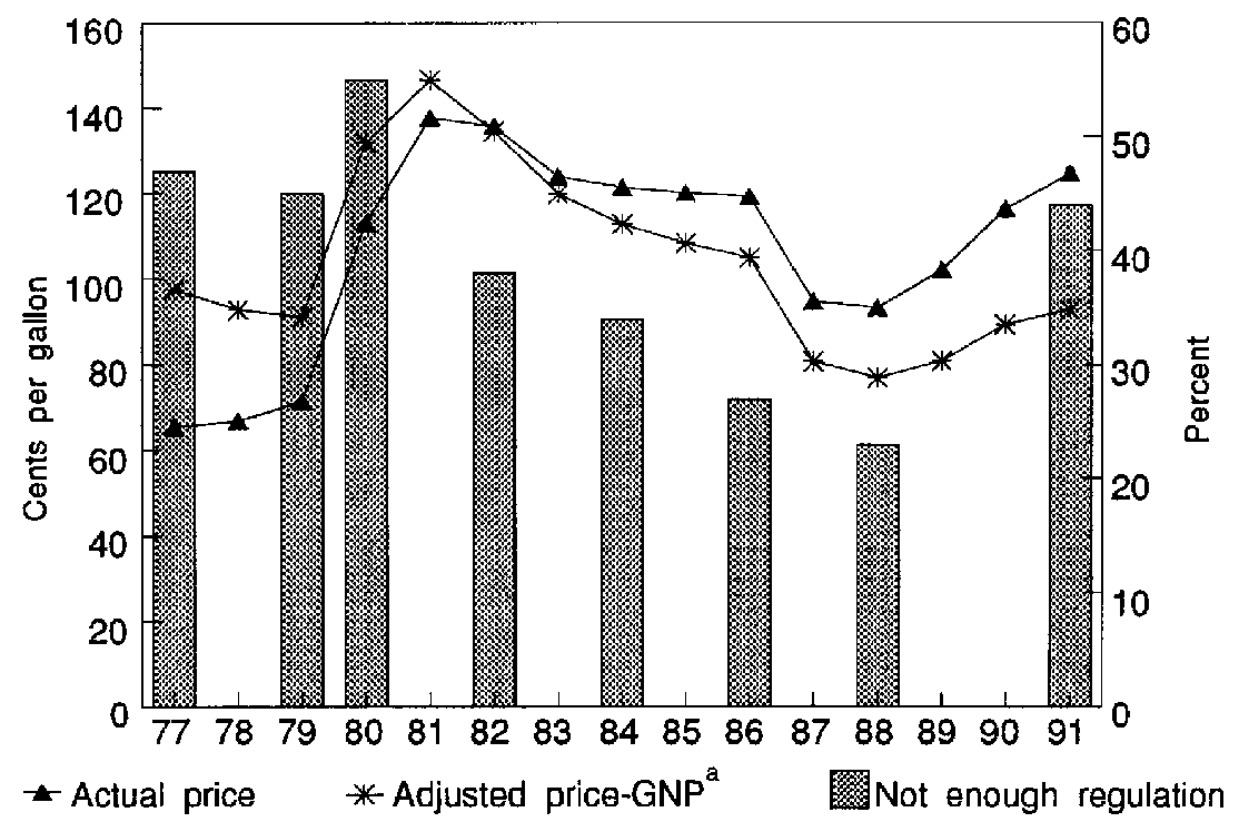

Source: Constructed by the author using data from the Roper Organization, the Energy Information Administration's Monthly Energy Review, National Income and Product Accounts, 1927-1982 and Survey of Current Business, 1983-1991.

anflation-adjusted price $(1982=1.00)$

Figure 8. Trends in public preferences on regulating oil and gas prices of gasoline, 1977-1991

Few data were available about preferred roles and responsibilities of government and industry in several areas, such as energy $R \& D$, provision of incentives, information programs, and the like. No systematic data addressing these policy preferences were located. However, governmental roles in regulating energy production and consumption are clearly viewed as important. Many appear to desire that the government ensure a pleasant sufficiency of supply at reasonable cost while avoiding draconian regulation to maintain it.

Electric utilities. Electric power is seen as critical, and the electric power industry is viewed as essential to the country. In the late $1970 \mathrm{~s}$, the public had a relatively low opinion of utilities. However, based on traditional norms of performance-reliability, service restoration, and customer service-utilities have recently received relatively high marks. In newer areas of performance, such as integrated resource planning (IRP) ${ }^{3}$ and protecting and improving the environment, utilities have room for improvement in public opinion. Yet, approval of electric utilities seems to be increasing, and electricity is often seen as a good value for the price. The stabilization of electricity prices following the price shocks in the late

${ }^{3}$ Formerly termed "least-cost utility planning," IRP is a process in which utility regulators require utilities to include social and environmental costs of energy alternatives in their planning. 
$11 / 11 / 93$

B. Farhar

Trends in Public Perceptions and Preferences on Energy and Environmental Policy (Feb. 1993)

Errata Sheet

Page xxviii, line 2: insert the word "conversion," ahead of the word "transmission." 
1970 s and early 1980 s could be a reason people seem to be feeling better about utilities. Consumers may not understand that $67 \%$ of the electricity generated at the source is lost in transmission and distribution; only $33 \%$ reaches the site where it is used.

As is the case with oil companies, much of the public tends to overestimate utility profits considerably, by more than three to onc. They thus tend to favor ulility regulation. Futurc utility roles will emphasize environmental protection and respectful service to customers and the community if public preferences are influential.

Automakers. Automobile companies seem to enjoy a somewhat more favorable public image than the other energy institutions; however, they are less central energy players, as well. Favorability toward them has increased considerably in the last decade. Majorities give domestic automakers good marks for creating innovative products and for the value and quality of the products and services they provide. Thus, most believe no more regulation is desirable; one in three believes more regulation of car manufacturers is needed. Several polls show widespread support for increasing automobile fuel efficiency and some support for increasing corporate average fuel economy (CAFE) standards.

Summary. Although survey items elicited the public's sense of blame and outrage over the way energy problems were being handled, these items clearly touched a raw nerve. Much of the public seemed to feel betrayed by these institutions. This loss of trust in U.S. institutions is not limited to the energy arena; it seems to have permeated U.S. society during the late 1970 s and 1980s. If the causes of the energy problem are perccived to be institutional, then individuals may believe they can do little to change things.

\section{Energy Alternatives}

Energy supply preferences appear to be increasingly environmentally driven. Although U.S. citizens are concerned about the adequacy of energy supplies, they favor a national energy policy that emphasizes energy efficiency and demand reduction over energy production (Figure 9). The public does not appear to be hesitant about mandating certain types of buildings and transportation conservation options.

The surveys used in this analysis offer considerable evidence that, when cost or price information is not included, renewable energy and energy efficiency have been the public's preferred energy alternatives since 1977. The data on preferences toward fossil fuels and nuclear energy from some items remain ambiguous. While no survey has found that the public prefers nuclear energy, coal, or oil over energy efficiency, renewable energy, and natural gas, sizable pluralities preferred nuclear energy and coal when survey questions offered them no other options. The data appear to show, however, a decrease in public preference for fossil fuels (except for natural gas) and nuclear energy, except for the 1989 data shown in Figure 10. This is consistent with increasing environmental concern (greenhouse effect, oil spills, nuclear accidents) and the perception that U.S. participation in the Persian Gulf war was directly related to our reliance on imported oil.

A 1989 survey asked respondents: "In order to reduce carbon dioxide emissions and provide for the country's overall need for energy in the future, which do you think should be employed most-finding ways to produce more traditional energy sources like coal, gas and oil . . or . . f finding ways to use energy more efficiently and to use renewable energy sources like solar and wind power?" Eighty-three percent selected energy efficiency and renewable energy; $12 \%$ selected greater production of fossil fuels [1072].

In 1987, when poll takers asked respondents which energy source they would like to see developed to "replace foreign oil five years from now," 54\% selected solar energy, 30\% selected hydropower, 22\% selected wind, and $16 \%$ energy from ocean tides-all of which are renewable energy technologies. Energy 
"Some people say that more power plants must be built in the next several years to meet increased demand for electricity or we will have power shortages in many areas. Other people say that we can meet increased demand by using the electricity from existing power plants more efficiently. Which point of view is closer to your own?" (March 1992) [1561]

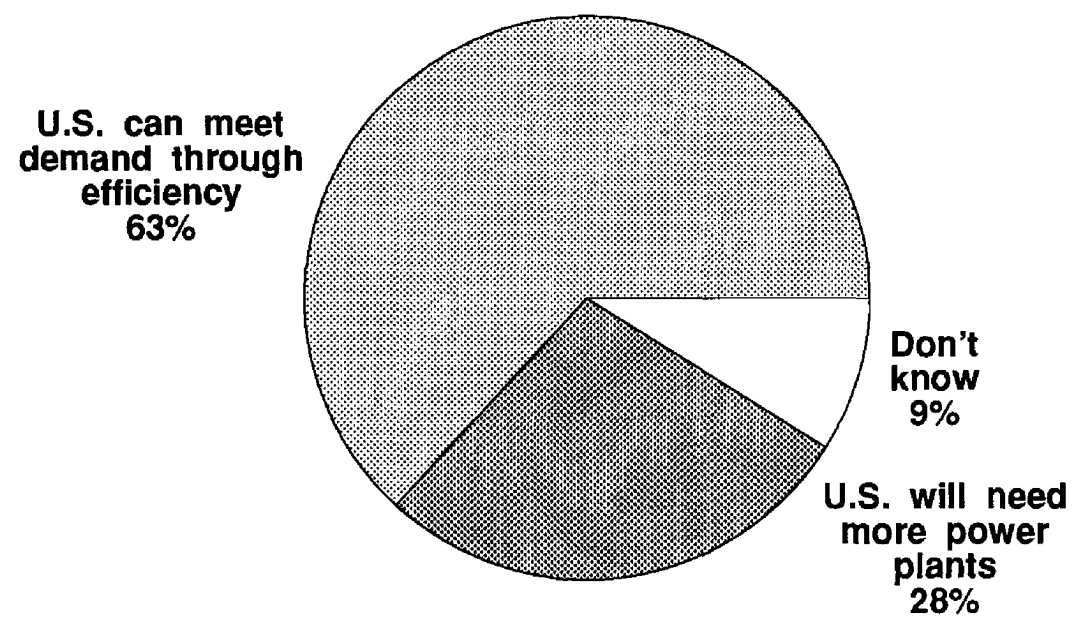

Source: (c) 1992. Used with permission of Frederick/Schneiders, Inc.

Figure 9. Preferences for efficiency or more power plants

efficiency was not included in the response options. However, other recent surveys showed that most of the public selected renewables and energy conservation as the preferred areas for $R \& D$ funding. By comparison, about one-quarter selected nuclear energy and another quarter selected fossil fuels.

The persistent trend in public preferences for renewable energy supply and energy efficiency over the past 15 years should be interpreted in light of actual adoption of energy efficiency and renewable energy features in buildings and transportation. Adoption of conservation and renewables in residential buildings may have slowed, but this is not due to changes in public preferences for these energy options relative to other options.

\section{$\underline{\text { Utility Electrical Energy }}$}

Public perceptions of energy cannot be fully understood without including the traditional coal and nuclear alternatives, which together are used to produce $75 \%$ of U.S. electricity. Evidence shows that both coal and nuclear energy are perceived as offering an alternative to dependence on foreign oil, although, in fact, these fuels are used for different purposes. Only $4 \%$ of electricity is generated from oil. Electricity has a reputation for being a clean fuel at the point of end use. But in viewing electricity as "clean," many may not link electricity generation with its environmental impact. A majority of those directly polled on this question, however, indicated concern for environmental impacts caused by electricity production. Large majorities said that they would be willing to pay more than $\$ 6$ per month more for electricity that comes from sources less harmful to the environment than existing ones. 
"Which of these energy sources do you think are realistically possible to use for replacing foreign oil during the next five years?"

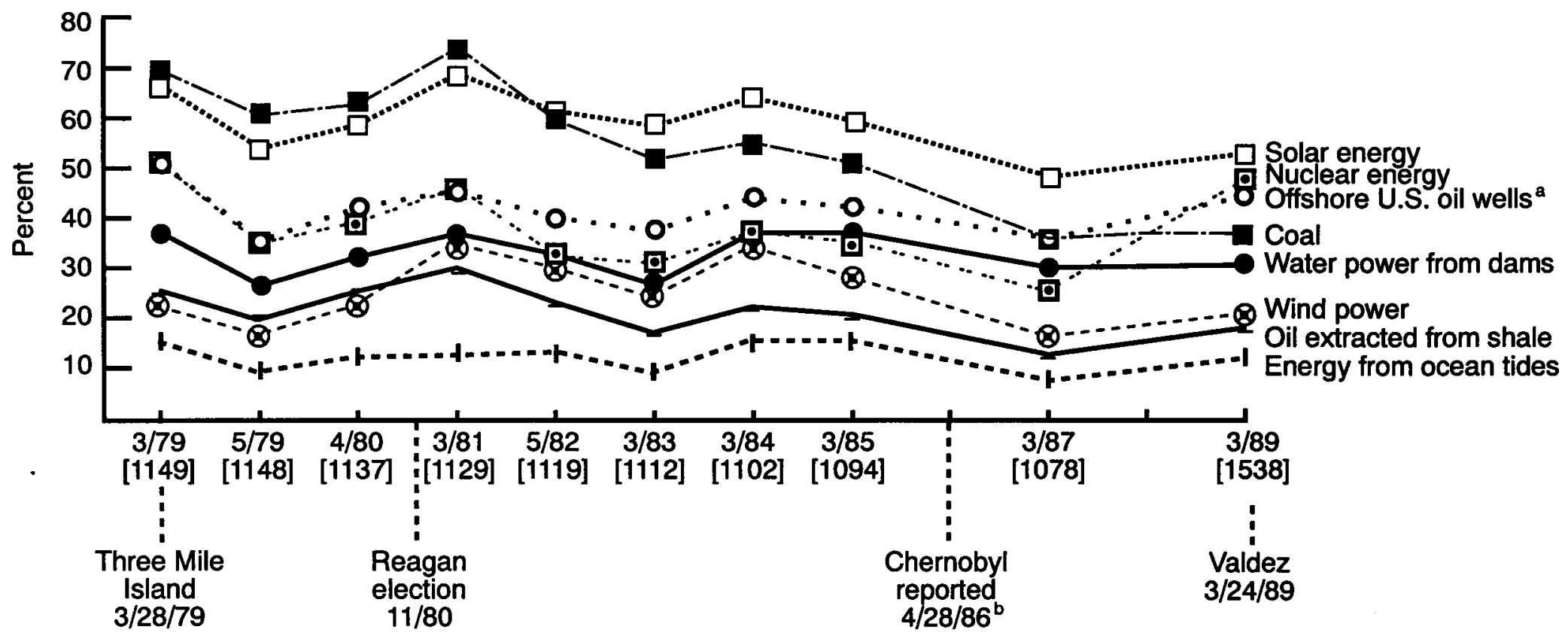

Source: Constructed by author based on data from the Roper Organization.

Note: Study numbers are in brackets below survey date.

a 1989 data collected in 1989 prior to the Valdez oil spill.

Actual accident occurred 4/26/86.

Figure 10. Preferred energy alternatives, 1979-1989 
Coal. Both coal use and nuclear power have lost favor during the last decade because of the public's environmental concerns. Even though automobile exhaust has been blamed for acid rain more frequently than coal burning, the public still regards burning coal as environmentally damaging. The public may more readily see coal burning as contributing to air pollution and global warming. While poll items have incorrectly indicated or implied that coal and oil could be traded off, a majority appear to prefer burning more coal to increasing the nation's dependence on imported oil. Few know about clean coal technologies (CCTs), and little evidence exists that CCTs would make coal seem environmentally acceptable. But most of those polled favor CCT development, and many erroneously believe that such technologies would significantly reduce U.S. dependence on oil imports.

Nuclear energy. No new nuclear power plants have been ordered or built in the United States in several years. Prior to the Chernobyl accident, the public seemed slightly more hopeful that the problems associated with nuclear energy could be ironed out than it has been since the accident. The evidence of significant discomfort, on the public's part, about the risk of nuclear power is extensive and compelling. The perceived problems are releases of radioactivity into the environment near nuclear power facilities and radioactive leaks at waste storage facilities. Most of the data show either a dramatic increase in the perceived risk of nuclear energy or a dramatic decrease in nuclear's favor over the past decade. This is despite scientific concern about the greenhouse effect and global warming; some scientists are calling for more nuclear- rather than coal-generated electricity.

The apparent lack of credible sources of information on nuclear energy is striking. The public appears not to believe anti-nuclear activists, the nuclear industry, or the government. However, the media were widely perceived as covering the Chemobyl accident well. Based on a lack of credible information, the situation appears to be that "the jury is still out" on nuclear energy.

With the specter of global climate change, however, more evidence will be needed before we can conclude that the public will continue to oppose nuclear energy. Insufficient evidence exists that indicates the public connects burning fossil fuels for electricity, automobiles, and home heat on the one hand, with global climate change on the other. Once this relationship is widely accepted, public opinion about nuclear energy and its perceived risks may be more accurately assessed, and the future acceptability of nuclear energy better estimated.

Policy preferences. Although few data were available, majorities appear to favor the following policies relative to utilities: IRP, demand-side management (DSM) programs, use of renewables to generate electricity, utility profit incentives for using and promoting efficiency and renewables, pollution controls, green pricing, and other activities to protect and improve the environment.

\section{Buildings Energy}

The potential is remarkable for reducing consumption of utility-supplied energy in U.S. residential and commercial buildings by using already available cost-effective technologies. One recent study estimated buildings energy consumption could be reduced by up to one-third by 2015 , when compared with "business-as-usual" projections. Many other estimates exist; they vary from $25 \%$ for existing residential buildings to $50 \%$ for new buildings, using different assumptions.

No solid trends were established from data using verbatim items replicated over time on conservation behavior. This suggests that the polling organizations and poll sponsors decided that public opinion on energy efficiency and the use of renewables was not of enough importance to continue to collect data consistently. The data that are available are based on a variety of questions asked of national, state, and local samples selected in a variety of ways. Any trend established from this data is thus approximate, at best. 
Decision factors. Reasons to engage in energy efficiency practices and to invest in efficiency and renewables have not been systematically studied at the national level for several years. Local market-area studies might be fruitful avenues for further research. However, for national policy purposes, more information is needed concerning the factors that motivate consumers. The smattering of poll data available suggests the public's perception of conservation in buildings is one of relative unimportance. For example, a 1990 national poll found that the majority said investment in efficiency and better energy use habits would save less than $10 \%$ of their utility bills.

Barriers to efficiency and renewables use, on the other hand, are significant. A 1989 poll found that sizeable percentages said "business and industry priorities" (38\%) and "decisions made by government" (29\%) were "the biggest obstacle to the country using energy more efficiently." Other major barriers were the upfront cost of energy improvements and the "hassle factor" in implementing energy improvements. Responses to these and other polls seem to indicate that individuals find it costly and time consuming to overcome institutional obstacles to efficient household energy use.

Voluntary residential conservation. The amount of conservation behavior being practiced, as estimated through self-report-either through lifestyle changes or through investments in retrofits-appeared to increase in the late 1970 s to the mid-1980s but to decrease since then. Earlier NREL reviews reported that most people said they were practicing some form of residential energy conservation. The practices mentioned most frequently were those that are more convenient and less costly, such as turning down the thermostat and turning off lights and appliances when not in use.

Taken together, data from national and state samples seem to indicate a pattern in which somewhat larger (though still low) proportions of the public during the early to mid-1980s, compared with the 1970s, invested in somewhat more costly items that would reduce a homes' use of utility-supplied energy. These items ranged from attic insulation to energy-efficient appliances, and even solar energy systems. Mentioned most frequently were the relatively less expensive measures-caulking, weatherstripping, water heater wrapping, window screening devices, and clock thermostats.

In 1990, however, self-reported conservation actions and investments were minimal. Gallup asked a national sample: "Do you happen to be doing anything to reduce your use of energy - that is, your use of gasoline, electricity, or natural gas?" Although almost two-thirds reported doing something, more than one-third reported that they were not doing anything at all. Actions being taken were the easiest to do (turning off lights and turning down the thermostat), just as in the seventies. Another survey by NBC News/The Wall Street Journal found that, when asked whether they took steps to reduce the use of electricity and gas in their homes, $68 \%$ said "regularly" and $22 \%$ said "occasionally." Only $5 \%$ said "never." In March 1990, Gordon S. Black/USA Today asked: "How much does your household cut back on heat in the winter or air conditioning in the summer to conserve energy?" More than half (52\%) said they cut back "somewhat"; $30 \%$ said "a great deal"; $5 \%$ said "not at all." Clearly, the urgency to engage in conservation has decreased markedly, at least as measured by the poll data on residential conservation behavior.

Some of this decline could be attributed to the fact that many households had already undertaken energy efficiency measures. These people would not repeatedly report that they had installed insulation, for example, in response to survey questions assessing conservation behavior. Some evidence for this can be found in the data on household energy consumption. Since 1980, per household site energy consumption ${ }^{4}$ has been reduced by $16.7 \%$; at the same time, the number of households grew by $13.5 \%$ (Morrison

${ }^{4}$ Site energy equals 3412 Btu of direct heat produced from $1 \mathrm{kWh}$ of electricity. Site energy includes only energy consumed at the site, ignoring the energy required to produce and transmit electricity. 
1992). Total U.S. household energy use at the site was 10.9 quads in 1979 and 10.2 quads in 1990, a $6.4 \%$ reduction, despite the increase in number of households (Morrison 1992). Another analysis found that energy use per household at the site dropped from 1970 to 1985 but increased slightly from 1985 to 1989 (U.S. Congress 1992, p. 18).

When residential energy use is examined from a source energy ${ }^{5}$ standpoint, however, it has increased. Source energy use in residential buildings was reported at 16.8 quads in 1989 and cost $\$ 104$ billion (U.S. Congress 1992). Space heating accounted for almost half of energy use, followed by water heating, refrigerators and freezers, space cooling, and lights. Source energy use has increased at an average annual rate of $1.2 \%$ for the last 20 years; however, the increase in use accelerated to a rate of $2.1 \%$ from 1985 to 1989. This increase is attributed to a growing population, shrinking household size, and increasing demand for electricity for air conditioning and other energy-intensive services (U.S. Congress 1992, p. 15).

Some evidence suggests that the public may be willing to increase conservation activity once again should energy shortages occur. In September 1990, NBC News/The Wall Street Journal asked a national sample: "Let me read you a list of ways people conserve energy. For each one, please tell me if you are likely or unlikely to try to conserve in this way if there is an energy shortage." Three-quarters of the sample said they were likely to use less heating fuel and air conditioning, while $62 \%$ said they would use appliances less.

Information sources. State and local governments and utility companies appear to be the most used information sources about energy efficiency and renewables. Written sources (newspapers and pamphlets) are the most popular information media.

Institutionalized inefficiency. The voluntary practice of energy efficiency and investment in energyconserving features and solar energy systems seems to have declined, or it may have shifted subtly in ways the polls are not capturing. The phaseout of the energy conservation and solar energy tax credits could have contributed to less conservation, as could have relatively low energy prices. However, these factors appear to be only part of the story. The other part appears to be public perception of and response to "institutionalized inefficiency."

Energy conservation and efficiency may have become a part of how U.S. households function. Current building practice has been producing homes that are more efficient than their older counterparts. Consumers are remodeling and improving existing homes and purchasing efficient appliances to replace older ones. What the polls do not recognize in their questioning is that if consumers reduce their outlay for residential energy costs, they could displace energy consumption clsewhere, to activities outside the home. Eating out, travel, and long commutes might reduce residential energy consumption, yet increase overall energy use.

Voluntary residential energy conservation practice and investment seem to have declined in the past few years, despite the persistence of concern about the energy situation and public preferences for energy efficiency and renewables. The public is supportive. Institutionalized inefficiency may be the most significant obstacle to more cost-effective adoption of efficiency and renewable energy measures. The public may insist that energy efficiency and using renewable energy be made routine, making it easier and cheaper for consumers to use them.

${ }^{5}$ Source energy, or primary energy, equals $10240 \mathrm{Btu}$ of heat from $1 \mathrm{kWh}$ of electricity. Source energy accounts for energy required to produce and transmit electricity. 


\section{Transportation Energy}

As global lifestyles evolve, the demand for transportation fuels increases. Perception of and knowledge about oil is of concern to policymakers, as is information on the public's view of conservation, alternative fuels, and alternative fuel vehicles. Most transportation fuel is currently supplied by gasoline formulated from oil.

Oil. About one-half of the U.S. public seems aware that the United States imports some of the oil it uses. However, only about one in four can accurately estimate the proportion of U.S. domestic petroleum demand that is imported. Most do not realize that U.S. dependence on foreign oil is increasing. And overall, the public is not highly knowledgeable about oil imports.

Public enthusiasm for offshore drilling has declined, despite the perception that the United States needs to reduce its dependence on foreign oil. In fact, offshore oil drilling poses an excruciating trade-off: national security versus the environment-both deeply felt values. This trade-off seems to lead to polarization in public opinion. Large percentages both favor and oppose offshore drilling for oil. However, the majority opposes new oil drilling in the Alaska National Wildlife Refuge (ANWR).

Most people who heard about the offshore oil spill at Valdez, Alaska, on March 24, 1989, developed a negative attitude toward Exxon immediately thereafter. A public boycott of Exxon products developed by May 1989, and a majority felt that Exxon had not done enough to help clean up the spill. Public attitudes toward Exxon were still negative 2 years after the spill. This is consistent with the public's negative attitude toward oil companies in general and with its increased environmental concern.

Voluntary transportation conservation. Few data are available on public participation in transportation conservation behavior. Most said they have not been driving less, car pooling, using mass transit, bicycling, or walking to get from one place to another. No data existed on self-reported observance of lower speed limits. Buying a fuel-efficient car was reported as the most popular form of conserving gasoline. Data on car purchases and purchase intentions show that $14 \%$ fewer drivers bought full-size automobiles during the past decade. And, a sizable proportion of full-size car owners planned to buy smaller cars next. Motivations to conserve cited by members of the public seem less important than barriers. Perceived barriers to gasoline conservation-inconvenience, time costs, lack of knowledge of potential car pool partners-seemed to outweigh the advantages. For commuters, saving on the costs of parking and gasoline, especially for those traveling more than 10 miles to work, seem to be the most important reason to conserve. One could speculate that fuel-efficient behavior could also be an expression of environmental values.

The public's perception of institutionalized inefficiency marks the transportation sector as well. The transportation infrastructure was built based on the widespread availability of inexpensive gasoline and mass-produced automobiles. The national economy relies heavily on the automotive and oil industries. Most of the nation's transportation and freight hauling systems are dependent on the combustion of fossil fuels. The perseverance of this deeply entrenched system constrains individual choices in considering and using transportation alternatives. Public opinion on transportation conservation seems to reflect these realities. Change could take considerable time and be costly to achieve.

Alternative fuels and alternative fuel vehicles. A few national data were located on alternative fuels; those that exist suggest that most people are unfamiliar with methanol, ethanol, or other alternative fuels and additives. Only $12 \%$ of new car buyers in 1990 said they were familiar with alternative fuels. Most people in one survey said they were willing to pay 2 cents per gallon more for gasoline that produces less air pollution. Another survey found opinion divided when people were asked whether they were willing to pay 20 cents more per gallon for "cleaner-burning alternative fuel"; $48 \%$ favored the idea and $50 \%$ 
opposed it. Other data showed that $43 \%$ of new car buyers in 1990 said they would be willing to pay $10 \%$ to $50 \%$ or more for fuel "that significantly reduces air pollution."

Factors identified as affecting fuel purchases suggest that gasoline remains the standard against which alternative fuels are competing in gaining consumer acceptance. When asked which form of alternative fuel they would use, a plurality of $42 \%$ said they didn't know; $17 \%$ said "solar power," $16 \%$ gas blends, $10 \%$ electricity, $7 \%$ methanol, $5 \%$ methane, and $3 \%$ said they would not use alternative fuels. Results from attribute analysis suggested that buyers of higher octane gasolines could be a market for methanol that could be targeted as a higher octane, cleaner burning, and more powerful fuel than gasoline. The target market could be as large as $10 \%$ of gasoline buyers.

The evidence also suggests that fuel operating cost is not a critical decision factor in car purchase decisions. Factors such as aesthetics, quality, image, and reliability appear to be more significant (Figure 11). Some data show that safety and performance are also important considerations. The significance of the decision factors varies by the type of car purchaser-the mass-market, sporty, family, economy-minded, or basic transportation buyers. In $1990,56 \%$ said they would probably buy an alternative-fuel vehicle "if all the bugs were worked out."

Factors identified in local-area studies that affect alternative fuel vehicle choices were vehicle range between refueling, fuel availability, dedicated versus multiple-fuel capability, purchase price, fuel operating cost, and perceived level of emissions reduction. Range between refueling is especially important to those who refuel more frequently than once a week.

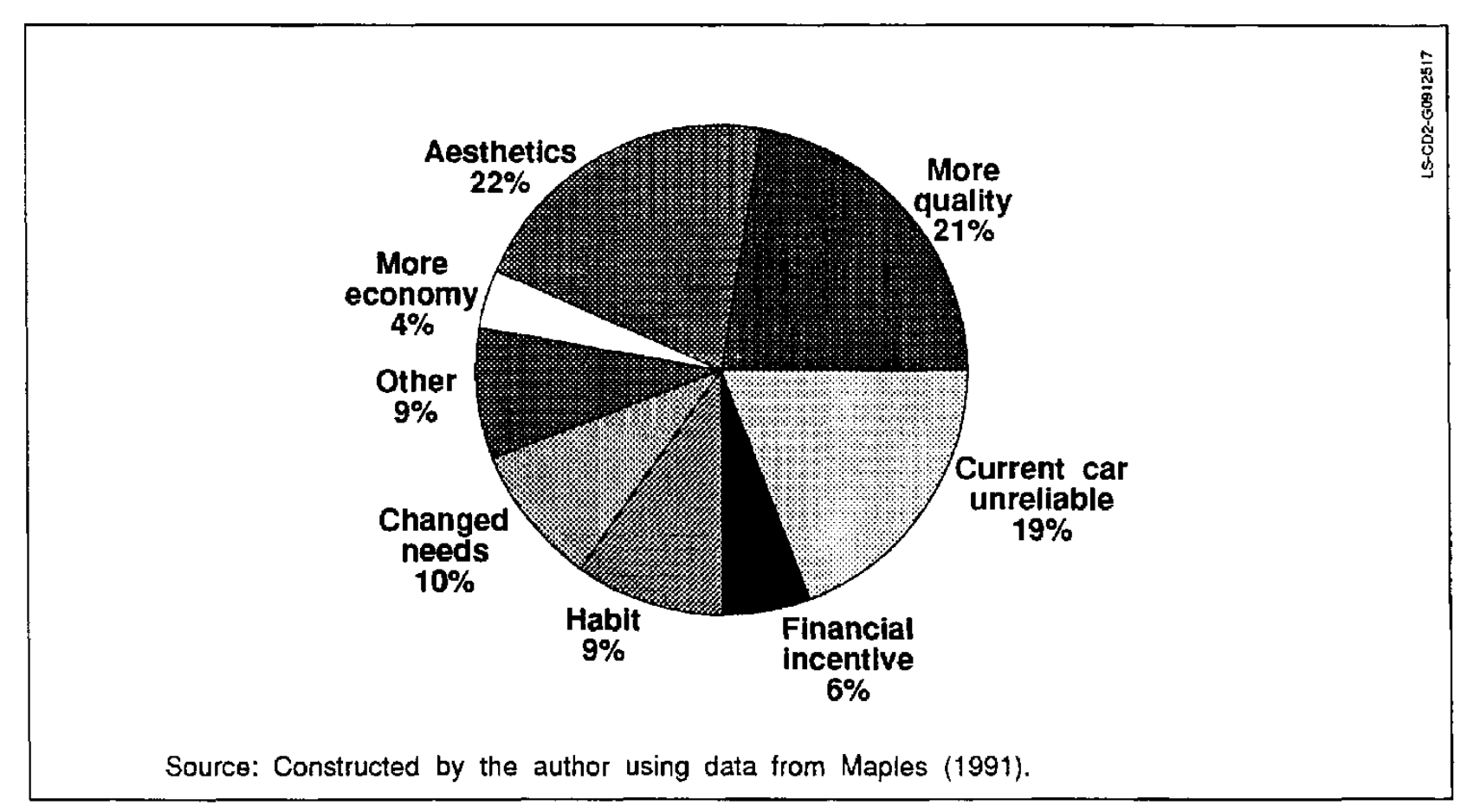

Figure 11. Reasons for buying a new car 
More data on decisions and behavior with respect to alternative fuels and alternative fuel vehicles no doubt exist in local-area studies. At the national level, however, few data are currently available.

\section{Transportation Policy Preferences}

The public's perceptions of other transportation policy issues are organized into four policy categories: (1) oil and gasoline, (2) conservation, (3) mass transit, and (4) alternative fuels and alternative fuel vehicles.

\section{Oil and gasoline policy}

Gasoline tax increases. More data exist on this policy than on most others. The public has consistently opposed gasoline tax increases. Regardless of item wording, majorities oppose such tax increases. The public tends to overestimate the amount of federal, state, and local gasoline taxes, actually 26 cents per gallon, by approximately 9 cents per gallon. The federal gasoline tax is 14.1 cents per gallon. A majority believe the taxes are "too high." When compared with other means of reducing the federal deficit, gasoline taxes were virtually the least popular action that could be taken. Despite the fact that energy efficiency advocates support gasoline tax increases to increase gasoline prices to a level at which conservation would occur, this policy cuts deeply against the grain. Other policies to reduce gasoline consumption would enjoy more widespread public acceptance than this one. Much of the public apparently does not believe that increasing gasoline taxes would result in reduced gasoline demand in any event.

The only exception to this pattern occurred when items asked about increased gasoline taxes to protect and improve the environment. When framed this way, increased gasoline taxes were more widely accepted. The use of revenues generated in this way to actually improve the environment may be critical to actual public acceptance of such taxes.

Oil and gasoline price controls. By 1990, almost two-thirds favored price controls on gasoline and home heating oil. Attitudes about price control policies appear to be influenced by gasoline prices. The higher the price of gasoline, the greater the proportion of the public calling for regulation of gasoline prices.

Oil import taxes and incentives for domestic production. Opinion seems divided on the desirability of taxing imported oil. Many tend to favor such taxation when the question is couched in terms of reducing the federal deficit or increasing international competitiveness. However, when presented in terms of raising the cost of gasoline, many tend to oppose the idea. An import tax on gasoline could reduce the federal deficit and increase international competitiveness, but it is not a widely accepted option.

Windfall profits tax. Excess taxes on profits were favored in the late 1970s and were still favored in 1992 by approximately two-thirds of the public. However, currently this sentiment seems less intense than in the late 1970s.

Severance taxes. No data on severance taxes were found past 1984; polling organizations have apparently not included such questions in recent years. Prior to that time, nearly two-thirds of those polled favored individual states imposing severance taxes on natural resources such as oil, gas, and coal.

Regulation of oil production. Most oppose an outright federal government takeover of the oil industry. However, in 1990, a majority favored the breakup of large oil companies to limit the influence the oil industry has on the domestic economy. Formation of a government-owned-and-operated oil corporation was also favored by a majority, although the data on this were somewhat limited. In general, the public seems unwilling to accept more stringent regulation of the oil industry. 
Strategic Petroleum Reserve (SPR). The limited data available suggest that the public favors the maintenance of the SPR.

\section{Conservation policy}

Fuel economy/corporate average fuel economy (CAFE) standards. The public strongly favors increasing automobile fuel efficiency, borne out by several polls. The limited evidence available on the point shows that the public favors increasing CAFE standards.

Financial incentives for purchasing fuel-efficient vehicles. A few of the survey items addressed the use of financial incentives to encourage transportation efficiency; these received favorable responses. Use of financial incentives for purchasing more fuel-efficient vehicles (and disincentives for "gas guzzlers") is an acceptable method for steering purchasers toward more efficient vehicles to reduce fuel consumption. The few data available suggest that public opinion has shifted toward favoring tax penalties on larger, less efficient automobiles. Opinion was divided on the desirability of offering tax incentives to oil companies to encourage domestic exploration and production. Although energy industry leaders favored this option, public interest agency leaders did not support the idea.

Ridesharing/car pooling. In 1989, most people were unwilling to see regulations that would require car pooling to and from work, although one-third were willing. Encouraging car or van pooling appears to be acceptable; however, the data are very limited.

Gasoline rationing. Only two items in all of the surveys studied asked about gasoline rationing; the majority continued to oppose the concept.

Limited access to gas stations. The evidence shows a pattern of public disinterest in or opposition to this idea.

No-drive days. In 1989, most were unwilling to see regulations that would require limited driving days. The majority did not want more restrictions on when and where automobiles are used. More recently, polling organizations have not asked about this option, however, and almost no data on it exist.

55-mph speed limit. Almost no data on the 55-mph speed limit were located after 1980. However, in 1989 , most people said that the good effects of the speed limit outweighed the bad effects. The available evidence is very limited; however, it appears to show declining support for the 55 -mph speed limit as public policy and less willingness to observe it currently than in the late seventies.

\section{Mass transit}

The majority seems to feel that enough is being spent on mass transit, although, in a 1991 survey, a plurality did favor privatization. In another study, a majority favored requiring people who drive to work in major metropolitan areas to take public transport one day a week. Favorability to mass transit has continued; however, no strong mandate for it has emerged.

\section{Alternative fuels and alternative fuel vehicle policy}

Alternative fuels policy. Few data were available on this topic. Most peoplc appeared to know little about alternative fuels. Virtually everyone in a December 1990 survey favored providing "financial incentives to use or develop alternative fuels such as fuels produced from grains." No conclusions are possible on alternative fuels policy; this is a research gap. 
Alternative fuel vehicle policy. From $42 \%$ to $56 \%$ of recent samples said that most cars should be required to use alternative fuels; opinion seems to be divided on such a mandate. Of a 1990 sample of new car buyers, a plurality of $48 \%$ said the government should require automakers to build cars that run on alternative fuels. Almost no other reliable data were available. In 1989, 76\% approved of requiring automakers to build low-polluting methanol-powered cars and sell them "in urban areas with the greatest air pollution," even if that meant higher car prices. Also, $80 \%$ wanted oil companies to develop alternative fuels, although only one-third thought they were actually doing so. Alternative fuel vehicle policy preferences are another research gap.

\section{Conclusions}

The Executive Summary has presented conclusions about the study's empirical findings. A second type of conclusion attempts to go beyond findings to interpret them, answering the question, "What does it all mean?" The conclusions discussed here offer a broad interpretation of the data and draw inferences from them. They touch on four areas: (1) environmental concerns, (2) institutionalizing efficiency and the use of renewables, (3) information and education, and (4) public trust and confidence. These areas need emphasis in the development of intelligent public policy.

Environmental concerns are beginning to drive energy choices. Problems such as global warming, stratospheric ozone depletion, acid rain, municipal solid waste, and air pollution in cities are primarily functions of energy production and consumption. As concern about the environment increases-itself driven by health and safety considerations-energy decisions are bound to be affected. The public has exhibited strong and consistent preferences for energy efficiency, energy conservation, and renewable energy for the past 15 years. These alternatives are widely perceived to be environmentally advantageous, particularly when compared with traditional energy sources, such as coal and nuclear power.

Conservation behavior may have slowed during the 1980s, yet most people believe that the energy situation remains serious. Why, then, are people not engaging in more lifestyle changes and investment in efficiency that would reduce energy use? One possible explanation is that the public wants U.S. energy institutions to change the way they do business when it comes to energy and the environment. If public opinion is followed, efficiency and renewables use will become "institutionalized"-a routine way of doing business. The burden of the change should fall on institutional, not just on family and individual, shoulders.

For example, can the public trust that efficiency has been institutionalized in building practice and that its cost has been institutionalized in mortgage finance? Or do home buyers have to take it upon themselves to retrofit the house, after purchase, with additional insulation, energy-efficient windows, and the latest high-efficiency lighting, appliances, and heating, ventilating, and air conditioning systems?

The results show a deep-seated need for public education about energy and the environment. Such education should begin in the elementary schools and extend through secondary education because lifestyle habits are engrained early. This education should also be central to college and university programs, thus establishing an ecological imperative in future leaders and decision makers. Continuing education and training for adults is also needed. In addition, information and education are needed for an informed electorate that supports intelligent public policy. Basic energy facts need to be provided frequently and broadly; the media have a critical role and responsibility in this regard.

Another major key is credibility. Public trust and confidence in energy institutions is not high. Business as usual is completely outmoded-institutional support systems must be initiated that keep pace with the public desire for change. 
People appear to be willing to shoulder the costs of institutional change, if they believe that the funds will actually be used to improve efficiency, employ renewables, increase sustainability, and protect and improve the environment. This will occur when institutional credibility is increased and credible leadership is established. Credibility building is crucial both for the public to believe factual information provided and for it to support effective policies.

To the degree that U.S. institutions are straightforward, share decision authority, and trust the public, they themselves will be trusted. The people are saying they care. They are looking for leadership, intelligent policies, and fairness on the part of U.S. public and private institutions. 
Polling is a form of listening. 


\section{Chapter 1}

\section{Introduction}

\section{Background}

In the years since the Arab oil embargo of 1973-1974, the public has been confronted with a roller coaster of energy events. On the positive side, after the 1973-1980 "energy crisis," much of the public seemed reassured by federal policy emphasis on free markets, the existence of falling oil and gasoline prices coupled with plentiful supplies, and stabilizing utility bills following deregulation of natural gas prices. More troubling energy-related events, however, included the Three Mile Island nuclear accident (March 28, 1979), news of the Chernobyl nuclear meltdown in the Soviet Union (April 28, 1986), ${ }^{1}$ the Valdez oil spill off the Alaskan coast (March 24, 1989), the onset of Desert Shield (August 6, 1990), and the Persian Gulf war (January 17 to February 27, 1991). Policymakers and economists have long argued that the public would lose interest in energy efficiency and the use of renewable energy technologies as the price of oil stabilized at record low levels (in real dollars) and as utility costs leveled out after dramatic increases in the late 1970s. And some evidence exists that earlier gains in energy conservation in buildings and transportation may have been eroded as consumers seemed to relax their vigilance about the energy situation. However, other evidence suggests that the public maintains a sense of the importance of energy efficiency and the use of renewable energy to the nation's well-being.

In the past few years, scientists have stressed the relationship between energy production (particularly the burning of fossil fuels) and potentially serious global change, such as acid rain, stratospheric ozone depletion, and global warming. Yet the National Energy Strategy, released in February 1991, called for both energy-supply and demand-side actions, and the extent to which the public makes the connection between energy decisions ${ }^{2}$ and environmental degradation remains unclear.

Using the type of information in this analysis, the congruence of policy options with public opinion can be assessed (Olsen et al. 1985). The study provides a framework for evaluating policy options, such as energy price increases, as to their likely public acceptability. This work enables policymakers to design policies that have the most potential for public acceptance. The study also provides a comprehensive body of information on public opinion polls in the light of which policymakers can assess findings from any one survey question they encounter in the future. Analysts can use this information to support a variety of projects, such as market assessments. Understanding perceptions about energy technologies, policies, and programs forms a framework against which policy options designed to encourage the use of new technologies or pursue other government agendas can be evaluated. Information on the perceived risks

\footnotetext{
${ }^{1}$ The Chernobyl accident actually occurred on April 26, 1986. Appendix F contains detailed chronological information on energy and environmental events.

${ }^{2}$ This term includes decisions on energy production, distribution, and consumption by individuals, households, utility companies, builders, automobile manufacturers, oil companies, government entities, and other private- and public-sector organizations.
} 
of energy-supply alternatives is pertinent to fuel cycle thinking. Knowing factors that affect consumer decisions on energy-related purchases and lifestyle behaviors can increase the accuracy of marketpenetration estimates and aid in modeling the potential contribution from efficiency and renewable technologies. Seemingly non-energy-related everyday behaviors (e.g., shopping, eating out, leisure time pursuits, and working at home) should be explored for the energy "embodied" in them, for these activities also affect energy use and the environment. And whether the nation's energy institutions are linked to environmental problems in the public's mind is important information for policymakers seeking to make decisions that accurately reflect the public will.

The public is a "market" for energy and environmental policy. Energy policy decisions have traditionally been based on factors other than public opinion. Public opinion may not be the best basis for policy decisions for a number of reasons, including lack of information and understanding on the part of the public or undesirable economic impacts of proposed actions. But policies carefully analyzed and honestly explained to the public are often supported by public opinion.

Government can design diverse policy options to achieve any given end. Instead of relying as heavily on engineering and economic estimates of policy impacts as has traditionally been done, government would be prudent to assess proposed policies against public opinion to discern which options are most likely to enjoy widespread public acceptability, under which conditions, and for which purposes. If this were more common practice, the effectiveness of national, state, and local energy policies would be enhanced. Government can follow private industry's lead in understanding markets as a necessity of doing business and acting accordingly. Public opinion polls are one vehicle for achieving this understanding.

This analysis seeks to characterize public opinion not by the results of single questions, but by grouping many similar questions to discern trends and patterns of opinion. The report presents results from a secondary analysis of public opinion surveys on energy-related topics from national probability samples and selected state/local samples. The data base includes some 2000 items from nearly 600 separate surveys conducted between 1979 and 1992 . Researchers traced items repeated verbatim over intervals of years, thus permitting analysis of trends in public opinion for the past decade.

\section{Accuracy of the Results}

This secondary analysis is based on the assumption that no science is value-free. Some value position is embedded in every scientific enterprise, even if only in the selection of the topic for investigation. The ubiquity of bias is explicitly recognized and guarded against by the scientific method. Bias is as much a part of polling as it is other endeavors. Despite the widespread use of poll data, some analysts have been concerned about relying on this information for several reasons. Poll sponsors may have an interest in showing favorability toward their product or service. Because omnibus national polls are paid for by numerous sponsors, the probability of this type of bias being reflected in their findings is reduced, if not eliminated. Polls paid for by single sponsors could result in more biased findings than those of omnibus surveys. However, this tendency is reduced when sponsors use more than one polling organization purposely to reduce the possibility of bias in the survey. By comparing results from a number of different surveys, as this one does, an analysis can reveal findings that fit an overall pattern. Anomalous findings that do not fit the pattern could be the result of bias.

Respondents sometimes become frustrated in answering surveys because a question does not make sense as presented or the response options offered do not permit an accurate picture of the viewpoint to be expressed. Bias in response can be introduced by the wording of questions and of the response options presented. This bias is reduced by asking open-ended items. It is also reduced when item wording has been based on careful qualitative field research or open-ended pilot interviewing. However, this type of 
interviewing prior to omnibus survey construction is rare; it may occur more frequently in special one-time surveys.

The order in which questions are asked can also affect responses. Protection against this type of bias, as well as the one from item wording itself, is again offered by examining results from several similar items used in a variety of studies. At times, a pattern of results can be discerned; sometimes a pattern does not emerge. When this occurs, some form of bias may exist.

In this analysis, findings that seem to be a function of bias are clearly noted, and the source of bias identified, whether it be sponsorship, item wording, forced-choice response codes, or simply anomalous findings for no apparent reason. Readers should view such results with greater-than-usual caution.

Another, far more subtle and pervasive, form of unintended influence affects survey findings. This type of influence ensues from the conceptualization of the problem embodied in the way questions are asked. It is perhaps best illustrated by examples. One example is that, although environmentalists and ecologists believe the ecosphere and the biosphere are each a single interrelated entity, pollsters asked the public whether they were more concerned about local or global environmental problems, as if these could somehow be differentiated. Asking the question in this way subtly fosters the notion that global climate change, for example, is a problem that affects "someone else," not the local community.

A second example is found in items asking who should pay for utility pollution prevention efforts. A fundamental debate has emerged as to whether utilities have a right to pollute (an idea that undergirds a concept like "emissions trading") or whether people have a right to live in a pollution-free environment. Put another way, no poll item asked whether utilities should have to pay people so that utilities can pollute their environment.

This form of unintended influence, or bias, has important implications for understanding the results of this study. Often, the type of problem definition used by pollsters and reflected in their questions does reflect prevailing cognitive frameworks or paradigms. To the degree that it does, the results are reflective of public opinion. Sometimes, however, this type of influence serves to reinforce the problem definition preferred by the prevailing power structure in the society. Inconvenient and uncomfortable alternative paradigms are ignored, and public opinion on these viewpoints is not sought. An example of this type of problem found in this study is that no poll asked about the idea of "sustainable development," which is a concept driving the attempt to synthesize the needs of domestic and world economic development coupled with protection of natural resources and the environment. At times, this type of bias is identified in the text. However, the reader should keep these limitations in mind in evaluating the findings.

Comparing results from items that are not identical in wording is not permitted in a statistical sense. However, common sense would say that where item wording is similar, patterns of results can be determined and some meaning can be taken from them. A pattern of similarity of results from many surveys rather than the results of one item asked at one point in time is clearly more reliable in reflecting public opinion accurately.

\section{Guide to the Report}

The report presents findings on a broad range of energy and environmental topics. It begins by tracing the dramatic increases in public concern about the environment over the past 15 years. The focus of environmental concerns has moved from aesthetics (e.g., anti-littering) to serious health and safety concerns (e.g., global warming and stratospheric ozone depletion) over these years. Many of the environmental problems now perceived as most significant are energy related. If the public perceives the link between energy and the environment, it may be motivated to support policies to protect and improve 
the environment. And, people may be willing to change daily habits and to pay for environmental protection and improvement. Chapter 2 presents evidence on environmental perceptions, preferences, and activism. Perception of the link between energy and environmental problems, such as global climate change, is described.

Many say that more effective national energy policies fostering energy efficiency, energy conservation, and the use of alternative forms of energy would reduce foreign oil imports. The 1991 Persian Gulf war can be viewed as a logical outgrowth of energy policies that have not given sufficient prominence to such policies. Chapter 3 presents public opinion on the Persian Gulf war, the reasons for it, and perceived actions that could have avoided it.

If people perceive a "real" energy crisis, they may be motivated to conserve energy and invest in efficiency and dispersed renewable energy systems. Similarly, if they connect energy use with environmental degradation, they may be more willing to change energy behavior and support the policies necessary to protect the environment. Chapter 4 presents information on changes in public definitions of the U.S. energy situation from the late 1970 s to early 1992 . While the salience of the energy situation has declined since the days of the Arab oil embargo and despite the recent low oil prices, the public has consistently responded that energy is an important national issue.

Chapter 5 presents information on the public's view of energy institutions and their respective roles and responsibilities. Attribution of responsibility for the energy situation is documented. The public cannot take appropriate action without credible information on energy matters. The credibility of the various public and private energy institutions is examined.

The public's preferences about energy supply and demand alternatives are traced over time in Chapter 6. National energy policy can emphasize increased supply or reduced demand; public preferences regarding these two fundamentally different approaches are also described in this chapter.

Continuing the discussion on energy alternatives, Chapter 7 presents data on trends in public perceptions and preferences regarding traditional centralized electricity sources-coal and nuclear energy. Preferences regarding utility company policies are also covered in this chapter.

Data are then presented for each of two major energy end-use sectors: buildings and transportation. These presentations include information on the public's awareness, decision factors, behavioral intention and action, and policy preferences. Chapter 8 focuses on the buildings sector and Chapter 9 on the transportation sector, including information on oil and alternative fuels. Because the data available on transportation were extensive, a separate chapter-Chapter 10-discusses transportation policy preferences.

Two types of conclusions are possible from a study of this kind. The first summarizes the empirical information presented - the findings. The Executive Summary presents a précis of the analytical findings. The second is interpretation of the empirical results, using broader brush strokes to paint the bigger picture. Chapter 11 presents interpretive conclusions.

Among the many questions the report addresses are the following:

1. What are the public's perceptions about the link between energy consumption and environmental problems such as global climate change? 
2. How much is the public willing to pay to protect and improve the environment? To change the energy production infrastructure? To change patterns of energy consumption in buildings and in transportation? Under what circumstances are they willing to pay more than they customarily have?

3. Does the public link externalities such as environmental damage and the Gulf War with energy policy?

4. How actively involved in recycling is the public? What are their preferences regarding municipal solid waste facilities?

5. How has the public's definition of the energy situation changed over the last 15 years? "Energy situation" includes perceived severity of the energy problem, its salience, future expectations, and perceived impacts.

6. What is the reputation of the major energy institutions in the United States-oil companies, utility companies, automobile manufacturers, and the government? How credible are they?

7. What are the public's preferences about energy supply and demand alternatives? Does the public prefer policies that emphasize reducing demand or increasing supply?

8. What are public preferences regarding electricity generation, particularly using coal and nuclear energy?

9. What has the public reported doing to increase residential and transportation efficiency and the use of renewables?

10. What are the public's policy preferences about energy use in buildings? In transportation?

These and other questions are answered insofar as public opinion data can shed light on them. Any changes in perspective over the last 10 to 15 years are presented.

The order of presentation is identical within chapters. Each chapter begins with a background and summary section; detailed documentation for the summary then follows. In all sections of chapters (except Chapter 3 on the Gulf War), findings are presented in reverse chronological order, with the most recent data first. In Chapter 3 only, findings are presented in chronological order. Certain items contain parentheses within them; this is literally how these items were presented. Parentheses are often used when a list of questions (actually a multi-part question) is being asked; for example, the same question could be asked for an entire set of industries. Parentheses save space by obviating the necessity to repeat the question for each industry.

Frequent gaps in trend data appear in this analysis. Most of these gaps occur during the period of 19801986 when gasoline prices were declining and utility bills had stabilized. This period of quiescence ended with the Chernobyl nuclear accident in 1986. Gasoline prices bottomed out in 1988 and began to increase during that year. Concomitantly, national polls began once again to include more questions on energy. 


\section{The Study's Approach ${ }^{3}$}

The National Renewable Energy Laboratory (NREL-formerly the Solar Energy Research Institute) published a major review of public opinion about energy in 1979 and updated it in 1980 (Farhar et al. 1979; Farhar et al. 1980). ${ }^{4}$ NREL published these reviews to provide information that can help policymakers to assess the congruence of energy policy options with public preferences. This study updates the earlier work.

This updated review and analysis of public opinion on energy relies on more data than were available for the earlier reviews. On-line capabilities simplified the basic search procedure. In 1990, the Roper Organization developed an on-line data base (Public Opinion On-Line) to include contents of public opinion polls back to 1940 . Indexed by search descriptors, this data base is available through the DIALOG on-line data base service. On-line searches were performed for items relating to energy, environment, transportation, buildings, and alternative fuels, as well as for specific policy alternatives such as energy-efficient mortgages. Searches focused on the period 1979 through 1991. In addition, other data from national surveys not entered in the DIALOG data base were gathered. ${ }^{5}$

Simultaneously, researchers contacted the 50 state energy offices, asking for energy-related surveys conducted in their states and localities over the past decade. In addition, colleagues at the U.S. Department of Energy (DOE) and at NREL supplied studies of which they were aware. The data base consisted of items from 557 surveys: 453 from national probability samples of adults in the United States, 45 from national probability samples of U.S. registered voters, and 19 from other U.S. national samples, conducted by major polling organizations such as Gallup, Roper, Harris, and Yankelovich/Clancy/Shulman. Another 40 studies involved sampling of special populations or state or local populations. The methodological quality of the surveys included in this review was judged to be sufficient to warrant drawing conclusions from the body of data. ${ }^{6}$ A few other studies reported in the text through bibliographic citations were used to access survey findings reported in the published literature.

Researchers produced items (either from the data base or from published studies) one to a page. These were hand-sorted into end-use sector categories, grouping together items pertaining to the four end-use sectors-buildings, transportation, utilities, and industry (including solid waste management)-and were then sorted by policy type, fuel type, or technology. Where data were available, these categories were further sorted into questions relevant to decision factors, knowledge and information, behavioral intention

\footnotetext{
${ }^{3}$ Appendix A gives a more detailed explanation of the study's methods. Appendix B presents the list of surveys included in this secondary analysis.

${ }^{4}$ In tracing changes in public opinion over time, this report frequently refers to the earlier reviews. This is done without citation to avoid repeating the references for those publications.

${ }^{5}$ The survey organizations participating in the DIALOG data base did not include all of their most recent data in the data base. Researchers used libraries and contacted polling organizations to obtain some of the more recent data. However, it is reasonable to assume that recent relevant survey items exist that were not located and included in this analysis. Nevertheless, the patterns of findings identified would be unlikely to change, even if other data were added.

${ }^{6}$ Researchers obtained "boilerplate" descriptions of national sampling procedures from survey organizations. Surveys that used probability sampling procedures ordinarily employed by major national polling organizations were judged to be of sufficient quality to include in the review. Other types of samples are identified in the text.
} 
and action, and policy preferences. Other types of items were sorted into such categories as environment and the Persian Gulf war. Within categories, items were arranged in reverse chronological order. Verbatim trend items ${ }^{7}$ were identified and grouped together to permit trend analysis. Each survey in the study was assigned a study number, which was recorded on a numerical list of surveys. At the end of the sorting process, which took several months, the entire body of data was divided into usable categories ready to be analyzed.

The citation system used in this report relies chiefly on four-digit "study numbers" that are found both in the text and on tables and figures. Study numbers may be looked up in Appendix B, where information is given on polling organization, study dates, universe sampled, sample size, and sponsorship. From this information, the study's full citation can be located in the bibliography. Other citations in the text used the standard author/year system; these citations can also be located in the bibliography.

In this report, numerals are used with units of time and measurement except when those units begin a sentence. Other numbers under 10 are written out.

Any secondary analysis ${ }^{8}$ of survey data is limited by the questions polling organizations and other researchers included or did not include in their opinion surveys. This analysis is no exception. Gaps in the analysis sometimes occur because questions were not asked. Some polling organizations withheld the most recent data from the DIALOG data base as a marketing device. Therefore, in a few instances, the most recent data (for example, from 1989 through 1991) were not available for reporting. Given these limitations, some gaps in the total picture remain inevitable. Nevertheless, given the extensive data available, the patterns of public opinion identified in this report would be unlikely to shift in any major way, even if other data were added.

${ }^{7}$ Verbatim trend items are questions that were repeated word for word in multiple surveys over time, usually asked of national samples drawn in identical or similar fashion.

${ }^{8} \mathrm{~A}$ secondary analysis relies on already collected data. 


\section{Chapter 2}

\section{Energy and Environment}

\section{Background and Summary}

Several analysts of American environmental values have concluded that the environment is a "consensual" populist issue. Support for the environment unites blocs of voters-liberals and conservatives, Democrats and Republicans (Cambridge Energy Research Associates/Opinion Dynamics 1992; Dunlap 1991a, p. 12; Dunlap 1991b; Dunlap and Scarce 1991). Growing percentages of the population believe that environmental problems are "serious, worsening, and increasingly threatening to human well-being" (Dunlap and Scarce 1991, p. 655). Public support for government intervention is growing. Typically, among policy options to protect and improve the environment, only restrictions on the use of automobiles fail to receive majority support in public opinion polls (Dunlap 1991a, p. 34).

Environmental concern developed in the late 1960s and reached a peak with the first Earth Day in 1970. Concomitantly, new agencies were created-the Environmental Protection Agency (EPA) and the Council on Environmental Quality (CEQ)-and new legislation was passed, including bills on clean air and water and the National Environmental Policy Act (NEPA). The Reagan Administration's anti-environmental orientation rekindled the environmental movement, and by Earth Day 1990, "public concern for environmental quality reached unprecedented levels" (Dunlap 1991b, p. 285; Dunlap and Mertig 1991).

Energy production and consumption and environmental well-being are intimately related, although government policy has not yet fully reflected this fact. For example, the burning of fossil fuels in power plants and internal combustion engines contributes significantly to carbon dioxide increases in the atmosphere and thus to global warming. Emissions from automobiles, factories, and power plants create global atmospheric environmental changes with potentially negative implications for the economy.

Environmental awareness and concern have spread throughout the world. The Earth Summit in Rio de Janeiro, Brazil, June 1-10, 1992, focused global attention on environmental problems. In preparation for the Rio meeting, the Gallup Organization, in partnership with Riley Dunlap of Washington State University, conducted a "Health of the Planet Survey" on environmental problems. They surveyed 22 nations from January through March 1992 [1560]. Gallup released preliminary findings from the survey in May 1992. These included the following:

- Environmental problems were viewed as serious in half of the countries surveyed.

- Majorities believe their health is being negatively affected by these problems.

- Both global and local environmental conditions were viewed as "very" or "fairly bad" by "significant percentages" in every nation.

- $\quad$ Air and water pollution were seen as quite serious. 
- Both industrialized and developing countries were seen as equally responsible.

- Majorities in 20 countries chose environmental protection over economic growth.

Guide to Chapter 2. This chapter presents data, especially from surveys taken during 1989, 1990, 1991, and 1992, about public perceptions of energy and environmental issues. Information on the level of concern about environmental problems is presented, and public perceptions of the most serious environmental problems are described. Solid waste management is one of the most pressing environmental issues U.S. society is facing. Public views on this problem, and on the waste-to-energy solution, are discussed. Global warming, stratospheric ozone depletion, and acid rain are three significant atmospheric environmental problems especially relevant to energy production and consumption; data are presented on public perceptions of these problems.

Assuming public favorability to environmental protection, a key concern becomes trade-offs. To what extent does the public favor environmental protection over economic growth? Over adequate energy supplies? Over national security concerns? Is the public willing to pay more to protect and improve the environment? What else is the public willing to exchange for environmental protection?

Environmentalism is a rising social movement. Poll data captured opinion on the environmental movement and information on environmental activism, including political, economic, and lifestyle behaviors. Polls seemed to focus particular attention on recycling. Policy preferences are discussed throughout the chapter in concert with each environmental problem addressed. Finally, general or crosscutting policy preferences for environmental protection and improvement are presented at the chapter's end. A summary of the chapter's findings follows below.

Level of environmental concern. The level of environmental concern is on the rise. The number of people believing environmental problems are getting worse has increased substantially in the past 9 years, although one survey reported some recent increased optimism. Opinion is that everyone should be more concerned - the federal government, business and industry, and the public. Although still not in the top three national concerns, the environment seems to be moving in that direction. Majorities in 20 of 22 countries polled chose environmental protection over economic growth if a trade-off is necessary. Majorities in the United States also now select environmental protection over energy supplies. However, opinion appears to be divided when trade-offs between the environment and national security are posed.

Recently, the public has begun to link energy and environmental concerns. Environmental harm from energy production is a concern that people are beginning to feel will hurt them personally within 5 years. There is more widespread concern that individuals will be harmed by environmental problems from burning coal and oil than from nuclear power, and from war and strife over energy supplies than from environmental problems caused by the search for new sources of energy.

Most serious environmental problems. EPA lists stratospheric ozone depletion, air pollution from vehicles and industrial plants, and the greenhouse effect and global warming as some of the worst environment problems. The concerns of the U.S. public mirror this list, although the ranking of importance varies by survey. The most important concerns are air pollution, water pollution, ozone depletion, waste disposal, hazardous waste sites, exposure to toxic chemicals, oil spills, and global climate change. Public concern about oil spills, the greenhouse effect, and ozone depletion increased dramatically between 1988 and 1990.

Municipal solid waste (MSW). Most of the public is aware of waste-disposal problems, and rapidly increasing percentages believe them to be "very serious." Although paper constitutes the most serious waste problem, many believe that disposable diapers, plastic packaging, styrofoam, aerosol containers, and 
plastic bottles constitute disposal problems. Disposition of waste through recycling and through waste-toenergy facilities are both favored options, although recycling is the option of choice.

Waste-to-energy. Although majorities of the public favor burning solid waste to produce electricity, the well-known "not in my backyard," or NIMBY, syndrome could be an impediment to siting waste-toenergy conversion facilities. Despite questions posing lower property taxes if a waste-to-energy conversion facility were sited within 10 miles, opinion was still divided about it. Concerns about aesthetics, odors, increased truck traffic, more noise, a decline in property values, and negative health effects were most frequently mentioned.

Global warming. Most people have heard about global warming, and awareness is increasing. However, understanding of its causes and effects is limited; misconceptions are apparent. The public also does not have a solid understanding of the chlorofluorocarbon (CFC) problem. The public believes that global warming is a serious environmental threat, and many believe that the ozone hole over the North American continent is certain or very likely to cause skin cancer and other health problems. Few data were available on acid rain by itself. A majority appears to be aware of the problem.

Acid rain. A majority of the public appears to be aware of the problem; however, global warming seems to have superseded acid rain as a more pressing environmental problem.

Environmental trade-offs. In the late seventies, questions about energy/environment trade-offs were posed. Currently, the trade-offs seem to be taking three major forms:

- Environment versus economic development or protection against economic losses

- $\quad$ Environment versus adequate energy supplies

- Environment versus national security concerns (dependence on foreign oil).

The percentage favoring environmental protection over adequate energy supplies has been increasing over time, with definite majorities now saying they favor environmental protection. Majorities now choose protecting the environment over economic growth, although a few state that such a trade-off is unnecessary. This minority believes that environmental protection and economic development go together - the concept of "sustainable development" (al though this term itself has not yet appeared in poll questions). Also, majorities indicate that they would like to see a balance between economic growth and preserving nature, with the emphasis on environmental protection.

Opinion is more divided on the question of environmental protection versus national security-pluralities tend to favor each side. The pattern of evidence seems to be that slightly larger pluralities favor environmental protection. However, global environmental problems are themselves seen as a security threat.

Willingness to pay. Many survey items asked about people's willingness to pay for environmental protection. The public says that it is willing to pay more taxes, more for oil and gasoline, more for electricity, and higher automobile prices to protect the environment-up to a point. People may need to believe that any extra costs they paid were actually used for environmental cleanup and protection. Given somewhat low levels of credibility of energy institutions on environmental issues, this could, in practice, constitute a major barrier to willingness to pay more.

However, when viewed strictly from the point of view of people's saying that they would be willing to pay, the findings are consistently supportive of the environment. Majorities have stated they are willing to pay $15 \%$ more taxes (type unspecified) or $\$ 50$ in more taxes (type and length of time unspecified). The proportions saying they are willing to pay more are increasing. Majorities say they would pay more for 
fossil fuels "to prevent global warming from having serious consequences." About two-thirds say they would pay $\$ 5$ to $\$ 30$ for this.

Increasing proportions state that they are willing to pay more for electricity if it was produced in a cleaner way to reduce air pollution. Majorities are willing to pay lower amounts per month, on the order to $\$ 6$ to $\$ 25$. When the suggested price increase reaches $\$ 50 /$ month, majorities state they are unwilling to pay that much, but pluralities of around $40 \%$ say that are willing to pay even that much more. Majorities are willing to pay for "stricter air quality regulations" or to "require electrical companies to cut back drastically on sulphur dioxide emissions." Most are also willing to pay more for "the things you buy" if business and industry increased its efforts to improve environmental quality.

Other trade-offs the public is willing to make to protect the environment include accepting a lower standard of living; almost two-thirds say they would do so. Protecting wilderness areas from energy development is an acceptable trade-off. Most believe that environmental clean-up will not harm, or it will benefit, the economy.

Environmentalism. Membership in national environmental organizations such as the National Wildlife Federation and the National Audubon Society has recently surged. In addition, local activism on environmental problems has given rise to a grassroots environmental movement of national proportions. These two social movements have converged into an emerging national consensus on the importance of environmental protection.

Signs are appearing that environmental activism is extending into other mainstream U.S. organizations. For example, a national survey of League of Women Voters leaders showed that League chapters nationwide are working on such issues as global warming, air quality, and recycling.

Evidence from the analysis shows empathy for the environmental movement, yet only minorities are activists. Majorities report that they are sympathetic to the environmental movement; about one in ten reports being active in an environmental group. Most believe that, while regulation is necessary, environmental protection also means changes in patterns of everyday living and in household expenditures.

Perceived health effects of environmental degradation are motivating environmentally protective behavior. To protect the environment, majorities report that they recycle, buy "green products," avoid products that they believe are harmful to the environment, and conserve their use of energy.

The public believes that business and industry are the major cause of environmental problems, and that they will take action only if government requires them. However, only about one in ten believes that the federal government is doing its job as well as it should be in environmental protection and pollution cleanup. Two-thirds believe more regulation will be required.

Belief that technology will solve environmental problems has declined over the past 10 years. Indeed, approximately one-third believe future scientific research is more likely to cause than to solve environmental problems.

Recycling. Public opinion and action support recycling of an array of materials, including aluminum, glass, plastic, and oil, as an effective means of dealing with solid waste disposal problems. Majorities favor mandatory recycling of certain materials. Recycling generally prevents facility-siting problems (by reducing the need for landfills). Waste-to-energy facilities are also favored and could possibly enjoy even greater public acceptance if coupled with recycling programs. Facility-siting issues would need to be sensitively dealt with to realize the full potential of MSW in dealing with both solid waste disposal and energy needs. 
In sum, despite favorable attitudes toward environmental protection, the public has reported relatively little direct action to protect and improve the environment. The public is beginning to connect energy use and environmental concern. The problem is better defined; the public is still working out its thinking on how to approach the solution.

Policy actions. Many say that the United States has spent too little on environmental protection. There is some evidence that, as late as 1988, public interest and energy industry leaders opposed each others' views on environmental controls to foster energy development. Public interest leaders opposed relaxing such controls; industry leaders were divided, but a majority favored relaxing controls. A majority of the public opposed relaxing environmental controls in favor of energy production.

The polls asked about numerous policy actions that could be taken to protect and improve the environment. The types of actions that would receive the most public support are as follows.

- $\quad$ Reforestation (a very popular option)

- $\quad$ Recycling programs and policies (these receive broad support)

- Power plant emissions controls and enforcement

- $\quad$ Reduced pollution from automobile emissions even if automobile costs rise

- New safety rules and emergency cleanup teams at oil facilities

- Developing new energy efficiency measures and solar and wind energy resources

- $\quad$ No drilling in the Alaska National Wildlife Refuge

- Strict controls or limits on nuclear power

- A number of actions on the part of utility companies to protect and improve the environment.

Some proposals are less popular. Creating more subcompact cars was not widely favored. Closing polluting factories resulting in job losses was not desired. Emissions trading was probably not well understood, and it was not particularly well liked. Although a majority of one study favored a "special tax on carbon dioxide," increased gasoline taxes have consistently been opposed. It may be that people would oppose paying a carbon tax if they understood it meant higher gasoline prices; or they might be willing to pay the higher cost if they believed the extra money would be used for environmental protection. The public also opposes the idea of international law overriding U.S. domestic law in dealing with global environmental problems. Using nuclear power as a replacement for electricity produced by fossil fuels has evoked a divided response.

The balance of this chapter presents detailed information on each of these topics.

\section{Level of Public Concern}

Assessment and expectations. How concerned is the public about environmental problems? Environmental concern has been increasing, some say increasing dramatically, since 1987. Data from polls show that, when costs of environmental mitigation and cleanup are not included, the public exhibits considerable environmental concern. For example, Table 2-1 and Figure 2-A show responses from 1983 through 1990. Respondents were asked to rate the overall quality of the environment compared with the previous 5 years [1425]. The proportion saying environmental quality was "slightly worse," "somewhat worse," and "very much worse" increased by 19 points in the 7 years between 1983 and 1990 . The proportion stating that the environmental quality had improved decreased by 6 points in the same period; those responding that it stayed the same decreased from $24 \%$ to $10 \%$. A shift in opinion seemed to occur between July 1987 and July 1988; during that year, the proportion stating that environmental quality was declining became, for the first time, higher (46\%) than the proportion stating it was improving (32\%). 
Table 2-1. Trends in Perceived Environmental Quality, 1983-1990

"How would you rate the overall quality of the environment compared to how it was 5 years ago?" (July each year) [1425]

\begin{tabular}{|c|c|c|c|c|c|c|c|}
\hline Response & 1983 & 1984 & 1986 & 1987 & 1988 & 1989 & 1990 \\
\hline \multicolumn{8}{|c|}{ Proportion responding (\%) } \\
\hline Very much better & 4 & 5 & 5 & 4 & 4 & 2 & 3 \\
\hline Somewhat better & 18 & 18 & 19 & 22 & 16 & 14 & 14 \\
\hline Slightly better & 15 & 16 & 13 & 15 & 12 & 12 & 14 \\
\hline About the same & 24 & 22 & 26 & 22 & 17 & 19 & 10 \\
\hline Slightly worse & 19 & 18 & 16 & 17 & 20 & 22 & 22 \\
\hline Somewhat worse & 10 & 10 & 11 & 11 & 17 & 17 & 21 \\
\hline Very much worse & 5 & 5 & 5 & 4 & 9 & 10 & 12 \\
\hline Don't know & 6 & 6 & 5 & 5 & 4 & 4 & 3 \\
\hline Totals $^{\mathbf{a}}$ & 101 & 100 & 100 & 100 & 99 & 100 & 99 \\
\hline
\end{tabular}

Source: Constructed by the author using data from Cambridge Reports/Research International.

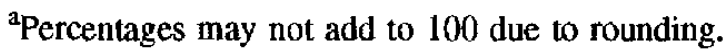

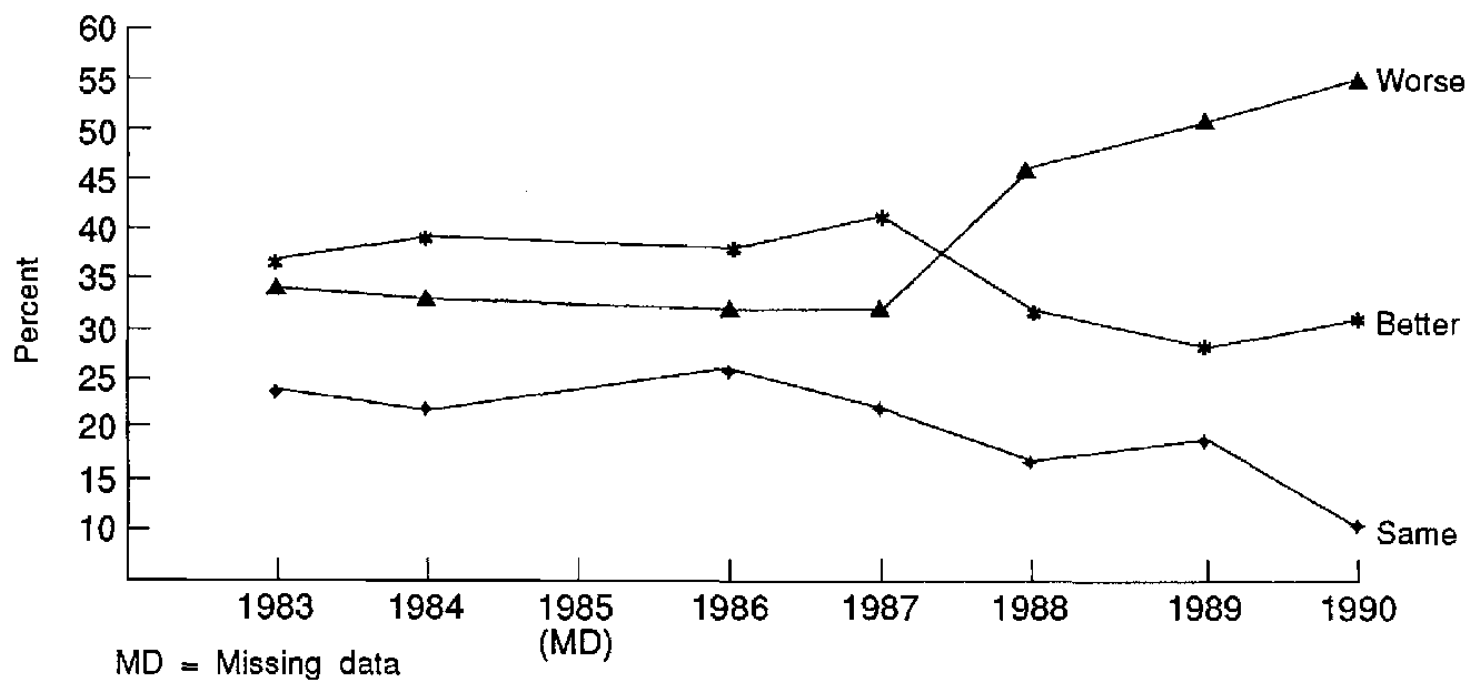

Source: Constructed by author using data from Cambridge Reports/Research international.

Figure 2-A. Trends in perceived environmental quality 
The public, already concerned, apparently expects environmental degradation to continue. Research/ Strategy/Management (RSM) and Greenberg/Lake, The Analysis Group asked a national sample: "Think for a minute about the quality of the environment in which you live. Everything considered, what do you think the quality of your environment will be like 3 years from now? Will it be better than it is today, about the same, or not as good as it is today?" [1025]. Two-fifths expected their environment to deteriorate; $40 \%$ expected no improvement; only $18 \%$ expected improvement.

U.S. News \& World Report reported on June 12, 1989 (p. 69) that "global environmental problems" were the "top priority threats to U.S. security in the opinion of 900 Americans surveyed" [1450]. Forty-seven percent of this sample, taken by the Roosevelt Center for American Policy Studies, selected global environmental problems. More than a third also selected "spread of nuclear and chemical weapons" $(47 \%)$, "domestic social concerns" (35\%), and "Third World poverty" (32\%).

However, Cambridge Energy Research Associates/Opinion Dynamics surveys in 1990, 1991, and 1992, in an anomalous finding, found an increased optimism. They asked: "Do you think the nation's environment has gotten better, gotten worse, or stayed about the same over the last year?" [1562]. A majority, $56 \%$, said it was "better" $(20 \%)$ or stayed the same $(36 \%)$ in 1992; a plurality of $40 \%$ said it had "gotten worse," which was also the modal response. However, the proportion believing this had decreased 13 points in 2 years, while those believing the environment was better increased by 11 points in the same period.

Similarly, the survey found that, in 1992, 46\% expected the environment to be better "10 years from now," an increase of 14 points from the 1990 survey [1562]. Those expecting worsening conditions declined from $49 \%$ in January 1990 to 31\% in January 1992.

Government and business concerns. In January 1991, an Advertising Age survey asked 1514 consumers whether they thought the public, the government, and industry were concerned enough about the environment [1450]. The public said that government was not worried enough (73\%) and that business and industry "were not worried enough $(76 \%)$ They also said that they themselves were not worried enough (68\%) about the environment. In April 1990, virtually everyone in the sample of adults from seven nonattainment cities responded "very concerned" (64\%) or "mildly concerned" (30\%) to the question: "How concerned would you say you are about pollution and environmental quality in your area? Would you say that you are ... very concerned . . . only mildly concerned . . . or not really that concerned?" [1428].

Business executives apparently agreed with the public that the environment is an important concern. USA Today reported responses of 251 executives of Fortune 1000 companies asked, in December 1990, to identify the single most serious threat to the U.S. economy. Environmental pollution was fifth in frequency of mention (by $8 \%$ ), after quality of public education (24\%), size of the federal deficit (23\%), the drug problem (15\%), and growing health care costs $(9 \%)$ [1450].

Linking energy and the environment. The public has begun to link energy and environmental concerns. In December 1990, RSM asked what worried the public the most about the nation's future energy needs [1025]. Table 2-2 and Figure 2-B present the results. Environmental harm from energy production was the most frequently mentioned concern $(26 \%)$ followed by national security damage from dependence on foreign oil $(24 \%)$, high costs $(23 \%)$, and insufficient supply $(21 \%)$. There was little difference in these concerns by region of the country. Respondents from the West were slightly more likely, and those in the South slightly less likely, to cite environmental concerns. Those in the South were more likely than those in other regions to fear that there "will not be enough to go around." 
Table 2-2. Concern about Future Energy Needs by Region

"When you think about America's energy needs in the future, what worries you most?" (December 1990) [1025]

\begin{tabular}{|l|c|c|c|c|c||}
\hline \hline Views & Nation & Northeast & Midwest & South & West \\
\hline Proportion responding (\%) & 26 & 26 & 27 & 23 & 28 \\
\hline \hline $\begin{array}{l}\text { That producing it will } \\
\text { hurt the environment }\end{array}$ & 24 & & & & \\
\hline $\begin{array}{l}\text { That national security } \\
\text { will be threatened by } \\
\text { our dependence on } \\
\text { foreign oil }\end{array}$ & 23 & 23 & 25 & 24 & 25 \\
\hline $\begin{array}{l}\text { That it will cost too } \\
\text { much }\end{array}$ & 21 & 22 & 15 & 24 & 19 \\
\hline $\begin{array}{l}\text { There will not be } \\
\text { enough to go around }\end{array}$ & 6 & 3 & 8 & 4 & 20 \\
\hline Don't know & 100 & 98 & 101 & 100 & 99 \\
\hline \hline Totals
\end{tabular}

Source: Research/Strategy/Management.

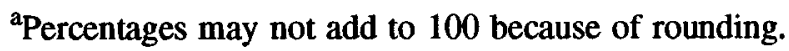

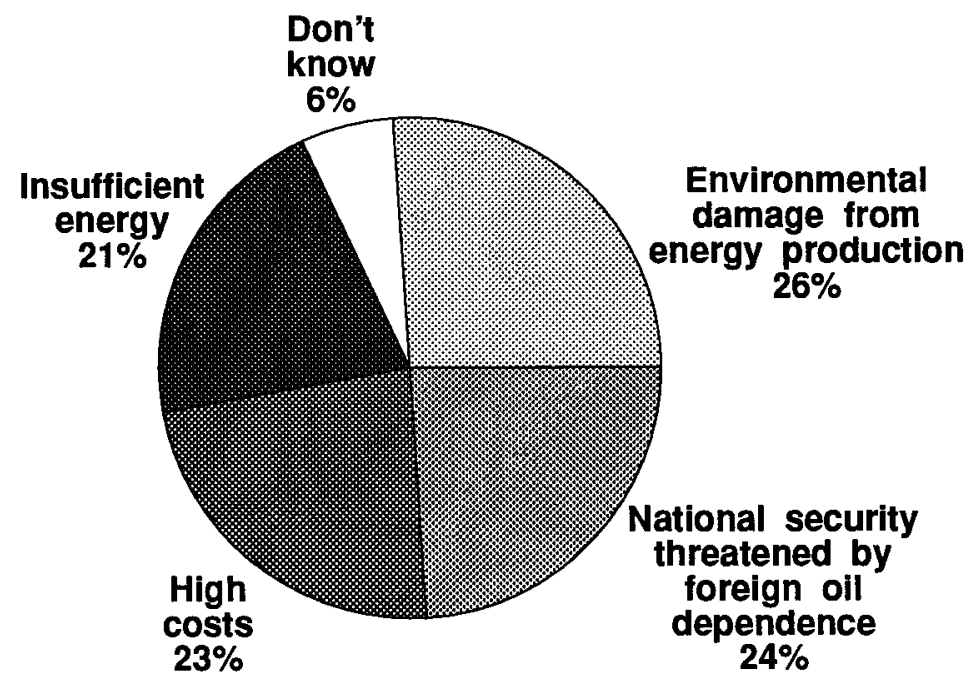

Source: Constructed by author using data from Research/Strategy/Management and Greenberg/Lake, The Analysis Group [1025].

Figure 2-B. Concern about future energy needs 
Environmental impacts on individuals. In January 1992, Cambridge Energy Research Associates/ Opinion Dynamics asked: "I'm going to name two problems at a time, and I'd like you to tell me, in each case, which problem you think is more likely to actually affect you personally in the next five years. Are you more likely to be hurt by [problem 1] or by [problem 2]?" [1562]. These trade-offs help to set environment and energy concerns into a somewhat broader perspective.

The first set of problems was:

- Higher taxes, or

- Environmental pollution.

Sixty-four percent selected "higher taxes"; 26\% "environmental pollution." This result was almost identical to the responses to this item in 1990 and 1991.

The second set was:

- $\quad$ Energy shortages, or

- $\quad$ Environmental problems caused by the use of coal, oil, and gas.

"Energy shortages" were cited by one-half in 1992, up from 36\% in 1990; 35\% mentioned "environmental problems," down from $48 \%$ in 1990.

The third set was:

- Environmental problems caused by burning coal and oil, or

- $\quad$ Environmental problems caused by nuclear power.

Perhaps reflecting increasing concern about the greenhouse effect, one-half selected problems from "burning coal and oil, " up from $45 \%$ in 1990, while 35\% cited "nuclear power" problems, down 5 points from 1990.

The fourth set was:

- Wars and strife caused by fighting over energy supplies, or

- $\quad$ Environmental problems caused by developing new energy sources.

Citing "wars and strife" were 51\%; 33\% selected "environmental problems" resulting from new energy source development.

Global and local problems. Opinion appears to be divided about global versus local problems; however, this could be at least partly an artifact of item wording. Roper asked two similar items in 1989 and in 1990 and got similar results. Roper's questions assumed that the local and global levels are unrelated, or even in competition, ignoring the well-known environmental slogan: "Think globally, act locally." This item phrasing probably affected the poll results.

In 1989, Roper asked: "Do you find you are more concerned about worldwide environmental problems such as the greenhouse effect that may result in global warming - or do you find that local environmental problems concern you more?" [1522]. Pluralities selected each option: 46\% selected local and 44\% selected global environmental problems. The following year, Roper asked: "Generally speaking, are you more concerned about worldwide environmental problems like global warming and saving the rain forests or do local environmental problems concern you more?" [1531]. Again, pluralities selected each 
response- $-48 \%$ chose local and $45 \%$ chose worldwide environmental problems.

The Washington Post asked, in March 1990: "Generally speaking, are you more concerned about worldwide environmental problems like global warming and saving the rain forests or do local environmental problems concern you more?" [1531]. Divided opinion resulted: 48\% said "local" and 45\% said "worldwide" environmental problems; $7 \%$ volunteered "both equally."

The Los Angeles Times, in a November 1989 survey, asked: "Do you find you are more concerned about worldwide environmental problems-such as the greenhouse effect that may result in global warming $\rightarrow$ or do you find that local environmental problems concern you more?" [1522]. Opinion was again divided with this type of question: $46 \%$ responded "local"; $44 \%$ responded "global"; and $6 \%$ volunteered "both."

\section{Most Serious Environmental Problems}

The U.S. EPA maintains a list of the worst environmental problems. Those problems, as reported in 1992's Statistical Record of the Environment, were as follows (the first three are energy related):

- Destruction of the stratospheric ozone layer

- Air pollution from factories and vehicles

- Greenhouse effect

- Radon in homes

- Drinking-water contamination

- $\quad$ Pesticide risk to farm workers.

A number of polls queried respondents on the perceived severity of environmental problems. Most of them presented a preselected list of forced-choice options; poll results are influenced by these response options. Only one open-ended item was located on perceived severity. The fact that importance rankings vary by survey may well be a result of variations in prompted choices.

A 1992 Gallup survey asked samples in 22 countries about "environmental problems facing many communities. Please tell me how serious you consider each one to be here in your community-very serious, somewhat serious, not very serious, or not serious at all?" [1560]. Problems listed were poor water quality; poor air quality; contaminated soil; inadequate sewage, sanitation and garbage disposal; too many people, overcrowding; and too much noise. The U.S. sample identified the following as "very serious": poor water $(22 \%)$, poor air $(18 \%)$, inadequate sewage $(18 \%)$, contaminated soil $(12 \%)$, too many people $(11 \%)$, and too much noise $(7 \%)$.

In a related item, this survey asked: "Now let's talk about the world as a whole. Here is a list of environmental issues that may be affecting the world as a whole. As I read each one, please tell me how serious a problem you personally believe it to be in the world-very serious, somewhat serious, not very serious, or not serious at all-or you don't know enough about it to judge?" [1560]. The problems listed and the proportion of the U.S. respondents identifying them as "very serious" are presented in Table 2-3. The data show that U.S. respondents were less likely than respondents in other countries to identify air pollution, global warming, and loss of ozone as "very serious" environmental problems.

Polling organizations gathered data in 1990 on the U.S. public's greatest environmental concerns. Table 2-4 shows trend results from Roper polls in December 1987/January 1988 and December 1989/ January 1990 [1548]. Approximately half of the 29 identified concerns were included in each month's item. The concerns mentioned most frequently included hazardous waste sites, water pollution, occupational exposure to toxic chemicals, oil spills, destruction of the ozone layer, and radiation from nuclear 
Table 2-3. Perceived Severity of Environmental Problems, U.S. and World Samples, 1992

"Now let's talk about the world as a whole. Here is a list of environmental issues that may be affecting the world as a whole. As I read each one, please tell me how serious a problem you personally believe it to be in the world-very serious, somewhat serious, not very serious, or not serious at all-or you don't know enough to judge?" [1560]

\begin{tabular}{|c|c|c|c|c|c|c|}
\hline \multirow[b]{4}{*}{ Issue } & \multicolumn{5}{|c|}{ Percentages indicating "Very serious" } & \multirow{4}{*}{$\begin{array}{c}\text { World } \\
\text { Mean } \\
\text { Response }^{\mathrm{a}}\end{array}$} \\
\hline & \multirow{3}{*}{$\begin{array}{l}\text { United } \\
\text { States }\end{array}$} & \multicolumn{4}{|c|}{ Other countries } & \\
\hline & & \multicolumn{4}{|c|}{ Range } & \\
\hline & & Low & Country & High & Country & \\
\hline Water pollution & 71 & 43 & $\begin{array}{c}\text { Japan and } \\
\text { Netherlands }\end{array}$ & 80 & Poland & 65 \\
\hline Loss of rain forest & 63 & 24 & Korea & 85 & Denmark & 68 \\
\hline Air pollution & 60 & 30 & Netherlands & 78 & $\begin{array}{l}\text { Poland and } \\
\text { Uruguay }\end{array}$ & 62 \\
\hline Loss of ozone & 56 & 36 & Philippines & 84 & Uruguay & 63 \\
\hline Contaminated soil & 54 & 27 & Korea & 77 & Mexico & 51 \\
\hline Loss of species & 50 & 33 & Korea & 81 & Mexico & 29 \\
\hline Global warming & 47 & 33 & Hungary & 73 & W. Germany & 53 \\
\hline
\end{tabular}

${ }^{2}$ Countries included in the study were:

- East Asia: Japan, Korea (Rep.), Philippines

- Eastern Europe: Hungary, Poland, Russia

- Latin America: Brazil, Chili, Mexico, Uruguay

- North America: Canada, United States

- Other Asia: India, Turkey

- Other Europe: Germany (West), Great Britain, Ireland, Netherlands, Switzerland

- Scandinavia: Denmark, Finland, Norway.

Source: Constructed by the author using data from Dunlap-Gallup.

power plant accidents. The greenhouse effect, 19 th on the list, was identified by $48 \%$; acid rain, $22 \mathrm{nd}$, was identified by $40 \%$ as "very serious." Indoor air pollution, 26th, was a "very serious" concern for $22 \%$.

Public concern about oil spills, the greenhouse effect, and ozone depletion has been increasing dramatically. In the 2 years between data collection periods, concern about oil spills increased by 22 points. The Valdez oil spill (March 24, 1989) occurred between these two periods. Concern about the greenhouse 
Table 2-4. Environmental Concerns

"Here are some things environmentalists have said are problems for us (Card shown). Would you please read down that list and then tell me for each one how serious an environmental problem you think it is-very serious, somewhat serious, not too serious, or not at all serious?" [1548]

\begin{tabular}{|c|c|c|}
\hline Problem $^{\mathbf{a}}$ & $\begin{array}{c}\text { Dec. } 1987 / \\
\text { Jan. } 1988 \\
\text { "Very serious" }\end{array}$ & $\begin{array}{c}\text { Dec. 1989/ } \\
\text { Jan. } 1990 \\
\text { "Very serious" }\end{array}$ \\
\hline \multicolumn{3}{|l|}{ Proportion responding (\%) } \\
\hline Active hazardous waste sites & 62 & 67 \\
\hline Abandoned hazardous waste sites & 61 & 65 \\
\hline Water pollution from industrial wastes & 58 & 63 \\
\hline Occupational exposure to toxic chemicals & 60 & 63 \\
\hline Oil spills & 38 & 60 \\
\hline Destruction of the ozone layer & 47 & 60 \\
\hline Radiation from nuclear power plant accidents & 58 & 60 \\
\hline Industrial accidents releasing pollutants & 51 & 58 \\
\hline Radiation from radioactive wastes & $\mathbf{5 5}$ & 58 \\
\hline Air pollution from factories & 48 & 56 \\
\hline Leaking underground storage tanks & 54 & 55 \\
\hline Coastal water contamination & 47 & 54 \\
\hline Solid waste and litter & b & 53 \\
\hline Pesticide risk to farm workers & 54 & 52 \\
\hline Water pollution from agricultural runoff & 50 & 51 \\
\hline Water pollution from sewage plants & 45 & 51 \\
\hline Air pollution from vehicles & 38 & 50 \\
\hline Pesticide residues in food & 52 & 49 \\
\hline Greenhouse effect & 33 & 48 \\
\hline Drinking water contamination & 49 & 46 \\
\hline Destruction of wetlands & 35 & 42 \\
\hline Acid rain damage & 36 & 40 \\
\hline Water pollution from city runoff & 35 & 35 \\
\hline Nonhazardous waste sites & 33 & 31 \\
\hline
\end{tabular}


Table 2-4. Environmental Concerns (continued)

\begin{tabular}{|c|c|c|}
\hline Problem $^{a}$ & $\begin{array}{c}\text { Dec. 1987I } \\
\text { Jan. 1988 } \\
\text { "Very serious" }\end{array}$ & $\begin{array}{c}\text { Dec. 1989/ } \\
\text { Jan. 1990 } \\
\text { "Very serious" }\end{array}$ \\
\hline \multicolumn{3}{|l|}{ Proportion responding (\%) } \\
\hline Biotechnology & 35 & 30 \\
\hline Indoor air pollution & 26 & 22 \\
\hline Radiation from X-rays & 22 & 21 \\
\hline Radon in homes & 21 & 17 \\
\hline Radiation from microwave ovens & 14 & 13 \\
\hline
\end{tabular}

Source: Constructed by the author using data from the Roper Organization and from the Statistical Record of the Environment, 1992, p. 720.

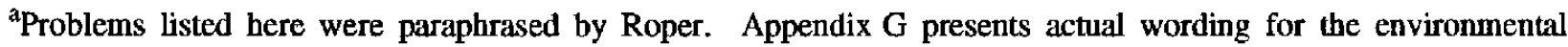
problems. Energy-related problems are in bold.

bot asked in Dec. 1987 or Jan. 1988.

effect increased 15 points, and concern about the ozone-layer destruction increased by 13 points. Both of these problems had widespread media exposure during that period. The proportion identifying air pollution from vehicles as "very serious" increased 12 points in the same period. Other problems with increasing mention as "very serious" by 7 or more points, included air pollution from factories, mills, processing plants, etc.; industrial accidents releasing pollutants; leaking underground storage tanks; and destruction of wetlands.

Cambridge Reports, using an open ended item, identified similar concerns in a national poll in September 1990 [1457]. Table 2-5 shows the results. When respondents were asked to identify the single most important environmental concern, air pollution was the most frequently named response (13\%). Other problems mentioned most frequently were water pollution $(8 \%)$, "just plain pollution" $(7 \%)$, and the greenhouse effect (7\%). Cambridge Research also asked a detailed question asking respondents to rank "potential threats to the overall quality of the environment: from "no threat at all" to "a large threat" [1457]. Table 2-6 presents the results. The most threatening concerns-selected by more than half of the sample - were water pollution, air pollution, high-level nuclear waste, ozone depletion, loss of wilderness areas, nonrecyclable packaging, landfills, oil spills, chemical plants, and acid rain. Many of these concerns are a consequence of energy production and consumption. Energy policies and everyday activities affect these environmental concerns. 
Table 2-5. Top Environmental Concerns

"What do you think is the single most important environmental problem facing the country today?" (Open-ended item) (September 1990) [1457]

\begin{tabular}{||c|c||}
\hline Environmental problem $^{\mathbf{a}}$ & Percentage responding \\
\hline Air pollution & 13 \\
\hline Water pollution & 8 \\
\hline Pollution & 7 \\
\hline Greenhouse effect & 7 \\
\hline Recycling & 5 \\
\hline Disposal of waste & 5 \\
\hline Lack of landfills & 4 \\
\hline Cleaner drinking water & 4 \\
\hline Water and air pollution & 4 \\
\hline Trash disposal & 3 \\
\hline Waste management & 3 \\
\hline Oil spills & 3 \\
\hline Industrial waste & 3 \\
\hline Deforestation & 3 \\
\hline Acid rain & 3 \\
\hline Car pollution & 2 \\
\hline Using up natural resources & 2 \\
\hline Litter & 12 \\
\hline Insecticides & 98 \\
\hline Other & $(1250)$ \\
\hline Don't know & \\
\hline \hline Total ${ }^{\text {b }}$ & 1 \\
\hline & \\
\hline
\end{tabular}

Source: Constructed by author using data from Cambridge Reports/Research International.

${ }^{a}$ Response categories are overlapping because the item was open-ended and coders could not reduce responses to mutually exclusive categories.

bay not add to 100 due to rounding. 
Table 2-6. Perceived Threats to Environmental Quality

"I am going to read you a list of potential threats to the overall quality of the environment. Please use any number from 1 to 7 , where 1 means "no threat at all" and 7 means "a large threat" to tell me how much you think each problem threatens the overall quality of the environment. The more you think the problem threatens overall environmental quality, the higher the number you would give it." (September 1990) [1457]

\begin{tabular}{|c|c|c|}
\hline Environmental threat ${ }^{a}$ & $\begin{array}{c}\text { Percentage } \\
\text { Selecting } \\
\text { 6-7 (large threat) }\end{array}$ & $\begin{array}{l}\text { Mean response } \\
\text { (Scale: } 1-7)\end{array}$ \\
\hline The pollution of our rivers, lakes, and oceans & 75 & 6.1 \\
\hline Air pollution & 71 & 5.9 \\
\hline High-level nuclear waste & 66 & 5.9 \\
\hline Depletion of the ozone layers in the atmosphere & 57 & 5.6 \\
\hline Air pollution caused by cars and trucks & 55 & 5.5 \\
\hline Loss of wilderness areas & 55 & 5.4 \\
\hline $\begin{array}{l}\text { The use of packaging and other materials that } \\
\text { cannot be recycled }\end{array}$ & 54 & 5.5 \\
\hline The disposal of solid waste in a landfill & 54 & 5.5 \\
\hline Oil spills & 54 & 5.4 \\
\hline Chemical plants & 53 & 5.4 \\
\hline Acid rain & 50 & 5.4 \\
\hline Using additives and pesticides in food production & 46 & 5.2 \\
\hline Low-level nuclear waste & 45 & 5.1 \\
\hline Threats to endangered animal species & 45 & 5.0 \\
\hline Global warming from the greenhouse effect & 42 & 5.1 \\
\hline Oil refineries & 24 & 4.4 \\
\hline Electricity generating plants & 16 & 3.9 \\
\hline $\begin{array}{l}\text { Electric and magnetic fields from electric } \\
\text { transmission lines }\end{array}$ & 10 & 3.5 \\
\hline $\begin{array}{l}\text { Electric and magnetic fields from household } \\
\text { appliances }\end{array}$ & 7 & 2.9 \\
\hline
\end{tabular}

${ }^{a}$ Most of these items are related to energy production or consumption.

Source: Constructed by author using data from Cambridge Reports/Research International. 
An NBC News/The Wall Street Journal survey repeated a 1990 item verbatim in 1991: "Which one of the following environmental problems do you think is the most serious facing the country today? Which one is the next most important?" [1486, 1194]. Table 2-7 summarizes the results. In 1991, hazardous waste $(41 \%)$, air pollution (34\%), solid waste $(32 \%)$, and water pollution (31\%) were the problems mentioned most frequently. Levels of concern appeared to be increasing about air pollution, water pollution, global warming, and the perspective that all of the environmental concerns were equally important.

Table 2-7. Perceived Severity of Environmental Problems, 1990-1991

"Which one of the following environmental problems do you think is the most serious facing the country today? Which one do you think is the next most important?"

\begin{tabular}{|c|c|c|c|c|c|c|}
\hline \multirow[b]{2}{*}{ Environmental problems } & \multicolumn{2}{|c|}{ Most serious } & \multicolumn{2}{|c|}{$\begin{array}{c}\text { Second } \\
\text { most serious }\end{array}$} & \multicolumn{2}{|c|}{ Total $^{\mathrm{a}}$} \\
\hline & 1990 & 1991 & 1990 & 1991 & 1990 & 1991 \\
\hline \multicolumn{7}{|l|}{ Proportion responding (\%) } \\
\hline Hazardous or toxic waste & 26 & 21 & 15 & 20 & 41 & 41 \\
\hline Air pollution & 17 & 13 & 23 & 21 & 40 & 34 \\
\hline Solid waste and garbage & 16 & 16 & 14 & 16 & 30 & 32 \\
\hline Water pollution & 15 & 12 & 21 & 19 & 36 & 31 \\
\hline Destruction of our natural resources & - & 15 & - & 12 & - & 27 \\
\hline Destruction of our natural areas & 7 & - & 7 & - & 14 & - \\
\hline Global warming & 7 & 9 & 6 & 11 & 13 & 20 \\
\hline All equally important & 11 & 13 & - & - & 11 & 13 \\
\hline Unsure & 1 & 1 & 14 & 1 & 15 & 2 \\
\hline Totall $^{b}$ & 100 & 100 & 100 & 100 & 200 & 200 \\
\hline $\mathbf{N}=$ & (1001) & (1004) & $(1001)$ & (1004) & (1001) & $(1004)$ \\
\hline Study number & [1194] & {$[1486]$} & [1194] & {$[1486]$} & [1194] & [1486] \\
\hline
\end{tabular}

Source: Constructed by author using data from Hart and Teeter Research Companies.

a Total of "most serious" and "second most serious."

bercentages add to 100 for each study year and to 200 in combining the totals for the two study years. 
The Los Angeles Times asked a national sample, in November 1989, "What do you consider the single most important environmental problem today? Is it . . (list read)? Is there another one of those you think is almost as important or not?" (Accept up to two replies) [1522]. The response options offered were, unfortunately, overlapping. The most frequently mentioned concerns were: "toxic wastes in the water supply" (46\%), "air pollution" (45\%), "damage to our rivers, lakes and oceans" (33\%), "global warming" (12\%), "destruction of wildlife and natural vegetation" (11\%), "traffic congestion" (11\%), "uncontrolled economic growth" (9\%), and "loss of open spaces" (5\%).

In October 1989, RSM asked a national sample: "When you think about the environment, what do you think is the most important problem facing it today - the one you are most concerned about?" [1072]. Figure 2-C charts the results. A majority (52\%) signified atmospheric problems as their highest concern; these included air pollution, smog, global warming/greenhouse effect, ozone layer, and acid rain. The second most frequently identified problem trailed far behind; $22 \%$ identified water quality as most important. "Water quality" included water pollution, water shortage, and quality of drinking water. Another 19\% identified solid waste as of greatest importance, including ground pollution, garbage, sewage, recycling, and industrial wastes. Ten percent cited toxics, which included toxic waste, chemical waste, and pesticides. Finally, $18 \%$ identified other environmental problems as most important; these included deforestation, overdevelopment, conservation, protection of wildlife, and pollution generally.

Consistently, then, the evidence shows that air and water pollution, exposure to hazardous and toxic wastes, waste disposal, and the greenhouse effect have been the public's central environmental concerns recently. Public concern has been increasing most rapidly about atmospheric degradation (air pollution, global warming, and ozone depletion) and oil spills.

"When you think about the environment, what do you think is the most important problem facing it today - the one you are most concerned about?" (October - November 1989) [1072]

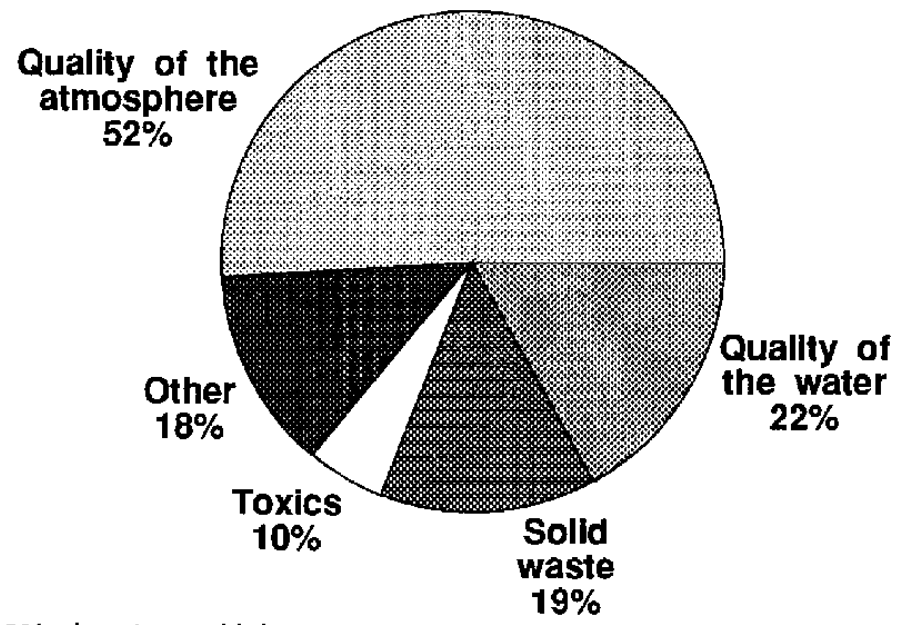

Adds to more than $100 \%$ due to multiple responses.

Source: Constructed by the author using data from Research/Strategy/Management.

Figure 2-C. Environmental concerns viewed as important, 1989 
A related environmental concern is depletion of natural resources. Roper asked national samples between 1981 and 1991 about natural resource depletion in the next 25 to 50 years. Table 2-8 shows the trend. Clean air and water headed the list of concerns in 1991. A majority were concerned that the country was in danger of running out of clean air within 50 years. A plurality $(44 \%)$ were also concerned that the United States would run out of drinking water during that period. More than one-third were concerned that the nation would lose its wilderness areas. The potential use of wilderness areas for extraction of minerals for energy purposes could be one cause of this concern. Relatively few respondents were concerned that the nation would run out of natural gas or coal within 50 years [1558].

Table 2-8. Trends in Perceived Resource Depletion, 1981-1991

"Here is a list of some natural resources (Card shown). Would you read down that list and call off any you think this country is in danger of running out of in the next 25 to 50 years?" [1558]

\begin{tabular}{||l|c|c|c||}
\hline Natural resource & Dec. 1981 & Dec. 1986 & Mar. 1991 \\
\hline Proportion indicating $(\%)^{\mathrm{a}}$ & 56 & 61 & 53 \\
\hline \hline Clean air & 44 & 47 & 43 \\
\hline Drinking water & 39 & 35 & 32 \\
\hline Trees for lumber and paper & 39 & 41 & 40 \\
\hline Wild animal life & 36 & 38 & 37 \\
\hline Wilderness areas & 32 & 28 & 29 \\
\hline Water for irrigated farmland & 31 & 32 & 28 \\
\hline Fish & 29 & 31 & 45 \\
\hline Oil & 29 & 29 & 24 \\
\hline Beaches for public use & 28 & 38 & 38 \\
\hline Farmland & 22 & 23 & 24 \\
\hline Parklands for public use & 21 & 27 & 27 \\
\hline Sufficient land for housing & 17 & 22 & 30 \\
\hline Natural gas & 13 & 16 & 14 \\
\hline Coal & 6 & 6 & 7 \\
\hline None & & 3 & 4 \\
\hline Don't know & & & \\
\hline \hline
\end{tabular}

Source: Roper Organization.

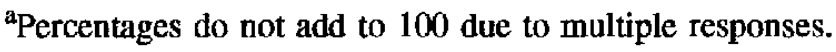




\section{Municipal Solid Waste (MSW)}

A few national poll items measured the perceived seriousness of the MSW problem and of the recycling effort. Roper asked an October 1991 national sample about how serious it perceived the municipal solid waste problem to be in its community. Table 2-9 shows the trend of increased seriousness between 1988 and 1990. The proportion stating that their community has a "very serious" problem increased 24 points in 2 years. Roper also asked, in mid-January 1991, what materials were thought to be causing severe solid waste problems from a forced-choice list of problems [1555]. Selected most frequently (by $40 \%$ or more of the half-sample asked this item) were disposable diapers, styrofoam, plastic bottles and packaging, old tires, aerosol containers, and junked cars. However, paper and paperboard are actually the most serious solid waste problems, at least in terms of quantity of waste (U.S. Environmental Protection Agency 1990). Figure 2-D shows the composition of U.S. MSW in 1988.

Roper also asked half-samples this item in 1988, 1989, and 1990 [1555]. Mentioned by majorities in 1990 were disposable diapers $(56 \%)$, plastic packaging (55\%), styrofoam (54\%), aerosol containers (53\%), and plastic bottles $(50 \%)$. These proportions were several points higher than in 1989, which in turn were higher than in 1988. This shows increasing proportions of the public are identifying specific materials as particularly troublesome disposal problems.

Table 2-9. Trends in Perceived Severity of Solid Waste Disposal Problems, 1988-1990

"Now l'd like to talk with you about the issue of consumer solid waste-that is, household garbage and trash as well as large consumer items such as discarded furniture and appliances. Some communities are beginning to experience problems in that they are running out of places to dispose of their solid wastes. Thinking about your own community, at the present time, would you say the problem of consumer solid waste disposal is very serious, somewhat serious, not that serious, or not at all serious?" (October each year) [1555]

\begin{tabular}{||l|c|c|c||}
\hline \hline Response & 1988 & 1989 & 1990 \\
\hline Proportion responding (\%) & \multicolumn{3}{|c||}{} \\
\hline \hline Very serious & 24 & 29 & 48 \\
\hline Somewhat serious & 34 & 37 & 30 \\
\hline Not that serious & 24 & 19 & 12 \\
\hline Not at all serious & 13 & 11 & 6 \\
\hline Don't know & 5 & 4 & 4 \\
\hline \hline Totals & 100 & 100 & 100 \\
\hline
\end{tabular}

Source: Roper Organization 


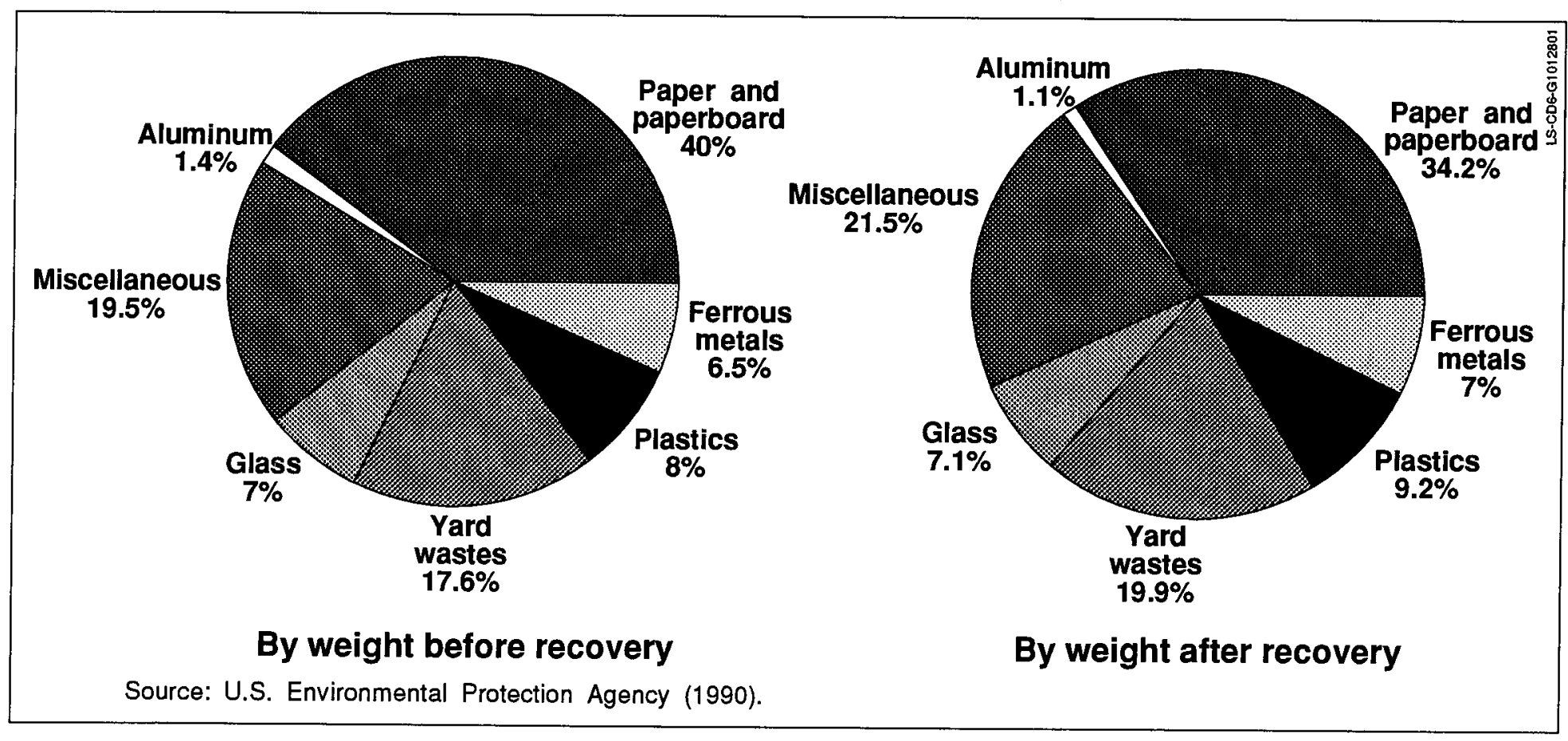

Figure 2-D. Composition of U.S. municipal solid waste, 1988 
A 1990 survey of New Mexico residents found that $37 \%$ believed the disposal of solid waste to be a "very serious" problem in the state, and 39\% said it was "serious"; only $4 \%$ said it was "not at all serious" [1459].

The National Energy Strategy called for two initiatives to encourage waste-to-energy conversion (U.S. Department of Energy 1992, p. 39). The first was a cost-shared contract with the Institute for Gas Technology and Olmstead County, Minnesota, to reduce emissions at a municipal waste-to-energy plant. The second initiative is forthcoming - the Department of Energy (DOE) is planning to publish a multiyear program plan and analysis of research needs for municipal waste-to-energy systems. A pilot test will examine the feasibility of a combined municipal solid waste and sewage sludge combustion process for electricity generation. Such systems could reduce the use of municipal landfills and consumption of fossil fuels.

The disposition of waste-whether through waste-to-energy facilities or through recycling -is significant to energy in yet another way. Energy is "embodied" in the products and packaging being disposed. To the extent that this embodied energy can be captured and reused, energy consumption involved in manufacturing products and packaging can be reduced. Energy consumed in mining and transporting raw materials can be offset to some degree, although the recycling options also require some transportation of waste materials to conversion facilities. Thus, the impacts of these programs go considerably beyond what first meets the eye.

Such waste-to-energy conversion initiatives appear congnent with public opinion. In August 1991, Roper asked a national sample: "Another solution to solid waste disposal is waste-to-energy conversion - where solid waste is burned to generate electricity. Some experts say that we would be better off converting waste into new products and packages, while others say it is more efficient to use our waste to generate electricity. Japan burns two-thirds of its waste this way to generate electricity, and Switzerland burns half of its waste to generate electricity. Currently in the United States, approximately one-tenth of waste is burned to generate electricity. Do you think waste-to-energy conversion is something we should be doing a lot more of here in the United States, a little more, same as we are now, or isn't it something you feel we should be pursuing at all in the United States?" [1437]. The majority (55\%) said we should be doing "a lot more" and another $23 \%$ said "a little more."

Another national sample, in response to a Cambridge Reports/Research International survey on actions electric utilities could take to help the environment, considered the item: "Promoting the use of power plants that produce electricity by burning solid waste" [1457]. A plurality of $43 \%$ said this was one of the "very most important things" a utility could do, while $11 \%$ said it was one of the less important things.

The NIMBY syndrome could throw a wet blanket over plans to establish waste-to-energy conversion facilities. In 1991, Roper asked about a facility 10 to 20 miles from the respondent's home; $50 \%$ said they would be unconcerned and 44\% said they would be concerned [1437]. Of the respondents who said they were not be concerned or they didn't know if such a facility were 10 to 20 miles from where they lived, Roper asked whether they would be concerned if it were built 5 to 10 miles from where they lived. A slightly larger majority, $58 \%$, claimed that they would not be concerned, while $33 \%$ said they would be, and $9 \%$ said they were unsure. Finally, Roper asked those who said they would not be concerned or didn't know if they would be concerned if an energy conversion facility were built 5 to 10 miles from where they lived, whether they would be concerned if it were built "five miles or less . . from where you live, would you be concerned or not?" [1437]. The majority, 51\%, said they would not be concerned, but $35 \%$ said they would be, and $14 \%$ said they didn't know.

Attempting to probe one condition that might make a nearby plant acceptable, Roper then asked: "If allowing a waste-to-energy conversion facility to be located 10 miles from your home lowered property 
taxes in your area by, say, 10 percent, would this make it a lot easier, somewhat easier, or slightly easier for you to accept having a waste-to-energy conversion facility in your neighborhood or would you find this situation unacceptable?" [1437]. " Ten percent said it would be "a lot easier to accept," $19 \%$ said "somewhat," $18 \%$ said "slightly easier to accept," and $41 \%$ said it would still be "unacceptable."

Roper continued a line of questioning with this sample about the potential negative impacts of such facilities: "Imagine you are about to have a waste-to-energy conversion facility located 10 miles from your home. How likely do you think that (effect mentioned) is to happen? Would you say very likely to happen, somewhat likely, not too likely, or not at all likely to happen?" [1437]. Proportions indicating "very" or "somewhat likely" were as follows:

- A lowered quality of life because of odors, increased truck traffic, or more noise $(72 \%)$

- $\quad$ A decline in property values $(71 \%)$

- $\quad$ Negative health effects, such as poor health or disease $(66 \%)$

- Unsightly appearance (64\%).

Roper apparently did not ask about positive effects of the facility; the question appears to be imbalanced, which would serve to bias the responses.

The NIMBY syndrome appears to affect waste-to-energy facility siting despite general approval of the concept. Since 1988, 121 planned waste-to-energy projects have been canceled (Berenyi and Gould 1991). Waste-to-energy facilities could enjoy social acceptability in local communities, depending on local conditions and the manner in which the siting decision process is conducted.

\section{Global Warming and Stratospheric Ozone Depletion}

Polls asked about people's awareness of global warming and ozone depletion, levels of concern, and policy actions that should be taken to deal with these problems.

Awareness. As noted, awareness of and concern about the greenhouse effect has been increasing rapidly. Several poll items specifically addressed this environmental problem. A 1992 national survey of League of Women Voters' (LWV) leaders (chapter officers and board members) found a majority (53\%) indicating knowledge levels on global warming as "very high" or "above average" [1569]. Almost all of the League respondents $(97 \%)$ viewed global warming as a "real environmental threat." Those considering themselves more knowledgeable were significantly more likely to identify global warming as a serious environmental threat (p. <.001) [1569, p. 5].

A majority of the LWV leaders ( $81 \%$ ) said that citizens and local officials do not have enough information to make informed decisions about public policy on global warming.

Cambridge Reports asked, in February 1990, of those who had heard of the greenhouse effect (74\%), "What do you think are some of the causes of the greenhouse effect (in the atmosphere that could cause global warming)?" [1568]. The causes mentioned most frequently in response to this open-ended item were as follows:

- $\quad$ Automobiles (32\%)

- Air pollution (30\%)

- $\quad$ Aerosol sprays (24\%)

\footnotetext{
${ }^{1}$ This item confounds distance from the hypothetical facility with lower property taxes.
} 
- $\quad$ Factories $(22 \%)$

- Deforestation (16\%)

- $\quad$ Ozone destruction (14\%).

Also mentioned were burning fossil fuels (8\%), burning coal (7\%), chemicals (7\%), fluorocarbons (7\%), and carbon dioxide and carbon monoxide $(5 \%)$. Sixteen percent of the respondents said they did not know. Added to the $26 \%$ who had not heard of the greenhouse effect, this suggests that $42 \%$ had little to no knowledge of the causes of the greenhouse effect.

The New York Power Authority (1989) surveyed adults in New York State in 1989 about energy and environmental problems. They found that "while $75 \%$ of the public says it has heard of the 'greenhouse effect,' just $41 \%$ connects it correctly with global warming . ..." The majority of young adults in the survey $(68 \%)$-those most likely to live long enough to experience the full impact of global warming - could not correctly identify the problem, including $27 \%$ who had never heard of it. The New York poll found that, when respondents were told of the greenhouse issue, $81 \%$ said they were concerned, and $60 \%$ said they wanted immediate action [1531].

The Analysis Group also asked, in September 1988: "Have you ever heard anything about a 'greenhouse effect?'" [1431]. More than half, 58\%, said they had, and 42\% said they had not. A follow-up question was: "In your own words, how would you describe the 'greenhouse effect?'" This open-ended item resulted in $14 \%$ saying they didn't know; $11 \%$ or fewer mentioned one of the following descriptions:

- Diminished/reduced ozone layer

- Weather is changing

- $\quad$ Pollution causes it

- Carbon dioxide deteriorates ozone layer

- Increase of earth's temperature

- We're ruining our world

- Destruction of ozone layer

- Depletion of ozone layer heats earth

- Something to do with ozone layer

- Trapped heat

- Pollution traps heat.

These responses show a primitive understanding at best (and, in some cases, lack of understanding) of the greenhouse effect, its causes, and its relationship with global climate change and stratospheric ozone depletion.

In $1984,37 \%$ thought that the greenhouse effect and ozone depletion would be a serious problem 25 to 50 years from then, or sometime between 2009 and 2034 (Table 4-2, in Chapter 4). When asked 6 years later whether they had ever heard of global warming and the greenhouse effect, $86 \%$ of a national sample said that they had; $14 \%$ said they had not [1025]. RSM stated that awareness of global warming grew from 58\% in October 1988 to $79 \%$ in November 1989, and to 86\% in December 1990 [1025; 1072].

Levels of concern. Approximately six out of ten people have been quite concerned about global warming. Gallup studied trends in concern about global warming from 1989 to 1991; Table 2-10 shows the trend data. The proportion indicating that they were personally worried "a great deal" or "a fair amount" about global warming stayed around $60 \%$ during the 3 years $(63 \%, 57 \%$, and $62 \%$, respectively). A minority of about one-third indicated that they were not particularly worried. RSM asked a similar item with a similar result in 1989 . They asked: 
Some scientists say that global warming resulting from a build up of carbon dioxide and other gases in the atmosphere will, over time, have a severe effect on the earth's climate, contributing to the continuous warming of our planet and leading to dramatic changes in weatherpatterns. How would you describe your own view of this issue? Would you describe yourself as extremely worried, somewhat worried, a little worried, or not worried at all about this issue? [1072].

Indicating they were "extremely worried" or "somewhat worried" were $60 \%$, while $38 \%$ said they were only "a little worried" or "not worried at all.

In November 1989, RSM asked respondents who were extremely or somewhat worried about global warming (60\%): "Which of the following possible consequences of global warming concerns you most?" [1072]. Half identified "severe drought and crop loss"; $26 \%$ identified "extremely hot summers and air pollution." Other impacts mentioned were "more powerful hurricanes and tornadoes (14\%) and "sea rise and coastal flooding" (5\%). Five percent didn't know.

Table 2-10. Trends in Concern about the Greenhouse Effect, 1989-1991

"I'm going to read you a list of environmental problems. As I read each one, please tell me if you personally worry about this environmental problem a great deal, a fair amount, only a little, or not at all. How much do you personally worry about . . . the "greenhouse effect' or global warming?"

\begin{tabular}{|c|c|c|c|}
\hline Response & $\begin{array}{l}\text { May } \\
1989\end{array}$ & $\begin{array}{c}\text { April } \\
1990\end{array}$ & $\begin{array}{c}\text { April } \\
1991\end{array}$ \\
\hline \multicolumn{4}{|c|}{ Proportion responding (\%) } \\
\hline A great deal & 35 & 30 & 35 \\
\hline A fair amount & 28 & 27 & 27 \\
\hline Only a little & 18 & 20 & 22 \\
\hline Not at all & 12 & 16 & 12 \\
\hline Don't know & 7 & 6 & 5 \\
\hline Totals $^{\mathrm{a}}$ & 100 & 99 & 101 \\
\hline $\mathbf{N}=$ & $(1239)$ & (1223) & $(1007)$ \\
\hline Survey numbers & {$[1316]$} & {$[1532]$} & [1493] \\
\hline
\end{tabular}

Source: Constructed by the author using data from the Gallup Organization.

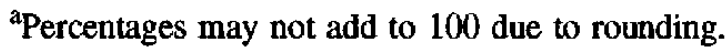


The Analysis Group also attempted to assess the level of concern in September 1988 by asking: "Would you describe yourself as extremely worried, somewhat worried, only a little worried, or not worried at all about [the greenhouse effect]?" [1431]. Responding that they were "extremely worried" or "somewhat worried" were $75 \%$; $24 \%$ said they were only a "little worried" or "not worried at all."

A 1988 poll asked about the credibility of warnings about the greenhouse effect.

There have been many reports in the last year, including those from a broad range of scientists, that the earth is warming up because of air pollution-what is normally called the "greenhouse effect." That could lead to a drying up of the central farming areas of the United States, the erosion of east coast beaches, and the deterioration of forests. Do you view these reports as a truthful warning of a real and important danger or do you view these reports as probably exaggerated and too alarmist?

Seventy-two percent saw global warming as a real danger, while $19 \%$ said it was alarmist, $4 \%$ said "both," and 5\% didn't know [1431].

Concern about ozone depletion was evident in January 1992 poll results. A plurality of $42 \%$ said it was "absolutely certain" or "very likely" that "the hole in the ozone layer will begin to cause dramatic increases in skin cancer and other health problems" [1562]. Another $30 \%$ said it was. "somewhat likely."

Another Analysis Group poll, taken in October 1988, assessed concern about acid rain, global warming, and energy security. The question asked was: "I am going to read you a list of issues facing the country. For each one, please tell me how often you really get upset about it - very often, frequently, from time to time, or almost never" [1431]. The global warming item was worded: "That the warming of the globe, due to the burning of fossil fuels, will cause irreversible changes in our climate and way of life." A majority, $57 \%$, said they were upset about this prospect "very often" (33\%) or "frequently" (24\%).

Policy preferences. The public appears to favor prompt policy actions, in concert with other nations, to mitigate the greenhouse effect. The 1992 LWV leaders' survey found that $91 \%$ of the League respondents said the federal government and private industry were not doing enough "to combat global warming" [1569]. State and local governments were not evaluated much better. Seventy percent of the League leaders could not list a single activity underway in their community to combat global warming. This may have been because of the lack of systems thinking documented elsewhere in this analysis. League leaders probably did not connect mitigating global warming with activities in their communities to conserve energy, prevent pollution, and recycle, for example.

Taking a position unique in the public preference data on gasoline taxes, the LWV leaders said they were willing to pay additional gasoline taxes if this "would significantly reduce U.S. greenhouse emissions" $[1569$, p. 6]. They were asked: "In most European countries, taxes on gasoline are more than $\$ 1$. Taxes are high to encourage energy conservation and to support government programs. Now that you are aware of this, how much tax per gallon on gasoline would you be willing to pay?" After being informed of the European model, $100 \%$ of League respondents said they were willing to pay at least 5 cents more, and $38 \%$ said they would be willing to pay more than 30 cents per gallon in additional gasoline taxes to mitigate greenhouse gas emissions.

In December 1990, RSM asked about two policy steps that the United States could take on global warming. The results of these items must be viewed with caution, however. The RSM items informed respondents about the connection between the burning of fossil fuels and global warming. They also stated that the United States is the largest contributor of global warming gases in the world. The items interpreted the actions of other nations on global warming and President Bush's statements. 
Both items began with the statement: "Scientists say to slow global warming, the world must reduce the amount of greenhouse gases such as carbon dioxide released into the atmosphere. Most carbon dioxide released in the United States comes from the burning of fossil fuels such as gasoline and coal."

The first question went on: "Because the United States is the largest contributor of global warming gases, some have argued that the United States must take the lead in fighting global warming. Others have argued that the United States should wait until there is an international agreement for all nations to move together to fight this problem. Which of these two positions comes closest to your own view?" [1025]. Sixty-eight percent responded that the United States should take the lead; $27 \%$ thought the country should wait for an international agreement; 5\% didn't know.

The second question went on: "Because of their concern about global warming, many industrial countries recently made commitments to limit or reduce their amount of carbon dioxide from fossil fuels released into the air. The Bush Administration believes that scientific predictions of global warming are too uncertain and refuses to commit the United States to any such carbon dioxide limit. Do you believe the U.S. should join other industrial countries in committing to carbon dioxide emissions limits, or should we wait for greater scientific certainty before making such a commitment?" Two-thirds said we should join with other countries; $26 \%$ wanted us to wait for more evidence; $4 \%$ didn't know.

If questions were phrased in other ways, these results might not be so heavily in favor of global efforts. However, international meetings, such as the one resulting in the Montreal Protocol and the Earth Summit in Rio de Janeiro in June 1992, have for some time spotlighted international efforts to counteract global warming. This could be reflected in survey findings showing favorability to them. And, at a minimum, the public may be coming to see the greenhouse effect as a global, not merely a national, problem.

A majority of the public communicates a sense of urgency in meeting global environmental challenges. Market Strategies and Greenberg/Lake asked a national half-sample in June 1991: "Let me read you statements that supporters have made about the proposal that the United States should use its position to get other nations to join together to take action against world environmental problems. Please tell me whether you find the supporters' arguments convincing or unconvincing. How about ... there are serious environmental threats like global warming and ozone depletion that require immediate attention. . . . Do you find this argument convincing or unconvincing? Would that be very or somewhat?" [1488]. More than three-quarters $(78 \%)$ found the statement that global warming and ozone depletion required immediate attention "very convincing" or "somewhat convincing"; $22 \%$ found the statement unconvincing.

The questioning continued: "How about . . . joint action with other countries could shift priorities to global environmental problems, like global warming, that are in the distant future when there are more immediate environmental threats close to home. ..." [1488]. A majority of 53\% said this statement was unconvincing; while $46 \%$ thought it was convincing. Thus, respondents appear to favor more immediate action on global warming; the implication is that the threat from global warming is seen as close to home.

Associated Press/Media General asked a national sample in May 1990: "(I'm going to list a few environmental issues. Please tell me what you think is appropriate for each one: urgent government action no matter the cost, prompt government action, limited government action, or no government action.) ... Global warming known as the greenhouse effect" [1355]. Just over one-third (34\%) said urgent action is appropriate; another $34 \%$ called for prompt action. One-fifth wanted limited action only, and $4 \%$ wanted no action; 9\% didn't know. The same item was asked in May 1989; the proportion calling for urgent action declined by 5 points by 1990 , whereas the proportion calling for limited action had increased by 7 points in that year. Those unsure decreased by 4 points.

Some possible ameliorative actions presented to respondents in the New York Power Authority (1989) 
poll, and the proportions favoring them, included the following [1537].

- $\quad$ Greatly reduce the number of trees being cut down and plant billions of trees, because trees absorb carbon dioxide and give off oxygen $(63 \%)$

- Improve antipollution systems in new cars even if it adds hundreds of dollars to the price of a car $(24 \%)$

- Create a new generation of cars that get 40 miles per gallon even if it means that all new cars must be subcompacts (20\%)

- Replace many of the coal-and oil-burning electric power plants with nuclear power plants because nuclear plants do not give off the gases that cause the greenhouse effect (11\%)

- Sharply increase the taxes on coal, oil, natural gas, and gasoline so that less of these fuels that cause the greenhouse effect will be used $(6 \%)$.

Policy debates concerning fossil fuel use and global warming are likely to intensify. Two examples are the debates about the proposed carbon tax and about the role of the United Nations in protecting the global environment. According to a recent DOE report, Limiting Net Greenhouse Gases in the United States (Bradley, Watts and Williams 1991), a carbon tax of $\$ 140 /$ metric ton of carbon would be needed in 2000 , and $\$ 200 /$ metric ton in 2010. In March 1992, John Rowe, CEO of the New England Electric System, spoke out in favor of a U.S. carbon emissions tax. If adopted, there would be a $\$ 3 / \mathrm{barrel}$ tax on oil and oil equivalents beginning in 1993 . The tax would increase by $\$ 1$ each year until leveling out to $\$ 10$ a barrel in the year 2000 (The Energy Report, March 9, 1992, pp. 177-178). However, John Grasser of the National Coal Association was quoted as saying: "A carbon tax would open the door to potentially huge job losses and it could triple the cost of coal." (p. 178). Michael Baroody of the Global Climate Coalition in Washington, D.C. also reportedly opposed a carbon tax, stating that measures to reduce greenhouse gas emissions could cause a sharp decline in the gross national product, loss of 600,000 jobs, and great economic losses. As reported in the chapter on transportation policy preferences, the public has steadfastly opposed increased gasoline taxes up until now.

Environment Opinion Study, Inc. conducted a survey in 1990 that asked: "Fuels like oil and coal not only pollute the air but also lead to a build-up of carbon dioxide in the atmosphere, which causes global warming. One proposal for reducing this build-up is to impose a special tax on factories and powerplants that produce carbon dioxide emissions. Do you strongly favor, somewhat favor, somewhat oppose, or strongly oppose this proposal to enact a special tax on carbon dioxide?" [1468]. Seventy percent favored a carbon tax (36\% strongly); $25 \%$ opposed it.

The public appears to prefer treating global warming from a national perspective. Majorities did not agree with the concept that the United Nations should have the force of law in curbing global warming. In November 1991, Market Strategies asked a half-sample about global warming policy. Fifty percent favored the idea that "UN resolutions should have the force of law and should rule over the actions and laws of individual countries, including the United States, where necessary to fulfill essential UN functions" [1462]. (This appears surprising in itself.) These respondents were then asked: "(Here are some examples of resolutions that the United Nations might pass. For each one, please tell me if you think it would or would not be all right for that resolution to have the force of law over our own laws) . . A resolution imposing reductions in the use of carbon-burning fuels that contribute to global warming including tougher fuel efficient requirements on international automobile makers, including U.S. companies." Of this special subsample, $86 \%$ said it would be all right for such a resolution to have the force of law; $14 \%$ said it would not be all right; $2 \%$ didn't know. This translates to $43 \%$ of the total 
sample indicating approval of the resolution having the force of law. Thus, a majority did not approve.

When the other half-sample was queried in the same manner ( $38 \%$ of them had agreed with the statement about UN resolutions), $84 \%$ said it would be all right; $16 \%$ said it would not. This translated to $32 \%$ of the total sample saying that the global warming resolution concerning fuel efficiency requirements would be acceptable. Again, a majority did not approve of the United Nations resolution having the force of law.

The Analysis Group asked, in September 1988 (prior to the 1988 presidential election), about the next president's most important goals. One of these goals was: "Acting to protect the ozone layer and slow the warming and changing of the earth's climate" [1431]. A majority, 52\%, said that this action was an "extremely important" goal for the next president (10 on a scale of 1 to 10$)$ and another $21 \%$ rated it as 8 or 9 on the scale.

\section{$\underline{\text { Acid Rain }}$}

Acid rain is another atmospheric environmental problem caused by emissions, particularly those from coalfired power plants, steel production, and other manufacturing. Similar to the questions on global warming, polls asked people about their awareness of acid rain, the severity of the acid rain problem, and levels of their concern about acid rain.

Awareness. In 1984, 70\% of a national sample said they were aware of acid rain [1183]. This subpopulation was asked whether we then knew enough about the causes of acid rain ("emissions from coal-burning plants") to impose regulations immediately. Half of this subpopulation said that there was enough evidence to impose regulations at that time; $41 \%$ said there was not.

Cambridge Reports repeated a January 1990 poll item on the causes of acid rain a year later. The item was:

Acid rain is a phenomenon that occurs when certain acidic gases in the atmosphere combine with moisture and fall to earth in the form of rain, snow, or other precipitation. Some of this gas exists naturally in the environment, and some of it is emitted by various man-made sources, such as automobile exhaust, home heating, and industrial plants and factories. Which do you think is more important as a cause of acid rain: automobile exhaust or emissions from coal-burning factories and plants? [1425].

They reported that a majority thought it came from automobile exhaust; approximately $30 \%$ thought it came from coal-burning "industrial factories and plants" [1425]. The item did not mention coal-fired power plants; for this reason, the results must be viewed with caution.

Perceived severity. In January 1991, three-quarters of the respondents in one survey said that acid rain was a serious problem, down five points from the year before [1425]. Those in this survey who said acid rain was a serious environmental problem (74\%) were asked: "Do you think the problem of acid rain has gotten better, gotten worse, or stayed about the same over the last 5 years?" [1425]. In January 1990, a majority (57\%) said the problem had become worse. One year later, in January 1991, a plurality of $46 \%$ agreed. Those indicating that the problem was about the same or improving were $48 \%$ of the 1991 sample, 10 points higher than the 1990 response.

Harris and Associates asked in March 1990: "How serious would you say . . . air pollution from acid rain, caused by sulfur dioxide emissions from power plants . . . is in the United States today-very serious, somewhat serious, or not serious at all?" [1272]. Sixty-four percent said it was "very serious," while 26\% said it was "somewhat serious." Only 6\% said it was "not very serious" or "not serious at all." 
Levels of concern. The Analysis Group asked a national sample of registered voters how often they got upset about acid rain, global warming, and U.S. dependence on imported oil. The statement on acid rain was: "That environmental pollution, like acid rain, will threaten our future" [1431]. A majority (57\%) said that this possibility upset them "very often" or "frequently." Even more voters $(61 \%)$ said they were often or frequently upset "that America is too dependent on foreign countries for oil and energy."

In sum, few data on acid rain by itself were available-items reflecting many environmental problems sometimes also included acid rain. A majority of the public appears to be aware of the problem; however, global warming seems to have superseded acid rain as a more pressing atmospheric environmental problem.

\section{Preferred Environmental Trade-offs}

Several years ago, pollsters focused on items asking people to choose between protecting the environment, on the one hand, and securing adequate energy supplies, on the other. Recently, they began to add items that asked people to choose between environmental protection and (1) economic development and (2) national security concerns. This section deals with these three types of trade-offs.

Environment/energy trade-offs. The earlier reviews summarized public opinion about trade-offs between energy and the environment as follows: "The existing data appear to indicate that public opinion about energy/environment trade-offs is polarized, with sizable minorities favoring each side of the issue. Public concern seems to lean toward adequate energy supplies (rather than protecting the environment), especially when shortage-related events occur" (Farhar et al. 1980, pp. 153-154).

During the intervening years, these attitudes have changed in favor of the environment. Roper followed attitudes toward these trade-offs from 1973 to 1990, although a 7-year gap exists between 1982 and 1989. Table 2-11 and Figure 2-E present the item wording asking respondents to choose between protecting the environment and adequate energy. The trend clearly shows a dramatic increase between 1981 and 1989 in the proportion choosing environmental protection and a decline in those choosing adequate energy from 1981 to 1990 . A 5-point decrease in those selecting environmental protection between 1989 and 1990 shows a slight reversal in the overall trend. Clearly, however, the public has become markedly less polarized on this issue than it was in 1980 when pluralities favored both sides of the issue. The proportion favoring environmental protection has been increasing over time; a definite majority now say they favor environmental protection over adequate energy.

When asked in 1990 whether they would favor or oppose, as part of a national energy strategy, a policy of "increasing use of coal even if this caused some environmental damage," 74\% said they were opposed [1025]. Penn and Schoen Associates, in its 1990 survey for Texaco, asked about elements of a national energy policy, as well. A majority of its sample opposed "modifying the Clean Air Act to reduce difficult requirements for a new, cleaner-burning gasoline in cars that would be more costly to produce and that would use more crude oil to make" [1206].

Roper also assessed trends in opinion about preferred spending on both environment and energy from 1973 to 1989 [1547]. Respondents were asked whether the nation was spending enough on "improving and protecting the environment" and on "increasing the nation's energy supply," among a list of other national problems. Table 2-12 highlights the results. The proportion indicating that we have spent "too little" on environmental protection increased markedly from $45 \%$ in 1973 to $62 \%$ in 1988 and $59 \%$ in 1989. In 
Table 2-11. Trends in Preference for Environmental Protection versus Adequate Energy, 1973-1990

"Some people say that the progress of this nation depends on an adequate supply of energy and that we have to have it even though it means taking some risks with the environment. Others say the important thing is the environment, and that it is better to risk not having enough energy than to risk spoiling our environment. Are you more on the side of adequate energy or more on the side of protecting the environment?" [1554]

\begin{tabular}{||l|c|c|c|c|c|c|c|c|c|c|c|c||}
\hline \hline Response & 1973 & 1974 & 1975 & 1976 & 1977 & 1979 & 1980 & 1981 & 1982 & 1989 & 1990 \\
\hline Proportion responding (\%) \\
\hline \hline Protect environment & 37 & 39 & 39 & 44 & 35 & 38 & 36 & 40 & 46 & 57 & 52 \\
\hline Adequate energy & 37 & 41 & 40 & 33 & 43 & 43 & 45 & 39 & 35 & 24 & 24 \\
\hline Neither-no conflict (vol.) & 12 & 12 & 13 & 13 & 14 & 10 & 12 & 13 & 14 & 11 & 15 \\
\hline Don't know & 14 & 8 & 9 & 11 & 8 & 9 & 7 & 7 & 5 & 8 & 9 \\
\hline Totals $^{\mathrm{a}}$ & 100 & 100 & 101 & 101 & 100 & 100 & 100 & 99 & 100 & 100 & 100 \\
\hline
\end{tabular}

${ }^{\text {a}}$ Percentages may not add to 100 due to rounding.

Source: Constructed by author using data from the Roper Organization. 
"Some people say that the progress of this nation depends on an adequate supply of energy and that we have to have it even though it means taking some risks with the environment. Others say the important thing is the environment, and that it is better to risk not having enough energy than to risk spoiling our environment. Are you more on the side of adequate energy or more on the side of protecting the environment?" [1554]

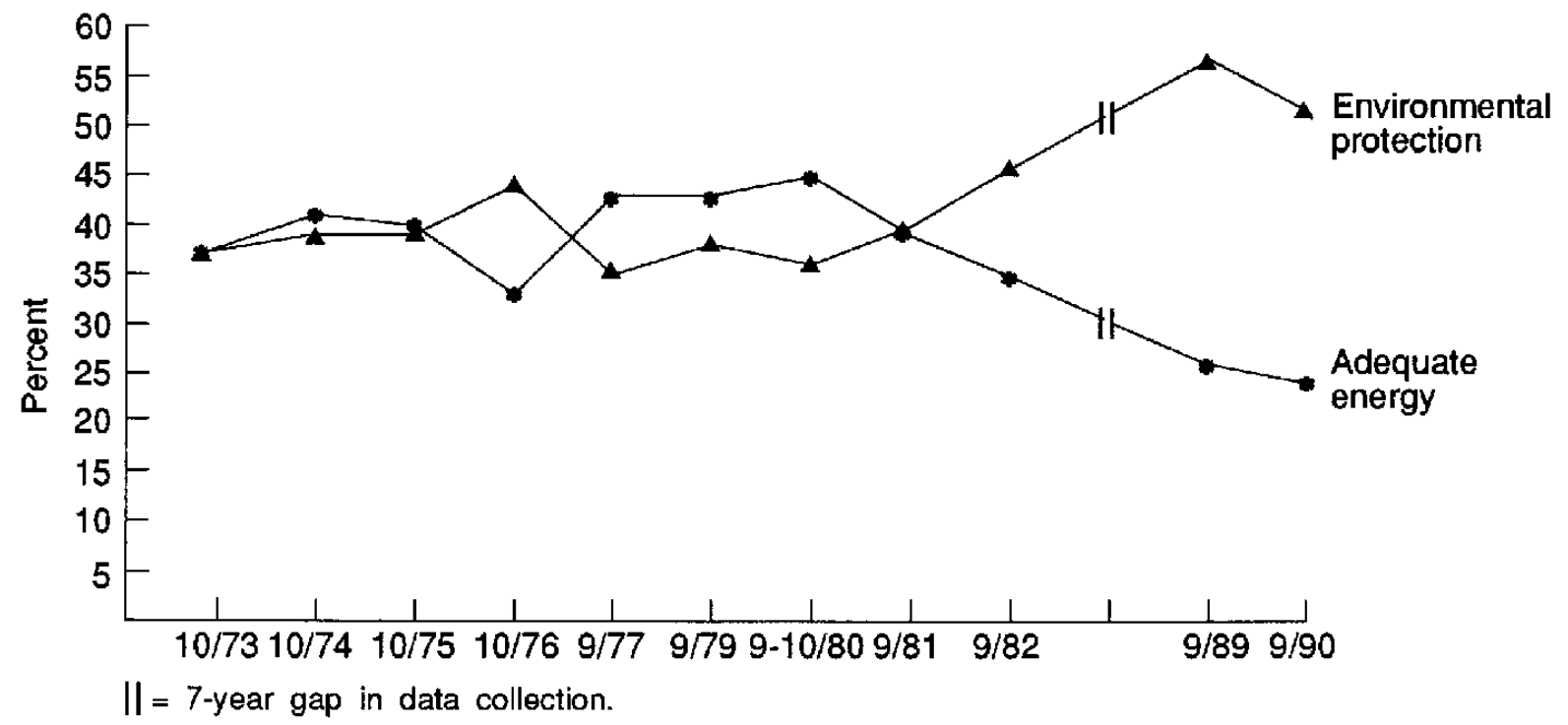

Source: Constructed by the author using data from the Roper Organization [1554].

Figure 2-E. Trends in preferences for environmental protection versus adequate energy

Table 2-12. Trends in Preferred Spending on the Environment and Energy

"Turning now to the business of the country-we are faced with many problems in this country, none of which can be solved easily or inexpensively. I'm going to name some of these problems, and for each one l'd like you to tell me whether you think we're spending too much money on it, too little money, or about the right amount. Spend 'too little' on ...." (December each year) [1547]

\begin{tabular}{|l|c|c|c|c|c|c||}
\hline \hline Problem $^{\text {a }}$ & 1973 & 1980 & 1984 & 1988 & 1989 \\
\hline \multicolumn{2}{|l|}{ Proportion responding (\%) } \\
\hline \hline $\begin{array}{l}\text { Improving and protecting the } \\
\text { environment }\end{array}$ & 45 & 47 & 54 & 62 & 59 \\
\hline $\begin{array}{l}\text { Increasing the nation's energy } \\
\text { supply }\end{array}$ & 66 & 63 & 40 & 36 & 32 \\
\hline
\end{tabular}

Source: Constructed by author using data from the Roper Organization.

ather problems listed in the item were the homeless, the poor, drug addiction, health, education, AIDS, cities, infrastructures, space exploration, military, and foreign aid. 
contrast, those stating we spent "too little" on energy supply development decreased by half during the same period (from $66 \%$ to $32 \%$ ).

Yankelovich, Skelly, and White assessed energy/environment trade-offs in 1985 and 1990. Similar to the Hart-Teeter Research item, the item included six policy options which involved regulation and covered pollution prevention from electric power plants, offshore drilling, industrial plants, and automobile emissions. Table 2-13 summarizes the results. In 1985, five of the six options were favored by majorities of the sample; the only option opposed by a majority was prohibiting offshore oil drilling. In 1990, 49\% favored even this option, while $44 \%$ opposed it. The favored regulations included

- Requiring control technologies to prevent power plant emissions, even if electricity rates rise

- Requiring decreased automobile emissions, even if it means higher prices and smaller cars

- Strictly enforcing pollution limits on industrial plants, even if workers might be laid off

- Imposing high taxes on polluting companies, even if their products would cost more

- Strictly controlling nuclear power plant construction, even if it means that no more would be built.

In each instance, majorities chose the environmental protection option, despite the negative or "downside" presented with each policy choice.

The LWV included an item on relaxing environmental controls in order to produce more energy [1534]. Figure 2-F shows that the general public, industry leaders, and public-interest-group leaders each have a different view of the trade-off. A majority of the industry-leader sample (52\%) favored relaxing environmental controls, whereas $48 \%$ of them opposed this idea. However, virtually all of the publicinterest-leader sample opposed relaxing environmental controls in favor of energy production. The public's view was different from either of the leaders'; a majority of 54\% opposed relaxing environmental controls, while $39 \%$ favored doing so. Of the two types of leaders, however, the public view is closer to the industry leaders' than the public-interest leaders'.

When this survey asked public interest leaders about opening the Alaska National Wildlife Refuge to energy development, $93 \%$ of them opposed this. Conversely, $83 \%$ of industry leaders favored such a move. These discrepancies between interest-group opinion and public opinion could contribute to an apparent growing sense of deadlock and lack of resolution of these issues on the national agenda.

Environment/economy trade-offs. The Gallup global environmental survey asked: "With which one of these statements about the environment and the economy do you most agree? 'Protecting the environment should be given priority, even at the risk of slowing down economic growth' or 'Economic growth should be given priority, even if the environment suffers to some extent" [1560]. Fifty-nine percent of the U.S. sample selected environmental protection over economic growth; this was fewer than the proportions in 13 other countries.

In 1990, Roper asked peoples' preferences in balancing "economic growth" and "preserving nature" [1552]. Figure 2-G summarizes the results. The majority, 56\%, preferred "having a balance with emphasis on preserving nature." Another fifth preferred "having a balance with emphasis on economic growth"; $15 \%$ selected solely "preserving nature" and $2 \%$ solely "economic growth."

Environment/national security trade-offs. NBC News/The Wall Street Journal posed a tough trade-off in 1991. They presented it this way: whether the United States should protect its environment even if this means being more dependent on foreign oil, or whether it should minimize dependence on foreign

- oil even if this means harmful effects on the environment. Figure $2-\mathrm{H}$ presents the verbatim item wording and distribution of opinion. Even with this difficult choice, a plurality of $46 \%$ chose environmental protection; $36 \%$ selected developing domestic energy resources to replace the use of foreign oil [1486]. 
Table 2-13. Trends in Preferred Policies to Protect the Environment Despite Economic Costs

"Protecting the environment often involves costs and other kinds of sacrifices. Do you favor or oppose ...." [1051, 1016]

\begin{tabular}{|c|c|c|c|c|c|c|}
\hline \multirow[b]{2}{*}{ Policy } & \multicolumn{3}{|c|}{ Sept. 1985} & \multicolumn{3}{|c|}{ Nov. 1990} \\
\hline & Favor & Oppose & Unsure & Favor & Oppose & Unsure \\
\hline \multicolumn{7}{|l|}{ Proportion responding $(\%)^{a}$} \\
\hline $\begin{array}{l}\text { Requiring more effective } \\
\text { pollution control equipment in } \\
\text { electric power plants, even if } \\
\text { rates for electricity were to go } \\
\text { up }\end{array}$ & 71 & 23 & 6 & 75 & 20 & 5 \\
\hline $\begin{array}{l}\text { Requiring automobiles to emit } \\
\text { fewer pollutants, even if this } \\
\text { means higher prices and } \\
\text { smaller cars for consumers }\end{array}$ & - & - & - & 72 & 23 & 5 \\
\hline $\begin{array}{l}\text { Strictly enforcing pollution } \\
\text { regulations against an } \\
\text { industrial plant in your area, } \\
\text { even if workers might be laid } \\
\text { off as a result }\end{array}$ & 73 & 17 & 10 & 66 & 25 & 9 \\
\hline $\begin{array}{l}\text { Prohibiting offshore drilling } \\
\text { for oil, even if this were to } \\
\text { cause higher gasoline prices }\end{array}$ & 38 & 53 & 9 & 49 & 44 & 7 \\
\hline $\begin{array}{l}\text { Imposing high taxes on } \\
\text { companies which pollute the } \\
\text { environment, even if these } \\
\text { companies' products would be } \\
\text { higher priced because of the } \\
\text { tax }\end{array}$ & 79 & 16 & 5 & - & - & - \\
\hline $\begin{array}{l}\text { Imposing strict controls on } \\
\text { the building of nuclear power } \\
\text { plants, even if this might } \\
\text { result in the building of no } \\
\text { more nuclear power plants in } \\
\text { this country }\end{array}$ & 62 & 29 & 9 & - & - & - \\
\hline
\end{tabular}

Source: Constructed by author using data from Yankelovich, Skelly, and White.

${ }^{\text {a}}$ Percentages add to 100 for each year. 


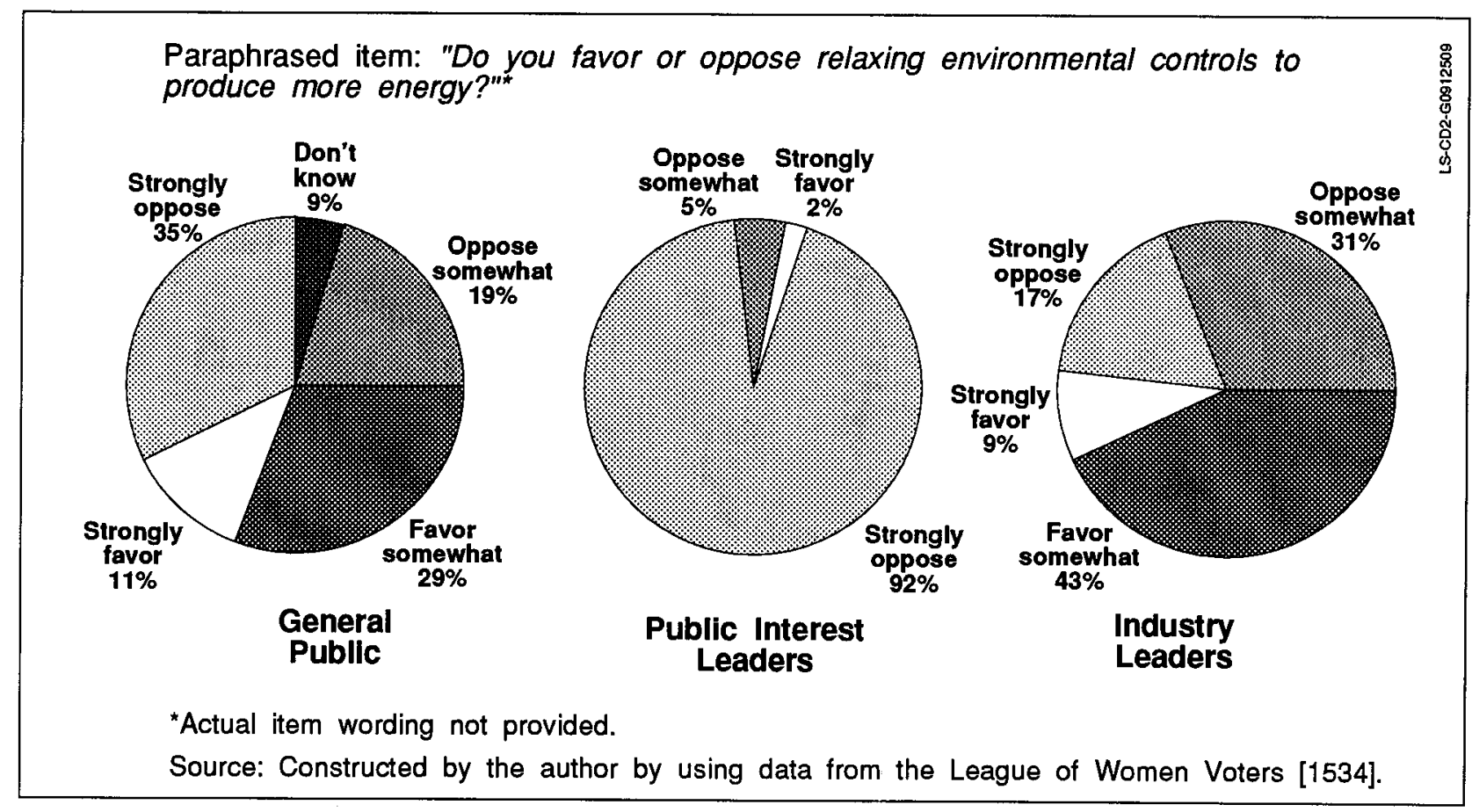

Figure 2-F. Comparison of general public and public interest and energy industry leader preferences on environmental trade-offs

"Sometimes there is a conflict between economic growth and preserving nature. (Card shown). Here is a list of different views about these two things-economic growth on the one hand and preserving nature on the other. Would you please tell me which one comes closest to your own opinion?"[1552]

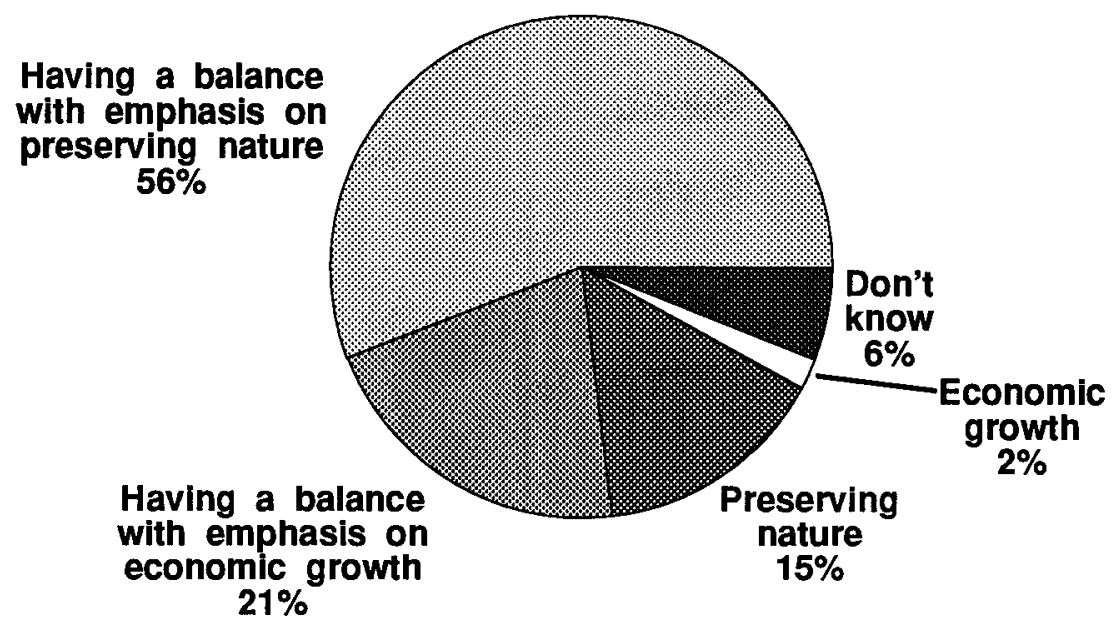

Source: Constructed by author using data from the Roper Organization.

Figure 2-G. Preferred balance between economic growth and preserving nature, 1990 
"Which of the following statements comes closest to your point of view about what the U.S. energy policy should be? Statement A: We should develop more of our domestic energy resources to minimize our dependence on foreign sources of energy even if this has harmful effects on our environment. Statement $B$ : We should protect our environment even if this means being more dependent on foreign sources of energy." (July 1991) [1486]

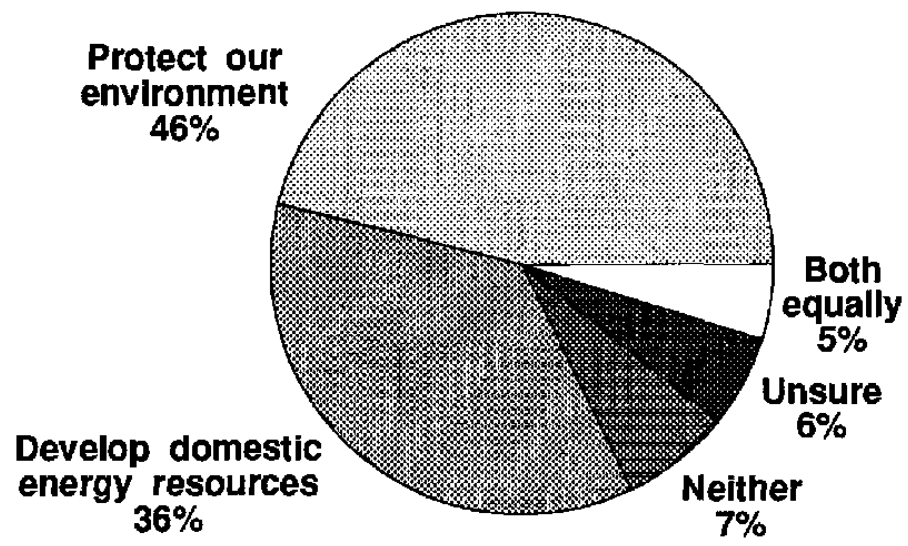

Source: Constructed by author using data from ABC News/The Wall Street Journal.

Figure 2-H. Preferred energy/environment trade-offs, 1991

These findings show that environmental protection and national security concerns are nearly equally balanced, and opinion is divided on the importance of these two values. Another piece of evidence on this comes from a July 1991 NBC News/The Wall Street Journal survey. It asked a national sample: "Some steps to reduce our dependence on foreign energy sources also have some harmful effects on the environment. Please tell me whether you think this action would or would not be worth it to reduce our dependence on foreign energy sources" [1486]. Table 2-14 shows the results. Majorities selected options that would reduce dependence on foreign oil, even if those options were harmful to the environment, except for decreasing restrictions on offshore oil drilling.

\section{Willingness to Pay for Environmental Protection}

A good many survey items asked about people's willingness to pay for environmental protection. These items attempt to go beyond the "motherhood" issues of a clean environment to getting respondents to consider out-of-pocket dollar costs as part of the trade-off equation. Majority concern for environmental protection extends even to personal costs. People seem to be willing to "put their money where their mouths are," at least up to a point.

Many say they are willing to ...

- $\quad$ Pay more taxes

- $\quad$ Pay more for oil and gasoline

- $\quad$ Pay more for electricity

- $\quad$ Accept a lower standard of living

- $\quad$ Pay higher automobile prices

... to protect the environment. 
Table 2-14. Dependence on Foreign Oil versus Environment Trade-Offs

"Some steps to reduce our dependence on foreign energy sources also have some harmful effects on the environment. Please tell me whether you think this action would or would not be worth it to reduce our dependence on foreign energy sources." (July 1991) [1486]

\begin{tabular}{||l|c||}
\hline Trade-0ff & Percentage saying "worth it" \\
\hline \hline $\begin{array}{l}\text { Require cars to be more fuel-efficient and pollute } \\
\text { less, even if it makes them more expensive }\end{array}$ & 55 \\
\hline $\begin{array}{l}\text { Delay new restrictions on the amount of pollution } \\
\text { that can be given off by coal-burning power plants }\end{array}$ & 52 \\
\hline $\begin{array}{l}\text { Allow more exploration and development in } \\
\text { protected wilderness areas }\end{array}$ & 51 \\
\hline $\begin{array}{l}\text { Require cars to be more fuel-efficient and pollute } \\
\text { less, even if this means they will be smaller and less } \\
\text { safe }\end{array}$ & 53 \\
\hline Loosen restrictions on offshore oil drilling & 51 \\
\hline
\end{tabular}

Source: NBC News/The Wall Street Journal.

Taxes. People say they are willing to pay more taxes to benefit the environment. For example, Gordon S. Black queried a March 1990 national sample: "Would you be willing to pay $15 \%$ more in taxes each year to significantly reduce air and water pollution?" [1283]. A large majority, 61\%, said they would be willing to pay that much, while $32 \%$ said they would not. Another 7\% said they didn't know or refused to answer.

The U.S. News and World Report, April 23, 1990, reported on trend data from Associated Press/Louis Harris and Associates [1450]. This national poll asked: "Would you be willing to raise your taxes in order to control pollution/improve the environment?" Two-thirds of the 1990 sample said they were willing, an increase of 15 points in 20 years. The proportion saying they were unwilling declined from $34 \%$ in 1970 to $29 \%$ in 1990 . Those unsure decreased from $12 \%$ to $2 \%$ in the 20 -year period.

In January 1992, a national poll asked about people's willingness to pay $\$ 50$ in increased taxes to solve listed environmental problems (or for potential solutions to them) [1562]. The item did not specify the type of taxes (e.g., income tax, property tax, or sales tax) or the period of time (e.g., $\$ 50$ per year or a one-time payment). Table 2-15 summarizes the data for seven environmental problems-water pollution, air pollution, wilderness area protection, ozone layer depletion, solid waste disposal, the greenhouse effect, and acid rain. Included in the list were development of renewable energy sources and of new energy conservation measures. Majorities (ranging from 59\% to 78\%) indicated that they would definitely or possibly be willing to pay more taxes; minorities of one-fifth to one-third were "probably" or "definitely" unwilling to do so. More than half were "definitely" willing to pay the $\$ 50$ tax to solve water pollution problems. And, consistent with results reported in other chapters of this report, pluralities of $47 \%$ and 
Table 2-15. Willingness to Pay More Taxes for Solving Major Environmental Problems

"I'm going to read you a list of major environmental problems and l'd like you to imagine that you could pay a $\$ 50$ tax increase to solve each of these problems. For each problem that I mention, please tell me whether you would definitely be willing to pay an extra $\$ 50$ in taxes to solve that problem, whether you might be willing, whether you probably would not be willing, or whether you definitely would not be willing to pay an extra $\$ 50$ in taxes to solve this problem." (January 1992) [1562]

\begin{tabular}{|c|c|c|c|c|}
\hline $\begin{array}{l}\text { Problem (or } \\
\text { Solution) }\end{array}$ & $\begin{array}{l}\text { Definitely } \\
\text { willing }\end{array}$ & $\begin{array}{l}\text { Might be } \\
\text { willing }\end{array}$ & $\begin{array}{l}\text { Probably or } \\
\text { definitely not } \\
\text { willing }\end{array}$ & $\begin{array}{l}\text { Don't } \\
\text { know }\end{array}$ \\
\hline \multicolumn{5}{|c|}{ Proportion responding (\%) } \\
\hline Water pollution & 52 & 26 & 20 & 2 \\
\hline $\begin{array}{l}\text { Development of new } \\
\text { energy sources such as } \\
\text { solar and wind power }\end{array}$ & 47 & 24 & 25 & 4 \\
\hline Air pollution & 44 & 29 & 25 & 2 \\
\hline $\begin{array}{l}\text { Development of new } \\
\text { energy conservation } \\
\text { measures }\end{array}$ & 43 & 27 & 25 & 5 \\
\hline $\begin{array}{l}\text { Protection of wilder- } \\
\text { ness lands from oil } \\
\text { and gas exploration }\end{array}$ & 42 & 24 & 31 & 3 \\
\hline $\begin{array}{l}\text { The depletion of the } \\
\text { ozone layer }\end{array}$ & 36 & 28 & 29 & 7 \\
\hline $\begin{array}{l}\text { Disposing of solid } \\
\text { waste--trash and } \\
\text { garbage from homes } \\
\text { and businesses }\end{array}$ & 35 & 30 & 33 & 2 \\
\hline $\begin{array}{l}\text { Dealing with the } \\
\text { greenhouse effect--the } \\
\text { gradual warming of } \\
\text { the earth }\end{array}$ & 33 & 28 & 32 & 7 \\
\hline Acid rain & 30 & 29 & 34 & 7 \\
\hline
\end{tabular}

Source: Constructed by the author using data from Cambridge Energy Research Associates/Opinion Dynamics.

${ }^{\text {a }}$ Row percentages add to 100 unless there is rounding error. 
$43 \%$, respectively, said they were "definitely willing" to pay the $\$ 50$ tax for development of "new energy sources such as solar and wind power" and "new energy conservation measures."

Gasoline. To protect and improve the environment, many would be willing to pay more for gasoline. In July 1991, NBC News/The Wall Street Journal asked: "Do you think the government should or should not require that all gasoline cause less pollution, even if it costs 15 or 20 cents more per gallon?" [1486].

Seventy-six percent responded that the government "should require that all gasoline be made much cleaner"; $18 \%$ said this should not be required; $6 \%$ were unsure.

In July 1991, Hart and Teeter asked two questions on paying more for gasoline to protect the environment. The first item asked: "As you may know, one of the major oil companies says that it has invented a new kind of gasoline that causes much less pollution but would cost 15 to 20 cents per gallon. If this new gasoline were now available, do you think you would or would not pay the extra money to buy it?" [1486]. Two-thirds said they would, and $27 \%$ said they would not; $1 \%$ said they did not drive, and $5 \%$ were unsure. Three-quarters of this sample said, in response to the second item, that "the government should require that all gasoline cause less pollution, even if it costs 15 or 20 cents more per gallon" [1486].

In 1990, Yankelovich/Clancy/Shulman asked: "Would you be willing to pay an extra 25 cents per gallon of gas to reduce pollution and global warming?" [1016]. A majority of 59\% said they would; $36 \%$ said they would not; $5 \%$ said they were not sure. Opinion was somewhat more divided when pollsters asked: "Would you be willing to pay an extra 50 cents per gallon of gas to reduce pollution and global warming?" Pluralities of $49 \%$ said they would not and $48 \%$ said they would be willing, while $3 \%$ were unsure.

When asked about national energy strategy options in December 1990, a majority (56\%) of a national sample "strongly" or "somewhat" favored "adding a federal gas tax of 10 cents per gallon earmarked for an environmental trust fund" [1025]. However, when the amount of gas tax was increased to 50 cents per gallon, the percentage favoring this option dropped to 37\%. And, as noted in the section on global warming, LWV leaders were willing to pay increased gasoline taxes if this "would significantly reduce U.S. greenhouse emissions."

In May 1990, Associated Press asked: "Would you like to see new safety rules and emergency cleanup teams in place at all major oil facilities, even if the expense would raise the price of oil and gasoline?" [1355]. Eighty percent said "yes," and 14\% said "no"; 6\% didn't know. This repeated a 1989 item, the results of which were virtually identical [1357].

In April 1990, Hart-Teeter Research asked: "(Everyone wants a clean environment, but the question comes down to ... a at what cost or inconvenience. I'm going to read some policy options and the problem associated with each. Tell me if you would favor or oppose each one.) . . . A 20-cent per gallon increase in the price of gasoline for cleaner-burning alternative fuels" [1194]. One-half opposed this idea; $48 \%$ approved of it, and $2 \%$ were unsure.

Another 1990 survey asked: "Now suppose the price you pay for fossil fuels like coal, oil, and natural gas had to go up to prevent global warming from having serious consequences; what is the maximum additional monthly cost you would be willing to pay?" [1025]. Fifteen percent said they would be willing to pay nothing more, and $8 \%$ either didn't know or refused to answer. This left $77 \%$ indicating a willingness to pay something more for environmental mitigation. The distribution of responses follows. 
- $\quad$ Less than $\$ 5$ more $(20 \%)$

- $\$ 5$ to $\$ 15$ more $(29 \%)$

- $\$ 15$ to $\$ 30$ more $(14 \%)$

- $\quad$ More than $\$ 30$ more $(14 \%)$.

Newsweek asked 14,000+ new car buyers, in 1990, what additional amount they would be willing to pay for a fuel that significantly reduces air pollution (see Table 2-16). Forty-three percent said they would be willing to pay from $10 \%$ more to $50 \%$ or more additional cost for such fuels. Twenty-four percent said they were unwilling to pay more, and 33\% said they didn't know.

Electricity. Samples indicate a willingness to pay more for electricity if it would protect the environment. In 1990, the Gordon S. Black survey asked respondents: "Would you be willing to pay $\$ 50$ more each month on your electric bill if it meant that electricity could be produced in a cleaner way that would reduce air pollution?" [1283]. Given this higher priced option, a majority of 51\% refused; a plurality of $41 \%$ said that they would pay the $\$ 50 ; 8 \%$ didn't know.

Cambridge Reports/Research International asked, in 1990: "How much more would you personally be willing to spend each month to have your electricity come from sources that are less harmful to the environment?" [1457]. The response options prevented discerning those who would pay nothing at all,

Table 2-16. Additional Amount Willing to Pay for Fuel That Significantly Reduces Air Pollution, 1990

\begin{tabular}{||l|c||}
\hline Responses & Percentage of new car buyers ${ }^{\mathbf{b}}$ \\
\hline \hline Nothing & 24 \\
\hline $10 \%$ more & 23 \\
\hline $20 \%$ more & 11 \\
\hline $30 \%$ more & 4 \\
\hline $40 \%$ more & 1 \\
\hline $50 \%$ or more & 4 \\
\hline Don't know & 33 \\
\hline Total & 100 \\
\hline
\end{tabular}

Source: Constructed by the author using data from Newsweek.

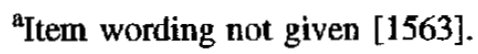

b 14,000+ new car buyers, 1990. 
because the first option was $\$ 0$ to $\$ 5$, and $22 \%$ responded in that manner. The remaining $78 \%$ said they were willing to pay more: $29 \%$ said they would pay $\$ 6$ to $\$ 10$ more; $21 \%$ said $\$ 11$ to $\$ 20$ more; and $26 \%$ said $\$ 21$ to $\$ 994$ more. 2

In 1990, Hart-Teeter Research Companies asked whether a national sample of registered voters would favor or oppose enforcing "stricter air quality regulations which would increase utility bills $\$ 10.00$ per month" [1194]. A majority (57\%) favored such an increase; $40 \%$ opposed it, and 3\% were unsure.

ABC News/The Washington Post asked in 1989: "As you may know, sulphur dioxide emissions from coal-burning power plants are a major cause of the acid rain that destroys forests and lakes. Do you approve or disapprove of requiring electric companies to cut back drastically on sulphur dioxide emissions even if that means higher electric bills?" [1371]. Eighty percent approved of this requirement; 17\% disapproved.

That same year, Associated Press asked: "To reduce air pollution, would you support or oppose ... strict pollution controls on oil- and coal-burning power plants, even if that would raise the price of electricity?" [1357]. Supporting such controls were 72\%; one in five opposed them; 8\% were unsure. And, Yankelovich, Skelly, and White asked in 1985: "Protecting the environment often involves costs and other kinds of sacrifice. Do you favor or oppose requiring more effective pollution control equipment in electric power plants, even if rates for electricity were to go up?" [1051]. Seventy-one percent favored effective pollution control despite increased electricity rates; $23 \%$ opposed the idea; $6 \%$ were unsure.

In March 1985 and again in April 1986, Louis Harris and Associates asked who should pay the cost of cleaning up acid rain. Table 2-17 presents the results. The responses remained virtually unchanged between the 2 years. The most preferred payers were utility shareholders (by almost three-quarters), followed by electricity consumers nationally (by approximately half).

The Indiana Division of Energy Policy mailed a questionnaire to 15,000 Indiana residents in December 1988 asking about the costs of ameliorating the acid rain problem in their state [1444]. Responding were 1089 residents. The question asked was: "The responses to this question will be forwarded to state legislators and Indiana Congressmen. Please consider your answer carefully. How much money would you be willing to spend in the form of an increase to your electric bill to reduce the emissions associated with acid rain?" Almost one-third $(31 \%)$ said they would be unwilling to pay anything more for their electricity. Another $29 \%$ responded with comments but did not indicate a dollar amount. Among the remaining respondents naming a dollar amount, the responses varied widely, ranging from $\$ 1$ to $\$ 1000$ per year. For all cases in which respondents would pay more than $\$ 0$ and less than $\$ 1000$ per year, the range was $\$ 1$ to $\$ 599$ per year; the mean response was $\$ 43.84$; the median was $\$ 25$; and the standard deviation was 50.03 , showing a wide variation in responses. The responses fall into three categories:

- Those who cannot afford to pay higher utility bills or who felt that utility bills should not be used to pay for reduced emissions.

- Those not wanting to pay because they failed to see a connection between the utility's cost of implementing emission controls in generating electricity and then charging their electricity customers for this cost.

\footnotetext{
${ }^{2}$ Respondents were asked the dollar amount of their average monthly electric bill. The range of responses was: $21 \%$ paid $\$ 0$ to $\$ 40 ; 23 \%$ paid $\$ 41$ to $\$ 65 ; 27 \%$ paid $\$ 66$ to $\$ 100$; and $15 \%$ paid $\$ 101$ to $\$ 994$.
} 
Table 2-17. Perception of Who Should Pay for Acid Rain Cleanup

"Although experts disagree on the environmental impact of rainfall with high acid levels, most agree that acid rain is caused by sulfur emissions from electric utility plants that burn coal and oil and by nitrogen oxide emissions from cars and trucks. If Congress passed a law that required ... (option listed) . . . to shoulder the substantial costs of cleaning up acid rain, would you consider such a law fair or unfair?" (March 1985 and April 1986) [1271; 1267]

\begin{tabular}{||l|c|c|c|c||}
\hline \multirow{2}{*}{ Response } & \multicolumn{2}{|c|}{1985} & \multicolumn{2}{c||}{1986} \\
\cline { 2 - 5 } & Fair & Unfair & Fair & Unfair \\
\hline Proportion indicating (\%) & \multicolumn{3}{||}{} \\
\hline \hline $\begin{array}{l}\text { The shareowners of investor- } \\
\text { owned electric utilities }\end{array}$ & 72 & 23 & 73 & 23 \\
\hline Electricity consumers nationally & 50 & 46 & 51 & 45 \\
\hline $\begin{array}{l}\text { Electricity consumers in eastern } \\
\text { and southern states where most } \\
\text { coal and oil is burned }\end{array}$ & & & & 46 \\
\hline \hline
\end{tabular}

Source: Constructed by the author using data from Louis Harris and Associates.

aPercentages for each year would total 100 if "not sure" responses were included.

bIn 1985, the item mentioned only "eastern," not "eastern and southern" states.

- Those who felt that if everyone contributed a small amount, a large benefit would ensue; also those who felt acid rain was an important problem.

Other comments suggested the perception that nuclear energy might still be a solution, advocated energy conservation, suggested a percentage increase in utility bills to offset emissions control costs, or raised questions about the effectiveness of methods to reduce acid rain.

Opinion Research Corporation (ORC) asked in 1984: "Would you favor or oppose restrictions on the use of coal by electric power plants in states that do not have acid rain problems, even if those restrictions would mean the electricity would cost more?" That year, $47 \%$ favored such restrictions and $41 \%$ opposed them. ORC also asked those aware of acid rain (70\% of its sample that year) how the higher electricity costs should be paid [1183]. A plurality of $41 \%$ indicated electricity customers should pay. Another $18 \%$ said federal taxes should be used, and $15 \%$ selected a special tax on electricity users. Another $26 \%$ of the sample didn't know or made other suggestions.

When reviewed together the results from the 1984 national poll by ORC and those from the 1985 and 1986 Louis Harris polls $[1271 ; 1267]$ appear inconsistent. The former poll found $41 \%$ saying electricity customers should pay. The latter found that although $50 \%$ in 1985 and $51 \%$ in 1986 thought it was fair 
for electricity customers nationally to share the burden, $72 \%$ in 1985 and $73 \%$ in 1986 said it was fair for "shareowners of investor-owned utilities" to pay. This seeming inconsistency is probably the result of differences in item wording and the response options presented.

There is a limit to the increase in electricity rates consumers say they are willing to pay, even for environmental protection. In 1988, CBS News/The New York Times asked a national sample: "The greenhouse effect, caused by air pollution, may be creating a weather pattern of hotter summers and more droughts. It may be necessary to use cleaner but more expensive ways of producing electricity in order to reduce this pollution. Would you be willing to see your electricity bill increase by $\$ 50$ a month in order to do this, or wouldn't you?" [1328]. A majority of 58\% said they would be unwilling to pay $\$ 50$ a month more, while $37 \%$ said they would be willing; $5 \%$ were unsure.

The economic costs involved in protecting and improving the environment are acknowledged by majorities of national samples. Table 2-18 shows that the public has increasingly supported stricter air pollution regulations despite economic costs. The proportions agreeing that stricter regulations are needed despite economic costs increased 15 points between 1988 and 1990, to $78 \%$. Most believed that environmental benefits warranted the costs they perceived to be involved.

Table 2-18. Trends in Preferred Trade-offs for Air Pollution Regulation

"Congress has passed amendments to the Clean Air Act that would make air pollution regulations stricter. Thinking about this issue, which of the following views are closer to your own?" a [1425]

\begin{tabular}{|c|c|c|c|}
\hline Views & $\begin{array}{l}\text { July } \\
1988\end{array}$ & $\begin{array}{l}\text { July } \\
1989\end{array}$ & $\begin{array}{c}\text { December } \\
1990\end{array}$ \\
\hline \multicolumn{4}{|l|}{ Proportion responding (\%) } \\
\hline $\begin{array}{l}\text { Even though there may be some economic } \\
\text { costs, we need stricter air pollution } \\
\text { regulations }\end{array}$ & 63 & 69 & 78 \\
\hline $\begin{array}{l}\text { The economic costs of stricter air pollution } \\
\text { regulations, including the loss of jobs, will } \\
\text { probably outweigh the environmental } \\
\text { benefits }\end{array}$ & 18 & 17 & 15 \\
\hline Don't know & 18 & 14 & 8 \\
\hline Totals ${ }^{b}$ & 99 & 100 & 101 \\
\hline
\end{tabular}

Source: Constructed by author using data from Cambridge Reports/Research International.

aSlightly different item wording, not reported, was used in 1988 and 1989.

bercentages may not equal 100 because of rounding. 
Lower standard of living. Costs of environmental protection can come in many forms. A trade-off item in a 1990 survey was: "Would you be willing to accept a lower standard of living if it meant a cleaner environment?" It seemed revealing of a strong commitment that $63 \%$ said they would be willing to accept a lower standard of living, while $27 \%$ said they would not, $9 \%$ didn't know, and $3 \%$ refused to answer [1283]. A 1989 poll in Ohio asked: "Is the cost of living more important than reducing pollution?" Disagreeing with this were 59\%; 33\% agreed, and 9\% didn't know.

Higher automobile prices. Newsweek asked new car buyers, in 1990, what additional amount they would be willing to pay for a car that significantly reduces air pollution. Table 2-19 shows that $40 \%$ said they would be willing to pay an additional cost, ranging from under $\$ 200$ more to $\$ 1,000$ or more, for such a vehicle. Newsweek analyzed the data by whether the purchasers bought domestic or imported autos; foreign car buyers were somewhat more willing to pay more for a less-polluting auto. Willingness to pay more was also associated with higher income, education, and occupational levels, and was inversely associated with age. A 1989 item asked: "Do you approve or disapprove of having much stronger controls on the pollution from automobile tailpipes even if that means higher auto prices?" [1371].

Approving were $82 \%$, despite the mention of higher prices; $17 \%$ disapproved. The poll also asked: "Do you approve or disapprove of requiring automakers to build and sell low-polluting methanol-powered cars in the urban areas with the greatest air pollution even if that means higher auto and gasoline prices?" [1371]. Approving of this regulation were $76 \% ; 23 \%$ disapproved.

Other trade-offs. Energy development at the cost of losing wilderness areas is another energyenvironment trade-off. A 1990 poll asked public favorability toward or opposition to "developing oil reserves on publicly owned wilderness lands, even if this caused some environmental damage" [1025]. A majority (58\%) "strongly opposed" such development, and $21 \%$ "somewhat opposed" it, totaling $79 \%$ opposed. Favoring such development were $19 \%$.

In 1990, Penn and Schoen Associates also asked: "(Here are some possible elements of a new national energy policy to promote conservation and reduce our dependence on foreign oil. For each element, please tell me if you would strongly favor it, moderately favor it, moderately oppose it, or strongly oppose it.) ... Opening up for exploration more of the reserves America has in wildlife preserves in Alaska" [1206]. A bare majority, 51\%, strongly or moderately favored development when it was couched in terms of reducing dependence on foreign oil, while $45 \%$ opposed it. These results echo those discussed earlier showing polarization in public opinion about which of these two values-environmental protection or national security - is more important.

The Penn and Schoen study also asked how strict its sample thought environmental controls should be, "even if it means more dependence on foreign oil" [1206]. Posed this way, the item drew a 74\% response favoring moderate controls, with $23 \%$ favoring strict controls. Four percent said they didn't know. CBS News/The New York Times asked in April 1989: "Do you favor or oppose drilling for oil in the Arctic National Wildlife Refuge in Alaska?" [1342]. Just more than one-half (51\%) opposed such drilling: while $31 \%$ favored it, and $18 \%$ were unsure. Yankelovich/Clancy/Shulman also asked: "Do you think the U.S. should increase oil exploration in Alaskan wilderness areas, or not?" [1045]. The response was polarized; $45 \%$ opposed such exploration and $43 \%$ favored it; $12 \%$ were unsure.

A January 1992 national poll asked: "Do you think that cleaning up most pollution in America will hurt the economy, or can pollution be cleaned up with little or no harm to the economy?" [1562]. Two-thirds said the cleanup can be done without harming the economy; $23 \%$ thought it would hurt the economy; $5 \%$ volunteered that it would actually benefit the economy; $10 \%$ were unsure. 
Table 2-19. Additional Amount Willing to Pay for a Car That Significantly Reduces Air Pollution, 1990

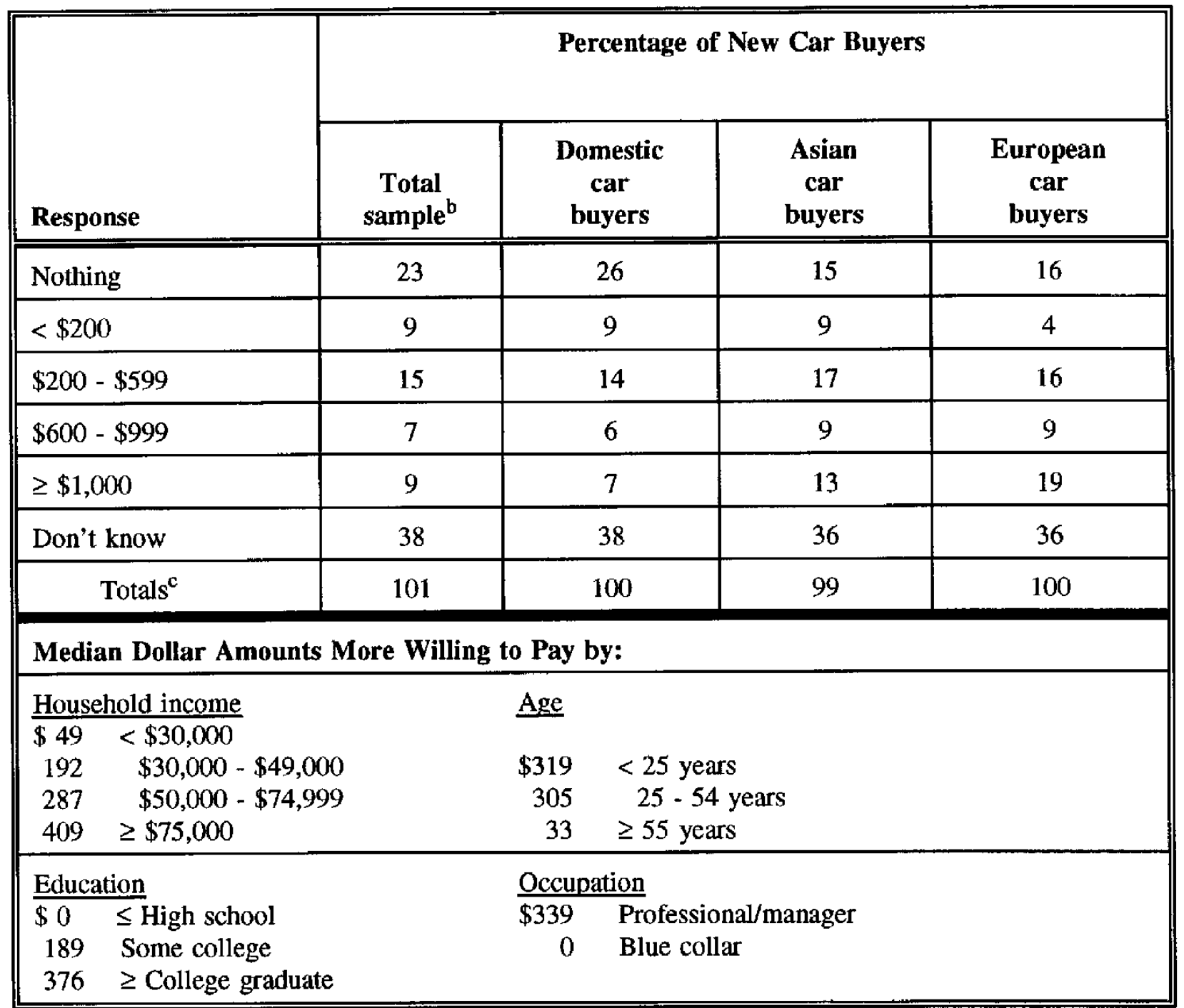

Source: Constructed by the author using data from Newsweek.

${ }^{a}$ Item wording not given [1563].

b $14,000+$ new car buyers, 1990.

${ }^{\mathrm{c}}$ May not add to $100 \%$ due to rounding. 
The 1992 Dunlap-Gallup global environmental survey asked: "Increased efforts by business and industry to improve environmental quality might lead to higher prices for the things you buy. Would you be willing to pay higher prices so that industry could better protect the environment or not?" [1560]. The percentage of U.S. respondents saying it was willing to pay higher prices to protect the environment was 65\%. Respondents in only five other countries seemed to be more willing: Denmark $(78 \%)$, Norway (73\%), Switzerland (70\%), Korea (71\%), and Great Britain (70\%).

\section{Environmentalism and Environmental Activism}

A measure of environmental activism is provided by membership in national environmental organizations. In 1990, the membership of these organizations was reported at nearly 8 million, or approximately $3 \%$ of the U.S. population. Table 2-20 lists the major groups along with memberships and budgets. Among these environmental groups, overlapping memberships could be frequent; therefore, the extent of environmental activism suggested by these figures is probably somewhat exaggerated.

Mitchell, Mertig and Dunlap (1991, p. 223) reported that "the most recent surge in membership [in national environmental organizations] occurred at the turn of the decade (1990)." They said that ". . the visibility of ecological problems ranging from toxic wastes, beach contamination, the Exxon Valdez oil spill, ozone destruction, and global warming" stimulated the membership increase. Based on opinion data, Dunlap (1991, p. 309) reported that environmental organizations enjoy "a high degree of credibility and legitimacy."

Table 2-20. Founding Date, Membership, and Budget of Major U.S. Environmental Groups

\begin{tabular}{|l|c|c|c||}
\hline Organization & Date founded & $\begin{array}{c}\text { Members } \\
(\mathbf{1 0 0 0})\end{array}$ & $\begin{array}{c}\text { Budget } \\
\mathbf{( \$ M )}\end{array}$ \\
\hline National Wildlife Federation & 1936 & 5800 & 85.3 \\
\hline National Audubon Society & 1905 & 550 & 35.0 \\
\hline Sierra Club & 1892 & 500 & 32.0 \\
\hline World Wildlife Fund & 1961 & 312 & 1.4 \\
\hline Wilderness Society & 1935 & 300 & 20.0 \\
\hline $\begin{array}{l}\text { Natural Resources Defense } \\
\text { Council }\end{array}$ & 1970 & 125 & 16.0 \\
\hline Natural Resources Defense Fund & 1967 & 100 & 15.0 \\
\hline $\begin{array}{l}\text { National Parks and Conservation } \\
\text { Association }\end{array}$ & 1919 & 95 & 3.8 \\
\hline Izaak Walton League & 1922 & 50 & 1.6 \\
\hline Friends of the Earth & 1969 & 30 & 2.5 \\
\hline
\end{tabular}

Source: Statistical Record of the Environment (1992), p. 711. 
Local environmental activism has developed into a grassroots environmental movement somewhat distinct from national environmental organizations, whose memberships tend to be white and middle class (Freudenberg and Steinsapir 1991). Grassroots environmentalism is a broad-based social movement with diversity in organizations, strata, range of problems, and tactics (Dunlap and Mertig 1991; Freudenberg and Steinsapir 1991). Local, national, and international organizations include the working class, women, and minorities. They address environmental problems ranging from local health hazards to global ecosystems, using tactics that vary from tree-spiking to lawsuits. Supportive public opinion has proven a valuable resource for environmentalism, according to Dunlap and Mertig (1991, p. 215).

This grassroots environmental movement, often attacked for its NIMBY stands as being too narrowly selfinterested, has begun to move toward a NIABY ("not in anyone's back yard") position. As NIABY is adopted, grassroots organizations will increasingly enter the national policy arena (Freudenberg and Steinsapir 1991, p. 243).

In April 1990, Gallup asked: "Do you consider yourself to be an environmentalist or not?" (Gallup cited in Dunlap and Scarce 1991, p. 670). Thirty-five percent said they were "strong environmentalists" and $38 \%$ said they were not strong environmentalists; $24 \%$ said they were not environmentalists; and $3 \%$ had no opinion. In addition, 59\% reported in July 1990 that they had not donated to nor been active in a group or organization working to protect the environment, and $40 \%$ said that they had (Dunlap and Scarce 1991, p. 670).

Evidence from this analysis shows empathy for the environmental movement, yet minority activism. Roper asked in 1980 and again in 1990: "In recent years, the environmental movement has been very active. Do you think of yourself as an active participant in the environmental movement, sympathetic towards the movement but not active, neutral, or unsympathetic towards the environmental movement?" [1556]. The proportion stating they were "active participants" increased from 7\% in 1980 to $13 \%$ in 1990. The majority, 52\% in 1990 and 55\% in 1980, stated they were "sympathetic, but not active." Only 3\% said they were "unsympathetic" in 1990; $26 \%$ said they were "neutral."

Although environmental activism has until fairly recently been the domain of established environmental organizations and of the grassroots environmental movement, signs are appearing that it is extending to other mainstream U.S. organizations. The $1992 \mathrm{LWV}$ survey, for example, found that more than half of League chapters have been or will be working on global warming issues between July 1, 1990, and July 30, 1990. Other topics League chapters are addressing include energy (60 chapters), air quality and emission control (37), transportation (54), and recycling and wastes (63) [1569].

Responsibility for action. Dunlap (1991a, p. 34) said that poll data showed the public views business and industry "as the major cause of environmental problems," and it believes that they should solve them. Yet, the private sector is increasingly seen as not protecting the environment (Dunlap and Scarce 1991, p. 655). Public belief is that business and industry will only take action when required to do so by government. Dunlap (1991a, p. 34) noted: "The preference for institutional solutions may represent a realistic assessment of the very limited contributions that individuals can make to solving large-scale problems such as ozone depletion and global warming."

The 1992 Dunlap-Gallup survey on the environment asked: "Which one of these do you believe should have the primary responsibility for protecting the environment in our nation-the government, business and industry, or individual citizens and citizens' groups?" [1560]. Proportions of the U.S. sample selecting "government" were 44\%; $29 \%$ chose "citizens' groups"; $20 \%$ chose "business and industry." 
Roper looked at entities that the public thought could be doing more to protect the environment. Table 2-21 shows the results. Most thought large corporations should be doing more, both in terms of manufacturing processes and products themselves. The American public, itself, was cited by $88 \%$ as capable of doing more; another $83 \%$ said they themselves should be doing more. In fact, majorities of $65 \%$ or more said that every group listed should be doing more to protect the environment.

LWV leaders did not believe that public institutions and private industry were doing enough to "combat global warming" [1569, p. 7]. League leaders were most critical of the federal government and private industry; $91 \%$ said they were not doing enough. Other levels of government, state (88\%) and local (87\%), were not evaluated much better. In contrast, $59 \%$ of the League leaders thought nonprofit groups were not doing enough.

Table 2-21. Perception of Efforts to Protect the Environment, 1990

"I'd like to know which groups in our society you feel are doing a good job with respect to environmental protection and which are not. For each of the following groups I read you, please tell me whether you feel they are doing all they should with respect to environmental protection, or whether you feel they should be doing more." [1549]

\begin{tabular}{|l|c|c|c||}
\hline Groups & $\begin{array}{c}\text { Should be } \\
\text { doing more }\end{array}$ & $\begin{array}{c}\text { Doing all } \\
\text { they can }\end{array}$ & Don't know \\
\hline Proportion responding (\%) & \multicolumn{2}{|c||}{} \\
\hline \hline The American public & 88 & 8 & 4 \\
\hline $\begin{array}{l}\text { Large corporations, in terms of the } \\
\text { consumer products they sell }\end{array}$ & 84 & 9 & 8 \\
\hline $\begin{array}{l}\text { Large corporations, in terms of the } \\
\text { way they manufacture products }\end{array}$ & 84 & 14 & 8 \\
\hline You, yourself & 83 & 14 & 3 \\
\hline The federal government & 81 & 15 & 5 \\
\hline Your state government & 79 & 17 & 7 \\
\hline Your local government & 76 & 18 & 12 \\
\hline $\begin{array}{l}\text { The businesses in your own } \\
\text { community }\end{array}$ & 70 & 25 & 10 \\
\hline The press & 65 & & 9 \\
\hline
\end{tabular}

Source: Roper Organization

${ }^{\text {a}}$ Percentages may not add to 100 due to rounding. 
Decision factors. In 1990, Roper asked: "Now I would like to ask you some questions about the environment. Although many people today are talking about the importance of the environment, people have different reasons for wanting to protect it. Here is a list of reasons that have been given for protecting the environment. (Card shown) Would you please look over this list and tell me which one or two you think are the most important?" Table 2-22 summarizes the responses. More than six in ten respondents cited human health reasons.

Dunlap (1991a, p. 35) reported a national study that asked why people were not engaging in actions "to clean up the environment or preserve resources." Nearly half $(49 \%)$ said they needed more information on what to do; $26 \%$ said actions were inconvenient; $10 \%$ said they remained unconvinced that their actions would make much difference; and 7\% said they would only take action "when a lot of other people" started doing so as well.

Roper presented a number of attitudinal statements to a 1990 national sample replicating those presented in a 1980 Council on Environmental Quality survey [1556]. Table 2-23 summarizes the responses. The items have embedded in them reasons for action or inaction toward the environment. They touched on health effects, endangered species, technological fixes, environment-economic trade-offs, and the perceived

Table 2-22. Perceived Reasons for Protecting the Environment, 1990

"Now I would like to ask you some questions about the environment. Although many people today are talking about the importance of the environment, people have different reasons for wanting to protect it. Here is a list of reasons that have been given for protecting the environment. (Card shown.) Would you please look over this list and tell me which one or two you think are the most important?" [1552]

\begin{tabular}{||c|c|}
\hline Reason & Percentage indicating $^{\mathbf{a}}$ \\
\hline \hline To protect human health from pollution & 63 \\
\hline $\begin{array}{l}\text { To protect natural resources for the use of future } \\
\text { generations }\end{array}$ & 42 \\
\hline To ensure that natural places and wildlife will always exist & 32 \\
\hline $\begin{array}{l}\text { To protect natural resources that our economy relies on, } \\
\text { such as timber and fisheries }\end{array}$ & 21 \\
\hline To preserve recreational areas, such as national parks & 17 \\
\hline None of these & 1 \\
\hline Don't know & 3 \\
\hline
\end{tabular}

Source: Roper Organization

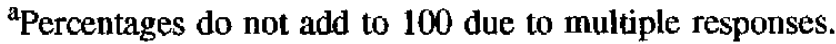


Table 2-23. Attitudes toward Technology and Environmental Protection

"Here are a number of statements about the environment and related topics on which / would like to ask your opinion. Would you please indicate for each whether you agree strongly, agree, disagree, or disagree strongly?" [1556]

\begin{tabular}{|c|c|c|c|}
\hline \multirow[b]{2}{*}{ Reason $^{a}$} & \multirow{2}{*}{$\begin{array}{c}1980 \\
\text { Agree }\end{array}$} & \multicolumn{2}{|c|}{1990} \\
\hline & & Agree & Disagree \\
\hline \multicolumn{4}{|l|}{ Proportion indicating $(\%)^{b}$} \\
\hline $\begin{array}{l}\text { To preserve the balance of } \\
\text { nature, endangered species } \\
\text { must be protected, even at the } \\
\text { expense of commercial } \\
\text { activity }\end{array}$ & - & 70 & 23 \\
\hline $\begin{array}{l}\text { Technology will find a way of } \\
\text { solving the problem of } \\
\text { shortages and natural } \\
\text { resources }\end{array}$ & 81 & 66 & 26 \\
\hline $\begin{array}{l}\text { An endangered species must } \\
\text { be protected even at the } \\
\text { expense of commercial } \\
\text { activity }\end{array}$ & 73 & 65 & 24 \\
\hline $\begin{array}{l}\text { People would be better off if } \\
\text { they lived a more simple life } \\
\text { without so much technology }\end{array}$ & 59 & 56 & 37 \\
\hline $\begin{array}{l}\text { I believe that plants and } \\
\text { animals exist primarily for } \\
\text { human use }\end{array}$ & 40 & 43 & 50 \\
\hline $\begin{array}{l}\text { It seems like almost } \\
\text { everything causes cancer; } \\
\text { there is no point in trying to } \\
\text { avoid specific chemicals or } \\
\text { foods }\end{array}$ & 47 & 39 & 57 \\
\hline $\begin{array}{l}\text { Future scientific research is } \\
\text { more likely to cause problems } \\
\text { than to find solutions to our } \\
\text { problems }\end{array}$ & 30 & 33 & 54 \\
\hline $\begin{array}{l}\text { Environmental problems are } \\
\text { not as serious as some people } \\
\text { would have us believe }\end{array}$ & 38 & 27 & 67 \\
\hline
\end{tabular}

Source: Roper Organization

${ }^{a}$ Each reason was presented to a half-sample in 1990.

bercentages shown for "agree" combine "strongly agree" and "agree" responses. Percentages shown for "disagree" combine "strongly disagree" and "disagree" responses. 
severity of environmental problems. In general, $70 \%$ of the sample believed that endangered species should be protected, although protecting endangered species at the expense of commercial activity was 8 points less popular than in 1980. Belief that technology would solve environmental problems declined 15 points in 10 years. Moreover, one-third (an increase of 3 points) believed future scientific research would be more likely to cause than to solve problems. Two-thirds disagreed with the idea that environmental problems are not serious, an 11-point increase from 1980. Fewer people also believed, in 1990 , that there was no point in trying to avoid specific chemicals or food to avoid cancer.

Although few data exist on reasons to engage in environmental protection, those that do suggest that health effects may be the most important motivator for environmental activity at the individual level. At the same time, business and industry are seen as the main causes of environmental degradation. As Dunlap (1991b:309) noted, better leadership is needed to harness concern and translate it into effective action. "The future of our environment as well as that of environmentalism, will be heavily influenced by the effectiveness of such leadership."

Environmental activism takes two forms-political activism (including consumer boycotts) and lifestyle changes. Some items specifically asked respondents about actions they themselves were taking to protect the environment directly. Numerous questions, discussed in the next section, dealt with recycling; other items addressed political activism and forms of lifestyle changes other than recycling; these are discussed below.

Political activism. The 1992 Dunlap-Gallup survey on the environment asked: "Have you, yourself, done any of the following things in the past year-avoided using certain products that harm the environment, been active in a group or organization that works to protect the environment? Voted or worked for candidates because of their position on environmental issues?" [1560]. A majority of U.S. respondents mentioned avoiding products (57\%). Almost a fifth (19\%) said they voted or worked for pro-environment candidates; $11 \%$ reported being active in an environmental group.

A Roper survey in 1980 and again in 1990 asked: " . . by any chance have you had occasion to write a letter or contact a public official directly about an environmental matter or not?" [1556]. Only $11 \%$ in 1990 and $12 \%$ in 1980 said that they had.

A May 1989 Gallup poll reported that $29 \%$ said they had "boycotted a company's products because of its record on the environment [1316]. Another 16\% reported doing "volunteer work for an environmental, conservation, or wildlife preservation group."

Dunlap (1991a, p. 34) said that pollsters themselves disagreed about the behavioral impact of environmentalism. He said that one polling organization saw a "sea-change in the marketplace" while another said that "actual behavior hasn't changed much." Dunlap himself argued that pro-environment opinions do not automatically translate into behaviors like voting. He said, "Perhaps the safest conclusion is that the environment seems to be gaining importance as an electoral issue and may sometimes be a factor, especially in state and local races" (p. 33).

Lifestyle changes. The 1992 survey of LWV leaders asked about "personal action to combat global warming." The activities mentioned most frequently were

- $\quad$ Buying energy-efficient appliances (80\%)

- Using energy-efficient lightbulbs $(77 \%)$

- $\quad$ Purchasing a fuel-efficient car (70\%).

Also mentioned by more than half of the League sample were walking or biking and tree planting. 
In April 1991, Gallup asked: "(Which of the following things, if any, have you or other household members done in recent years to try to improve the quality of the environment?) . . . . Cut your household's use of energy by improving insulation or changing your heating or air conditioning system?" [1493]. Almost three-quarters (73\%) said they had done this. When asked: "Replaced a 'gas-guzzling' automobile with one that is more fuel efficient," $67 \%$ said they had done this; $31 \%$ said they had not. These items directly connected energy behavior with environmental protection.

In March 1990, Roper asked about the frequency with which people took a series of actions that "people have told us they have done about the environment" [1549]. Table 2-22 lists seven recycling behaviors reported. Another eight actions were included in this list. These follow, along with the percentage of the sample indicating it practiced the behavior regularly.

- Buy products in pumps rather than in aerosol cans (30\%)

- Use biodegradable, low-phosphate soaps and detergents (27\%)

- Use biodegradable plastic garbage bags (25\%)

- Avoid buying products from companies which you don't feel are environmentally responsible (12\%)

- Use gasoline with methanol to cut down on air pollution (11\%)

- Contribute money to an environmental group such as the Sierra Club, Green Peace, Audubon Society $(6 \%)$

- Cut down on use of automobile by using public transportation, car pooling, etc. (6\%)

- Write letters to politicians expressing opinions on environmental issues (4\%)

- Do volunteer work for local environmental groups (4\%).

Some items specifically asked respondents about actions they themselves were taking directly to protect the environment. Numerous questions asked about recycling, other actions to protect the environment, and energy conservation behaviors, which lend themselves to environmental protection. Results from items on recycling and other actions are described here; results from items on energy-conserving behavior are reported in the chapters on buildings and transportation.

Based on his studies of environmental activism, Dunlap (1991a) recommended that environmentalists encourage both political action on behalf of pro-environment policies and candidates, and lifestyle changes (p. 35). He also said that organized consumer boycotts are more effective than individual consumer choices (p. 36).

In summary, most people do little directly to help improve and preserve the environment. Despite extensive evidence indicating strong and growing environmental concern, and despite recognizing that individuals as well as institutions should be taking more action to protect and improve the environment, surprisingly few people are taking action during their everyday lives. The actions most frequently taken, 
given existing levels of knowledge, include recycling behaviors, buying "green products" such as biodegradable garbage bags, and avoiding products from companies that are seen as damaging to the environment. The need for cognitive connection between daily activities and their environmental impacts is apparent. Public education to increase awareness of this linkage would be one part of the solution.

\section{Recycling}

In the past several years, recycling has emerged as an important response to environmental problems at the local level. Concern with environmental values, voluntary simplicity as a lifestyle (measured as early as 1978 in California by Leonard-Barton), and running out of landfill space have contributed to active recycling policies and efforts (Leonard-Barton and Rogers 1979).

The National Recycling Coalition has a membership of 1635 organizations, testimony to the grassroots nature of this response. A third of these are governmental agencies, mostly local and regional. The beverage industry composes $9 \%$ of its membership, recycling center operators $8 \%$, and materials processors another 7\% [1450]. The Institute of Scrap Recycling Industries (ISRI) has scrap metals recycling brokers and processors, metal consumers and producers, wastepaper recycling brokers and processors as well as consumers, equipment manufacturers and dealers, service organizations, waste haulers, and buy-back center operators [1450]. These two organizations have members in virtually every state. Most members, numerically, are in California (310), Illinois (210), Minnesota (154), Michigan (141), New Jersey (135), and Wisconsin (133). The evolution of the recycling infrastructure is related to public attitudes and behavior favorable to recycling for environmental protection.

Environmentalism appears to be the strongest motivator for recycling, although some recycling programs offer reimbursement to the recycler for materials, such as aluminum cans or bottles. One piece of empirical evidence to support this comes from a New Mexico survey that asked reasons for recycling. Mentioned most frequently were concern for the environment, litter reduction, conserve landfill space, conserve energy, influence of family and friends, "feels good," and money [1459].

Awareness of recycling opportunities could remain a problem. The New Mexico survey found that $61 \%$ of their respondents said they would not know where to take their recyclables if they wanted to begin recycling. No doubt this would vary by community and region.

Nevertheless, significant proportions of samples have reported that they are recycling, and this behavior appears to be increasing. Roper asked, in December 1990, an item last used in early 1980: "In the past two years have you ever sorted newspapers or bottles for recycling?" [1556]. In 1980, $49 \%$ said they had; in 1990, 63\% said they had. Gordon S. Black Corporation/U.S.A. Today asked, in March 1990: "Does your household currently recycle either newspapers, bottles, or cans?" [1283]. Seventy-one percent reported that they did recycle. According to the Statistical Record of the Environment, U.S. News and World Report conducted a survey in February 1991 asking about recycling and other environmentally relevant behaviors [1450, p. 712]. Of 1413 U.S. citizens surveyed, $46 \%$ reported that they recycled bottles or cans, $26 \%$ said they recycled paper, and $14 \%$ said they buy recycled products. The publication reported that $35 \%$ "do nothing to save the Earth."

When asked if they "recycle bottles and aluminum cans," 62\% of a 1991 national sample said "regularly," $18 \%$ said "occasionally," 5\% said "rarely," and 13\% said "never" [1194]. Gallup asked a 1989 sample: "Which of the following things, if any, have you or other household members done in recent years to try to improve the quality of the environment?" [1296]. More than three-quarters (78\%) said they "voluntarily recycled newspapers, glass, aluminum, motor oil or other items." 
Roper has been asking about no-deposit/no-return bottles versus returnable bottles since 1973 [1555]. The proportion has been increasing-from $34 \%$ in 1973 to $40 \%$ in 1990 . Similarly, the proportion using returnable bottles has declined from $41 \%$ in 1973 to $30 \%$ in 1990 . The ready availability of nodeposit/no-return bottles and cans compared with the increasing scarcity of bottles for which customers pay a deposit may make this option more difficult for consumers to put into effect.

Table 2-24 shows trend data for 2 years on recycling behavior. Increasing proportions reported having engaged in seven different recycling behaviors, up a few points between 1989 and 1990. Since the time between measurements was only 1 year, these gains are probably significant in reflecting an increasing commitment to recycling through personal behavior. To speculate, people may feel that recycling is something they have control over-action they can personally and individually take that will help the environment.

Roper also reported, in 1991, that approximately a third of a national sample reported that they were "somewhat" or "very careful" about guarding against waste in their use of glass, water, paper, and plastic [1553]. These were proportions higher than those reported in June 1980 in response to the same item.

Table 2-25 exhibits data on recycling behavior reported by a New Mexico sample [1459]. Recycling behavior varies significantly by the material to be recycled. For example, batteries were much more likely to be recycled than household chemicals, which are most frequently thrown in the trash and likely to end up at the landfill [1459]. If garages recycle the batteries and motor oil left with them, then a large proportion of this material would be recycled.

When asked if they would still subscribe to magazines and newspapers known not to use recycled paper, a majority (52\%) of a 1991 national sample said they were not likely to cancel their subscriptions [1450, p. 717].

Finally, a majority of a 1990 Louisiana sample reported that it was recycling household trash. Mentioned most often were aluminum, followed by much smaller percentages mentioning paper, plastic, and glass [1430]. Most respondents (approximately $90 \%$ in each housing type sampled) in a 1986 Connecticut sample reported willingness to separate trash if recycling programs existed. A plurality of a 1984 Alabama sample $(45 \%)$ reported that within the past year it had turned in paper, tin cans, or oil for recycling [1448].

\section{Policy Preferences}

A number of polls in this analysis asked people their preferences on policy options that would protect and improve the environment. Many items are described in the policy preferences sections of chapters dealing specifically with utilities, buildings, and transportation. Others were presented in the sections of this chapter dealing with specific environmental problems like global warming. Discussed in this section are general and crosscutting items on environmental protection as well as items dealing specifically with recycling.

Regulation. Between the fall of 1973 and the fall of 1990, Roper also collected trend data on policy preferences about environmental regulation. Pollsters asked: ". . do you think environmental protection laws and regulations have gone too far, or not far enough, or have struck about the right balance?" Table 2-26 and Figure 2-I show the trend. The percentage indicating that more environmental regulation is needed has risen consistently for 17 years, from $34 \%$ in 1973 to $54 \%$ in 1990 - a 20-point increase. Interestingly, the percentage indicating that they didn't know decreased from $21 \%$ in 1973 to $9 \%$ in 1990 , suggesting that opinion is not only becoming more favorable to the environment but is also held with more conviction [1554]. 
Table 2-24. Trends in Reported Recycling Behavior, 1989-1990

"Here is a list of things that people have told us they have done about the environment. (Card shown.) Would you please read down the list and for each one tell me if you or someone in this household makes a real effort to do it on a regular basis, or does it from time to time when it's convenient, or doesn't really bother about it? First, retum beer or soda bottles or cans to a store or recycling center." (March 1989 and March 1990) [1549] ${ }^{\mathrm{a}}$

\begin{tabular}{||l|c|c|c|c|c|c||}
\hline & \multicolumn{3}{|c|}{1989} & \multicolumn{3}{c||}{1990} \\
\cline { 2 - 7 } & $\begin{array}{c}\text { Do on a } \\
\text { regular } \\
\text { basis }\end{array}$ & $\begin{array}{c}\text { Do from } \\
\text { time to } \\
\text { time }\end{array}$ & $\begin{array}{c}\text { Don't } \\
\text { really } \\
\text { bother } \\
\text { about }\end{array}$ & $\begin{array}{c}\text { Do on a } \\
\text { regular } \\
\text { basis }\end{array}$ & $\begin{array}{c}\text { Do from } \\
\text { time to } \\
\text { time }\end{array}$ & $\begin{array}{c}\text { Don't } \\
\text { really } \\
\text { bother } \\
\text { about }\end{array}$ \\
\hline Proportion responding (\%)
\end{tabular}

Source: Constructed by author using data from the Roper Organization.

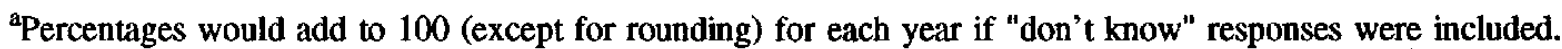


Table 2-25. Self-Reported Recycling Behavior in New Mexico, $1990^{\mathrm{a}}$

\begin{tabular}{||l|c|c|c|c||}
\hline Behavior & Motor oil & $\begin{array}{c}\text { Household } \\
\text { chemicals }\end{array}$ & $\begin{array}{c}\text { Yard } \\
\text { waste }\end{array}$ & Batteries \\
\hline Proportion responding (\%) & \multicolumn{5}{|c||}{} \\
\hline \hline Leave at garage & 59 & - & - & 40 \\
\hline Throw in trash & 8 & 60 & 38 & 4 \\
\hline Take to landfill & 6 & 23 & 19 & 4 \\
\hline Dump on ground & 11 & 4 & - & - \\
\hline Pour down sink & 1 & 6 & - & - \\
\hline Recycle & 12 & 5 & $29^{\mathrm{b}}$ & $52^{\mathrm{c}}$ \\
\hline \hline \multicolumn{1}{||c|}{ Totals } & 97 & 98 & 86 & 100 \\
\hline
\end{tabular}

Source: Institute for Public Policy, New Mexico State Energy, Minerals, and Natural Resources Department [1459].

a Item wording not reported; data collected July 1990.

${ }^{b}$ Composting yard waste was considered recycling. Another $7 \%$ said they burn yard waste.

${ }^{c}$ Recycling batteries included recycling, selling, or trading in batteries.

${ }^{\mathrm{d}}$ Columns do not add to 100 due to unreported data.

Hart-Teeter Research acknowledged in its April 1990 item on trade-offs that preference for a clean environment has become a "motherhood" issue. They asked: "Everyone wants a clean environment, but the question comes down to ... at what cost or inconvenience. I'm going to read some policy options and the problem associated with each. Tell me if you would favor or oppose each one" [1194].

Table 2-27 presents the findings. The policy options included were regulatory rather than voluntary, and covered both air pollution and solid waste. The option most favored (by $93 \%$ ) was requiring people to separate waste so that it could be recycled. Large proportions also favored banning fast food styrofoam containers, requiring automobile emissions testing and prevention, banning disposable diapers, and requiring automobile pollution control equipment that would add $\$ 600$ to the cost of a new car. Almost all of the proposed policy options were favored by majorities.

The most opposed option was closing pollution-producing factories which would result in the loss of jobs. A gasoline price increase of 20 cents per gallon was also opposed by half of the sample. 
Table 2-26. Trends in Preferences for Amount of Environmental Regulation

". . . At the present time, do you think environmental protection laws and regulations have gone too far, or not far enough, or have struck about the right balance?" [1554]

\begin{tabular}{|c|c|c|c|c|c|c|c|c|c|c|c|}
\hline Response & $\begin{array}{l}\text { Oct. } \\
1973\end{array}$ & $\begin{array}{l}\text { Oct. } \\
1974\end{array}$ & $\begin{array}{l}\text { Oct. } \\
1975\end{array}$ & $\begin{array}{l}\text { Oct. } \\
1976\end{array}$ & $\begin{array}{l}\text { Sept. } \\
1977\end{array}$ & $\begin{array}{l}\text { Sept. } \\
1979\end{array}$ & $\begin{array}{c}\text { Sept./ } \\
\text { Oct. } \\
1980\end{array}$ & $\begin{array}{l}\text { Sept. } \\
1981\end{array}$ & $\begin{array}{l}\text { Sept. } \\
1982\end{array}$ & $\begin{array}{l}\text { Sept. } \\
1989\end{array}$ & $\begin{array}{l}\text { Sept. } \\
1990\end{array}$ \\
\hline \multicolumn{12}{|l|}{ Proportion responding (\%) } \\
\hline Not far enough & 34 & 25 & 31 & 32 & 27 & 29 & 33 & 31 & 37 & 55 & 54 \\
\hline Struck about right balance & 32 & 44 & 37 & 35 & 39 & 36 & 33 & 38 & 38 & 27 & 26 \\
\hline Gone too far & 13 & 17 & 20 & 15 & 20 & 24 & 25 & 21 & 16 & 11 & 11 \\
\hline Don't know & 21 & 15 & 12 & 18 & 14 & 11 & 10 & 10 & 9 & 7 & 9 \\
\hline Totals ${ }^{\mathrm{a}}$ & 100 & 101 & 100 & 100 & 100 & 100 & 101 & 100 & 100 & 100 & 100 \\
\hline
\end{tabular}

${ }^{\text {a}}$ Percentages may not add to 100 due to rounding.

Source: Constructed by the author using data from the Roper Organization. 


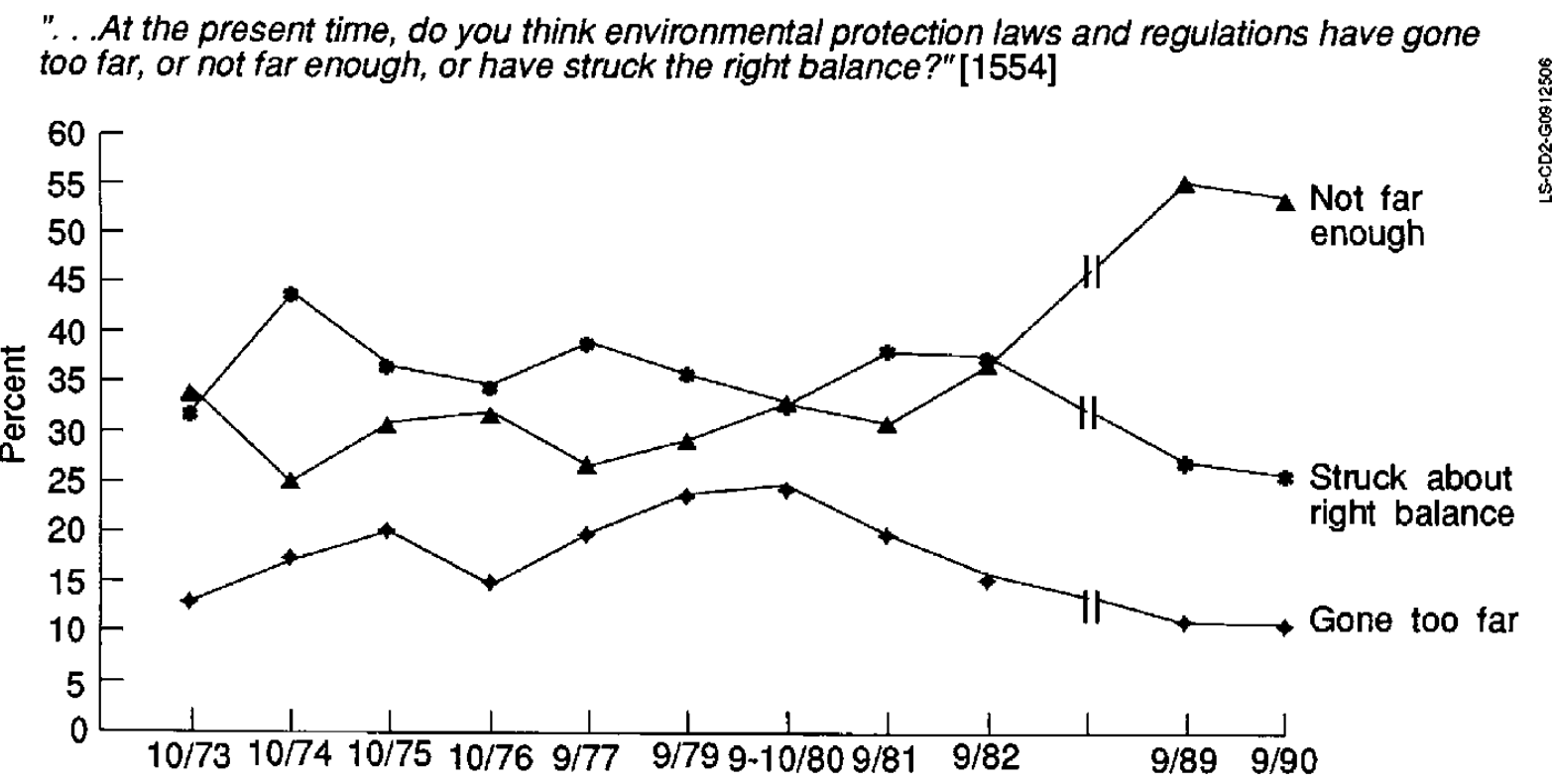

II= 7-year gap in data collection.

Source: Constructed by the author using data from the Roper Organization [1554].

Figure 2-I. Trends in preferences for amount of environmental regulation, 1973-1990

Recycling. The public strongly supports recycling efforts and policies. American City and County conducted an April 1991 poll asking about a national deposit law [1450]. They reported that 44\% "strongly support" and 26\% "somewhat support" such a law, while 21\% oppose it. In April 1991, Adweek asked whether more legal restrictions were needed for "recycling" (47\% favored) and "separating garbage from trash" (33\% favored) [1450]. A 1990 national survey resulted in 71\% indicating that "helping to set up public recycling centers in the community" was one of the most important things electric utilities could do to help the environment [1457].

Public support for mandating recycling has run high in some polls. For example, a 1990 New Mexico study reported that between $72 \%$ and $87 \%$ of respondents in New Mexico communities favored mandatory recycling programs at that time [1459]. Recent national evidence continues to support this policy preference.

In August 1991, Roper asked: "We're hearing more these days about trade-offs-in other words, sacrificing one thing for the sake of another. For example, some people have given up things they enjoy eating-such as fried or fatty foods-because they feel it is a healthy thing to do. But others feel the possible health benefit is really too small considering the sacrifice of giving up one's favorite foods. (Card shown) Now here is a list of some trade-offs having to do with protecting the environment. Considering both the advantages and disadvantages of each one, please tell me whether you think the sacrifice would be worth making or not" [1553].

The identified trade-off on recycling was: "Every household could be required to recycle newspapers, plastics, tin cans, and glass containers, but this would inconvenience consumers and require higher local taxes to pay for recycling programs." Stating that the "sacrifice is worth making" were $72 \% ; 22 \%$ said it was not; $6 \%$ didn't know. 
Table 2-27. Preferred Policy Trade-offs in Environmental Protection Policies

"Everyone wants a clean environment, but the question comes down to . . at what cost or inconvenience. I'm going to read some policy options and the problem associated with each. Tell me if you would favor or oppose each one." (April 1990) [1194]

\begin{tabular}{|c|c|c|c|}
\hline Policy and problem & Favor & Oppose & Unsure \\
\hline \multicolumn{4}{|l|}{ Proportion responding (\%) } \\
\hline $\begin{array}{l}\text { Require people to separate garbage } \\
\text { and solid waste so it can be recycled }\end{array}$ & 93 & 6 & 1 \\
\hline $\begin{array}{l}\text { Ban styrofoam containers used by } \\
\text { fast food chains and other types of } \\
\text { packaging that add to the solid waste } \\
\text { problem }\end{array}$ & 84 & 14 & 2 \\
\hline $\begin{array}{l}\text { Require testing and repairs of your } \\
\text { car each year for air pollution } \\
\text { emissions }\end{array}$ & 80 & 19 & 1 \\
\hline $\begin{array}{l}\text { Ban disposable diapers, which would } \\
\text { reduce the amount of solid waste in } \\
\text { landfills }\end{array}$ & 74 & 23 & 3 \\
\hline $\begin{array}{l}\text { Require pollution control equipment } \\
\text { to reduce auto emissions that would } \\
\text { add } \$ 600 \text { to the cost of a new car }\end{array}$ & 68 & 28 & 4 \\
\hline $\begin{array}{l}\text { Enforce stricter air quality } \\
\text { regulations, which would increase } \\
\text { utility bills } \$ 10.00 \text { per month }\end{array}$ & 57 & 40 & 3 \\
\hline $\begin{array}{l}\text { In major metropolitan areas, require } \\
\text { people who drive to work to take } \\
\text { public transportation one day a week }\end{array}$ & 57 & 41 & 2 \\
\hline $\begin{array}{l}\text { Limit the number of large cars that } \\
\text { could be produced }\end{array}$ & 51 & 44 & 5 \\
\hline $\begin{array}{l}\text { A } 20 \text {-cent per gallon increase in the } \\
\text { price of gasoline for cleaner-burning } \\
\text { alternative fuels }\end{array}$ & 48 & 50 & 2 \\
\hline $\begin{array}{l}\text { Close pollution producing factories, } \\
\text { which would result in the loss of } \\
\text { jobs }\end{array}$ & 33 & 59 & 8 \\
\hline
\end{tabular}

Source: Constructed by author using data from Hart-Teeter Research Companies. 
In the same poll, Roper asked respondents to choose between recycling plastics into new products or "because the raw material of plastics is petroleum, another way to dispose of used plastics is to burn them for energy" [1553]. The majority (57\%) preferred recycling plastics over burning them.

In October 1990, Roper asked about various ways to deal with solid waste problems. Table 2-28 shows that the public preferred to recycle aluminum cans, plastics, glass bottles, and paper. However, in the case of styrofoam, a plurality (47\%) selected reduced use as the best way of dealing with the problem.

Solid waste is seen largely as a community problem. Cities clearly favor recycling as the response of choice in dealing with waste disposal. In $1988,12 \%$ of cities reported that refuse disposal facilities were among those "that most need repairing" [1450]. One year later, the American City and County Issues Survey asked about future trash disposal needs. A plurality of cities (43\%) selected "resource recovery," $38 \%$ "public landfill," 15\% "private landfill," and 10\% "other" in response [1450].

Table 2-28. Preferences in Dealing with Municipal Solid Waste, 1988-1990

(Card shown respondent) "This card lists various ways in which we can deal with consumer solid waste problems. Please tell me which way you favor the most for dealing with each of the following products. First, aluminum cans?" (October 1988 and October 1990) [1555]

\begin{tabular}{|c|c|c|c|c|c|c|c|c|c|}
\hline \multirow[b]{2}{*}{ Favored solution } & \multicolumn{2}{|c|}{$\begin{array}{l}\text { Aluminum } \\
\text { cans }\end{array}$} & \multicolumn{2}{|c|}{ Plastics } & \multicolumn{2}{|c|}{$\begin{array}{c}\text { Glass } \\
\text { bottles }\end{array}$} & \multicolumn{2}{|c|}{ Paper ${ }^{\mathbf{a}}$} & \multirow{2}{*}{$\frac{\text { Styrofoam }^{\mathrm{a}}}{1990}$} \\
\hline & 1988 & 1990 & 1988 & 1990 & 1988 & 1990 & 1988 & 1990 & \\
\hline \multicolumn{10}{|c|}{ Proportion responding (\%) } \\
\hline $\begin{array}{l}\text { More recycling of the } \\
\text { product }\end{array}$ & 77 & 75 & 35 & 47 & 63 & 67 & 63 & 65 & 23 \\
\hline $\begin{array}{l}\text { Reduce our use of the } \\
\text { product }\end{array}$ & 7 & 8 & 25 & 28 & 11 & 11 & 5 & 10 & 47 \\
\hline $\begin{array}{l}\text { Improve our ability to } \\
\text { dispose of the product }\end{array}$ & 9 & 10 & 30 & 20 & 14 & 14 & 15 & 13 & 23 \\
\hline $\begin{array}{l}\text { Do nothing-there } \\
\text { really isn't a problem } \\
\text { at the present time }\end{array}$ & 5 & 4 & 4 & 1 & 7 & 4 & 11 & 5 & 2 \\
\hline Don't know & 4 & 3 & 7 & 4 & 5 & 4 & 6 & 7 & 6 \\
\hline Totals $^{b}$ & 102 & 100 & 101 & 100 & 100 & 100 & 100 & 100 & 101 \\
\hline
\end{tabular}

Source: Constructed by author using data from the Roper Organization.

\footnotetext{
aAsked of half-samples.

bercentages may not add to 100 due to rounding.
} 
Public opinion supports the municipalities in resource recovery efforts, and that support appears to have increased in the late eighties. Roper found that, in October 1990, 29\% of a national poll thought their community had "strict regulations and controls on recycling bottles, cans, newspapers, etc." [1555]. Table 2-29 shows public preferences for five approaches that local communities could take to ameliorate the problem of solid waste disposal. Mandatory recycling and deposits on bottles and cans were favored by approximately three-quarters of the sample, and waste-to-energy by a majority (52\%).

Table 2-29. Trends in Preferences for Community Approaches to Solid Waste, 1988-1990

"Here are some solutions to the problem of solid waste and litter which are being tried in various states and communities. (Card shown.) For each one, please tell me whether you would favor or oppose this type of approach in your state or community." (October 1988 and October 1990) [1555]

\begin{tabular}{||l|c|c|c|c||}
\hline \multirow{2}{*}{ Approach } & \multicolumn{2}{|c|}{1988} & \multicolumn{2}{c||}{1990} \\
\cline { 2 - 5 } & Favor & Oppose & Favor & Oppose \\
\hline Proportion responding (\%) & \multicolumn{2}{|c||}{} & \\
\hline \hline $\begin{array}{l}\text { Mandatory recycling of other bottles } \\
\text { and cans }\end{array}$ & 72 & 19 & 76 & 20 \\
\hline Mandatory recycling of newspapers & 69 & 22 & 75 & 23 \\
\hline $\begin{array}{l}\text { A mandatory 5 or 10 cent deposit on } \\
\text { all bottles and cans of soft drinks and } \\
\text { beer, which is refunded when the } \\
\text { bottle or can is returned }\end{array}$ & & & & \\
\hline $\begin{array}{l}\text { A prohibition against plastic and } \\
\text { styrofoam packaging at delis, fast food } \\
\text { restaurants, and other places which } \\
\text { sell takeout foods }\end{array}$ & 72 & 20 & 71 & 25 \\
\hline $\begin{array}{l}\text { More use of incineration plants to } \\
\text { burn household garbage and trash }\end{array}$ & - & -34 & 66 & 33 \\
\hline \hline
\end{tabular}

Source: Constructed by author using data from the Roper Organization.

aIf "don't know" responses were added for each approach, rows would total $100 \%$ for each year.

${ }^{b}$ In 1988 , this item mentioned only a 5-cent deposit. 
Despite public support, however, the actual amount of recycling has not been great. Frequently, the market for recycled materials, particularly newspapers, has not been there. As a local example, in January 1992, the Giant grocery stores in Maryland stopped collecting newspapers for recycling because of lack of a market for them. Roper asked a national sample why there was a lack of recycling, and listed five potential reasons. Selected by 34\% in 1990 (and by 26\% in 1988) was "public resistance to recycling"; smaller proportions selected reasons involving government or business/industry "foot dragging," high costs, and lack of adequate technology [1555]. Roper did not include lack of a market in its list of possible reasons.

Besides the policy alternatives already discussed, other policy options were also examined in the polls. Roper asked about policies with respect to CFCs, stating that they are "used for refrigeration, making insulation materials, in the electronics industry, and in health care. "But," the item continued, "CFCs are believed to contribute to global warming and are blamed for harming the ozone layers which surround the earth and protect it from the sun's ultraviolet rays. Industrial scientists say it may be decades before safe alternatives for CFCs are available for some uses. Meanwhile, for some other uses of CFCs, industry is developing and beginning to produce replacements that are much less likely to deplete the ozone layer and much less likely to contribute to global warming" [1553]. The responses and proportions indicating they would favor them follow.

- Continuing to use CFCs until safe alternatives are available (52\%)

- Banning CFCs as replacement products become available that are less harmful, even though they are more expensive and may cause some environmental problems of their own (45\%)

- Banning CFC and replacement products that pose any threat to the environment (42\%)

- Banning all CFCs, even though there are not yet replacement products for some uses (29\%).

The public does not have a sophisticated understanding of the CFC problem; majority opinion seemed to favor continuing $\mathrm{CFC}$ use, although substantial pluralities leaned toward banning CFCs. These data were collected prior to the announcement that the ozone hole was forming over the northern North American continent in the fall of $1991 .^{3}$

The public is skeptical about using market forces to cut industrial emissions to meet Clean Air Act requirements or "emissions trading." Roper asked two related, quite complicated items concerning the free market approach to meeting the Clean Air Act requirements on emissions. Each question started:

President Bush has proposed some amendments to the Clean Air Act that call for a new approach to fighting air pollution. An overall limit will be set on the amount of emissions each company will be allowed. If a company is able to reduce emissions below the level set for it, the company can sell the unused portion of the emissions to another company that is having difficulty meeting its standard. Some people say this is a good idea because it provides incentives for companies to do even better than the standard set for them and it can be cheaper for the buyer than immediately installing the necessary equipment to cut pollution. Others say that this approach is a bad idea because even though it cuts down on the overall level of air pollution it still allows some companies to keep polluting the air and not immediately solve their problems.

${ }^{3}$ Appendix $\mathrm{F}$ contains information on the dates of public announcements about global warming and ozone depletion. 
The two questions then followed this statement.

The first question was: "What do you think? Is this approach a good or a bad idea?" [1546]. Thirty-five percent said it was a good idea; $28 \%$ said it was a bad idea. Another $23 \%$ had mixed feelings, and $13 \%$ said they didn't know.

The second question was: "Do you think that this is a proposal which primarily meets the nation's interests, or which primarily meets businesses' interests?" Half responded that it primarily met businesses' interests, $21 \%$ the nation's interest, $13 \%$ both, and 15\% didn't know [1546].

Moreover, only $11 \%$ of a 1990 Roper sample said that they were "very confident" that the federal government "is doing its job as well as it should be" in "protecting the environment and cleaning up pollution" [1552]. Another 34\% reported that they were "somewhat confident," while 53\%, the majority, were either "not too confident" or "not at all confident" that this was occurring.

Cambridge Reports presented a list of "several things electric companies could do to protect and improve the environment" and asked them to rate them from 1 (one of the less important things) to 7 (one of the most important things) [1457]. ${ }^{4}$ This line of questioning implicitly links energy production with environmental damage. The findings show that the "most important" actions (6 or 7 on a scale of 1 to 7) that utilities could take, selected by $70 \%$ or more of the sample, were the following:

- Develop safe ways to dispose of radioactive nuclear waste

- $\quad$ Plant trees to help reduce carbon dioxide in the atmosphere

- $\quad$ Phase out use of CFCs and other chemicals that can harm the ozone layer

- $\quad$ Promote building codes that require proper insulation and other energy-efficiency measures

- $\quad$ Protect wildlife habitats from development

- Help to set up public recycling centers in the community.

Actions identified as most important by $50 \%$ to $69 \%$ of the sample (achieving responses of 6 or 7 on a scale of 1 to 7 ) were as follows.

- Recycle paper and other materials at its own facilities

- Cut vegetation away from transmission lines rather than using herbicides

- $\quad$ Fund environmental research

- Develop clean coal technologies that will reduce emissions from coal-burning power plants

- Provide free information on environmental issues

- Provide information about weatherization and other low-cost measures that can improve the energy efficiency of homes

- $\quad$ Promote use of energy-efficient lighting

- Offer rebates or loans to help customers buy energy-efficient heating and cooling systems or other major appliances

${ }^{4}$ Appendix $\mathbf{H}$ presents the full set of responses for this item. 
- Promote the use of cogeneration, where steam used to make electricity is also used for heating or other applications

- Provide college scholarships for local students to study environmental sciences

- Use waste from coal-burning plants in concrete and other building materials, reducing the need to dispose of it in landfills

- Reclaim land from mining and other utility operations for agricultural, recreational, or other uses

- Inform the public about the strength of electric and magnetic fields from electric transmission lines near populated areas

- Develop electric "smart" houses that allow customers to monitor and automatically regulate their use of household appliances

- Design electric household appliances to reduce the strength of their electric and magnetic fields

- $\quad$ Promote electric heat pumps to replace less efficient heating and cooling systems.

Majorities of the sample identified these actions as important. Many other environmental actions listed did not achieve majority concurrence.

A January 1992 national poll asked: "Recently there has been some controversy about how to solve environmental problems. Some people say that most pollution can be solved if we simply use law enforcement to make people and businesses obey the rules. Other people say that solving pollution problems will involve both spending money and making changes in how we live. Which of these is closer to your opinion?" [1562]. A majority, 52\%, said, "Most environmental problems can be solved only by spending money and changing the behavior of all Americans." Forty percent said, "Most environmental problems can be solved by forcing polluters to obey the law." These proportions were virtually identical to those found in March 1991. The results suggest a perception that, in truth, both will be required.

In fact, the survey found that, in 1992, approximately two-thirds believed that "more government regulation will be needed to solve pollution problems."

The Analysis Group asked, in September 1988, about the importance of a list of goals for President Bush when he took office in January 1989. "Finding sources of energy that do not endanger the environment" was mentioned by 56\% as an "extremely important" goal (10 on a scale of 1 to 10) [1431]. As mentioned in the chapter on preferred energy alternatives, the proportion of the public in September 1990 seeing various energy sources as "no environmental threat at all" is as follows [1457]: solar energy (52\%), hydropower $(32 \%)$, natural gas $(11 \%)$, nuclear energy $(6 \%)$, coal $(4 \%)$, and oil $(3 \%)$.

These and other pieces of evidence, taken together, suggest that the public is beginning to connect energy use and environmental damage. 


\section{Chapter 3}

\section{The 1991 Gulf War}

\section{Background and Summary}

On August 2, 1990, Iraq invaded Kuwait. That action set in motion the chain of events that culminated in the Persian Gulf war. In response to the invasion, the United States initiated Operation Desert Shield within days, bringing troops to the area on August 6, 1990. Hostilities actually started on January 17, 1991, under the code name Desert Storm, and ended on February 27, 1991. This chronology of events suggests four stages in the development of the situation: (1) the events prior to the Iraqi invasion of Kuwait, (2) the interim period between the invasion and the onset of the war with the United States and its allies, (3) the war itself, and (4) the post-war period. In this chapter only, data are presented in chronological order organized into these four stages. The chapter's empirical findings are summarized below.

Between 1979 and 1988, a number of polls asked questions about the United States' presence in the Middle East. Numerous surveys examined relationships with Middle East countries and U.S. policies toward the Arab countries. The last of many such surveys located for this analysis was taken in September 1988.

In one year, between August 1990 and July 1991, several polls exhaustively sampled the topic, testing the waters of public opinion sometimes every other day, sometimes once a week. The most frequently examined poll questions changed before and after the war. Before the war, the polls asked about preferred responses to Middle East actions, such as military escorts for oil tankers in the Persian Gulf. Both before and after the war, the polls asked about perceived reasons for the war and how favorable the public was to the action. Also, public perceptions of the war's impact on oil supplies and the environment as well as other impacts were examined. Conditions under which the use of the military would be an acceptable response were frequently explored.

Relations between the United States and the Middle East became tense through problems with Libya, the Iran-U.S. hostage situation, and the Iran-Iraq war. When Iraq invaded Kuwait on August 2, 1990, the U.S. public feared a repeat of earlier oil shortages.

Many polls monitored public opinion about the Persian Gulf war. To summarize their findings, prior to the war, extensive support existed for protecting an uninterrupted supply of oil to the United States and the world, even if military action was required to do so. Opinion was divided on the necessity of actually going to war prior to the war's start.

After the Iraqi invasion on August 2,1990, the reason majorities saw for our troops' presence in the Middle East was primarily to protect oil sources, and also to deter Iraqi aggression. Other reasons mentioned during this time were neutralizing Iraq's chemical and nuclear weapons capability, overthrowing Saddam Hussein (the Iraqi dictator), and protecting Israel. By and large, protecting oil supplies was judged a "good reason" for U.S. military involvement. 
Before the war began, although the public feared another gasoline shortage, opinion was somewhat divided on how serious a threat to the nation's oil supply the situation in Kuwait actually was. Majorities expected, and saw, gasoline price increases, which they laid at the feet of oil company greed. Most were also concerned or "upset" about environmental impacts from oil spills and refinery fires set by Iraq in Kuwait. During the war itself, primary justification for the military action shifted toward the moral principle of stopping Iraqi aggression; protecting oil supplies became more secondary.

When asked how the nation could have avoided going to war, majorities agreed that increased research and development (R\&D) on energy sources other than oil and waging a campaign for energy efficiency and conservation "in autos, homes, offices, and factories" would have helped avoid the war. The war caused a polarization among those who favored and opposed drilling for oil in protected wilderness areas, even when environmental risks were considered. Many called for peacemaking efforts, but a majority agreed that the United States should not settle for a compromise that would give Iraq any concessions on disputed oil fields.

The polls did not ask questions about the United States having 10 to 12 years between the 1973-1974 Arab oil embargo and the onset of hostilities in 1991 to become markedly more energy efficient and to significantly reduce U.S. dependence on foreign oil. Based on other evidence in this report, if the public had been asked, majorities would probably have responded favorably to policies that strongly promoted efficiency and reduced oil imports. The public might even have viewed such policies, even if costly, as making the expensive war unnecessary.

After the war, opinion was divided on whether the war made the world's access to Middle East oil more secure. Opinion was also divided on whether the nation should maintain a military presence in the Middle East. Most are aware that the nation's dependence on foreign oil resulted in a military conflict costly in terms of both human lives and monetary resources. Whether the public factors this awareness into its thinking about domestic energy policies, and its behavior, remains to be seen.

The balance of this chapter provides the detailed empirical findings in chronological order.

\section{Pre-War Period: Up to August 2, 1990}

Seeds of the conflict. The seeds for the Persian Gulf conflict may have been planted at least as early as the 1973-1974 Arab oil embargo. Attitudes toward Arab countries were still negative in 1980, when $82 \%$ of a Louis Harris and Associates sample agreed with the statement: "If we yield to Arab terms over oil now, we will soon find the Arabs dictating much of the U.S. foreign policy, and that is wrong" [1252]. Eighty percent agreed that: "The Arabs are getting rich on the dollars we are paying them for their oil, and as a result, we and the rest of the world are suffering bad inflation and an economic recession, which is wrong." However, $61 \%$ disagreed with the statement that "it would be good if some country or group of countries took over the Arab oil fields by force and internationalized the oil at lower prices" [1252]. A majority of $66 \%$ disagreed with the statement: "As long as American oil companies are operating in Arab countries, those oil companies will look after our interests" [1252].

Other tensions have long standing. In $1980,86 \%$ were afraid that if the Iran-Iraq war spread to other oilproducing states in the Persian Gulf, it could "cause a disastrous oil shortage in Western Europe, Japan, and the United States" [1386]. In 1981, opinion was divided on whether the United States should stop buying oil from Libya, even if that meant somewhat less oil or increased oil prices in the United States [1368]. Most of those in the latter survey favored American oil companies pulling out of Libya and stopping all imports of Libyan oil and natural gas into the United States [1255]. 
From March 1979 through September 1981, majorities of 55\% to 63\% consistently opposed decreasing U.S. support for Israel, including providing Israel with military weapons, even if this would ease the flow of Arab oil to the United States [1410, 1385, 1252, 1373, 1369, 1385]. In October 1981, ABC News/The Washington Post asked whether their sample agreed with the statement: "The United States should cooperate with the Arab nations to ensure an adequate oil supply even if that means lessening our ties to Israel" [1368]. A plurality of $43 \%$ disagreed with this, while $39 \%$ agreed; $18 \%$ were unsure. And, in November of that year, $36 \%$ agreed "that the United States should cooperate with the Arab nations to ensure an adequate oil supply even if that means lessening our ties to Israel"; 50\% disagreed [1367]. No poll data on attitudes toward U.S.-Israeli ties were located in later data.

Approval for the use of military force. The use of military force to protect the country's oil interests in the Middle East has long been approved by majorities of the public, although pluralities have opposed this. In 1979, 60\% said the United States "should take any steps necessary against the oil-producing nations to ensure continued energy supplies" [1224]. Majorities ranging from 51\% to $64 \%$ favored using troops to ensure the flow of oil $[1349,1348,1377,1243,1231]$. However, there was a limit to how far the public thought military action should go at that time. In another June 1979 sample, $61 \%$ said that the United States shoukd not use military action to force the Organization of Petroleum Exporting Countries (OPEC) countries to increase their production of oil [1146].

When asked in July 1987 how important it was for the United States to increase its military presence to ensure the flow of oil through the Gulf, 83\% said it was "very important" or "fairly important" [1300]. More than half (53\%) approved of U.S. ships escorting Kuwaiti oil tankers in the Persian Gulf and providing U.S. Navy escorts to help ensure adequate oil supplies for the United States and its allies in May 1987 [1377]. In June 1987, opinion was divided (49\% pro and 49\% con) about U.S. Navy intervention [1376]. In late September 1988, a majority of 53\% approved of "the use of U.S. military forces, if necessary, to ensure that our supply of oil is not disrupted"; and 51\% approved of conducting "covert or secret military actions to ensure the continued flow of oil" [1323]. Pluralities of $44 \%$ and $45 \%$, respectively, opposed those actions.

Approval for other actions. During the pre-war period, three polls showed opposition to the use of military force to protect oil sources. An Opinion Research Corporation poll in November 1980 showed that 53\% opposed "using U.S. troops to ensure that the U.S. has an adequate supply of oil from the Middle East" [1176]. A Roper poll in August 1986 asked about justifying the use of U.S. troops in other parts of the world, specifically "if Iranian troops seized Saudi Arabia's oil fields" [1082]. A plurality of 48\% opposed troop deployment while 32\% favored it under those circumstances. And, in October 1986, Gallup found a 51\% majority opposed to using U.S. troops if the Arabs cut off all oil shipments to the United States; $36 \%$ favored military intervention if this occurred [1292].

In September 1988, stronger approval went to actions short of military intervention. For example, $77 \%$ approved having the United States join with other nations that import Mideast oil to form a peacekeeping force in the area [1323]. Eighty-two percent favored diplomatic talks and 84\% favored further development of domestic oil, other domestic energy sources, and strategic oil reserves [1323].

Additional poll items explored actions other than military movements that the United States might take in its relationship with the Arab countries. In May 1979, NBC News/The Associated Press asked whether the United States "should withhold shipments of food and other American exports until the oil-producing countries agreed to give us sufficient oil at reasonable prices" [1224]. At that time, 71\% said yes. In December 1979, when OPEC was reportedly going to increase oil prices again, $87 \%$ agreed that "the United States should redouble its efforts to get other major industrial countries to be much tougher in negotiating with OPEC" [1415]. The same proportion agreed with "tougher measures to conserve energy here at home," but $80 \%$ opposed a $\$ 0.50 /$ gallon tax on gasoline. 
In May 1987, the Los Angeles Times asked: "In your opinion, what is the most important U.S. foreign policy objective in the Persian Gulf? Is it to protect free access to international waters, to show the flag, to promote friendlier relations with moderate elements in Iran, to support the Iraqi side in the war, to guard sea lanes for the shipment of oil, to halt Russian expansion southward into the Gulf, or what?" [1240]. The most frequent responses were $33 \%$ for protecting free access, and $28 \%$ to "guard sea lanes for shipment of oil."

\section{Interim Period: August 2, 1990, to January 16, 1991}

Prior to the Gulf war, Operation Desert Shield brought hundreds of thousands of U.S. troops to the Middle East, as the United States readied itself for possible conflict. During this period, an economic embargo was established. Survey items tended to focus on public perceptions of the reasons for military involvement, whether the public thought the reasons warranted military involvement, and the consequences that the public thought would ensue from the Persian Gulf situation.

Reasons for military involvement. Pollsters asked numerous questions about the public's perception of the reasons for U.S. military involvement in the region. Table 3-1 summarizes responses to 11 items asking about the public's perceptions of the main reasons for the U.S. presence in the Middle East. While the wording of questions varied considerably, a pattern of findings is evident. Proportions ranging from as low as $9 \%$ to as high as $55 \%$ said the United States was in the region to protect oil sources for itself and other countries, as well as to protect oil prices. Approximately an equal plurality, ranging from $26 \%$ to $55 \%$, maintained that the United States was there to deter Iraqi aggression or protect other countries. A number of other related reasons were cited, including restoring the Kuwaiti government, neutralizing Iraq's chemical and nuclear weapons capability, and overthrowing Saddam Hussein. A slight preponderance held that the primary reason was to protect our oil supplies (majorities or pluralities responded in this manner in 7 out of 11 studies that asked about this).

Perceived justification for military involvement. Several items also asked respondents to evaluate reasons for the Gulf war-did they view them as good and sufficient reasons for military involvement in the Middle East, or not? Table 3-2 summarizes the results from nine polls that, for the most part, were similar in thrust and focus, although they used different item wording. Most of the polls found that majorities (sometimes large majorities) ranging from $57 \%$ to $78 \%$ said that protecting oil supplies and prices was a good reason for military involvement; one poll found that $62 \%$ said protecting oil supplies was not a good reason for the war. To the items including lowering oil prices, most responded that it was not a good reason for the war. Opinion appeared divided on whether halting Iraqi aggression was a good reason; one poll found 50\% saying it was not and $47 \%$ saying it was a good reason. Another found $81 \%$ saying that "preventing Iraq from attacking Israel" was a "very important" or "somewhat important" reason for sending troops to the Middle East. This item, asked November 14, 1990, was repeated verbatim on December 6, 1990; the results did not differ.

On August 7, 1990, 71\% approved and 20\% disapproved of sending troops "if there were a threat to our supply of oil in the Middle East" [1390]. On August 8, 1990, Gallup asked: "If there is another gasoline crisis in the United States as a result of the Iraqi/Kuwaiti situation, with long lines and higher gas prices, would you favor or oppose direct U.S. military action against Iraq?" [1298]. Opinion was divided; 45\% were opposed to military action under these circumstances and $44 \%$ were for it; $11 \%$ were unsure. And, on August 9, 1990, 50\% disagreed (and 41\% agreed) with The New York Times poll statement, "Coming to the aid of Saudi Arabia just helps protect the profits of the big multi-national oil companies" [1186]. That same date, $68 \%$ agreed (and $27 \%$ disagreed) with "The United States should have a say about who controls oil in the Middle East because it affects the economy of every Western country" [1186]. 
Table 3-1. Perceived Reasons for the Persian Gulf War

Prototypical item wording: "Do you think that the main American goal in the Middle East is to protect the oil supply or to deter aggression?" (Item wording follows table.)

\begin{tabular}{||l|c|c|c|c|c||}
\hline \multirow{2}{*}{ Date } & & \multicolumn{4}{|c|}{ Percentage responding $^{\text {b }}$} \\
\cline { 3 - 6 } & Study Number & $\begin{array}{c}\text { Protect oil } \\
\text { sources and } \\
\text { prices }\end{array}$ & $\begin{array}{c}\text { Deter } \\
\text { Iraqi } \\
\text { aggression; } \\
\text { protect others }\end{array}$ & Other $^{\text {c }}$ & $\begin{array}{c}\text { Don't } \\
\text { know }\end{array}$ \\
\hline \hline $1 / 11 / 91$ & {$[1011]$} & 29 & 42 & 25 & 4 \\
\hline $1 / 11 / 91$ & {$[1510]$} & 37 & 55 & - & 8 \\
\hline $12 / 11 / 90$ & {$[1025]$} & 50 & 28 & 14 & 8 \\
\hline $11 / 14 / 90$ & {$[1017]$} & 51 & 34 & 9 & 6 \\
\hline $11 / 13 / 90$ & {$[1030]$} & 43 & 26 & 17 & 14 \\
\hline $11 / 12 / 90$ & {$[1003]$} & 9 & 34 & 50 & 6 \\
\hline $11 / 8 / 90$ & {$[1023]$} & 36 & - & 61 & 4 \\
\hline $10 / 30 / 90$ & {$[1034]$} & 35 & 46 & 13 & 6 \\
\hline $10 / 8 / 90$ & {$[1024]$} & 55 & 20 & 19 & 6 \\
\hline $9 / 4 / 90$ & {$[1189]$} & 50 & 39 & 9 & 2 \\
\hline $8 / 16 / 90$ & {$[1031]$} & 46 & 30 & 16 & 8 \\
\hline
\end{tabular}

Source: Constructed by author from studies listed.

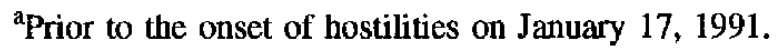

${ }^{b}$ Rows total $100 \%$ except for rounding errors.

c"Other" responses were:

Restore Kuwaiti government (11\%) [1011]

Combination of reasons (12\%) [1011]; (15\%) [1023]

Neutralize Iraq's growing chemical and nuclear weapon capability (14\%) [1025]

Overthrow Saddam Hussein (13\%) [1034]; (9\%) [1189]

Restoration of independence to Kuwait (46\%) [1023]

Protecting and freeing U.S. hostages (50\%) [1003]. 


\section{Study No. $\quad$ Item wording}

[1003] "In the crisis, which of the following is the most important goal? Protecting and freeing U.S. hostages; getting Iraq out of Kuwait; ensuring a sufficient supply of oil to U.S./other countries; protecting Saudi Arabia from Iraqi invasion."

[1011] "Of these three reasons, which do you think is the main reason United States military forces are in the Persian Gulf-1, to protect the supply of oil to the United States, or 2, to restore the government of Kuwait, or 3, to stop Iraq from attacking Saudi Arabia and other Middle Eastern countries? (If more than one answer, say:) Which do you think is the main reason? Protect oil; restore Kuwaiti government; stop Iraq attacks; protect oil and restore Kuwaiti government; restore Kuwaiti government and stop Iraqi attacks; protect oil and stop Iraqi attacks; other combinations."

[1017] "Do you think that the main American goal in the Middle East is to protect the oil supply or to deter aggression?"

[1023] "Of the following two alternatives, which do you feel is the most important reason for establishing an international force in the Gulf?"

[1024] "Do you think the United States sent military troops to the Middle East mainly to stop an Iraqi invasion of Saudi Arabia, or mainly to protect the supply of oil to the U.S.?"

[1025] "The United States has stationed hundreds of thousands of troops in the Middle East. Which of the following reasons best explains why we are there: liberating Kuwait from Iraqi occupation; secure Middle East oil supplies for the U.S. and its allies; neutralize Iraq's growing chemical and nuclear weapon capability?"

[1030] "Do you think the U.S, sent military troops to the Middle East mainly because the U.S. has a duty to protect its friends, or mainly because the price of oil will increase too much if we let the Iraqis control oil fields in the Middle East?"

[1031] Same as 1030.

[1034] "I'm going to read you three reasons some people think U.S. troops are in Saudi Arabia. Please tell me which one you think is the single most important reason U.S. troops are there. To protect the world's oil supply; to force Iraq to withdraw from Kuwait; to overthrow Saddam Hussein."

[1189] Same as 1034.

[1510] "What do you think is the primary reason the United States is prepared to go to war with Iraq? Do you think it is more to protect our supply of oil and our economic interests, or do you think it is more to stop aggression and protect other countries in the Middle East?" 
Table 3-2. Evaluation of Reasons for Going to War in the Persian Gulf

Example item wording: "I'm going to read to you some reasons people give for going to war against Iraq. Please tell me whether you think each is a good reason for the U.S. to go to war against Iraq." a

\begin{tabular}{|c|c|c|c|c|c|c|c|}
\hline \multirow[b]{3}{*}{ Date } & \multirow[b]{3}{*}{ Study No. } & \multicolumn{6}{|c|}{ Percentage responding ${ }^{\mathbf{b}}$} \\
\hline & & \multicolumn{2}{|c|}{$\begin{array}{l}\text { Protect oil supplies } \\
\text { and prices }\end{array}$} & \multicolumn{2}{|c|}{ Lower oil prices ${ }^{b}$} & \multicolumn{2}{|c|}{$\begin{array}{l}\text { Stop Iraqi } \\
\text { aggression; protect } \\
\text { other nations }^{b}\end{array}$} \\
\hline & & Good & Not good & Good & Not good & Good & Not good \\
\hline $1 / 4 / 91$ & [1014] & 69 & 28 & - & - & - & - \\
\hline $12 / 6 / 90$ & {$[1022]$} & 60 & 36 & 31 & 66 & - & - \\
\hline $11 / 15 / 90$ & [1029] & 57 & 38 & 30 & 67 & - & 一 \\
\hline $11 / 14 / 90$ & [1017] & - & - & - & - & 47 & 50 \\
\hline $11 / 14 / 90$ & [1346] & 66 & 28 & - & 5 & - & - \\
\hline $11 / 13 / 90$ & [1030] & 31 & 62 & - & 7 & - & - \\
\hline $9 / 21 / 90$ & [1035] & 77 & - & - & - & - & - \\
\hline $8 / 23 / 90$ & [1048] & 78 & 18 & - & 4 & - & - \\
\hline $8 / 9 / 90$ & [1286] & - & - & 一 & - & 81 & - \\
\hline
\end{tabular}

Source: Constructed by the author using data from the studies identified.

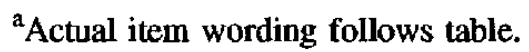

${ }^{\text {b}}$ Row percentages would add to 100 if "other" and "don't know" responses were added.

Item wording for Table 3-2

Study No. Item wording

[1014] "Is 'To prevent Iraq from having control of a major source of the world's oil' a good reason or not a good reason for the United States to go to war (with Iraq)?"

[1017] "(Here are some arguments that have been made for using military force against Iraq in the next few months. For each, please tell me if it is a good reason or a poor reason for using force soon.) ... Many nations are being hurt economically by high oil prices."

[1022], "(I'm going to read to you some reasons people give for going to war against Iraq. Please tell me [1029] whether you think each is a good reason for the U.S. to go to war against Iraq or whether it is not a good reason to go to war?) . . . To prevent Iraq from controlling a larger share of Mideast oil and threatening the U.S. economy." "To lower oil prices." 
Item wording for Table 3-2 (continued)

Study No. Item wording

[1030]

[1035]

[1048] "(Please tell me if each of the following are good reasons or poor reasons for getting involved in this Middle East conflict) . . . To protect the oil supply in the Middle East."

[1286] "(How important to you are each of the following possible reasons for sending U.S. troops this week to the Middle East?) Would you say . . . preventing Iraq from ultimately attacking Israel . . . is a very important reason, somewhat important, not very important, or not important at all?" (81\% said "very" or "somewhat important.")

[1346] "I am going to mention several reasons that have been offered to explain why the United States should be involved in the Mideast crisis. For each of the following reasons, would you please tell me whether you think it justifies a major war, a limited military involvement, but not a major war, or it does not justify U.S. military involvement at all? . . . Do you think the U.S. is justified in getting involved in a major war to protect our oil supplies in the Persian Gulf, or does it justify a limited military involvement but not a major war, or protecting our oil supplies in the Persian Gulf does not justify a U.S. military involvement at all?" (16\% said "major war"; 50\% said "limited military involvement.")

Hart and Teeter Research asked the same series of questions on August 18, September 4, and December 8 , 1990. The series was prefaced by the statement: "(I'm going to mention some things that may or may not happen in the Middle East and for each one, please tell me whether the U.S. should or should not go to war in connection with it." The question was: " . . If the U.S. develops a major shortage of oil that increases the price of gasoline to over $\$ 2$ per gallon?" [1018]. Most (from 64\% to $77 \%$ ) said no military action was warranted under these circumstances. Even when queried further, "If the U.S. develops a major shortage of oil that threatens an economic recession and closes some of our factories?," $50 \%$ to $68 \%$ said no military action was warranted. On January 10 , just one week before firing commenced, a national poll asked: "Two of Iraq's goals in Kuwait are to control the oil fields which stretch across the Iraq-Kuwait border and to gain a sea outlet on the Persian Gulf. Suppose Iraq were to withdraw its troops from all areas of Kuwait except the border oil fields and two seaports. Do you think we should accept this situation, or should we go to war to remove these troops?" [1001]. A 49\% plurality said we should go to war, while $34 \%$ said we should accept the situation; $17 \%$ were not sure.

Thus, while opinion on the necessity of going to war remained divided prior to the war, there did seem to be extensive support for the idea of protecting an uninterrupted supply of oil to the United States and the world, even if military action were required to do so. 
Perceived impacts of the Middle East situation. Some items asked what people thought might happen if war ensued. For example, Penn and Schoen Associates asked: "How long do you think the Iraqi crisis will last?" The modal response (27\%) was a year; $3 \%$ thought just a few days or weeks; $5 \%$ said a few weeks; $7 \%$ a month; $16 \%$ a few months; $19 \%$ many months; and $22 \%$ didn't know.

Gallup asked: "As a result of the events in Kuwait, how likely is it that there will be another gasoline crisis here in the United States with long lines and higher prices? Do you think it is very likely, somewhat likely, not too likely, or not at all likely?" [1040, 1313]. On both August 3 and August 9, $1990,70 \%$ said they expected another gasoline crisis. In this same vein, CBS News asked: "Do you think the invasion of Kuwait has meant a real threat to the supply of oil to the United States, or not?" Opinion was divided on this question; $46 \%$ thought not, and $43 \%$ saw a real threat; $11 \%$ were unsure. However, at about the same time, Associated Press found a 52\% majority saying that "the situation in the Middle East is likely to create oil shortages in the next few months, with rising prices and long lines at service stations" [1361].

Similarly, 50\% of a CBS News/The New York Times poll on August 16, 1990, said that the invasion of Kuwait meant "a real threat to the supply of oil to the United States"; $44 \%$ said it was not a real threat [1031]. Louis Harris approached the same question from a different angle: "If you had to say, would you call President Bush's plan of action against Iraq a success or not if oil price increases caused inflation in the United States to go up to close to $10 \%$ or more?" In response, $65 \%$ stated the Bush action would "not be a success" if that happened; $28 \%$ said it would be a success. Penn and Schoen Associates, in their survey for Texaco, Inc., on the Iraqi crisis, asked: "Do you think that the Iraqi crisis is a serious threat to our economy and our way of life or not?" [1206]. Nearly three-quarters (73\%) saw it as a serious threat.

The economic boycott. Prior to the war, the United States declared an economic boycott against Iraq, attempting to force Iraq to withdraw from Kuwait without military aggression. The public appeared to support the economic boycott if it did not have what were perceived as severe effects at gas stations-long lines, high prices, and shortages. Several poll items asked about the boycott. For example, on August 3, 1990, Gallup asked: "As a result of the Iraqi invasion of Kuwait, would you favor or oppose encouraging all U.S. allies to boycott Iraqi oil imports?" [1298]. Favoring the boycott were 76\%; opposing it were 13\%. CBS News asked: "Right now, do you think placing an embargo on imports of oil from Iraq is a good idea even if it means higher oil prices in the United States, or should the United States continue to import oil from Iraq? What if the price of gasoline went up to $\$ 2 /$ gallon because of the embargo. Would you think an embargo on oil from Iraq is still a good idea, or would you say the United States should then import oil from Iraq?" [1350]. Half said it was a good idea to embargo, even with prices at $\$ 2.00 ; 11 \%$ said it was a good idea, but not if the price went to $\$ 2.00$. The rest of the respondents thought the United States should continue to import oil, or didn't know. Given a 25-cent increase in oil prices, however, $84 \%$ favored the boycott on August 8, 1990 [1042]. Another poll the next day found 83\% favoring the boycott when no gasoline price increases were mentioned [1049].

On August 8, 1990, Gordon S. Black asked: "President Bush's economic sanctions include a ban on Iraqi oil, which could wind up raising the cost of gasoline in the United States to $\$ 2 /$ gallon. How much more are you willing to pay for a gallon of gas than you paid last week in order to make the ban work?" [1004]. Willing to pay nothing more were $24 \% ; 25$ cents more were $21 \%$; 50 cents more were $16 \%$; 75 cents more were 5\%; and one dollar or more were $27 \%$; $8 \%$ didn't know. One day later, Yankelovich/Clancy/ Shulman found $52 \%$ opposed to "taking strong actions against Iraq even if it leads to the price of gasoline being $\$ 2 /$ gallon or more" and 50\% opposed to such actions if they caused "gas shortages and long gas lines" [1049]. 
Avoiding the war. When asked, the public seemed willing to admit that more could have been done prior to the Persian Gulf situation that would have helped to avoid a military confrontation. Market Strategies asked for some Monday-morning quarterbacking from the American public. What, they asked, could we have done to avoid the Middle East situation? And, how much would it have helped? Table 3-3 shows the data in response. Majorities agreed that every strategy mentioned would have helped at least a little. The items selected most frequently as likely to have helped a great deal were (1) "supported increased R\&D of energy sources other than oil" and (2) "waged a campaign to increase energy efficiency and conservation in autos, homes, offices, and factories." Other items dealt with, in decreasing order of importance, increasing domestic oil sources, saving more oil in the strategic petroleum reserve, improving corporate average fuel economy standards, and taxing foreign oil [1035].

Another poll asked: "The crisis with Iraq has made the United States pay more attention to its energy policies and how well we have conserved energy in the past 10 years. As a nation, do you think that the United States has done a good job or a poor job conserving energy?" [1049]. Sixty-five percent said the nation was doing a "poor job"; $31 \%$ said it was doing a "good job"; $4 \%$ were unsure. These were the only items located that linked the Persian Gulf situation directly with U.S. energy policy.

Other items asked about conditions and tradeoffs that might mean the United States could avoid going to war. On August 9 and 23, 1990, Yankelovich/Clancy/Shulman asked whether respondents would favor or oppose taking "strong actions against Iraq" even if it had costs to American citizens [1049]. Majorities of 54\% on August 9 and $64 \%$ on August 23 favored strong action even if it made "Americans pay a lot more to heat or air condition their homes." Likewise, 58\% favored such action even if it caused "gas shortages and long gas lines" or led to "the price of gasoline being \$2/gallon or more" [1048].

On August 17, 1990, Louis Harris and Associates asked: "There are times when it is worth the country making sacrifices in blood and money to achieve a more important return. Do you feel it is worth the loss of American lives and billions of dollars in this present Mideast crisis to make sure American oil supplies in the Middle East are not cut off by a military power such as Iraq, or not?" [1261]. A majority of 52\% said it was not worth it, but a plurality of $44 \%$ said it was worth it.

Stiffening opposition against Iraq. By October 18, 1990, opinion, though still divided, seemed to be stiffening against Iraq. When Gallup asked whether the United States should pursue a compromise involving Iraq pulling out of Kuwait but keeping a strategic offshore island and some disputed oil fields, 59\% said "no concessions"; 30\% called for compromise; $11 \%$ didn't know [1036]. And, on November 8, $1990,71 \%$ agreed with using military forces in the Gulf crisis to protect the West's oil supplies [1023]. However, on November 14, 1990,65\% said it was not worth "risking the lives of American soldiers in order to protect our oil supplies" [1346]. In addition, the prospect of war posed a threat to environmental concern. A plurality of $49 \%$ agreed (and $43 \%$ disagreed) with the statement: "In view of the crisis in the Gulf, drilling for oil in protected areas of the United States should now be allowed, even though there is a risk to the environment" [1028].

On November 29, 1990, Gallup asked ahout concessions the United States could make to Iraq. Sixty-eight percent favored "agreeing to host an international summit combining discussion of the Iraqi/Kuwaiti situation with discussion of the Palestinian problem in Israel" [1007]. However, 64\% opposed "allowing Iraq to re-draw the border between Iraq and Kuwait to give Iraq some of Kuwait's territory and oil fields" [1007].

On December 8, 1990, the Los Angeles Times asked: "If Saddam Hussein releases the hostages and pulls his troops out of most of Kuwait but holds on to an oil field and some other land in Kuwait, what do you think the next step should be? Should we remove our military troops from the Mideast, or should we leave our military troops and enforce the economic embargo, but don't use military force against Iraq, or 
Table 3-3. Actions That People Believe Could Have Avoided the Gulf War

"Here are some things that some people thought we should have done but did not do before the situation in the Persian Gulf happened. As I mention each one, please tell me if you think it would have helped a lot, helped a little, or not helped at all, to make the confrontation with Iraq unnecessary." (September 1990) [1035]

\begin{tabular}{|c|c|c|c|c|}
\hline \multirow[b]{2}{*}{ Item $^{\mathrm{a}}$} & \multicolumn{4}{|c|}{ Would have ... } \\
\hline & Helped a lot & Helped a little & $\begin{array}{c}\text { Not helped } \\
\text { at all }\end{array}$ & Don't know \\
\hline \multicolumn{5}{|l|}{ Proportion responding (\%) } \\
\hline $\begin{array}{l}\text { Supported increased R\&D } \\
\text { of energy sources other } \\
\text { than oil }\end{array}$ & 59 & 26 & 13 & 1 \\
\hline $\begin{array}{l}\text { Waged a campaign to } \\
\text { increase energy efficiency } \\
\text { and conservation in autos, } \\
\text { homes, offices, and } \\
\text { factories }\end{array}$ & 51 & 30 & 17 & 2 \\
\hline $\begin{array}{l}\text { Given more incentives to } \\
\text { oil companies for } \\
\text { exploration and recovery } \\
\text { operations in places outside } \\
\text { the Middle East }\end{array}$ & 47 & 31 & 20 & 2 \\
\hline $\begin{array}{l}\text { Further increased our } \\
\text { government strategic oil } \\
\text { reserves }\end{array}$ & 46 & 31 & 20 & 3 \\
\hline $\begin{array}{l}\text { Continued the mandatory } \\
\text { annual improvement in } \\
\text { miles per gallon of U.S. } \\
\text { autos, discontinued in } 1984\end{array}$ & 41 & 34 & 23 & 2 \\
\hline $\begin{array}{l}\text { Put a tax on foreign oil of } \\
5 \text { cents per gallon more } \\
\text { each year for } 10 \text { years, } \\
\text { totaling } 50 \text { cents at the end } \\
\text { of } 10 \text { years }\end{array}$ & 19 & 36 & 41 & 3 \\
\hline
\end{tabular}

Source: Constructed by the author using data from Market Strategies.

${ }^{a}$ Row percentages total 100 except where rounding error occurs. 
should we invade Iraq if it doesn't leave all of Kuwait?" [1019]. To this somewhat confusing item, 46\% said we should leave our military troops there; $29 \%$ said we should invade Iraq; $17 \%$ said we should remove our military force; and $8 \%$ didn't know.

Hart and Teeter found, on December 8, 1990, a 51\% majority in accord that "The U.S. should accept an agreement with Iraq in which Iraq releases all of the hostages and withdraws from Kuwait, with some concessions being made to Iraq on the control of disputed oil fields" [1018]. Thirty-nine percent said the United States should not accept an agreement. Virtually everyone on December 29, 1990, said they would not support withdrawal of U.S. troops from Saudi Arabia "if Iraq could influence the price of oil for the rest of the world" [1005]. And, 89\% said they believed that "If we withdraw from Saudi Arabia without getting Saddam Hussein and the Iraqis out of Kuwait, Hussein will use his control of Middle Eastern oil to build up his army to the point where he can use it against Israel" [1005].

Gallup asked, on January 11, 1991, just 5 days before hostilities commenced: "If Iraq were to withdraw from most of Kuwait - except for two offshore islands and some oil fields on the Iraq border-would you be less likely to support taking military action against Iraq, more likely, or would this not affect your opinion about taking military action against Iraq?" [1510]. Forty-three percent said they would be less likely to support military actions if Iraq were to withdraw from most of Kuwait. But $46 \%$ said that such a withdrawal would have no effect on their opinion-they would still support taking military action against Iraq. Apparently, at that point, events had gone almost too far to avert the war.

\section{The Gulf War: January 17 to February 27, 1991}

Reasons for the war. Louis Harris and Associates asked, on February 21, 1991: "Which one do you think is the foremost aim of the United States in the Gulf?" [1509]. A plurality (39\%) responded, "to oust Iraq from Kuwait"; $32 \%$ said, "to overthrow Saddam Hussein"; 14\% said, "to protect the oil supply of Western nations in the Middle East"; $6 \%$ said, "to demonstrate the power of the United States to the rest of the world."

The Los Angeles Times also asked about the perceived reasons for the war. They asked: "How about to protect our oil supplies in the Persian Gulf [as an argument people have made in support of the United States decision to go to war against Iraq]" [1507]. A plurality of $49 \%$ said this was an "excellent" or "good" reason, while another $49 \%$ said it was "not so good" or "poor."

During the war, many people (60\%) attributed U.S. involvement in the war to "not having a conservation or alternative energy policy in the United States" [1502].

CBS News/The New York Times asked for the public's perceptions of the main reasons for the war after the Iraqi attack on Israel had begun. They identified "stopping Iraqi attacks" as the "main reason U.S. military forces are fighting in the Persian Gulf," by $43 \%$ [1008]. Other frequently mentioned reasons were "protecting oil" (15\%) and "restoring Kuwaitis" (23\%). Similar results were obtained when the item was repeated during those weeks [1009].

On January 20, 1991, ABC News/The Washington Post asked: "Which of these two views best describes yours: (A) The United States has sent troops to the Persian Gulf because of a moral principle that we cannot allow Iraq or any other country to invade another, or (B) The United States has sent troops to the Persian Gulf because of the economic reality that we cannot let Iraq or any other country gain too much control over the flow and price of Middle Eastern oil" [1015]. The majority (54\%) agreed with statement A, while 35\% agreed with statement B, 6\% said "both"; and 3\% said "neither." This repeated an item asked on November 30,1990, during the pre-war Desert Shield period. At that time, a plurality of $48 \%$ agreed with statement B, while $41 \%$ agreed with A; $7 \%$ said "both"; and $2 \%$ said "neither" [1026]. 
In the six-week period before the war began, opinion thus shifted by 13 points in the direction of justifying the war on moral principle rather than on the basis of economic interests.

The Gulf war's impacts. CBS News asked: "During the war in the Persian Gulf, do you expect the cost of gasoline to go up, go down, or stay about the same?" [1013]. A majority of 54\% expected gasoline prices to increase; another third (36\%) thought they would stay the same; only $6 \%$ expected them to go down.

The fiscal impact of the war was another question. Time/CNN asked: "Do you favor or oppose (1) taxing imported oil, (2) an increase in gasoline taxes as a way to pay for the war against Iraq?" [1505]. A majority of $54 \%$ favored taxing imported oil, while $39 \%$ opposed it. However, only $35 \%$ favored an increase in gasoline taxes, and $61 \%$ opposed it. This result is consistent with other evidence on the public's view of gasoline taxes.

Environmental impacts were yet another source of concern. Gallup asked: "How worried are you that Iraq's setting fire to oil refineries in Kuwait will lead to major ecological problems in the region-very worried, somewhat worried, not too worried, or not worried at all?" [1503]. Sixty-one percent said they were "very" or "somewhat worried" about these ecological impacts; 36\% said they were not.

\section{Post-War Period: After February 27, 1991}

Reasons for the war. In July 1991, Associated Press asked: "How about . . to prevent Iraq from having control of a major source of the world's oil . . . ? Was that a good reason or not a good reason for the United States to have gone to war against Iraq?" [1492]. Almost three out of four (72\%) said that was a good reason; $25 \%$ said it was not.

Within 2 weeks of the cease-fire, Market Strategies attempted to gauge the perceived severity of the threat to U.S. and world oil supplies by asking about two different kinds of dictators. The first one "invades and occupies by force a neighboring country providing oil to the United States" and the second one does this "to a country providing oil to the world." When asked how seriously they viewed this behavior, $72 \%$ of a half-sample identified the threat to U.S. oil as "extremely" or "very serious" and $81 \%$ so identified it from the world standpoint.

Immediately after the cease-fire, on March 1, 1991, ABC News/The Washington Post asked: "Which of these two views best describes yours: (A) The United States has sent troops to the Persian Gulf because of a moral principle that we cannot allow Iraq or any other country to invade another, or (B) The United States has sent troops to the Persian Gulf because of the economic reality that we cannot let Iraq or any other country gain too much control over the flow and price of Middle Eastern oil" [1504]. The majority (56\%) agreed with statement A; 34\% agreed with statement B: $9 \%$ volunteered that they agreed with both statements; $1 \%$ agreed with neither statement; and $1 \%$ didn't know.

The war's impacts. Gallup asked in July 1991: "As a result of the Persian Gulf war, do you think the world's access to Middle East oil is now more secure?" [1489]. Opinion on this outcome of the war was divided: $47 \%$ responded affirmatively; $40 \%$ thought no; $13 \%$ were unsure.

Market Strategies and Greenberg-Lake attempted to gauge the degree of public upset following the war. In June 1991, they asked: "Let me read you some statements about things that some people think may happen as a result of the war. Again, please tell me how often this upsets you. Does (the item) upset you almost all the time, a lot, sometimes, or almost never?" [1488]. Following are three items and the proportion of respondents stating that these upset them "all the time" or "a lot." 
- The oil released in the Persian Gulf has done more damage to the environment than the Exxon Valdez spill in Alaska (69\%)

- The United States uses as much Middle East oil as before the war, and may be just as vulnerable to the actions of unstable Arab states (49\%)

- The flow of oil from Kuwait has stopped, and may be reduced for many years because of the damage done during the war $(35 \%)$.

Continuing military presence. In May 1991, a national poll asked: "Do you think the United States should maintain a larger military presence in the Middle East than before the war in order to protect friendly nations and safeguard vital U.S. interests, such as oil?" [1494]. Opinion was again divided, with $48 \%$ saying the nation should not maintain such a presence, and $43 \%$ saying we should.

In March 1991, The Washington Post poll asked: "There has been some discussion about the circumstances that might justify using U.S. troops in other parts of the world. I'd like to ask your opinion about several situations. Would you favor or oppose the use of U.S. troops if the Arabs cut off oil to the United States?" [1490]. Opinion was divided-49\% favored using U.S. troops, and 41\% opposed this action. 


\section{Chapter 4}

\section{The Energy Situation}

\section{Background and Summary}

What people define as real is real in its consequences. Earlier reviews of public opinion revealed that most people in the late 1970s did not believe there was an energy "crisis," as had been announced by the Carter Administration, but instead perceived a serious national energy problem. About three-quarters had defined this as a serious problem during the previous 5 years, and about $40 \%$ had said it was "very serious." Inflation, unemployment, and crime were grave concerns at that time. The energy problem was considered neither the most nor the least important problem facing the nation. A majority foresaw energy shortages and rising energy costs in the foreseeable future. About half thought that the nation's supply of oil and natural gas was beginning to dwindle.

During the Organization of Petroleum Exporting Countries (OPEC) oil embargo (1973-1974), majorities ranging from $50 \%$ to $78 \%$ thought the oil companies contrived the energy problem for their own benefit. The percentage believing that energy shortages were "real" (rather than "contrived") increased until it became the majority view by early 1979. Much of the public attributed energy shortages to the wasteful use of energy, oil companies, the federal government, OPEC countries, industry and business, and environmentalists. Also, the growing population and the finite nature of fossil fuel resources were mentioned as causes for the nation's energy problems. The energy problem affected most of the public and especially affected lower-income groups. Impacts varied from inconvenience in getting gasoline to job losses.

Have these perceptions of the energy situation changed during the past 10 to 12 years? This chapter presents data on the perceived severity of the energy situation, expectations for the future, perception of the significance of the energy problem vis-à-vis other national problems, and perceived impacts of the energy situation. A summary of the chapter's empirical findings follows.

A number of surveys have asked respondents to gauge the seriousness of the nation's energy situation. The surprising feature of trend data on perceived severity is its consistency. Although perceived severity appears to have declined somewhat between 1979 and 1991, it appears to have increased during 1990 and 1991 , during the Gulf war. In 1991, Gallup reported that $84 \%$ judged the energy situation as "very serious" or "fairly serious," similar to percentages in 1979. The energy "roller coaster" seems to cause people to retain caution in their assessment of the seriousness of the energy situation. This caution is in evidence despite low gasoline and oil prices, stable utility costs, and plentiful supplies. It may be related to the perception of difficulties that could ensue from substantial U.S. reliance on imported oil.

How confident is the public about future energy security? The pattern emerging from the data is that people are more confident about the adequacy of energy supplies in the relatively short term and less confident about energy security in 20 to 50 years. Confidence in near-term energy security has been increasing. Although about half of respondents in 1979 thought that a severe energy shortage was "very likely" within a year, only $16 \%$ did in 1987 . Proportions indicating that a severe energy shortage was "very" or "somewhat likely" dropped from 79\% to 51\% between 1979 and 1987. 
Conviction that energy will continue to be a long-range problem is increasing. The likelihood that the public will perceive a serious future energy problem increases as time goes on. And, the public expects energy prices to increase in the future. Consumers expect gasoline and utility prices to increase more than prices for other consumer goods and services.

The ranking of national problems has changed somewhat in the last decade. In 1979, inflation, unemployment, and crime were viewed as the most significant national problems. The most significant problems emerging in 1991 appear to be: (1) the condition of the U.S. and local economies (including the federal deficit, government spending, unemployment, poverty, and homelessness); (2) the state of education in the country, particularly primary and secondary education; (3) crime, drugs, and the association between the two; (4) health care and health care costs; and (5) the environment. Energy problems seem to have little salience. The data to support this are relatively numerous.

In sum, the "energy problem" has declined in importance over the past 12 years relative to other national problems. Since evidence shows that environmental concerns are increasing in national prominence, this lack of salience suggests that much of the public has not yet linked energy production and consumption with their environmental impacts.

The balance of this chapter presents the empirical findings on the public's definition of the energy situation.

\section{Perceived Severity of the Energy Situation}

A number of surveys since 1978 have asked respondents to gauge the seriousness of the nation's energy situation. Typical item wording was: "How serious would you say the energy situation is in the United States-very serious, fairly serious, or not at all serious?" Figure 4-A presents trend data on the perceived severity of the U.S. energy situation, with data beginning in February 1979 and ending in February 1991. Although the wording of the items was not identical, it was similar enough to use the results to assess trends in opinion over time.

The important feature of this trend is its consistency, and the fact that perceived seriousness has been increasing. Concern was highest in 1979, 1983, and 1991. However, proportions expressing the view that the energy situation is "very serious," "somewhat serious," or "fairly serious" remain at high levels ( $\geq 75 \%)$ throughout the period under study. In 1991, toward the end of the Gulf war, Gallup reported that 84\% judged the energy situation as "very serious" or "fairly serious."

Other findings, taken together, support the notion that the public considers the energy situation as serious. When asked in 1991 how personally concerned they were about "our increasing dependence on fossil fuels," $29 \%$ of a national sample said "very concerned," while $41 \%$ said "somewhat concerned," and $26 \%$ said "not very or not at all concerned" [1437]. In June 1991, Market Strategies asked a national sample: "The United States is importing a growing percentage of its oil; currently about half is imported. Some people think that we should conserve our own oil by using Middle East oil. Others think that we are growing increasingly dependent on Middle East oil. How important (from this list) do you think it is to reduce this growing use of foreign oil?" [1488]. One-third of the sample said it was "extremely important," and another 35\% said "very important." A quarter said it was "somewhat important," while only $7 \%$ said it was "not very" or "not at all" important.

In September 1988, the Daniel Yankelovich Group reported that $26 \%$ of a national sample characterized U.S. dependence on oil imports from foreign countries as "extremely serious," $36 \%$ as "very serious," and $28 \%$ as "somewhat serious" [1323]. In May 1987, $80 \%$ of a national sample said it was "very" or "somewhat" important to reduce the amount of gasoline that is used in the United States [1210]. 
Prototypical item wording: "How serious would you say the energy situation is in the United States - very serious, fairly serious, or not at all serious?"

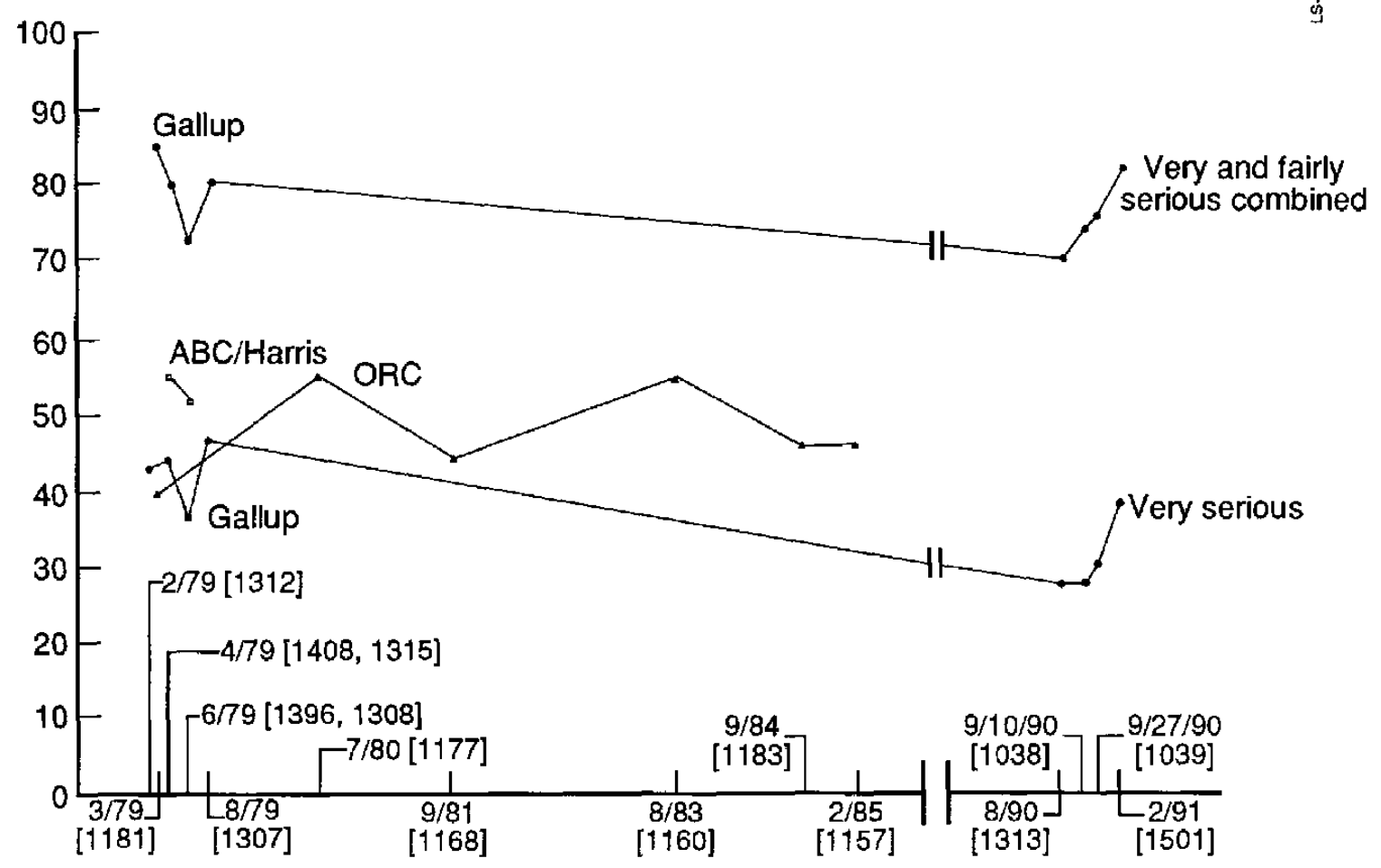

Source: Constructed by author using data from Gallup, Opinion Research Corporation, and $A B C$ News/Harris.

Notes: - - 1 - represents a significant break in time.

Study numbers are in brackets.

Gallup: "How serious would you say the energy situation is in the United States - very serious, fairly serious, or not at all serious?" $[1312 ; 1315 ; 1308 ; 1307 ; 1313 ; 1038 ; 1039$; 1501]

Opinion Research Company: "From what you have heard or read, how serious would you say the need is to save energy - would you say it was very serious, somewhat serious, or not serious at all?" $[1157 ; 1160 ; 1168 ; 1177 ; 1181 ; 1183]$

ABC News/Harris: "How serious do you think the basic energy problem is in the country today - very serious, only somewhat serious, or hardly serious at all?" [1396; 1408]

Figure 4-A. Trends in perceived severity of the U.S. energy situation, 1979 - 1991 
Although perceived severity appears to have declined somewhat between 1979 and 1991, it appears to have increased during 1990 and 1991. The energy roller coaster seems to cause people to be cautious in their assessment of the energy situation. This caution is in evidence despite low gasoline and oil prices, stable utility costs, and plentiful supplies. It may be related to the perception of difficulties that could ensue from substantial U.S. reliance on imported oil or to the outbreak of hostilities in the Persian Gulf.

\section{Perceptions about the Future Energy Situation: National Security}

How confident is the public about future energy security? Perceptions about the likely future consequences of energy policies and actions are key to today's decisions and lifestyles. The pattern emerging in the data is that people are more confident about the adequacy of energy supplies in the relative short term and less confident about energy security 20 to 50 years out. Of course, this result could be due to uncertainty about any future, not simply the U.S. energy future. Nevertheless, such results could be significant, given long-range global problems such as climate change. This discussion is organized around the future in 1 year, 5 years, 10 years, and 20 to 50 years, and in the indeterminate future.

One year. Confidence in near-term energy security increased through 1985, and has been diminishing since then. Figure 4-B shows that concern peaked in 1979 when half of respondents said that a severe energy shortage was very likely within a year. As it happened, the Three Mile Island nuclear power plant accident occurred on March 28, 1979, approximately midway through the data-collection period for this survey, which ran from March 24 through March 31, 1979. Confidence was highest when this proportion dropped to $16 \%$ in 1984 . However, proportions expecting severe near-term energy shortages increased 17 points between March 1989 (51\%) and September 1990 (68\%). This may have occurred because of developments at that time in the Persian Gulf. Proportions indicating that a severe energy shortage was "very" or "somewhat likely" declined slightly between 1975 and 1990. In 1975, 39\% said such shortages were "very likely," while $29 \%$ said this in 1990 [1554]. Thus, public confidence over this 13-year period has increased slightly overall.

Five years. Four surveys taken in 1987 and 1988 showed increasing confidence that an energy shortage (including gasoline, oil, and electricity) would not occur in 5 years [1431, 1417, 1210]. These polls by ABC News/Money Magazine, Opinion Research Corporation (ORC), and The Analysis Group showed that $27 \%$ in May 1987 thought a shortage "very likely," and 22\% in September 1988 expressed the identical opinion. The plurality (ranging from $37 \%$ to $40 \%$ ) assessed a shortage within 5 years as being "somewhat likely."

In 1988, a Market Opinion Research poll showed that a future oil shortage was viewed as an "extremely" or "very serious" threat to the country's national security interests by a $44 \%$ plurality [1231]. Another third said it would be "somewhat serious." In 1986, 61\% of Connecticut residents polled said a fuel shortage was "very" or "somewhat likely" within five years, a decline of 8 points from 1982 [1461]. In 1984, most Alabama residents polled $(72 \%)$ thought energy supplies would be "relatively plentiful" for the next 5 years (through 1989) [1448].

Table 4-1 and Figure 4-C show verbatim trend data on the perceived necessity of importing oil. The proportion believing that the United States cannot get along without foreign oil remained about the same, 35\% in 1975 and $36 \%$ in 1990, at the beginning and end of the period. It fluctuated relatively little during that time. About half of national samples from 1975 through 1990 were inclined to think the nation "can get along without" imported oil. The proportions responding in this manner fluctuated from a low of $37 \%$ in 1976 to a high of $56 \%$ in 1982. 
"A few years ago, there was an energy shortage in this country, with gasoline, oil, and electricity in short supply. What do you think the chances are that in the next year this country will have another severe energy shortage like the one a few years ago-very likely, somewhat likely, somewhat unlikely, or very unlikely?" [1554]

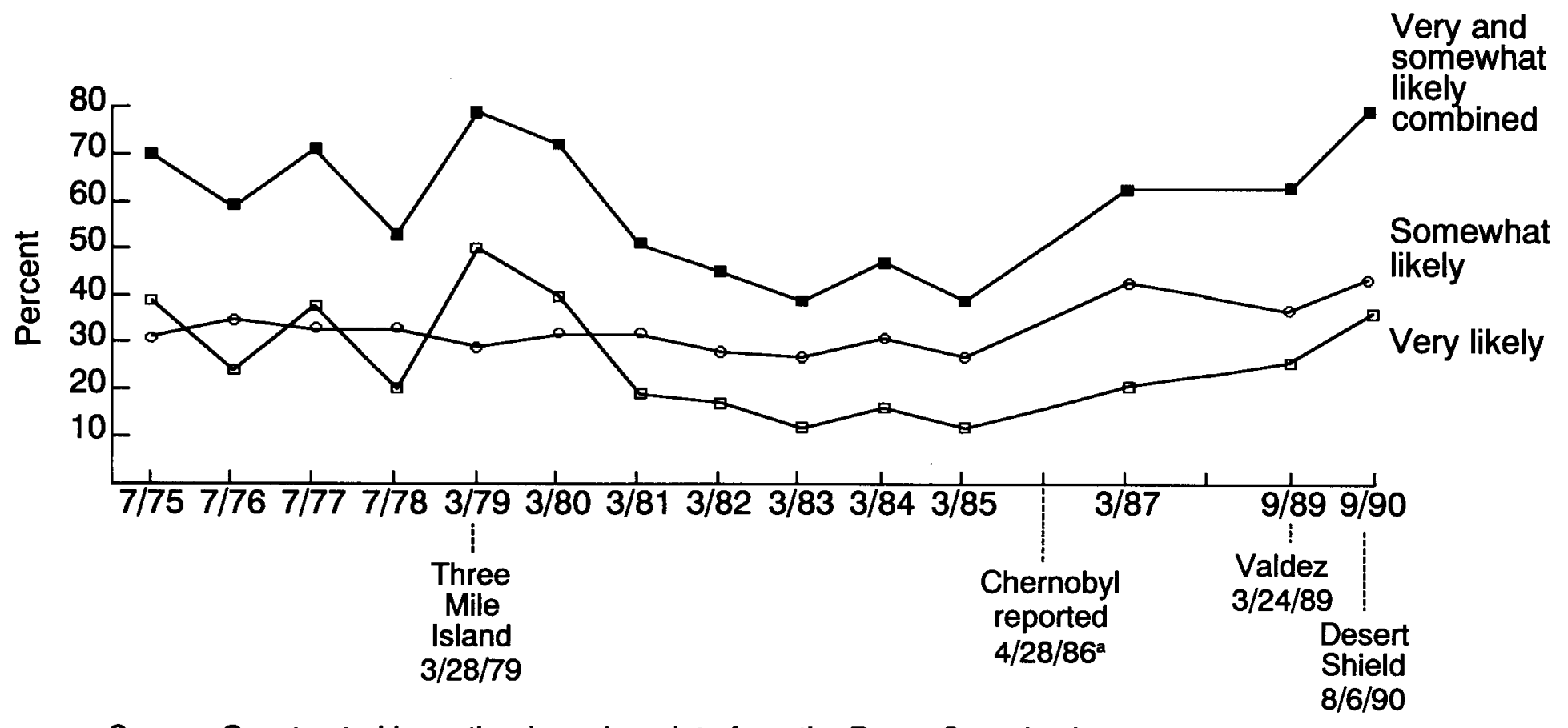

Source: Constructed by author based on data from the Roper Organization.

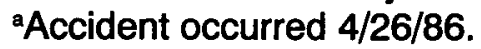

Figure 4-B. Trends in anticipated near-term energy shortages 


\section{Table 4-1. Perceived Dependence on Foreign Oil}

"It has been said if the United States stopped importing foreign oil now we would have severe energy shortages, and even brown-outs. Some people have said there are ways this could be coped with-through conservation and use of other energy sources. Others have said we couldn't get along without foreign oil. How do you feel about our dependency on foreign oil during the next five years-do you think we could get along without it by conservation and use of other energy sources, or that we cannot get along without importing foreign oil?"

\begin{tabular}{|c|c|c|c|c|c|c|c|c|c|c|c|c|c|c|c|}
\hline Survey date & $4 / 75$ & $3 / 76$ & $3 / 77$ & $3 / 78$ & $3 / 79$ & $4 / 79$ & $3 / 80$ & $\mathbf{3 / 8 1}$ & $\mathbf{3} / \mathbf{8 2}$ & $\mathbf{3 / 8 3}$ & $3 / 84$ & $\mathbf{3 / 8 5}$ & $\mathbf{3 / 8 7}$ & $3 / 89$ & $9 / 90$ \\
\hline \multicolumn{16}{|c|}{ Proportion responding (\%): } \\
\hline $\begin{array}{l}\text { Can get along } \\
\text { without it }\end{array}$ & 50 & 37 & 38 & 38 & 41 & 50 & 53 & 47 & 56 & 51 & 54 & 47 & 49 & 45 & 49 \\
\hline $\begin{array}{l}\text { Cannot get along } \\
\text { without it }\end{array}$ & 35 & 48 & 50 & 48 & 49 & 42 & 39 & 41 & 36 & 38 & 36 & 41 & 38 & 42 & 36 \\
\hline Don't know & 15 & 16 & 12 & 15 & 9 & 9 & 8 & 12 & 8 & 11 & 10 & 12 & 13 & 13 & 15 \\
\hline Total $^{\mathrm{a}}$ & 100 & 101 & 100 & 101 & 99 & 101 & 100 & 100 & 100 & 100 & 100 & 100 & 100 & 100 & 100 \\
\hline $\mathbf{N}=$ & - & - & - & - & $(2004)$ & (2007) & $(2002)$ & $(2000)$ & $(2000)$ & $(2000)$ & $(2000)$ & - & (1980) & (1977) & (1988) \\
\hline Survey number ${ }^{b}$ & {$[1554]$} & {$[1554]$} & [1554] & {$[1554]$} & [1149] & [1148] & [1137] & [1129] & [1119] & [1112] & [1102] & [1554] & {$[1078]$} & {$[1554]$} & [1554] \\
\hline
\end{tabular}

Source: Constructed by author using data from Roper Organization.

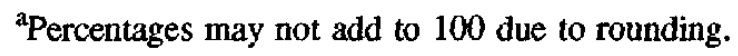

${ }^{b}$ Appendix B lists public opinion surveys included in this study by number. 
"It has been said if the United States stopped importing foreign oil now we would have severe energy shortages, and even brown-outs. Some people have said there are ways this could be coped with - through conservation and use of other energy sources. Others have said we couldn't get along without foreign oil. How do you feel about our dependency on foreign oil during the next five years - do you think we could get along without it by conservation and use of other energy sources, or that we cannot get along without importing foreign oil?"

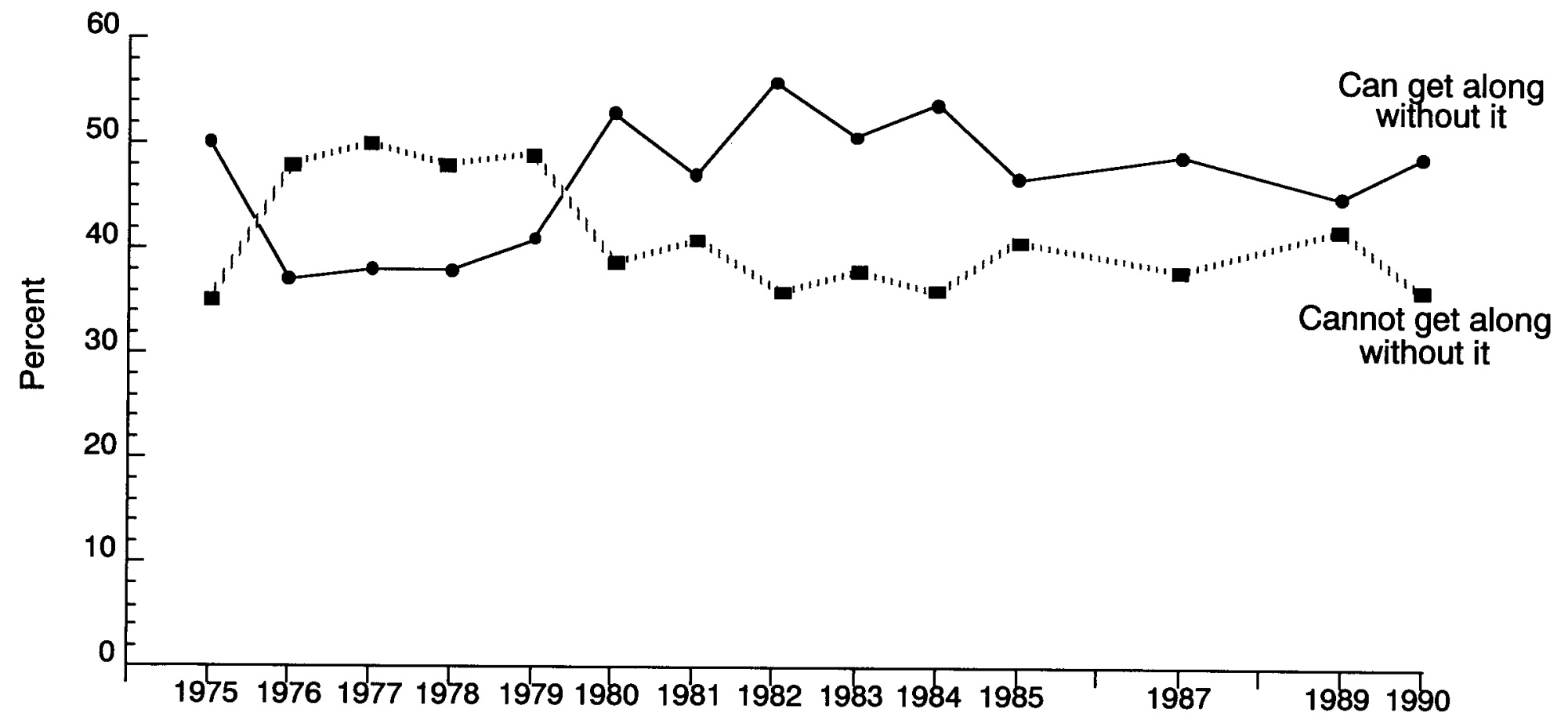

Source: Constructed by author based on data from the Roper Organization.

Figure 4-C. Trends in perceived dependence on foreign oil 
Ten years. Interestingly, given current knowledge, in 1979 more than two-thirds of a national sample thought that by 1990 the United States would "suffer from a severe energy shortage, with gasoline, heating fuel, and electricity all rationed" [1441]. And in 1979, a Harris/ABC Poll reported that 55\% thought the energy shortage would be "very serious" by 1989 [1408]. Of course, these particular dire outcomes did not occur. But shortages could have occurred if the Gulf war had not happened.

NBC News/The Wall Street Journal found $77 \%$ of a 1986 national sample judging another energy crisis as likely within the next 10 years-that is, by 1996 . Only 5\% thought it was not likely at all [1199]. Another national sample, in 1987, saw an energy shortage as "very" to "fairly likely" (63\%) in 10 years, while $11 \%$ thought it not at all likely [1534]. This study, sponsored by the League of Women Voters, gathered comparable data for samples of public interest and energy industry leaders. Both groups were more likely than the public to foresee an energy shortage within a decade (71\% and $76 \%$ of these leader groups, respectively). The causes the leaders identified for the shortage were primarily disruptions in U.S. oil imports (identified by $39 \%$ of public interest and $64 \%$ of industry leaders) and failure to develop ways to use energy more efficiently ( $38 \%$ of public interest and $1 \%$ of industry leaders) [1534].

The large discrepancy in opinion between public interest ${ }^{1}$ and industry leaders ${ }^{2}$ about the potentially pivotal role of efficiency seems to illuminate the contradictory policy preferences held by business and industry on the one hand, and environmental and consumer advocates on the other. Each perceives a different cause for the problem and thus favors a different solution. Such divergence may be contributing to difficulty in formulating national energy policy. Further complicating the picture, neither view may be congruent with widespread public opinion.

Twenty to fifty years. A handful of items asked respondents to consider the longer term view. In 1980, Roper asked a national sample: "Do you think a shortage of energy supplies will or will not be a serious problem in the year 2000?" [1132]. In 1982 and again in 1984, national samples were asked to consider different kinds of problems "people might or might not be facing 25 to 50 years from now." For each of a list of problems, the item asked, ". . tell me whether you think it will or will not be a serious problem your children or grandchildren will be facing 25 to 50 years from now" [1097; 1113].

From 1980 through 1984, the proportion anticipating long-term serious energy problems declined from about two-thirds to half. In $1980,68 \%$ thought energy shortages would be a serious problem in 20 years (by 2000), while $26 \%$ thought they would not [1132]. In 1982, 59\% thought energy would be a serious problem their children or grandchildren would be facing in 25 to 50 years [1113]. And 50\% agreed with that in 1984 [1097].

Roper also queried 1980 and 1984 samples about intergenerational energy-problem severity in relation to other serious problems. Table 4-2 shows how these national samples rated the severity of energy problems in the distant future in comparison with other problems, such as water pollution, food and water shortages, overpopulation, and the greenhouse effect. Of a list of 14 problems, shortages of energy supplies ranked second in 1980 and ninth in 1984. At the same time, 37\% identified the greenhouse effect as a potential

${ }^{1}$ Public interest leaders included 31 from national environmental, consumer, and energy research groups, 32 from local and regional chapters of national consumer or environmental groups, and 47 from local or regional grassroots citizens groups working on energy issues.

${ }^{2}$ Energy industry leaders included 14 from rural electric cooperatives, 23 from public power systems, 22 from investor-owned utilities, 15 from the nuclear power industry, 19 from large coal producers, 14 from large petroleum companies, 15 from independent oil/gas producers, 26 from natural gas distributors and transporters, and 13 from solar/alternative energy companies. 
Table 4-2. Anticipated Intergenerational Salience of Energy and Environmental Problems (20 to 50 Years Hence)

\begin{tabular}{||l|c|c||}
\hline \multirow{2}{*}{ Item } & \multicolumn{2}{|c|}{$\begin{array}{c}\text { Proportion identifying item as "will } \\
\text { be a serious problem" in 25 to 50 years (\%) }\end{array}$} \\
\cline { 2 - 3 } & $1980^{\mathbf{a}}$ & $\mathbf{1 9 8 4 ^ { \mathbf { b } }}$ \\
\hline \hline Severe water pollution & 69 & 71 \\
\hline Severe air pollution & 68 & 70 \\
\hline Atomic warfare & 65 & 65 \\
\hline Lack of privacy (government surveillance, data \\
files, etc.)
\end{tabular}

Source: Constructed by author using data from the Roper Organization.

aItem wording in 1980: "Here is a list of some different kinds of problems people might or might not be facing in the year 2000. Would you go down that list, and for each one tell me whether you think it will or will not be a serious problem your children or grandchildren will be facing in the year 2000?" List included shortage of energy supplies, atomic warfare, severe air pollution, severe water pollution, shortage of water supplies, shortage of food, overpopulation, lack of privacy (government surveillance, data files, etc.), restrictions and regimentation because of the increasing complexity of life, gases from aerosol cans destroying the protective ozone barrier around the earth, decreasing temperatures of the world, and preserving our democratic form of government.

${ }^{b}$ Item wording in 1984: "Here is a list of some different kinds of problems people might or might not be facing 25 to 50 years from now. Would you go down that list, and for each one tell me whether you think it will or will not be a serious problem your children or grandchildren will be facing 25 to 50 years from now?" List included shortage of energy supplies, atomic warfare, severe air pollution, severe water pollution, shortage of water supplies, shortage of food, overpopulation, lack of privacy (government surveillance, data files, etc.), restrictions and regimentation because of the increasing complexity of life, decreasing temperatures of the world, preserving our democratic form of government, the "greenhouse effect"-an accumulation of air pollution over the earth that will cause the earth's temperature to rise-anti-semitism, and illegal immigration. 
serious problem in the distant future. This was before the greenhouse effect had gained widespread currency as a serious environmental problem (in 1988).

Gallup employed a similar item used in 1988, asking: "I am going to read you a list of potential problems facing the United States. For each one please tell me how concerned you are that it will happen" (in the indeterminate future) [1297]. Following are those potential problems and the percentage of respondents indicating "very concerned" or "somewhat concerned":

- A decline in the quality of education in the United States (89\%)

- The loss of jobs in the United States because of foreign competition (88\%)

- $\quad$ Federal deficit (84\%)

- A decline in the quality of American products compared to imported products (82\%)

- The United States committing troops to combat in Central America (82\%)

- The growth of foreign investment in the United States (79\%)

- $\quad$ Energy shortages (76\%)

- The loss of U.S. leadership in science and technology $(75 \%)$

- A military conflict with the Soviet Union (63\%).

Indeterminate future. Conviction that energy will continue to be a long-range problem is increasing. When Research/Strategy/Management (RSM) asked an open-ended question as to whether an energy crisis similar to the one experienced in the 1970s will ever "happen again," two-thirds of a 1990 national sample said that it will, while $24 \%$ said it will not [1025]. Table 4-3 and Figure 4-D show the trend on this item since 1981. While proportions saying an energy crisis will happen again have risen and fallen over the decade, the proportion is 7 points higher in 1990 than in 1981 . The likelihood that the public will perceive a serious future energy problem appears to increase with time.

\section{Perceived Salience of the Nation's Energy Problem}

The idea of salience has to do with how citizens compare energy problems with other problems that the nation faces, such as crime or medical costs. This illuminates not only how seriously energy concerns are viewed, but also how central and significant they are in the overall context of national concerns. Generally, researchers produce data on salience by asking for comparisons of energy problems with other problems, or asking, in open-ended fashion, for the most important problems facing the nation or local community.

Ranking of national problems. The ranking of national problems has changed in the last decade. Emerging as the most significant problems appear to be (1) the state of the U.S. and local economies (including the federal deficit, government spending, unemployment, poverty, and homelessness); (2) the state of education in the country, particularly primary and secondary education; (3) crime, drugs, and the association between the two; (4) health care and health care costs; and (5) the environment. Energy problems seem to have fallen off the scope in terms of direct salience.

The data to support this are relatively numerous. In March 1991, a list of eight domestic problems preselected by Hart and Teeter Research for NBC News/The Wall Street Journal did not include energy. Respondents chose education, poverty and homelessness, and crime as the top three problems. Environment was selected as the top problem by $7 \%$ of the respondents [1500].

Table 4-4 shows that, again using a preselected list of domestic goals, the top three selected were the federal deficit, education, and health care. Developing dependable and secure sources of energy, included in the list by RSM, came in last; $6 \%$ selected that goal as the most important domestic goal for the President to address [1025]. 
Table 4-3. Anticipated Future Energy Crises

"Some people say the "energy crisis" like the United States experienced in the 1970s-things like gasoline shortages, sharply higher prices, and oil supply disruptions-will not happen again. Other people say we will once again have periods of energy crisis, just as we did in the 1970s. Which view is closer to your own?"

\begin{tabular}{|l|c|c|c|c|c|c||}
\hline Response & 1981 & 1985 & 1987 & 1988 & 1988 & 1990 \\
\hline \multicolumn{7}{||l|}{ Proportion responding (\%) } \\
\hline \hline Will happen & 60 & 49 & 64 & 49 & 67 & 67 \\
\hline Will not happen & 25 & 37 & 24 & 33 & 26 & 24 \\
\hline Don't know $^{\mid}$ & 15 & 13 & 12 & 18 & 7 & 9 \\
\hline \hline Total $^{\mathrm{a}}$ & 100 & 99 & 100 & 100 & 100 & 100 \\
\hline Survey number & {$[1431]$} & {$[1431]$} & {$[1431]$} & {$[1431]$} & {$[1431]$} & {$[1025]$} \\
\hline
\end{tabular}

Sources: Constructed by author using data from Research/Strategy/Management and Greenberg/Lake, The Analysis Group.

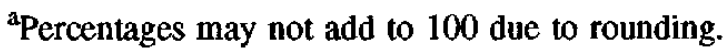

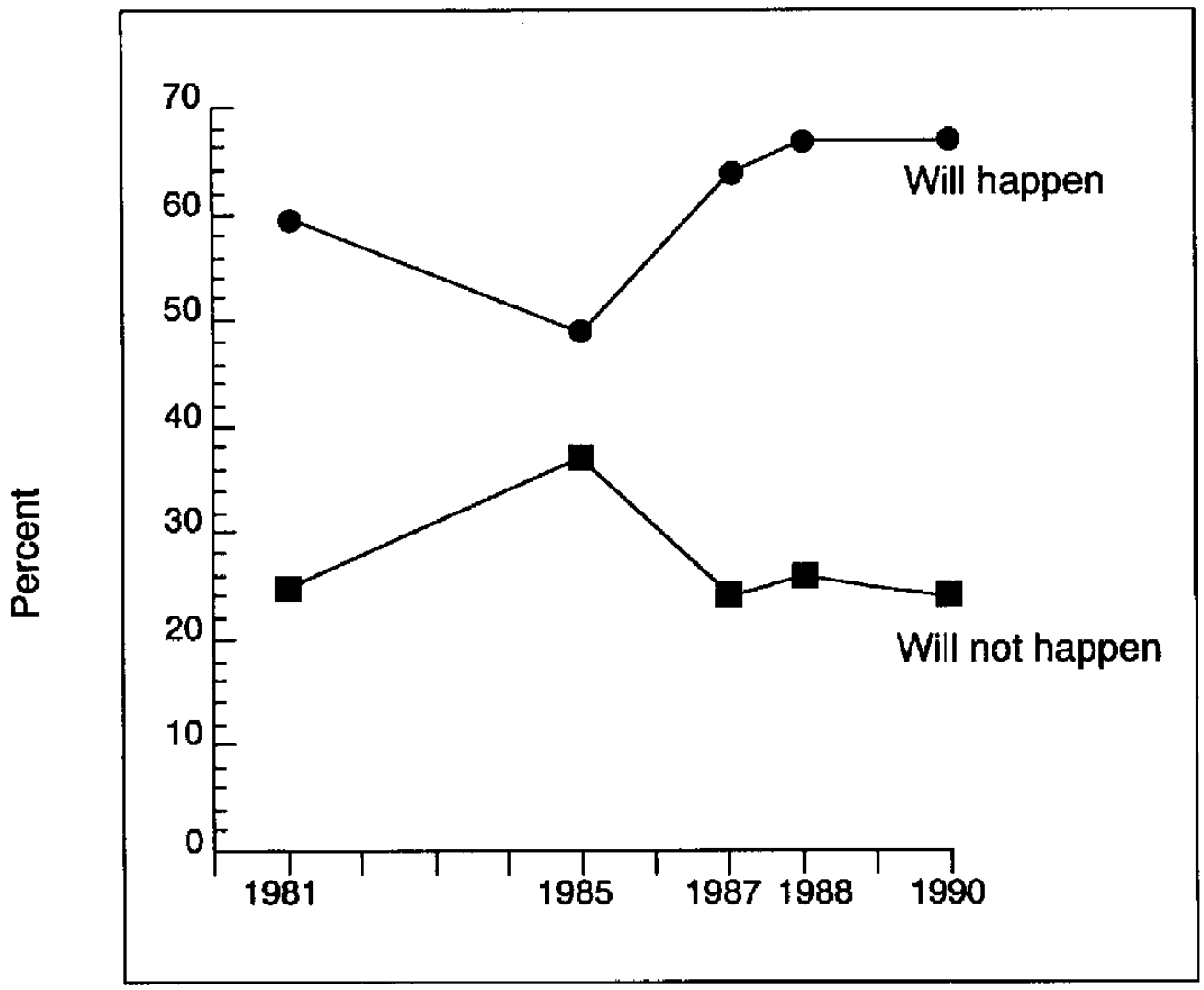

Figure 4-D. Trends in anticipated future energy crises 
Table 4-4. Perceived Salience of Domestic Goals

"Other than the state of the economy, which of the following domestic goals would you say is the most important for the President to address? And, which one of these domestic goals is the next most important?" (December 1990) [Rotated] [1025]

\begin{tabular}{||l|c|c|c||}
\hline Domestic goals & Most important & $\begin{array}{c}\text { Next most } \\
\text { important }\end{array}$ & Total $^{\mathrm{a}}$ \\
\hline Proportion responding (\%) & 28 & 14 & 42 \\
\hline \hline Reduce the federal deficit & 21 & 21 & 42 \\
\hline $\begin{array}{l}\text { Improve quality of primary and } \\
\text { secondary education }\end{array}$ & 18 & 18 & 36 \\
\hline Provide more affordable health care & 14 & 16 & 30 \\
\hline Strengthen laws to crack down on crime & 11 & 17 & 28 \\
\hline Protect the environment & 6 & 9 & 15 \\
\hline $\begin{array}{l}\text { Develop dependable and secure sources } \\
\text { of energy }\end{array}$ & 3 & 5 & 8 \\
\hline Don't know & & & \\
\hline
\end{tabular}

Source: Research/Strategy/Management and Greenberg/Lake, The Analysis Group.

aTotal of "most important" and "next most important."

In September 1990, Cambridge Reports/Research International asked a national sample of electricity customers: "What do you think is the most important problem facing the U.S. today?" (open-ended) [1457]. This is a stronger, more accurate way to assess the salience of national problems than using a forced-choice list of responses. Respondents identified the top three problems as the Middle East (28\%), drugs $(12 \%)$, and government spending (12\%). They also mentioned the economy (7\%) and the environment (5\%). Energy issues were eleventh on the list, mentioned by $2 \%$; even fewer respondents mentioned inflation, unemployment, taxes, government corruption, lack of trust in government, too much foreign aid, the Persian Gulf, and abortion.

Similar open-ended items were asked of national samples in earlier years. In June 1988, The Washington Post asked respondents: "In your opinion, what do you think is the biggest problem facing your local community today?" [1526]. Far and away the most frequent response was bad local economy/ unemployment (30\%), followed by drugs (14\%), crime $(7 \%)$, and drugs and crime combined (7\%). Energy was not mentioned. Relevant to the environment, $3 \%$ cited waste disposal/garbage/pollution.

In February 1987, the query from Yankelovich/Clancy/Shulman for Time was: "What are the main issues or problems facing the country that particularly worry or concern you?" [1455]. "Other domestic 
problems" was the modal response (33\%), which is a result that can be attributed to incomplete coding of responses. Sixteen percent mentioned unemployment/jobs; $15 \%$ war/danger of war; $14 \%$ nuclear arms race/control/freeze; $9 \%$ inflation and high prices; and 5\% drugs. Crime was down to a 3\% mention. Environment was mentioned by $2 \%$; toxic substances and hazardous wastes by $2 \%$; gasoline prices/shortages/OPEC were named together by $1 \%$.

A 1989 Gallup survey asked whether the energy problem, along with seven other national problems, was no better or worse than it had been, a problem where progress is being made, or where we are losing ground (see Table 4-5). A plurality of $38 \%$ said that we are making progress on the energy problem. However, $36 \%$ said the problem is no better or no worse, and almost one in five said we are losing ground [1320]. In comparison, the most progress was being made in tensions between the United States and the Soviet Union, cited by $79 \%$. For all other problems, fewer thought that we were making progress. Majorities thought we were losing ground on international terrorism $(53 \%)$ and in the stability of our financial institutions (52\%).

In May 1988, a Gallup national survey asked about nine potential problems facing the nation, as discussed earlier. Energy ranked near the bottom of the list, with a relatively low $26 \%$ saying they were "very concerned" and 47\% "somewhat concerned." Problems receiving more frequent expressions of severe concern were the declining quality of education in the United States $(89 \%)$, losses of jobs due to foreign competition (88\%), and the growth of the federal deficit (84\%) [1297].

Spending on national problems. Salience can also be measured by comparing perceptions about spending allocated to solving national problems. Between 1980 and 1989, verbatim trend items established the declining salience of energy as a national problem during that period. Roper asked whether we were spending too much money, too little, or about the right amount of money on 12 national problems - one of them "increasing the nation's energy supply"-for 16 years from 1973 through 1989. The "big three" national problems, measured as those on which we spend "too little," were crime, drugs, and health. Table 4-6 shows the trend data on these items for the 10 years from 1980 through 1989 . In 1980, energy was considered as important a problem as drugs (63\% said we spent "too little" on it). Proportions saying we spent "too little" on energy decreased to about a third in 1989. A plurality of about $40 \%$ consistently indicated through that period that spending on energy was about right.

In September 1985, ORC, asked: "The federal government finances many programs. I am going to read you a list of some of the activities that now receive some form of aid from the federal government. For each, please tell me if you think federal aid in that area should be increased, stay at its present levels, or be decreased" [1156]. Table 4-7 shows the results. Government funding for energy research and development (R\&D) was eighth on a list of 14 areas of federal funding, with half of the respondents approving increased funding of it. Sixth on the list was funding for environmental cleanup. In comparison, increased funding for medical research headed the list, with $73 \%$ in favor.

Leader views. The data also suggested that the way the public views the importance of the energy problem may be similar to the way the nation's leaders view it. In 1986, Miller queried a sampling of science policy leaders, environmental leaders, utility leaders, and congressional science staff about science and technology issues. Among the questions they asked were: "What do you think is the most important public policy issue that involves science and technology? What is the next most important public policy issue that involves science and technology?" [1427]. The forced choice response categories provided were education, level of R\&D, new technology, public understanding of science, military, energy, environment and population, and "others." Congressional staff mentioned energy issues as a high priority more frequently $(22 \%)$ than other types of respondents; in this open-ended context, $10 \%$ of utility leaders mentioned energy issues, $9 \%$ of environmental leaders, and $6 \%$ of science policy leaders. 
Table 4-5. Perceptions of Society's Problems

"I'd like your opinion on a different set of problems. For each one, tell me if you think it is a problem that is no better or no worse than it had been, a problem where progress is being made, or a problem where we are losing ground....our ability to meet our energy needs (Energy), tensions between the U.S. and the Soviet Union (Soviet Union), the budget deficit (Budget), farm problems (Farm), the trade deficit (Trade deficit), third world debt (Third World), international terrorism (Terrorism), and the stability of our financial institutions (Financial)." (January 27, 1989) [1320]

\begin{tabular}{|c|c|c|c|c|c|c|c|c|}
\hline Categories & Energy & $\begin{array}{l}\text { Soviet } \\
\text { Union }\end{array}$ & Budget & Farm & $\begin{array}{l}\text { Trade } \\
\text { deficit }\end{array}$ & $\begin{array}{l}\text { Third } \\
\text { World }\end{array}$ & International & Financial \\
\hline \multicolumn{9}{|l|}{ Proportion responding (\%) } \\
\hline No better or no worse & 36 & 14 & 27 & 30 & 27 & 26 & 24 & 26 \\
\hline Making progress & 38 & 79 & 16 & 17 & 19 & 7 & 18 & 15 \\
\hline Losing ground & 19 & 4 & 50 & 44 & 43 & 43 & 53 & 52 \\
\hline Don't know & 7 & 4 & 7 & 9 & 11 & 24 & 5 & 7 \\
\hline Total $^{\mathrm{a}}$ & 100 & 101 & 100 & 100 & 100 & 100 & 100 & 100 \\
\hline$N=$ & $(2048)$ & $(2048)$ & $(2048)$ & $(2048)$ & $(2048)$ & (2048) & $(2048)$ & $(2048)$ \\
\hline
\end{tabular}

Source: Constructed by author using data from the Gallup Organization.

${ }^{\text {a}}$ Percentages may not add to 100 due to rounding. 
Table 4-6. Perceptions of Money Spent on Increasing the Nation's Energy Supply

"Turning now to the business of the country-we are faced with many problems in this country, none of which can be solved easily or inexpensively. I'm going to name some of these problems, and for each one l'd like you to tell me whether you think we're spending too much money on it, about the right amount, or too little money . . increasing the nation's energy supply."

\begin{tabular}{|c|c|c|c|c|c|c|c|c|c|c|}
\hline Survey date & $12 / 6 / 80$ & $12 / 5 / 81$ & $12 / 4 / 82$ & $12 / 3 / 83$ & $12 / 1 / 84$ & $12 / 7 / 85$ & $12 / 6 / 86$ & $12 / 87$ & $12 / 88$ & $12 / 89$ \\
\hline \multicolumn{11}{|c|}{ Proportion responding (\%) } \\
\hline Too much & 7 & 7 & 7 & 6 & 6 & 8 & 6 & 7 & 6 & 4 \\
\hline About right & 21 & 30 & 37 & 41 & 42 & 42 & 44 & 44 & 42 & 49 \\
\hline Too little & 63 & 53 & 45 & 40 & 40 & 36 & 34 & 34 & 36 & 32 \\
\hline Don't know & 9 & 11 & 11 & 13 & 12 & 14 & 16 & 15 & 16 & 15 \\
\hline Total $^{\mathbf{a}}$ & 100 & 101 & 100 & 100 & 100 & 100 & 100 & 100 & 100 & 100 \\
\hline $\mathrm{N}=$ & $(2000)$ & $(2000)$ & $(2000)$ & $(2000)$ & (1977) & (1980) & (1997) & - & - & (1960) \\
\hline Survey number & [1132] & [1122] & [1113] & [1105] & [1097] & [1087] & {$[1080]$} & [1547] & [1547] & [1547] \\
\hline
\end{tabular}

Source: Constructed by author using data from the Roper Organization.

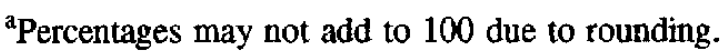


Table 4-7. Preference for Levels of Federal Funding on National Problems

"The federal government finances many programs. I am going to read you a list of some of the activities that now receive some form of aid from the federal government. For each, please tell me if you think federal aid in that area should be increased, stay at its present level, or be decreased." (September/October 1985) [1156].

\begin{tabular}{|c|c|c|c|c|}
\hline Activity & Increased & $\begin{array}{c}\text { Stay at } \\
\text { current level }\end{array}$ & Decreased & $\begin{array}{l}\text { Don't know/ } \\
\text { no opinion }\end{array}$ \\
\hline \multicolumn{5}{|l|}{ Proportion responding $(\%)^{\mathrm{a}}$} \\
\hline $\begin{array}{l}\text { Government funding for medical } \\
\text { research }\end{array}$ & 73 & 21 & 5 & 1 \\
\hline $\begin{array}{l}\text { Government support for medical care } \\
\text { for the aged }\end{array}$ & 72 & 24 & 3 & 1 \\
\hline Government aid for higher education & 61 & 28 & 10 & 1 \\
\hline Government aid to agriculture & 58 & 26 & 12 & 4 \\
\hline $\begin{array}{l}\text { Government aid to elementary and } \\
\text { secondary education }\end{array}$ & 58 & 31 & 8 & 3 \\
\hline $\begin{array}{l}\text { Government funds to clean up the } \\
\text { environment }\end{array}$ & 56 & 35 & 8 & 1 \\
\hline $\begin{array}{l}\text { Government financial aid programs } \\
\text { for needy college students }\end{array}$ & 53 & 34 & 11 & 2 \\
\hline $\begin{array}{l}\text { Government funding for energy } \\
\text { research and development (R\&D) }\end{array}$ & 50 & 35 & 13 & 2 \\
\hline $\begin{array}{l}\text { Government support for post- } \\
\text { secondary vocational and technical } \\
\text { training }\end{array}$ & 43 & 43 & 11 & 3 \\
\hline $\begin{array}{l}\text { Government support for the school } \\
\text { lunch program }\end{array}$ & 36 & 47 & 15 & 2 \\
\hline $\begin{array}{l}\text { Government funding for highways } \\
\text { and transportation }\end{array}$ & 27 & 57 & 14 & 2 \\
\hline $\begin{array}{l}\text { Government support for social } \\
\text { welfare programs }\end{array}$ & 27 & 39 & 32 & 2 \\
\hline $\begin{array}{l}\text { Government funding for the space } \\
\text { program }\end{array}$ & 23 & 45 & 30 & 2 \\
\hline $\begin{array}{l}\text { Government spending on national } \\
\text { defense }\end{array}$ & 23 & 38 & 37 & 2 \\
\hline
\end{tabular}

Source: Constructed by author using data from Opinion Research Corporation (ORC).

${ }^{a}$ Each row adds to $100 \%$. 
Although the public and policy leaders may not view energy as among the most significant problems facing the nation, interestingly, developing a national energy policy is viewed as significant by a large majority. Table 4-8 presents results of a verbatim trend item Roper asked in 1976, 1978, and again in 1991. Developing a national energy policy was mentioned most frequently as a problem that people said they would like their congressmen and senators to "give major attention to" in 1976 (74\%) and 1978 (78\%), and second most frequently mentioned in 1991 (64\%). Clearly, the public has long sought a coherent national energy policy. This item suggests that people are looking to Congress to provide it. In 1991, developing a national health insurance program was the only policy problem mentioned more frequently $(73 \%)$ than a national energy policy.

In sum, energy has declined in importance over the past 12 years relative to other national problems. Since evidence shows that the environment is increasing in prominence in national concerns, this finding, by itself, suggests that most of the public has not yet linked energy production and consumption with its environmental impacts.

Table 4-8. Perceived Salience of a National Energy Policy

"Here are some things people have said Congress should be working on. (Card shown.) Obviously, one Congressman or one Senator can give major attention to only a limited number of problems. l'd like you to tell me for each of those things whether it is something you'd like to see your Congressman or Senator give major attention to, or whether you would rather have him or her devote attention to more important things." [1558]

\begin{tabular}{|l|c|c|c||}
\hline Item & March 1976 & March 1978 & March 1991 \\
\hline Proportion indicating "Give major attention to" (\%) & \\
\hline \hline $\begin{array}{l}\text { A program to provide national } \\
\text { health insurance for everyone }\end{array}$ & 58 & 55 & 73 \\
\hline $\begin{array}{l}\text { The development of a national } \\
\text { energy policy }\end{array}$ & 74 & 78 & 64 \\
\hline $\begin{array}{l}\text { Stricter regulations on the way } \\
\text { dangerous chemicals can be } \\
\text { transported from one place in the } \\
\text { country to another. }\end{array}$ & 57 & 67 & 64 \\
\hline \begin{tabular}{l} 
Tax reform \\
\hline $\begin{array}{l}\text { Stricter labeling regulations for } \\
\text { food products }\end{array}$
\end{tabular} & 50 & 67 & 63 \\
\hline
\end{tabular}

Source: Constructed by the author using data from the Roper Organization.

a In 1991 only, the item also included banking system reform, eliminating workplace discrimination, and campaign finance reform. 


\section{Impacts of the Energy Situation}

The earlier reviews found numerous items assessing the impacts of the energy situation. Most of the public reported experiencing some effect of the energy problems in the 1970s. These impacts ranged from such minor inconveniences as waiting in line to buy gasoline to the significant life-changing impact of losing one's job (Farhar et al. 1980). Most of the poll items since 1980 that dealt with impacts focused on perceptions of energy prices - of both oil and electricity. Few recent data exist on this topic.

From the spring of 1987 through the fall of 1990, large majorities perceived price increases in gasoline and oil (see Table 4-9).

Table 4-10 shows how price increases for oil and gasoline compare with price increases for other major consumer expenditures-automobiles, housing, clothing, and taxes. In September 1990, virtually everyone said that oil and gasoline prices were going up, and $60 \%$ said electricity rates were increasing as well [1041]. Of 11 items listed by ABC News/The Washington Post, many more respondents thought oil and gasoline prices were increasing rather than prices for any other item.

Table 4-9. Percentages Perceiving Gasoline Price Increases, 1987-1990

\begin{tabular}{||l|c|c|c|c|c|c||}
\hline Item & $\begin{array}{c}\text { May } \\
\mathbf{1 9 8 7}^{\mathrm{a}}\end{array}$ & $\begin{array}{c}\text { May } \\
\mathbf{1 9 8 9}^{\mathrm{b}}\end{array}$ & $\begin{array}{c}\text { Aug. } \\
\mathbf{1 9 9 0}^{\mathrm{c}}\end{array}$ & $\begin{array}{c}\text { Aug. } \\
\mathbf{1 9 9 0}^{\mathrm{d}}\end{array}$ & $\begin{array}{c}\text { Aug. } \\
\mathbf{1 9 9 0}^{\mathrm{e}}\end{array}$ & $\begin{array}{c}\text { Sept. } \\
\mathbf{1 9 9 0}^{\mathrm{b}}\end{array}$ \\
\hline \hline \% citing increase $^{\mathrm{f}}$ & 26 & 91 & 91 & 95 & 84 & 98 \\
\hline $\mathrm{N}=$ & $(1011)$ & $(1513)$ & $(677)$ & $(1227)$ & $(773)$ & $(1011)$ \\
\hline Study number & {$[1210]$} & {$[1372]$} & {$[1206]$} & {$[1313]$} & {$[1350]$} & {$[1041]$} \\
\hline
\end{tabular}

Source: Constructed by author using data from $\mathrm{ABC}$ News and The Washington Post, Penn and Schoen Associates, Gallup Organization, CBS News, $\mathrm{ABC}$ News and The Washington Post, and Opinion Research Corporation.

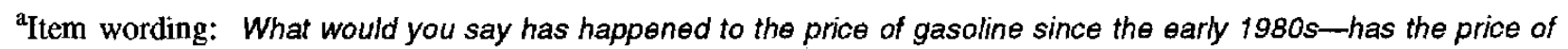
gasoline increased, decreased, or stayed about the same?"

bItem wording: "More specifically, would you say that...oil and gasoline prices...are going up, going down, or aren't they changing much these days?"

"Item wording: "In the last few weeks, how much would you say, in percentage terms, the price of gasoline has risen in your neighborhood?"

'Item wording: "Has the price of gasoline in your area gone up within the last week or two, or not?"

'Item wording: "In the last week or so, have prices for gasoline in your community gone up, gone down, or stayed about the same?"

${ }^{\mathrm{f}}$ Figure 10-A plots actual gasoline prices and GNP-adjusted prices from 1977 through 1991 in the nation. In 1987, when only $26 \%$ cited an increase, gasoline prices were actually declining. In 1989 and 1990, gasoline prices were increasing. 
Table 4-10. Perceived Price Increases

"Would you say that . . xxx prices" . . . are going up, going down, or aren't they changing much these days?" (September 1990) [1041]

\begin{tabular}{|c|c|c|c|c|}
\hline Item & Going up & $\begin{array}{c}\text { Not } \\
\text { changing }\end{array}$ & Going down & $\begin{array}{l}\text { Don't know/ } \\
\text { no opinion }\end{array}$ \\
\hline \multicolumn{5}{|c|}{ Proportion responding $(\%)^{\mathrm{b}}$} \\
\hline Oil and gasoline & 98 & 1 & 1 & - \\
\hline Grocery prices & 76 & 24 & - & - \\
\hline Automobile prices & 76 & 17 & 2 & 5 \\
\hline Housing costs & 72 & 17 & 9 & 3 \\
\hline Clothing prices & 70 & 27 & 1 & 2 \\
\hline Electrical rates & 60 & 36 & 1 & 3 \\
\hline Federal taxes & 60 & 34 & 1 & 6 \\
\hline Local real estate taxes & 58 & 19 & 1 & 22 \\
\hline Prices for appliances & 48 & 40 & 2 & 10 \\
\hline State income taxes & 46 & 32 & 1 & 20 \\
\hline Local sales taxes & 46 & 47 & - & 7 \\
\hline
\end{tabular}

Source: Constructed by author using data from $\mathrm{ABC}$ News/The Washington Post.

${ }^{2} \mathrm{xxx}=$ items listed in left column.

b Each row adds to $100 \%$.

Gasoline prices dropped markedly early in 1986. Two-thirds of a national sample said, in April, that they personally had felt the effects of the decline in energy prices. During that month, five different polls asked whether the price drop was good for the economy, with the results shown in Table 4-11. Pluralities to majorities said that oil price decreases were "good" for their local or state economies, or for the national economy.

Nevertheless, NBC News/The Wall Street Journal used an item that same month, which stated: "Vice President Bush has said that a continued drop in oil prices could damage the American oil industry and threaten national security. Do you agree or disagree with his statement?" Although majorities or pluralities of national samples had indicated that the price drop was good, 52\% said they agreed with Mr. Bush's statement, while $38 \%$ disagreed, and $10 \%$ were unsure [1199]. The item wording that included Mr. Bush's name may have caused more respondents to agree with his position. Also, there 
Table 4-11. Perceived Impacts of Oil Price Declines on the Economy

\begin{tabular}{|c|c|c|c|c|c|}
\hline Opinion & $4 / 22 / 86^{a}$ & $4 / 22 / 86^{b}$ & $4 / 28 / 86^{c}$ & $4 / 28 / 86^{d}$ & $4 / 10 / 86^{\mathrm{e}}$ \\
\hline \multicolumn{6}{|c|}{ Proportion responding (\%) } \\
\hline Good & 58 & 46 & 43 & 56 & 64 \\
\hline Bad & 17 & 27 & 35 & 15 & 23 \\
\hline Not much difference & 23 & 24 & 20 & 28 & 7 \\
\hline Not sure & 2 & 3 & 3 & f & 6 \\
\hline Total $^{\mathrm{g}}$ & 100 & 100 & 101 & 99 & 100 \\
\hline$N=$ & $(1877)$ & (1877) & (1505) & $(1505)$ & $(1601)$ \\
\hline Study number & [1281] & [1281] & {$[1365]$} & {$[1365]$} & [1344] \\
\hline
\end{tabular}

Source: Constructed by author using data from Louis Harris and Associates, ABC News/Washington Post, and CBS News/New York Times.

aItem wording: "Do you think the decline in the price of oil is good for your state, bad, or doesn't it make much difference?"

bitem wording: "As you know, the price of oil has fallen sharply over the past few months. Do you think that for the country as a whole that decline is doing more good than harm, more harm than good, or doesn't it make much difference?"

'Item wording: "What about for the American economy as a whole? Do you think the oil price drop is a good thing for America's economy or is it a bad thing or doesn't it make much difference one way or another?"

Item wording: "Actually, the price of crude oil as sold by the barrel has fallen a great deal since the beginning of the year. That means gasoline and fuel oil cost less for consumers but it also means trouble for the economies of America's oil and gas producing states. Generally speaking, do you think the oil price drop is a good thing for your personal economic situation or a bad thing or doesn't it make much difference to you one way or the other?"

'Item wording: "Overall, do you think the recent drop in oil and gasoline prices is good or bad for the United States?"

$\mathrm{f}=$ less than $0.5 \%$.

'Totals may not add to 100 due to rounding. 
probably was confusion at the time about the cause-and-effect relationship between gasoline and oil prices and the condition of the U.S. economy.

Roper asked a national sample in December 1984: "Suppose there were no federal, state, or local taxes on gasoline. How much do you think the price of a gallon of gas would come down?" The range of responses was from 5 cents or less to 51 cents or more; the median estimate was 24 cents. Many consumers were almost correct in their response: in reporting the survey results, Roper said that the price would actually come down about 22 cents [1097] although the current gasoline tax is 14.1 cents per gallon. A companion question was: "Suppose the oil companies-not the gas stations, but the oil companies-were to pass all of their profits along to the consumer in the form of lower gasoline prices. How much do you think the price of a gallon of gas would come down?" The range of responses was identical to the prior question; the respondents' median estimate was 30 cents. In this instance, consumers overestimated oil company profits. Roper reported that the price would actually be reduced by about 5 cents [1097].

In 1983 and 1985, Roper repeated an item verbatim on the value of electricity in relation to other goods and services. Table 4-12 presents the 1983 results for this item, which asked: "Here is a list of some different kinds of things most people buy or spend money for. Thinking of what you get for what you pay, would you read down that list and for each one tell me whether in most instances you get excellent value for the dollar, or good value, or only fair value for the dollar, or poor value for the dollar?"3 The perceived best values in 1983 were mail service and health insurance. The poorest values were electricity, automobile repair/services, and income taxes. A similar pattern held in 1985, when mail service, life insurance, and health insurance were cited as the best values, while income taxes, automobile repair, local telephone service, and electricity were seen as the poorest values [1093]. In 1985, gasoline was seen as an "excellent" value by $3 \%$, a "good" value by $21 \%$, a "fair" value by $39 \%$, and a "poor" value by $34 \%$, while 3\% "didn't know" [1092].

With respect to expectations concerning energy prices, data from 12 polls reported the public's view of gasoline prices (Table 4-13). In virtually every survey, majorities expected gasoline prices to be somewhat higher or a great deal higher, regardless of how far into the future the survey question asked them to project. For example, in August $1990,70 \%$ of a national sample expected higher gasoline prices in 1 month; almost half expected higher prices in 6 months. In 1980,1986, and 1987, more than 56\% of respondents expected higher gasoline prices 1 year from then. NBC News/The Wall Street Journal asked, in April of 1986, when prices were relatively low: "How long do you think the current lowered prices of oil and gasoline will last . . . less than a year, up to five years, 5 to 10 years, or permanently?" Almost three-quarters $(73 \%)$ expected the low prices to last less than a year, while only $2 \%$ expected them to last "permanently" [1199].

Impacts of oil price fluctuations have also been the subject of poll questions. An August 1990 Harris survey asked: "If you had to say, do you think a year from now inflation will be rising due to higher oil prices or not?" The vast majority-83\%—said this would happen, while $14 \%$ did not expect inflation to increase. Harris also asked, at the same time: "Some people argue that cheap oil now will lead to more expensive oil later on, because U.S. oil production will decline. Do you think they are right, or not?" Calling this correct were $59 \% ; 34 \%$ said it was not correct, and $7 \%$ said they were not sure [1281].

${ }^{3}$ Response categories included were: electricity, hospital care, doctors' services, life insurance, automobile insurance, health insurance, local property taxes, federal income taxes, telephone service, mail service, automobile repair/services, and public transportation. 
Along these lines Roper asked, in March 1986, about the impacts of oil price decreases: "Oil prices have come down from their peak of over $\$ 40 /$ barrel to under $\$ 15 /$ barrel [1086]. Here is a list of things that could happen as a result of this price drop. Would you please read down that list and tell me which of those things, if any, you think will happen as a result of the drop in oil prices?" Table 4-14 shows the results. The effect most frequently mentioned (by $72 \%$ ) was that gasoline prices would come down.

Table 4-15 shows results from three items repeated verbatim for 3 years, from 1982 through 1984, concerning anticipated utility prices, as well as supermarket, housing, gasoline, clothing, and restaurant prices. The percentages expecting utility costs to rise, although they declined from $92 \%$ to $87 \%$ across the 3 years, were markedly higher than for any other commodity or service (see Tables 4-16 through 4-18). Also, the proportion expecting sharp price increases declined from $57 \%$ in 1982 to $45 \%$ in 1984 . This decline may have reflected some increasing stabilization of utility costs during that period.

These data, taken together, show that most of the public has expected increasing oil and gasoline prices, and increasing utility costs.

Table 4-12. Perception of Dollar Value Spent on Electricity

"Thinking of what you get for what you pay, tell me whether in most instances you get excellent value for the dollar, or good value, or only fair value for the dollar, or poor value for the dollar spent on electricity."

\begin{tabular}{||l||c|c||}
\hline Survey date & $\mathbf{4 / 3 0 / 8 3}$ & $\mathbf{5 / 0 4 / 8 5}$ \\
\hline Proportion responding (\%): & \\
\hline \hline Excellent value & 4 & 5 \\
\hline Good value & 21 & 28 \\
\hline Fair value & 33 & 35 \\
\hline Poor value & 41 & 30 \\
\hline Don't know & 1 & 2 \\
\hline \hline Total & 100 & 100 \\
\hline & $(2000)$ & $(1988)$ \\
\hline \hline Survey number & {$[1111]$} & {$[1093]$} \\
\hline
\end{tabular}

Source: Constructed by author using data from the Roper Organization. 
Table 4-13. Expectations for Future Gasoline Prices

Actual wording of items given below. Responses are organized by distance into the future that gasoline prices were anticipated.

\begin{tabular}{|c|c|c|c|c|c|}
\hline Poll date & $\begin{array}{l}\text { Much/ } \\
\text { somewhat } \\
\text { higher }\end{array}$ & Same & $\begin{array}{c}\text { Much/ } \\
\text { somewhat } \\
\text { lower }\end{array}$ & $\begin{array}{l}\text { Don't } \\
\text { know }\end{array}$ & $\begin{array}{c}\text { Study } \\
\text { number }\end{array}$ \\
\hline \multicolumn{6}{|c|}{ Proportion responding (\%) } \\
\hline & {$[1206]$} \\
\hline Six months from now & & & & & \\
\hline $\begin{array}{l}\text { Aug. } 1990^{\circ} \\
\text { Jan. } 1986^{\mathrm{c}}\end{array}$ & $\begin{array}{l}48 \\
64\end{array}$ & 20 & $\begin{array}{l}15 \\
31\end{array}$ & $\begin{array}{r}16 \\
5\end{array}$ & {$[1206]$} \\
\hline Nov. $1980^{\mathrm{d}}$ & 89 & - & 9 & 2 & [1382] \\
\hline \multicolumn{6}{|l|}{ One year from now } \\
\hline $\operatorname{Jan} .1988^{\mathrm{e}}$ & 56 & 33 & 8 & 4 & [1416] \\
\hline Dec. $1986^{\mathrm{f}}$ & 58 & 38 & - & 4 & [1201] \\
\hline July $1986^{\mathfrak{g}}$ & 70 & 12 & 8 & 10 & [1233] \\
\hline Apr. $1986^{\mathrm{b}}$ & 74 & 20 & 4 & 2 & [1365] \\
\hline May $1980^{i}$ & 83 & 10 & 4 & 3 & [1405] \\
\hline \multicolumn{6}{|l|}{ Next few years/10 years } \\
\hline Jan. $1985^{j}$ & 55 & 26 & 16 & 2 & [1362] \\
\hline Dec. $1983^{k}$ & 46 & 35 & 15 & 4 & [1105] \\
\hline Oct. $1979^{l}$ & 86 & 一 & 3 & 11 & [1143] \\
\hline
\end{tabular}

Sources: Constructed by author using data from the Roper Organization, Penn \& Schoen Associates, Louis Harris \& Associates, Liebermann Research, Inc., Analysis Group, ABC News/The Washington Post; ABC News/Louis Harris \& Associates, ABC News.

" "A month from now, do you expect gasoline prices to be much higher, somewhat higher, the same as now, somewhat lower, or much lower?"

b"Six months from now, do you expect gasoline prices to be much higher, somewhat higher, the same as now, somewhat lower, or much lower?"

"Now during this year, do you think the price of oil will drop sharply from $\$ 25$ a barrel to $\$ 15$ a barrel?"

d"In the next six months, do you think it is very likely, somewhat likely, or not very likely that the cost of energy will go up again, because the OPEC countries will raise oil prices again?"

e"One year from now, do you think oil and gasoline prices are likely to be a great deal higher than they are right now, somewhat higher than they are now, somewhat lower than they are right now, a great deal lower than they are now, or about where they are now?"

f "Now l'd like to ask you about three things, and for each one l'd like you to tell me whether you think it will or will not happen in 1987.... The price of oil remaining as low as it has been in 1986."

"What do you think will happen to gas and oil prices in the next 12 months? Go up, stay the same, or go down?"

$\mathrm{h}$ "One year from now, do you think oil and gasoline prices are likely to be higher than they are right now, lower than they are now, or about where they are now?" 
Table 4-13. Expectations for Future Gasoline Prices (continued)

i "In the next 12 months, do you expect the price of gasoline to go up even faster than it has in the past year, as fast, less fast, stay the same, or go down?"

j"Please tell me whether in the next few years oil and energy prices will rise a great deal, go up a little, stay about the same, or go down?"

k"For gasoline prices, tell me whether you think they are likely to increase over the next few years, or likely to decrease, or likely to stay about the same as it is now?"

1"Would you tell me what a gallon of gas that costs one dollar today will cost 10 years from now?"

Table 4-14. Perceived Impacts of 1986 Oil Price Decreases ${ }^{\mathrm{a}}$

"Oil prices have come down from their peak of over forty dollars a barrel to under fifteen dollars a barrel. Here is a list of things that could happen as a result of this price drop. Would you please read down that list and tell me which of those things, if any, you think will happen as a result of the drop in oil prices?" (March 1986) [1086]

\begin{tabular}{||l|c|}
\hline Impacts & Percentage of responses $^{\mathrm{a}}$ \\
\hline \hline Gasoline prices will come down & 72 \\
\hline Oil companies' profits will decrease & 37 \\
\hline Some foreign governments will default on their loans & 34 \\
\hline Some U.S. oil companies will fail & 32 \\
\hline The rate of inflation will drop & 32 \\
\hline The U.S. will become less concerned with energy conservation & 29 \\
\hline Some U.S. banks will fail & 21 \\
\hline Oil company profits will increase & 20 \\
\hline There will be more prosperity & 17 \\
\hline There will be less unemployment & 14 \\
\hline The 55-mile-per-hour speed limit will become unnecessary & 10 \\
\hline None & 1 \\
\hline Don't know & 7 \\
\hline
\end{tabular}

Source: Roper Organization.

${ }^{\text {a} P e r c e n t a g e s ~ a d d ~ t o ~ m o r e ~ t h a n ~} 100 \%$ due to multiple responses. 
Table 4-15. Perception of the Cost of Utilities

"What do you personally think will happen to the cost of utilities in the next six months-will it get a little cheaper, stay the same, get a little more expensive, get a good deal more expensive, or rise sharply?"

\begin{tabular}{|l||c|c|c||}
\hline Survey date & $1 / 17 / 82$ & $1 / 14 / 83$ & $1 / 17 / 84$ \\
\hline Proportion responding (\%) & \multicolumn{3}{|c||}{} \\
\hline \hline Good deal more expensive/rise sharply & 57 & 53 & 45 \\
\hline A little more expensive & 35 & 37 & 42 \\
\hline Stay the same & 6 & 6 & 10 \\
\hline A little cheaper & 1 & 1 & 1 \\
\hline Not sure & 2 & 2 & 2 \\
\hline \hline Total & \\
\hline & 101 & 99 & 100 \\
\hline \hline Survey number & $(1003)$ & $(1001)$ & $(1008)$ \\
\hline
\end{tabular}

Source: Constructed by author using data from Louis Harris \& Associates.

aPercentages may not add to 100 due to rounding. 
Table 4-16. Consumer Price Expectations, 1981

"What do you personally think will happen to...the cost of utilities (Utilities), supermarket prices (Supermarket), the cost of housing (Housing), gasoline prices (Gasoline), the price of clothing (Clothing), restaurant prices (Restaurant) . . in the next six months-will they get a little cheaper, stay the same, get a little more expensive, get a good deal more expensive, or rise sharply?" (January 1981) [1249]

\begin{tabular}{|c|c|c|c|c|c|c|}
\hline Categories & Utilities & Supermarket & Housing & Gasoline & Clothing & Restaurant \\
\hline \multicolumn{7}{|c|}{ Proportion responding $(\%)$ : } \\
\hline $\begin{array}{l}\text { Good deal more } \\
\text { expensive/rise sharply }\end{array}$ & 57 & 30 & 28 & 23 & 21 & 17 \\
\hline A little more expensive & 35 & 54 & 29 & 38 & 45 & 53 \\
\hline Stay the same & 6 & 10 & 26 & 25 & 25 & 20 \\
\hline A little cheaper & 1 & 3 & 12 & 8 & 4 & 2 \\
\hline Not sure & 2 & 3 & 6 & 6 & 5 & 7 \\
\hline Total $^{\mathfrak{a}}$ & 101 & 100 & 101 & 100 & 100 & 99 \\
\hline$N=$ & $(1003)$ & $(1003)$ & (1003) & (1003) & -- & (1003) \\
\hline
\end{tabular}

Source: Constructed by author using data from Louis Harris \& Associates.

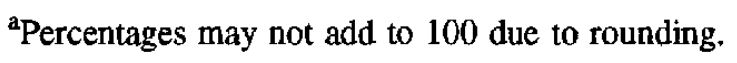


Table 4-17. Consumer Price Expectations, 1983

"What do you personally think will happen to...the cost of utilities Ntilities), supermarket prices (Supermarket), the cost of housing (Housing), gasoline prices (Gasoline), the price of clothing (Clothing), restaurant prices (Restaurant) . . in the next six months-will they get a little cheaper, stay the same, get a little more expensive, get a good deal more expensive, or rise sharply?" (January 1983) [1247]

\begin{tabular}{|c|c|c|c|c|c|c|}
\hline Categories & Utilities & Gasoline & Supermarket & Housing & Clothing & Restaurant \\
\hline \multicolumn{7}{|l|}{ Proportion responding (\%) } \\
\hline $\begin{array}{l}\text { Good deal more } \\
\text { expensive/rise sharply }\end{array}$ & 53 & 23 & 15 & 19 & 17 & 13 \\
\hline A little more expensive & 37 & 39 & 56 & 30 & 42 & 47 \\
\hline Stay the same & 6 & 18 & 20 & 29 & 30 & 29 \\
\hline A little cheaper & 1 & 15 & 5 & 17 & 7 & 3 \\
\hline Not sure & 2 & 5 & 3 & 5 & 5 & 8 \\
\hline Total $^{\mathrm{a}}$ & 99 & 100 & 99 & 100 & 101 & 100 \\
\hline$N=$ & $(1001)$ & $(1001)$ & (1001) & $(1001)$ & $(1001)$ & $(1001)$ \\
\hline
\end{tabular}

Source: Constructed by author using data from Louis Harris \& Associates.

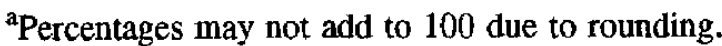




\section{Table 4-18. Consumer Price Expectations, 1984}

"What do you personally think will happen to ... the cost of utilities (Utilities), supermarket prices (Supermarket), the cost of housing (Housing), gasoline prices (Gasoline), the price of clothing (Clothing), restaurant prices (Restaurant) . . . in the next six months-will they get a little cheaper, stay the same, get a little more expensive, get a good deal more expensive, or rise sharply?" (January 1984) [1245]

\begin{tabular}{|c|c|c|c|c|c|c|}
\hline Categories & Utilities & Supermarket & Housing & Gasoline & Clothing & Restaurant \\
\hline \multicolumn{7}{|c|}{ Proportion responding (\%) } \\
\hline $\begin{array}{l}\text { Good deal more } \\
\text { expensive/rise sharply }\end{array}$ & 45 & 21 & 23 & 8 & 10 & 10 \\
\hline A little more expensive & 42 & 54 & 39 & 27 & 46 & 50 \\
\hline Stay the same & 10 & 19 & 23 & 42 & 37 & 31 \\
\hline A little cheaper & 1 & 4 & 7 & 17 & 3 & 2 \\
\hline Not sure & 2 & 2 & 7 & 6 & 4 & 7 \\
\hline Total $^{\mathrm{a}}$ & 100 & 100 & 99 & 100 & 100 & 100 \\
\hline$N=$ & $(1008)$ & $(1008)$ & $(1008)$ & $(1008)$ & $(1008)$ & $(1008)$ \\
\hline
\end{tabular}

Source: Constructed by author using data from Louis Harris \& Associates.

${ }^{a}$ Percentages may not add to 100 due to rounding. 


\section{Chapter 5}

\section{Energy Institutions}

\section{Background and Summary}

Four public and private institutions have played a pivotal role in the evolving energy situation-oil companies, the federal government, utility companies, and automobile manufacturers. Earlier reviews of public opinion reported that most people perceived the government to be responsible for taking action to improve the energy situation, but many also felt that public and private industry shared in this responsibility. Attribution of the primary responsibility for the energy situation has been to institutions rather than to individuals. This chapter examines public opinion data concerning the perceptions about these energy institutions, whether favorable or unfavorable, and the public's expectations for organizations.

In general, energy institutions do not enjoy high levels of trust. The seeds for this mistrust seem to have been planted during the mid- to late-seventies when the Arab oil embargo strained the adaptive capacity of the nation's oil production and service delivery infrastructure. The legacy of that period seems to be an ongoing distrust, although fluctuating oil prices appear to affect trust levels, as well. The oil industry is one of the least favored industries in the United States. Nevertheless, a majority of the public views the oil industry as essential to the nation. The chapter's empirical findings are summarized below.

Attribution of responsibility. During the late 1970s, the oil companies and the federal government were viewed as most responsible for the energy situation. The most recent data show that oil companies and Iraq were most blamed for energy difficulties; also blamed were Congress, any current administration, American consumers, utilities, and environmentalists.

Although survey items were phrased to elicit the public's sense of blame and outrage over the way energy problems were being handled, these items clearly touched a raw nerve. Much of the public seemed to feel betrayed by energy institutions. This loss of trust in U.S. institutions is not limited to the energy arena; it seems to have permeated U.S. society during the late 1970s and the 1980s. If the causes of the energy problem are perceived to be institutional, then individuals may believe they can do little to change things.

The oil industry. Securing adequate energy supplies is seen as the central responsibility of oil companies, almost regardless of the cost. While 8.5 of 10 want oil companies to search for new oil, only 6 of 10 believe they are actually doing this. Two-thirds want oil companies to develop new products, but only about half think oil companies do so. Eight out of ten want them to develop alternative fuels, yet only one in three thinks they are.

A major reason for the oil industry's lack of popularity is public perception of oil-company profiteering. Virtually everyone blamed the oil companies for unfairly taking excess profits during the 1990 Iraq invasion of Kuwait and the ensuing crisis in the Middle East. However, the public incorrectly estimates oil company profits at 10 to 20 times the actual ones, according to the most recent data available. Thus believing profits are too high, many think the oil industry is inadequately regulated. The proportions calling for more oil industry regulation appear to rise and fall with the price of gasoline. 
Other reasons for the lack of confidence in oil companies are a perception that the quality of products provided needs to be improved, that service is declining, that innovation is lacking, and that the industry is not interested in the well-being of its customers. A very small amount of evidence suggests that oil companies may also be viewed as "environmentally incorrect." Taken one by one, oil company reputations tend to fare better than the industry as a whole.

Government. In 1981, opinion was divided about President Reagan's proposal to close down the U.S. Department of Energy; pluralities both favored and opposed this idea. In 1990, however, a majority of $55 \%$ held highly or moderately favorable opinions of the Department of Energy (DOE). The public tended to see Congress and the Bush Administration as more likely to help avoid than cause an energy crisis. The preferred governmental roles appeared to be deciding which energy resources are developed and encouraging private investment. Public preferences leaned toward private industry development of alternative fuels. Most seemed to want government to avoid crises and maintain stability, encouraging private industry rather than supplanting or restricting it severely.

Few data are available about preferred roles and responsibilities of government and industry in a number of areas, such as energy research and development (R\&D), provision of incentives, information programs, and the like. No systematic data addressing these policy preferences were located. In 1985, 6.5 out of 10 said the government should fund energy development and 7.1 out of 10 said that it should set the priorities as to which energy resources are developed. However, governmental roles in regulating energy consumption and production are clearly viewed as important. These are discussed in Chapter 6 on energy alternatives. Many appear to desire a pleasant sufficiency of supply at reasonable cost while avoiding draconian regulation to maintain it.

Electric utilities. Electric power is seen as critical, and the electric power industry is viewed as essential to the country. In the late 1970 s, the public had a relatively low opinion of utilities. However, based on traditional norms of performance-reliability, service restoration, and customer service-utilities have recently been getting relatively high marks. In newer areas of performance, such as integrated resource planning (IRP) and protecting and improving the environment, utilities have room for improvement in public opinion. Yet, approval of electric utilities seems to be increasing, and electricity is often seen as a good value for the price. The stabilization of electricity prices following the price shocks in the late 1970 s and early 1980 s could be a reason people seem to be feeling better about utilities.

As is the case with oil companies, much of the public tends to overestimate utility profits considerably, by more than three to one. They thus tend to favor utility regulation. Future utility roles will emphasize environmental protection and respectful service to customers and the community, if public preferences are influential.

Automakers. Automobile companies seem to enjoy a somewhat more favorable public image than the other energy institutions; however, they are less central energy players, as well. Favorability toward them has increased considerably in the last decade. Majorities give domestic automakers good marks for creating innovative products and the value and quality of the products and services they provide. Thus, most believe no more regulation is desirable; one in three believes more regulation is needed.

The balance of the chapter presents the detailed empirical findings on these topics.

\section{Attribution of Cause and Responsibility}

If the causes of the energy problem are laid at the feet of the institutions in society rather than of individual actors en masse, then individuals may feel there is little they can do directly to solve the problem. Earlier reviews reported that much of the public believed that unnecessary consumption of 
energy was responsible for the energy situation. However, oil companies and the federal government, through action and inaction, were seen as the institutions most responsible for the nation's energy problems.

Items querying the public about whether the energy problem or oil shortage was perceived as "real" or "contrived" were plentiful through 1980. In that year, for example, $51 \%$ of a national sample agreed with the statement from Roper: "There never was any real oil shortage-it was contrived for economic and political reasons" [1134].

In 1979 and 1980, Roper, Harris, and other polls showed that more Americans blamed domestic oil companies for higher gasoline and oil prices and shortages than blamed foreign oil exporters [1405; 1144; $1222 ; 1336 ; 1252 ; 1147]$. In $1981,67 \%$ blamed high oil and gas prices on oil companies, 52\% Arab countries, $34 \%$ the administration, $27 \%$ the Congress, $16 \%$ consumers themselves, and $12 \%$ electric power companies.

This pattern of blame has continued into the 1990s. Table 5-1 shows results of a verbatim trend item from the Roper Organization attributing blame for the "current energy crisis in the United States," with

Table 5-1. Trends in Attribution of Responsibility for the Energy Situation, 1974-1990

"Here is a list of groups who have been mentioned in one way or another as being to blame for the current energy crisis in the United States. (Card shown.) Would you go down that list and for each one tell me whether you think they deserve major blame for the energy crisis, some blame, or no blame at all?" [1554]

\begin{tabular}{||l|c|c|c|c|c|c|c||}
\hline \multirow{2}{*}{$\begin{array}{l}\text { Potentially } \\
\text { responsible entities }\end{array}$} & \multicolumn{6}{|c|}{ Major blame (\%) } & \multicolumn{2}{|c|}{1990} \\
\cline { 2 - 9 } & $1 / 74$ & $2 / 75$ & $1 / 76$ & $1 / 77$ & $\mathbf{6 / 7 9}$ & $\begin{array}{c}\text { Major } \\
\text { blame }\end{array}$ & $\begin{array}{c}\text { Some } \\
\text { blame }\end{array}$ \\
\hline Oil companies & 56 & 57 & 57 & 55 & 72 & 49 & 38 \\
\hline Iraq & - & - & - & - & - & 47 & 35 \\
\hline Other Arab countries & 22 & 38 & 37 & 32 & 51 & 31 & 47 \\
\hline Congress & 26 & 26 & 26 & 28 & 34 & 30 & 54 \\
\hline The Administration & 39 & 28 & 28 & 24 & 36 & 27 & 55 \\
\hline American consumers & 18 & 20 & 18 & 31 & 23 & 26 & 48 \\
\hline $\begin{array}{l}\text { Electric power } \\
\text { companies }\end{array}$ & 15 & 26 & 29 & 31 & 25 & 20 & 51 \\
\hline Environmentalists & 10 & 11 & 9 & 13 & 15 & 10 & 42 \\
\hline
\end{tabular}

Source: Constructed by author using data from the Roper Organization.

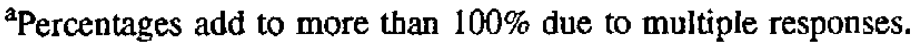


findings from 1974 through 1990. (The item was not asked between June 1979 and September 1990.) The oil companies were still mentioned most frequently in 1990 (albeit by a plurality of $49 \%$, compared with a majority of $56 \%$ in 1974) as deserving "major blame." The questions asked during the 1970s did not include Iraq as a response category; in 1990, 47\% attributed major blame and $35 \%$ some blame to Iraq, for a total of $87 \%$. Also blamed, either for "major" or "some" responsibility, were Congress (84\%), the administration (82\%), the other Arab countries (78\%), American consumers (74\%), electric power companies $(71 \%)$, and environmentalists (52\%).

Using a related verbatim trend item, Roper asked, in March 1987 and again in March 1989: ". . whether you think [for a list of groups] their current actions and policies are likely to bring on an energy crisis, or likely to avoid one, or not have any effect on whether there is an energy crisis or not?" [1538]. Table 5-2 presents the findings. Phrased this way, the item elicited the response that the Arab countries were most likely to bring on an energy crisis (by $73 \%$ ), and least likely to avoid one (by 10\%), than any other group. However, the oil companies also came in for a large share of the blame, with a majority of 53\% in 1989 saying oil companies were likely to bring on an energy crisis (although this majority was nine points lower than in 1987) rather than to avoid one (26\%). Seen as most likely to be able to avoid an energy crisis in 1989 were Congress (43\%), the administration (45\%), and environmentalists (38\%).

The legacy of distrust of oil companies appears to have continued since the mid-1970s to the present time.

\section{The Oil Industry}

What does the public expect from oil companies? Most saw securing adequate energy supplies as a fundamental responsibility. Opinion Research Corporation (ORC) asked a 1984 national sample: "How strongly do you agree or disagree with the point of view that says: 'Regardless of how expensive it is for energy companies to continue the exploration and development of domestic oil and natural gas supplies, it is the responsibility of the energy companies to look to the future and continue to make every effort to increase domestic oil and natural gas supplies?" [1183]. Eighty-four percent agreed with this statement.

A serious difference exists between activities the public would like oil companies to perform, and those it perceives they actually do perform. In 1984, Roper presented a list of potential responsibilities for oil companies and asked a national sample whether it agreed with them. They asked about "ways an oil company can invest its money"; respondents could indicate whether they thought oil companies should invest in a "major way" or in a "minor way" or "not at all" [1100].

In a related item, Roper asked: "(All business companies use part of their profits to improve their business in one way or another. Here are some of the ways an oil company can invest its money. For each of those things, would you tell me whether you think most oil companies today are investing in it in a major way, or in a minor way, or not at all?)" [1100]. The investment opportunities listed included acquiring other energy companies, getting into other industries that have nothing to do with energy, developing alternative fuels to oil, searching for new sources of oil, and developing new products that can be made from oil.

Juxtaposing the responses on these two items yields information on how closely the public felt oil company activities matched those it thought were desirable. While $85 \%$ wanted oil companies to search for new sources of oil, the proportion who thought they were actually doing so was 24 points lower. Similarly, while $67 \%$ wanted oil companies to develop new products, only $36 \%$ thought they were doing it. On the other hand, $45 \%$ thought oil companies were busy acquiring other energy companies, although only $23 \%$ thought they should. And, while $80 \%$ wanted oil companies to develop altemative fuels, only $29 \%$ thought they were doing so. 
Table 5-2. Perception of Effectiveness of Various Groups in Causing or Avoiding Energy Crises, 1987 and 1989

"Here is a list of groups that can have an effect one way or another on whether we have an energy crisis in the next few years. (Card shown.) Would you read down that list and for each one tell me whether you think their current actions and policies are likely to bring on an energy crisis, or likely to avoid one, or not likely to have any effect on whether there is an energy crisis or not?" (Asked of half-sample) [1538]

\begin{tabular}{||l|c||c|c|c|c||}
\hline \multirow{2}{*}{$\begin{array}{l}\text { Potentially } \\
\text { causal entities }\end{array}$} & $\begin{array}{c}\text { March 1987 } \\
\begin{array}{c}\text { Likely to } \\
\text { bring on } \\
\text { energy crisis }\end{array}\end{array}$ & $\begin{array}{c}\text { Likely to } \\
\text { bring on } \\
\text { energy crisis }\end{array}$ & $\begin{array}{c}\text { Likely to } \\
\text { avoid energy } \\
\text { crisis }\end{array}$ & $\begin{array}{c}\text { No } \\
\text { effect }\end{array}$ & $\begin{array}{c}\text { Don't } \\
\text { know }\end{array}$ \\
\hline Proportion responding $(\%)^{\mathrm{b}}$ & 73 & 71 & 10 & 7 & 12 \\
\hline \hline Arab countries & 62 & 53 & 26 & 10 & 11 \\
\hline Oil companies & 33 & 36 & 34 & 20 & 11 \\
\hline American consumers & 38 & 34 & 35 & 20 & 12 \\
\hline $\begin{array}{l}\text { Electric power } \\
\text { companies }\end{array}$ & 39 & 34 & 18 & 30 & 18 \\
\hline Israel & 28 & 29 & 43 & 15 & 14 \\
\hline Congress & 26 & 27 & 38 & 21 & 14 \\
\hline Environmentalists & 31 & 24 & 45 & 17 & 14 \\
\hline The Administration & & & & & \\
\hline
\end{tabular}

Source: Constructed by author using data from the Roper Organization.

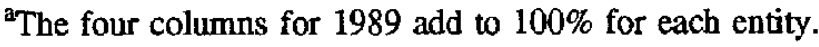

bercentages add to more than $100 \%$ due to multiple responses.

Another 1984 item stated: "There has been a lot in the news recently about mergers and possible mergers between large oil companies-Texaco and Getty Oil, Standard Oil of California and Gulf Oil, and several others. Do you think these mergers are very good for the country as a iwhole, mostly good, mostly bad, or very bad for the country as a whole?" [1101]. A 52\% majority said they were "mostly bad" or "very bad," while $30 \%$ said they were "mostly good" or "very good." 
The oil industry enjoys much less favorability than do many other U.S. industries. Table 5-3 summarizes verbatim trend data from 1978 through 1990 on favorability toward the automobile industry and the oil industry. Of 19 industries included on a list, ${ }^{1}$ Roper asked: ". . . is your opinion of that industry highly favorable, or moderately favorable, or not too favorable, or rather unfavorable?" [1555]. This 12-year trend shows fluctuations in favorability toward both the automotive and oil industries; however, the automotive industry received consistently higher marks than the oil industry, which remained second from the last on a list of 19 industries.

Figure 5-A traces favorability toward the U.S. oil industry by actual and adjusted gasoline prices. Favorability increases as gasoline prices come down and decreases as prices rise. The volatility in opinion toward the oil industry appears to be a function of prices.

Oil companies are widely perceived as profiting excessively from difficulties in world oil supplies and world oil market conditions. A recent piece of evidence on this came from two $1991 \mathrm{ABC}$ News/The Washington Post polls (one in January and the other in March) asking: "(I'm going to name a few countries, people and other things. For each, please tell me if you have gained respect or lost respect for it as a result of the war in Iraq, or if your opinion has not changed) . . . United States oil companies" [1504, 1506]. In January, 49\% said their opinion remained unchanged; in March, 52\% indicated the same. Having lost respect were $37 \%$ in January and $31 \%$ in March. Only $7 \%$ reported having gained respect for oil companies in January and 16\% in March. Hart and Teeter obtained similar results in January 1991 [1002].

Between August 7 and 12,1990, several polls asked about the public's view of oil company motivations in raising gasoline prices. By and large, U.S. oil companies took the blame for the price increases. On August 7, 1990, CBS News asked: "Do you think the recent increases in gasoline prices are due to the situation in the Middle East, or do you think gasoline companies and owners are just using the Middle East situation as an excuse to raise prices?" [1350]. Eighty-four percent believed that the price increases occurred because the oil companies were using the Middle East situation as an excuse. Similarly, on August $8,1990,86 \%$ said the oil companies were trying to "take advantage of the situation and raise prices unfairly" [1361]. Another poll that day found $87 \%$ agreeing that "oil suppliers are just using the situation to make more money" [1042]. A Gallup poll on August 9, 1990, found 93\% saying "American oil companies are taking advantage of the Mideast situation by raising prices unfairly" [1286]. Yankelovich/Clancy/Shulman found 87\% agreeing with this in a different poll taken the same day [1049]. And, yet a different Gallup poll, with data collected between August 9 and August 12, 1990, found 91\% saying that "the oil companies only raised prices to take advantage of the situation" [1313].

Also on August 9, 1990, The New York Times asked: "Oil companies have sharply increased the price of oil and gas in the last week or so (since invasion of Kuwait by Iraq). Do you think that is mainly because: (1) the companies have less oil available now, or (2) they expect to have less oil available soon, or (3) the oil companies are basically greedy?" [1186]. More than two-thirds (68\%) said the oil companies were "basically greedy"; $25 \%$ said they expected less oil to be available in the future.

${ }^{1}$ The industries included, in descending order of favorability in 1990, were as follows: National retail chain stores, food companies, the computer and information systems industry, local telephone companies, (the automobile industry), the wood and paper industry, long distance telephone companies, the drug and pharmaceutical industry, the television broadcasting industry, the airline industry, the drug industry, the advertising industry, the banking industry, the liquor industry, beer companies, the chemical industry, the insurance industry, the credit card industry, (the oil industry), and the tobacco industry. 
Table 5-3. Trends in Favorability toward Automobile and Oil Industries

"Now let me ask you about a few specific industries. Using this card (card shown), first the automobile industry-is your opinion of that industry highly favorable, or moderately favorable, or not too favorable, or rather unfavorable? What about (next item)?" (October, each year) [1555]

\begin{tabular}{|l|c|c|c|c|c|c|c|c|c|c|c|c||}
\hline \hline Category & 1978 & 1980 & 1981 & 1982 & 1983 & 1984 & 1985 & 1986 & 1987 & 1988 & 1989 & 1990 \\
\hline Proportion indicating "highly" and "moderately favorable" (\%) \\
\hline The automobile industry & 56 & 46 & 51 & 43 & 71 & 72 & 77 & 73 & 71 & 72 & 72 & 74 \\
\hline The oil industry & 40 & 20 & 31 & 26 & 45 & 54 & 62 & 59 & 61 & 56 & 55 & 35 \\
\hline
\end{tabular}

Source: Constructed by author using data from the Roper Organization.

${ }^{a}$ Other industries included (in descending order of favorability in 1990): National retail chain stores, food companies, the computer and information systems industry, local telephone companies, (the automobile industry), the wood and paper industry, long distance telephone companies, the drug and pharmaceutical industry, the television broadcasting industry, the airline industry, the drug industry, the advertising industry, the banking industry, the liquor industry, beer companies, the chemical industry, the insurance industry, the credit card industry, (the oil industry), and the tobacco industry. 
"Now let me ask you about a few specific industries. (For the oil industry) Is your opinion of that industry highly favorable, or moderately favorable, or not too favorable, or rather unfavorable?" (October of each year) [1555].

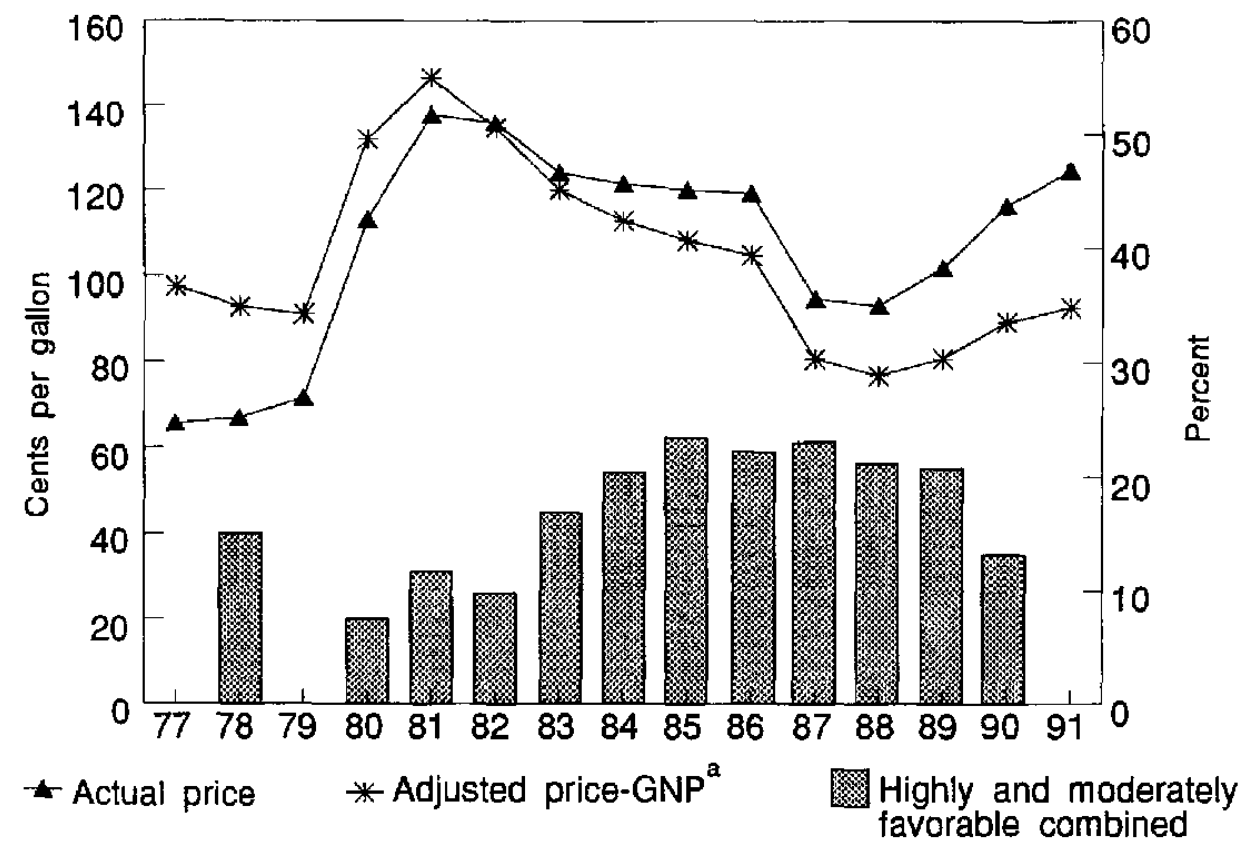

Source: Constructed by the author using data from the Roper Organization, the Energy Information Administration's Monthly Energy Review, National Income and Product Accounts, 1927-1982 and Survey of Current Business, 1983-1991

anf́lation-adjusted price $(1982=1.00)$

Figure 5-A. Trends in favorability toward the U.S. oil industry by gasoline prices, 1977-1991

On August 18, Hart and Teeter asked: "The price of U.S. gasoline has gone up recently. Who do you believe is most responsible for this: President Saddam Hussein, President Bush for boycotting the oil from Kuwait and Iraq, or U.S. oil companies for raising their prices?" [1193]. Seventy percent said "oil companies"; 13\% said Hussein; 6\% President Bush; 7\% volunteered "all"; $4 \%$ were unsure.

Louis Harris and Associates asked in 1990: "How much confidence do you have in the people running the major oil companies in this country - a great deal, some but not a lot, or hardly any confidence at all?" [1262]. The majority, 51\%, responded "some but not a lot," and a plurality of $40 \%$ said "hardly any confidence." Only $7 \%$ said they had "a great deal" of confidence in oil company managers. These results were similar to those in 1989, when Harris asked about confidence levels "as far as people in charge of running oil companies." Ninety-two percent expressed "only some," "hardly any," or "not sure" [1264].

Interestingly, the electric power industry was viewed as more essential to the country than the oil industry. Roper asked in July 1989: "Now I'd like to ask you about several different industries, all of which are important to this country, to one degree or another. Using this card (card shown), would you tell me just how important you feel the ... industry is to this country? [1544]. The proportion indicating that the oil industry is "absolutely essential" to this country was $61 \%$ in 1976, when this item was asked, and 50\% in 1989 , a drop of 11 points. Indicating that the electric power industry was "absolutely essential" was $71 \%$ in 1989 . The nuclear power industry was seen as essential by $27 \%$. 
While the oil industry may not be perceived as centrally important to the economy, there are probably other reasons for the relatively low regard in which the industry is held. Table 5-4 presents information elicited in 1989 when Roper asked about product quality, innovation, and the value for the dollar of goods and services of 20 industries. Oil industry rankings were compared with those for foreign and domestic automobile companies. Foreign automobile manufacturers rated tops across the three categories. Rating second, although majorities of respondents gave them high marks, were domestic automobile companies. The oil industry was 19 th on the list of the industries, outranking only the tobacco companies. While $52 \%$ rated the oil industry "excellent" or "good" for its quality of products or services, only $38 \%$ so rated it for creating innovative products and $38 \%$ for value provided. These results echo those shown in Table 5-3, where the oil industry ranked second to last. They suggest problems oil companies must overcome if they are to improve their public image.

Table 5-4. Perception of Quality, Innovation, and Value of Oil Industry and Automobile Industry Products and Services

"Here is a list of industries. (Card shown) Would you please read down that list and for each one tell me whether you think the industry is doing an excellent, good, only fair, or poor job in terms of the value for the dollar of the products or services they offer? . . . of creating innovative products for consumers? . . of the quality of products or services they sell to consumers?" a (March, April, May 1989) [1538, 1542, 1543]

\begin{tabular}{||l|c|c|c||}
\hline \multirow{2}{*}{ Industry } & \multicolumn{3}{|c|}{ "Excellent and good" combined } \\
\cline { 2 - 5 } & $\begin{array}{c}\text { Quality of } \\
\text { products or } \\
\text { services }^{\mathbf{b}}\end{array}$ & $\begin{array}{c}\text { Creating } \\
\text { innovative } \\
\text { products }\end{array}$ & $\begin{array}{c}\text { Value for the dollar } \\
\text { of the products } \\
\text { and services }\end{array}$ \\
\hline Proportion indicating (\%) & 68 & 74 & 62 \\
\hline \hline Foreign automobile companies & 58 & 61 & 59 \\
\hline Domestic automobile companies & 52 & 38 & 38 \\
\hline The oil industry & & & \\
\hline
\end{tabular}

Source: Constructed by the author using data from the Roper Organization.

${ }^{2}$ Other industries included, in rank order of favorable response, were: the home electronics industry, the home appliance industry, the bome computer industry, food companies, the telephone equipment industry, the nonprescription drug industry, (foreign automobile companies), the television broadcasting industry, the fast-food industry, the prescription drug industry, the cosmetics and toiletries industry, (domestic automobile companies), the candy and chewing gum industry, the cable television industry, the beer industry, the liquor industry, the airlines, (the oil industry), and the tobacco industry.

\footnotetext{
${ }^{b}$ Asked in March.

cAsked in April.

${ }^{d}$ Asked in May.
} 
The service arm of the oil industry-gasoline stations-are perceived as part of the problem. When asked "whether you think the overall level of service" gas stations provide to customers is "getting better, getting worse, or staying about the same," 59\% said it was "getting worse" (in September 1990) [1188].

When it comes to the public perception of how interested various industries are "in the well being of their customers," oil companies fare less well than do other industries. In 1987, this question addressed the food processing and manufacturing, telephone, drug, cosmetic, automobile, electric utility, chemical, and oil industries. The food, drug, and automobile industries ranked highest; the chemical and oil industries ranked lowest, with $10 \%$ indicating those industries were "very interested" and $36 \%$ "moderately interested" in the well-being of their customers [1073].

Table 5-5 presents trend data from 1979 and 1987 on this theme, showing that oil company interest in customers, perceived by only $20 \%$ in 1979 , was perceived by $46 \%$ in 1987 . Respondents consistently viewed electric utilities as more customer oriented [1144, 1073].

Roper produced an interesting result in 1987 by asking opinion about specific oil companies by name, rather than about "the industry" in the abstract. Taken one by one, oil companies tended to fare better than the industry as a whole. For example, $62 \%$ were "highly favorable" or "moderately favorable" toward Amoco and $67 \%$ toward Texaco. In 1985, Exxon was viewed favorably by $66 \%$. However, in May 1989 ,

Table 5-5. Perception of the Oil and Electric Utility Industries' Interest in the Well Being of Their Customers

"We'd like your impression as to how interested the electric utility industry [Electric] and oil industry [Oil] are in the well being of their customers." (September 1979 and September 1987) [1144; 1073]

\begin{tabular}{||l|c|c|c|c|}
\hline \multirow{2}{*}{ Response } & \multicolumn{2}{|c|}{1979} & \multicolumn{2}{c|}{1987} \\
\cline { 2 - 5 } & Electric & Oil & Electric & Oil \\
\hline Proportion responding (\%) & \multicolumn{3}{|c|}{} \\
\hline \hline Very interested & 9 & 5 & 14 & 10 \\
\hline Moderately interested & 36 & 15 & 43 & 36 \\
\hline Not very interested & 31 & 30 & 27 & 34 \\
\hline Not at all interested & 21 & 46 & 13 & 16 \\
\hline Don't know & 3 & 4 & 2 & 5 \\
\hline \hline Total $^{\mathrm{a}}$ & 100 & 100 & 99 & 101 \\
\hline \multicolumn{1}{|l|}{$\mathrm{N}=$} & $(2009)$ & $(2009)$ & $(1990)$ & $(1990)$ \\
\hline
\end{tabular}

aPercentages may not add to 100 due to rounding. 
2 months after the Valdez oil spill, 57\%, when rating Exxon as an "oil company you can put your confidence in," said it was "only fair or poor" [1265]. Thus, oil companies may be seen as uncaring about the environment.

Oil companies have also been seen as taking handsome profits. Table 5-6 presents data from March and June 1982 and March 1986 on perception of oil profits. In March 1982, most people thought profits were too high; the percentage had dropped 35 points by March 1986. As Figure 10-A shows, the adjusted price of gasoline had dropped somewhat during that period. More current data are not available.

The public believes that oil companies make far more profit than they actually do. In 1981, ORC asked about public perception of the average oil company's profit on each dollar of sales; the mean estimate was 62 cents [1171]. The actual profit that year was 5.9 cents. Similarly, the public's mean estimate of profit in 1986 was $43 \%$, when actual oil company profit was $1.8 \%$ [1153].

Given the perception of excessive oil company profits, it is interesting that, of 12 industries asked about, the oil industry was most likely to be viewed as a candidate for regulation. Roper asked whether the industries "should be allowed to raise or lower their prices or rates as they see fit, or should they have to get permission from the government before raising or lowering their prices or rates?" [1555]. In July $1984,68 \%$ said oil companies should have to get government permission to raise their prices; in 1987 ,

Table 5-6. Perceptions of Oil Company Profits

"(Here is a list of some different U.S. industries. Would you read down that list, and for each one tell me whether you would say its profits are too high, high but all right, moderate, low but all right, or too low?) . . . Oil"

\begin{tabular}{||l|c|c|c|}
\hline Item & $\begin{array}{c}\text { March } \\
1982\end{array}$ & $\begin{array}{c}\text { June } \\
\mathbf{1 9 8 2}\end{array}$ & $\begin{array}{c}\text { March } \\
\mathbf{1 9 8 6}\end{array}$ \\
\hline Proportion indicating (\%) & & & \\
\hline \hline Too high & 83 & 65 & 48 \\
\hline High but all right & 9 & 20 & 13 \\
\hline Moderate & 4 & 6 & 23 \\
\hline Low but all right & 1 & 1 & 5 \\
\hline Too low & 0 & - & 1 \\
\hline Don't know & 3 & 100 & 100 \\
\hline \hline Total & 100 & $(2000)$ & $(1993)$ \\
\hline & $\mathrm{N}=$ & {$[1116]$} & {$[1086]$} \\
\hline Study number & {$[119]$} & & \\
\hline
\end{tabular}

Source: Constructed by the author using data from the Roper Organization. 
$65 \%$ said this; in $1990,78 \%$ said this--an increase of 10 points in 6 years. The proportions saying that oil companies are not sufficiently regulated tends to be positively associated with the price of gasoline (see Figure 10-A).

In 1987, replicating an item asked in 1981 and 1984, a national poll asked whether there was too much, not enough, or about the right amount of government regulation of the electric power and oil industries at that time [1075]. Opinion was divided. In 1987, 30\% said there was not enough regulation of the oil industry, 33\% said regulation was "about right," and 25\% said there was "too much" regulation. In the 6 years between 1981 and 1987, those calling for more regulation decreased 19 points. Up-to-date data for this trend were unavailable.

Most people thought that the U.S. oil industry took unfair advantage of the Persian Gulf tensions by swiftly raising gasoline prices after Iraq invaded Kuwait on August 2, 1990. Several polls asked whether these gasoline price hikes were seen as justified by events in the Middle East. The overwhelming response was that oil companies used the situation to unfairly increase prices. (Table 5-7 summarizes the data.) No doubt as a consequence of this perception, on January 23, 1991, 37\% of a national sample of registered voters reported that they had "lost respect for oil companies" who played a role in the war with Iraq; $49 \%$ said their opinions remained unchanged; and 7\% said they had "gained respect" [1002].

Skepticism about oil companies remains the legacy of the 1973-1974 Arab oil embargo period. It was reinforced by oil company behavior during the 1990-1991 Persian Gulf crisis. Yet, most seem to believe the oil industry could be a constructive partner in solving national energy problems. Penn and Schoen Associates, in its survey for Texaco, asked: "Do you think that the oil companies are part of the problems America is facing or do you believe that they can be an important part of the solution to our dependence on foreign oil?" [1206]. Sixty-three percent said they can be part of the solution. However, agreement with the statement might have been even higher if the "or" in the item had instead been an "and."

\section{The Government}

The chapter on energy production versus energy consumption provides information on preferences for a national policy and for various policy levers, such as regulation or incentives, that the government can employ to achieve desired policy ends. Discussed here is some information about how the federal government is evaluated in performing its role generally.

For example, Roper has been collecting trend data on favorability toward federal agencies, including DOE, since 1983. Table 5-8 summarizes the data for 12 federal agencies. Favorability toward DOE started the survey period with a plurality of $42 \%$ in favor; it enjoyed its highest level of favorability in 1986 . In $1990,55 \%$ held a "highly favorable" or "moderately favorable" opinion [1550]. Favorability toward DOE fell approximately in the low middle range among the agencies included in the item.

When President Reagan proposed closing down DOE, three polls during 1981 asked respondents whether they favored or opposed the idea. Roper's poll in January 1981 resulted in $51 \%$ opposed and $21 \%$ in favor of eliminating DOE [1131]. An ABC News poll in September 1981 resulted in 49\% disagreeing and $42 \%$ agreeing with the proposal [1420]. Harris, in his September 1981 poll, found 50\% opposed to "closing down the Department of Energy" and $40 \%$ in favor [1260].

Seen as most likely to avoid an energy crisis were first, Congress, by a plurality of $43 \%$, and second, environmentalists, by $40 \%$. The administration and consumers were also seen as more likely to avoid rather than cause a crisis. However, opinion was almost equally divided about utilities, and oil companies were three times as likely to be viewed as likely to bring about rather than avoid an energy crisis. In 1985, ORC repeated an item it had used in 1984: "Which of these roles should the federal government 
Table 5-7. Perceptions of Oil Industry Exploitation of the Persian Gulf War (1990)

Example item: "The price of gasoline has increased in the United States after Iraq's invasion of Kuwait. Do you think that oil companies have raised their prices fairly or unfairly?" (August 1990) [1049]

\begin{tabular}{||c|c|c||}
\hline Date & Study number & $\begin{array}{c}\text { Using the situation } \\
\text { to make more money }\end{array}$ \\
\hline Proportion indicating (\%) & \multicolumn{2}{|c|}{} \\
\hline $8 / 7 / 90$ & {$[1350]$} & 84 \\
\hline $8 / 8 / 90$ & {$[1042]$} & 87 \\
\hline $8 / 8 / 90$ & {$[1361]$} & 86 \\
\hline $8 / 9 / 90$ & {$[1186]$} & 68 \\
\hline $8 / 9 / 90$ & {$[1049]$} & 87 \\
\hline $8 / 9 / 90$ & {$[1313]$} & 91 \\
\hline $8 / 9 / 90$ & {$[1286]$} & 93 \\
\hline $8 / 18 / 90$ & {$[1193]$} & 70 \\
\hline
\end{tabular}

Source: Constructed by the author using data from Yankelovich/Clancy/Shulman.

Actual item wording:

[1042] "As you may know, gas and oil prices increased immediately after Iraq invaded Kuwait. Which of the following statements comes closest to your view of this price increases: (A) Oil suppliers probably have good reasons to increase prices (B) oil suppliers are just using the situation to make more money."

[1186] "Oil companies have sharply increased the price of oil and gas in the last week or so since invasion of Kuwait by (raq). Do you think that is mainly because: (1) the companies have less oil available not, or (2) they expect to have less oil available soon, or (3) the oil companies are basically greedy?"

[1193] "The price of U.S. gasaline has gone up recently. Who do you believe is most responsible for this: President Saddam Hussein, President Bush for boycotting the oil from Kuwait and Iraq, or U.S. oil companies for raising their prices?"

[1286] "Do you think that American oil companies are taking advantage of the Mideast situation by raising prices unfairly, or not?"

[1313] "Do you think that the price increase by the oil companies was necessary because of the Iraqi situation, or do you think the oil companies only raised prices to take advantage of the situation?"

[1350] "Do you think the recent increases in gasoline prices are due to the situation in the Middle East, or do you think gasoline companies and owners are just using the Middle East situation as an excuse to raise prices?"

[1361] "Do you think the recent increases in gasoline prices in the United States are a legitimate result of Iraq's attack on Kuwait, or do you think the oil companies are taking advantage of the situation and raising prices unfairly?" 
Table 5-8. Trends in Favorability toward Federal Agencies, Including the Department of Energy

"Now let me ask you about a few specific federal departments. Using this card (card shown) . . is your opinion of them highly favorable, or moderately favorable, or not too favorable, or rather unfavorable?" (April of each year) [1550]

\begin{tabular}{||l|c|c|c|c|c|c||}
\hline & \multicolumn{6}{|c||}{$\begin{array}{c}\text { Percentages indicating "highly favorable" and } \\
\text { "moderately favorable" combined }\end{array}$} \\
\hline Agency $^{\mathbf{a}}$ & $\mathbf{1 9 8 3}$ & $\mathbf{1 9 8 5}$ & $\mathbf{1 9 8 6}$ & $\mathbf{1 9 8 8}$ & $\mathbf{1 9 8 9}$ & 1990 \\
\hline \hline Postal Service & 70 & 70 & 74 & 62 & 75 & 70 \\
\hline Department of Agriculture & 58 & 55 & 54 & 59 & 63 & 64 \\
\hline Department of Transportation & 53 & - & - & - & 58 & 59 \\
\hline Department of State & 54 & 57 & 63 & 57 & 58 & 58 \\
\hline Department of Defense & 54 & 54 & 66 & 57 & 57 & 56 \\
\hline Department of Energy & 42 & 53 & 60 & 58 & - & 55 \\
\hline Department of Commerce & 49 & 55 & 57 & 53 & 56 & 55 \\
\hline Department of Labor & 38 & 51 & 55 & 54 & 54 & 55 \\
\hline Department of Treasury & 55 & 59 & 59 & 56 & 59 & 54 \\
\hline $\begin{array}{l}\text { Department of Health and } \\
\text { Human Services }\end{array}$ & & & & & & \\
\hline Department of the Interior & 41 & - & - & - & - & 54 \\
\hline Department of Justice & - & 53 & - & - & - & 49 \\
\hline
\end{tabular}

Source: Constructed by author using data from the Roper Organization.

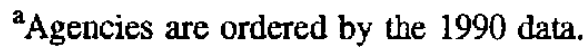

play in setting the priorities as to which energy resources are developed?" [1157]. Almost two-thirds (63\%) said the government "should play a major role"; one-quarter said it "should play a minor role" or "have no role at all"; and $8 \%$ said it should be "completely responsible." In terms of funding energy development, 54\% said the government "should play a major role," $31 \%$ said a minor role or none at all, and $11 \%$ said it should be completely responsible. Thus, in $1985,71 \%$ said the government should set these priorities, and $65 \%$ said it should fund energy development.

Penn and Schoen asked, in 1985, whether the government should "encourage private investment and contribution with tax incentives" or whether the government should become "directly involved in funding drilling for domestic oil and gas resources as a part of a program to make us less dependent on foreign oil" [1207]. The majority (59\%) said the government should encourage private investment, while $27 \%$ called for direct government involvement. In 1984, $71 \%$ of an Alabama sample agreed that "government 
has a responsibility to ensure adequate energy supplies in the future" [1448]. In 1982, 67\% of a national sample said that the government had not done enough to plan for future energy needs. And, in 1981, in response to an item asking about who should have the primary role in developing "alternative fuels, such as solar energy, synthetic fuels, etc.," $49 \%$ said private industry and $35 \%$ said the federal government [1129].

As far back as $1979,40 \%$ of a Gallup sample said that Congress "should have the major responsibility for setting energy policies," and 35\% said the President should [1294]. In those days, 89\% of an NBC News/Associated Press sample said that American science and technology would be "very or partially successful in solving our energy problems" [1222]. People thought then that the government and "big energy companies" should work jointly on development of new sources of energy (78\% agreed) [1394]. And, consistently, opinion has opposed government takeovers of private industry, including taking over nuclear power (56\% opposed), oil companies (58\% opposed), the oil industry (68\% opposed), or "most businesses in this country" ( $92 \%$ opposed; $2 \%$ were "unsure.")

In 1979 , however, $56 \%$ of a Gallup sample said they had "more trust and confidence in the ability of private industry to develop new energy resources" than they had in the federal government, while $26 \%$ preferred the government [1306]. But, when the question asked respondents to choose between "oil companies" and the federal government, $43 \%$ chose the government and $29 \%$ had more trust in the oil companies, while 18\% said it made no difference [1307]. In April 1979, 44\% said that Congress was doing a "poor" job of "handling our energy problems"; by May, this percentage had increased 11 points to $55 \%$ [1224].

The evidence points to a preferred federal role in energy policy that, if effective, would avoid crises and maintain stability. Government would preferably cooperate with private industry rather than try to supplant or take over its roles. However, the public appeared to exhibit somewhat more trust in private industry - except for the oil companies - than in the federal government's ability to provide supply.

Few data are available about preferred roles and responsibilities of government and industry in a number of areas, such as energy $R \& D$, provision of incentives, information programs, and the like. No systematic data addressing these policy preferences have been located. The public appears to desire a pleasant sufficiency of supply at reasonable cost while avoiding draconian policies to maintain it.

\section{Electric Utility Companies ${ }^{2}$}

Although electric utility companies traditionally had a reputation for service-particularly in the 1940 s and 1950s-after the 1973-1974 Arab oil embargo, they encountered some public relations problems. In the seventies, active energy conservers became discouraged when they found that their utility bills stayed level or even increased despite their conservation efforts. As one respondent put it:

Doesn't it strike you kind of funny that they come out and say that you are using too much electricity and you have to cut back. But now they charge me more for units because I am using less, so they have to double the price (Farhar et al. 1979, p. 76).

ORC presented data showing that most people did not view with favor the "electric light and power industry." Table 5-9 shows that, in 1979, 61\% of respondents and, in 1983, 72\% had a "very unfavorable" or "mostly unfavorable" opinion of the industry. However, utility prices have since stabilized (albeit at

\footnotetext{
${ }^{2}$ No data were located on public opinion about gas utilities.
} 
Table 5-9. Favorability toward Energy Industries, 1979-1983

"How favorable or unfavorable are your opinions or impressions of the . . . (type of industry)?" (July 1979, June 1981 and 1983) $[1159,1165,1174]$

\begin{tabular}{|c|c|c|c|c|c|c|}
\hline & \multicolumn{2}{|c|}{1979} & \multicolumn{2}{|c|}{1981} & \multicolumn{2}{|c|}{1983} \\
\hline & $\begin{array}{c}\text { Very/mostly } \\
\text { favorable }\end{array}$ & $\begin{array}{l}\text { Very/mostly } \\
\text { unfavorable }\end{array}$ & $\begin{array}{l}\text { Very/mostly } \\
\text { favorahle }\end{array}$ & $\begin{array}{l}\text { Very/mostly } \\
\text { unfavorable }\end{array}$ & $\begin{array}{c}\text { Very/mostly } \\
\text { favorable }\end{array}$ & $\begin{array}{l}\text { Very/mostly } \\
\text { unfavorable }\end{array}$ \\
\hline \multicolumn{7}{|c|}{ Proportion responding (\%) } \\
\hline $\begin{array}{l}\text { Oil and gasoline } \\
\text { industry }\end{array}$ & 17 & 83 & 26 & 74 & 24 & 76 \\
\hline $\begin{array}{l}\text { Nuclear power } \\
\text { industry }\end{array}$ & 25 & 75 & 24 & 76 & 19 & 81 \\
\hline Natural gas industry & 36 & 64 & 39 & 61 & 37 & 63 \\
\hline $\begin{array}{l}\text { Electric light and } \\
\text { power industry }\end{array}$ & 39 & 61 & 一 & 一 & 28 & 72 \\
\hline Coal industry & 40 & 60 & 35 & 65 & 28 & 72 \\
\hline
\end{tabular}

Source: Constructed by author using data from Opinion Research Corporation. 
higher levels), and public relations seem to have improved somewhat since the late seventies and early eighties.

Electric power is seen as a critical commodity. A 1989 Roper poll found that $92 \%$ of a national sample identified the "electric power industry" as either "absolutely essential" or "very important" to this country [1544]. If anything, electricity is becoming more crucial to our operations as we increasingly rely on appliances, motors, and computers in our homes, offices, and factories. With electric cars in the offing, especially for use in air quality nonattainment metropolitan areas, the role for electricity could become even more significant.

A series of polls asked respondents to evaluate the service they received from their utility companies. In December 1990, 42\% rated their electric utility company as "excellent" or "above average" in "promoting energy efficiency" [1025]. Given the widespread commitment to the potential of energy efficiency, these do not appear to be high enough marks to be congruent with public preferences in this area of performance.

In 1990, Maritz Marketing Research asked: "Overall, how satisfied are you with the quality of service you receive from the public utilities, such as the gas company, electric company, or the phone company in your area?" [1232]. Virtually everyone was "satisfied" (69\%) or "very satisfied" (24\%).

Cambridge Reports/Research International asked for ratings of electric utilities' performance in its major survey on electric utilities and the environment. They asked: "Now, I would like to know how you rate your electric company overall on a scale of 1 to 7 , where 1 means very unfavorable and 7 means very favorable. The more favorable you generally feel toward your electric company, the higher the number you would give" [1457]. The mean score was 5.1; $40 \%$ gave the electric utilities the highest scores (6 or 7); in comparison, $7 \%$ gave them the lowest scores (1 or 2). Consumers were more satisfied with some aspects of utility service than others, however. As Cambridge Reports phrased it:

Not surprisingly, the areas of performance where electric companies are currently most nearly meeting customers' expectations are those by which the industry has traditionally evaluated itself: electric service reliability, service restoration, and customer service. Areas that currently receive performance ratings in line with their moderate to lower importance ratings are-in order of importance-providing cost-control programs, keeping the public informed, minimizing public exposure to EMF [electro-magnetic fields], and making donations to the community. The key finding. . . is that three areas of emerging concern-planning for future energy needs, not harming the environment, and taking proactive steps to protect the environment-receive relative performance ratings much lower than their relative importance in customers' minds would warrant [1457: p. 35].

Responses to some of the Cambridge survey items were:

- Electric rates, rated from "completely unfair and unreasonable" to "completely fair and reasonable" (mean score: 4.4 )

- Caring about its customers and their problems in the broadest sense, rated from "not concerned at all" to "very concerned" (mean score: 4.7 ) 
How believable it is when it talks about issues that concern customers, rated from "not at all believable" to "very believable" (mean score: 4.5 ).

These scores show that utility companies generally have room for improving their performance and their public image.

Broad consumer approval of utility service seems to be increasing. A 1989 Roper poll found "the electric company" ranked fourth in terms of excellence of service provided on a list of 12 types of services (that included supermarkets, doctors, banks, phone companies, department stores, credit card companies, mail order companies, and so on). Thirteen percent rated their electric utility as providing "excellent" and 64\% as providing "good" service, identical to the ratings given in 1989 and 8 points higher than the rating given in 1987 [1540].

Ohio utility customers responded to a series of surveys conducted by the electric utility, Monongahela Power and Light, between 1981 and 1989 [1473]. The company received "excellent" or "very good" ratings from $72 \%$ of these randomly selected customers. According to the 1989 survey, customers considered electricity the best value for the price from a list of goods and services that included such basics as food, clothing, telephone service, postage, gasoline, natural gas, taxes, heating oil, and prescription drugs. Customers were most satisfied with "good and reliable service," "prompt restoration of service," "courtesy of employees," and "reasonable rates." They were less satisfied with the cost of electric service, time required for new connections, "spraying" rights of way, and the inconvenience of power interruptions requiring customers to reset electronic clocks, and so on. Customers learned about the utility primarily through its bill stuffers. In 1989, the sample identified the main factors affecting electric rate increases as "government/environmental regulations" (41\%) and "labor costs" (40\%).

A 1990 poll asked: "Which public utility in your area currently provides the best service?"; $29 \%$ identified the electric utility, 19 points more than the next-ranked utility-telephone. Others on the list with lower rankings were gas, water/sewer, garbage collection, and cable television [1232]. This same survey asked: "If you could improve the quality of service from the public utilities in your area, which one of the following attributes would be most important to you?" The plurality $(28 \%)$ identified "easier access to employees about problems," while $16 \%$ said "showing a caring attitude," and $16 \%$ said "handling requests quickly and efficiently." This preference for an attitude of service is an important theme for utilities to recognize if they wish to improve their public image.

Electric utility companies are seen as somewhat credible when communicating about the environmental, safety, and health effects of electricity production and distribution. The Cambridge Reports/Research International study on utilities asked its sample of electricity customers: "I'd like you to tell me how believable your electric company is when it talks about the possible health or environmental effects of electric and magnetic fields" [1457]. On a scale of 1 to 7 , with 1 being "not at all believable" and 7 "very believable," the mean response was 4.4. Ranking the utility as "very believable" (6 or 7 ) were 19\%; ranking the utility as "not at all believable" ( 1 or 2$)$ were $11 \%$. The modal response was 5 ( $25 \%$ selected it).

A study in Louisiana found that $60 \%$ of its sample would turn to a power company for information about reducing power costs, while $20 \%$ did not know where to ask for such information [1430].

As with the oil industry, the public's perception of utility profits could affect its view of the industry. No recent data were located on this point; however, ORC produced some information in polls it took in 1979, 1981, and 1986. As is the case with oil company profits, the public tended to overestimate utility company profits. ORC asked: "What percent profit on each dollar of sales do you think your local electric utility company makes, after taxes?" $[1153,1171,1179]$. In 1979, ORC reported that the median 
net profit margin for electric utilities was 10.9 cents on a dollar of sales [1179]. The public estimated utility profit at almost four times that much, at 42 cents. In 1981, utility profits were again overestimated by a factor of almost 5; median net profits were 10.1 cents on each dollar of sales, and the mean public estimate was 49 cents. In 1986, the mean public estimate was 40 cents; actual profit (in 1985) was 12.1 cents [1153]. A 1981 survey reported that $55 \%$ thought their local electric utility company was making "too much profit" [1171].

Perhaps owing to their overestimate of utility company profits, as well as the monopoly status of utility companies, most customers favor regulating utilities. Eighty percent of a 1984 sample knew that a federal or state agency regulated how much gas and electric utilities could charge and how much profit they could make [1182]. Most (73\%) agreed in 1990 that the electric power industry should be allowed "to raise or lower their prices or rates ... only with government permission" [1555]. That same year, 37\% responded that the electric power industry "does not have enough government regulation now," while $43 \%$ thought the amount of regulation was "about right" [1555]. This bore out earlier 1985 results from an item that asked: "What do you think the government's role in ... the electric power . . . industry should be?" [1187]. Responding that the government should "control prices and profits but not own it" were 59\% of the sample.

Public expectations for utility roles in the future are changing. The Cambridge Reports study asked about the "most important things that different people may expect from their electric company" [1457]. The items, and the mean response on a scale of 1 (unimportant) to 7 (most important), are as follows:

- $\quad$ Restoring service quickly in an emergency (mean score: 6.3 )

- $\quad$ Reliable, high-quality service without frequent interruptions.(mean score: 6.1 )

- Making sure that its activities and facilities do not harm the environment (mean score: 6.1 )

- Employees who are understanding and courteous, and help customers when they have questions or problems (mean score: 6.1 )

- Careful planning for the future energy needs of the area (mean score: 5.9 )

- $\quad$ Taking proactive steps to protect and improve the environment (mean score: 5.8 )

- Programs and services-such as information, energy audits, or weatherization - to help customers control their energy use and the size of their bills (mean score: 5.6)

- Keeping the public informed about the company and its policies (mean score: 5.5 )

- Minimizing the public's exposure to electric and magnetic fields associated with electric transmission and distribution lines (mean score: 5.3 )

- Donations of money and volunteers to help community organizations (mean score: 4.7 ).

The theme of environmental protection and respectful service to customers and the community are touchstones of public expectations for electric utility performance in the years ahead. 


\section{Automobile Manufacturers}

Auto companies are relevant to energy, not only because of the "embodied energy" in their products, but also because of fuel efficiency. Higher miles-per-gallon cars mean lower operating costs, less carbon emissions, and less fossil-fuel consumption per mile traveled. At the time of the 1973-1974 Arab oil embargo, automobile manufacturers were primarily producing large cars; compact or subcompact cars (such as GM's Corvair) were considered unique and probably unsafe. A small amount of data on the reputation enjoyed by auto companies was located in the data set for this analysis.

As Table 5-3 shows, overall favorability toward the automobile industry has increased by 23 points (from $51 \%$ to $74 \%$ ) between 1981 and 1990 [1555]. In terms of specific companies asked about, Ford went up 16 points (from $57 \%$ to $73 \%$ "highly" or "moderately" favorable) and GM went up 14 points (from $64 \%$ to $78 \%$ ) between 1980 and 1991 [1553].

Table 5-4 shows that foreign automobile companies were regarded as superior to domestic ones in terms of "value for the dollar of the products or services they offer" [1543]. Sixty-two percent of a 1989 Roper sample gave foreign companies higher marks; however, domestic automobile companies were only 3 points behind. In terms of creating innovative products, $74 \%$ gave foreign makers good marks and $61 \%$ gave domestic ones good marks. Finally, in terms of "the quality of products or services they sell to consumers," foreign makers ranked 10 points higher (at 68\%) than their domestic counterparts (58\%). Responses on these factors suggest some of the reasons behind the superior overall favorability ratings for foreign makers.

Poll findings since 1981 show that the public wants increased regulation of the automotive industry. Roper collected verbatim trend data using this item: "Now here is another list of industries. (Card shown) Would you tell me for each one whether you think there is too much government regulation of it now, or not enough government regulation now, or about the right amount of government regulation now?" [1555]. This item was repeated in 1981, 1984, 1987, and 1990. Those indicating that there was insufficient government regulation increased by 6 points, from $26 \%$ in 1981, 1984, and 1987 to $32 \%$ in 1990. However, $50 \%$ in 1990 stated that the amount of regulation was "about right." Opinion was divided about regulating industry profits $-50 \%$ responded that the automobile industry should be allowed to raise or lower its prices as it saw fit, while $44 \%$ said that it "should have to get permission from the government before raising or lowering their prices" [1555]. There are no data on perceived automobile company profits, however, in the data set. Anecdotally, though, much has been made in recent years about "sticker shock" in automobile showrooms.

Automobile companies seem to enjoy a somewhat more favorable public image than the other energy institutions; however, they are less central players, as well. 


\section{Chapter 6}

\section{Energy Alternatives}

\section{Background and Summary}

Overwhelmingly, the most recent available evidence from the past 2 to 3 years indicates that the public favors energy demand reduction first and foremost. Energy production is viewed as important, yet generally as secondary, unless it involves renewables or alternative fuels. The public's favorability toward and emphasis on policies to reduce demand has been increasing over the past few years.

Energy supply preferences appear to be increasingly environmentally driven. Although U.S. citizens are certainly concerned about the adequacy of energy supplies, they clearly favor a national energy policy that would emphasize energy efficiency and demand reduction over energy production. The public does not appear to be hesitant about mandating certain types of conservation options, which will be explored more fully in the sections on preferred buildings and transportation energy policy options in Chapters 8 and 10 . The chapter's empirical findings are summarized below.

Taken together, the surveys reported in this chapter offer considerable evidence that, when cost or price information is not included, renewable energy and energy efficiency have been the preferred energy alternatives since 1977, and that they remain so today. The data on preferences toward fossil fuels and nuclear energy from some items remains ambiguous. While no survey has found that the public prefers nuclear energy, coal, or oil over energy efficiency, renewable energy, and natural gas, sizable pluralities preferred nuclear energy and coal when survey questions offered no other options. The data appear to show, however, a decrease in public preference for fossil fuels (except natural gas) and nuclear energy, except for the 1989 data shown in Figure 6-B, appearing later in this chapter. This result is consistent with increasing environmental concerns (greenhouse effect, oil spills, nuclear accidents) and a perception that the Persian Gulf war was the effect of U.S. reliance on imported oil as a significant energy supply option. However, as the sections on public perceptions of nuclear energy show, the public has, for several years, consistently opposed the further development of nuclear energy.

The persistent trend in public preferences for renewable energy supply and energy efficiency over the past 15 years should be interpreted in light of actual adoption of energy efficiency and renewable energy features in buildings and transportation. Adoption of conservation and renewables in residential buildings may have slowed, but it is not due to changes in public preference for these energy options relative to other options. The balance of the chapter presents the detailed preferred energy alternatives.

\section{National Energy Policy: Production versus Consumption}

The earlier reviews did not report findings on the dichotomy between reducing demand and increasing supply per se. However, a 1979 Harris survey reported that $60 \%$ preferred "a country which gets the energy it needs by better insulating its homes, driving cars that use less gasoline, and conserving more energy," whereas $26 \%$ preferred "a country which gets the energy it needs by digging more coal mines and drilling more oil, building more power plants, and producing more energy" [1254]. 
The "production versus consumption" debate was central in the formulation of the Bush Administration's National Energy Strategy (NES). Some 1990 polls taken while the NES was being developed asked the public its opinion of the NES or of President Bush's energy plan. Before reviewing these results, however, we might well ask how aware the public was of the plan's details. The NES was released in February 1991. In April, Roper asked: "Recently, President Bush announced his proposal for a national energy plan. How much have you heard or read about the President's new energy plan-have you heard a lot about it, a fair amount, only a little, or practically nothing about it?" [1559]. The plurality, 43\%, indicated they had heard "practically nothing" about the plan. Another $31 \%$ responded, "only a little," and $15 \%$ said, "a fair amount." Only $3 \%$ said they had heard "a lot" about the plan, while $8 \%$ said they didn't know.

This lack of knowledge was borne out by a Booz-Allen Hamilton (BAH) survey taken in April 1991. BAH reported that the NES was not well understood (Pasternack 1991). BAH reported that the perceived major objectives of the Bush NES were as follows:

- $\quad$ Developing U.S. sources (29\%)

- Legislation imposing stringent conservation (18\%)

- Encourage voluntary conservation by individuals (15\%)

- $\quad$ Encourage research and development (R\&D) (14\%)

- $\quad$ Promote nuclear energy (5\%)

- Encourage voluntary conservation by businesses $(4 \%)$

- Don't know (16\%).

Half of a Roper sample was asked: "Do you think President Bush should have gone further in the direction of conservation, or more in the direction of new energy supplies, or that he struck the right balance between conservation and new energy?" The plurality (38\%) said they didn't know; 22\% said the president had struck the "right balance"; $21 \%$ said he should have opted for more new energy; $19 \%$ said he should have stressed conservation more [1559].

The other half of the Roper sample was asked: "The President's energy plan is designed to bring supply and demand into balance by increasing energy supplies, rather than emphasizing lower consumption. Some have said our real problem is wasting energy and he should have gone further on conservation measures, because increasing energy supplies as he proposed will mean both rising energy costs and disruption of the environment. Others say the real problem is not having enough energy and he should have gone much more in the direction of encouraging new supplies of energy even if it means greater profits to the energy companies and relaxing environmental standards somewhat. Do you think President Bush should have gone further in the direction of conservation, or more in the direction of new energy supplies, or that he struck the right balance between conservation and new energy?" [1559].

When phrased in this way, this complex question elicited an 8-point higher response in favor of more emphasis on conservation (27\%) compared with the item asked the other half-sample (21\%). The same proportion said "new energy" (21\%) and "right balance" $(21 \%)$, while the "don't know" responses decreased by 7 points.

When asked specifics, majorities favored four of nine policies proposed in the NES. The four favored policies and the percentages favoring them were:

- Requiring auto manufacturers to produce cars that are more energy efficient $(80 \%)$

- $\quad$ Give financial incentives to companies to develop new types of fuel (68\%)

- Increase government spending on development of new energy supplies and technology (60\%)

- $\quad$ Pay consumers a bonus to trade in their older, less fuel-efficient cars (53\%). 
The options that failed to achieve majority favorability were as follows:

- Impose a new tax on cars that do not meet a required level of fuel efficiency (38\%)

- Make it easier for new nuclear power plants to get approval for energy production (35\%)

- $\quad$ Impose a tax on imported oil (33\%)

- $\quad$ Open up the Alaska National Wildlife Refuge (ANWR) in Alaska for oil drilling and exploration (31\%)

- $\quad$ Raise federal taxes on gasoline (11\%).

BAH reported that its April 1991 survey showed that "most people believe that developing energy supply is the most effective means of making the U.S. more energy independent" (Pasternack 1991). According to results of their survey, percentages selecting the different approaches as "extremely effective" or "very effective" were as follows:

- Develop U.S. sources (78\%)

- $\quad$ Encourage R\&D (72\%)

- Legislation with stringent conservation (53\%)

- $\quad$ Encourage voluntary conservation by businesses (48\%)

- $\quad$ Encourage voluntary conservation by individuals (48\%)

- Promote nuclear energy (43\%).

Some evidence supports the notion that alternative energy production options are favored more than conventional ones. Market Strategies September 1990 poll asked a national sample: "I know I am asking for 20-20 hindsight, but which of these things I just read do you think would have helped the most to make the confrontation with Iraq unnecessary?" (open-ended) [1035].

More than one-fifth (21\%) said: "Supported increased R\&D of energy sources other than oil"-the plurality response. Another production-related option was selected by $13 \%$ : "Given more incentives to oil companies for exploration and recovery operations in places outside the Middle East." Conservation options were selected by fewer than $10 \%$ each; the ones offered were: "Waged a campaign to increase energy efficiency and conservation in autos, homes, offices, and factories (7\%); "Continued the mandatory annual improvement in miles per gallon of U.S. autos, discontinued in 1984" (3\%); and "Put a tax on foreign oil of an added 5 cents per gallon more each year for ten years" $(93 \%)$.

A Hart and Teeter Research Companies poil for NBC News/The Wall Street Journal in August 1990 asked about proposals that "America should pass in order to avoid an energy shortage" [1193]. Five production and consumption options were listed; the most popular was "Develop tougher conservation measures that would mean less gas consumption."

Finally, a December 1990 survey (prior to the release of the NES) queried respondents about 19 possible national policy options "to reduce our dependence on oil," some of which favored increased energy production and some conservation [1025]. Tables 6-1a and 6-1b show the results for the most and least preferred conservation options and the most and least preferred production options, organized by policy type (incentive, regulation, tax, federal spending, or permitting). Table 6-1a and Table 6-1b are rich in information concerning the shape of public opinion concerning energy policy and the limitations in measuring public preferences about it.

Without question, the results document strong public preferences for policies fostering demand reduction over supply increases. For example:

- All but one of the top ten preferred policy options are conservation options; the one exception was biofuels production, a renewable resource. 
Table 6-1a. Most Preferred Energy Policies to Decrease Demand and Increase Production ${ }^{\mathrm{a}}$

"Let me read you some policies the government might try as part of a national energy strategy. For example, here are several things the United States could do to reduce our dependence on oil. Please tell me whether you strongly favor, somewhat favor, somewhat oppose, or strongly oppose each one as a method of reducing our dependence on oil. " b [19 options listed, 12 for decreasing demand and 7 for increasing production] (December 1990) [1025] (Options are paraphrased)

\begin{tabular}{|c|c|c|c|}
\hline \multicolumn{4}{|c|}{$\begin{array}{l}\text { Most Preferred Options to Decrease Demand } \\
\text { (Percentage Favoring) (Majorities Only) (Rank) }\end{array}$} \\
\hline Incentive & Regulation & Tax & Spending \\
\hline $\begin{array}{l}\text { Re-establish solar tax } \\
\text { credits ( } 86 \% \text { favor; } \\
2 \text { nd })^{c}\end{array}$ & $\begin{array}{l}\text { Require building efficien- } \\
\text { cy standards to be met } \\
\text { for VA/FHA mortgage } \\
\text { financing ( } 91 \% \text { favor; } \\
1 \text { st) }\end{array}$ & $\begin{array}{l}\text { "Gas guzzler" tax } \\
\text { ( } 62 \% \text { favor; } 9 \text { th) }\end{array}$ & $\begin{array}{l}\text { Expand federal } \\
\text { spending on mass } \\
\text { transit ( } 80 \% \text { favor; } \\
\text { 6th) }\end{array}$ \\
\hline $\begin{array}{l}\text { Provide a tax rebate on } \\
\text { fuel-efficient new cars } \\
\text { ( } 82 \% \text { favor; } 5 \text { th) }\end{array}$ & $\begin{array}{l}\text { Increase CAFE standards } \\
\text { to } 40 \text { mpg by } 2000(84 \% \\
\text { favor; } 4 \text { th) }\end{array}$ & $\begin{array}{l}\text { Increase gas tax } \$ 0.10 \\
\text { for environmental fund } \\
\text { (56\% favor; 10th) }\end{array}$ & $\begin{array}{l}\text { Provide federal funds } \\
\text { to expand car pooling } \\
\text { (74\% favor; } 7 \text { th) }\end{array}$ \\
\hline $\begin{array}{l}\text { Provide cash to scrap } \\
\text { old cars ( } 72 \% \text { favor; } \\
\text { 8th) }\end{array}$ & $\begin{array}{l}\text { Require federal and state } \\
\text { regulators to provide } \\
\text { incentives for utility } \\
\text { investment in DSM } \\
\text { programs ( } 86 \% \text { favor; } \\
\text { 3rd) }\end{array}$ & $\begin{array}{l}\text { Tax oil imports } \\
\text { (50\% favor; } 11 \text { th) }\end{array}$ & \\
\hline \multicolumn{4}{|c|}{$\begin{array}{l}\text { Most Preferred to Increase Energy Production Options } \\
\text { (Percentage Favoring) (Majorities Only) (Rank) }\end{array}$} \\
\hline \multicolumn{4}{|l|}{$\begin{array}{l}\text { Provide incentives to } \\
\text { use or develop biofuels } \\
\text { ( } 89 \% \text { favor; } 1 \text { st) }\end{array}$} \\
\hline $\begin{array}{l}\text { Provide tax breaks to } \\
\text { oil companies to } \\
\text { increase domestic oil } \\
\text { and gas production } \\
\text { ( } 50 \% \text { favor; } 2 \text { nd) }\end{array}$ & & & \\
\hline
\end{tabular}

Source: Constructed by author using data from Research/Strategy/Management and Greenberg/Lake, The Analysis Group.

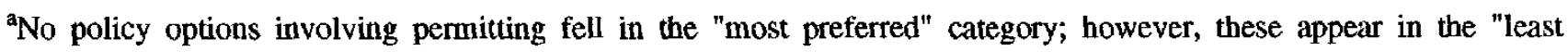
preferred" category.

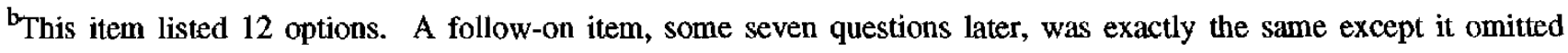
reference to dependence on oil.

${ }^{c}$ Ordinal numbers in parentheses refer to ranking by proportion favoring the option. Options to decrease demand and to increase production are ranked separately. 
Table 6-1b. Least Preferred Energy Policies to Decrease Demand and Increase Production ${ }^{\mathrm{a}}$

\begin{tabular}{||l|l||}
\hline \multicolumn{2}{|c|}{$\begin{array}{c}\text { Least Preferred Options } \\
\text { (Percentage Opposing) (Rank) }\end{array}$} \\
\hline Tax & Permitting \\
\hline \hline $\begin{array}{l}\text { Phase in \$0.50/gal. federal gas tax for an } \\
\text { environmental fund (60\% oppose; 12th) }\end{array}$ & $\begin{array}{l}\text { Accelerate oil development in ANWR (47\% } \\
\text { favor, 46\% oppose; 3rd) }\end{array}$ \\
\hline & $\begin{array}{l}\text { Build more nuclear power plants in the U.S. } \\
\text { (62\% oppose; 4th) }\end{array}$ \\
\hline & $\begin{array}{l}\text { Open more offshore areas to oil drilling even if it } \\
\text { caused environmental damage (72\% oppose; 5th) }\end{array}$ \\
\hline & $\begin{array}{l}\text { Increasing coal use even if it caused } \\
\text { environmental damage (74\% oppose; 6th) }\end{array}$ \\
\hline & $\begin{array}{l}\text { Develop oil reserves on publicly owned } \\
\text { wilderness lands, even if this caused some } \\
\text { environmental damage (79\% oppose; } 7 \text { th) }\end{array}$ \\
\hline
\end{tabular}

Source: Constructed by author using data from Research/Strategy/Management and Greenberg/Lake, The Analysis Group.

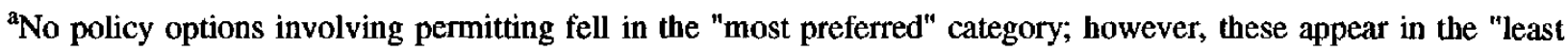
preferred" category.

bo incentive, regulation, or spending policy options fell in the "least preferred" category.

- All but one of the six least preferred options were production options; the one exception provided for a $\$ 0.50 /$ gal. increase in the federal gasoline tax, the least preferred policy option.

- Regulation/mandating was involved in three of the top four policy options favoring conservation.

- Incentives were involved in the second, fifth, and eighth favored options.

- Increased federal spending was called for in only two of the top 11 options.

- Increasing taxes, while still favored by majorities, were the lower-ranked options.

The most opposed conservation option was phasing in a $\$ 0.50 /$ gal. federal gasoline tax for an environmental fund ( $60 \%$ were in opposition). The most opposed production options were developing oil reserves in wilderness areas (79\% opposed); increasing coal use (74\% opposed); and offshore oil drilling (72\% opposed). Opinion was divided on drilling in the Alaska National Wildlife Refuge (ANWR) (47\% favored, $46 \%$ opposed).

The most recent data on demand reduction versus supply enhancement were collected in March 1992. Figure 6-A shows that $63 \%$ believed increased demand for electricity can be met through using electricity more efficiently [1561]. 
"Some people say that more power plants must be built in the next several years to meet increased demand for electricity or we will have power shortages in many areas. Other people say that we can meet increased demand by using the electricity from existing power plants more efficiently. Which point of view is closer to your own?" (March 1992) [1561]

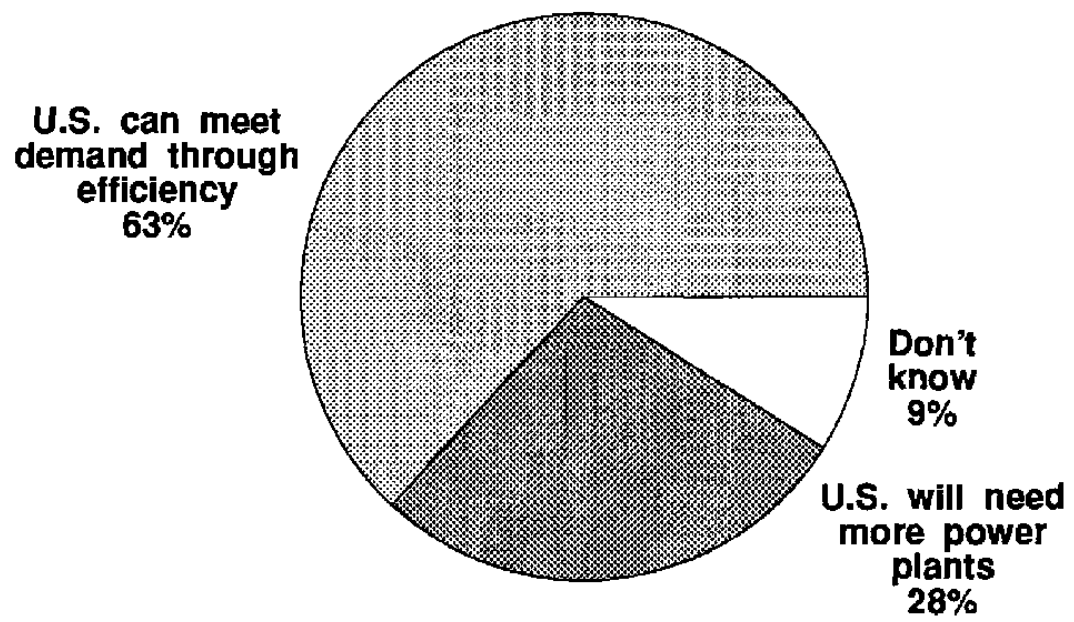

Source: (C) 1992. Used with permission of Frederick/Schneiders, Inc.

Figure 6-A. Preferences for efficiency or more power plants

Recent polls confirm the preference for policies that foster efficient energy use. Table 6-2 shows results from a March $1991 \mathrm{ABC}$ News/The Washington Post poll, showing that approximately two-thirds of a national sample favored requiring "more efficient cars and other fuel conservation standards," and about a quarter favored encouraging companies to "increase supplies of oil, gas, and nuclear power" [1504]. However, the item confounded the choice between policy emphasis on efficiency or production and policy emphasis on regulation or incentives. If we assume for the sake of argument that the public generally prefers policies encouraging voluntary action rather than regulation and mandatory action, then the results showing significantly higher percentages favoring policies emphasizing efficiency, even when they involved regulation, are particularly striking.

Research/Strategy/Management (RSM) and Greenberg/Lake, The Analysis Group queried a national sample in December 1990: "Some people say the Iraq crisis demonstrates the need to increase our oil supply by opening up domestic oil and gas exploration off our coasts and in natural wilderness areas. Others say it makes more sense to reduce our demand for oil by requiring more fuel-efficient cars, encouraging car pooling and promoting mass transit alternatives. Which point of view comes closest to your own opinion of what we ought to do?" [1025]. Three-quarters of the sample selected reducing demand/more efficiency; one-fifth chose increasing supply/open drilling; 4\% didn't know. Favoring reduced demand were conservative Republicans (76\%), moderate/liberal Republicans (79\%), conservative Democrats (65\%), and moderate/liberal Democrats (79\%). Reducing demand was slightly more favored in the West (78\%) and slightly less favored in the South (70\%); the Northeast and Midwest fell in between [1025]. 
Table 6-2. Policy Preferences: Increase Supplies or Decrease Demand

"Now l'm going to mention two specific issues that likely will be discussed in the weeks ahead. The first issue is a federal policy on energy . . . President Bush has recommended . . . that the federal government should pass laws that encourage companies to increase supplies of oil, gas, and nuclear power. Others say that the federal government should pass laws that require more efficient cars and set other fuel conservation standards. Which of these two plans would you, personally, favor?" (March 1991) [1504]

\begin{tabular}{|c|c|c|c|}
\hline Policy option & $\begin{array}{l}\text { Half sample } \\
\mathbf{X}\end{array}$ & $\begin{array}{l}\text { Half sample } \\
\text { Y }\end{array}$ & $\begin{array}{c}\text { Mean response } \\
\text { for both } \\
\text { samples }\end{array}$ \\
\hline \multicolumn{4}{|l|}{ Proportion responding (\%) } \\
\hline $\begin{array}{l}\text { Require more efficient cars and set } \\
\text { other fuel conservation standards }\end{array}$ & 72 & 65 & 68.5 \\
\hline $\begin{array}{l}\text { Encourage companies to increase } \\
\text { supplies of oil, gas, and nuclear power }\end{array}$ & 21 & 28 & 24.5 \\
\hline Neither (volunteered) & 2 & 2 & 2 \\
\hline Both equally (volunteered) & 4 & 4 & 4 \\
\hline Don't know & 1 & 1 & 1 \\
\hline Totals & 100 & 100 & 100 \\
\hline $\mathbf{N}=$ & $(1215)$ & $(1215)$ & $(2430)$ \\
\hline
\end{tabular}

Source: Constructed by author using data from $\mathrm{ABC}$ News and The Washington Post.

Similarly, Penn and Schoen Associates (for Texaco) asked a national sample (in August 1990): "Do you think the government needs to adopt a new national energy policy to encourage conservation and to reduce U.S. dependence on foreign oil or is such a policy not really needed?" [1206]. Responding in favor of such a policy were $87 \%$; only $10 \%$ said that it was not really needed. In the same survey, $86 \%$ said they favored "embarking on a voluntary effort to ask Americans to conserve fuel"; $13 \%$ opposed such an effort.

Another question in this genre, asked in December 1990, was: "In order to help provide for the country's overall need for energy in the future, which do you think should be emphasized most?" Table 6-3 shows the results. The production of energy using alternative sources was the favored option $(59 \%)$, followed by demand reduction (25\%), and more production of fossil fuels $(11 \%)$. This pattem of opinion held true for all regions of the country [1025]. 
Table 6-3. Preferences for Energy Production and Demand Reduction by Region

"In order to help provide for the country's overall need for energy in the future, which do you think should be emphasized most?" (December 1990) [1025]

\begin{tabular}{|l|c|c|c|c|c||}
\hline Option & Northeast & Midwest & South & West & Nation \\
\hline Proportion responding (\%) & \multicolumn{2}{|l|}{} \\
\hline \hline $\begin{array}{l}\text { Finding different energy } \\
\text { sources such as solar and wind }\end{array}$ & 63 & 59 & 55 & 60 & 59 \\
\hline $\begin{array}{l}\text { Finding ways to use less } \\
\text { energy }\end{array}$ & 22 & 26 & 25 & 27 & 25 \\
\hline $\begin{array}{l}\text { Finding ways to produce more } \\
\text { oil, gas, and coal }\end{array}$ & 10 & 12 & 13 & 8 & 11 \\
\hline Don't know & 5 & 4 & 7 & 5 & 5 \\
\hline
\end{tabular}

Source: Research/Strategy/Management and Greenberg/Lake, The Analysis Group.

RSM queried a national sample in October 1989: "In order to reduce carbon dioxide emissions and provide for the country's overall need for energy in the future, which do you think should be employed most ... [rotated] . . . finding ways to produce more traditional energy sources like coal, gas and oil . . . or ... finding ways to use energy more efficiently and to use renewable energy sources like solar and wind power?" [1072]. Again, 83\% chose using more efficiency and renewables, while $12 \%$ opted for more production of coal, gas, and oil.

RSM repeated, in December 1990, an item similar to one asked in October 1989: "Some say new power plants must be built in the next several years to meet increased demand or we will have power shortages in many places. Others say that using the electricity we have more efficiently could make it unnecessary to build new power plants. Which point of view is closest to your own?" [1025]. The October 1989 item added, after the reference to new power plants, the phrase "benefit the environment, and save consumer's money" [1072]. This phrasing elicited a $76 \%$ favorable response to efficiency and a $20 \%$ favorable response to more power plants. In 1990, the responses were $66 \%$ in favor of efficiency and $28 \%$ in favor of new power plants. To speculate, the 10-point difference in response to efficiency reflected the difference in wording; the 1989 item listed three benefits, while the 1990 item listed only one.

Gallup polls in 1987 and 1988 repeated the item: "In order to help provide for the country's overall need for energy in the future, which do you think should be emphasized most: finding ways to produce more energy, or finding ways to use less energy?" [1431]. In both years, half the samples selected using less energy, while $38 \%$ in 1988 and $39 \%$ in 1987 chose producing more energy. About $10 \%$ in both years chose "both." 
Table 6-4 presents trend results from two national polls, one in 1978 and one in 1987, and compares the results with 1988 polls of public interest and energy industry leaders [1534]. The item was: "Should the United States emphasize finding ways to produce more energy or finding ways to use less energy to meet the country's overall need for energy?" In 1978, 57\% preferred finding ways to produce more energy, $30 \%$ favored using less energy, and 10\% volunteered that "both" should be done. In 1988, however, $50 \%$ preferred using less energy and $39 \%$ producing more energy; $9 \%$ volunteered "both."

The results of the 1987 leaders' polls showed that, on this fundamental point of energy policy, public interest leaders are more nearly aligned with the public's preferences than are energy industry leaders. Whereas $50 \%$ of the public preferred a policy emphasis on efficiency, $89 \%$ of public interest leaders preferred this, but only $24 \%$ of energy industry leaders shared this preference. When a plurality of $39 \%$ of the public chose producing more energy, $6 \%$ of public interest leaders selected this option, while twothirds of the energy industry leaders selected it.

How important does the public believe achieving energy independence is? No data specifically addressed this question. Table 6-5 presents trend data from Gallup items from 1982 and 1986 asking about the importance of "securing adequate supplies of energy" [1292, 1321, 1322]. In 1982, data were also collected from opinion leaders. Virtually no change in public opinion occurred during the 4 years.

Table 6-4. Public and Leader Preferences on Energy Efficiency versus Energy Production "Should the United States emphasize finding ways to produce more energy or finding ways to use less energy to meet the country's overall need for energy?" [1534]

\begin{tabular}{||l|c|c|c|c||}
\hline Options & $\begin{array}{c}1978 \\
\text { Harris poll }\end{array}$ & $\begin{array}{c}1988 \\
\text { Gallup poll }\end{array}$ & $\begin{array}{c}1988 \\
\text { Public interest } \\
\text { leaders }\end{array}$ & $\begin{array}{c}1988 \\
\text { Energy industry } \\
\text { leaders }\end{array}$ \\
\hline Proportion responding (\%) & \multicolumn{3}{|l||}{} \\
\hline \hline $\begin{array}{l}\text { Finding ways to produce } \\
\text { more energy }\end{array}$ & 57 & 39 & 6 & 67 \\
\hline $\begin{array}{l}\text { Finding ways to use less } \\
\text { energy }\end{array}$ & 30 & 50 & 89 & 24 \\
\hline Both (volunteered) & 10 & 9 & 2 & 3 \\
\hline Neither (volunteered) & - & 1 & - & - \\
\hline Don't know & 3 & 1 & 3 & 100 \\
\hline \hline Totals & 100 & 100 & 100 & $(161)$ \\
\hline
\end{tabular}

Source: Constructed by the author using data from Gallup and the League of Women Voters.

${ }^{a} \mathrm{~N}$ not reported for this survey. 
Table 6-5. Perceptions of U.S. Foreign Policy Goals, 1982 and 1986

"Please say whether you think that securing adequate supplies of energy is a very important, somewhat important, or not an important policy goal at all of the United States."

\begin{tabular}{||l|c|c|c||}
\hline Category & $\begin{array}{c}\text { General public } \\
\mathbf{1 0 / 2 9 / 8 2}\end{array}$ & $\begin{array}{c}\text { Opinion leaders } \\
\mathbf{1 1 / 3 / 8 2}\end{array}$ & $\begin{array}{c}\text { General public } \\
\mathbf{1 0 / 3 0 / 8 6}\end{array}$ \\
\hline Proportion responding (\%) & \multicolumn{3}{|l||}{} \\
\hline \hline Very important & 70 & 72 & 69 \\
\hline Somewhat important & 23 & 27 & 25 \\
\hline Not at all important & 3 & 2 & 3 \\
\hline Don't know & 5 & 0 & 3 \\
\hline \hline Total ${ }^{a}$ & 101 & 101 & 100 \\
\hline & $(1547)$ & $(341)$ & $(1585)$ \\
\hline \hline Study number & {$[1322]$} & {$[1321]$} & {$[1292]$} \\
\hline
\end{tabular}

Source: Constructed by author using data from Gallup.

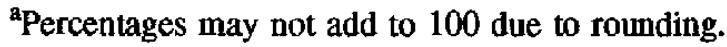

Almost everyone said securing adequate energy supplies was "very important" or "somewhat important." Opinion leader results followed closely those from the general public sample. No up-to-date data on this point were located, and opinion on this point could have changed since 1986.

In an item related to this debate, Gallup asked a national sample (in 1987), and the League of Women Voters asked public interest and energy industry leaders (in 1988), about the preferred role of the federal government in energy policy [1534]. Public opinion was divided on this point: $46 \%$ said that "government should take a more active role"; $47 \%$ said energy supplies should be "determined by the marketplace." Yet, among public interest leaders, $82 \%$ said the government should be more active, and $44 \%$ of the energy industry leaders agreed with them. A majority of industry leaders, however, wanted marketplace determination of energy supplies, compared with $12 \%$ of public interest leaders. (Data are shown in Table 6-6.) The League of Women Voters report stated that the poll found few satisfied with governmental efforts on behalf of securing adequate energy supplies. Industry respondents wanted less regulation and more incentives. Public interest respondents complained that government programs have favored fossil fuels and nuclear energy rather than renewable energy sources.

\section{Comparisons among Energy Alternatives}

In 1980, when data were last reviewed, solar energy and energy conservation were the most preferred energy alternatives (Farhar et al. 1979; Farhar et al. 1980; Farhar-Pilgrim and Unseld 1982). In 1987, 
Table 6-6. Support for More Government Action on Energy ${ }^{\mathbf{a}}$

\begin{tabular}{|c|c|c|c|}
\hline Action item & $\begin{array}{c}1987 \\
\text { General Public }\end{array}$ & $\begin{array}{c}1988 \\
\text { Public interest leaders }\end{array}$ & $\begin{array}{c}1988 \\
\text { Industry leaders }\end{array}$ \\
\hline \multicolumn{4}{|c|}{ Proportion responding (\%) } \\
\hline $\begin{array}{l}\text { Government should } \\
\text { take a more active } \\
\text { role }\end{array}$ & 46 & 82 & 44 \\
\hline $\begin{array}{l}\text { Energy supplies } \\
\text { should be determined } \\
\text { by the marketplace }\end{array}$ & 47 & 12 & 55 \\
\hline Don't know & 7 & 6 & 1 \\
\hline Total & 100 & 100 & 100 \\
\hline $\mathbf{N}=$ & (1103) & $(110)$ & $(161)$ \\
\hline
\end{tabular}

Source: Constructed by author using data from Gallup and the League of Women Voters [1534].

${ }^{\text {aItem }}$ wording not reported. Data from the two surveys were collected three months apart, in December 1987 and March 1988.

respondents were still choosing solar energy as the preferred form, as shown in Table 6-7. When a halfsample of respondents ${ }^{1}$ asked which energy source respondents would like to see developed to "replace foreign oil five years from now," 54\% selected solar energy, $30 \%$ selected hydropower, $22 \%$ selected wind, and $16 \%$ selected energy from ocean tides, all of which are renewable energy technologies. Unfortunately, Roper did not include energy efficiency in the list of response options [1078].

Researchers have documented preferred energy alternatives using verbatim trend items. The Roper Organization replicated such an item in 1979 two times, and again in 1980, 1981, 1982, 1983, 1984, 1985, 1987, and 1989 (see Figure 6-B). Respondents were asked: "Which of these energy sources do you think are realistically possible to use for replacing foreign oil during the next five years?" In April 1979, respondents selected coal most frequently (68\%), followed by solar energy (65\%), offshore U.S. oil wells $(51 \%)$, and nuclear energy (50\%).

Each of these proportions had fallen by May 1979, as the Carter Administration was drawing to a close. In March 1981, after President Reagan was elected, more respondents selected virtually all of the energy supply options. Coal remained the top pick $(71 \%)$, followed by solar energy (67\%). By this time, the proportions selecting the other energy options had fallen off considerably. By May 1982, solar energy $(61 \%)$ just passed coal $(60 \%)$ in being selected as a realistic source.

${ }^{1}$ A half-sample occurs when one question is asked of half of a polling organization's normal national probability sample; an alternate question is usually asked of the other half-sample. The two questions are normally rotated. The half-sample is still a national probability sample; however, the sampling error is somewhat higher than for responses from the full sample. 
Table 6-7. Energy Source Development Preferences

"Which of these energy sources would you most like to see developed so that we can replace foreign oil five years from now?" (March 1987) [1078]

\begin{tabular}{|c|c|}
\hline Energy source & $\begin{array}{c}\text { Most like to see } \\
(\%)\end{array}$ \\
\hline Solar energy & 54 \\
\hline Water power from dams on rivers & 30 \\
\hline Oil from offshore U.S. oil wells & 25 \\
\hline Wind power & 22 \\
\hline Coal & 20 \\
\hline Nuclear energy & 16 \\
\hline Energy from ocean tides & 16 \\
\hline None of these & 1 \\
\hline Don't know & 6 \\
\hline$N=$ & (1980) \\
\hline
\end{tabular}

Source: Roper Organization.

apercentages add to more than 100 due to multiple responses.

The last data in this sequence were collected beginning March 11, 1989, and ending March 18, 1989, immediately prior to the Valdez oil spill off the coast of Alaska on March 24, 1989. Solar energy remained at the top of the list $(51 \%)$, followed by nuclear energy (47\%), offshore U.S. oil (43\%), coal $(36 \%)$, hydropower $(31 \%)$, wind power $(21 \%)$, shale oil $(18 \%)$, and energy from ocean tides $(13 \%)$.

Several interesting features of the 1989 data are as follows:

- All of the energy sources increased in frequency of mention as realistic

- Solar energy remained the most preferred energy supply source, increasing 4 points (to $51 \%$ ) in 2 years, and it remained the only source selected by a majority

- The proportion mentioning nuclear energy increased 22 points (to $43 \%$ ) in 2 years

- The proportion favoring offshore oil wells increased 9 points to $43 \%$ (prior to the Valdez incident). 
"Which of these energy sources do you think are realistically possible to use for replacing foreign oil during the next five years?"

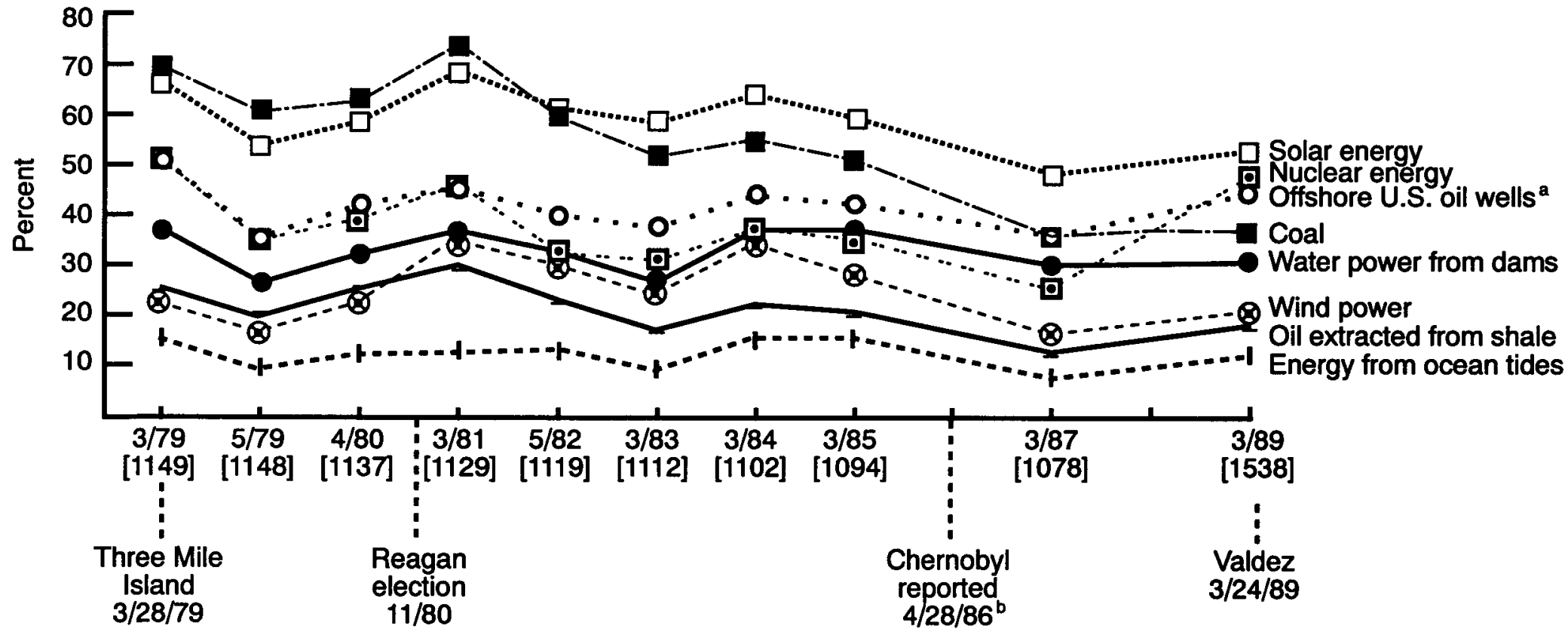

Source: Constructed by author based on data from the Roper Organization.

Note: Study numbers are in brackets below survey date.

$a_{1} 1989$ data collected in 1989 prior to the Valdez oil spill.

Actual accident occurred 4/26/86.

Figure 6-B. Preferred energy alternatives, 1979-1989 
Apparently, confidence in all of the energy supply options fell off between 1979 and 1987. As noted, fewer respondents selected each of the energy sources over time. ${ }^{2}$ However, some sources fell further than others. For example, respondents selecting both nuclear energy and coal fell by half, while those selecting solar energy fell by $28 \%$, offshore oil by $33 \%$, wind power by $23 \%$, shale oil by $44 \%$, energy from ocean tides by $33 \%$, and hydropower by $19 \%$.

However, this trend was reversed between 1987 and 1989. One may speculate that the widespread attention devoted to greenhouse gas emissions and global warming, with fossil fuels as their cause, may have affected public preferences for energy alternatives. The increase in favorability toward nuclear energy as a realistic replacement for foreign oil within 5 years is the most dramatic reversal of opinion on nuclear energy observed in the entire data set. This increase in selection of nuclear energy in 1989 might have been a function of concern about greenhouse gas emissions from fossil fuel burning. However, this is only one data point, and it is an anomaly. Most of the other recent data on nuclear energy, presented in Chapter 7 on the utility sector, show that the majority of the public generally considers nuclear energy to be a high-risk technology and does not favor its use.

The types of items that lead to least response bias are those that include the major energy alternatives, including efficiency. In 1989 and in 1990, two national polls by RSM and The Analysis Group replicated this item: "Suppose you were the person responsible for funding research and development in the Department of Energy. Four areas want your money for R\&D-oil and coal, nuclear energy, energy conservation, and solar, wind and other renewable energy sources. Which of these four would you fund with the most money-[rotate] oil and coal, nuclear energy, energy conservation, or solar, wind and other renewable energy sources?" Table 6-8 shows the results. The proportion selecting renewables to receive the most funding increased from $38 \%$ to $47 \%$ between 1989 and 1990 . Combining the most funding and second most funding choices, in $199075 \%$ selected renewables, two-thirds energy conservation, $26 \%$ oil and coal, and $25 \%$ nuclear energy [1025; 1072].

Frederick/Schneiders, Inc. conducted a national survey of voters from March 18-21, 1992 [1561]. Seventy-six percent named solar and other renewable energy sources, energy efficiency, and natural gas combined as their choice for $R \& D$ funding priorities. Combined responses for nuclear energy, coal, and oil totaled $19 \%$. Figure 6-C summarizes the data.

Renewables and efficiency ${ }^{3}$ are the preferred future energy sources in all regions of the country. Table 6-9 and Figure 6-D show the data from a December 1990 poll [1025] asking which energy alternatives should be emphasized most. Nationally, renewables were selected most frequently (59\%) and efficiency second most frequently $(25 \%)$. The variation by region in preference for renewables was 8 points (from $55 \%$ in the South to $63 \%$ in the Northeast) and for efficiency was 5 points (from $22 \%$ in the Northeast to $27 \%$ in the West).

\footnotetext{
${ }^{2}$ Once again it was unfortunate that energy efficiency was not included in the list of "energy sources" from which respondents were asked to choose.

${ }^{3}$ Technically, energy efficiency and energy conservation can be distinguished, where conservation means using less energy and efficiency means gaining more output for the level of energy used. In this report, however, the two terms are used interchangeably unless otherwise noted. After 1981, the U.S. Department of Energy substituted the term "efficiency" for "conservation" because officials thought the public viewed conservation as "sacrifice," which they thought was unpopular.
} 
Table 6-8. Preferred Research and Development on Energy Sources

"Suppose you were the person responsible for funding research and development in the Department of Energy. Four areas want your money for research and development-oil and coal, nuclear energy, energy conservation, and solar, wind and other renewable energy sources. Which of these four would you fund with the most money-(rotate) oil and coal, nuclear energy, energy conservation, or solar, wind and other renewable energy sources?"

\begin{tabular}{||l|c|c|c|c|c|c||}
\hline \multirow{2}{*}{ Energy option } & \multicolumn{2}{|c|}{ Most funding } & Second most funding & \multicolumn{2}{c||}{ Total a $^{\text {a }}$} \\
\cline { 2 - 7 } & 1989 & 1990 & 1989 & 1990 & 1989 & 1990 \\
\hline Proportion responding (\%) & 38 & 47 & 31 & 28 & 69 & 75 \\
\hline \hline Renewables & 34 & 28 & 35 & 39 & 69 & 67 \\
\hline Energy conservation & 15 & 10 & 14 & 15 & 29 & 25 \\
\hline Nuclear energy & 9 & 12 & 15 & 14 & 24 & 26 \\
\hline Oil and coal & 4 & 3 & 4 & 3 & 8 & 6 \\
\hline Don't know/refused & 100 & 100 & 99 & 99 & 199 & 199 \\
\hline Total ${ }^{\text {b }}$ & $(1200)$ & $(1200)$ & $(1200)$ & $(1200)$ & $(1200)$ & $(1200)$ \\
\hline & {$[1072]$} & {$[1025]$} & {$[1072]$} & {$[1025]$} & {$[1072]$} & {$[1025]$} \\
\hline \hline Study number & & & & & & \\
\hline
\end{tabular}

Source: Constructed by author using data from Research/Strategy/Management.

aTotal of "most" and "second most."

bercentages may not add to 100 due to rounding; totals of the columns add to 199 because they include proportions from both "most" and "second most" funding items (200\% except for rounding).

Nevertheless, the public apparently does not view renewables as a panacea. For example, a 1990 national poll asked: "Think about renewable sources of energy such as solar or wind power. Can renewable energy sources produce enough energy to meet a lot of our energy needs, some of our needs, or only a little of our needs by the year 2000?" [1025]. A quarter responded "a lot," 44\% said "some," $24 \%$ said "a little," and 7\% didn't know. This pattern of response held across all regions of the country.

Cambridge Reports queried a national sample in September 1990 about the degree of perceived environmental threat from seven potential sources of electricity [1457]. Figure 6-E displays the results. Figure 6-E arranges the electricity sources in order of increasing perceived environmental threat from left to right. Two-thirds of respondents said solar represented no environmental threat; $51 \%$ said nuclear power posed a "large environmental threat." Solid waste incineration (waste-to-energy), coal, oil, and nuclear power are viewed as posing the most threat to the environment. 


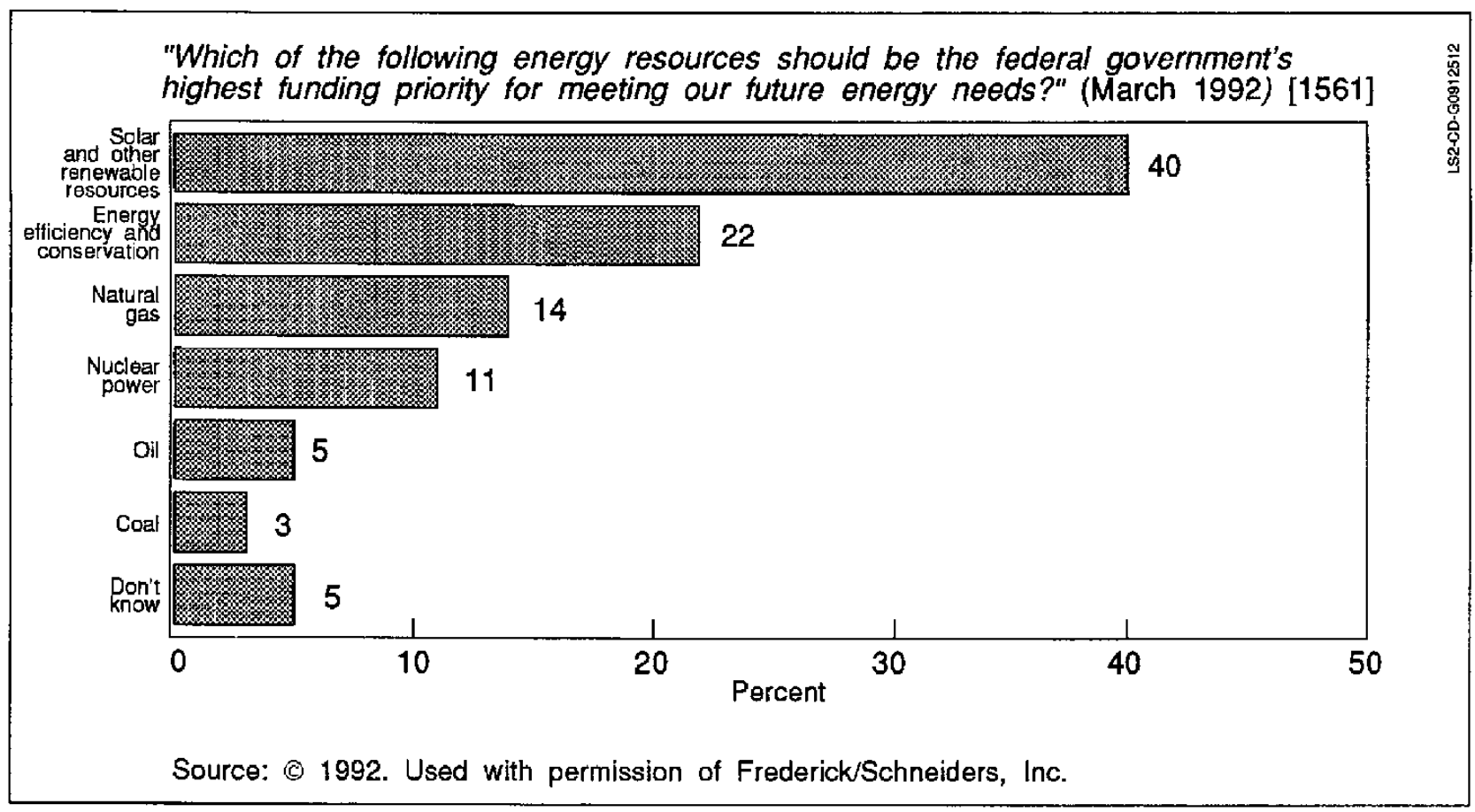

Figure 6-C. Funding priority of energy resources

A 1989 survey asked respondents: "In order to reduce carbon dioxide emissions and provide for the country's overall need for energy in the future, which do you think should be employed most-finding ways to produce more traditional energy sources like coal, gas and oil . . . or . . . finding ways to use energy more efficiently and to use renewable energy sources like solar and wind power?" Eighty-three percent selected energy efficiency and renewable energy; $12 \%$ selected greater production of fossil fuels [1072].

The League of Women Voters cited a 1987 Gallup survey that asked respondents to indicate from a list of energy sources which one the nation should make the greatest effort to develop over the next 20 years [1534]. More than half (54\%) selected solar energy. Other responses were: nuclear energy, 12\%; natural gas, $12 \%$; coal, $10 \%$; and domestic oil, $8 \%$.

These results contrast with those from the League of Women Voters' questioning of public interest and energy industry leaders on their preferences for future energy sources (see Table 6-10). Interestingly, both public interest and industry leaders strongly favored energy efficiency and renewable energy technology ${ }^{4}$ development. Marked differences occurred, however, in leaders' favorability to developing coal, oil, and nuclear energy. While $91 \%$ of industry leaders favored developing coal, only $35 \%$ of public interest leaders did. Similarly, $82 \%$ of industry leaders favored developing domestic oil, compared with $31 \%$ of public interest leaders. Favoring nuclear energy development were $81 \%$ of industry leaders, but only $5 \%$

\footnotetext{
${ }^{4}$ The renewable energy technologies included on the response list are noted in Table 6-10.
} 
Table 6-9. Preferred Energy Alternatives by Region

"In order to help provide for the country's overall need for energy in the future, which do you think should be emphasized most?" (December 1990) [1025]

\begin{tabular}{||l|c|c|c|c|c||}
\hline \multirow{2}{*}{ Energy Option } & \multicolumn{5}{|c|}{ Percentage responding } \\
\cline { 2 - 6 } & Nation & Northeast & Midwest & South & West \\
\hline \hline $\begin{array}{l}\text { Finding different energy sources } \\
\text { such as solar and wind }\end{array}$ & 59 & 63 & 59 & 55 & 60 \\
\hline Finding ways to use less energy & 25 & 22 & 26 & 25 & 27 \\
\hline $\begin{array}{l}\text { Finding ways to produce more oil, } \\
\text { gas and coal }\end{array}$ & 11 & 10 & 12 & 13 & 8 \\
\hline Don't know & 5 & 5 & 4 & 7 & 5 \\
\hline Totals $^{\text {a }}$ & 100 & 100 & 101 & 100 & 100 \\
\hline
\end{tabular}

Source: Constructed by author using data from Research/Strategy Management and Greenberg/Lake, The Analysis Group.

${ }^{2}$ Percentages may not add to 100 due to rounding.

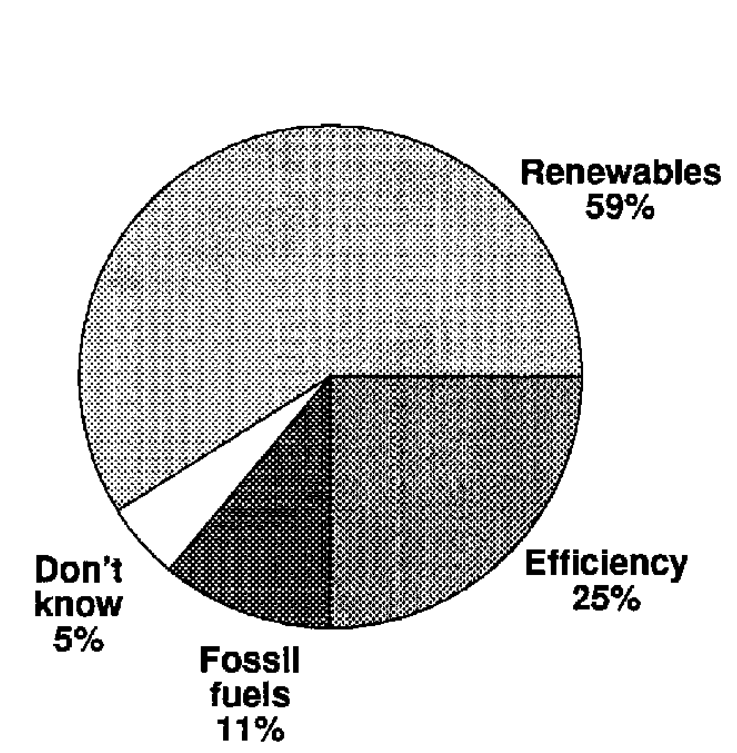

Source: Constructed by the author using data from Research/Strategy/Management and Greenberg/Lake, The Analysis Group.

Figure 6-D. Preferred energy alternatives, 1990 
"Now I am going to read you a list of several energy sources that are used to generate electricity. As I read each one, please use any numbers from 1 to 7 , where 1 means 'no environmental threat at all and 7 means a large environmental threat' to tell me how much of an environmental threat you think that energy source is when used to generate electricity." (September 1990) [1457]

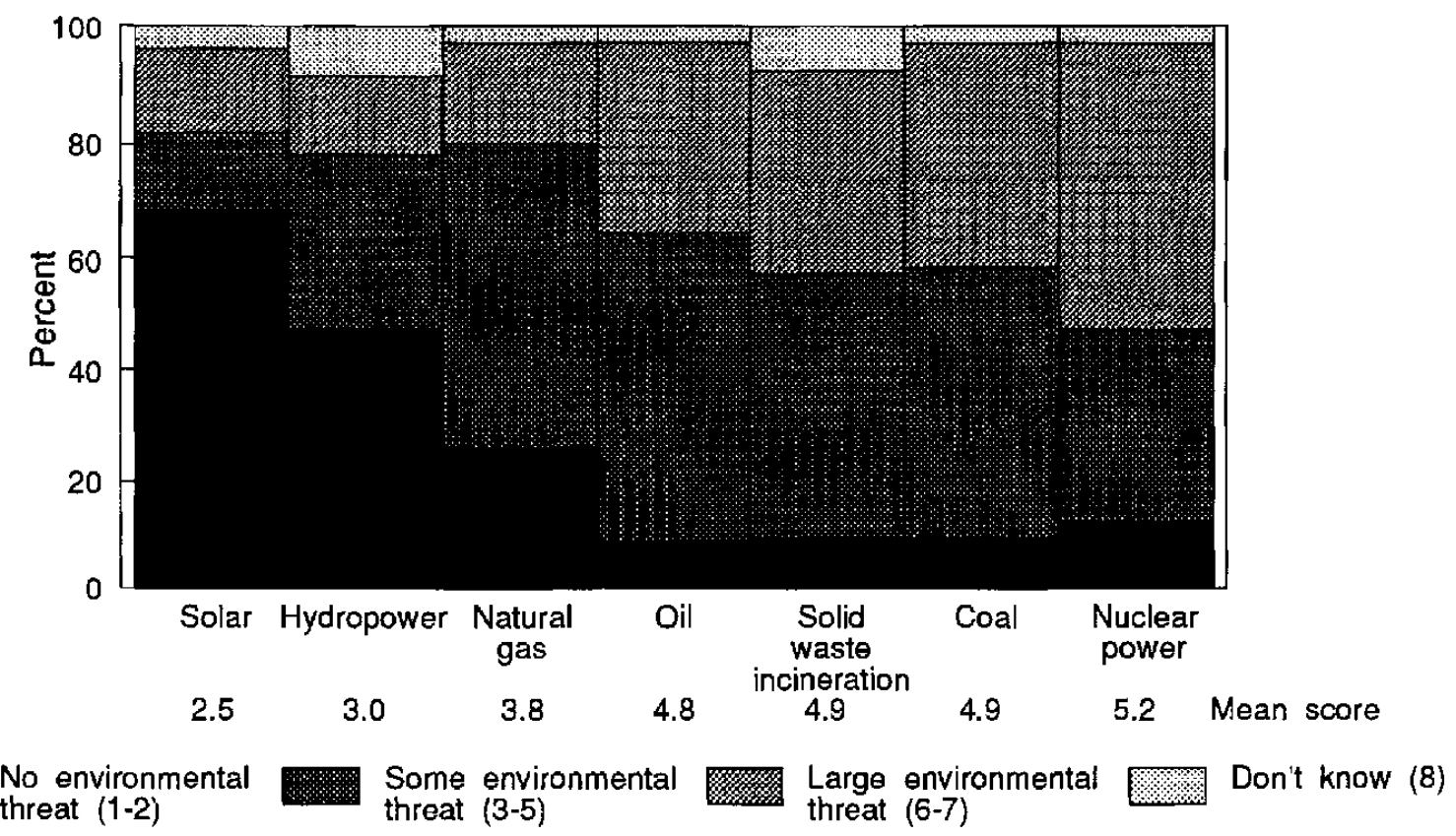

Source: Constructed by the author using data from Cambridge Reports/Research International

Figure 6-E. Electricity supply alternatives by level of perceived environmental threat

of public interest leaders. The leaders' opinions also diverged on hydropower: $90 \%$ of industry and $70 \%$ of public interest leaders favored its development. Public interest leaders $(87 \%)$ were also more likely to favor alternative fuels than were industry leaders (75\%). Both, however, agreed on imported oil; only $16 \%$ of each group favored its development.

The Ohio Office of Consumer's Counsel (OCC) asked Ohio utility customers, in October 1990: "Consumer's Counsel is participating in a U.S. Dept. of Energy committee that is preparing a national energy strategy. Which of the following energy sources should be more fully developed (or get more attention) to meet the nation's future electricity needs?" [1482]. "Renewables (solar, wind, biomass, etc.)" were most frequently selected, by $32 \%$. "Conservation, efficiency" was the second choice, favored by 27\%. Lower ranking options were coal (20\%), nuclear (14\%), oil (4\%), and natural gas (3\%) [1534]. These results contrast with those elicited when survey items included only some of the energy supply alternatives actually available. Table 6-11 shows results from an item used in a 1989 Yankelovich/ Clancy/Shulman survey [1045] and replicated 2 years later in 1991 [1496]. This item included nuclear power, coal, and oil, but excluded natural gas, renewables, and energy efficiency. The item asked: "In 
Table 6-10. Public Interest and Energy Industry Leaders' Preferences for Future Energy Sources, 1987

\begin{tabular}{|l|c|c||}
\hline \multirow{2}{*}{ Energy option } & \multicolumn{2}{|c|}{$\begin{array}{c}\text { Percentages indicating "strongly favor" } \\
\text { and "favor" combined }\end{array}$} \\
\cline { 2 - 4 } & Public interest leaders & Industry leaders \\
\hline \hline Energy-efficient technologies & 98 & 99 \\
\hline Conservation measures & 96 & 97 \\
\hline Geothermal energy & 81 & 90 \\
\hline Photovoltaic cells & 94 & 78 \\
\hline Cogeneration & 92 & 89 \\
\hline Solar energy heating & 96 & 81 \\
\hline Hydroelectric energy & 70 & 90 \\
\hline Alternative fuels & 87 & 75 \\
\hline Natural gas & 71 & 88 \\
\hline Wind energy & 95 & 56 \\
\hline Coal & 35 & 91 \\
\hline Domestic oil & 31 & 82 \\
\hline Nuclear energy & 5 & 16 \\
\hline Imported oil & 16 & 81 \\
\hline
\end{tabular}

Source: The League of Women Voters/Gallup, December 1987 [1534].

aItem wording not reported.

${ }^{b}$ Percentages add to more than 100 due to multiple responses.

Note: Renewable energy technologies are in bold.

thinking about this country's future energy needs, which of these energy sources do you think we should rely on more for our future needs and which should we rely on less?" Opinion was divided on the role of both nuclear power and coal, with nearly even pluralities responding that the country should rely on both more and less. In 1991, 44\% said the country should rely on nuclear power more, and $48 \%$ said less. Similarly, $43 \%$ said the country should rely on coal more, and $49 \%$ said less. 
Table 6-11. Perceptions on Future Energy Reliance

"In thinking about this country's future energy needs, which of these energy sources do you think we should rely on more for our future needs and which should we rely on less?" (Nuclear power, coal, oil) (April 20, 1989 and May 16, 1991)

\begin{tabular}{||l|c|c|c|c|c|c||}
\hline \multirow{2}{*}{ Categories } & \multicolumn{3}{|c|}{1989} & \multicolumn{3}{c||}{1991} \\
\cline { 2 - 8 } & $\begin{array}{c}\text { Nuclear } \\
\text { power }\end{array}$ & Coal & Oil & $\begin{array}{c}\text { Nuclear } \\
\text { Power }\end{array}$ & Coal & Oil \\
\hline Proportion responding (\%) & 45 & 42 & 33 & 44 & 43 & 27 \\
\hline \hline Rely more & 47 & 51 & 62 & 48 & 49 & 68 \\
\hline Rely less & 8 & 7 & 5 & 8 & 8 & 5 \\
\hline Not sure & 100 & 100 & 100 & 100 & 100 & 100 \\
\hline Total & $(1012)$ & $(1012)$ & $(1012)$ & $(1000)$ & $(1000)$ & $(1000)$ \\
\hline & {$[1045]$} & {$[1045]$} & {$[1045]$} & {$[1496]$} & {$[1496]$} & {$[1496]$} \\
\hline \hline Survey number & $\mathrm{N}=$ & & & & \\
\hline \hline
\end{tabular}

Source: Constructed by author using data from Yankelovich/Clancy/Shulman.

Interestingly, while little change occurred in the divided opinion on nuclear and coal, opinion on oil shifted-68\% said that the country should rely less on oil in 1991 compared with $62 \%$ in 1989 . (Pollsters collected data in April 1991, after Desert Storm.)

Finally, perception of risk has been hypothesized to affect public preferences for energy supply sources. A 1990 Cambridge Reports/Research International survey asked a national sample to compare energy sources in terms of their threat to the environment. Table 6-12 shows the results. Solar energy was viewed by two-thirds as posing no environmental threat-far and away the most environmentally benign source from a perceptual viewpoint. Hydropower was viewed by a plurality (46\%) as nonthreatening. A quarter of the sample identified natural gas as nonthreatening, $12 \%$ nuclear power, $9 \%$ both solid waste incineration and coal, and $8 \%$ oil [1457].

Roper replicated an item in five national surveys: one in January 1985 [1095]; one in June 1986 [1084]; some 3 months after the nuclear accident at Chernobyl; one in January 1990 [1548]; and finally another in March 1991 [1558]. Unfortunately, this verbatim trend item did not include efficiency or renewables as response options. If it had, this would have provided comparative empirical information about the perceived risk of these two energy options-information that is difficult to locate. The energy supply alternatives included in the item were nuclear, natural gas, coal, and oil. Table 6-13 shows the results. 
Table 6-12. Energy Supply Alternatives by Perceived Environmental Threat

"Now I am going to read you a list of several energy sources that are used to generate electricity. As I read each one, please use any number from 1 to 7 , where 1 means no environmental threat at all and 7 means a large environmental threat, to tell me how much of an environmental threat you think that energy source is when used to generate electricity." (September 1990) [1457]

\begin{tabular}{|l|c|c||}
\hline Energy option & $\begin{array}{c}\text { Mean Score } \\
\text { (Scale: 1-7) }\end{array}$ & $\begin{array}{c}\text { Percentage responding } \\
\text { 1-2 (no environmental threat) }\end{array}$ \\
\hline \hline Solar & 2.5 & 67 \\
\hline Hydropower & 3.0 & 46 \\
\hline Natural gas & 3.8 & 25 \\
\hline Oil & 4.8 & 8 \\
\hline Solid waste incineration $^{\mathrm{a}}$ & 4.9 & 9 \\
\hline Coal $^{\mathrm{b}}$ & 4.9 & 9 \\
\hline Nuclear power $^{\mathrm{c}}$ & 5.2 & 12 \\
\hline
\end{tabular}

Source: Constructed by author using data from Cambridge Reports/Research International.

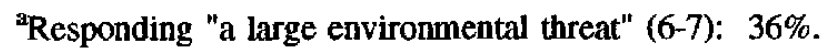

${ }^{b_{R}}$ Responding "a large environmental threat" (6-7): $40 \%$.

'Responding "a large environmental threat" (6-7): $51 \%$.

Respondents were asked: "Here is a list of possible energy sources. Please tell me which one source you think is [followed by a list of characteristics] . . .

- $\quad$ Safest to use

- Best for the environment

- Most economical for consumers

- The one we're least likely to run out of

- The one you find most acceptable for widespread use

- The one you find least acceptable for widespread use

- $\quad$ The one responsible for the most deaths through accidents over the past few years

- $\quad$ The one responsible for the least deaths through accidents over the past few years

- Potentially the most dangerous to human life."

Of these options, a larger percentage of samples, by 2 or 3 to 1 , repeatedly chose natural gas over the other options listed as the safest source for humans and the environment, most economical to consumers, and most acceptable for widespread use. For example, in 1990, two-thirds said that natural gas was the most acceptable for widespread use. Most respondents perceived neither coal nor nuclear energy as safest to use or most economical for consumers. 
Table 6-13. Levels of Perceived Risks of Nuclear Energy, Natural Gas, Coal, and Oil over Time

"Here is a list of possible energy sources. Please tell me which one source you think is. . ."

\begin{tabular}{|c|c|c|c|c|c|c|c|c|c|c|}
\hline \multirow[b]{2}{*}{ Category } & \multicolumn{5}{|c|}{ January $1985^{\mathfrak{a}}$} & \multicolumn{5}{|c|}{ June $1986^{b}$} \\
\hline & Nuclear & $\begin{array}{l}\text { Natural } \\
\text { Gas }\end{array}$ & Coal & Oil & $\mathbf{D K}^{\mathbf{e}}$ & Nuclear & $\begin{array}{c}\text { Natural } \\
\text { Gas }\end{array}$ & Coal & Oil & $\mathbf{D K}^{\mathrm{e}}$ \\
\hline \multicolumn{11}{|l|}{ Proportion responding (\%) } \\
\hline The safest to use? & 6 & 46 & 26 & 16 & 7 & 5 & 47 & 21 & 20 & 7 \\
\hline Best for the environment? & 13 & 62 & 8 & 8 & 10 & 9 & 64 & 7 & 11 & 10 \\
\hline $\begin{array}{l}\text { The most economical for } \\
\text { consumers? }\end{array}$ & 14 & 44 & 24 & 8 & 11 & 11 & 45 & 21 & 11 & 11 \\
\hline $\begin{array}{l}\text { The one we're least likely to } \\
\text { run out of? }\end{array}$ & 32 & 21 & 27 & 9 & 12 & 29 & 23 & 24 & 10 & 15 \\
\hline $\begin{array}{l}\text { The one you find most accept- } \\
\text { able for widespread use? }\end{array}$ & 9 & 59 & 9 & 16 & 7 & 7 & 58 & 8 & 18 & 9 \\
\hline $\begin{array}{l}\text { The one you find least } \\
\text { acceptable for widespread use? }\end{array}$ & 59 & 4 & 20 & 9 & 8 & 59 & 4 & 20 & 7 & 9 \\
\hline $\begin{array}{l}\text { The one responsible for the } \\
\text { most deaths through accidents } \\
\text { over the past few years? }\end{array}$ & 22 & 18 & 33 & 7 & 20 & 43 & 13 & 16 & 6 & 21 \\
\hline $\begin{array}{l}\text { The one responsible for the } \\
\text { fewest deaths through accidents } \\
\text { over the past few years? }\end{array}$ & 21 & 23 & 16 & 18 & 22 & 15 & 23 & 22 & 16 & 24 \\
\hline $\begin{array}{l}\text { Potentially the most dangerous } \\
\text { to human life? }\end{array}$ & 82 & 5 & 4 & 1 & 8 & 86 & 4 & 2 & 1 & 6 \\
\hline
\end{tabular}

Source: Constructed by author using data from the Roper Organization.

${ }^{\mathrm{a}}[1095],{ }^{\mathrm{b}}[1084],{ }^{\mathrm{c}}[1548],{ }^{\mathrm{d}}[1558],{ }^{\mathrm{e}} \mathrm{DK}=$ Don't know. 
Table 6-13. Levels of Perceived Risks of Nuclear Energy, Natural Gas, Coal, and Oil over Time (continued)

\begin{tabular}{|c|c|c|c|c|c|c|c|c|c|c|}
\hline \multirow[b]{2}{*}{ Category } & \multicolumn{5}{|c|}{ January $1990^{c}$} & \multicolumn{5}{|c|}{ March $1991^{\mathrm{d}}$} \\
\hline & Nuclear & $\begin{array}{c}\text { Natural } \\
\text { Gas }\end{array}$ & Coal & Oil & $\mathbf{D K}^{\mathrm{e}}$ & Nuclear & $\begin{array}{c}\text { Natural } \\
\text { Gas }\end{array}$ & Coal & Oil & $\mathbf{D K}^{\mathrm{e}}$ \\
\hline
\end{tabular}

Proportion responding (\%)

\begin{tabular}{|c|c|c|c|c|c|c|c|c|c|c|}
\hline The safest to use? & 7 & 61 & 13 & 10 & 9 & 8 & 60 & 12 & 9 & 11 \\
\hline Best for the environment? & 13 & 64 & 5 & 5 & 12 & 15 & 61 & 5 & 5 & 15 \\
\hline $\begin{array}{l}\text { The most economical for } \\
\text { consumers? }\end{array}$ & 12 & 54 & 14 & 6 & 14 & 11 & 58 & 11 & 5 & 15 \\
\hline $\begin{array}{l}\text { The one we're least likely to run } \\
\text { out of? }\end{array}$ & 35 & 25 & 15 & 8 & 17 & 28 & 29 & 15 & 9 & 19 \\
\hline $\begin{array}{l}\text { The one you find most acceptable } \\
\text { for widespread use? }\end{array}$ & 8 & 67 & 4 & 10 & 10 & 10 & 64 & 6 & 9 & 11 \\
\hline $\begin{array}{l}\text { The one you find least acceptable } \\
\text { for widespread use? }\end{array}$ & 50 & 5 & 24 & 9 & 12 & 48 & 5 & 26 & 7 & 13 \\
\hline $\begin{array}{l}\text { The one responsible for the most } \\
\text { deaths through accidents over the } \\
\text { past few years? }\end{array}$ & 35 & 12 & 15 & 10 & 28 & 34 & 9 & 14 & 10 & 33 \\
\hline $\begin{array}{l}\text { The one responsible for the } \\
\text { fewest deaths through accidents } \\
\text { over the past few years? }\end{array}$ & 13 & 28 & 17 & 9 & 33 & 12 & 31 & 13 & 9 & 35 \\
\hline $\begin{array}{l}\text { Potentially the most dangerous to } \\
\text { human life? }\end{array}$ & 76 & 4 & 5 & 2 & 12 & 73 & 5 & 5 & 2 & 14 \\
\hline
\end{tabular}

Source: Constructed by author using data from the Roper Organization.

${ }^{\mathrm{a}}[1095],{ }^{\mathrm{b}}[1084],{ }^{\mathrm{c}}[1548],{ }^{\mathrm{d}}[1558],{ }^{\mathrm{e}} \mathrm{DK}=$ Don't know. 
Opinion changed between 1985 and 1986 regarding accidental death. Far more respondents in 1986 than in 1985 said that nuclear energy was responsible for the most deaths through accidents. This response could reflect the effect of the Chernobyl accident on March 22, 1986 on the perceived risk of nuclear power.

The March 1991 data bear out the trend identified earlier regarding nuclear energy's relative status. While $59 \%$ in June 1986 said nuclear energy was "least acceptable for widespread use," that proportion had declined to a $48 \%$ plurality in March 1991. Similarly, after Chernobyl (in June 1986), 43\% said nuclear energy was the source "responsible for the most deaths through accidents over the past few years"; this had declined by 9 points by March 1991. Finally, the proportion stating that nuclear energy is "potentially the most dangerous to human life" decreased by 13 points in the same 5 years (86\% to $73 \%$ ) [1558]. 


\section{Chapter 7}

\section{The Utility Sector}

\section{Background and Summary}

Public opinion about energy cannot be fully understood unless one considers the traditional coal and nuclear alternatives for electricity production. Data concerning utility companies, and these fuel sources, are presented in this chapter. A scattering of findings about utility policies such as "integrated resource planning" (IRP) (formerly called "least-cost utility planning") - all that were available-is included. In 1990 , coal was used to produce $56 \%$ of the nation's source electricity, nuclear power $21 \%$, hydroelectric power $10 \%$, natural gas $9 \%$, and petroleum $4 \%$ (see Figure 7-A). ${ }^{1}$ As noted in Chapter 6 on preferred energy alternatives, neither coal nor nuclear energy are strongly preferred options, largely owing to the environmental problems attendant to their use. Yet each may be perceived as offering a certain degree of energy security as an alternative to dependence on foreign oil.

Much information relevant to the utility sector is presented throughout this report. Information on the anticipated future prices of electricity is included in the section on impacts of the energy situation in Chapter 4. The reputation of utilities and public preferences for the role utilities should play are discussed in Chapter 5. Actions that utilities could take to protect the environment are discussed in Chapter 2, as is willingness to pay more for electricity if power plant emissions were more effectively controlled.

However, complex interrelationships characterize the national energy equation. Oil is used more for transportation fuel and other products such as petrochemicals and asphalt; less of it is used to produce electricity and as a heating fuel (U.S. Energy Information Administration 1992). Furthermore, electricity will be required to power the electric and hybrid vehicles now being produced on a limited basis by major automobile manufacturers. Such vehicles will be required in Los Angeles, for example, in response to air quality problems there. Yet while the use of electric cars may reduce automobile emissions in a local area, the fuels used to produce electricity may themselves cause environmental harm elsewhere, if more power plants are needed.

Oil is used to produce only $4 \%$ of the nation's electricity. Yet evidence shows that both coal and nuclear energy (which together are used to produce $75 \%$ of U.S. electricity) are perceived as offering an alternative to dependence on foreign oil. Electricity has a reputation for being a clean fuel at the point of end use. However, in viewing electricity as "clean," many may not link electricity generation with environmental degradation. Majorities indicate concern for environmental impacts caused by electricity production. Large majorities indicate that they would be willing to pay $\$ 6 /$ month more for electricity that

\footnotetext{
${ }^{1}$ The Environmental Information Administration (EIA) reported that, in 1990, 0.003\% of electricity generated for distribution was produced from geothermal, wood, waste, wind, photovoltaic, and solar thermal energy. Of course, this figure does not include decentralized, off-grid electricity production from these renewable sources.
} 


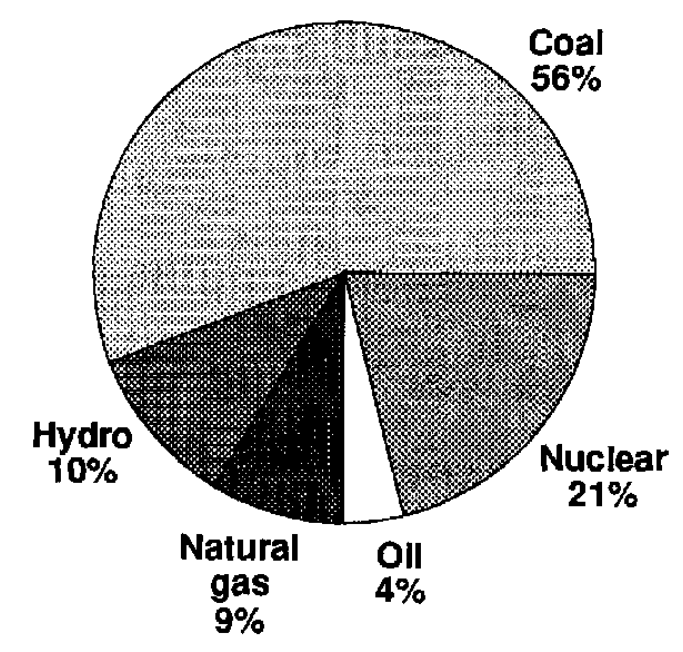

Source: Constructed by the author using data from the Energy Information Administration 1990.

Figure 7-A. Percentages of fuels used to generate electricity in 1990

comes from sources less harmful to the environment than existing ones. Other empirical findings are summarized below.

Policy preferences. Although few data were available, majorities appear to favor the following policies relative to utilities: IRP, DSM programs, use of renewables to generate electricity, utility profit incentives for using and promoting efficiency and renewables, pollution controls, green pricing, and other activities to protect and improve the environmnent.

Coal. Coal use has decreased in favorability over the last decade because of environmental concerns. Although poll items have indicated or implied that coal and oil could be traded off, as noted, only $4 \%$ of electricity is produced using oil. However, a majority appear to prefer burning more coal to increasing dependence on foreign oil. Few know about clean coal technologies (CCTs), and little evidence exists that they would make coal environmentally acceptable. However, most favor development of clean coal technologies. Many erroneously believe, however, that CCT deployment would significantly reduce U.S. dependence on oil imports.

Public perceptions of coal appear to derive from the lack of systems thinking about the ways in which electricity is generated. Poll items tend to ask about specific technologies, fuels, policies, and programs, and they tend not to capture information about the public's total impression. Nevertheless, the evidence strongly suggests that public perceptions on energy lack "total fuel cycle" thinking. For that matter, those framing poll questions may not have a systems perspective, either. 
Nuclear energy. Extensive evidence shows consistently negative opinion concerning nuclear energy. Perceived nuclear risks are releases of radioactivity near nuclear power plants or from radioactive waste transport and storage facilities. Although some observers have commented that increased use of nuclear energy might help to solve the problem of global warming, public opinion toward nuclear energy remains staunchly negative. The lack of public trust in information from the institutions responsible for nuclear energy is striking. Although the case is not clear-cut, it seems that policies to continue research and development (R\&D) funding for nuclear energy may be incongruent with public opinion on nuclear energy. More evidence will be needed before it is possible to conclude that the public will become more favorable to nuclear energy owing to global climate change.

The balance of this chapter presents the available empirical findings on some general utility policy issues; it then discusses coal and nuclear energy.

\section{Some Utility Policy Preferences}

A number of items touched on preferences relative to public policy toward utility companies. In this section, the following topics are discussed: fuel switching, burning high sulphur fuels, IRP, demand-side management (DSM) programs, use of renewables, utility profit incentives, pollution controls, green pricing, and utility environmental protection.

Fuel switching. In January 1990, Roper asked: "The situation in the Arab world has raised prices on imported oil, resulting in higher fuel costs to consumers. Some people say it would be good if the United States could be independent of these Arab oil producing countries, but there would be problems connected with this. We'd like to ask you how you feel about some of these means to becoming independent" [1554]. Five different options were mentioned, four of which were verbatim trend items also asked in January 1975 and January 1977.2 The one selected least frequently was: "All electric utility companies could be required to switch from oil to coal in producing electricity, but this would add to pollution problems somewhat. Would you be willing to see us do this or not?" The majority of $56 \%$ said, in 1990 , they would be unwilling for this requirement to be passed. The proportions favoring this idea were $36 \%$ in $1975,34 \%$ in 1977 , and $31 \%$ in 1990 . It appears that sensitivity to pollution problems had increased somewhat in the intervening 15 years, albeit modestly.

Burning high sulphur fuels. In 1991, Roper repeated the item asked in 1981 about other policy options that would affect utilities: "As you know, our economy is not in the best of shape. At the same time, the government is scheduled to put many new safety and environmental standards on business. Some people say these new safety and environmental rules must be lifted or postponed because they raise both costs and prices and therefore will depress the economy. Others disagree, and say these new standards must be put into effect to protect workers, the public, and the environment regardless of their effect on the economy. Here's a list of steps that could be taken to lift regulations on business. (Card shown) For each one would you tell me if you would be in favor of such a step or opposed to it?" $[1557]^{3}$

One of the eight suggested options concerned utility companies: "Allow utility companies to burn cheaper high sulphur fuels." The proportion opposed to this idea increased by 21 points in 10 years, from $44 \%$ in 1981 to $65 \%$ in 1991.

\footnotetext{
${ }^{2}$ Appendix H-1 presents the full set of responses on this item.

${ }^{3}$ Appendix H-2 presents the full set of responses on this item.
} 
IRP. In recent years, some public utility commissions, in regulating investor-owned utilities, have pursued the idea that utilities should find the most cost-effective ways of providing energy services from a social and economic perspective. In essence, using this concept, methods of both reducing demand and increasing supply would be evaluated and would compete on a "level playing field" for utility investment. This approach, originally termed "least-cost utility planning," is now known as "integrated resource planning" (IRP). A few of the poll items touched on public perceptions regarding IRP. For example, the League of Women Voters survey, in March 1988, asked public interest and utility industry leaders about their support for various energy policies and programs, one of which was "promote least-cost planning in the electric utility industry" [1534]. Substantial majorities of both types of leaders favored this approach (89\% of public interest leaders and $80 \%$ of industry leaders).

DSM programs. Utilities have for some years provided information to customers about how to conserve residential energy. More recently, utilities have offered financial incentives, such as rebates, to encourage the purchase of energy-efficient appliances and other equipment or have even provided such features as energy-efficient light bulbs free-of-charge. Initiatives of this type have come to be known as DSM programs because they focus on energy demand rather than supply.

Many utility customers apparently approve of DSM programs. In October 1989 Research/Strategy/ Management (RSM) asked national voters whether they agreed or disagreed with the statement: "An important way for utilities to reduce their use of fossil fuels like oil and coal is for utilities to help their customers use electricity more efficiently" [1072]. A majority (55\%) "strongly agreed" and another 36\% "somewhat agreed." Only 7\% disagreed and 2\% said they didn't know.

Use of renewables. This same survey asked whether respondents agreed with the statement: "An important way for utilities to reduce their use of fossil fuels like oil and coal is to use renewable energy sources like solar, wind, and water" [1072]. Virtually everyone (88\%) agreed, $61 \%$ of them strongly.

Utility profit incentives. Public utility commissions in California and New England are experimenting with another novel concept in utility regulation. They are permitting utility companies in their service areas to earn profit on their investments in DSM programs if such programs actually result in buildings consuming less energy. This innovation appears to be popular with the public. For example, the Analysis Group asked, in September 1988, whether a national sample favored or opposed: "New regulations and incentives for utility companies requiring that they help consumers conserve energy and that the utilities are rewarded for being energy efficient" [1431]. Eighty-five percent of the respondents "strongly favored" or "somewhat favored" such an approach. And, a national poll asked whether respondents favored or opposed: "Requiring federal and state regulators to provide incentives to utilities for investing in energy efficiency improvements in their customer's homes and buildings" [1025]. Eighty-six percent "strongly favored" or "somewhat favored" such a requirement.

Pollution controls. Interestingly, despite the public's apparent concern about emissions and air pollution, $46 \%$ "strongly agreed" that "the more we use electricity to replace other energy sources, the cleaner the environment will be" [1457]. And, 73\% "strongly agreed" that "we will rely on electricity even more in the future than we do today" [1457].

However, in 1990, 77\% of a national sample supported "strict pollution controls on oil- and coal-burning power plants, even if that would raise the price of electricity" [1355]. And, as noted, in September 1990,

\footnotetext{
${ }^{4}$ As is discussed in the section on nuclear energy, $49 \%$ agreed that nuclear power is also an important way for utilities to reduce their use of fossil fuels like oil and coal [1072].
} 
$56 \%$ opposed the following suggestion: "All electric utilities could be required to switch from oil to coal in producing electricity, but this would add to pollution problems somewhat" [1554].

These and other results suggest that, because electricity has a reputation for being a clean fuel, the public is not making the connection between the way electricity is most frequently generated and the ensuing environmental impacts. The burning of fossil fuels to produce electricity produces emissions that contribute to global warming; nuclear generation of electricity produces radioactive wastes and requires eventual decommissioning of the nuclear power plants. The public appears to be aware of these side effects of electricity production, yet continues to see electricity as a "clean" fuel. It would be interesting to explore more precisely the public perception of electricity's cleanliness.

Green pricing. The public has indicated concern for environmental impacts caused by producing electricity. As discussed in Chapter $2,29 \%$ said they would be willing to pay $\$ 6$ to $\$ 10 /$ month more to "have your electricity come from sources that are less harmful to the environment"; $21 \%$ said they would pay $\$ 11$ to $\$ 20$ more, and $26 \%$ said they would be willing to pay more than $\$ 21$ more per month [1457].

Utility environmental protection. Chapter 2 also touched on some of the actions customers wanted utilities to take to protect and improve the environment. Table $\mathbf{H}-3$ in Appendix $\mathbf{H}$ exhibits the findings from a September 1990 poll, on 20 different actions utilities could take. Besides tree planting, the most preferred options were phasing out use of chlorofluorocarbons and promoting energy-efficient building codes. Also deemed very important were utilities' protecting wildlife habitats from development, developing clean coal technologies to reduce emissions, and funding environmental research. Least preferred options, relative to the list as a whole, included replacing other energy sources with electricity, directly controlling customers' major appliances to shift loads, and allowing recreation under transmission lines [1457].

\section{Coal as a Supply Option}

Earlier reviews found that coal was perceived as an effective energy supply source because it was readily available domestically. Perceived benefits included reduced dependence on foreign oil and ready availability. Large majorities supported coal use if no environmental damage would result. However, in the late 1970s evidence existed of some degree of environmental concern about the production and use of coal, which concerned those in the West more than those in the Midwest.

The rise in environmentalism during the 1980s has changed the position of coal relative to other energy options. As evidence presented in the chapter on preferred energy alternatives shows, coal has decreased in favorability as an energy supply source over the last decade. In addition, since the late 1970s we have seen the advent of CCTs, technologies intended to reduce noxious emissions from power plant stacks, including primarily "scrubbers." Some of the poll items relevant to coal asked the public about their perceptions of CCTs.

The public opinion data available on coal and CCTs was limited; however, the evidence available is discussed in this section.

Perceived relative advantage. In 1991, Cambridge Reports posed two trade-off items, juxtaposing increased coal use with averting electricity shortages and with reduced dependence on foreign oil. Figure 7-B shows the trend results on preferences in using coal to provide for future electricity needs. Majorities favored coal use to provide for "additional supplies of electricity," including $60 \%$ in 1989, 54\% in 1990 , and $56 \%$ in 1991. Selecting coal use over increased dependence on foreign oil were $73 \%$ to $75 \%$ of the 1989, 1990, and 1991 Cambridge Report samples [1425]. The study reported that even among respondents identifying coal buming as a significant environmental threat, a majority would prefer burning 


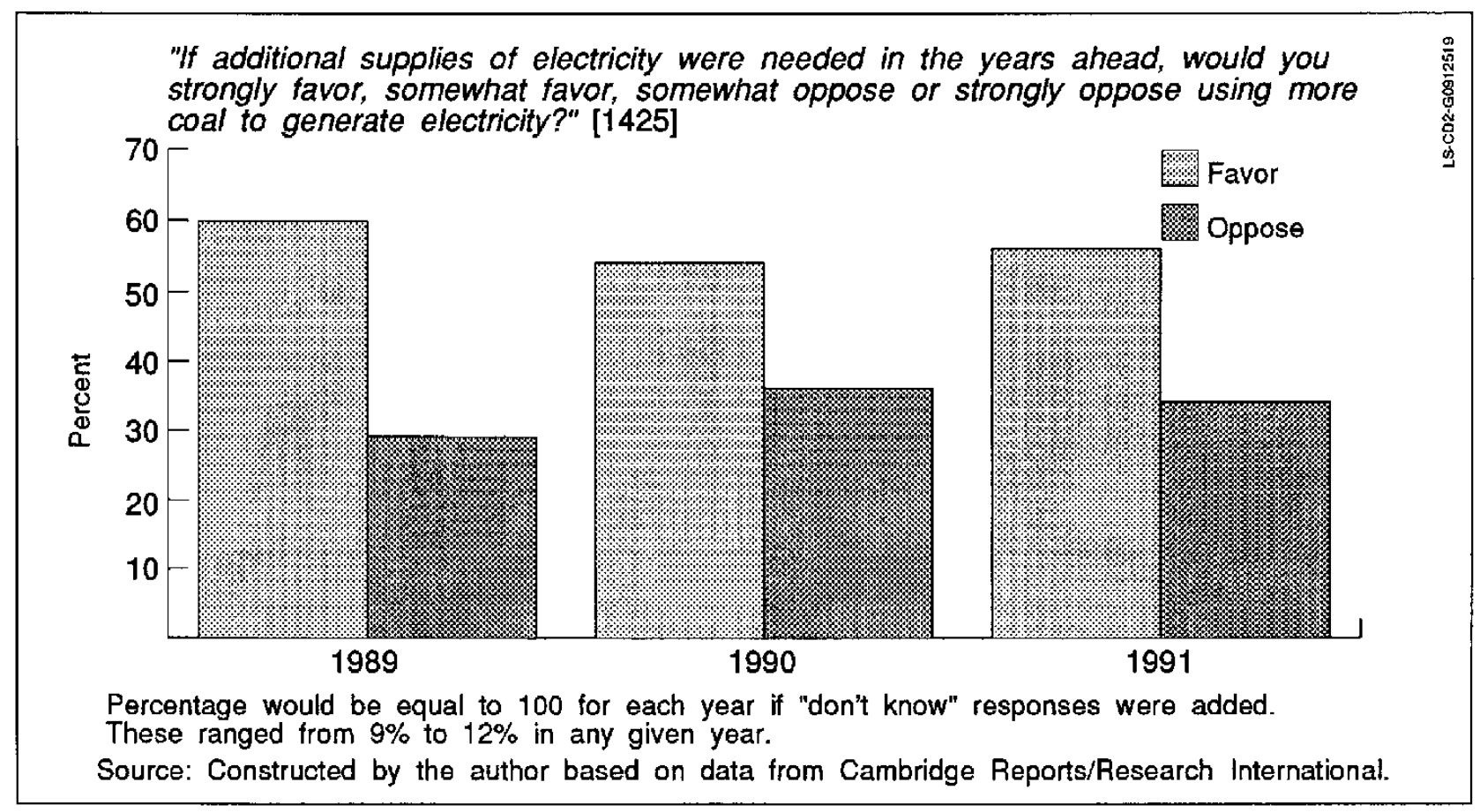

Figure 7-B. Trends in preferences for burning of coal to generate additional electricity

more coal to increasing energy dependence [1425]. In other words, these respondents would prefer more coal burning to increasing oil imports. Actually, coal is used primarily to produce electricity, and oil is not, so they do not readily substitute for each other.

The public attributed two advantages to CCTs: (1) reduced dependence on foreign oil and (2) improved environmental quality. Cambridge Reports asked: "If industry and government made a concerted effort to develop and use clean coal technologies, do you think this would significantly reduce our dependence on foreign oil, or not?" [1425]. This item implicitly assumes that the use of coal and oil is interchangeable in electricity production. Approximately three-quarters of respondents replied affirmatively (70\% in 1989, 75\% in 1990, and $76 \%$ in 1991). This result is an example of the lack of systems thinking often evident in this body of survey data.

The same study asked: "If industry and government made a concerted effort to develop and use clean coal technologies, what impact do you think this would have on the overall quality of the environment? Do you think this would improve, worsen, or have no impact on the overall quality of the environment?" [1425]. Approximately two-thirds said use of CCTs would improve environmental quality (63\% in 1989 , $72 \%$ in 1990 , and $67 \%$ in 1991). Very few thought CCT use would worsen overall environmental quality ( $8 \%$ in $1989,4 \%$ in 1990 , and $6 \%$ in 1991). However, the items with these wordings appear designed to elicit favorable responses to coal burning. 
Perceived risk. Coal has long had the reputation of damaging the environment. Cambridge Reports asked: "Do you think it is possible to burn coal to create energy without harming the environment, or not?" [1425]. (Electricity was not mentioned in this item.) The proportion believing it is possible to do this increased from $42 \%$ in 1989 to $49 \%$ in 1991; those believing it impossible remained at approximately one-third throughout the period (35\% in $1989,30 \%$ in 1990 , and $33 \%$ in 1991).

A majority in this study, 53\%, said that "automobile exhaust" was a more important contributor to acid rain than were "emissions from coal-burning factories and plants" (29\%)" [1425].

In 1990 and 1991, most people saw burning coal as a "moderate" threat to overall air quality. Sizable minorities of around one-fifth saw coal burning as a "large threat," and very few saw it as "no threat at all" [1425]. Two-thirds of those identifying coal burning as a "large threat" opposed increased reliance on coal, compared with $47 \%$ of those viewing reliance on coal as a "moderate threat" and $23 \%$ of those identifying it as a "minimal threat" or "no threat at all." These findings lend support to the notion that environmental concern and position toward coal use are closely linked.

The Cambridge study also asked about reductions in sulfur dioxide emissions from U.S. coal-fired power plants in the last 5 years. Forty-four percent said they thought these emissions had been reduced at least "a moderate amount" in the past 5 years, while 34\% thought "a small amount" or "not at all." Approximately one-quarter didn't know.

Even in 1982, Louis Harris and Associates found that $27 \%$ said "air pollution by coal-burning electric power plants" was a "very serious" environmental problem; $43 \%$ said it was a "somewhat serious" problem [1279]. And, in 1983, 77\% of a Louis Harris and Associates sample said they were willing to see more coal used "only if it did not violate current environmental standards" [1282].

Knowledge and information sources. Concerning CCTs, awareness is low. Cambridge Reports asked in January 1991: "New technologies-often called clean coal technologies-are being developed to produce electricity from coal efficiently, cheaply, and cleanly. Have you heard or read anything about these clean coal technologies, or not?" [1425]. This item had also been used in 1989 and 1990. The 3-year trend showed approximately the same proportion indicating they had heard about CCTs-just over a quarter of the sample (27\% in 1991). Most had not heard of them (70\% in 1991).

This study also asked: "How much money do you think the coal and electric utility industries have spent on developing clean coal technologies? Do you think these industries have spent a lot of money, a moderate amount, a small amount, or virtually nothing at all to develop clean coal technologies?" [1425]. In 1989, 1990, and 1991 - the 3 years in which the item was asked-approximately one-fifth of respondents said these industries had spent "a lot," approximately one-third said "a moderate amount," and almost one-quarter said "a small amount." About one-fifth didn't know. There was little change in these proportions over time. The item, of course, omitted consideration of federal funding for CCT research and development.

A related question asked: "If industry and government made a concerted effort to develop and use clean coal technologies, what impact do you think this would have on the cost of energy? Do you think this would raise, lower, or have no impact on the cost of energy?" [1425] (Again, electricity was not cited as the energy being produced by the coal.) Anticipating price increases were $40 \%$ in 1991 , down from 47\% in 1990 and $44 \%$ in 1989 . Approximately one-third erroneously thought prices would be lowered by implementing CCTs; and 17\%, in 1991, said it would have no impact on prices; $9 \%$ didn't know. 
The study also asked about the perceived impact of CCT deployment on energy dependence. Approximately three-quarters of the 1989, 1990, and 1991 samples said this would "significantly reduce our dependence on foreign oil" [1425].

Favorability to the coal option. As Cambridge Reports has noted, energy supply preferences appear increasingly to be driven environmentally. It seems reasonable to speculate that the poll results on coal are a function of increased environmental concern. Cambridge Reports reported that opposition to increased coal use was correlated with higher incomes, political liberalism and political moderation, and living outside industrial states [1425]. The Cambridge Reports study asked: "In general, do you favor or oppose increased use of coal?" Figure 7-C displays trend results on this item from 1978 through 1991. The trend shows that the proportion favoring increased coal use declined markedly, by 16 points, between 1978 and 1991; the proportion opposed increased from $30 \%$ to $42 \%$ in that same period.

Cambridge Reports also asked: "Would you personally like to see more coal burned in your local area or not?" [1425]. In 1987, 34\% responded "yes" and 49\% "no." In 1991, the proportions were 27\% "yes" and $60 \%$ "no." This reflects the same pattern of decreased favorability to coal use as the more general item.

"In general, do you favor or oppose increased use of coal?" [1425]

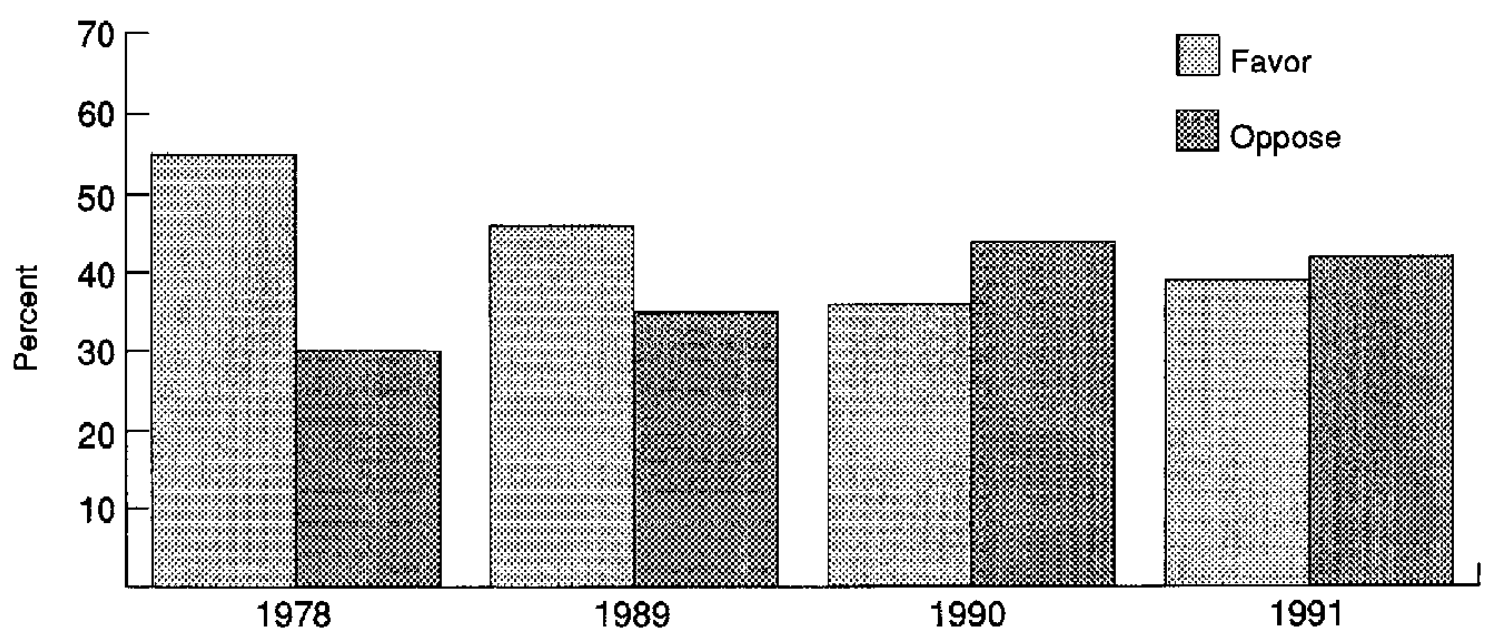

Percentage would be equal to 100 for each year if "don't know" responses were added. These ranged from $15 \%$ to $20 \%$ in any given year.

Source: Constructed by the author using data from Cambridge Reports/Research International.

Figure 7-C. Trends in favorability to increased coal burning, 1978-1991 
In April 1991, Yankelovich/Clancy/Shulman asked a national sample: "Would building a new coal-fueled power plant in your community be acceptable or unacceptable to you?" [1496]. A majority, 51\%, said it would be "acceptable," $41 \%$ said it would be "unacceptable," and $8 \%$ were unsure.

Favorability toward coal use was higher in the mid-1980s than it is today. Opinion Research Corporation (ORC) asked, in 1984: "(Let me go through a list of some different types of products. As I name each, I'd like you to tell me whether-to the best of your knowledge-the U.S. buys more of this from other countries than it sells, sells more than it buys, or trades it about evenly with other countries) . . Coal" [1154]. A plurality of $43 \%$ correctly said that the nation sells more coal than it buys, while $47 \%$ indicated an incorrect response or didn't know. ${ }^{5}$ The perception that coal might help the balance of trade may have led to favorable responses to "speeding up the development of our coal reserves." ORC identified this in 1983 , when $80 \%$ of a national sample "mildly favored" or "strongly favored" coal development.

Policy preferences. The League of Women Voters study asked public interest and industry leaders about their support for a variety of energy policies and programs. Among those listed was "develop clean-coal technologies" [1534]. Virtually all (95\%) of the industry leaders and most (77\%) of the public interest leaders favored this policy. The same item also included a policy to "increase R\&D funding for fossil fuel resources" [1534]. The results revealed a wide gulf in preferences between the industry and public interest respondents: $38 \%$ of public interest leaders favored this policy, whereas $85 \%$ of industry leaders favored it.

In 1984, 64\% of an Alabama sample supported increased use of coal "to help meet future energy needs" [1448]. This proportion had increased to $71 \%$ by 1987 [1434]. The Alabama sample also heavily favored "increasing the state government's role in developing Alabama coal, oil and natural gas" [1434].

Summary. Approximately three-quarters of national samples perceived acid rain as a serious problem in 1990 and 1991, as discussed in Chapter 2. Even though automobile exhaust has been blamed for acid rain more frequently than coal burning, the public still regards burning coal as environmentally damaging. Few are aware of CCTs, and little evidence exists that the public believes CCTs would make coal burning acceptable from an environmental point of view. The only reason for increased coal use that the public seems to accept is reduced dependence on foreign oil; however, no data were available to show whether the public is aware that oil and coal are not interchangeable in the energy equation. For example, coal is not a liquid fuel and does not have the same uses as oil; oil is ordinarily not used to generate electricity as is coal.

The continued perception that electricity is a clean fuel appears to result from the public failing to understand the major fuels used to produce electricity and the environmental impacts that ensue from using those fuels. This lack of "systems" or "total fuel cycle" thinking appears to characterize public perceptions of the U.S. energy situation, as well as U.S. energy policy itself.

\section{Nuclear Energy as a Supply Option}

Atmospheric scientists are becoming increasingly convinced that anthropogenic global climate change is occurring, and that it results at least in part from the combustion of fossil fuels, including gasoline, oil, and coal. Because the United States has plentiful supplies of coal, this fuel could be viewed as a secure source for electricity for buildings and automobiles. But because burning coal could contribute to accelerated global warming, many atmospheric scientists have called for the use of energy efficiency, renewables, and nuclear energy as the foundation of the nation's future energy security.

\footnotetext{
${ }^{5} \mathrm{ORC}$ did not report results for $10 \%$ of the sample.
} 
The question then becomes, does the public associate concern about global warming with the burning of fossil fuels for both transportation and electricity generation? And, if so, does this mean that the public will begin to rethink its long-held opposition to nuclear energy and begin to accept nuclear power as a way to mitigate the greenhouse effect?

Two major nuclear accidents-Three Mile Island and Chernobyl-cast a pall over the promise of the peaceful uses of nuclear power, which scientists, the government, and the nuclear industry had presented as clean, environmentally benign, available in virtually endless quantities, and inexpensive. The earlier reviews of public opinion found that the benefits associated with nuclear power in the public mind were reduced utility bills, economic benefits to the community where such a power plant was located, and societal benefits from a clean domestic fuel supply (Farhar et al. 1979).

Three Mile Island. The past 12 years have not been good ones for nuclear energy. On March 28, 1979, the Three Mile Island (TMI) nuclear accident occurred. Between then and April 9, when the crisis was declared ended, some radioactivity was released into the atmosphere around Harrisburg, Pennsylvania. The governor urged children and pregnant women to evacuate the area for a time. TMI had an immediate negative effect on public opinion about nuclear energy. It accelerated a decline in favorability toward nuclear energy that had begun in 1973.

Chernobyl. A full-scale meltdown occurred at the Chernobyl nuclear power plant in the Soviet Union on April 26, 1986. This event also resulted in a negative response from the U.S. public toward nuclear energy, which can be traced in public opinion data. The Soviets did not immediately announce the disaster; it was only after the Swedes had detected radioactivity in the atmosphere that the U.S.S.R. admitted, on April 28, 1986, that there had been a nuclear catastrophe. Thirty-two direct fatalities were officially reported at the time of the explosion itself. Numerous cases of illness, including increased rates of leukemia and other forms of cancer, were subsequently reported.

In May 1991, the International Atomic Energy Agency (IAEA) (reported as "pro-nuclear" by the Associated Press), disputed claims of increased cancer rates from the Chernobyl accident (Associated Press, May 21, 1991). An IAEA study found that people in the contaminated area believed that they were sick because of anxiety and stress. "It's not so much the radiation that's doing it, it's their fear and their concern," one of the IAEA researchers was quoted as saying (p. 1).

Yet information about the effects of the Chernobyl accident continued to filter out from formerly secret archives. The Chicago Tribune $(2 / 2 / 92$, p. 1) reported that the Chernobyl disaster affected millions of people in Belarus where cancer rates have increased rapidly and the "ecology has been ruined." The story reported that contaminants, already in the soil making the area uninhabitable for 240 years, had been plowed under. The Tribune said that actions such as these, done in haste, have pushed radioactive elements deep into the earth, thus probably contaminating the area's groundwater.

During the week of April 20,1992, Ukraine authorities said publicly that cancer and other radiation-related illnesses had caused 6,000 to 8,000 deaths in the six years since the disaster. As of April 1992, another 15,000 individuals were identified as suffering from radiation-related diseases. Ukrainian officials said that, as of January 1, 1992, 1.5 million people, including 350,225 children, had undergone follow-up medical tests. They said that each year of the testing resulted in fewer and fewer healthy individuals. The former Soviet republics were reportedly still struggling to recover from the Chernobyl disaster (Associated Press, April 26, 1992). ${ }^{6}$

${ }^{6}$ The Associated Press prepared a story with these details in 1992 , on the sixth anniversary of the Chernobyl nuclear accident. 
In September 1992, World Health Organization (WHO) researchers reported a substantial increase in rare thyroid cancer among young children in Belarus, a former Soviet republic just to the north of the accident site. The 102 cases are about 80 times the normal rate; the cancers appeared sooner and progressed faster than expected (Wall Street Journal, 9/3/92, p. B8). It may be some years before the full impact of the Chernobyl disaster on public health is known.

Perceived relative advantage. Electricity is evidently viewed as a critical service. As recently as July 1989 , Roper reported that $61 \%$ identified the nuclear power industry as "absolutely essential" or "very important" [1544]. Gallup reported 50\% of a June 1986 national sample identifying nuclear power plants as "extremely" or "somewhat important" to "meeting the future power needs of the nation" [1293]. However, a plurality of $47 \%$ responded that nuclear energy was "not too" or "not at all" important. These results, which seem to show positive public support for nuclear energy, comprise only a fraction of the items located on nuclear energy. They are inconsistent with the bulk of the findings on nuclear energy. The weight of public opinion seems to be otherwise.

The idea that nuclear energy is inexpensive seems to have disappeared. After the several financial disasters involving nuclear power plants in New England and in the Pacific Northwest, little has recently been said about nuclear energy being an inexpensive supply source. Only one item was located that asked about nuclear costs. In April 1991, Yankelovich/Clancy/Shulman asked: "How do you think a new nuclear power plant in your area would affect your energy bill? Do you think it would make your energy costs higher, lower, or would costs remain about the same?" [1496]. Thirty-six percent thought such a plant would make their bills higher, $36 \%$ said utility costs would remain about the same, and $16 \%$ thought their bills would decrease; $12 \%$ were unsure.

Seeking to identify the nuclear power benefit/cost ratio, Roper asked, in March 1985, and again in March 1987: ". . . whether, on balance, you think the good effects [of nuclear energy] outweigh the bad, or whether the bad effects outweigh the good?" [1094, 1078]. In 1985, opinion was precisely divided, with $38 \%$ selecting each option, $13 \%$ volunteering "both," and with $11 \%$ unsure. The 1987 results were similarly polarized, with $42 \%$ saying "the bad outweighs the good" and $41 \%$ saying, "the good outweighs the bad." An April 1986 poll reported that $45 \%$ said the need for nuclear power did not outweigh the risks involved, while $42 \%$ thought it did [1351].

These results from public polls contrast sharply with those from a 1986 survey of science policy leaders, environmental leaders, utility leaders, and congressional science staff [1427]. Table 7-1 shows the results. Among utility leaders sampled, for example, $88 \%$ said the benefits of nuclear power were substantially greater than the risks, and only $2 \%$ thought the risks substantially outweighed the benefits. Of Congressional science staff, 55\% agreed that the benefits far outweighed the risks; $52 \%$ of science policy leaders agreed. On the other hand, $39 \%$ of environmental leaders judged the risks of nuclear power to be substantially greater than the benefits, but $31 \%$ of even these leaders indicated that the benefits were much greater than the risks.

Anti-nuclear activism. As of 1984, most people did not identify with the anti-nuclear movement, nor did they consider themselves anti-nuclear activists. ORC found 3\% calling themselves active participants in the anti-nuclear movement, 34\% "sympathetic but not active," 39\% neutral, and 24\% "unsympathetic" [1183]. Also in 1984, Gordon Black/U.S.A. Today asked: "Are you more or less likely to vote for a candidate endorsed by the groups opposing nuclear power, or would the endorsement not make a difference in how you would vote?" [1285]. The plurality, $42 \%$, said it would make no difference, while $27 \%$ said they would be less likely to vote for the candidate, and $24 \%$ said they would be more likely to do so. No more recent self-reports on behavior related to nuclear energy was located, however. It may be that the public would exhibit more sympathy to anti-nuclear activities in the post-Chernobyl period (after 1986). 
Table 7-1. Leaders' Risk-Benefit Assessment of Nuclear Power, 1986

"Many current issues in science and technology may be viewed as a judgment of relative risks and benefits. Thinking about the use of current nuclear reactors to generate electricity, there is broad agreement that there are some risks and some benefits associated with nuclear power. In your opinion, would you say that the risks are greater than the benefits, or that the benefits are greater than the risks? Would you say that the benefits are substantially greater than the risks, or only slightly greater than the risks? Would you say that the risks are substantially greater than the benefits, or only slightly greater than the benefits?" (January 1986) [1427]

\begin{tabular}{|c|c|c|c|c|c|}
\hline \multirow[b]{2}{*}{ Types of leaders } & \multicolumn{3}{|c|}{ Benefits exceed risks } & \multicolumn{2}{|c|}{ Risks exceed benefits } \\
\hline & $\begin{array}{c}\text { Much } \\
\text { greater }\end{array}$ & $\begin{array}{l}\text { Slightly } \\
\text { greater }\end{array}$ & $\begin{array}{l}\text { About } \\
\text { equal }\end{array}$ & $\begin{array}{l}\text { Slightly } \\
\text { greater }\end{array}$ & $\begin{array}{l}\text { Much } \\
\text { greater }\end{array}$ \\
\hline \multicolumn{6}{|c|}{ Proportion responding (\%) } \\
\hline Utility leaders $(N=89$ ) & 88 & 8 & 2 & 0 & 2 \\
\hline $\begin{array}{l}\text { Congressional science } \\
\text { staff }(\mathrm{N}=96)\end{array}$ & 55 & 22 & 0 & 9 & 14 \\
\hline $\begin{array}{l}\text { Science policy leaders } \\
(N=508)\end{array}$ & 52 & 19 & 3 & 7 & 19 \\
\hline $\begin{array}{l}\text { Environmental leaders } \\
(\mathrm{N}=150)\end{array}$ & 31 & 19 & 1 & 10 & 39 \\
\hline
\end{tabular}

Source: After J. D. Miller 1986.

An aware public? The continuance of nuclear power as an electricity supply alternative has apparently relied heavily on the opinions of the physical science community, the utility industry, and government legislators and officials. Anecdotally, these sources often say that the public is not knowledgeable about nuclear energy, and that it perceives unrealistically high levels of risk from nuclear facilities. Policymakers may have used these arguments, whether accurate or inaccurate, to discount public opposition to the use of nuclear energy.

Do the polls offer any evidence concerning how knowledgeable people are about nuclear energy? The answer is, very little. Most poll questions simply asked whether people were aware of a nearby nuclear power plant, their estimate of the proportion of U.S. electricity generated by nuclear power, and their assessment of their own awareness levels on nuclear accidents. This information is insufficient to reach conclusions about the level of public awareness or the level of accuracy of information the public has about nuclear energy. The limited evidence available suggests that the public is not knowledgeable.

The polling organizations did not provide information on the accuracy of responses. For example, an April 1991 national poll asked: "Is there currently a nuclear power plant in operation within 50 miles of where you live?" [1496]. The majority, 59\%, said there was not, $31 \%$ said there was, and $10 \%$ said they were not sure. How accurate these responses were was not reported. In 1986, similar items were asked 
by Roper [1084] and by the Associated Press [1360]. In their 1986 survey, Associated Press asked of a survey subpopulation that said they lived less than 10 miles from a nuclear plant (3\%): "If an accident that required evacuation were to occur at the nuclear power plant near your home, would you know which evacuation route to take, or not?" Half said they knew; half said they did not [1360].

Another 1986 survey queried: "Do you think most Americans know enough about the effects of radiation to make informed decisions concerning nuclear power, or not?" [1360]. Most (78\%) said they did not; $16 \%$ thought they did. Two-thirds responded that they had heard or read about "the discussion concerning the construction of nuclear power plants" [1293].

Most people have heard about Chernobyl. In 1988, most also said that they had been following the news stories about "the problems at nuclear reactor plants" "very closely" (28\%) or "fairly closely" (44\%) [1318]. In April 1986, just after the Chernobyl accident, 92\% said they had heard about it [1198], and, in July that year, $80 \%$ said they were following the Chernobyl news story "very closely" or "fairly closely" [1295]. By October 1986, 85\% of a Harris poll said they had heard or read a lot about "radioactive discharge from nuclear power plants" [1244].

Also in 1988, Gallup, in a survey sponsored by the National Geographic Society, asked: "The environmental impact of the nuclear accident at Chernobyl was widespread. Why do you think that the effects of the accident were not limited to the country in which it occurred? Would you say it was because of ocean currents, sun spots, wind patterns, or a thinning of the ozone layer?" [1290]. The accurate response was the wind patterns, and $78 \%$ gave it.

When asked in 1987 whether they "understand the pros and cons of nuclear power pretty well, understand some but not all things about it, or don't understand much about it at all," $31 \%$ estimated that they had the top level of understanding, 34\% a moderate level, and 29\% little or no understanding [1079]. Even the leaders participating in a 1986 survey [1427] did not feel that they were completely informed. They were asked: "Do you feel very well informed, moderately well informed, or not very well informed about the safety of today's U.S. nuclear power plants?" Utility leaders (62\%), Congressional science staff $(29 \%)$, science policy leaders (24\%), and environmental leaders (22\%) estimated that they were "well informed."

As to credibility of information sources, the public rated the job the media did in covering the Chernobyl accident as either "excellent" (21\%) or "good" (50\%) in July 1986 [1295]. But when asked in May 1986: "How much trust do you have in what the critics of nuclear power tell you about the risks of nuclear power?," 53\% said "some trust," 37\% said "very little trust," and only $9 \%$ said "a great deal of trust." Even the government was not regarded as a highly credible information source on nuclear energy. When asked: "Regardless of your own feelings about nuclear power, how much trust do you have in what the government tells you about the risks of nuclear power: a great deal, some, or very little?," $46 \%$ said "some trust," 39\% said "very little trust," and 14\% said "a great deal of trust" [1364].

A sprinkling of other items in 1986 and earlier asked about the percentage of U.S. electricity supplied by nuclear power plants and a few other miscellaneous matters, but no pattern of information sources or knowledgeability could be established from these.

Although most thought the media covered the Chernobyl story well, the rest of the available evidence suggests that the public has no source of information on nuclear energy that it believes. A lack of credible sources of information could itself lead the public to discount a fair amount of the information it does receive about nuclear energy. 
Favorability and opposition toward nuclear energy. The overwhelming pattern in data from 26 surveys was majority opposition to building more nuclear power plants in the United States. Table 7-2 presents data from these studies; Appendix E provides item wording. Virtually all of these surveys, ranging from April 1979 (post-TMI) through June 1991 (post-Chernobyl), asked preferences concerning the use of nuclear energy in the United States rather than in the local community. Sample majorities to pluralities ranging from $78 \%$ to $42 \%$ have consistently opposed building more nuclear power plants in the country. Only 5 of the 26 surveys found a larger majority or plurality favoring nuclear power; four of these were 1979 surveys, and one was a 1986 Roper poll, the results of which are an anomaly when viewed in the context of other polls taken at that time.

Figure 7-D shows the trend in increasing opposition to nuclear energy from 1975 through 1992 from selected surveys.

A small amount of evidence suggests that if these items had focused on the local community, opposition would have been even more intense than it was. In June 1986, 36\% said they supported "nucleargenerated electricity" and 35\% said they did not support it [1360]. However, in April of that year, 70\% said they would disapprove if the nuclear power plants for generating electricity were built in their community [1351].

Public opposition to nuclear power plants increased not only in the United States, but also in seven other countries, according to the Worldwatch Institute, cited in the 1992 Statistical Record of the Environment. After the Chernobyl accident, majorities of $64 \%$ to $83 \%$ of samples from the United Kingdom, West Germany, Italy, Yugoslavia, Canada, and Finland were opposed to nuclear power plant construction. And, in France, the citadel of nuclear power, 52\% were opposed.

One item showed majority favorability to nuclear power. Roper reported in 1989 that $51 \%$ said they would like to see continued advances in "nuclear power for peaceful purposes," while $25 \%$ said it has "gone as far as it should," and 17\% said it has "gone too far now" [1545].

These results, although sparse, suggest a possibility that when "electricity" and "peaceful" are used in a survey item on nuclear power, public response tends to be more positive toward nuclear energy than when these terms are not used. The word "nuclear" may have strong associations with weaponry; some of the fear expressed toward nuclear energy may actually be, in part, a fear of nuclear weapons. This possible effect could be tested empirically rather easily. If the observation proved to be correct, it should make us cautious in our interpretation about results on public favorability and/or opposition toward building more nuclear power plants.

The public might favor more R\&D of nuclear energy while opposing construction of more nuclear power plants. For example, $66 \%$ of a January 1983 sample said it was "somewhat important" or "very important" for the federal government to continue its financial support of R\&D of nuclear power [1164]. And the need for electricity is at least implicitly recognized when the public responds in opposition to phasing out currently operating nuclear power plants.

RSM asked a national sample of voters in October 1989 whether they agreed that "an important way for utilities to reduce their use of fossil fuels like oil and coal is to use more nuclear power" [1072]. Although 23\% "strongly" agreed and 26\% "somewhat" agreed (totaling 49\%), the percentages favorable to DSM programs and the use of renewable energy to generate electricity were considerably higher ( $91 \%$ and $88 \%$, respectively). 
Table 7-2. Trends in Favorability toward Nuclear Energy, 1986-1991

Prototypical item wording: "Do you favor or oppose building more nuclear power plants in the United States? In your community?" a

\begin{tabular}{|c|c|c|c|c|}
\hline Date & Oppose & Favor & Unsure & Study No. \\
\hline \multicolumn{5}{|c|}{ Proportion responding (\%) } \\
\hline $06 / 91$ & 48 & 41 & 11 & [1491] \\
\hline $04 / 91$ & 52 & 40 & 8 & {$[1496]$} \\
\hline $04 / 91$ & 60 & 34 & 6 & {$[1496]^{*}$} \\
\hline $12 / 90$ & 62 & 32 & 5 & [1025] \\
\hline $07 / 90$ & 52 & 36 & 11 & [1232] \\
\hline $04 / 90$ & 57 & 36 & 7 & [1194] \\
\hline $03 / 90$ & 57 & 33 & 9 & [1283] \\
\hline $11 / 89$ & 62 & 33 & 4 & [1072] \\
\hline $01 / 89$ & 37 & 50 & 13 & [1358] \\
\hline $12 / 88$ & 61 & 30 & 9 & [1277] \\
\hline $09 / 88$ & 59 & 36 & 5 & [1431] \\
\hline $07 / 88$ & 57 & 37 & 7 & {$[1374]$} \\
\hline $05 / 86$ & 78 & 19 & 3 & {$[1364]$} \\
\hline $05 / 86$ & 40 & 45 & 15 & {$[1202]$} \\
\hline $05 / 86^{b}$ & 59 & 34 & 7 & [1351] \\
\hline $04 / 86^{b}$ & 65 & 27 & 8 & [1198] \\
\hline $04 / 86^{b}$ & 67 & 29 & 4 & [1418] \\
\hline $01 / 85$ & 55 & 36 & 9 & [1378] \\
\hline $02 / 83$ & 51 & 37 & 12 & [1282] \\
\hline $01 / 82$ & 53 & 37 & 10 & [1214] \\
\hline $11 / 81$ & 56 & 32 & 12 & [1215] \\
\hline $11 / 80$ & 47 & 47 & 6 & [1384] \\
\hline $05 / 79$ & 42 & 52 & 6 & [1397] \\
\hline $04 / 79$ & 43 & 44 & 13 & [1401] \\
\hline $04 / 79$ & 45 & 47 & 8 & [1409] \\
\hline $04 / 79$ & 42 & 52 & 6 & {$[1411]$} \\
\hline
\end{tabular}

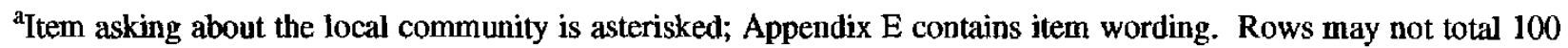
due to rounding.

${ }^{b}$ Post-Chernobyl nuclear power-plant accident (04/26/86) survey. 


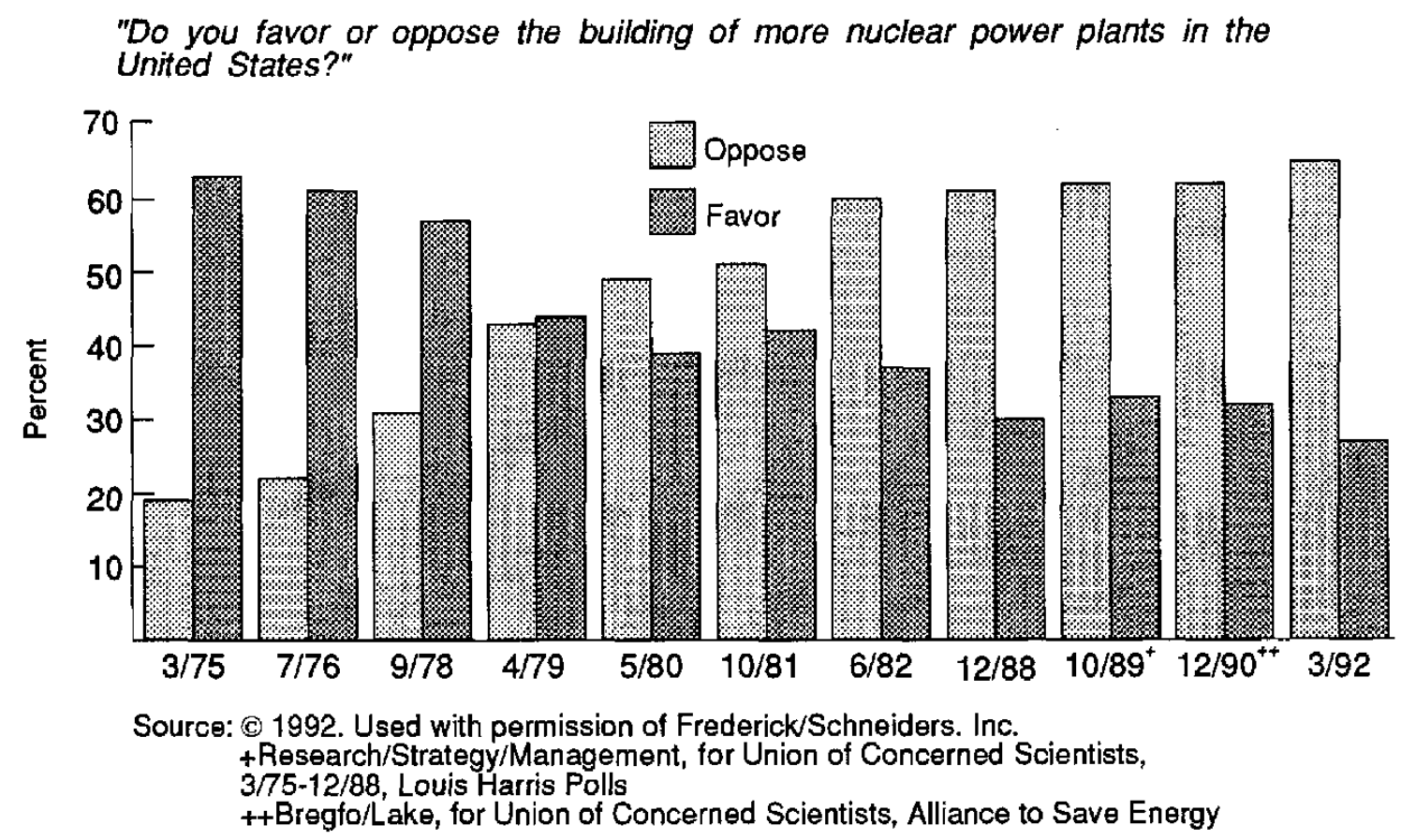

Figure 7-D. Trends in favorability and opposition toward nuclear energy

In January 1989, the Associated Press asked: "Should currently operating nuclear power plants continue operating, or should they be phased out gradually, or should they be closed down immediately?" [1358]. The plurality, $48 \%$, said the plants should continue to operate; $35 \%$ said they should be phased out gradually; $9 \%$ said they should be closed down immediately. A follow-up question was asked of the $35 \%$ preferring the gradual phaseout: "Would you want all nuclear power plants shut down within 5 years, 10 years, 15 years, or 20 or more years?" A third of those respondents said within 5 years, $36 \%$ said within 10 years, and $26 \%$ said 15 or more years.

Perceived risk of nuclear energy. The most conservative interpretation of the data on favorability and opposition to the use of nuclear power, giving every benefit of the doubt to nuclear energy, has to yield to the evidence on the perceived risk of nuclear energy. Without question, the public is currently worried, and has been worried for some time, about nuclear safety. The evidence to support this is substantial and centers around two fundamental problems: (1) the possibility of a nuclear accident resulting in radioactive contamination and (2) the storage of radioactive waste, which also could mean radioactive contamination. These are environment, safety, and health problems of significant proportions, which could cost massive amounts of resources to resolve, if, indeed, they are even capable of solution.

NBC News asked in July 1991: "Some people think we should build more nuclear power plants because they don't burn coal or oil which create air pollution. Others think that we should not build any more nuclear power plants because of the threat of accident or radiation. Which do you agree with?" [1486]. More than half (57\%) said we should not build, 35\% said that we should build more nuclear power plants. 
Figure 7-E shows the results of a verbatim trend item, asked between August 1979 and May 1986, on whether we should continue to build nuclear power plants. The proportion indicating that they feel it is "too dangerous" to continue to build these plants increased over the period, from $43 \%$ in 1979 to $57 \%$ in 1986.

Yankelovich/Clancy/Shulman asked in 1991: "How likely to you think it is that a nuclear power accident-like that occurring at Chernobyl 5 years ago-will occur in this country?" [1496]. Responding that such an occurrence was "very" or "somewhat likely" were $54 \% ; 42 \%$ thought it unlikely. This same survey asked: "In building nuclear power plants please tell me if each of the following is a very serious issue, a somewhat serious issue or not a serious issue" [1496]. The following proportions indicated "a very serious issue":

- Disposal of radioactive waste $(89 \%)$

- $\quad$ Safety of plant workers $(77 \%)$

- $\quad$ Possibility of an accident $(75 \%)$

- $\quad$ Cost of the plant (56\%).

When asked in 1986, and again in 1989, whether they thought "nuclear power plants in the United States are safer now than they were 10 years ago," 63\% agreed at both times [1358, 1360].

"On the subject of nuclear power. In general, do you feel we should continue to build nuclear power plants or do you feel it's too dangerous to continue to build these plants?" $[1066,1061,1060,1051,1047]$

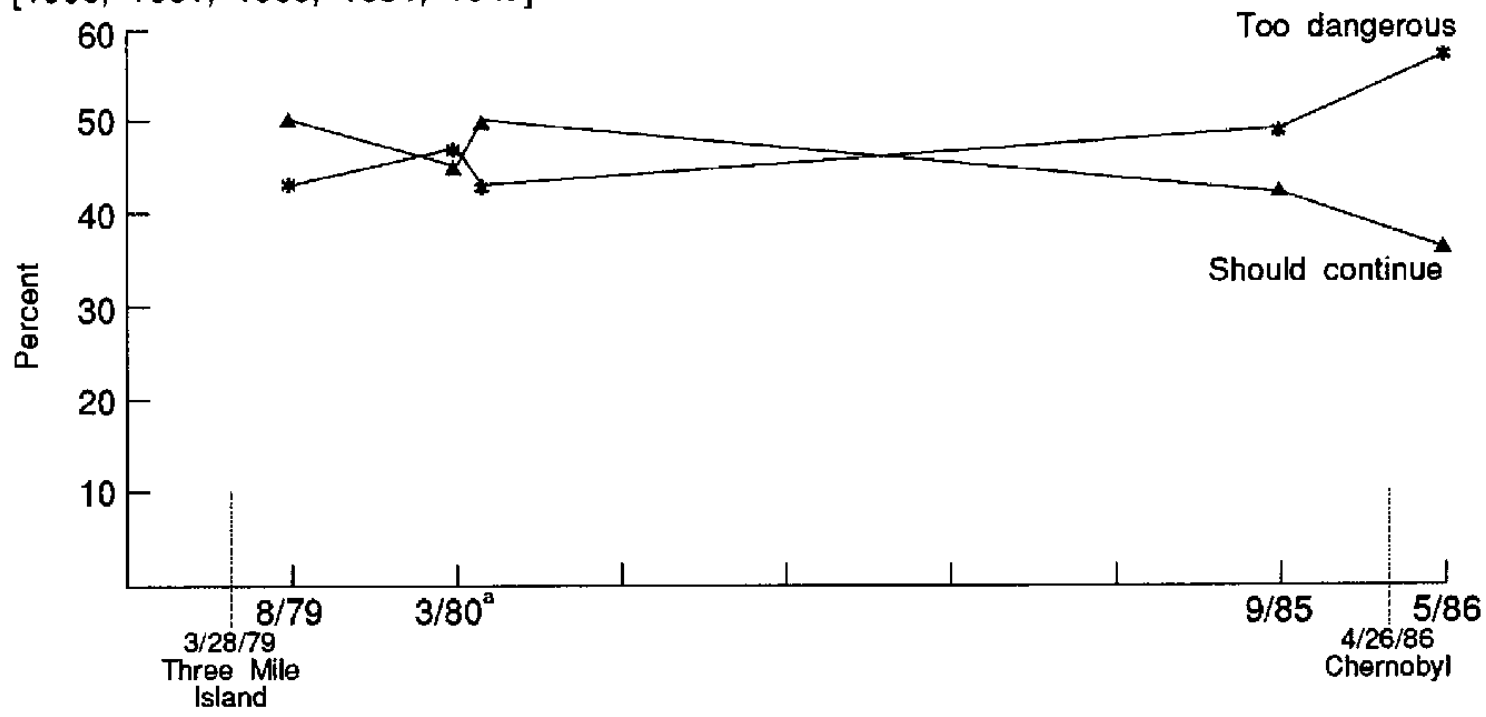

Source: Constructed by author using data from Yankclovich, Skelly and White.

Two surveys were performed during March 1980.

Figure 7-E. Trends in preferences concerning continuing to build nuclear power plants, 1979-1986 
The public's concern about nuclear danger has been increasing since 1973, several years before both TMI and Chernobyl. Figure 7-F shows the results from a verbatim trend item Roper used between 1973 and 1990 [1554]. In 1973 opinion was divided, although the larger plurality felt a nearby nuclear power plant would present dangers. The percentage saying that having a nuclear energy plant someplace near them would be dangerous increased steadily between 1973 and at least 1982, and it may have leveled off by 1990. For some reason, Roper did not report any data on this trend for the years 1984 through 1988 . The proportion stating that a nearby nuclear power plant would pose dangers fell 3 points between 1989 and 1990 , but this is approximately within the margin of error for these surveys. Similarly, there was a 3-point increase among those saying it would be safe (from 22\% to 25\%). Yet, 26\% in 1983 and 25\% in 1990 said it would be safe, which suggests no change during that period.

Concern about the risk of living near a nuclear power plant increased between April 1979 and May 1986 (both TMI and Chernobyl occurred during the intervening period). Table 7-3 shows trend data indicating that the proportion assessing propinquity to a nuclear power facility as a "high risk" situation increased from 45\% in April 1979 to 58\% in May 1986. More recent data on this trend have not been located; Roper may not have collected the data or may not have reported the information. In June 1986, Gallup also found $73 \%$ against the construction of a nuclear power plant nearby [1293]. This was up from $60 \%$ in April 1979.

"There are differences in opinion about how safe nuclear power plants are. Some people say they are completely safe, while others say they present dangers and hazards. How do you feet that it would be safe to have a nuclear energy plant someplace near here or that it would present dangers?" [1107, 1554]

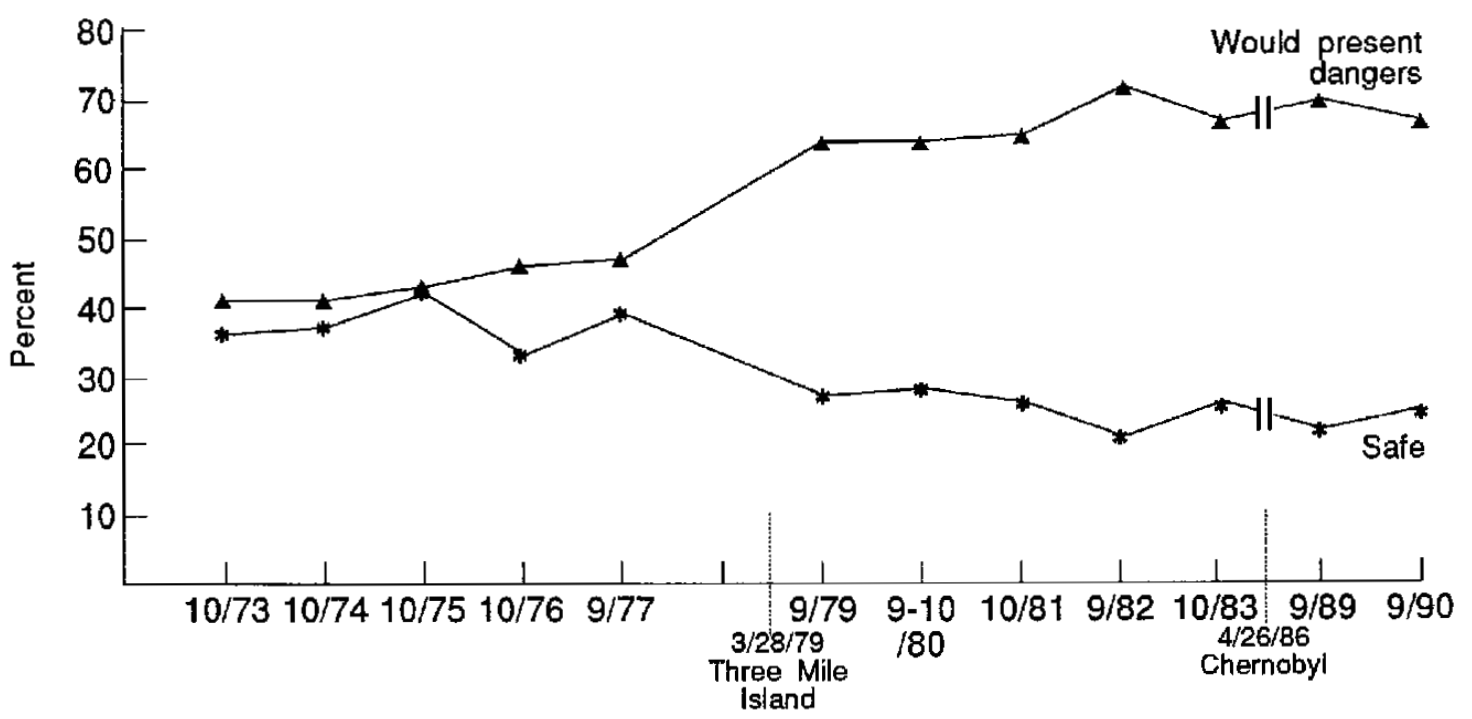

Source: Constructed by author using data from the Roper Organization.

II = 6-year gap in data collection.

Figure 7-F. Trends in perceived risk of nearby nuclear power facility, 1973-1990 
Table 7.3. Trends in Perceived Degree of Risk of Living near a Nuclear Power Plant, 1979-1986

"(. . . we hear a lot these days about things that can be risks to people's health or safety. Here is a list of a number of them. Would you read over that list, and then for each one tell me whether it is something you think involves a high degree of risk to a person, or involves a moderate risk, or involves only a minor risk?) . . . Living near a nuclear power plant."

\begin{tabular}{||l|c|c|c|c|c||}
\hline \hline Response & $\begin{array}{c}\text { April } \\
\mathbf{1 9 7 9}\end{array}$ & $\begin{array}{c}\text { June } \\
\mathbf{1 9 7 9}\end{array}$ & $\begin{array}{c}\text { April } \\
\mathbf{1 9 8 1}\end{array}$ & $\begin{array}{c}\text { Sept. } \\
\mathbf{1 9 8 5}\end{array}$ & $\begin{array}{c}\text { May } \\
\mathbf{1 9 8 6}\end{array}$ \\
\hline \multicolumn{5}{||}{ Proportion responding (\%) } \\
\hline \hline High risk & 45 & 45 & 46 & 48 & 58 \\
\hline Moderate risk & 32 & 27 & 27 & 28 & 25 \\
\hline Minor risk & 19 & 24 & 22 & 21 & 15 \\
\hline Don't know & 3 & 4 & 5 & 3 & 2 \\
\hline \hline Totals ${ }^{\text {a }}$ & 99 & 100 & 100 & 100 & 100 \\
\hline & $(2007)$ & $(2000)$ & $(1999)$ & $(1996)$ & $(1994)$ \\
\hline Study numbers & {$[1148]$} & {$[1146]$} & {$[1128]$} & {$[1089]$} & {$[1084]$} \\
\hline
\end{tabular}

Source: Constructed by the author using data from the Roper Organization.

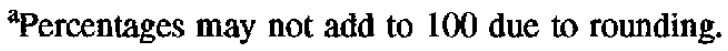

If there were a leveling off of the proportion indicating that a nearby nuclear plant would pose a danger, it could have been due to increased concern about global warming, as noted earlier. The data are at present insufficient to discern whether this is the case.

Radioactive releases, whether from a accident or from waste disposal facilities, would have profound consequences on environment, safety, and health. The 1990 Cambridge Reports study found that $83 \%$ said one of the very most important things utilities could do for the environment was "develop safe ways to dispose of radioactive waste" [1457]. Energy industry leaders participating in the 1988 League of Women Voters survey supported a policy to "resolve the issue of nuclear waste disposal" (98\% support) [1534]. Eighty-one percent of the public interest leaders in that study agreed.

The federal government has the responsibility for finding a location to store radioactive wastes; some states, nominated for such storage sites, have resisted fiercely, while others have been more amenable. A 1992 poll asked whether the federal government should be able to override state preferences in siting radioactive waste. Figure 7-G summarizes the responses. The vast majority (81\%) opposed this idea. And, as Figure 7-H shows, most of the public wants to retain two public-safety hearings before siting nuclear power plants, not to do away with one of them, as has been proposed by the Nuclear Regulatory Commission and recently passed by Congress as part of the 1992 Energy Policy Act [1561]. 
"Do you agree or disagree that the government should be allowed to establish a nuclear waste disposal site in a particular state even if that action overrides the state's or community's public health or environmental laws?" [1561]

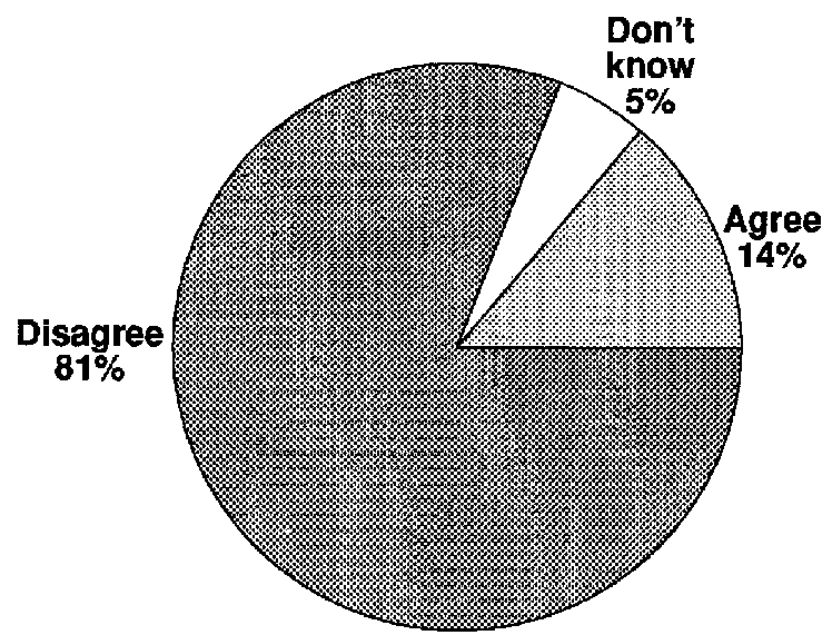

Source: (c) 1992. Used with permission of Frederick/Schneiders, Inc.

Figure 7-G. Perceived right of the federal government to establish nuclear waste sites

A 1986 Harris poll, taken after Chernobyl, asked: "How concerned are you at the present time about radioactive discharge from nuclear power plants-very concerned, somewhat concerned, not too concerned, or not at all concerned?" [1244]. Seventy percent responded that they either were "very" (46\%) or "somewhat" (24\%) concerned. Roper found $82 \%$ concerned about nuclear power plants as a source of exposure to radiation in their daily lives in July and again in August 1986 [1082, 1083]. This was up 17 points from 1979 [1145].

In May 1986, 58\% of an ABC News/The Washington Post poll responded that radioactive waste from nuclear power plants cannot be disposed of safely [1364].

Perception of danger from nuclear power plants could come from fear of radioactive releases, whether or not such releases are a result of a nuclear accident or meltdown. In January 1989, 50\% thought it "highly likely" or "likely" that "a serious accident at a nuclear power plant in the United States" would occur; 44\% thought it "unlikely" or "highly unlikely" [1358]. The same survey, which was conducted by the Associated Press, reported that $56 \%$ believed it was not "possible to safely store long-term radioactive waste from nuclear power plants."

CBS News/The New York Times asked, in 1988: "One way to reduce air pollution is to burn less coal and use more nuclear power to produce electricity. Do you think we should use more nuclear power, or do you think nuclear power has too many problems of its own?" [1328]. The majority $(54 \%)$ responded that nuclear power has "too many problems of its own"; $31 \%$ thought we should use more nuclear power. 
"Under current law, a public safety hearing is held before construction begins on a nuclear power plant, and after the plant is built, a second hearing may be held to consider new safety issues, such as the quality of construction. Congress is now debating a proposal to eliminate the second safety hearing in order to bring nuclear plants on-line more quickly. Do you favor this proposal?" (March 1992) [1561]

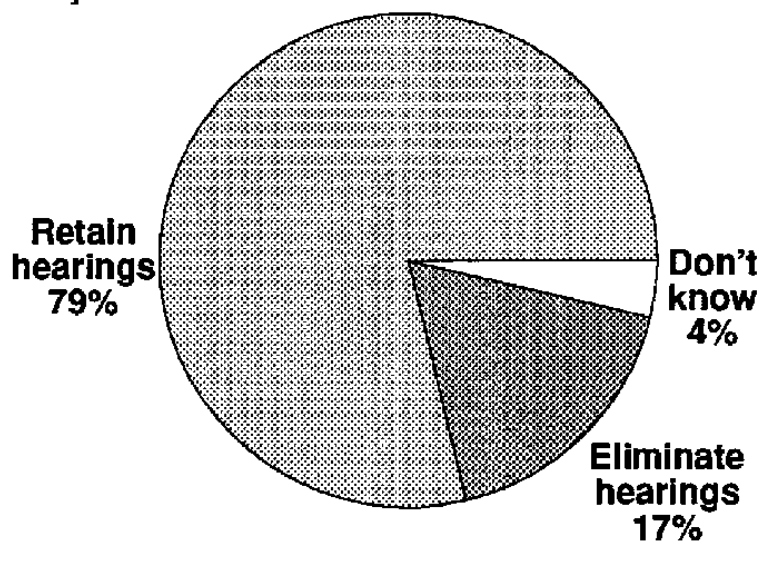

Source: (1) 1992. Used with permission of Frederick/Schneiders, Inc.

Figure 7-H. Preference on the number of safety hearings required before nuclear power plant construction is allowed

One of the proposals in response to concern about nuclear safety has been to shut down nuclear power plants. Mark Clements Research/Glamour magazine repeated an item verbatim each year between 1983 and 1987 to a national sample of women aged 18 to 65: "(I am going to read some statements to you about current issues. Please indicate if you strongly agree, slightly agree, slightly disagree, or strongly disagree.) . . . Nuclear power plants should be shut down until proven safe" $[1422,1423,1324,1325$, $1214,1213,1225]$. Women's concerns increased by 4 points over this 4-year period, which spanned the Chernobyl accident. In 1983, two-thirds agreed, (47\% of them "strongly"), that existing power plants should be shut down until proven safe. By $1987,71 \%$ agreed, (53\% of them "strongly") that they should be shut down.

A July 1990 survey of opinion leaders ${ }^{7}$ ranked the "electric utilities'" effects on the environment as best (by $44 \%$ ) from a list of five industries, and the "nuclear power industry's" effects as second best (by 33\%) $[1450$, p. 715$]$. These two industries ranked higher than the automobile, chemical, and oil industries, which were perceived by the participating leaders as having the worst environmental effects (with $35 \%$ stating oil was worst, $27 \%$ that the chemical industry was worst, and $21 \%$ stating that the automobile industry was worst).

${ }^{7}$ Included in the sample were federal officials and legislators, state officials and legislators, personnel from business and financial institutions, public interest group representatives, academics, and national and local news media reporters. 
Some hoped that in the future nuclear energy could become a safe source of energy. Half of a May 1986 national sample responded this way in response to a query on this point, while a plurality of $43 \%$ said nuclear power cannot become a safe source in the future, and 7\% said they didn't know [1364]. Half of an April 1986 sample was "optimistic about our ability to run nuclear generating plants without serious accidents" [1288].

Response to Chernobyl. In response to the Chernobyl accident, one national poll asked whether "nuclear power plants are safer in the United States than in the Soviet Union, less safe, or about as safe" [1364]. A majority (55\%) said U.S. plants were safer; only $2 \%$ said they were less safe. A majority (57\%) thought there was no danger that the United States "might be contaminated by radioactive fallout" from the Chernobyl accident [1288]. Another post-Chernobyl sample agreed, with 52\% saying they were not concerned that the accident could affect them [1351]. Similarly, 61\% of an ABC News poll on April 17 said they were "not worried at all" that radiation from the Soviet Union nuclear power plant accident would hurt them [1418]. However, $70 \%$ of one sample and $92 \%$ of another polled at the same time (April 1986) said that such an accident was "very likely" or "somewhat likely" to happen in the United States [1198]. And, 58\% told an ABC News poll that the Chernobyl accident had made them more fearful about such an accident happening in the United States [1418].

Attempting to compare the perception of nuclear risk in the post-Chernobyl period to other types of risk, Roper asked: "There is the kind of accident that both the Soviet Union and the United States have had in which a space mission fails and astronauts are killed. There is the kind of accident that happened at TMI and at Chernobyl in which the lives of residents in the area are lost or threatened. NEITHER IS GOOD, but which do you find the MORE acceptable risk-the risk involved in space shots or the risk involved in a nuclear power plant?" [1202]. The majority (56\%) responded that the space shot risk was more acceptable; one-quarter said that the nuclear plant risk was more acceptable; $19 \%$ said they didn't know.

When asked in May 1986 whether they thought the Chernobyl accident reflected "the inherent danger of nuclear power that exists in all countries, or that it only shows the weaknesses of the nuclear system and nuclear engineering that exist in the Soviet Union?," 52\% thought the accident reflected the inherent dangers of nuclear power [1202].

Regulation. Given the high levels of public concern about nuclear safety, we would expect that the public would favor stringent regulation of nuclear power. This appears to be the case. In October 1990, Roper reported that "about 3 in 4 Americans are confident that the government is doing a good job of making sure that medicine, consumer products, and food are safe for public use. But less than half are impressed with the performance of federal regulators in the areas of nuclear power, the environment, banking, and nuclear weapons production" [1552, p. 264]. Roper was referring to the fact that percentages responding "very confident" or "somewhat confident" of the government's job of regulating were $49 \%$ on nuclear powers, $45 \%$ on protecting the environment, $44 \%$ on making sure financial institutions stay healthy, and $41 \%$ on nuclear weapons.

An Associated Press poll asked, in January 1989: "Should the federal government be tougher when it comes to enforcing safety rules at nuclear power plants, or is it tough enough now, or is it too tough?" [1358]. Most said the safety rules "should be tougher" (79\%). The same poll asked: "Do you think nuclear power plants that have been completed but have not been licensed to generate electricity should be allowed to operate, or not?" Sixty percent said they should not be allowed to operate.

Sixty percent of the public believed their opinions on nuclear power would have at least some effect. Roper asked, in September 1987: "(Here are a number of things that can affect our lives in this country. Would you read down that list, and for each one tell me how much effect you think the opinion of the 
American people can have on it-a lot, some, very little, or none?) . . . The future of nuclear power plants." [1073]. While one-quarter responded "a lot," another $26 \%$ said "very little," and the plurality (35\%) said "some"; $10 \%$ thought the American people could have no effect at all.

Concern about the adequacy of nuclear regulation has existed for more than a decade. In 1984, 50\% thought that government regulation of nuclear energy was insufficient, while $30 \%$ said it was "about right," and 10\% thought it was "too much" [1098]. In 1981, Roper asked: "Do you feel the Nuclear Regulatory Commission goes too far in regulating the activities under its supervision, doesn't go far enough, or does about the right amount?" A plurality, 43\%, said it "doesn't go far enough," while 39\% said it "does about the right amount"; 9\% said it "goes too far" [1125]. In November 1980, 91\% said that the "federal government ... should continue to make spot inspections of nuclear plants" [1384].

In June 1986, Gallup asked: "Do you feel that nuclear power plants operating today are safe enough with the present safety regulations, or do you feel that their operations should be cut back until more strict regulations can be put into practice?" [1293]. Two-thirds responded that they should be cut back pending more strict regulations; $25 \%$ said they were safe enough; 9\% didn't know. The Associated Press, in a June 1986 poll, also found that a plurality of $44 \%$ said the nuclear industry in the United States "does not have adequate safeguards," while $35 \%$ thought that it did [1360].

A number of items asked about public preferences concerning how decisions should be made about the use of nuclear power. For example, in January 1989, an Associated Press poll asked: "Should a governor have the authority to shut down an operating nuclear power plant in his or her state?" [1358]. Agreeing that a governor should were $62 \%$ of the sample; $31 \%$ thought not. This sample was then asked: "Should a governor have the authority to keep a nuclear power plant from opening in his or her state?" A majority, $58 \%$, said that a governor should have this authority.

It was also interesting that $80 \%$ were opposed to U.S. companies selling nuclear power plants to Mainland China in April 1987 [1077]. Likewise, 83\% opposed selling them to the Soviet Union [1077]. To speculate, these results may have stemmed from fears about nuclear proliferation.

ORC stated in an August 1983 poll: "After the Three Mile Island nuclear reactor accident in 1979, Congress enacted legislation requiring each operating nuclear power plant to have a standby plan for evacuating residents with a ten-mile radius of the plant in case of a nuclear accident. This plan must be approved by local and state authorities." [1161]. The poll asked about agreement or disagreement with the following statements about this evacuation planning:

- The federal government should share the cost of evacuation planning ( $81 \%$ disagreed)

- Utilities should be expected to finance off-site preparedness, including installing sirens, setting up communications centers, and rebuilding roads and bridges that would be used in an evacuation (77\% agreed)

- The federal government should take full responsibility for the evacuation planning (55\% agreed)

- $\quad$ No evacuation plan would really work in highly populated areas (49\% agreed, $45 \%$ disagreed)

- It gives anti-nuclear groups too much power to influence local residents to refuse to cooperate in tests of evacuation plans (48\% agreed; $39 \%$ disagreed)

- It gives local authorities too much power over nuclear plants by allowing them to refuse to approve evacuation plans ( $44 \%$ agreed, $44 \%$ disagreed) 
- Evacuation plans are not necessary because it is so unlikely that an unmanageable nuclear accident will occur (79\% disagreed).

The public clearly thought evacuation plans were an appropriate precaution for nuclear neighbors, and that utility companies should be responsible for financing them. The federal government was seen as the appropriate agency to oversee the evacuation planning.

Regulating nuclear energy is seen as a necessity, consonant with the public view of nuclear technology as a risky enterprise. Much as the public appears to view electricity as the energy alternative of choice, regulatory protection, while not trusted as completely efficacious, is considered essential in employing nuclear energy.

Summary. No new nuclear power plants have been ordered or built in the United States in several years. Prior to the Chernobyl accident, the public might have been more hopeful that the problems associated with nuclear energy could be ironed out. For example, a 1984 ORC survey found $54 \%$ expressing confidence in the standards and procedures by which nuclear power plants were built [1183]. Yet, half of another 1984 sample said they were "not very confident" or "not at all confident" that "most safety problems involving nuclear power" had then been solved [1183].

The evidence of significant discomfort on the public's part about the risk of nuclear power is compelling. The perceived problem revolves around releases of radioactivity into the environment near nuclear power facilities or radioactive waste storage facilities. Although the Roper Organization found an increase in the proportion of the public identifying nuclear power as a realistic future alternative (see Chapter 6), other data do not show either a dramatic decrease in the perceived risk of nuclear energy or a dramatic increase in favorability toward nuclear power. This is despite scientific concern about the greenhouse effect and global warming, which has led some scientists to call for more nuclear-rather than coal-generated electricity.

Some results, though sparse, suggest that public response to nuclear energy tends to be more positive when the words "electricity" and "peaceful" are used in survey items. It may be that fear of nuclear energy is linked, at least in part, with its association with nuclear weaponry.

The seeming lack of credible sources of information on nuclear energy is striking. The public apparently trusts neither anti-nuclear activists, nor the nuclear industry, nor the government. Most said the media covered the Chernobyl story well. The situation appears to be that "the jury is still out" on nuclear energy, in part because of lack of credible information.

More evidence will be needed before we can conclude, however, that the public will continue to oppose nuclear energy despite global change. Insufficient evidence currently exists that the connection is made in the public's mind about the causal relationship between burning coal to generate electricity, using gasoline for automobiles, and using oil for home heat, on the one hand, and global climate change on the other. Once evidence of this relationship is widely accepted, public opinion about nuclear energy and its perceived risks can be more accurately assessed, and the future acceptability of nuclear energy better anticipated. 


\section{Chapter 8}

\section{Efficiency and Renewables in Buildings}

\section{Background and Summary}

The potential is striking for reducing consumption of utility-supplied energy in U.S. residential and commercial buildings by using already available cost-effective technologies. One recent study estimated buildings energy consumption could be reduced by up to one-third by 2015 , when compared with "business-as-usual" projections. ${ }^{1}$ Many other estimates exist; they vary from $25 \%$ for existing residential buildings to $50 \%$ for new buildings, using different assumptions.

Many households have already undertaken energy efficiency measures, and a few have installed technologies relying on renewable energy, such as small wind machines, passive solar designs, and solar domestic hot water systems. Since 1980 , per household energy consumption has been reduced by $16.7 \%$; concomitantly the number of households grew by $13.5 \%$ (Morrison 1992). Total U.S. household energy use was 10.9 quads $^{2}$ in 1979 and 10.2 quads in 1990, a 6.4\% decrease, despite the increase in number of households. However, average household size decreased during that period and per-household energy use at the site increased slightly from 1985 to 1989 (U.S. Congress 1992). The chapter's empirical findings on buildings are summarized below.

Virtually all opinion data related to buildings concerns residential energy use. The polls contained some questions on households' reasons to use energy more efficiently, on knowledge and information sources used, and on actions actually taken. More of this type of data were found in state rather than in national polls, however. Data on these topics, and on buildings energy policy preferences, are presented in this chapter.

No solid trend data using verbatim items replicated over time were available on self-reported conservation behavior between 1979 and 1992. This suggests that polling organizations themselves and poll sponsors had decided that public opinion on energy efficiency and use of renewables was not of enough importance to continue to collect data consistently. The data available are based on various questions asked of national, state, and local samples selected in different ways. The evidence is thus approximate, at best.

Reasons to engage in energy-efficiency practices and to invest in efficiency and renewables have not been systematically studied at the national level for several years. Local market-area studies might be fruitful avenues for further research on this question. The smattering of poll data available suggests a perception of relatively unimportant reasons for conserving. For example, a 1990 national poll found that majorities said investment in efficiency and better energy use habits would save less than $10 \%$ of their utility bills [1025]. Barriers to household efficiency, however, seem significant. A 1989 poll found that pluralities

\footnotetext{
l"Business as usual" means no policy changes.

${ }^{2}$ Quad $=$ one quadrillion Btu. These figures refer to site energy, not source energy.
} 
said "business and industry priorities" (38\%) and "decisions made by government" (29\%) were "the biggest obstacle to the country using energy more efficiently" [1072]. Other major barriers were the upfront cost of energy improvements and what might be termed the "hassle factor" in arranging for energy improvements. Responses to these and other polls seem to indicate that individuals find it costly and time consuming to overcome institutional obstacles to efficient household energy use.

The amount of conservation behavior being practiced as estimated through self-report-either through lifestyle changes or through investments in retrofits-appeared to increase in the late 1970s to the mid1980 s but to decrease subsequently. The earlier review reported that most people said they were practicing some form of residential energy conservation (Farhar et al. 1979). The practices mentioned most frequently were those that were more convenient and less costly, such as turning down the thermostat and turning off lights and appliances when not in use.

Taken together, data from national and state samples seem to indicate a pattern in which somewhat larger (though still low) proportions of the public during the early to mid-1980s, compared with the late 1970s, invested in somewhat more costly items that would reduce homes' use of utility-supplied energy. These items ranged from attic insulation to energy-efficient appliances, and even solar energy systems. Mentioned most frequently in these studies were the relatively less expensive measures-insulation, caulking, weatherstripping, water-heater wrapping, window-screening devices, and clock thermostats.

In 1990, however, self-reported conservation actions and investments were minimal. Gallup asked a national sample: "Do you happen to be doing anything to reduce your use of energy -that is, your use of gasoline, electricity, or natural gas?" Although two-thirds reported some action, more than one-third reported that they were not doing anything at all [1313]. Actions being taken "were the easiest to do" (turning off lights and turning down the thermostat), just as in the seventies. Another survey by NBC News/The Wall Street Journal found that, when asked whether they took steps to reduce the use of electricity and gas in their homes, $68 \%$ said "regularly" and $22 \%$ said "occasionally." Only 5\% said "never" [1194]. In March 1990, Gordon S. Black/USA Today asked: "How much does your household cut back on heat in the winter or air conditioning in the summer to conserve energy?" [1283]. More than half (52\%) said they cut back "somewhat"; $30 \%$ said "a great deal"; $5 \%$ said "not at all." The urgency to engage in conservation has decreased markedly, at least as measured by the poll data on self-reported conservation behavior.

Some of this decline may be attributed to the fact that many households had already undertaken energy efficiency measures. These people would not be repeatedly reporting installation of insulation, for example, in response to surveys assessing conservation behavior. Some evidence for this can be found in the data on household energy consumption. Morrison (1992) reported that, since 1980, per household energy consumption has been reduced by $16.7 \%$; concomitantly, the number of households grew by $13.5 \%$ [1538]. Total U.S. household energy use at the site, 10.9 quads in 1979 , was only 10.2 quads in 1990, a $6.4 \%$ reduction despite the increase in number of households [1538]. Another analysis found that energy use per household at the site dropped from 1970 to 1985 but increased slightly from 1985 to 1989 (U.S. Congress 1992 , p. 18) Of course, lifestyle changes and other factors could also play a part in accounting for these results.

When residential energy use is examined from a source energy standpoint, however, it has recently increased. Source energy use in residential buildings was reported at 16.8 quads in 1989 , at a cost of $\$ 104$ billion (U.S. Congress 1992). Space heating accounted for almost half of energy use, followed by water heating, refrigerators and freezers, space cooling, and lights. Source energy use has increased at an average annual rate of $1.2 \%$ for the last 20 years; however, the increase in use accelerated to a rate of $2.1 \%$ from 1985 to 1989 . This increase is attributed to a growing population, shrinking household size, 
and increasing demand for electricity for air conditioning and other energy-intensive services (U.S. Congress 1992, p. 15).

Some evidence suggests that the public may be willing to increase conservation activity once again, should energy shortages occur. In September 1990, NBC News/The Wall Street Journal asked a national sample: "Let me read you a list of ways people conserve energy. For each one, please tell me if you are likely or unlikely to try to conserve in this way if there is an energy shortage" [1188]. Three-quarters of the sample said they were likely to use less heating fuel and air conditioning, while $62 \%$ said they would use appliances less.

State and local governments and utility companies appear to be the most frequently used sources of information about energy efficiency and renewables. Written sources (newspapers and pamphlets) are the most popular information media.

The voluntary practice of energy efficiency and investment in energy-conserving features and solar energy systems may have declined or it may have shifted subtly in ways the polls are not capturing. The phaseout of the energy conservation and solar energy tax credits could have contributed to less conservation, as could relatively low energy prices. However, these factors appear to be only part of the story. The other part appears to be public perception of "institutionalized inefficiency."

Energy conservation and efficiency may have become a part of how U.S. households function. Current building practice has been producing homes that are more efficient than their old counterparts. Consumers are remodeling and improving existing homes and purchasing efficient appliances to replace older ones. What the polls do not recognize is that if consumers reduce their outlay for residential energy costs, they could displace energy consumption elsewhere, to activities outside the home. Eating out, travel, and long commutes might reduce residential energy consumption, yet increase overall energy use.

Energy efficiency practice in U.S. residences may not be as bad off as these results might suggest. Household energy consumption has continued to decline since 1980. Many households obviously took action to retrofit their dwellings, at least up to a point. A good many retrofits have already been accomplished. Further retrofits might not seem as cost-effective to newer home occupants, particularly with current level utility costs. In the meantime, building practice has continuously improved the operating efficiency of new housing.

As noted, voluntary residential energy conservation practice and investment seem to have declined in the past few years, despite the persistence of concern about the energy situation and public preferences for energy efficiency and renewables. The public is supportive; institutional barriers may be hindering more widespread household involvement in efficiency practice and investment. "Institutionalized inefficiency" may be a significant obstacle to more cost-effective adoption of efficiency and renewable measures. If this is true, policy should look toward ways to make efficiency and the use of renewables as easy as or easier for consumers to use than inefficiency and the use of utility-supplied energy from conventional sources.

The balance of this chapter provides the detailed empirical findings on these topics.

\section{Decision Factors}

The last 12 years of polling have produced almost no data on household energy efficiency decision factors. Few national data on decision factors for household use of solar energy have been collected since 1980. From the evidence available, motives to conserve energy seemed insubstantial and barriers seemed significant. 
The earlier reviews noted that "most studies on energy opinion are atheoretical, which limits their usefulness for policy purposes and perpetuates research gaps" (Farhar et al. 1980). The research gaps identified in 1979 and 1980 have indeed been perpetuated. The following hypotheses resulted from analyses completed at that time:

1. That willingness to conserve energy and adopt solar energy was a function of belief in an energy crisis.

2. That belief in an energy crisis itself was a function of

a. attributing the energy problem to dwindling fossil fuel supplies rather than to profit motives of oil companies

b. experiencing negative impacts from energy shortages or rising costs

c. awareness of energy facts and issues

d. environmental concern

e. exposure to credible information sources and high knowledge.

3. That adoption of efficiency and renewables was a function of their perceived effectiveness, relative advantage, low risks, and information on how to go about doing it (or where to find out).

The empirical evidence at that time suggested that decreases in utility bills were a more important motivator for engaging in energy efficiency and adopting renewables than concern about an energy crisis.

One clue to why no national polls explored consumer motivation to engage in more household energy efficiency is offered by an item Research/Strategy/Management (RSM) asked in October 1989: "We've made significant gains in energy efficiency since 1970. Experts say that the country can use energy even more efficiently. Which do you think is the biggest obstacle to the country using energy more efficiently-(read and rotate) consumer demand, business and industry priorities, or the decisions made by government?" [1072]. Selected most frequently was "business and industry priorities," (38\%), followed by "decisions made by government" (29\%). About one-quarter chose "consumer demand." This suggests a perception that individual households may have done a significant proportion of what they were able to do without needing further systematic assistance from public and private institutions.

Respondents to national polls have continued to indicate that conservation is important. In April 1989, Yankelovich/Clancy/Shulman asked: "Do you think there is a need in this country for stricter conservation measures to preserve energy, or do you think we have generally done enough already?" [1045]. Threequarters called for "stricter conservation," while only $21 \%$ said that we have done enough. NBC News repeated a 1982 item in 1986: "Do you think it is still as important for Americans to conserve energy as it was a few years ago, or don't you think so?" [1199]. In 1982, 91\% said it was important; in 1986, 89\% still indicated importance.

However, some national poll evidence suggests that consumers may not believe energy conservation is effective. Perceptions of reductions possible, as elicited from a 1990 national sample, appear minimal. RSM and Greenberg/Lake, The Analysis Group asked: "Think about the total amount of money you spend for energy each month. That would include your gas and electric bills and so forth. There are two ways you might reduce that monthly energy bill. First, you might develop better energy use habits like turning out the lights, keeping your tires inflated and the thermostat adjusted properly. Second, you might invest in more energy efficient technologies like more ceiling insulation or better appliances" [1025].

When asked, "How much do you think you could reduce your energy bill by developing better habits," $56 \%$ altogether indicated a reduction of less than $10 \%$. Eleven percent of the sample responded "not at 
all." Only $22 \%$ thought changes in habits would reduce bills by $15 \%$ or more. Similarly, $58 \%$ indicated that "investing in more energy efficient techniques" would result in savings of less than $10 \%$, and $16 \%$ of the sample expected no savings whatsoever. Consumers cannot be expected to invest in efficiency when they perceive, rightly or wrongly, that such investment is ineffective in achieving desired ends, like lower utility bills.

At least part of this perception may be based on ignorance of the cost-saving impact of energy-efficiency investments and part on the delayed manner in which savings are realized. For initial, upfront investments, consumers realize savings on their utility bills for years into the future over what they would otherwise have spent. A 1989 survey of Ohio utility customers asked about the payback period consumers required for conservation investments. The plurality, 43\%, had no understanding at all of the payback period concept. Almost one in five expected payback within 1 year, another $15 \%$ within 2 years, and the balance of the sample within 5 years.

As noted, no national samples explored decision factors per se. A few state and local surveys included such items; the balance of this section reports on the limited amount of data available from these surveys.

Only two surveys asked about reasons to conserve energy. A 1984 Alabama sample reported that saving money, societal benefits (undefined), and conserving scarce resources were the three most important reasons [1448]. A 1987 sample of West Virginia households reported that the cost of energy was the most important reason to conserve. This sample was asked the conditions under which they would be willing to cut energy use by $5 \%$. A plurality of $46 \%$ said they had already cut their energy use by 5\% [1475]. Another $43 \%$ said that loss of income would be a sufficient reason for them to cut energy use by $5 \%$. And a third said that if they were convinced the energy crisis were real, they would be willing to conserve. Thirty-two percent said they would if they possessed information about how to conserve, and $30 \%$ said that if fuel prices increased enough to reduce the household's savings or add to its debts they would be willing to conserve. About a fifth (22\%) said they would conserve energy if others were willing to conserve. Finally, $6 \%$ indicated they would not be willing to conserve under any circumstances.

Clearly, reasons to conserve household energy have not been compelling.

Barriers to household energy conservation, on the other hand, seem significant. A December 1990 national poll asked: "What are some of the things preventing you from making the changes leading to more efficient use of energy?" (open-ended) [1025]. The modal response was "I'm doing all I can," mentioned by $34 \%$ of the sample. Other responses combined yielded $44 \%$ objecting to the high cost of home improvement or of energy efficient features. Another $16 \%$ said it was inconvenient or difficult to change habits.

These major barriers - the upfront cost of energy improvements and what might be termed the "hassle factor" in arranging for energy improvements or adjusting daily energy consuming practices-were borne out by four state surveys between 1982 and 1987. A 1982 Iowa survey showed that reasons mentioned most frequently included "can't afford it now," "cost/benefit trade-off is too low," "don't know what to do next," "too hard to install by myself," "plan to move and don't want to make the investment." [1443]. A 1985 survey of Connecticut households found respondents saying: "money, can't afford, too expensive" and "time, too busy" [1460].

A trend item in West Virginia reported in 1987 found that "habit," "don't believe there is a need to conserve," and "selfishness" were mentioned most often [1475]. Ohio customers in 1989 perceived little to be gained from conservation [1476]. 
Decision factors about renewables have been the topic of two studies located. In 1988, Central Maine Power Company sponsored a survey of Maine residential wind generator owners [1464]. Motivations for windmill owners to install windmills were self-reported as follows: "save energy" (36\%), "experiment with windmills" (32\%), "save money" (12\%), "tax break" (4\%), "conservation" (4\%), "boost sales" (4\%), "investment in the future" (4\%), and "independence from the utility company" (4\%). These owners were asked about the impact of the wind-produced energy on their electricity bills. More than half (56\%) said it was "about what expected," 35\% said "less than expected," and 6\% said "more than expected." Overall, $80 \%$ reported satisfaction with their windmills, with $25 \%$ saying "very satisfied" and $56 \%$ saying "somewhat satisfied." About $13 \%$ were "very dissatisfied."

Because $60 \%$ reported that the level of electricity savings was less than expected, and $80 \%$ were satisfied with their experience, the results suggest that decision factors motivating windmill ownership are not primarily economic and may be motivated more by environmental and conservation values, values of selfsufficiency, and by the enjoyment of having a windmill "toy" to play with.

The most systematic attempt to define household motivations to adopt solar energy was the Solar Energy Research Institute (SERI-now the National Renewable Energy Laboratory [NREL]) study, which collected data from a national probability sample of homeowners and a national purposive sample of 3809 solar homeowners in 1980 [1533]. These samples were asked similar items about decision factors. The homeowners sample was asked: "I am going to read a list of possible advantages of using solar energy that could enter into your decision about using solar energy in your home. For each item on the list, please tell me how important it would be for you in making such a decision." The solar homeowners sample was asked: "Here is a list of factors that might have influenced your decision to adopt solar energy. For each item on the list, please enter the number on the scale that shows how important this advantage actually was to you in making your decision to use solar energy." The questionnaire used the same response codes as were used for the homeowners. (These response codes had been constructed after a number of qualitative interviews with solar and nonsolar homeowners prior to the surveys.)

Table 8-1 shows the results. Homeowners mentioned most frequently economic motivations to adopt solar energy, including longer term and more immediate reductions in energy costs and protection against rising costs. Noneconomic values mentioned frequently were environmental protection and increasing the comfort of the home. A factor analysis showed three factors affecting solar adoption: (1) economic motivation, (2) societal benefits, and (3) personal satisfaction (such as getting to innovate or experiment, and increasing status, prestige, or self-esteem).

Solar homeowners also mentioned economic factors as the top three reasons for having adopted solar energy. Other important reasons they cited were increased comfort of the home, increased reliability of energy supply, societal benefits (environmental protection, easing energy shortages, reducing the need for power plants), increased awareness of household energy use, and increased self-sufficiency.

Majorities of homeowners were more likely to select reasons presented (13 selected) than were solar homeowners (six selected). However, these differences could be due to the fact that homeowners were personally interviewed and solar homeowners completed a mail questionnaire. The pattern of responses was not markedly different between the two samples.

Reasons to engage in energy efficiency practices and to invest in efficiency and renewables have not been systematically studied at the national level for several years. Local market-area studies might be fruitful avenues for market research. However, for national policy purposes, more information is needed concerning the factors that motivate consumers. Barriers to efficiency and renewables use are significant. Responses to survey items seem to indicate that inefficiency is institutionalized, and that individuals find it costly and time consuming to overcome institutional obstacles to efficient household energy use. 
Table 8-1. Perceived Benefits of Residential Solar Use, 1980

For homeowners: "I am going to read a list of possible advantages of using solar energy that could enter into your decision about using solar energy in your home. For each item on the list, please tell me how important it would be for you in making such a decision." (Response categories: not all important, slightly important, somewhat important, important, very important.)

For solar homeowners: "Here is a list of factors that might have influenced your decision to adopt solar energy. For each item on the list, please enter the number on the scale that shows how important this advantage actually was to you in making your decision to use solar energy." Percentage indicating "important" and "very important." (November 1980) [1533]

\begin{tabular}{||l|c|c||}
\hline Item & \multicolumn{2}{|c||}{$\begin{array}{c}\text { Solar } \\
\text { homeowners }\end{array}$} \\
\hline Proportion responding (\%) & \multicolumn{2}{|c||}{} \\
\hline \hline Saving money over the long term & 84 & 71 \\
\hline Reducing utility bills now & 82 & 87 \\
\hline Protecting against rising costs & 79 & 49 \\
\hline Having a more reliable supply of energy & 77 & 56 \\
\hline Conserving natural resources; protecting the environment & 71 & 34 \\
\hline Increasing comfort of home & 70 & 56 \\
\hline Easing energy shortage & 68 & 69 \\
\hline Increasing overall self-reliance & 65 & 49 \\
\hline Increasing independence from utility company & 65 & $44,35^{\text {c }}$ \\
\hline Availability of income tax credits & 64 & 33 \\
\hline Reducing need for more large power plants & 63 & 28 \\
\hline Increasing independence from federal government policies & 61 & 24 \\
\hline Increasing resale value of home & 27 & 35 \\
\hline Getting to innovate or experiment & 14 & 10 \\
\hline Increasing status, prestige, self-esteem & - & 43 \\
\hline Increasing awareness of household energy use & - & 25 \\
\hline Increasing awareness of the natural environment, for example, \\
weather patterns & & \\
\hline
\end{tabular}

Source: Constructed by author using data from NREL and Gallup.

${ }^{a}$ National probability sample, personal interview, $\mathrm{N}=2023$.

Wational purposive sample, mail questionnaire, $\mathrm{N}=3809$.

${ }^{c}$ Availability of federal income tax credits (44\%); availability of state tax credits (35\%). 


\section{Knowledge and Information Sources}

The earlier reviews of public opinion data found very little information on knowledge and information sources on the use of efficiency and renewables in buildings. Yet specific knowledge of how to conserve energy effectively and how to use renewables is essential if these alternatives are to contribute to the national energy equation. The reviews found a slight amount of empirical evidence that levels of technical knowledge on how to save energy effectively were low in the general public. At that time, in 1980, researchers concluded: "So little is known about public awareness concerning energy that more research is required to define knowledge levels and information requirements." (Farhar et al. 1980: p. 165). The researchers recommended greater emphasis on programs to extend public awareness of energy facts and issues and technical knowledge, particularly in energy conservation and solar energy.

Since that time, virtually no information has been gathered by national polling organizations on knowledge and awareness levels in the population about how to use household energy efficiently or about the decentralized use of renewable energy sources. At the national level, the SERI/ Gallup and Council on Environmental Quality surveys in 1980 are the most recent data located. Beyond this, data from 10 state and local surveys and some of the special population studies, constitute most of the information currently available on this topic. These studies focused on information sources used, the credibility of information sources, audits as an information source, energy topics on which populations wanted information, and technological awareness.

Information sources used. In 1990, Louisiana residents polled (40\%) said that they were likely to ask a local or state governmental agency for energy efficiency information [1430]. A majority of Louisiana opinion leaders $(90 \%)$ said that they would be willing to receive a "brief newsletter which provided information on energy conservation trends, tips, updates and legislative challenges" [1435]. When asked, in 1988, whom they contacted for conservation information, 52\% of a sample of Nevada households participating in the Low-Income Home Energy Assistance Program (LIHEAP) said their utility company; $17 \%$ mentioned a government agency, 5\% friends and neighbors, 5\% the cooperative extension, and $22 \%$ "other" [1223].

In West Virginia in 1987, half of the sample said they preferred to receive information on energy through newspapers [1475]. The next most popular source was television (43\%); 37\% said "tapes and pamphlets available in the County Extension Office." A plurality (46\%) of a 1987 Alabama sample was aware that the State of Alabama provided energy conservation information or services to the public [1434]. The 1984 Alabama sample was asked whether they had received information on energy conservation during the past year; $49 \%$ said that they had [1448]. Of those responding affirmatively, virtually everyone mentioned friends and relatives, followed by radio $(97 \%)$, hardware/lumber companies (96\%), educational institutions $(95 \%)$, television (89\%), newspapers (86\%), and journals/magazines (80\%). Utility companies were mentioned least frequently (25\%).

When asked in 1982, "Where would you go to get information about any home weatherization project?," half of an Iowa sample said their utility company, followed by a contractor (12\%), the college (10\%), a friend (8\%), the hardware store (6\%), the library (3\%), and government (3\%) [1443]. A 1981 New Jersey sample of audited households most frequently reported that they had heard about the audit from their utility company [1216].

The 1980 SERI/Gallup national survey of homeowners asked: "How likely it is that you would use each source to get information about solar energy, assuming these were available to you" [1533]. Majorities of the sample chose the following, in descending order of frequency of mention: 
- $\quad$ People who have solar energy systems (80\%)

- Demonstration buildings or model solar homes (75\%)

- Books, journals, and reports about solar energy (73\%)

- $\quad$ Magazines and newspapers (70\%)

- $\quad$ Energy fairs, exhibits, home shows (66\%)

- Television and radio programs (65\%)

- Friends, relatives, neighbors and acquaintances (53\%)

- Local contractors (heating, plumbing, etc.) (53\%)

- Homebuilders, architects (51\%).

This study also asked respondents how likely is it that they would contact a list of "organizations that have information about solar energy." Mentioned by majorities were the following:

- Solar companies $(69 \%)$

- $\quad$ State energy or solar office $(62 \%)$

- Federal information organization (56\%)

- Federal energy agency or laboratories $(54 \%)$

- Utility companies (54\%)

- State or county agricultural extension service agents (50\%).

However, because these data are so dated, they should be viewed with caution. They probably do not accurately reflect current preferences. They are cited only as examples of the type of national level data once available.

In sum, state and local governments and utility companies appear to be the most used information sources about energy efficiency and renewables. Written sources (newspapers and pamphlets) are the most popular information media.

Credibility of information sources. The slight amount of evidence available suggests that utility companies have gained in credibility as information sources about household efficiency. State governments have also been preferred sources. A plurality of a West Virginia sample in 1987 indicated that the Governor's Fuel and Energy Office "should play an important role in energy conservation education among the State's population-raising awareness of the need of information about the energy conservation issue" [1475]. This was the most frequently selected role for this office.

The West Virginia poll also queried households, between 1978 and 1987, about sources of reliable information. Table 8-2 presents the verbatim trend data on this item. The data show an increase in confidence in public utility companies of 16 points between 1980 and 1987 . The most reliable sources were considered to be public interest groups, the federal government, and state government [1475].

In 1984, a plurality of Alabama residents polled said that utility companies "probably do the best job of providing conservation information to the public," followed by $27 \%$ selecting state government and $20 \%$ private industry [1448].

Audits as an information source. In September 1990, Cambridge Reports asked a national sample: "Thinking about your local utilities-your electric company and your gas company-do any of these utilities offer energy efficiency programs?" [1457]. Almost three-quarters (73\%) said that they did, while $27 \%$ were unsure or said they did not. Utilities are no longer required under the Residential Conservation Service (RCS) Program to offer residential energy audits, although in practice many utilities have found this to be good practice in dealing with high bill complaints, public relations, peak shaving, delay of capacity expansion, and other reasons. 
Table 8-2. Trends in Perceived Credibility of Energy Information Sources

(West Virginia)

"What or who do you consider to be reliable sources of information about the current energy situation?" (June 1987) [1475] $]^{a}$

\begin{tabular}{|l|c|c|c|c|c|c|c|c||}
\hline \hline Information source & 1978 & $1979^{\mathrm{b}}(1)$ & $1979(2)$ & $1980(1)$ & $1980(2)$ & 1981 & 1987 \\
\hline Proportion selecting (\%) \\
\hline \hline Public interest groups & 36 & 36 & 42 & 38 & 40 & 37 & 40 \\
\hline Federal government & 43 & 41 & 40 & 36 & 33 & 36 & 37 \\
\hline County extension office & 32 & 41 & 41 & 35 & 40 & 41 & 37 \\
\hline State government & 30 & 29 & 35 & 28 & 27 & 31 & 29 \\
\hline Public utilities & - & 17 & 18 & 12 & 18 & 19 & 28 \\
\hline Private industry & 17 & 16 & 13 & 12 & 14 & 12 & 16 \\
\hline Other & 6 & 7 & 4 & 4 & 2 & 4 & 6 \\
\hline There are none & 22 & 17 & 19 & 23 & 25 & 18 & 16 \\
\hline \multicolumn{1}{|l|}{$\mathrm{N}=$} & $(752)$ & $(738)$ & $(710)$ & $(607)$ & $(502)$ & $(443)$ & $(983)$ \\
\hline
\end{tabular}

Source: Applied Research, Evaluation and Planning, West Virginia University Extension Service.

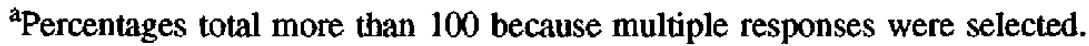

b(1) and (2) refer to separate surveys taken in 1979 and in 1980.

${ }^{c}$ Public utilities were included in the private industry category in the 1978 survey.

The West Virginia poll asked about willingness to participate in home energy audit programs if offered by various agencies [1475]. In $1987,45 \%$ said they were willing to participate with utility company audits, $42 \%$ in audits offered by West Virginia University's County Extension Offices, $35 \%$ in the state's Fuel and Energy Office, and $28 \%$ in those offered by local community service groups. More than a quarter of the sample (28\%) said they were unwilling to participate [1475]. When asked how much they were willing to pay for an audit, $56 \%$ said they were unwilling to pay anything, $9 \%$ up to $\$ 5,10 \%$ up to $\$ 10,14 \%$ up to $\$ 15$, and $11 \%$ more than $\$ 15$.

A 1981 poll sampled audited New Jersey households, asking them about costs. Opinion was divided over whether "audits should be provided free of charge with the cost spread equally to all homeowners" [1438]. Nevertheless, $85 \%$ of the audited homeowners considered the $\$ 15$ charge to be "a good bargain." Those audited said that it was helpful in showing them ways to save energy $(85 \%)$, it was thorough (83\%), and that they made changes to save energy they would not have made without the audit $(60 \%)$. The most 
useful items were a list of needed measures, with estimates of cost and length of payback period, and a home energy savings workbook or technical pamphlet.

The 1980 SERI/Gallup national survey of homeowners also asked about interest in audits. A majority (51\%) said that they had already received an audit or were interested in doing so [1533]. A third said they were unwilling to pay anything at all for an audit; $30 \%$ said they would pay under $\$ 25,17 \%$ said $\$ 25-\$ 49$, $7 \%$ said $\$ 50-\$ 74,4 \%$ said $\$ 75-\$ 99$, and $4 \%$ said $\$ 100$ or more. These data are mentioned only because they appear to be the only national-level data on interest in audits as an energy information source; however, they are almost 12 years old; opinion on these matters may well have changed.

Most recently, homes may be subjected to home energy rating systems (HERS) to measure their efficiency and provide a list of cost-effective improvements that, when implemented, would reduce utility costs. These systems may be used to replace or supplement existing utility audit and other demand-side management (DSM) information programs.

Energy topics. When asked in 1991 whether they would like to receive information about retrofitting their homes, the vast majority of Louisiana respondents (80\%) said no [1430]. Consumers may have been afraid they would be contacted by sales people if they responded affirmatively to the survey item. The majority of the sample said they were likely to call and ask a local or state governmental agency for energy-efficiency information. In 1989, 34\% of Ohio utility customers said that they would like more information on energy conservation from Monongahela Power Company, their utility company [1473]. This was the most frequently mentioned of 12 topics asked about.

The 1987 West Virginia, from 1978 through 1987, study queried respondents on energy topics about which they would like more information. Identifying "home energy conservation" were $66 \%$ of the 1987 sample, an increase of 23 points since the same question was asked in 1981, and the highest rate of mention since they began surveying in 1978. Information about alternative (nonsolar) sources of energy was identified by $40 \%$; information on solar energy was mentioned by $36 \%$, a decrease of 1.5 points since 1981. Also mentioned were "causes and effects of the energy problem" (22\%), farm energy management (10\%), and business-related conservation (9\%) [1475].

The Georgia Office of Energy Resources surveyed its users in 1985 to evaluate its program's effectiveness [1442]. The researchers reported that of the $41 \%$ of those requesting energy information for building a new home, $89 \%$ said they incorporated energy efficiency ideas into their house plans and $75 \%$ included solar options. Of the $61 \%$ requesting information on existing homes, $70 \%$ claimed they added energy saving measures to their homes.

In summary, it appears that respondents requesting information about energy conservation are those most interested in and likely to take some action, while those who are passive recipients may be less likely to do so. These state and local surveys suggest that consumer interest remains about how to conserve home energy.

Technical awareness and knowledge. The earlier reviews located a few items asking respondents about ways in which they could conserve energy in their homes. No data were located asking about this since the 1980 national surveys by SERI and the Council on Environmental Quality (CEQ). This results in a gap in knowledge.

Program awareness. A few studies asked samples whether they were aware of local programs. In Ohio, $65 \%$ were aware of weatherization programs, while $71 \%$ were unaware of special rates and discount plans [1476]. A majority of an Alabama sample knew in 1987 that the state offered energy conservation information to the public [1434]. In Connecticut in 1985, $77 \%$ had heard about energy conservation 
services offered by utility companies; $62 \%$ had heard of CONN SAVE energy audits; $54 \%$ had heard of government low-interest loan programs for energy improvements; $47 \%$ had heard about government fuel assistance programs; and $27 \%$ had heard about a state sales tax exemption for purchase of renewable energy systems [1460]. Twenty percent had received an audit; $22 \%$ had used energy conservation services; $6 \%$ had used fuel assistance; $5 \%$ had used the sales tax exemption.

A 1984 Portland, Oregon, survey asked about awareness of Oregon's income tax credit for the purchase of solar energy systems; 32\% responded affirmatively [1463]. Most (81\%) were unaware of the city's low-interest loans for the installation of solar energy systems. In comparison, SERI's national survey found that $46 \%$ were aware of the federal tax credit for solar energy in 1980 [1533].

A majority of Alabama residents were aware in 1984 that their state provided energy conservation information or services to the public (52\%), and $45 \%$ were aware of the existence of their state energy office [1448].

In general, however, given these few results, awareness of energy programs appears to be somewhat limited considering that every state has an energy office responsible for carrying out the State Energy Conservation Program, with responsibilities for communicating energy-efficiency information to the public and stakeholder groups. Similarly, many utilities support demand-side management programs that promulgate energy-efficiency information through audits and inspections, seminars, and other means. The survey evidence is limited enough that definitive conclusions are difficult to draw. With that caveat, however, although awareness of energy-efficiency itself appears widespread, knowledge of cost-effective energy improvements and where to get information about them seems limited in the general population.

\section{Behavioral Intention and Action}

No solid trend data using verbatim items replicated over time were available on self-reported conservation behavior. This suggests that polling organizations themselves and poll sponsors had decided that public opinion on energy efficiency was not of sufficient importance to continue to consistently collect data on it. The data available for this analysis of conservation behavior are based on various questions asked of national and local samples selected in different ways. The evidence is thus approximate, at best.

Since the late 1970s, data from national and state samples, taken together, seem to indicate a pattern in which somewhat larger (though still low) proportions of the public during the early to mid-1980s than in the late 1970 s invested in somewhat more costly items that would reduce the use of utility-supplied energy in homes. These items ranged from attic insulation to energy-efficient appliances, and even solar energy systems. Mentioned most frequently in these studies were the relatively less expensive measuresinsulation, caulking, weatherstripping, water heater wrapping, window screening devices, and clock thermostats $[1533 ; 1460 ; 1313 ; 1223 ; 1476 ; 1480 ; 1445 ; 1438 ; 1440 ; 1117]$.

The amount of self-reported conservation behavior-either through lifestyle changes or through investment in retrofits-appeared to have increased in the late 1970s to the mid-1980s but has been decreasing recently. The earlier reviews reported that most people said they were practicing some form of residential energy conservation in the late seventies. The practices mentioned most frequently at that time were those that were more convenient and less costly, such as turning down the thermostat and turning off lights and appliances when not in use.

Table 8-3 summarizes data on conservation practices and measures (including solar energy features) asked about in the surveys since the earlier reviews. Mentioned as having been installed most frequently were insulation, caulking, weatherstripping, water heater wrapping, window screening devices, and clock thermostats. 
Table 8-3. Residential Conservation Actions Taken

"Which of these things do you happen to be doing to cut down on your use of electricity and heating fuel in your home?" (Prototypical item wording)

\begin{tabular}{|c|c|c|c|c|c|c|c|c|c|c|c|c|c|}
\hline Measure & $\begin{array}{l}\text { Earlier } \\
\text { Studies }\end{array}$ & $\begin{array}{l}1980^{a} \\
\text { Nat'l }\end{array}$ & $\begin{array}{l}1980^{b} \\
\text { Nat'l }\end{array}$ & $\begin{array}{c}1982 \\
\mathrm{NJ}^{\mathbf{c}} \\
\text { Non- } \\
\text { audited }\end{array}$ & $\begin{array}{c}1982 \\
\text { NJ } \\
\text { Audited }\end{array}$ & $\begin{array}{c}1982 \\
\text { IA }^{d} \\
\text { Rural }\end{array}$ & $\begin{array}{c}1982 \\
\text { IA } \\
\text { Urban }\end{array}$ & $\begin{array}{c}1985^{\mathrm{e}} \\
\mathrm{CT}\end{array}$ & $\begin{array}{c}1987^{\mathrm{f}} \\
\text { OH }\end{array}$ & $\begin{array}{l}1988^{g} \\
\text { NV }\end{array}$ & $\begin{array}{c}1989^{h} \\
\text { OH }\end{array}$ & $\begin{array}{l}\text { Aug. } \\
1990^{i} \\
\text { Nat'l }\end{array}$ & $\begin{array}{c}1990^{j} \\
\mathbf{L A}\end{array}$ \\
\hline \multicolumn{14}{|l|}{ Proportion responding (\%) } \\
\hline $\begin{array}{l}\text { Turn off lights when not in } \\
\text { use }\end{array}$ & 75 & & 51 & & & & & & & & & 10 & \\
\hline Lower thermostat & 75 & 64 & 31 & & & & & & 74 & & & & \\
\hline $\begin{array}{l}\text { Turn off appliances when } \\
\text { not in use }\end{array}$ & 70 & & 44 & & & & & & & & & 3 & \\
\hline $\begin{array}{l}\text { Running washer/dishwasher } \\
\text { efficiently }\end{array}$ & 33 & & & & & & & & & & & 3 & up to 64 \\
\hline Decrease a/c use & 33 & 35 & 38 & & & & & & & & & 7 & \\
\hline Caulking & & & & 49 & 67 & & & 61 & 72 & & 24 & & up to 65 \\
\hline Weatherstripping & 25 & 76 & 19 & 49 & 67 & 86 & 84 & 61 & 68 & 56 & 24 & & up to 65 \\
\hline Wrap water heater & & & & 16 & 34 & 40 & 31 & 41 & 26 & 36 & 17 & & \\
\hline Shower flow restrictor & & & & 21 & 27 & 18 & 26 & 45 & & 31 & 19 & 2 & \\
\hline Insulation in attic & 10 & 61 & 19 & 24 & 43 & 73 & 57 & 47 & 71 & 43 & & 1 & up to 65 \\
\hline Insulate pipes & & & & 16 & 34 & 22 & 17 & 36 & & & & & \\
\hline Wall insulation & & & & & & 78 & 67 & 22 & 54 & 38 & & & \\
\hline Floor insulation & & & & & & 28 & 35 & 24 & 25 & 27 & & & \\
\hline Storm doors or windows & 16 & 60 & 9 & 19 & 32 & 94 & 89 & 48 & & 23 & 71 & & \\
\hline Doublepane windows & & & & & & & & & 56 & 43 & & & up to 65 \\
\hline Triple pane windows & & & & & & & & & 6 & & 6 & & \\
\hline $\begin{array}{l}\text { Buy energy-efficient } \\
\text { appliances }\end{array}$ & & 37 & & & & & & & & & & & \\
\hline
\end{tabular}


Table 8-3. Residential Conservation Actions Taken (continued)

\begin{tabular}{|c|c|c|c|c|c|c|c|c|c|c|c|c|c|}
\hline Measure & $\begin{array}{l}\text { Earlier } \\
\text { Studies }\end{array}$ & $\begin{array}{l}1980^{\mathrm{a}} \\
\text { Nat'l }\end{array}$ & $\begin{array}{l}1980^{b} \\
\text { Nat'l }\end{array}$ & $\begin{array}{c}1982 \\
\mathrm{NJ}^{\mathbf{c}} \\
\text { Non- } \\
\text { audited }\end{array}$ & $\begin{array}{c}1982 \\
\text { NJ } \\
\text { Audited }\end{array}$ & $\begin{array}{c}1982 \\
\text { IA }^{d} \\
\text { Rural }\end{array}$ & $\begin{array}{c}1982 \\
\text { IA } \\
\text { Urban }\end{array}$ & $\begin{array}{c}1985^{\circ} \\
\mathrm{CT}\end{array}$ & $\begin{array}{c}1987^{f} \\
\text { OH }\end{array}$ & $\begin{array}{c}\mathbf{1 9 8 8}^{\mathrm{g}} \\
\mathrm{NV}\end{array}$ & $\begin{array}{c}1989^{h} \\
\text { OH }\end{array}$ & $\begin{array}{l}\text { Aug. } \\
\text { 1990 } \\
\text { Nat'l }\end{array}$ & $\begin{array}{c}199^{\mathrm{j}} \\
\text { LA }\end{array}$ \\
\hline \multicolumn{14}{|l|}{ Proportion responding (\%) } \\
\hline Duct taping & & & & 16 & 34 & & & & 25 & & & & \\
\hline Clean/test furnace & & & & & & & & 68 & & & & & \\
\hline Lower water temperature & & 59 & 11 & 23 & 37 & & & 61 & & & & & up to 64 \\
\hline Clock thermostat & & 12 & & 8 & 15 & 14 & 20 & 15 & & 13 & & & 28 \\
\hline Retention head burner & & & & & & & & 9 & & & & & \\
\hline Solar water heater & & 2 & 1 & & & & & 4 & & & & & \\
\hline Using wood to heat & 10 & 18 & 10 & & & & & 1 & & & & & \\
\hline $\begin{array}{l}\text { Solar screens, window } \\
\text { coverings, film over win- } \\
\text { dows, and landscaping to } \\
\text { control temperature of } \\
\text { home }\end{array}$ & & 48 & & & & & & & 26 & & 25 & & 32 \\
\hline Wear heavier clothes & & & & & & & & & & 80 & & & \\
\hline $\begin{array}{l}\text { Vent damper or automatic } \\
\text { flue }\end{array}$ & & & & 4 & 6 & & & & & & & & \\
\hline Heat pump & & 4 & & & & & & & & & & & \\
\hline Passive solar homes & & 2 & & & & & & & & & & & \\
\hline Not doing anything & & & & & & & & & & & & 34 & \\
\hline Survey number & & {$[1533]$} & {$[1177]$} & \multicolumn{2}{|c|}{$[1438]$} & {$[1443]$} & {$[1460]$} & {$[1460]$} & {$[1480]$} & {$[1223]$} & [1476] & [1313] & {$[1430]$} \\
\hline
\end{tabular}

Source. Constructed by author using data from SERI/Gallup, Opinion Research Corporation, Grapentine Company, Strategic Consumer Research, Saurage-Thibodeaux Research, Inc., Eagleton Institute of Politics, Institute for Social Research, Office of the Consumers' Council, Alice M. Crites et al., Gallup Organization.

a "Listed on this card are several activities or measures that conserve energy. Please tell me which, if any, you have done since you've lived here." 
Table 8-3. Residential Conservation Actions Taken (continued)

b"What are some of the ways, if any, you are trying to save energy in your home?"

" "I'm going to read you a list of things you might have done to conserve energy. For each one, please tell me if you have done this in the last two or three years. If we've already covered some, please be patient. First have you ..."

d"I'm going to read you a list of energy saving features. Please tell me if you have any of these features in your home by answering YES or NO to each item."

e "There are a number of things people have done around their homes to conserve energy. I'm going to read you a list of some of them. As I read each one, please indicate if it has been done in your home in the past year."

Item wording was not reported.

gitem wording was not reported.

${ }^{\mathrm{h}}$ Item wording was not reported.

¿"Do you happen to be doing anything to reduce your use of energy-that is, your use of gasoline, electricity, or natural gas? (If yes ask:) What is that?" jitem wording was not reported.

范 
Iowa households sampled in December 1981 reported making major repairs and changes to their homes. Of those who had done so, $61 \%$ reported having weatherized their homes [1443]. In November 1985, two-thirds of Connecticut residents believed that more could be done to improve the efficiency of their homes [1460]. In 1990, Louisiana residents reported residential conservation actions [1430]. Sixty-five percent reported that they had "retrofitted" their home, defined in the item to include caulking, weatherstripping, adding insulation, or adding double-paned glass. Sixty-four percent said they had controlled hot water use by employing their dishwasher's energy-efficient cycle, turning down the temperature on their water heater, and/or turning off their water heater when on vacation. Thirty-two percent reported passive solar actions, such as installing solar screens, film, or landscaping to control their home's temperature. Finally, $28 \%$ said they had installed automatic thermostats.

In 1990, however, self-reported conservation actions and investments were minimal. When Gallup asked: "Do you happen to be doing anything to reduce your use of energy-that is, your use of gasoline, electricity, or natural gas?," more than one-third reported that they were not doing anything at all, although two-thirds reported at least some action [1313]. Actions being taken were the easiest to do (turning off lights and turning down the thermostat).

Another 1990 study by NBC News/The Wall Street Journal found that, when asked whether they took steps to reduce the use of electricity and gas in their homes, $68 \%$ said "regularly," and $22 \%$ said "occasionally." Only 5\% said "never" [1194].

In March 1990, Gordon S. Black/USA Today asked: "How much does your household cut back on heat in the winter or air conditioning in the summer to conserve energy?" [1283]. More than half (52\%) said they cut back "somewhat," 30\% said "a great deal," and 5\% said "not at all."

When the question is framed in terms of how careful Americans are in conserving a variety of resources, such as time, food, water, energy, and others, most thought some care is taken. Table 8-4 shows that, in May 1991, more than half (58\%) reported that they thought others at least "somewhat careful" in their use of heating fuel, $44 \%$ in gasoline use, and $41 \%$ in electricity consumed [1553].

Table 8-4. Perceived Thrift in U.S. Energy Use

"Here is a list of resources most of us use. (Card shown.) For each one, would you please tell me how careful you think most Americans are when it comes to guarding against waste in their use of it-very careful, somewhat careful, somewhat careless, or very careless?" a ${ }^{\text {[1553] }}$

\begin{tabular}{||l|c|c|c|c||}
\hline \multirow{2}{*}{ Resource } & June 1980 & \multicolumn{3}{|c||}{ May 1991 } \\
\cline { 2 - 5 } & $\begin{array}{c}\text { Total } \\
\text { careful }\end{array}$ & $\begin{array}{c}\text { Very } \\
\text { careful }\end{array}$ & $\begin{array}{c}\text { Somewhat } \\
\text { careful }\end{array}$ & $\begin{array}{c}\text { Total "very" and } \\
\text { somewhat careful" }\end{array}$ \\
\hline Proportion responding (\%) & \multicolumn{4}{|c|}{} \\
\hline \hline Heating fuel & 67 & 14 & 44 & 58 \\
\hline Gasoline & 56 & 10 & 34 & 44 \\
\hline Electricity & 44 & 9 & 32 & 41 \\
\hline
\end{tabular}

Source: Constructed by author using data from the Roper Organization.

${ }^{2}$ Other items included in the item were food, metal, time, glass, water, paper, and plastic. 
Some evidence suggests that the public may be willing to conserve once again, should energy shortages occur. In September 1990, NBC News/The Wall Street Journal asked a national sample: "Let me read you a list of ways people conserve energy. For each one, please tell me if you are likely or unlikely to try to conserve in this way if there is an energy shortage" [1188]. Three-quarters of the sample said they were likely to use less heating fuel and air conditioning, while $62 \%$ said they would use appliances less.

Nevertheless, the voluntary practice of energy efficiency and investment in energy-conserving features and solar energy systems seems to have declined to a relatively low level. The phaseout of the energy conservation and solar energy tax credits ${ }^{3}$ has no doubt contributed to this situation, as have relatively low energy prices. However, these factors appear to be only part of the story. The other part appears to be public perception of institutionalized inefficiency.

Energy efficiency practice in the United States may not be as badly off as these results might suggest, however. While the perceived severity of the energy situation has clearly declined over the past decade, many households obviously took action to retrofit their dwellings, at least up to a point. Further retrofits might not seem as cost-effective to newer home occupants, particularly as current utility costs are relatively stable. In the meantime, building practice has improved the operating efficiency of new housing in the United States. The sense of urgency to conserve energy has decreased markedly since the late seventies, at least as measured by polls.

\section{Policy Preferences}

A number of items in recent surveys have queried the public on its attitude toward buildings-related policies. Results of these touch on actions the federal government could take to foster buildings energy efficiency. For example, the National Energy Strategy (NES) (U.S. Department of Energy 1991), released in February 1991, called for the following specific actions:

- Expand buildings efficiency research and development

- Improve state and local building codes

- Tighten efficiency standards for federal buildings

- Increase use of energy-efficient mortgages and HERS

- Improve the energy efficiency of public housing

- Update cost-effective efficiency standards for appliances and equipment

${ }^{3}$ Between 1979 and 1985, federal income taxpayers were permitted a $15 \%$ credit for the cost of energy conservation measures that did not exceed $\$ 2,000$, and $40 \%$ for solar measures not exceeding $\$ 10,000$ that were retrofitted on their residences. These credits were subtracted from the final tax bill owed by the taxpayer and could be carried forward for years until the full credit was taken. Taken together, the Internal Revenue Service classified these incentives as the residential energy tax credits. States followed the federal government lead by passing tax credits for various conservation and solar measures for state income taxes. In 1983, 28 states had solar credits, and in 1985, 30 states (60\%) offered them. However, the credits expired at the end of 1985 in 12 states, leaving 18 states (36\%) with active tax credits in 1986.

From 1979 through 1984, 28 million households claimed the credits (Vories and White 1990). Data from the Internal Revenue Service showed substantial variation in propensity to apply for the credits as a function of income (U.S. Department of Energy 1987). For the 1982 tax year, the IRS reported that $3,135,528$ individual tax returns used an energy credit, or $3.29 \%$ of all returns. An average of approximately $\$ 185$ credit per household was claimed, for a total of $\$ 582,857,000$ in tax credits. 
- Expand energy-efficiency labeling

- Support state and utility energy conservation programs.

Would initiatives such as these meet with public approval?

In December 1990, RSM and Greenberg/Lake, The Analysis Group asked a national sample: "Let me read you just a few more policies the government might try as part of a national energy strategy for the future. For each one please tell me if you would strongly favor, somewhat favor, somewhat oppose or strongly oppose it as part of a national energy policy" [1025]. Table 8-5 lists the two items pertaining to buildings and the percentages either "strongly favoring" or "somewhat favoring" them. To understand the significance of the responses reported in Table 8-5, one must realize that these were the most frequently favored policy options-the top 2-of the 19 presented.

The NES recommended an initiative to develop the broader application of mortgage financing incentives for energy improvements in housing. Such a policy to develop energy-efficient mortgages is clearly congruent with national opinion. Although the NES did not call for the reinstatement of the conservation and solar tax credits, such a policy would also find widespread public acceptability.

Table 8-5. National Energy Strategy Policy Preferences for Buildings

"Let me read you some policies the government might try as part of a national energy strategy. For each one tell me if you favor or oppose it as a part of a national energy policy." (December 1990) [1025]

\begin{tabular}{|l|c|c|c||}
\hline \multicolumn{1}{|c|}{} & $\begin{array}{c}\text { Strongly } \\
\text { favor }\end{array}$ & $\begin{array}{c}\text { Somewhat } \\
\text { favor }\end{array}$ & $\begin{array}{c}\text { Total } \\
\text { "strongly" and } \\
\text { "somewhat } \\
\text { favor" }\end{array}$ \\
\hline Proportion responding (\%) & & & \\
\hline \hline $\begin{array}{l}\text { Requiring new homes financed by FHA and VA } \\
\text { mortgages to meet federal standards for energy } \\
\text { efficiency }\end{array}$ & 68 & 23 & 91 \\
\hline $\begin{array}{l}\text { Re-establishing federal tax credits for consumers } \\
\text { who use renewable energy sources such as solar } \\
\text { or wind power }\end{array}$ & 54 & 32 & 86 \\
\hline
\end{tabular}

Source: Constructed by author using data from Research/Strategy/Management and Greenberg/Lake, The Analysis Group.

af 19 energy policy options presented, this one was favored by the highest proportion of respondents. See Table $6-2$ in Chapter 6 for a list of the 19 policy options. 
Cambridge Reports conducted a national survey on utilities and the environment in September 1990, asking its sample: "Next I am going to read you a list of several things electric companies could do to protect and improve the environment. While all of these things may be important, I'd like you to tell me exactly how important each is to you personally. Please use any number from 1 to 7 , where 1 means one of the less important and 7 means one of the very most important things electric companies could do to protect and improve the environment" [1457]. ${ }^{4}$

A number of the options listed pertain to the efficiency of buildings. Table 8-6 shows those options along with the mean responses. The modal response was 7 ("very most important") in all instances except the final item, where it was 5.

The most popular policy preferences were chlorofluorocarbon (CFC) phaseout, promoting energy-efficient building codes, and providing information on weatherization and other low-cost measures.

In 1980, SERI/Gallup measured policy preferences regarding the use of solar energy in homes. The policies and the proportion endorsing them were as follows:

- $\quad$ Educate and inform consumers (91\%)

- Provide financial incentives, such as grants, low-cost loans, or other kinds of financial assistance $(87 \%)$

- Inspect solar energy systems to see how they are working (85\%)

- Conduct home energy audits, in which an inspector would look over a house and make recommendations on how energy can be saved and what kinds of solar energy could be used (83\%)

- Cover guarantees or warranties for solar energy systems if a company goes out of business (67\%)

- Require by law or ordinance passive solar design and/or solar domestic hot water in new home construction (54\%).

Preferences expressed were that the federal government should inform consumers, provide financial incentives, and back solar warranties if companies go out of business; that state government should list solar contractors, inform consumers, and provide financial incentives; and that utilities should conduct home energy audits, inform consumers, inspect systems, and list solar contractors [1533].

In 1988, the League of Women Voters asked a sample of public interest leaders and a sample of energy industry leaders whether the government should take a more active role in energy policy or whether energy supplies should be determined by the marketplace [1534]. Four policies relevant to buildings were included in the survey, and virtually all of the public interest leaders and majorities of the industry leaders supported these policies. These policies follow. The percent of public interest and industry leaders, respectively, who supported the policies is shown in parentheses.

- Develop more incentives for energy-efficient buildings and homes $(99 \%, 83 \%)$

- Increase R\&D funding for energy-efficient technologies $(100 \%, 94 \%)$

- $\quad$ Educate the public about energy conservation $(100 \%, 94 \%)$

- Increase R\&D funding for alternative, renewable energy resources $(98 \%, 64 \%)$.

\footnotetext{
${ }^{4}$ Appendix $\mathrm{H}$ presents the response categories and data on these items (Table $\mathrm{H}-3$ ).
} 
Table 8-6. Preferred Buildings Policy Options to Protect the Environment

"Next I am going to read you a list of several things electric companies could do to protect and improve the environment. While all of these things may be important, l'd like you to tell me exactly how important each is to you personally. Please use any number from 1 to 7 , where 1 means one of the less important and 7 means one of the very most important things electric companies could do to protect and improve the environment." (September 1990) [1457]

\begin{tabular}{||l|c|c||}
\hline Item & $\begin{array}{c}\text { Mean } \\
\text { (Scale 1-7) }\end{array}$ & $\begin{array}{c}\text { Percentage responding } \\
\text { 6-7 (most important) }\end{array}$ \\
\hline $\begin{array}{l}\text { Phase out use of CFCs and other } \\
\text { chemicals that can harm the ozone layer }\end{array}$ & 6.0 & 73 \\
\hline $\begin{array}{l}\text { Promoting building codes that require } \\
\text { proper insulation and other energy- } \\
\text { efficiency measures }\end{array}$ & & 72 \\
\hline $\begin{array}{l}\text { Providing information about } \\
\text { weatherization and other low-cost } \\
\text { measures that can improve the energy- } \\
\text { efficiency of homes }\end{array}$ & 6.0 & 64 \\
\hline Promoting use of energy-efficient lighting & & 62 \\
\hline $\begin{array}{l}\text { Offering rebates or loans to help } \\
\text { customers buy energy-efficient heating } \\
\text { and cooling systems or other major } \\
\text { appliances }\end{array}$ & 5.8 & 62 \\
\hline $\begin{array}{l}\text { Developing electric "smart" houses that } \\
\text { allow customers to monitor and } \\
\text { automatically regulate their use of } \\
\text { household appliances }\end{array}$ & 5.7 & 53 \\
\hline $\begin{array}{l}\text { Promoting electric heat pumps to replace } \\
\text { less efficient heating and cooling systems }\end{array}$ & 5.7 & 55 \\
\hline $\begin{array}{l}\text { Directly controlling customers' major } \\
\text { appliances to reduce demand for } \\
\text { electricity at certain times }\end{array}$ & 5.5 & \\
\hline
\end{tabular}

Source: Constructed by author using data from Cambridge Reports. Appendix $\mathrm{H}$ contains the full set of data from this item (Table $\mathbf{H}-3$ ). 
These policy actions are congruent with public preferences to implement financial incentives, such as the solar and conservation tax credits and energy-efficient mortgages.

A few state surveys also included information on public policy preferences. A survey of Louisiana opinion leaders in July 1990 found that they wanted energy-conservation education programs in state school systems. About one-half thought such programs were important. A 1987 survey of Alabama residents asked respondents to indicate support or opposition to a list of possible policy areas. Among the five most supported policies were "provide larger tax credits for improving home efficiency," supported by 93\% [1434]. A 1985 survey in Connecticut queried respondents about state policy priorities. The needs of low income households were considered important (26\%), followed by residential (18\%), large business $(18 \%)$, transportation (16\%), and other (13\%) [1460].

Clearly, virtually everyone polled supports some government action to promote energy efficiency and the use of renewable energy technologies in buildings. 


\section{Chapter 9}

\section{Efficiency and Renewables in Transportation}

\section{Background and Summary}

Transportation is an increasingly significant use of energy. Most transportation fuel is currently supplied by gasoline formulated from oil. Data on public perception of and knowledge about oil are thus included in this chapter. In addition, data concerning conservation of transportation fuel-gasoline-and the use of alternative fuels and vehicles, which would substitute for gasoline, are presented in this chapter.

No trend data using verbatim items over time were available on self-reported transportation conservation behavior. As was the case with data on buildings conservation behavior, polling organizations and poll sponsors had apparently decided that public opinion on efficiency and the use of renewable energy in transportation was not of enough significance to continue to collect data consistently on it. The evidence available on these topics is thus approximate, at best. Similar to the situation with buildings conservation, however, the amount of conservation behavior being practiced, as estimated through self-report, appeared to increase in the late 1970 s and decline more recently. Buying more fuel-efficient automobiles is the most popular method of conserving gasoline.

This chapter discusses knowledge and awareness of oil imports. Much of the public still appears to be unfamiliar with basic facts on oil. The chapter then examines data on offshore oil and the Valdez oil spill incident of March 24, 1989. Then, data on gasoline conservation are presented. Finally, the chapter presents available findings on alternative fuels and vehicles, including information on vehicle purchase decisions and on experiences of innovators in using alternative fuel vehicles. The chapter's empirical findings are summarized below.

More energy is being used for transportation as lifestyles evolve, and most transportation fuel comes from oil. Forty-three percent of the 17 million barrels of oil consumed each day in the United States is used in automobiles; gasoline consumption has risen $20 \%$ since the early 1970s (Wall Street Journal, 1/30/91). About one-half of the public seems aware that the United States imports about half the oil it uses. Only about one in four is able to accurately estimate the proportion of U.S. domestic petroleum demand that is imported. Most do not realize that U.S. dependence on foreign oil is increasing. The public is not highly knowledgeable about oil imports.

Most people heard about the Exxon oil spill at Valdez, Alaska on March 24, 1989, and a negative attitude toward Exxon developed after the oil spill. A boycott of Exxon products developed by May 1989, and majorities felt that Exxon had not done enough to help clean up the spill. Public attitudes toward Exxon remained negative even two years after the spill, consistent with the generally negative attitudes toward oil companies and with increasing environmental concerns (see Chapters 5 and 2, respectively).

The Valdez incident dampened public enthusiasm for offshore drilling, despite dependence on foreign oil. In fact, offshore oil drilling poses an excruciating trade-off: national security versus the environment - both deeply held values. This trade-off leads to polarization in public opinion. Pluralities 
both favor and oppose offshore drilling for oil. However, majorities oppose new oil drilling in the Alaska National Wildlife Refuge (ANWR).

Few data were available on self-reported transportation conservation behavior. Most said they have not been driving less, car pooling, using mass transit, bicycling, or walking to get from one place to another. No data existed on self-reported observance of lower speed limits. Buying a fuel-efficient car was the most popular form of conserving gasoline. The data on car purchases and purchase intentions show that $14 \%$ fewer drivers bought full-size automobiles during the past decade. And, a sizable proportion of fullsize car owners planned to buy smaller cars next. Motivations to conserve cited by members of the public seem less important than barriers. Commuters' saving on costs of parking and gasoline, especially those traveling 11 miles or more to work, seem to be the most important reason. Fuel efficiency behavior could also be an expression of environmental values. Perceived barriers to gasoline conservationinconvenience, time costs, lack of knowledge of potential car pool partners-seem to outweigh the advantages.

Institutionalized inefficiency marks the transportation sector as well as the buildings sector. The transportation infrastructure was built based on the widespread availability of inexpensive gasoline and mass produced automobiles. The national economy relies heavily on the automotive and oil industries. Much transportation and freight hauling became dependent on the internal combustion engine. The existence of this system constrains individual choices in considering and using transportation alternatives. Public opinion on transportation conservation seems to reflect these realities. Change could take considerable time and be costly to achieve.

Very few national data were located on alternative fuels; that which exists suggests that most people are unfamiliar with methanol, ethanol, or other alternative fuels and additives. Twelve percent of new car buyers in 1990 said they were familiar with alternative fuels. The plurality of these buyers did not know which alternative fuels (of five presented-solar power, gas blends, electricity, methanol, and methane) they would or would not use. Thirteen percent said they would be unwilling to use any alternative fuel at all. When queried about factors affecting alternative fuel choices, the car buyers said those fuels would need to be as safe and inexpensive, and perform as well as gasoline. Most people say they are willing to pay $\$ 0.02 /$ gallon more for gasoline that produced less air pollution. However, data presented in Chapter 2 showed that $43 \%$ of new car buyers said they would be willing to pay $10 \%$ to $50 \%$ or more in additional cost for fuel "that significantly reduces air pollution." Results from attribute analysis suggested that buyers of higher octane fuels could be a market for methanol, which could be targeted as a higher octane, cleaner burning, and more powerful fuel than gasoline. The target market could be as large as $10 \%$ of gasoline buyers.

The evidence suggests that economy of operating cost is not a critical decision factor in car purchase decisions. Noneconomic factors such as aesthetics, quality, image, and reliability appear to be more significant. Some data show that safety and performance are also important considerations. The significance of the decision factors varies by type of car purchasers, which includes mass-market, sporty, family, economy-minded, and basic-transportation buyers.

Factors identified in local-area studies that affect alternative fuel vehicle (AFV) choices were vehicle range between refueling, fuel availability, dedicated versus multiple-fuel capability, purchase price, fuel operating cost, and perceived level of emissions reduction. Range between refueling is especially important to those who refuel more frequently than once a week.

More data on decisions and behavior with respect to alternative fuels and AFVs no doubt exist in localarea studies. At the national level, however, few data are currently available. This knowledge should be 
consolidated to determine whether a research gap exists. The Energy Information Administration's new Transportation Energy Consumption Survey will not include AFVs.

The balance of this chapter presents the empirical findings on these topics.

\section{Oil Imports}

How knowledgeable is the public about basic energy facts relative to transportation? For example, how much does the public know about the nation's oil imports and their impacts? And, if people knew more, would they be more likely to espouse national policies that would decrease our dependence on foreign oil?

Table 9-1 presents trend data on public knowledgeability about oil imports. Earlier reviews found only two survey items asking whether the United States imported oil or not. In 1979, two-thirds said that we imported oil, and one-third did not know that we imported oil. The public's awareness that the United States actually imports approximately half of the oil it uses, and that this percentage has been increasing each year for several years, is declining. In 1991, 46\% said we produce enough oil to meet our present energy needs, compared with $38 \%$ who said this in 1979 . Only one-half of the 1991 national sample said that we have to import oil.

In 1991, Gallup asked those who responded that we have to import oil (50\%): "Some people say that we really don't need Mideast oil, that we now have enough oil available in Texas, Alaska, Mexico, Venezuela, and other places on this side of the ocean to fill our needs. Do you strongly agree, somewhat agree, somewhat disagree, or strongly disagree with this statement?" Almost two-thirds agreed with the statement, and $20 \%$ strongly agreed. Continuing the line of questioning, Gallup went on to query those who had not strongly agreed with the previous statement: "Some other people say that if we wanted to,

Table 9-1. Public Perception about the Existence of U.S. Oil Imports

"From what you have heard or read, do you think we produce enough oil in this country to meet our present energy needs or do we have to import some oil from other countries?"

\begin{tabular}{|c|c|c|c|}
\hline Response & 1979 & 1980 & 1991 \\
\hline \multicolumn{4}{|c|}{ Proportion responding (\%) } \\
\hline Produce enough oil & 38 & 29 & 46 \\
\hline Have to import oil & 46 & 63 & 50 \\
\hline Don't know & 16 & 7 & 4 \\
\hline Total $^{\mathrm{a}}$ & 100 & 99 & 100 \\
\hline$N=$ & (511) & (1576) & (1013) \\
\hline Study number & [1315] & {$[1203]$} & [1501] \\
\hline
\end{tabular}

Source: Constructed by author using data from Gallup.

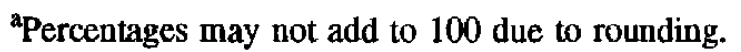


we could increase oil exploration and production on this side of the ocean enough to meet our needs. Do you strongly agree, somewhat agree, somewhat disagree, or strongly disagree with this statement?" [1501]. Twenty-one percent strongly agreed, 53\% somewhat agreed, and $22 \%$ disagreed, whereas $5 \%$ didn't know.

In August 1990, Penn and Schoen Associates, for Texaco, Inc., asked a national sample: "Do you think that the American oil companies buy 50\% of their supply from the open world market or do they get almost all of their unrefined oil from their own wells?" [1206]. Most respondents (72\%) said that they buy on the open market.

Yankelovich queried in a 1988 survey [1323]: "In view of U.S. energy needs overall, how dependent do you think we are today on imported oil-very dependent, somewhat dependent, not very dependent, or not at all dependent?" Eighty-eight percent responded that we are dependent, with $47 \%$ responding "very dependent," and $41 \%$ "somewhat dependent."

Roper repeated an item verbatim from 1979 through 1983: "About how long do you think the world's supply of oil is likely to last-5 years, 25 years, 50 years, or 100 years, or 200 years, or what? " [1112]. Estimates changed only a point or two over time. Responses clustered around "don't know," which was the modal ${ }^{1}$ response at each interval, followed by $15 \%$ to $18 \%$ estimating that oil would last 100 years.

The public has difficulty estimating the proportion of U.S. domestic petroleum demand that is imported. Table 9-2 shows the share of imports in domestic demand. The highest proportion of actual imports in history was $47.7 \%$ in 1977; the second highest was 1990, during which the United States imported $47 \%$ of its domestic demand (American Petroleum Institute 1992). In 1973, at the time of the Arab oil embargo, the United States imported $36.1 \%$ of its oil; since that time, the year of lowest imports was 1985 , at $31.5 \%$.

Table 9-3 shows the public's estimates of the proportion of oil imported between 1979 and 1991. The percentage making accurate estimates varies by year, in part because of different item wording and response categories provided. However, at no time, has more than $27 \%$ of the public estimated accurately the share of imported oil since 1979.

Most did not realize that U.S. dependence on foreign oil was increasing. In 1988, the Daniel Yankelovich Group asked [1323]: "In the past 5 years or so, do you think U.S. energy dependence on oil imports has increased, decreased, or stayed about the same?" This question replicated an Opinion Research Corporation (ORC) item used in 1987 [1210]. In both 1987 and 1988, 30\% said energy dependence has increased, and about $20 \%$ said it had decreased. However, in 1987, 23\% thought it had stayed the same, whereas in $1988,42 \%$ gave this response. Also, in 1987, $26 \%$ said they did not know, compared with $8 \%$ in 1988.

A few other items asked factual questions about oil. Gallup asked, in 1989: "Compared to Western Europe, do you think the tax on gasoline in the United States is higher, lower, or about the same?" [1320]. The correct response, that the U.S. tax is lower, was selected by $53 \%$. The remainder of the sample were unsure or gave an incorrect response. In 1988, Gallup asked: "Which of the places listed on this card is not known for having large oil reserves? Texas, Japan, the Persian Gulf, Alaska, and the North Sea?" [1290]. Correctly responding "Japan" was $72 \%$ of the sample. In 1985, Roper determined that $60 \%$ of respondents had heard about the "regulations that would gradually reduce and finally eliminate the lead in all the gasoline used in cars today" [1091].

\footnotetext{
${ }^{1}$ Modal $=$ most frequently occurring response.
} 
Table 9-2. Share of Imports in U.S. Domestic Petroleum Demand

\begin{tabular}{|c|c|}
\hline Year & Imports as \% of demand \\
\hline 1973 & 36.1 \\
\hline 1974 & 36.7 \\
\hline 1975 & 37.1 \\
\hline 1976 & 41.9 \\
\hline 1977 & 47.7 \\
\hline 1978 & 43.5 \\
\hline 1979 & 45.3 \\
\hline 1980 & 40.3 \\
\hline 1981 & 35.7 \\
\hline 1982 & 32.4 \\
\hline 1983 & 31.6 \\
\hline 1984 & 33.3 \\
\hline 1985 & 31.5 \\
\hline 1986 & 37.9 \\
\hline 1987 & 39.6 \\
\hline 1988 & 42.5 \\
\hline 1989 & 46.2 \\
\hline 1990 & 47.0 \\
\hline
\end{tabular}

Source: American Petroleum Institute, years as given.

In 1984, ORC asked whether the United States buys more oil, sells more oil, or trades oil evenly on the world market [1154]. To this question, 78\% responded correctly - that the United States buys more oil than it sells or trades evenly.

In 1986, ABC News/The Washington Post determined that $9 \%$ of a national sample said they were "someone who gets some income from the oil or natural gas industry" [1363].

In sum, only about half of the public seems aware that the United States relies significantly on imported oil. One in four is able to accurately estimate the proportion of domestic petroleum demand that is imported. Most do not realize that U.S. dependence on oil imports is increasing. 
Table 9-3. Public Estimates of Oil Imports to the United States

\begin{tabular}{|c|c|c|c|c|c|c|c|}
\hline $\begin{array}{l}\text { Estimate of } \\
\text { Proportion Imported }\end{array}$ & $1979^{\mathrm{a}}$ & $1980^{b}$ & $1981^{c}$ & $1984^{d}$ & $1990^{c}$ & $1990^{\mathrm{a}}$ & $1991^{\mathrm{a}}$ \\
\hline \multicolumn{8}{|l|}{ Percentage responding } \\
\hline $\begin{array}{l}\text { Actually imported } \\
(\%)^{* * *}\end{array}$ & 45.3 & 40.3 & 35.7 & 32.4 & 31.6 & 47 & $\begin{array}{l}\text { Data not } \\
\text { available }\end{array}$ \\
\hline$<10 \%$ & 5 & 6 & 6 & & & 2 & \\
\hline Up to 19 & & & & & & 2 & 6 \\
\hline $10-25$ & 14 & 14 & 12 & & & & \\
\hline $20-29$ & & & & & & 6 & 10 \\
\hline Less than one-third & & & & $21 *$ & $14 *$ & & \\
\hline $25-35$ & 22 & 21 & 21 & & & & \\
\hline $30-39$ & & & & & & 3 & 12 \\
\hline $35-50$ & 23* & $24 *$ & $27 *$ & & & & \\
\hline $40-49$ & & & & & & 6* & 10 \\
\hline About half & & & & 37 & & & \\
\hline 50 or more & 20 & 18 & 18 & & & & \\
\hline $50-59$ & & & & & & 18 & 18 \\
\hline One-third-two-thirds & & & & & 49 & & \\
\hline $60-69$ & & & & & & 9 & 8 \\
\hline More than two-thirds & & & & 33 & 29 & & \\
\hline $70-79$ & & & & & & 9 & 8 \\
\hline 80 or more & & & & & & 7 & 4 \\
\hline Don't know & 17 & 16 & 16 & 9 & 9 & 39 & 24 \\
\hline $\mathrm{N}=$ & $(2003)$ & $(2005)$ & $(2000)$ & $(1019)$ & $(677)$ & $(1227)$ & $(1013)$ \\
\hline Study number & [1151] & [1139] & [1131] & [1183] & [1206] & [1313] & {$[1501]^{* *}$} \\
\hline
\end{tabular}

Source: Constructed by author using data from the Gallup Poll and the Roper Organization.

"Iten wording: "Using this card, at the present time, how much of the oil used in the United States would you say we have to import from other countries?"

bItem wording: "About what proportion of its oil would you say the United States imports from other countries? Would you say two-thirds or more? About half, about one-third, or less than one-third?"

"Item wording: "How much of the oil that is sold in the United States is imported-Less than a third, one-third to twothirds, or more than two-thirds?"

Item wording: "About how much - that is, what percent-of the oil used in this country do we presently import from other countries?"

${ }^{*}$ Correct response.

${ }^{* *}$ Asked of survey subpopulation that said we must import some oil (50\%).

${ }^{* * *}$ American Petroleum Institute Basic Petroleum Data Book, Petroleum Industry Statistics, Vol. XI, Number 1, 1992, Washington, D.C. 


\section{Offshore Oil and the Valdez, Alaska, Oil Spill}

On March 24, 1989, because of negligence on the part of its crew, an Exxon Oil Company tanker spilled copious quantities of oil into the coastal waters off Valdez, Alaska, extensively damaging the coastline and killing wildlife. This event led to outcries by environmentalists and others against U.S. reliance on oil, offshore oil drilling, and alleged oil company malfeasance generally. Some polls collected data on aspects of the Valdez oil spill; these are discussed in this section.

The public viewed the Valdez oil spill as a disaster. Louis Harris and Associates asked in May 1989: "How serious was the impact on the environment from the oil spill created in Alaska (in the Exxon Valdez accident)—very serious, somewhat serious, not very serious, or not serious at all?" [1265]. Responding "very serious" were $84 \%$; another $13 \%$ said the spill was "somewhat serious." Most people (79\%) said they had discussed the story with friends, family, and coworkers [1296]. Most also said they were following the news stories on the oil spill "very closely" $(52 \%)$ or "fairly closely" (37\%). Also in May, Gallup asked about the size of the area affected by the oil spill; the modal response $(72 \%)$ was that it affected "an area the size of a small state." Opinion seemed divided on how well the press did in covering the story. Gallup asked: "In general, how would you rate the job the press has done in covering the Alaska oil spill?" [1296]. As of May 1989, a plurality of 44\% said "good"; 19\% said "excellent," $21 \%$ "only fair," and $13 \%$ "poor."

Evidently, the public did not see the oil spill as an isolated accident. When asked in April, soon after the spill, "Do you think it is likely or unlikely that another major oil spill will occur in Alaska in the next 10 years?," 59\% said "likely" and 34\% said "unlikely" [1045]. Half of a January 1992 poll said it was "absolutely certain" or "very likely" [1562]. In August of that year, ABC News/The Washington Post asked: "How would you rate the job most oil shipping companies are doing these days in trying to prevent environmental problems from oil spills-excellent, good, not so good, or poor?" [1370]. Majority opinion (72\%) was "not so good" or "poor." That same poll found 55\% agreeing that "tighter regulations governing tanker shipping would prevent major spills" [1370].

Opinion toward Exxon. Most people (76\%) knew that Exxon was the oil company responsible for the Valdez oil spill [1044]. Gallup asked in April 1991, some 2 years after the oil spill: "As a result of the 1989 Exxon Valdez oil spill in Alaska, the Exxon Corporation agreed to pay a $\$ 100$ million criminal fine as well as a $\$ 1$ billion civil penalty. On Tuesday, a federal judge rejected the agreement for the $\$ 100$ million fine saying it was too lenient. Do you agree with the judge's ruling that the fine was not enough, or do you think the amount agreed upon was adequate?" [1497]. A majority, 56\%, agreed with the judge; $35 \%$ said the fine was adequate.

The public developed a negative view toward Exxon after the oil spill. In mid-April 1989, NBC News/The Wall Street Journal asked: "After the oil tanker spill in Alaska last month, do you think the Exxon Corporation did all it could to clean up from the spill, or do you think it could have done more?" [1200]. Most respondents (77\%) thought Exxon could have done more. In May, Louis Harris asked respondents to "rate the job that Exxon has done on several aspects of the Valdez oil spill" [1265]. The items and the ratings were as follows:

- Cooperating with the local, state, and federal government agencies in trying to contain the damage (66\% fair or poor; $31 \%$ excellent or pretty good)

- Being willing to pay most of the costs for the cleanup (53\% fair or poor; $42 \%$ excellent or pretty good) 
- Being willing to put an environmentalist leader on its Board of Directors to be sure the environmentalist point of view is represented at the highest levels ( $46 \%$ fair or poor; $44 \%$ excellent or pretty good)

- Taking the blame for the oil spill in the first place $(51 \%$ fair or poor; $46 \%$ excellent or pretty good).

In fact, the public view of Exxon's response to the spill was so negative that $7 \%$ said, in response to a Gallup poll, that they were already boycotting Exxon products by May 7, 1989; another 41\% said they would seriously consider joining a boycott [1316]. At the same time, 11\% told Yankelovich/Clancy/ Shulman interviewers that they had "stopped buying gasoline from Exxon gas stations because of Exxon's role in the oil spill in Alaska" [1044]. Another 11\% said they had considered boycotting Exxon gasoline, and $72 \%$ said they had not. In August 1989, 5 months after the spill, 60\% said that Exxon was not doing enough to help clean up the spill in Prince William Sound [1370].

In sum, public attitudes toward Exxon remained significantly negative, even 2 years after the Exxon Valdez oil spill. This attitude seems consistent with the generally negative attitudes toward oil companies the public has displayed for several years and with increasing concerns about the environment documented in this report and elsewhere.

Opinion on offshore oil. Several poll items asked opinion about offshore oil, both before and after the Valdez incident. In 1991, NBC News/The Wall Street Journal asked: "Some people think the government should loosen some restrictions on offshore oil drilling because we are importing more than half of our oil from foreign countries, which is more expensive. Others think that the government should not loosen any restrictions on offshore drilling because the risk to the environment is too great. Which do you agree with?" ${ }^{\prime \prime}[1500]$. Opinion was divided: $51 \%$ did not want restrictions to be loosened, $41 \%$ did, and $8 \%$ were unsure. These results are consistent with those for coal use when the option of increasing coal use is compared with reducing dependence on foreign oil (as reported in the chapter on public perceptions of the utility sector).

Likewise, Penn and Schoen Associates, in its survey for Texaco, posed an item asking about "possible elements of a new national energy policy to promote conservation and reduce our dependence on foreign oil." Interviewers asked about "opening up for exploration some of the vast oil reserves America has off shore which are currently under moratorium" [1206]. This item phrasing elicited 70\% "strongly" or "moderately" favoring offshore oil exploration.

Roper reported that 1990 data showed "no consensus on oil drilling in coastal waters," again reflecting results when offshore drilling was connected in the item with reduced dependence on foreign oil. The item was: "The Department of Interior permits leasing most lands under coastal waters beyond the threemile limit to private industry for oil and gas exploration. The Interior Department says we need the programs to reduce our dependence on foreign oil, and says the exploration is conducted under strict environmental safeguards. Many people, including some congressmen, are opposed to this plan, because they think it isn't environmentally safe and will do serious harm to coastal waters and marine life. All things considered, how do you feel-are you in favor or opposed to offshore leasing for oil and gas exploration?" [1552]. Pluralities of exactly 42\% were both favorable and opposed in August 1990. The item was also used in 1982 and 1985; those in favor of offshore oil drilling constituted $44 \%$ of the 1982 sample and $47 \%$ of the 1985 one. Opposed were $42 \%$ in 1982 and $35 \%$ in 1985 . Opposition thus increased and favorability declined after the Valdez spill. Nevertheless, the number in favor fell only five points. Westerners rejected offshore leasing 53\% to 33\%, while Southerners supported it (50\% to 34\%) [1552]. 
A January 1992 poll by Cambridge Energy Research Associates and Opinion Dynamics repeated an item used in 1990 and 1991 about proposed solutions for environmental problems that involve "costs for people" [1562]. One of the solutions listed was "Restricting offshore oil drilling even if it means importing more oil." Majorities opposed this option in the 3 years of sampling: $55 \%$ in 1990 ; $52 \%$ in 1991; and 53\% in 1992. Pluralities, however, favored the idea: 38\% in 1990 and 1991, and 39\% in 1992.

Evidence for the split in opinion on new oil drilling was also supplied by a May 1990 Associated Press poll, which asked: "Do you think the federal government should allow new oil drilling . . off the coast of California? Off the coast of Florida? In the Arctic National Wildlife Refuge in Alaska?" [1355]. Table 9-4 and Figure 9-A show the preferences for each. A plurality of $44 \%$ opposed new offshore drilling in California and Florida; a majority of $61 \%$ opposed new drilling in the Alaska National Wildlife Refuge. These results were virtually identical to those obtained in 1989 when the same item was used.

A January 1992 poll asked about "programs that have been proposed for tackling environmental problems," repeating an item asked in 1990 and 1991 [1562]. In 1992, a majority of 54\% favored a policy "forbidding oil and gas exploration in the Arctic National Wildlife Refuge in Alaska." This proportion was similar to the $57 \%$ responding this way in 1990 and $48 \%$ in 1991.

A December 1990 poll asking about national energy strategy options included: "Opening more offshore areas along both coasts to oil drilling, even if this caused some environmental damage" [1025]. Opposed were $72 \%$ of the sample; $25 \%$ favored the idea, and $2 \%$ were unsure. And, in April 1990, Hart-Teeter Research asked preferences about the government loosening "some restrictions on offshore drilling because we are importing more than half of our oil from foreign countries which is more expensive. Others think the government should not loosen any restrictions on offshore drilling because the risk to the environment is just too great" [1194]. A majority, 54\%, said that the risks were too great; $38 \%$ favored loosening some restrictions. CBS News/The New York Times poll in March 1990 produced similar findings. When asked, "Would you favor increasing drilling for oil and natural gas off the California and Atlantic coasts, or do you think the risks of oil spills are too great?" 55\% responded that the risks were too great [1343]. Favoring drilling were $35 \%$.

The post-Valdez results are in stark contrast to results from some earlier polls in the 1980 s. For example, ORC asked, in August 1983: "How do you feel about increased drilling for oil and natural gas offshore in U.S. waters?" [1160]. Strongly or mildly favoring increased drilling were $70 \%$ of the sample; $22 \%$ opposed it. ORC also found, in January 1982, $71 \%$ favoring government encouragement of offshore drilling "as a way to improve our energy situation" [1164]. Nevertheless, ORC reported that $65 \%$ of its sample said the problem of possible damage to the environment as a result of offshore drilling for oil and natural gas was "very serious" or "somewhat serious" [1164]. Earlier polls also found majorities favoring offshore drilling [1333, 1216, 1237, 1129, 1137, 1149].

There can be little question that the Valdez incident dampened public enthusiasm for offshore drilling, despite dependence on foreign oil. However, even though pluralities rather than majorities remain opposed to new offshore drilling, opinion is divided on this issue. The polarization may ensue from the public attempting to balance its desires for both oil self-sufficiency-which would mean more domestic drilling - and environmental protection -which can be difficult to achieve with drilling. Despite this division in opinion, a clear majority opposes new drilling in the Alaska National Wildlife Refuge.

\section{Gasoline Conservation}

In the United States, most people rely heavily on personal automobiles as their primary means of transportation. Data showing this are extensive. For example, a West Virginia sample reported in 1987 that $96 \%$ used a personal car and $2 \%$ a borrowed car as their principal means of transportation; $1 \%$ rode the 
Table 9-4. Preferences for New Oil Drilling in California, Florida, and the Alaska National Wildlife Refuge, 1990

"Do you think the federal govermment should allow new oil drilling off the coast of California? Off the coast of Florida? In the Arctic National Wildlife Refuge (ANWR)?" (May 1990) [1355]

\begin{tabular}{||l|r|r|r|}
\hline Response & California & Florida & ANWR \\
\hline Proportion responding (\%) & 36 & 36 & 24 \\
\hline \hline Yes & 44 & 44 & 61 \\
\hline No & 21 & 20 & 15 \\
\hline Don't know & 101 & 100 & 100 \\
\hline Totals $^{\mathrm{a}}$ & \multicolumn{3}{|c|}{} \\
\hline
\end{tabular}

Source: Constructed by the author using data from Associated Press/Media General.

${ }^{2} \mathrm{~N}=1143$; percentages may not equal 100 due to rounding.

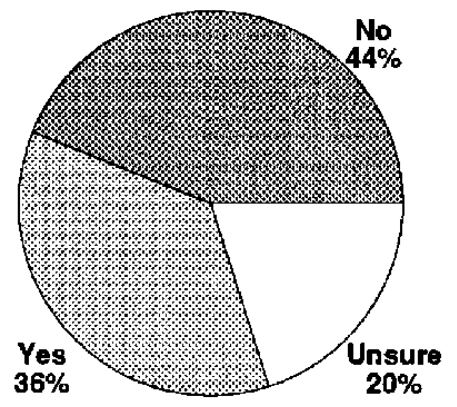

Offshore California

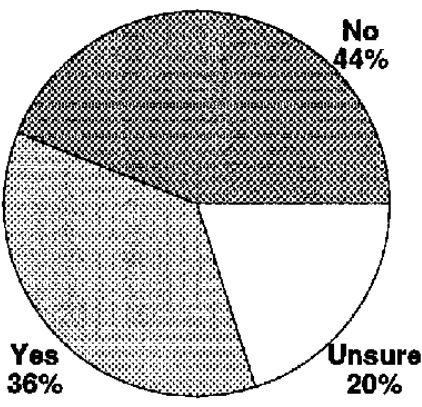

Offshore

Florida

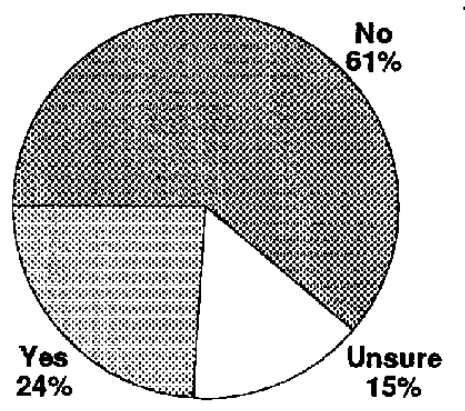

Alaska National Wildlife Refuge

Figure 9-A. Preferences for new oil drilling in California, Florida, and the Alaska National Wildlife Refuge, 1990 
bus, $1 \%$ walked, and $1 \%$ used a taxi. Several authors reported that transportation is the most rapidly increasing form of energy use owing to lifestyle changes (Schipper 1991a and b). Gasoline is the fuel-ofchoice for the internal combustion engine; transportation conservation behavior thus means using less gasoline. Given the nation's reliance on imported oil, the implications of this for increased national security and the improved balance of payments are extensive.

Two general ways to conserve gasoline are driving less and increasing the energy efficiency of vehicles. Methods of driving less include car pooling, using public transportation, planning trips more carefully, and walking or bicycling. Earlier surveys found that majorities viewed reducing their driving as both infeasible and undesirable. Nevertheless, large majorities reported that they were indeed driving less. Data indicated that, if mass transit were made available, a third to a half of the population would be willing to use it, but about half might not even try it. Buying a fuel-efficient automobile is another way of conserving gasoline-this was increasingly mentioned as a conservation measure in the earlier reviews of public opinion. Most of the public reported in the late 1970s that they were driving slower because of the 55-mph speed limit.

Decision factors. Most economists take the position that if gasoline prices were higher, people would drive less. Three survey items asked about this; the results suggest that higher prices, at least up to a point, might be less compelling than economists think. In 1990, Penn and Schoen Associates (for Texaco) asked: "Have the higher prices of gasoline led you to start conserving fuel or have they not had any effect on your consumption?" Sixty-four percent said that the higher prices had no effect, while $36 \%$ said they started conserving. They then asked the subsample who said that gasoline prices had no effect on their consumption: "At what price per gallon would you start cutting back on your fuel use?" [1206]. A plurality of $38 \%$ said at $\$ 1.25$ to $\$ 1.50$ per gallon. Another $22 \%$ said at $\$ 1.51$ to $\$ 1.75$ per gallon, $10 \%$ at $\$ 1.76$ to $\$ 2.00$, and $8 \%$ at more than $\$ 2.00$. About one-quarter were unsure.

In 1986, $\mathrm{ABC}$ News/The Washington Post asked: "Do you think you'll be doing more driving because gasoline is cheaper or not? (If they said more): Is that a lot more or somewhat more?" [1365]. Almost two-thirds of the sample (63\%) said they would not drive more; $32 \%$ said they would drive "somewhat" or "a lot" more. Four percent volunteered that they didn't drive, and 1\% didn't know.

In April 1991, the Los Angeles Times asked: "(As you may know, last fall Congress and the President agreed to change the tax code by increasing the tax on luxury items such as expensive cars and fur coats to ten percent, and by doubling the federal gasoline taxes.) . . . Specifically, because of these new taxes, have you reduced your driving, or not?" More than three-quarters, $76 \%$, said they had not decreased their driving; $17 \%$ said they had; $7 \%$ said they didn't drive or were unsure.

On the other hand, a Louisiana survey in June 1990 found that saving gasoline was the most important reason to participate in a car pool. One in ten car pool participants said it was to reduce costs.

A 1990 poll asked about guilt as a reason to conserve gasoline, which, for some people, is apparently a motivation to watch their gasoline consumption. Gordon S. Black Corporation asked: "(For each of the following items, please tell me whether it would make you feel very guilty, somewhat guilty, not very guilty, or not at all guilty. If the activity doesn't apply to you, just say so.) . . Making unnecessary trips in your motor vehicle. Would that make you feel very guilty, somewhat guilty, not very guilty, or not at all guilty?" [1283]. Responding that they would feel "very guilty" were 13\%. One-third said they would feel "somewhat guilty," and $42 \%$ said they wouldn't feel guilty. Nine percent volunteered that the question did not apply to them. 
Discomfort in taking public transportation could be a reason to avoid it. Research and Forecasts asked (for Mitchum Anti-Perspirant and Deodorant): "(How often do you feel anxious or stressful when in the following situations? Would you say always, sometimes, rarely, or never?) . . . When taking crowded public transportation?" [1527]. Thirty percent stated that they were "always" or "sometimes" stressed when using crowded public transportation; 55\% responded "rarely" or "never"; 13\% said this did not apply to them.

For individuals to conserve transportation fuels, other means of getting around have to be available to them. In 1991, the National Opinion Research Center found that $4 \%$ of a national sample ${ }^{2}$ said they needed but were unable to use public transportation to get to work, shop, or for other reasons [1458]. This meant that virtually everyone (96\%) was not in the circumstance of needing, but not being able to use, public transport.

Finally, environmentalism or the desire to help protect and improve the environment may be a motivator for a certain amount of gasoline conservation. Although no items were located that asked directly about this, several of the items asking respondents about actions taken to aid the environment by driving less, car pooling, and so on, implicitly assume that this was the reason. Given the lack of data, it is difficult to assess systematically the degree to which transportation behavior is environmentally motivated.

Behavioral intention and behavior. Numerous poll items asked two kinds of questions about gasoline conservation—actions that respondents had already taken, and actions they would be willing to take under certain conditions. Items asked about combinations of driving less, car pooling, or using mass transit to conserve gasoline. Some items focused solely on car pooling, mass transit, buying fuel-efficient cars, and other activities that would, in effect, conserve gasoline. The results from these items, in terms of frequency of respondents indicating they engaged in activities, vary by item wording.

Combinations of transportation conservation behaviors. In August 1991, Roper asked: "(Here is a list of things that people have told us they have done about the environment. Would you please read down the list and for each one tell me if you or someone in your household makes a real effort to do it on a regular basis, or does it from time to time when it's convenient, or doesn't really bother about it?) . . . Cut down on use of automobile by using public transportation, car pooling, etc." [1437]. The vast majority-70\% - said they "don't really bother about it"; $11 \%$ said they cut back on car use "on a regular basis" and $19 \%$ "from time to time."

When asked in 1991 how frequently they engaged in "reducing driving by car pooling and taking public transportation," 18\% said "regularly," 16\% "occasionally," 14\% "rarely," 40\% "never," and 12\% said this did not apply to them or they were unsure [1194]. And, ORC asked: "Which of the following things have you, or other household members, done in recent years to try to improve the quality of the environment?" [1528]. Thirty-nine percent reported that they had reduced the amount of driving they did to conserve fuel and/or switched to public transportation.

In April 1991, Gallup asked: "(Which of the following things, if any, have you or other household members done in recent years to try to improve the quality of the environment?) . . . Cut down on the use of a car by car pooling or taking public transportation?" [1493]. Forty-six percent said they have cut back their automobile use, but the majority, 53\%, said they had not. In May 1989, Gallup had also asked this item, and $42 \%$ reported that they had "cut down on the use of a car by car pooling or taking public transportation" [1296].

\footnotetext{
${ }^{2}$ Question was asked of a two-thirds sample.
} 
In 1990, Martilla \& Kiley and Market Strategies asked national voters: "(For each of the following steps that people could take to clean up the environment or preserve resources, please tell me whether you are already taking that step, would definitely be willing to do it, might be willing to do it, or probably would not be willing to do it.) ... Reduce driving, use mass transit" [1468]. Sixteen percent reported that they were already doing this. A quarter said they were "definitely willing." The majority, however, were not willing to make a definite commitment to reduced driving; 59\% said they "might be willing, probably would not be willing, or were unsure."

In February 1990, Roper asked about activities people have taken "about the environment" [1453]. One of the options listed was "cut down on use of automobile by using public transportation, car pooling, etc." Most respondents ( $76 \%$ ) said they "don't really bother about." Fourteen percent were "doing it from time, to time," and $89 \%$ were doing it regularly.

Continuing the old concept of sacrifice from the late seventies, the Los Angeles Times asked, in November 1989: "In order to improve the environment, are you prepared to make personal sacrifices, or not? . . . Are you willing, or not, to cut down on the number of cars in your family, or drive them less, or rideshare in order to conserve energy?" [1522] Eighty-three percent said they were "willing" and $14 \%$ said "unwilling"; $3 \%$ were unsure. ${ }^{3}$

A statewide study repeated an item on changes in transportation conservation behavior in West Virginia households between 1978 and 1987 [1475]. The trend data are summarized in Table 9-5. The data show that, in 1987, majorities reported they were maintaining their cars regularly, driving more slowly, purchasing more fuel-efficient cars, and cutting down on use of recreational vehicles. Fifteen percent said they were participating in car pools, and $9 \%$ said they were using public transportation. The proportion reporting the purchase of fuel-efficient cars increased from approximately one-half to two-thirds during the nine-year period. The proportion reporting driving more slowly declined 16 points between 1978 and 1987. Fewer West Virginians reported using car pools and public transport in 1987 than had in the late 1970 s and early 1980s.

The West Virginia study asked in 1987 what measures people were willing to take if gasoline became "unaffordable" [1457]. Multiple responses were permitted. Twenty-one percent said they would use mass transit; $33 \%$ join a car pool; $23 \%$ join an employer-based van or car pool; $20 \%$ reduce work trips by adopting 10-hour days; and 36\% "other" means.

A 1987 study in Alabama asked about conservation actions used by Alabamians, including transportation conservation [1434]. Reporting that they car pooled were $17 \% ; 40 \%$ said they drove less; $27 \%$ reported using a more fuel-efficient automobile; $11 \%$ said they drove slower; and $4 \%$ said they had their cars tuned-up.

Car pooling/ridesharing. Earlier reviews found that $5 \%$ to $14 \%$ of the driving population said they belonged to car pools. Table 9-6 shows U.S. Census data on modes of transportation to work. In 1980, $19.7 \%$ of workers car pooled; by 1990 , the percentage had dropped to $13.4 \%$. The average work commute time rose slightly between 1980 and 1990 .

${ }^{3}$ This item confounds so many different ideas, including improving the environment, personal sacrifices, willingness, car ownership, driving less, ridesharing, and energy conservation, that it is difficult to interpret the responses to it. 
Table 9-5. Trends in Reported Changes in Transportation Behavior to Conserve Fuel (West Virginia Households)

\begin{tabular}{|c|c|c|c|c|c|}
\hline Change $^{\mathbf{a}}$ & 1978 & $1979^{b}$ & $1980^{c}$ & 1981 & 1987 \\
\hline \multicolumn{6}{|l|}{ Proportion responding (\%) } \\
\hline $\begin{array}{l}\text { Began a program of regular car } \\
\text { maintenance }\end{array}$ & 68 & 82 & 83 & 83 & 84 \\
\hline Drove more slowly & 94 & 89 & 85 & 84 & 70 \\
\hline $\begin{array}{l}\text { Purchased a motor vehicle that gets } \\
\text { better gas mileage }\end{array}$ & 51 & 49 & 58 & 53 & 67 \\
\hline $\begin{array}{l}\text { Cut down on use of recreational } \\
\text { vehicles like snowmobiles, boats, } \\
\text { campers, etc. }\end{array}$ & 52 & 88 & 76 & 78 & 54 \\
\hline Joined a car pool & 13 & 23 & 22 & 20 & 15 \\
\hline Increased use of buses and taxis & 12 & 23 & 24 & 22 & 9 \\
\hline
\end{tabular}

Source: Constructed by author using data from Smith et al. [1475]

${ }^{\text {a}}$ Percentages do not total 100 because each item was asked as a separate question. Exact item wording was not provided.

${ }^{b}$ Two surveys were taken in 1979 and in 1980; data shown are from the second survey each year.

Table 9-6. Means of Transportation to Work in the United States, 1980 and 1990

\begin{tabular}{|c|c|c|}
\hline Means of Transportation & $\begin{array}{c}1980 \\
(\%) \\
\end{array}$ & $\begin{array}{l}1990 \\
(\%) \\
\end{array}$ \\
\hline Drove alone & 64.4 & 73.2 \\
\hline Carpooled & 19.7 & 13.4 \\
\hline Used public transportation & 6.4 & 5.3 \\
\hline Walked only & 5.6 & 3.9 \\
\hline Worked at home & 2.3 & 3.0 \\
\hline Bicycled & 0.5 & 0.4 \\
\hline Used motorcycle & 0.4 & 0.2 \\
\hline Total $^{\mathrm{a}}$ & 99.3 & 99.4 \\
\hline Average travel time (mins.) & 21.7 & 22.4 \\
\hline Total workers $(100 \%)$ & $96,617,296$ & $115,070,274$ \\
\hline
\end{tabular}

Source: U.S. Census, 1980 and 1990, Journey-to-Work and Migration Statistics Branch, Population Division (May 1992).

aPercentages do not add to 100 due to rounding errors. 
In November 1990, Yankelovich/Clancy/Shulman asked: "(Here are some things that people might do about the environment. For each, please tell me if it is something that you do regularly, occasionally when you have the time, or something you do not do.) . . . Car pool to work" [1016]. Seventy percent reported that they do not car pool; $12 \%$ said they car pool "occasionally" and 17\% "regularly." This contrasts somewhat with results from a Hart-Teeter survey in April 1990, reporting that $6 \%$ car pool to work, and $57 \%$ drive their own car [1194].

In September 1990, when asked how likely it would be that they would car pool "if there is an energy shortage," pluralities of 49\% said "unlikely," and 47\% said "likely" [1188]. Gallup, in a 1990 survey, asked an open-ended item about actions taken to reduce energy use; 3\% reported participating in a car pool [1313].

A 1990 Louisiana study found that $90 \%$ of respondents chose to drive alone rather than to participate in a car pool; only $10 \%$ were active in car pools [1430].

Two studies, in Ohio and lowa, explored car pooling in some more depth.

Ohio study. A survey, conducted by the Craig Group of Columbus, Ohio, for the Mid-Ohio Regional Planning Commission (MORPC) and published in February 1990, attempted to determine the perceptions, attitudes, and commuting behavior of persons in the central Ohio work force [1436].

The Craig Group surveyed by telephone 454 randomly selected adult commuters in the Columbus metropolitan area. For comparison purposes, an additional sample of 100 adults, drawn from commuters who had previously contacted the MORPC for information on programs, was interviewed.

One-half of the respondents worked outside their city of residence. The average number of miles commuted to work was 11.4 , and the average travel time was 19.9 minutes going to work and 21.4 minutes returning home. Between $65 \%$ and $75 \%$ of respondents commuted between seven and nine in the morning and between four and six-thirty at night.

Nine out of ten respondents reported that they drove to work alone. Drivers said that their principal reason for driving to work alone was that potential co-riders were unknown. A majority said that they made no stops on the way to work, but almost $90 \%$ of the drivers made stops on the way home. Most drivers paid no parking fee, with $80 \%$ parking in employer-provided spaces. Fewer than half used their cars during work hours. Seven of ten respondents said that they began and ended work at generally the same time every day. Forty percent reported encountering moderate to heavy traffic congestion on the way to work; most of the sample reported such congestion on the way home.

Thirteen percent of the sample said that they had participated in a car pool within the previous month; one-half of these used their ridesharing arrangement five days a week. Less than $20 \%$ of the respondents said that they would use a special car-pool-designated parking facility if it were not far from home.

Nine percent had commuted on the bus in the previous month; of these, $40 \%$ used it daily. Sixty percent said that they could not get to work by public transit.

More than $90 \%$ said that their employers offered no incentives to commute by means other than driving alone. Most agreed that employers should help with transportation problems, possibly naming a transportation coordinator at work to assist commuters.

Asked about commuting preferences, despite the fact that $90 \%$ did so, only one-half said that they would prefer to drive alone to and from work. Preferring car pooling were $30 \%$, and about $14 \%$ preferred public 
transit. Those who preferred driving alone were asked about five sets of conditions under which they might consider ridesharing or public transit. These conditions included cost of gasoline, length of commuting time, cost of parking, distance from parking lot to workplace, and availability of special traffic lanes that would reduce commuting time. Of these factors, the one showing the most positive response was the cost of parking. Two-thirds of the solitary drivers said that they would switch methods of commuting if their parking costs reached $\$ 125.00 /$ month. The remaining solitary drivers indicated that they could not think of any condition that would persuade them to switch to ridesharing or public transit.

Iowa study. In December 1981, the Iowa Energy Policy Council commissioned a study to determine conservation behaviors in home weatherization and ridesharing [1443]. Researchers analyzed the results to determine barriers, incentives, and general attitudes towards conservation practices, and data were used to create a marketing campaign targeting both conservation practices in Iowa.

One-third of the general public respondents had car pooled at some time; approximately $25 \%$ of those living in urban areas had taken the bus at some time. Many indicated that they felt car pooling was inconvenient, and that buses tend to make one late for work. Although a majority agreed that driving a car was tiring, this did not correlate with a strong desire to participate in ridesharing.

Among those living more than 6 miles from work, a higher percentage had participated in a car pooling program, feeling that driving is tiring and that car pooling saves money. In urban areas, this group accounted for almost $25 \%$ of the sample.

Almost one-third of respondents in all age and income categories agreed that ridesharing or public transit would be attractive if employers would share in the expense. Younger people, however, generally displayed a greater reluctance to car pool or use public transit.

When attitudes towards ridesharing were compared with home conservation and weatherization practices, a strong correlation appeared between those who had taken measures to conserve energy at home and those who were strongly in favor of ridesharing or public transit.

The study identified some barriers to a ridesharing program. These barriers included the following:

- Nearly $70 \%$ of households have at least one vehicle that averages greater than $16 \mathrm{mpg}$, providing less of an economic incentive to car pool.

- $\quad$ Sixty-three percent of respondents live less then 5 miles from their workplace and consequently display greater reluctance to participate in ridesharing programs. Participation is highest among those who live 11 miles or more from their work, but only $17 \%$ of the sample fall into this category.

- Up to $30 \%$ of respondents had no opinion on statements concerning ridesharing, indicating a considerable lack of knowledge of the concept.

- Many people were simply unwilling to give up the convenience of driving themselves to work.

Use of public transportation. Gordon S. Black asked, in March 1990: "How often do you use mass transportation instead of using your own motor vehicle?" [1283]. The majority, 55\%, said they never use mass transit; $11 \%$ said "frequently"; $10 \%$ said "occasionally." 
Hamilton, Frederick and Schneiders asked: "Which of the following things have you done in the last 3-4 days? . . . Used public transportation such as buses or trains?" [1529]. Most (89\%) reported they had not. used public transportation; $11 \%$ said they had.

Driving less. In September 1990, Hart and Teeter Research asked: "(Let me read you a list of ways people conserve energy. For each one, please tell me if you are likely or unlikely to try to conserve in this way if there is an energy shortage.) ... Driving less" [1188]. Almost two-thirds (66\%) said they were likely to drive less; $31 \%$ said they were unlikely to do so, even if there were an energy shortage.

The Statistical Record of the Environment reported a U.S. News \& World Report survey of February 4, 1991, asking Americans what actions they were taking "to save the Earth" [1450, p. 712]. Mentioned most frequently were recycling behaviors; however, $8 \%$ reported that they "cut down on driving."

In August 1990, Gallup asked what actions, if anything, a national sample were taking to reduce their use of energy. One in four reported that they were "driving less" [1313].

Other actions. The 1990 Gallup survey asking about actions taken to reduce energy use elicited a $2 \%$ response of "bought a gas-saving car" [1313]. This open-ended item also found $2 \%$ indicating that they ride a bicycle and walk [1313].

Gallup asked an open-ended item in April 1991 about actions taken to "improve the quality of the environment" [1493]. Sixty-seven percent said they had "replaced a 'gas-guzzling' automobile with one that was more fuel efficient."

A 1988 Indiana study asked about specific actions taken to improve fuel efficiency [1444]. Ninety-five percent said they maintained proper tire inflation, and $81 \%$ reported that they maintained their cars according to the manufacturer's recommended maintenance schedule.

Summary. Majorities of samples said that they have not been driving less, car pooling, using mass transit, bicycling, or walking. Surveys over the past decade have not asked whether people are driving at slower speeds to conserve gasoline. Proportions of samples indicating that they actually have driven less range from $11 \%$ to $25 \%$, while the range of those indicating they have car pooled was from $6 \%$ to $17 \%$. However, one-third of an Iowa sample had car pooled and $25 \%$ of those in urban areas had used the bus at some time. A few studies showed that about $10 \%$ of samples indicate recent or regular use of mass transit. Up to $90 \%$ of samples indicate that they drove solo to work. The most popular form of conserving gasoline, mentioned by a majority, was buying a more fuel-efficient car.

As is the case with buildings energy efficiency, the reasons to engage in gasoline conservation appear to be less significant than are the barriers to it. The most important reasons to conserve appear to be saving on costs of parking and gasoline, especially for commuters traveling longer distances to work.

Improving the environment is another reason cited, as is relief or avoidance of guilt by driving less. Because those who conserve household energy also tend to conserve transportation energy, gasoline conservation may also be a lifestyle expression of deeply held values.

Barriers to gasoline conservation behavior include the inconvenience of car pooling and mass transit. Most commuters make stops on the way home from work; car pooling could interfere with efficiency in running errands. Almost one-third of commuters work varying schedules, making car pooling infeasible. Also potential car pool partners may be unknown to many employees. Riding mass transit too frequently results in employee tardiness to work, according to polls. So, what alternative modes of commuting save 
in costs may be spent in longer commutes. The disadvantages, with specific exceptions based on unique geographic and social circumstances, seem to outweigh the advantages.

In Chapter 8, the idea of "institutionalized inefficiency" was introduced. Expanding the concept to include the transportation sector seems warranted. Not only have the nation's cities and suburban areas been developed in dependence on the ready availability of automobiles and gasoline, but also, the oil and automotive industries became backbones of the American economy. The nation was linked by an extensive interstate system of highways. Trucking became an important form of transport for domestic freight. In the last analysis, this institutional infrastructure constrains individual choice. Public opinion on transportation conservation seems to reflect these realities. This does not mean individual choices are unimportant or that change cannot occur. It does signify, however, that change will take considerable time, that it will be costly to achieve, and that it depends on decisions among public and private institutions as well as among consumers.

\section{Alternative Fuels and Alternative Fuel Vehicles}

Very few data were located concerning knowledge, attitudes, or behavior concerning alternative fuels. One item, asked by Roper in 1989 and 1990, mentioned "things that people have told us they have done about the environment"; one of the items listed was: "Use gasoline with methanol to cut down on air pollution" [1549]. Almost a quarter (24\%) said in March 1989 that they did this "on a regular basis" or "from time to time." In 1990, this proportion had decreased to $20 \%$.

Newsweek asked its sizable sample of new car buyers in 1990 how familiar they were with "the issue of alternative fuels" [1563]. Table 9-7 presents the results for the total sample and by educational level. The car buyers tended to be unfamiliar with alternative fuels: $60 \%$ said they were only "slightly" or "not at all familiar" with them. About one in eight said they were quite familiar with alternative fuels. As educational level increases, so does awareness of alternative fuels, up to $16 \%$ "completely" or "very familiar" among college graduates. Among those with a high school education or less, $47 \%$ said they knew nothing about alternative fuels.

Newsweek also asked new car buyers about their comparative preferences among alternative fuels [1563]. Table 9-8 presents the data, by gender, on which alternative fuels the sample would use. The most popular alternative fuels were "solar power" (17\%) and "gas blends" (16\%); the plurality response, selected by $42 \%$, was "don't know." Thirteen percent said they would be unwilling to use any alternative fuel. Methane (16\%) and electricity $(15 \%)$ were the fuels more respondents were unwilling to use. Men were more likely than women to prefer gas blends; women (55\%) were more likely than men (31\%) not to know their preferences. Newsweek also analyzed the appealing alternative fuels by age. The only notable differences were that those $55+$ years of age $(10 \%)$ were less likely than younger respondents to select "solar power" (23\% of those under 25 and $20 \%$ of those $25-54$ years of age). Likewise the older respondents were more likely $(22 \%)$ to prefer "gas blends" than the younger ones $(11 \%$ and $14 \%$, respectively) [1563].

Finally, Newsweek used a forced-choice item to gain insight into factors affecting alternative fuel choices [1563]. The factors the new car buyers identified as "extremely" or "very important" in 1990 were as follows: 
Table 9-7. Awareness of Alternative Fuels by Educational Level, $1990^{\mathrm{a}}$

\begin{tabular}{||l|c|c|c|c||}
\hline \multirow{2}{*}{ Response } & \multicolumn{4}{|c|}{ Percentages of new car buyers } \\
\cline { 2 - 5 } & \multirow{2}{*}{$\begin{array}{c}\text { Total } \\
\text { sample }^{\mathrm{b}}\end{array}$} & $\begin{array}{c}\text { High school } \\
\text { or less }\end{array}$ & $\begin{array}{c}\text { Some } \\
\text { college }\end{array}$ & $\begin{array}{c}\text { College } \\
\text { graduate } \\
\text { or more }\end{array}$ \\
\cline { 2 - 5 } & 3 & 2 & 3 & 4 \\
\hline Completely familiar & 9 & 7 & 8 & 12 \\
\hline Very familiar & 27 & 23 & 27 & 31 \\
\hline Somewhat familiar & 23 & 21 & 25 & 25 \\
\hline Slightly familiar & 37 & 47 & 37 & 29 \\
\hline Not at all familiar & 99 & 100 & 100 & 101 \\
\hline \hline Total $^{\mathrm{c}}$ & & & & \\
\hline
\end{tabular}

Source: Constructed by author using data from Newsweek.

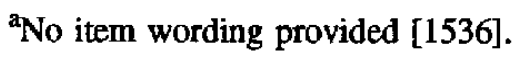

b $14,000+$ new car buyers in 1990.

May not add to $100 \%$ due to rounding.

- $\quad$ Safe to use as gasoline $(87 \%)$

- $\quad$ Available in most service stations (86\%)

- $\quad$ Provides performance equal to that of gasoline (84\%)

- $\quad$ As easy to use as gasoline when refueling $(81 \%)$

- $\quad$ Requires no modifications to car to use it $(76 \%)$

- $\quad$ Costs no more than gasoline $(66 \%)$.

Fifty-six percent agreed that most cars should be required to use alternative fuels. These decisions factors suggest that gasoline remains the standard against which alternative fuels are competing in gaining customer acceptance.

Knowledge and information sources. A 1990 survey asked residents of six cities in noncompliance with air quality standards: "Recently there has been a lot of talk about alternative fuels and alternative fuel vehicles to replace gasoline powered cars and trucks. How familiar would you say you are with the ideas being discussed when people talk about alternative fuels and alternative fueled vehicles?" [1428]. Fourteen percent said they were "very familiar" with them; $41 \%$ said "somewhat familiar"; the balance of the sample was not knowledgeable. 
Table 9-8. Preferences for Alternative Fuels by Gender, $1990^{\mathrm{a}}$

\begin{tabular}{||l|c|c|c|c||}
\hline \multirow{2}{*}{ Response $^{\mathrm{b}}$} & \multicolumn{4}{|c|}{ Percentages of new car buyers } \\
\cline { 2 - 5 } & $\begin{array}{c}\text { Total } \\
\text { sample }\end{array}$ & Mould use & Would not use \\
\cline { 2 - 5 } & 17 & 16 & Female & $\begin{array}{c}\text { Total } \\
\text { sample }\end{array}$ \\
\hline \hline Solar power & 16 & 22 & 18 & 10 \\
\hline Gas blends & 10 & 13 & 10 & 9 \\
\hline Electricity & 7 & 9 & 7 & 15 \\
\hline Methanol & 5 & 6 & 5 & 8 \\
\hline Methane & 3 & 4 & 3 & 16 \\
\hline None & 42 & 31 & 3 & 13 \\
\hline Don't know & 100 & 101 & 55 & 50 \\
\hline Totals & & 101 & $121^{\mathrm{e}}$ \\
\hline \hline
\end{tabular}

Source: Constructed by author using data from Newsweek.

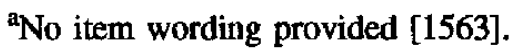

${ }^{b}$ Compressed natural gas was not included as a response option.

${ }^{c} 14,000+$ new car buyers in 1990 .

${ }^{d}$ May not add to $100 \%$ due to rounding.

eEither multiple responses were permitted, or the reported data are in error.

A 1990 Louisiana study of adult residents asked: "If you needed information on how to reduce your automobile operating costs, where would you go or who would you call?" [1430]. A plurality, 45\%, had no idea where to turn for such information. Most frequently mentioned were automobile mechanics, by 18\%. Fewer than one person in ten mentioned auto dealers, relatives and friends, their insurance company, the print media, and gasoline stations.

In Indiana, a 1988 study summarized 639 requests for energy publications by title of publication. Requested by $57 \%$ was the publication, "How to Make Any Car an Economy Car" [1444]. This was the second most requested publication, following only "40 Ways to Cool Your Home."

Fuel purchase decisions. A national poll item asked how prices affected gasoline purchase decisions. Roper asked, in 1985: "(Many people go for the expensive priced brands in some products and for the moderately priced brands in other products and for the inexpensive priced brands in still other products. Here is a list of a number of products. Would you go down that list, and for each one tell me when buying it whether you tend to go for the premium priced brand because it's the best quality, or go for the 
popular priced brand because it's the best value, or go for the low priced brand because there's no reason to pay more?) . . G Gasoline" [1090]. The plurality, 38\%, chose the lowest price, one-third the popular price, and $18 \%$ the premium prices; $2 \%$ said "it varies." Nine percent said they never buy gasoline.

Sperling et al. (1991) studied, using attribute analysis, registered vehicle owners in California and New York concerning switching to alternative fuels. The researchers asked: "Would you switch to a fuel that produced less air pollution if it were priced ... [bid amount] . . . higher than the gasoline you normally buy?" They found that $85 \%$ said they would pay 2 cents more and $24 \%$ said they would pay 45 cents more per gallon. As bid amount increased, willingness to pay decreased.

The most significant predictor variables for spending more were gender (female drivers were willing to spend more on cleaner fuels) and premium gas buyers (also willing to spend more). Although those more highly educated were more likely to pay more for less polluting fuels, educational level was not an important predictor variable.

Sperling et al, also asked: "Would you switch to a fuel that gave your car about $10 \%$ more power if it was priced higher than the gasoline you normally buy?" Sixty-five percent said they would pay 3 cents more for the more powerful fuel; $18 \%$ said they would pay 40 cents more. Higher income respondents and males were more willing to pay for more power, as were unleaded premium gasoline buyers, who were two times more willing to pay for more powerful fuels. No difference in willingness to pay more for more powerful fuels was found between California and New York. Drivers generally perceived power as slightly less valuable than lower pollution.

Premium gas accounted for $23 \%$ of sales in 1989. Drivers gave the following reasons for purchasing it: based on own experience (39\%), car knocks or pings (16\%), owner's manual recommendation (12\%), higher octane number $(9 \%)$, mechanic's recommendation $(5 \%)$, prefer higher grade unleaded $(5 \%)$, and other (3\%). The authors thought that buyers of higher octane fuels could be persuaded to buy methanol. Methanol, they said, should be targeted as a premium fuel-higher octane, cleaner burning, and more powerful. The size of the target market for methanol was estimated at about $10 \%$ of the total sample; however, other factors could affect this.

Some drivers are willing to pay more for environmentally correct fuel. Data presented in Chapter 2 (see Table 2-16) show responses to an item asking the additional amounts new car buyers would be willing to pay for fuel that significantly reduces air pollution [1563]. Forty-three percent said they would be willing to pay from $10 \%$ more to $50 \%$ or more additional cost for such fuels. Twenty-four percent said they were unwilling to pay more, and 33\% said they didn't know.

Vehicle purchase decisions. The proportion of the public driving full-size automobiles declined by 14 points between 1979 and 1989, according to Roper trend data. Table 9-9 presents the data showing that the proportion of persons classifying their car as "compact" has remained virtually unchanged in that 10-year period. Mid-size car drivers increased only slightly, by four points. Those driving other types of vehicles, including subcompacts, vans, utility vehicles, and pickups, increased in 1988 and 1989; however, most of these types of vehicles were not included in the earlier polls.

When Roper asked respondents with what size car they expected to replace their current vehicle, even fewer selected a full-size automobile than said they were currently driving one (22\% compared with $28 \%$ ) (see Table 9-10). The trend data show that the proportion planning to buy a full-size car increased from $19 \%$ in 1979 to $34 \%$ in 1985 , then dropped off to $22 \%$ by 1989 . Those indicating plans to buy a compact car decreased by 11 points from 1979 to 1989 , from $27 \%$ to $16 \%$. One in five planned to buy other types of vehicles by 1989 . Approximately one-third of the market planned to buy mid-size cars 
Table 9-9. Trends in Distribution of Perceived Car Sizes

"Here is a list of car sizes. (Card shown.) How would you classify the size of the car you have (driven most often)?" [1541]

\begin{tabular}{|c|c|c|c|c|c|c|c|c|c|c|c|}
\hline & 1979 & 1980 & 1981 & 1982 & 1983 & 1984 & 1985 & 1986 & 1987 & 1988 & 1989 \\
\hline \multicolumn{12}{|c|}{ Proportion responding (\%) } \\
\hline Full size & 42 & 41 & 38 & 39 & 41 & 40 & 43 & 39 & 38 & 29 & 28 \\
\hline Mid-size & 32 & 30 & 32 & 34 & 32 & 31 & 31 & 33 & 33 & 35 & 36 \\
\hline Compact & 18 & 20 & 19 & 20 & 21 & 20 & 20 & 22 & 23 & 21 & 20 \\
\hline Other ${ }^{\mathrm{a}}$ & 8 & 10 & 10 & 7 & 6 & 7 & 7 & 7 & 6 & 19 & 22 \\
\hline Totals $^{\mathrm{b}}$ & 100 & 101 & 99 & 100 & 100 & 98 & 101 & 101 & 100 & 104 & 106 \\
\hline
\end{tabular}

Source: Constructed by the author using data from the Roper Organization.

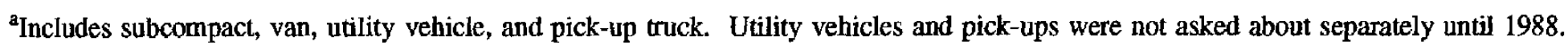

bercentages may not add to 100 due to rounding. In 1979, 1981, 1984, and 1986, 1\% responded that they did not know how to classify the car they drove by size. There may be an error in the 1988 and 1989 data as reported by Roper, since data add to $104 \%$ and $106 \%$, respectively. 
Table 9-10. Trends in Size of Next Car to be Purchased

"When you replace that car, which of the sizes of car on that list do you think you will buy?" [1541]

\begin{tabular}{|c|c|c|c|c|c|c|c|c|c|c|c|}
\hline & 1979 & 1980 & 1981 & 1982 & 1983 & 1984 & 1985 & 1986 & 1987 & 1988 & 1989 \\
\hline \multicolumn{12}{|c|}{ Proportion responding (\%) } \\
\hline Full size & 19 & 12 & 15 & 18 & 28 & 28 & 34 & 29 & 31 & 22 & 22 \\
\hline Mid-size & 31 & 31 & 31 & 37 & 39 & 37 & 37 & 39 & 37 & 34 & 33 \\
\hline Compact & 27 & 32 & 32 & 29 & 21 & 20 & 17 & 18 & 18 & 18 & 16 \\
\hline Other ${ }^{a}$ & 9 & 12 & 11 & 8 & 6 & 6 & 5 & 6 & 5 & 17 & 21 \\
\hline Don't know & 14 & 13 & 12 & 8 & 7 & 9 & 7 & 7 & 8 & 9 & 9 \\
\hline Totals $^{b}$ & 100 & 100 & 101 & 100 & 101 & 100 & 100 & 199 & 99 & 100 & 101 \\
\hline
\end{tabular}

Source: Constructed by the author using data from the Roper Organization.

ancludes subcompact, van, utility vehicle, and pick-up truck. Utility vehicles and pick-ups were not asked about separately until 1988.

${ }^{b}$ Percentages may not add to 100 due to rounding. In $1979,1981,1984$, and $1986,1 \%$ responded that they did not know how to classify the car they drove by size. There may be an error in the 1988 and 1989 data as reported by Roper, since data add to $104 \%$ and $106 \%$, respectively. 
throughout the 10-year period [1541]. This is approximately the same percentage indicating that they owned mid-size cars.

The evidence indicates that slightly more buyers were planning to purchase mid-size cars between 1982 and 1987 than currently owned them. Similarly, somewhat fewer buyers were planning to purchase fullsize cars throughout the 10-year period than currently owned them. Thus, a sizable proportion of full-size car owners planned to buy smaller cars next or didn't know what to do next.

Economy of operating cost is apparently not a critical decision factor in car purchase decisions, at least based on self-report. In fact, noneconomic factors seem to play a more significant role in the decision than economic ones. Table 9-11 and Figure 9-B summarize reasons the total new car market in 1990 gave for purchasing a new car, as measured by Newsweek (Maples 1991). Aesthetics, quality, and reliability were the most frequently mentioned types of decision factors. The factor mentioned least often was increased economy: wanting a car with better gas mileage or wanting a more economical car to operate. Maples (1991) reported that Newsweek analysts found the desire for better gasoline mileage was lowest among all car purchasing groups: 15th of 17 reasons to buy for the total industry, 14th for the total domestic market, 16th for the total import market, 15th for persons 55 and older, and 14th for first time new car buyers.

In 1986, when gasoline prices were lower, ABC News/The Washington Post asked: "If gasoline prices remain at their current lower levels, do you think many people will start buying bigger, less fuel efficient cars than they currently have or don't you think that will happen?" [1365]. A majority, 55\%, thought that people would not buy larger vehicles because of lower gasoline prices; a plurality of $43 \%$ thought that they would. A follow-up question asked: "What about you? The next time you buy a car, do you think there's a good chance you'll buy a bigger, less fuel-efficient car than you currently have if gasoline prices remain at their current lower levels or not?" [1365]. Almost three in four (73\%) said they would not buy a bigger car; $23 \%$ said they would.

Finally, in 1985, Roper found that $35 \%$ of a national sample thought foreign cars "are a lot better" in gas economy and mileage; $36 \%$ said they were "a little better" [1092].

When Newsweek [1563] asked about reasons a particular car was selected, "gas mileage/fuel economy" was 15 th of 31 reasons mentioned; $24 \%$ rated it "extremely important" and 34\% "very important." This compares with, for example "reliability," which $67 \%$ rated "extremely important" and another $25 \%$ rated "very important."

Newsweek's factor analysis of their 1990 new car buyer data yielded five market clusters: (1) demanding mass market (42\%); (2) economy (30\%); (3) family (16\%); (4) sporty (9\%); and (5) basic transportation (3\%). Among these clusters, economy (including gas mileage, rebate/low interest, price/deal offered, and warranty) was fourth most important to the demanding mass-market cluster (after quality, size, and image) and second most important to the economy cluster.

Chapter 2 presents data in Table 2-19 showing that $40 \%$ of new car buyers in 1990 said they were willing to pay from less than $\$ 200$ to $\$ 1,000$ or more in additional cost for a car that significantly reduces air pollution. Many of the survey items on vehicle choice decision factors have apparently not included environmental attributes; this result and the increased emphasis on the environment generally suggest that results would change if they did.

Research/Strategy/Management, in October 1989, asked registered voters: "(Suppose you could buy a new car today. Please tell me how important each of the following would be to your purchase decision.) 
Table 9-11. Reasons for Buying a New Car

\begin{tabular}{||c|c||}
\hline Reason & Percentage \\
\hline $\begin{array}{l}\text { Aesthetics } \\
\text { Other car owned was too old; grew tired of old car; like } \\
\text { appearance of new car }\end{array}$ & 22 \\
\hline $\begin{array}{l}\text { More quality } \\
\text { Needed a more reliable car; wanted better performance; } \\
\text { wanted better workmanship }\end{array}$ & 21 \\
\hline $\begin{array}{l}\text { Current auto unreliable or unworkable } \\
\text { Costly repairs on old car; old car damaged in accident }\end{array}$ & 19 \\
\hline $\begin{array}{l}\text { Changed needs } \\
\text { Needed an additional car; needed a larger car }\end{array}$ & 10 \\
\hline $\begin{array}{l}\text { Habit } \\
\text { Regularly buy new car, this was the year }\end{array}$ & 9 \\
\hline $\begin{array}{l}\text { Financial incentive } \\
\text { Rebate/low interest rate; dealer offered attractive deal; } \\
\text { limited time special offer }\end{array}$ & 6 \\
\hline $\begin{array}{l}\text { More economy } \\
\text { Wanted car with better gas mileage; wanted more } \\
\text { economical car to operate }\end{array}$ & 4 \\
\hline Other & 9 \\
\hline Total & 100 \\
\hline \hline
\end{tabular}

Source: Constructed by author using data from Newsweek's 1990 National Survey of New Car Buyers, reported by Maples (1991).

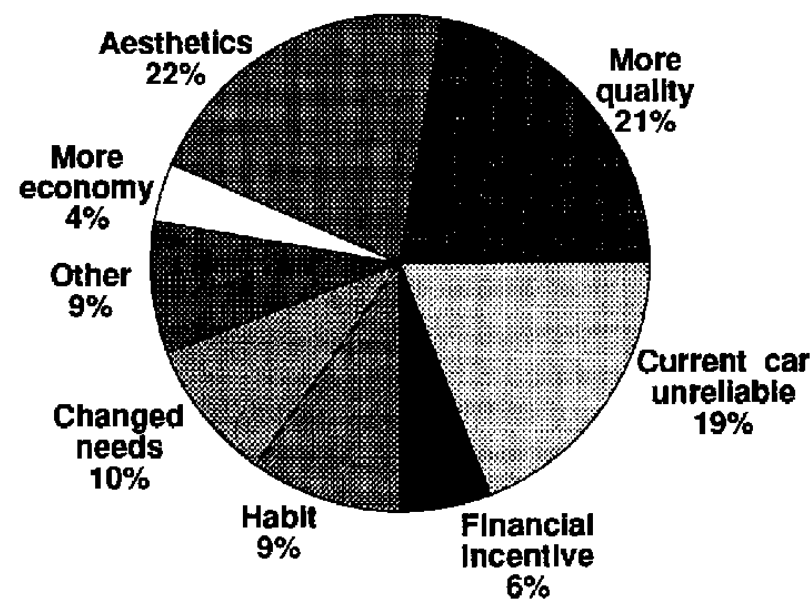

Source: Constructed by the author using data from Maples (1991).

Figure 9-B. Reasons for buying a new car 
Would fuel economy be extremely important, very important, only somewhat important, or not very important?" [1072]. The decision factors asked about and the proportion identifying them as "extremely important" or "very important" are as follows.

- $\quad$ A safety demonstration (79\%)

- $\quad$ Fuel economy $(76 \%)$

- $\quad$ Power and performance $(58 \%)$

- $\quad$ Size and comfort $(56 \%)$

- $\quad$ Avoiding a special tax placed on less fuel efficient cars (41\%)

- A cash rebate or federal tax credit for the purchase of a fuel efficient car (39\%).

When this same question asked about "avoiding a special tax placed on less fuel efficient cars," $41 \%$ said this would be "extremely" or "very" important, 30\% said "somewhat important," and $27 \%$ said "not very important" [1072]. When "a cash rebate or federal tax credit for the purchase of a fuel efficient car" was asked about, $39 \%$ said it would be "extremely" or "very important," while $32 \%$ said "somewhat," and $28 \%$ said "not very important."

Bunch et al. (1991) studied a random sample of Southern California households, using a stated preference modeling approach [1514]. Using a sophisticated research design, they included electric and unspecified AFVs (which could include methanol, ethanol, compressed natural gas, and propane) as well as dedicated or multiple-fuel versions. Attributes hypothesized to affect choice were purchase price of vehicle, fuel operating cost, vehicle range between refueling, fuel availability (fraction of stations having fuel), dedicated versus multiple-fuel capability, and level of emissions reduction. These attributes were established as significant based on extensive preliminary qualitative work.

When an AFV has considerably less range than existing gasoline vehicles, this study found that the first important attribute for vehicle choice was range between refueling. Owners who need to refuel more than once a week were more sensitive to range than others. Fuel availability was the second most important attribute.

For fuel choice, cost and perceived emissions levels were important; the latter attribute can compensate for different fuel prices. Choices were less sensitive to fuel availability when range and costs were similar to gasoline.

Alternative fuel vehicles. In 1975, Power-Robertson and Company conducted a mail survey of 300 electric vehicle owners [1512]. These owners were generally in professional or managerial occupations with higher incomes and owned electric cars as second vehicles, used for short trips. Three-quarters of them said they would recommend an electric car to a friend because they were satisfied with their cars and because the cars provided "good economy." Disadvantages cited were lack of dependability, poor dealer support, and lack of safety. Improvements recommended most frequently were roll-up windows, extended range between charges, more riding comfort, and faster speeds. However, $78 \%$ said they were "very likely" or "somewhat likely" to buy another electric car from a Detroit auto manufacturer.

J. D. Power and Associates conducted a second study of 195 electric car owners in 1977 [1513]. Most owned the Sebring-Vanguard CitiCar. Again, these car buyers were older (46.5 years), with higher median incomes than average economy car buyers at that time. The most important decision factors were the current fuel shortage or energy crisis (21\%) and the basic economy of an electric vehicle (19\%). Low operating costs were also identified as an important factor. Buyers considered other small economy cars, especially imports, before buying their electric cars. Eighty-seven percent said they would not have purchased any other car if their electric vehicle had not been available at that time. 
Most of the vehicles were driven by the male head-of-household, who was also the principal purchaser. The cars were driven for a median distance one-third that of gasoline-powered cars ( 75 miles per week). The most popular use was for errands and shopping, which fits the low-mileage range for the vehicles. The owners had eight batteries to provide running power, which they charged daily. The normal range on one charge was 31 miles.

The owners found that their vehicles were too slow for highway use, limited in range, and lacked room for passengers and cargo. However, they viewed their cars as easy to park, more maneuverable in traffic, and fun to drive. Owners said the cars were best for driving in heavy city traffic and worst for hilly roads, carrying friends or family, and country roads. The owners liked the following best: economy of operation $(45 \%)$, ease of handling and parking (19\%), and unique, different, and novelty features of having such a car (19\%).

The Wirthlin Group asked a 1990 sample in six cities whether they would be likely to buy an alternative fuel car for "your next new car" [1428]. A majority (56\%) said they "probably would buy an alternative fuel car if all the bugs were worked out." Four percent said they definitely would buy an alternative fuel car, while the rest of the sample said they probably or definitely would not, or did not know. When asked when they would get their next new car, van, or truck, $19 \%$ said within the next year, $22 \%$ said within 1 to 2 years, $33 \%$ said within 2 to 5 years, $15 \%$ said longer than 5 years, and $9 \%$ said "never." 


\section{Chapter 10}

\section{Transportation Efficiency Policy Preferences}

\section{Background and Summary}

The earlier reviews found patterns of public policy preferences on transportation efficiency. Most of the public at that time were opposed to raising gasoline prices to reduce consumption. Most believed that gasoline rationing would be effective in reducing consumption; nevertheless, most opposed gasoline rationing. Gasoline rationing, however, was preferred to price increases. At that time, most opposed special taxation for "gas guzzler" cars. Although the public was polarized on the issue, slight majorities favored relaxing emission controls on automobiles to increase gas mileage. Most favored the 55-mph speed limit.

Some empirical support was found for the notion that gasoline price increases were perceived as unfair and hard on consumers. Also some evidence was found for broad public support for government regulation of automobile manufacturing to increase average gas mileage.

A great deal of data was located in the 12-year period of this analysis on transportation policy preferences. Much of this information fell early in the period (in the late 1970s and early 1980s), and has not been replicated recently. Policy options covered in this chapter include the following:

- $\quad$ Oil and Gasoline Policy

- Gasoline tax increases

- $\quad$ Oil and gasoline price controls

- $\quad$ Oil import taxes and incentives for domestic production

- Windfall profits tax

- $\quad$ Severance taxes

- $\quad$ Regulation of oil production

- $\quad$ Strategic Petroleum Reserve (SPR)

- $\quad$ Conservation Policy

- $\quad$ Fuel economy/corporate average fuel economy (CAFE) standards

- $\quad$ Financial incentives for purchasing fuel-efficient vehicles

- Ridesharing/car pooling

- Gasoline rationing

- $\quad$ Limited access to gas stations

- No-drive days

- $\quad$ 55-mph speed limit

- $\quad$ Mass Transit Policy 
- Alternative Fuels and Alternative Fuel Vehicles Policy

- $\quad$ Alternative fuels

- $\quad$ Alternative fuel vehicles.

Each of these topics is addressed from a policy preference viewpoint.

\section{Oil and gasoline policy}

Gasoline tax increases. More data exist on this policy option than most others. The public has consistently opposed gasoline tax increases. Regardless of item wording, majorities oppose such tax increases. The public tends to overestimate the amount of federal, state, and local gasoline taxes, actually 26 cents per gallon, by approximately 9 cents per gallon; a majority believe the taxes are "too high." 1 When compared with other means of reducing the federal deficit, gasoline taxes were virtually the least popular action that could be taken. Despite the fact that energy-efficiency advocates urge that gasoline taxes increase as a means to increase gasoline prices to a level at which conservation would occur, this policy cuts deeply against the grain. Other policies to reduce gasoline consumption would enjoy more widespread public acceptance than this one. Much of the public apparently does not believe that increasing gasoline taxes would result in reduced gasoline demand in any event.

The only exception to this pattern occurred when items asked about increased gasoline taxes to protect and improve the environment. When framed this way, increased gasoline taxes were more widely accepted. However, the use of revenues generated in this way to actually improve the environment may be critical to actual public acceptance of such taxes.

Oil and gasoline price controls. By 1990, almost two-thirds favored price controls on gasoline and home heating oil. Attitudes about price control policies appear to be influenced by gasoline prices. The higher the price of gasoline, the greater the proportion of the public calling for regulation of gasoline prices.

Oil import taxes and incentives for domestic production. Opinion seems divided on the desirability of taxing imported oil. Many tend to favor this when it is couched in terms of reducing the federal deficit or increasing international competitiveness. However, when it is presented in terms of raising the cost of gasoline, many tend to oppose the idea. An import tax on gasoline could reduce the federal deficit and increase international competitiveness, but it is not a widely accepted option. Opinion is divided on the desirability of offering tax incentives to oil companies to encourage domestic exploration and production. Although energy industry leaders favored this option, public interest opinion leaders did not support the idea.

Windfall profits tax. Excess profits taxes were favored in the late seventies, and they were still favored in 1992 by approximately two-thirds of the public. However, this sentiment seemed less intense in 1992 than in the late seventies.

Severance taxes. No data on this were found past 1984; polling organizations have apparently not included questions about this in recent years. Prior to that time, nearly two-thirds of samples favored severance taxes by individual states on natural resources such as oil, gas, and coal.

Regulation of oil production. Most oppose an outright federal government takeover of the oil industry. However, in 1990, a majority favored breakup of large oil companies to limit the power of the oil industry

\footnotetext{
${ }^{1}$ The federal gasoline tax is currently 14.1 cents a gallon.
} 
over the domestic economy. Formation of a government owned and operated oil corporation was also favored by a majority. Data were somewhat limited, however. In general, the public seems unwilling to accept more stringent regulation of the oil industry.

Strategic Petroleum Reserve (SPR). The limited data available suggest that the public favors the maintenance of the SPR.

\section{Conservation policy}

Fuel economy/CAFE standards. The public strongly favors increasing the fuel efficiency of automobiles, borne out by several polls. The limited evidence available on the point shows that the public strongly favors increasing CAFE standards.

Financial incentives for purchasing fuel-efficient vehicles. The few data available suggest that public opinion has shifted toward favoring tax penalties on larger, fuel-inefficient automobiles. A few items addressed using financial incentives to encourage transportation efficiency; these received favorable response. Financial incentives for purchasing vehicles that are more fuel efficient (or disincentives for "gas guzzlers") is a very acceptable method for steering people to more efficient vehicles to reduce fuel consumption.

Ridesharing/car pooling. In 1989 , most were unwilling to see regulations requiring car pooling to and from work, although one-third were willing. Encouraging car or van pooling appears to be acceptable to majorities. However, the data are very limited.

Gasoline rationing. Only two items asked about this; majorities continued to oppose gasoline rationing.

Limited access to gas stations. The evidence shows a pattern of public disinterest in or opposition to this idea.

No-drive days. In 1989, most were unwilling to see regulations requiring limited driving days. Most do not want more restrictions on when and where automobiles are used. Polling organizations have not been asking about this option, however, and almost no data on it exist.

55-mph speed limit. Almost no data after 1980 were located on the 55-mph speed limit. However, in 1989, most said that the good effects of the speed limit outweighed the bad effects. The available evidence is very limited; however, it appears to show declining support for the 55-mph speed limit as public policy and less willingness to observe it currently than in the late seventies.

\section{Mass transit policy}

Most people seem to feel that enough is being spent on mass transit. Only a plurality favored privatizing mass transit in 1991. A majority in one study favored requiring people who drive to work to take public transport one day a week in major metropolitan areas. Favorability to mass transit has continued; however, no strong mandate for it has emerged.

\section{Alternative fuels and alternative fuel vehicles policy}

Alternative fuels. Almost no data were available on this topic. Most people appear not to know much about alternative fuels. One item showed divided opinion on requiring all new cars to run on alternative fuels, with a plurality favoring it. No conclusions are possible on alternative fuels policy; this is a research gap. 
Alternative fuel vehicles. Most were unwilling, in 1989, to see regulation requiring that new cars be able to run on alternative fuels. Of a 1990 sample of new car buyers, a plurality of $48 \%$ said the government should require automakers to build cars that run on alternative fuels. Almost no other reliable data were available. This is another research gap.

The balance of the chapter presents the details of these empirical findings organized into four sections: (1) oil and gasoline policy, (2) conservation policy, (3) mass transit policy, and (4) alternative fuels and alternative fuel vehicles policy.

\section{Oil and Gasoline Policy}

Gasoline tax increases. One of the most persistently measured transportation policy options has been increasing gasoline taxes. And, in one the most consistent patterns in the entire body of poll data, the public has opposed such increases. Table 10-1 summarizes data from 31 surveys asking about gasoline tax increases between 1983 and 1992. Without exception, majorities of respondents polled opposed or strongly opposed gasoline tax hikes. The questions used to obtain these results varied widely; Appendix D provides the actual item wording employed. However, the evidence is only made more persuasive by the fact that, regardless of item wording, majorities opposed such tax increases.

To augment the data presented in Table 10-1, the following examples of actual questions used and the results they elicited are discussed. In 1990, using a series of related poll questions, Roper discovered that the public tended to overestimate the amount of federal gasoline tax. The federal, state, and local tax is actually 26 cents per gallon, as measured in industry surveys [1551]. In July 1990, the public's median estimate was that the combined taxes were 35 cents per gallon [1551]. A majority (55\%) said the taxes were "too high," while $25 \%$ said they were "about right" [1551]. When asked what they thought the tax on a gallon of gas ought to be, the median estimate was 20 cents, which is 6 cents below what the tax actually is, but 15 cents less than what the public thinks it is. Poll data on increasing the gasoline tax should be understood in this context.

In December 1990, Roper asked: "The situation in the Arab world has raised prices on imported oil, resulting in higher fuel costs to consumers. Some people say it would be good if the United States could be independent of these Arab oil producing countries, but there would be problems connected with this. We'd like to ask you how you feel about some of these means to becoming independent" [1554]. Of five options listed, one was: "The Federal Government could invest in new energy exploration and technology, but this would require a higher tax on gasoline to pay for it. Would you be willing to see this happen or not?" Opinion was almost equally divided between those willing (46\%) and those unwilling (44\%) to see this happen; $10 \%$ were unsure. ${ }^{2}$

If a federal gasoline tax were increased 10 cents per gallon or less, a majority (56\%) would favor it if the money were used for environmental purposes [1025]. Research/Strategy/Management (RSM) and Greenberg/Lake, The Analysis Group found that, in December 1990, 37\% favored: "Adding a federal gas tax of $\$ .50$ per gallon phased in over several years and earmarked for an environmental trust fund" [1025]. However, $42 \%$ "strongly opposed" such a tax, and 18\% "somewhat opposed" it, for a total of $60 \%$ against.

${ }^{2}$ This item confounded two elements: (1) gasoline tax as a resource and (2) use of the resource to fund new energy exploration and technology. Appendix $\mathrm{H}$ contains the full item with complete response data. 
Table 10-1. Public Opposition to Gasoline Tax Increases

Prototypical item wording: "Do you favor or oppose increasing gasoline taxes?" a

\begin{tabular}{|c|c|c|c|c|}
\hline Date & & Oppose & Favor & Study number \\
\hline \multicolumn{5}{|c|}{ Proportion responding (\%) } \\
\hline Jan. & 1992 & 77 & 22 & [1477] \\
\hline July & 1991 & 69 & 27 & [1486] \\
\hline Apr. & 1991 & 50 & 11 & [1487] \\
\hline Mar. & 1991 & 50 & 49 & [1499] \\
\hline Oct. & 1990 & 62 & 36 & [1012] \\
\hline Oct. & 1990 & 81 & 19 & [1037] \\
\hline Sept. & 1990 & 76 & 24 & [1421] \\
\hline Aug. & 1990 & 71 & 27 & [1206] \\
\hline Aug. & 1990 & 78 & 17 & [1286] \\
\hline July & 1990 & 59 & 38 & [1191] \\
\hline May & 1990 & 57 & 40 & {$[1339]$} \\
\hline May & 1990 & 55 & 44 & [1190] \\
\hline Mar. & 1990 & 71 & 26 & [1050] \\
\hline Jan. & 1990 & 72 & 26 & [1192] \\
\hline Dec. & 1989 & 54 & 43 & [1185] \\
\hline Apr. & 1989 & 77 & 21 & {$[1045]$} \\
\hline Jan. & 1989 & 63 & 34 & {$[1320]$} \\
\hline Jan. & 1989 & 64 & 26 & [1516] \\
\hline Dec. & 1988 & 54 & 44 & {$[1278]$} \\
\hline Nov. & 1988 & 76 & 22 & [1359] \\
\hline Oct. & 1987 & 76 & 21 & [1258] \\
\hline Feb. & 1988 & 70 & 27 & [1046] \\
\hline May & 1987 & 63 & 31 & [1210] \\
\hline Apr. & 1987 & 60 & 39 & [1268] \\
\hline Apr. & 1986 & 67 & 28 & [1291] \\
\hline Apr. & 1986 & 53 & 44 & {$[1270]$} \\
\hline Apr. & 1986 & 54 & 45 & [1270] \\
\hline Feb. & 1986 & 61 & 36 & [1241] \\
\hline Feb. & 1986 & 53 & 44 & [1196] \\
\hline Aug. & 1983 & 77 & 18 & [1160] \\
\hline Aug. & 1983 & 68 & 28 & {$[1160]$} \\
\hline
\end{tabular}

Source: Constructed by author using data from cited studies.

${ }^{a}$ Appendix D contains item wording by study number. 
Martilla and Kiley and Market Strategies surveyed national voters in June 1990. They asked: "Some experts have recommended a dramatic increase in the federal gasoline tax, from 9 cents to one dollar a gallon. They say that because a tax like this will lead Americans to use less gas, and to buy cars that get much higher gas mileage, it is the single most effective thing we can do to reduce air pollution. They say that the funds raised from the tax could be used to expand public transportation, making it easier for people to drive less. With this in mind, would you favor or oppose increasing the federal tax on gasoline from 9 cents to one dollar a gallon?" [1468]. Opposing the proposed tax increase were $72 \%$ of voters; one-quarter favored it. ${ }^{3}$

In October 1990, Gallup queried a national sample about a new national budget plan, as follows: "Congress and the President have recently agreed upon a new federal budget plan. The new plan will increase taxes on the wealthy, increase the gasoline tax by 5 cents per gallon, raise taxes on cigarettes and alcoholic beverages, place a luxury tax on expensive boats, cars, jewelry and furs, raise taxes on airline tickets, and increase the amount of income which is subject to the Medicare tax. Congressional leaders and the administration say these new taxes are necessary to reduce the federal deficit. Overall, do you favor or oppose this new plan?" [1474]. The majority (59\%) said they favored the plan, while 37\% opposed it. In this context of several other, more palatable tax increases, such as those on the wealthy and on luxuries, the 5-cent gasoline tax increase apparently slipped through.

Several polls have used items that compared gasoline taxes with other means of reducing the federal deficit to gauge the public's ranking of various revenue-increasing options. Increasing gasoline taxes has repeatedly been found to be virtually the least popular action that could be taken. For example, Table 10-2 shows that, in 1987 when reducing the federal deficit was a "hot topic" on Capitol Hill, Louis Harris and Associates presented respondents with nine different ways to cut the federal budget deficit by $\$ 23$ billion.

Six options were favored more than increased energy taxes, and only two were favored less- the everunpopular raising the income tax and cutting spending on entitlement programs such as Medicare and health programs long considered "sacred cows" [1258].

That same year, ABC News/The Washington Post asked: "I am going to mention some things that have been proposed to help balance the federal budget, and for each please tell me whether you approve or disapprove of that proposal. Do you approve or disapprove raising taxes on gasoline to help balance the federal budget?" Disapproving were $73 \%$; approving were $27 \% ; 1 \%$ were unsure [1376]. Gallup had a similar result with a 1987 item asking about raising a small amount of additional revenue to reduce the deficit. Only $4 \%$ in one survey and $8 \%$ in another favored "an increase in gasoline and diesel fuel taxes" [1456].

Similarly, Hart-Teeter Research Companies asked in May 1990: "Let us suppose that in order to reduce the federal budget deficit some taxes had to be raised, and the choice came down to increasing the income tax rate for upper income earners or increasing the tax on gasoline. Which would you favor-increasing the income tax rate for upper income eamers or increasing the tax on gasoline?" Increasing income taxes for the wealthy was chosen by $68 \% ; 28 \%$ favored increasing the gasoline tax; $2 \%$ volunteered that both taxes should be raised; and $2 \%$ were unsure [1190].

${ }^{3}$ This item confounded five elements: (1) increase in federal gasoline tax, (2) purpose of tax would be to use less gasoline, (3) purpose of tax would be to get consumers to buy more fuel-efficient cars, (4) outcome would be to reduce air pollution, (5) revenues could be used to develop public transportation. 


\section{Table 10-2. Preferred Ways to Cut the Federal Budget Deficit}

"(Negotiators from the White House and Congress are trying to come up with an agreement on both spending cuts and tax increases in order to cut the federal budget deficit by $\$ 23$ billion. Tell me if you favor or oppose each of these provisions.)...raising energy taxes (Energy taxes), forcing the allies to pay a much larger share of the cost of their own defense (Allied defense), increasing excise taxes on tobacco and alcoholic products (Excise taxes), matching every dollar of a tax increase with cut in federal spending (Matching federal), cutting other federal spending (Federal spending), cutting defense spending (Defense spending), enacting a value added tax (Value tax), raising the income tax (Income tax), and cutting spending on entitlement programs, such as Medicare and health programs (Entitlement)?" (October 1987) [1258].

\begin{tabular}{|l||c|c|c|c|c|c|c|c|c|c||}
\hline \multicolumn{1}{|c|}{ Categories } & $\begin{array}{c}\text { Energy } \\
\text { taxes }\end{array}$ & $\begin{array}{c}\text { Allied } \\
\text { defense }\end{array}$ & $\begin{array}{c}\text { Excise } \\
\text { taxes }\end{array}$ & $\begin{array}{c}\text { Matching } \\
\text { federal }\end{array}$ & $\begin{array}{c}\text { Federal } \\
\text { spending }\end{array}$ & $\begin{array}{c}\text { Defense } \\
\text { spending }\end{array}$ & $\begin{array}{c}\text { Value } \\
\text { tax }\end{array}$ & $\begin{array}{c}\text { Income } \\
\text { tax }\end{array}$ & $\begin{array}{c}\text { Entitlement } \\
\text { programs }\end{array}$ \\
\hline \hline \multicolumn{1}{|l|}{ Proportion responding (\%): } \\
\hline Favor & 21 & 87 & 75 & 69 & 71 & 58 & 24 & 19 & 14 \\
\hline Oppose & 76 & 11 & 24 & 27 & 24 & 41 & 56 & 79 & 84 \\
\hline Not sure & 3 & 2 & 1 & 4 & 5 & 1 & 20 & 2 & 2 \\
\hline \hline Total & 100 & 100 & 100 & 100 & 100 & 100 & 100 & 100 & 100 \\
\hline & $(1251)$ & $(1251)$ & $(1251)$ & $(1251)$ & $(1251)$ & $(1251)$ & $(1251)$ & $(1251)$ & $(1251)$ \\
\hline
\end{tabular}

Source: Louis Harris and Associates. 
And again, Gallup asked in January 1989: "This card lists various kinds of tax increases and the amount of money each might raise over a 5-year period. The budget deficit could be more than $\$ 500$ billion over this period. Taking into account the amount of money each would raise, and your opinion about these taxes, which, if any, would you favor as a means of reducing the federal budget deficit?" [1320]. Eight different options were listed; the most frequently selected one (by 69\%) was to "raise taxes on wine and beer to the same rate as liquor taxes ( $\$ 20$ billion)." Twenty percent selected "increase gasoline taxes by 12 cents per gallon ( $\$ 50$ billion)." The only less popular actions were taxing $85 \%$ of Social Security benefits (10\%) and adding a 5\% surtax to income taxes (9\%).

In May 1988, Gallup explored the relative popularity of gasoline tax increases in a series of forced-choice items. Each item began: "Here is a list of ways in which government revenues could be increased or government expenses cut." Respondents were then asked:

- $\quad$ "Please circle the number for each action, if any, that you would support in order to reduce the federal deficit." Multiple responses were permitted. In response, $16 \%$ selected "increasing taxes on gasoline." Of the 20 -item list, the only items less popular were "cutting spending for scientific research," "eliminating automatic cost-of-living increases in payments to Social Security beneficiaries," "cutting back Medicare benefits," and "eliminating the food stamp program."

- $\quad$ "Which one of the ways you mentioned do you favor most strongly (as a way to reduce the federal deficit)?" One percent selected "increasing taxes on gasoline."

- $\quad$ "Which one do you favor second most strongly (as a way to reduce the federal deficit)?" Again, $1 \%$ selected increasing gasoline taxes.

- $\quad$ "Are there any of these ways of reducing the federal budget deficit that you would strongly oppose?" Of the 20 items, $15 \%$ strongly opposed increasing the gasoline tax. Seven other items were more strongly opposed, including those listed above, plus "cutting spending for defense" and "ending price supports for farmers."

The League of Women Voters' purposive sample of public interest and energy industry leaders was not as opposed to increasing gasoline taxes as the public. In 1987, 72\% of public interest and 53\% of energy industry leaders supported an increased gasoline tax.

A 1987 Opinion Research Corporation (ORC) poll asked: "If the federal gasoline tax were increased, do you think this would reduce the amount of gasoline that is used a great deal, a fair amount, only a little, or not at all?" [1210]. Three-quarters responded that they thought gasoline would be conserved "only a little" (42\%) or "not at all" (33\%). This finding is significant because it helps to explain why the public opposes increases in the gasoline tax. It says that the public considers that it would have to keep using the amount of gasoline it does despite gasoline tax increases. Gasoline tax increases were not viewed as effectively contributing to fuel conservation.

In summary, energy efficiency advocates and economists frequently advocate gasoline-tax increases as a means to get prices to such high levels that consumers would conserve gasoline. This policy option, however, cuts deeply against the grain of public opinion. If public acceptability is taken into account, other policies to reduce gasoline consumption could enjoy more widespread public acceptance than this one. The public apparently does not believe that increasing gasoline taxes would result in reduced gasoline demand in any event. 
Oil and gasoline price controls. The earlier reviews found that most of the public were opposed to raising prices of gasoline to reduce consumption. This opposition is probably related to the consistent opposition to increasing the gasoline tax, as well.

Several recent items explored public attitudes toward regulating oil and gasoline prices versus letting the market determine prices. Roper measured preference for increased government regulation of oil and gas prices from 1977 through 1991 [1557]. Table 10-3 shows the trend results along with the average retail cost of gasoline leading up to the survey data collection period. The percentage desiring more regulation in 1991 , a plurality of $44 \%$, is close to the 1977 plurality of $47 \%$. Those wanting price controls reached a majority of $55 \%$ in 1980 , and declined thereafter with the price of gasoline. The percentage rose again in 1991 after gasoline prices began to increase again (see Figure 10-A). Plotted against the adjusted and actual prices of gasoline, this trend line matches those curves closely. The higher the price of gasoline, the more respondents say there is not enough regulation of oil and gasoline prices. This suggests that public opinion about the adequacy of regulation is responsive to the price of gasoline.

The oil industry has frequently been viewed as a candidate for regulation (see Chapter 5). The industry was also seen as exploiting the Persian Gulf situation. Iraq invaded Kuwait August 2, 1990. Retail gasoline prices for unleaded regular gasoline in August averaged 119.0, in September 129.4, in October 137.8, in November 137.7, and in December 135.4. In August 1990, Penn and Schoen Associates asked about possible elements of a national energy policy in 1990. One of the elements was "allowing gasoline prices to rise to world market levels to encourage conservation and provide incentives for more exploration" [1206]. Opinion was divided; $46 \%$ favored and 48\% opposed this idea. This study also asked: "Do you think that the government should impose price controls on the price of gasoline or leave the price to market forces?" Half of the sample favored price controls, while $43 \%$ favored market forces. Following along a sequence, Penn and Schoen (for Texaco, Inc.) asked: "Do you think that price controls would lead to shortages and long lines or not?" A plurality of $47 \%$ thought they would not; $42 \%$ thought they would. The next item asserted: "Price controls can cause shortages of products because some makers can no longer afford to bring products to the market at the mandated prices. If it was a choice between price controls that would bring shortages and long lines - and free market forces that would mean higher prices but no lines, which would you choose?" With this item, which biased the response, 55\% chose free market forces/no lines, and $36 \%$ chose price controls/long lines.

Harris asked a national sample in August 1990: "Do you favor or oppose price controls on gasoline and home heating oil?" [1262]. Almost two-thirds (64\%) favored them, while one-third (34\%) opposed them. Gallup asked, in August 1990: "Would you support or oppose new laws to put a limit on the amount gasoline prices can rise?" [1286]. Most respondents said they would support such a limit (81\%). Moreover, $80 \%$ responded affirmatively to Yankelovich/Clancy/Shulman's item: "Do you think there should be laws that limit the amount that oil companies can raise their prices during crisis situations or not?" [1049].

In 1986, when gasoline prices were at their lowest level in years, the public appeared to favor deregulation of oil prices. Several surveys reported majorities favoring deregulation $[1084,1085,1281,1365]$. That year, one survey found $60 \%$ responding that "the United States should prevent oil prices from falling too far because such a drop could damage our oil industry and leave this country dependent on foreign oil" [1199].

In 1982, two-thirds of a national sample said that it had been bad for consumers that since 1981 "oil companies had not been subject to government price controls and oil companies could decide for themselves what prices to charge for gasoline" [1248]. In 1983, 48\% thought deregulation had been "against the public's interest" [1106]; in 1981, 46\% agreed [1127]. In 1981, three-quarters of a national 
Table 10-3. Trends in Public Preferences on Regulating Oil and Gasoline Prices

"Now l'm going to name some things, and for each one would you tell me whether you think there is too much government regulation of it now, or not enough government regulation now, or about the right amount of government regulation now?" "The price of oil and gas" (February of each year) [1557]

\begin{tabular}{|c|c|c|c|}
\hline Year & $\begin{array}{c}\text { Proportion }(\%) \text { indicating } \\
\text { "not enough government } \\
\text { regulation" }\end{array}$ & $\begin{array}{l}\text { Average retail } \\
\text { price of gasoline, } \\
\text { unleaded regular }\end{array}$ & $\begin{array}{c}\text { Adjusted } \\
\text { price }^{a}\end{array}$ \\
\hline 1977 & 47 & $65.6^{b}$ & 97.474 \\
\hline 1979 & 45 & $71.6^{\mathrm{c}}$ & 91.094 \\
\hline 1980 & 55 & 113.1 & 131.972 \\
\hline 1982 & 38 & 135.8 & 134.655 \\
\hline 1984 & 34 & 121.6 & 112.906 \\
\hline 1986 & 27 & 119.4 & 104.921 \\
\hline 1988 & 23 & 93.3 & 76.917 \\
\hline 1991 & 44 & 124.7 & 92.783 \\
\hline
\end{tabular}

Source: Constructed by the author using data from the Roper Organization and the Energy Information Administration's Monthly Energy Review.

${ }^{2}$ GNP deflaters applied to Energy Information Agency (EIA) report figures from National Income and Product Accounts, 1927-1982; Survey of Current Business, July issues, 1983-1991.

${ }^{b} 1977$ average, cents per gallon including tax. The 1976 average price was 61.4. Costs for leaded gasoline were lower. The 1977 average for leaded gasoline was 62.2 cents per gallon. Source: EIA Monthly Energy Review.

cJanuary average given for 1979 and all subsequent years, because the poll data collection period ensued early in February.

sample opposed oil price increases "so the oil and gas companies will be encouraged to find new oil and gas fields" [1129]. Responding to a trade-off item, $52 \%$ of a 1981 sample chose "lower prices even if it means tight supplies" [1130]. In 1980, government price controls on oil and natural gas were favored by a 53\% majority [1335].

These data show that a surrogate for public opinion about price control policies might be calculated increments and decrements in average real gasoline prices. The exact relationship, if one can be established, remains to be determined; however, this evidence suggests that public opinion toward energy policy is influenced by prices, along with other energy-related events. 
"Now I'm going to name some things, and for each one tell me whether you think there is too much government regulation of it now, or not enough government regulation now, or about the right amount of government regulation now?" "The price of oil and gas" (February of each year) [1557].

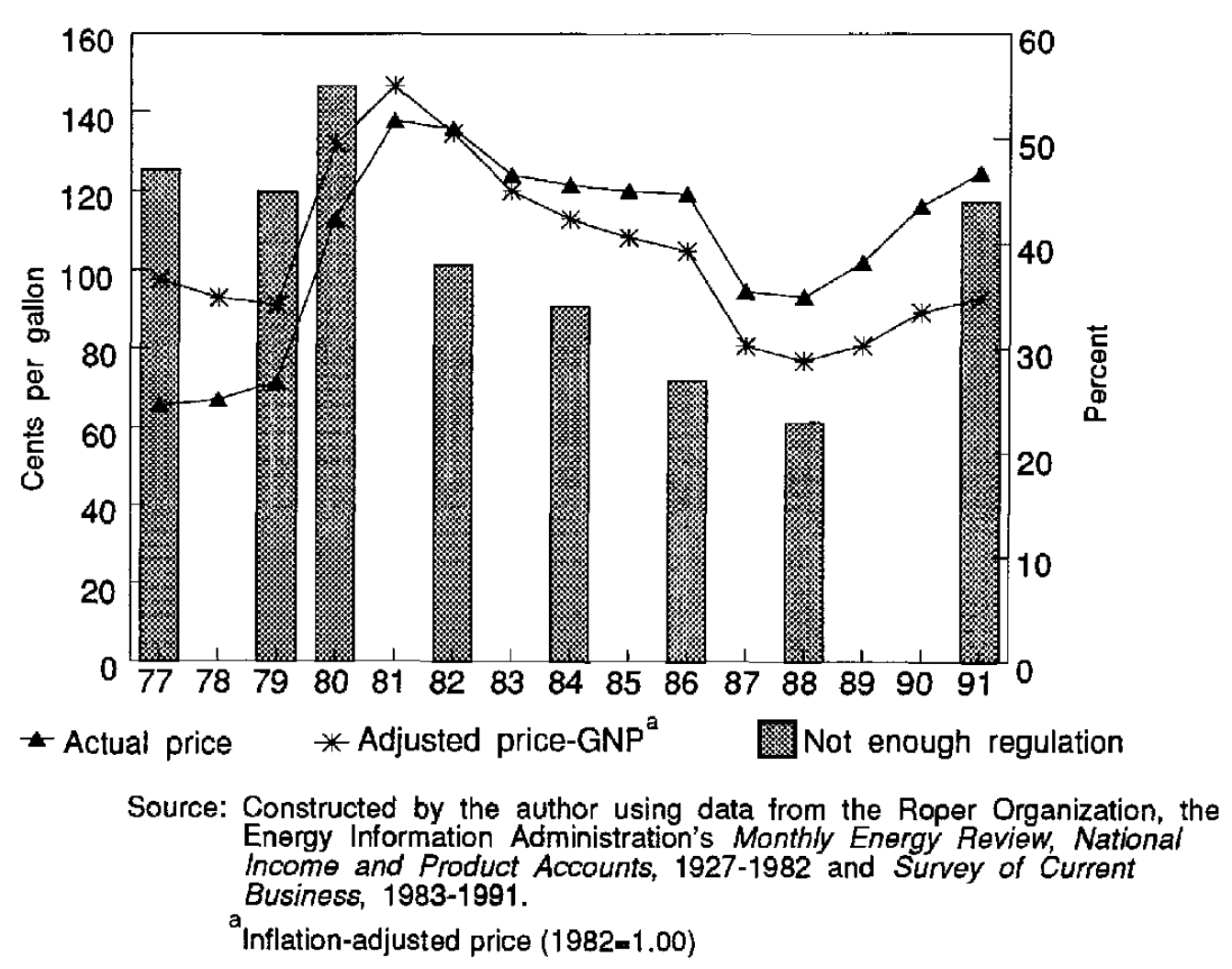

Figure 10-A. Trends in public preferences on regulating oil and gas prices of gasoline, 1977-1991

Oil import taxes and incentives for domestic production. Domestic oil production is a concern, as noted in Chapter 6. In its 1990 survey, RSM included the following option: "Providing tax breaks to oil companies for the exploration and development of new oil and natural gas wells" [1025]. Half of the respondents favored this alternative, and 46\% opposed it. The August 1990 poll by Penn and Schoen Associates for Texaco, Inc., asked about "possible elements of a new national energy policy to promote conservation and reduce our dependence on foreign oil." One of the elements included was "providing oil companies with tax incentives to keep open refineries in the United States that would otherwise be closed down because of new and costly environmental regulations" [1206]. Favoring this incentive for oil companies were $63 \%$; opposing it were $31 \%$. Another element asked about was: "Providing tax incentives for the development of alternate energy sources, such as the conversion of coal into gas" [1206]. Eighty-six percent favored this option. A third element included was: "Offering oil companies tax incentives to increase their exploration for oil in the United States," resulting in 59\% favorability and 38\% opposition.

The 1988 League of Women Voters survey found that $69 \%$ of energy industry leaders favored "provide new tax incentives for oil and gas exploration." But only $12 \%$ of public interest leaders favored such an incentive [1534]. 
A few poll items have measured public opinion about taxing imported oil right along between 1979 and 1991. In general, the public seems somewhat divided on this issue. The tendency is to be favorable to the idea of taxing imported oil when couched in terms of reducing the federal deficit or increasing international competitiveness. When this option is couched in terms of raising the cost of gasoline at the pump, the public tends to become less supportive of it.

The most recent data came from a November 1991 Harris poll asking: "If there were no other way to cut the deficit while maintaining spending on programs such as Social Security, would you be willing to see ... an increase in the tax on imported oil ... or not?" $[1441]{ }^{4}$ Under these conditions, a bare majority (52\%) said they would be willing; $45 \%$ said they would be unwilling. Harris also asked whether they would be willing to see an increase in the gasoline tax under these circumstances; $68 \%$ said they were unwilling, consistent with virtually all the poll data that show that the public opposes gasoline tax increases under any circumstances.

When asked if they would "favor or oppose a tax of 5 cents a gallon on imported oil to reduce the use of imported oil and encourage domestic production" in June 1991, 55\% said they would favor this, and $43 \%$ opposed it [1448]. The same study asked whether they would favor or oppose a tax of 5\% per barrel on imported oil for the same purposes; $59 \%$ favored this idea and $39 \%$ opposed it.

The Los Angeles Times asked, in April 1991: "If some government services have to be cut back, would you favor or oppose increasing the tax on imported oil, which would send up the price of gasoline but also reduce our dependence on foreign oil and encourage conservation?" [1487]. Under these conditions, 57\% said they would favor the tax, while $35 \%$ were opposed. At almost the same time, in March 1991, Hart and Teeter Research Cos. asked a national sample: "Would you favor or oppose increasing the tax on imported oil, which would send up the price of gasoline but also reduce our dependence on foreign oil and encourage conservation?" [1500]. Again, a majority (55\%) favored the tax, while 37\% opposed it.

RSM and Greenberg/Lake, The Analysis Group asked about policies that could be part of a national energy strategy in December 1990 . One option was: "Imposing a tax on all crude oil imported into the United States." [1025]. Half the sample favored this option, 46\% opposed it, and 4\% didn't know. Among options that could have helped to prevent the Persian Gulf war, 3\% of a 1990 national sample identified adding a 5-cent tax on imported oil per gallon each year for 10 years [1035]. Yankelovich/ Clancy/Shulman asked, in September 1990, "Would you favor or oppose raising taxes on imported oil?" [1032]. More than half (52\%) opposed the idea.

When put in terms of encouraging oil industry competitiveness on world markets, $70 \%$ favored "changes in the U.S. tax law which would put American oil companies on a more equal footing" with foreign competitors [1206]. Harris used this item in 1989: "It is estimated that if the federal government were to put a $\$ 10$-barrel tax on oil imported into this country, it would go a long way toward eliminating the federal deficit. Would you favor or oppose such a ten-dollar tax on imported oil, even if it meant a rise in the cost of energy?" [1256] Opposing such a tax was a majority of $51 \% ; 46 \%$ were in favor.

In December 1988, Harris asked: "If an oil imports tax combined with spending reductions would eliminate the federal deficit in 3 years, would you favor or oppose that tax?" [1278]. Fifty-five percent said they would favor it; $40 \%$ were opposed. At about the same time, a majority (56\%) favored a much less costly oil import fee of 25-cents per gallon "to reduce our dependence on foreign oil" [1431]. In February $1988,53 \%$ said they would favor reducing the federal budget deficit by "instituting a tax on imported oil" [1046]. NBC News/The Wall Street Journal reported that $46 \%$ favored "a tax on oil

\footnotetext{
${ }^{4}$ This items confounds deficit reduction and Social Security spending with oil import taxes.
} 
imported to this country" in January 1988 , while $40 \%$ opposed it. This item replicated one asked in April 1986, when 53\% favored such a tax and 36\% opposed it [1199].

In 1988, the League of Women Voters' survey of public interest and energy industry leaders found an identical percentage of each group, 55\%, supporting imposing a fee on imported oil [1534]. However, at about the same time, ORC asked a national sample: "The United States has a large trade deficit, which means more money is spent on imports, including oil, than is spent by other countries buying our raw materials, products, and services. Do you think raising the federal gasoline tax would lower the use of gasoline enough to help reduce our trade deficit, or don't you think the use of gasoline would go down enough to matter?" [1210]. Stating that use would not go down enough were 78\%. Also in the spring of 1987, Harris asked: "How much would you object to a $\$ 5$ a barrel tax on oil imports into the United States?" [1268]. Almost a third (31\%) said they would object "a great deal," 22\% "not a lot," $19 \%$ "only a little," and 25\% "not at all."

In April 1986, Harris asked: ". . . Now if it meant that if combined with spending reductions, the new tax would mean no more federal deficits in 3 years, would you favor or oppose . . a an oil imports fee?" [1270]. Favoring it was a majority (55\%), opposing it were 37\%. Also in 1986, Roper used a lengthy item the crux of which was: ". . would you like to see a five dollar a barrel tax on imported oil, or a smaller tax increase on all kinds of energy, or no increase in any kind of energy tax?" [1086]. A plurality (46\%) favored "no increase in any kind of energy tax"; $18 \%$ favored each of the other two options presented. The Los Angeles Times, in February 1986, asked: ". . would you favor higher tariffs on oil imports or would you rather consider some other way to raise money for the government, instead?" Favoring the oil import tax were $45 \%$; favoring "some other way" were $46 \%$. In $1985,53 \%$ told the Analysis Group that an oil import tax was a "good idea" and 40\% said it was a "bad idea" [1362].

In 1984, ORC found that 54\% opposed or strongly opposed imposing an additional tax on imported oil [1158]. In 1983, another ORC survey resulted in two-thirds opposing such a tax [1160]. In May 1980, $52 \%$ said they opposed "a tariff - tax-on imported oil that would raise the price of gasoline by 10 cents to 15 cents per gallon, if it would end our dependence on foreign aid" [1511].

In sum, opinion remains divided. Given the strong consistent public opposition to increases in gasoline taxes, an import tax on gasoline, although it could have significant positive consequences such as the ones mentioned in the polls (reducing the deficit and increasing international competitiveness), is not a widely accepted option. Favorability to the idea seems to have increased slightly over the past 12 years, but opinion remains essentially divided on this transportation policy option.

Windfall profits tax. Data from the late seventies suggested that oil companies were perceived as taking excess profits. Options such as a profits tax or controls on profits were favored at that time. They are still favored today. A Harris poll taken in August 1990 asked: "Do you favor or oppose tough taxes on oil company profits?" [1262]. Favoring such taxes were $64 \%$; opposing them were $32 \%$, with $4 \%$ unsure.

In September 1990, Roper posed the following question: "The situation in the Arab world has raised prices on imported oil, resulting in higher fuel costs to consumers. Some people say it would be good if the United States could be independent of these Arab oil producing countries, but there would be problems connected with this. We'd like to ask you how you feel about some of these means to becoming independent" [1554]. Five options were listed, one of which was: "The government could impose an excess profits tax on oil companies to encourage their putting more money into exploration. Would you be willing to see this done or not?" Agreeing that this should be done were $65 \% ; 23 \%$ disagreed; $12 \%$ were unsure. 
No other items on windfall profits were located for a 10-year period, back to June 1980. At that time, $51 \%$ of a Roper sample said that the windfall profits tax on oil companies was "a good thing," while $27 \%$ said it was "a bad thing," and 22\% didn't know [1136]. In October 1979, CBS News/The New York Times asked: "Do you think the government should allow the oil companies to keep these profits to encourage them to find more oil and gas, should it heavily tax the increased profits, or should the government take over and run the oil companies?" [1331]. More than one-fifth (23\%) favored government takeover of the oil companies. About one-third favored the profits tax, and $31 \%$ favored the use of profits for oil exploration.

With respect to how the windfall profits tax should be used, in June 1979 ABC News/Louis Harris and Associates presented five options. They asked: "It has been proposed that some of the monies from the windfall profits tax (on the profits oil companies will make from decontrolled oil prices) be used ..." [1393]. Responses were: (1) to help the elderly, the poor, and those on fixed incomes who are having hard times due to inflation and higher energy costs ( $82 \%$ favored); (2) to develop more mass transportation for people to use to get to and from work ( $80 \%$ favored); (3) by the government to develop more oil and alternate energy sources (77\% favored); (4) to provide funds for big joint projects by government and industry to develop new sources of energy ( $70 \%$ favored); and (5) by the energy companies to develop more oil and alternate energy sources ( $66 \%$ favored).

While majorities still favor excess profits taxes, the public does not seem as stringent in its demands for excess profit taxes today as it was in the late seventies.

Severance taxes. Almost no data exist on public favorability toward severance taxes. ORC replicated an August 1983 item verbatim in September 1984 on this policy option: "A severance tax on natural resources is a tax placed by individual states on the natural resources-such as oil, gas, coal, and uranium--that are developed in those states and then taken out of the states. I am going to read two statements about severance taxes. For each one, please tell me whether you agree strongly, agree somewhat, disagree somewhat or disagree strongly ... Severance taxes are an effective way to compensate states for the development of their natural resources" [1183].

The proportions agreeing "strongly" or "somewhat" remained virtually identical between 1983 and 1984, at $64 \%$ agreeing and $23 \%$ disagreeing, with approximately 1 in 10 unsure.

The second statement was: "In order to be fair to consumers in other states, a national ceiling should be imposed on state severance taxes." Sixty-four percent agreed and 22\% disagreed with this statement, as well.

The public favorability toward severance taxes must be taken with caution, however, because no data were found later than 1984.

Regulation of oil production. Just as incentives can be used to encourage oil production, regulation is another policy lever the government employs to accomplish desired responses. In general, regulation tends to be a less popular policy response than, say, incentives. Under certain circumstances, the public is willing to support regulation. However, there is little current interest in regulations as a policy response. The types of regulation discussed in this section include requiring energy-conserving actions and regulating or nationalizing oil companies. 
Table 10-4 presents data from a December 1989 Roper poll, which is of interest because the 11 options included in it are regulatory. These options are framed in terms of air quality, and each one mentions a disadvantage to the regulation. Four fuel-reducing policies were included in this list-requiring that new cars be able to run on alternative fuels ( $42 \%$ willing to see happen), requiring car pooling to and from work (33\% willing), requiring new cars to run on natural gas ( $22 \%$ willing), and requiring limited driving days $(13 \%$ willing). These options are presented in the context of seven other regulatory alternatives for environmental protection. As Table 10-4 documents, they are among the least favored alternatives: These types of regulations are clearly not congruent with public policy preferences.

Distrust of the oil companies has remained since the 1973-1974 Arab oil embargo. Harris asked a 1990 sample: "(Do you favor or oppose) . . . the federal government breaking up the big oil companies to keep them from being so powerful over the economy?" [1021]. Sixty percent said they favored this action, while 37\% opposed it. In the same series, Harris also asked: "Do you favor or oppose . . . the federal government creating a government-owned and operated oil corporation to keep the private oil companies honest in their pricing and their operations?" Sixty percent also favored this step. Finally, Harris asked: "(Do you favor or oppose) . . . a federal government takeover of the oil industry?" A majority (65\%) opposed such an action, while $30 \%$ favored it.

In 1980, 34\% favored "nationalization of all the big oil companies," while 48\% opposed it [1511]. A 1979 sample was asked this question, and $62 \%$ said nationalization "would be a mistake" [1146]. Another survey found that even if oil companies were nationalized, $53 \%$ believed the gasoline shortages would continue [1146]. The 1980 survey also found 53\% favoring the statement: "Setting an absolute limit on the amount of oil we can import into this country, even if it means shortages of oil and gasoline in the years ahead" [1511]. In April 1980, 58\% of a sample agreed that the government should regulate oil more [1063].

In general, the public is apparently unwilling to accept serious regulation of the oil industry. Such regulation may be seen as going against values of free enterprise in the U.S. political economy.

Strategic petroleum reserve (SPR). In 1990, Congress reauthorized the SPR. After Operation Desert Storm began in January 1991, the Department of Energy (DOE) sold more than 17 million barrels in the SPR's first emergency use. DOE has begun to purchase oil to restore the depleted reserve, now at 568 million barrels, back to 750 million barrels (McConnell 1992, pg. 163).

The public appears to favor the maintenance of the SPR, based on the limited data available. In May 1980, a national poll asked "(I'm going to read you a list of proposals dealing with the energy crisis, and I'd like you to tell me whether you generally favor or oppose each one). . Creating a federal oil reserve where the United States would store up large amounts of oil as protection against a cutoff of foreign oil" [1511]. Approving of this were $78 \%$ of the sample; $12 \%$ opposed it, and $10 \%$ were unsure.

Only a handful of items have focused on or included the SPR since then. One of these was the League of Women Voters' query to public interest and industry leaders, both of whom supported increasing the SPR (73\% of public interest and $85 \%$ of industry leaders) in 1988 . Gallup asked a national sample in May 1988: "(I am going to read you a number of new proposals that have been suggested for increasing government revenues to reduce the federal budget deficit. For each one, please tell me whether you favor or oppose it) ... Selling the Strategic Petroleum Reserve" [1297]. Three-quarters of the sample opposed selling the SPR, $18 \%$ were unsure, and $7 \%$ favored it. 
Table 10-4. Preferences for Regulations to Improve Air Quality

"There is a great deal of discussion these days about the quality of the air we breathe and what we can do to improve it. Here is a list of some things that have been proposed. (Card shown respondent) Would you please read down that list and for each one tell me if it is something you think would do enough good so you would be willing to see it happen in this community or you don't think it would do enough good to be worth the inconveniences or extra cost? First, require charcoal barbecues to be started with an electric starter rather than lighter fluid even though it takes longer and you need to run an electrical cord to the barbecue." (December 1989) [1546]

\begin{tabular}{|c|c|c|c|}
\hline Proposed regulations & $\begin{array}{l}\text { Willing to } \\
\text { see happen }\end{array}$ & $\begin{array}{l}\text { Not worth } \\
\text { cost }\end{array}$ & $\begin{array}{l}\text { Don't } \\
\text { know }\end{array}$ \\
\hline \multicolumn{4}{|l|}{ Proportion responding $(\%)^{\mathrm{a}}$} \\
\hline $\begin{array}{l}\text { Require spray pumps only instead of aerosols even though } \\
\text { some things work better in aerosol cans and other things } \\
\text { like paint might not work at all in a pump spray. }\end{array}$ & 63 & 28 & 9 \\
\hline $\begin{array}{l}\text { Force all utilities to install scrubbers to clean their } \\
\text { emissions even though it would mean an increase in your } \\
\text { utility bills due to the high expense of the equipment. }\end{array}$ & 51 & 36 & 13 \\
\hline $\begin{array}{l}\text { Force all companies, even small businesses, to comply } \\
\text { with very strict air pollution standards, even though it } \\
\text { might put some of them out of business, thereby causing a } \\
\text { loss of jobs. }\end{array}$ & 50 & 39 & 11 \\
\hline $\begin{array}{l}\text { Ban the use of high sulfur coal to reduce acid rain even } \\
\text { though this might make the U.S. more dependent on other } \\
\text { countries for its energy supplies. }\end{array}$ & 49 & 36 & 15 \\
\hline $\begin{array}{l}\text { Allow only water-based paints, varnishes and finishes even } \\
\text { though they don't look as good as the oil-based ones. }\end{array}$ & 45 & 43 & 12 \\
\hline $\begin{array}{l}\text { Require dry cleaners to install a lot of new equipment to } \\
\text { control the fumes from the chemicals they use, which } \\
\text { would mean fewer dry cleaners and higher costs because } \\
\text { the equipment is so expensive. }\end{array}$ & 44 & 42 & 14 \\
\hline $\begin{array}{l}\text { Require all new cars to run on alternative fuel like ethanol } \\
\text { or methanol even though they would get fewer miles to the } \\
\text { gallon and require a larger fuel tank, which means less } \\
\text { trunk space. }\end{array}$ & 42 & 45 & 13 \\
\hline $\begin{array}{l}\text { Require charcoal barbecues to be started with an electric } \\
\text { starter rather than lighter fluid even though it takes longer } \\
\text { and you need to run an electrical cord to the barbecue. }\end{array}$ & 34 & 59 & 8 \\
\hline
\end{tabular}


Table 10-4. Preferences for Regulations to Improve Air Quality (continued)

\begin{tabular}{||l|c|c|c||}
\hline Proposed regulations & $\begin{array}{c}\text { Willing to } \\
\text { see happen }\end{array}$ & $\begin{array}{c}\text { Not worth } \\
\text { cost }\end{array}$ & $\begin{array}{c}\text { Don't } \\
\text { know }\end{array}$ \\
\hline Proportion responding (\%) & & \\
\hline \hline $\begin{array}{l}\text { Require car pooling to and from work even though it } \\
\text { means having to stick to the car pool schedule and not } \\
\text { having a car at work in case of a personal emergency. }\end{array}$ & 33 & 58 & 8 \\
\hline $\begin{array}{l}\text { Require all new cars to run on natural gas rather than } \\
\text { gasoline even though the U.S. would be dependent on } \\
\text { other countries to supply the natural gas. }\end{array}$ & & & \\
\hline $\begin{array}{l}\text { Set up odd-even driving days so that if your car's license } \\
\text { plate ended with an odd number you could only drive it on } \\
\text { odd numbered days. }\end{array}$ & 13 & 64 & 13 \\
\hline
\end{tabular}

Source: The Roper Organization.

${ }^{a}$ Row percentages add to 100 (except for rounding).

In May 1990, Penn and Schoen Associates (for Texaco, Inc.) asked: "The U.S. government has stockpiled 600 million barrels of oil for emergencies. Do you think it should use some of these reserves now to try to reduce prices or should it wait to use those reserves only when actual shortages appear?" [1206]. The vast majority $(81 \%)$ favored selling the stockpiled reserves "only when actual shortages appear," while $17 \%$ favored using them at the time to reduce prices.

Finally, when Market Strategies asked a national sample in September 1990 which of a list of options would have done the most to avoid the Iragi war, $9 \%$ cited "further increasing our government strategic oil reserve" (mentioned fourth most frequently in a list of 10 options) [1035].

The establishment and maintenance of the SPR is clearly congruent with public opinion.

\section{Conservation Policy}

Fuel economy/CAFE standards. The public strongly favors increasing the fuel efficiency of automobiles. The earlier reviews reported that buying a smaller car was increasingly mentioned as a conservation measure (up to $26 \%$ by 1978). Much public support existed for goyernment regulation of automobile manufacturing to increase the gasoline mileage of new cars.

The pattern of public support for increasing gasoline mileage has been borne out over several recent polls, although majorities favoring it are smaller when regulation is mentioned than when it is not. In 1992, Martilla and Kiley/The Detroit Free Press asked a national sample: "(When it comes to each of the following areas, please tell me which automobiles you feel are generally better-Japanese or American) ... fuel economy?" Selecting the Japanese option were $61 \% ; 18 \%$ chose the American car, $10 \%$ said it made no difference, and $11 \%$ were unsure [1451]. 
. . . fuel economy?" Selecting the Japanese option were $61 \% ; 18 \%$ chose the American car, $10 \%$ said it made no difference, and $11 \%$ were unsure [1451].

When framed within the context of global environmental problems, fuel economy is favored by most respondents. For example, Market Strategies asked a national sample in November 1991, "(Here are some examples of resolutions that the United Nations might pass. For each one, please tell me if you think it would or would not be alright for that resolution to have the force of law over our own laws?) . . . A resolution imposing reductions in the use of carbon-burning fuels that contribute to global warming including tougher fuel efficiency requirements on international automobile makers, including U.S. companies" [1462]. Eighty-six percent said they would favor such a resolution.

A 1990 national poll asked: "Federal fuel economy standards require that auto companies produce cars that, on average, get 27.5 miles per gallon. Would you favor or oppose an increase in federal fuel economy standards for auto companies requiring that cars, on average, get 40 miles to the gallon by the year 2000? (If favor/oppose, ask:) Would that be strongly (favor/oppose) or just somewhat (favor/ oppose)?" [1025]. Again, 84\% said they would favor such a standard, 63\% strongly. This poll asked the follow-on item: "Would you still favor this proposal if you knew that a new car would cost the buyer $\$ 500$ more?" Eighty-nine percent said they would still favor the standard, 9\% said they would change their minds, and $2 \%$ said they didn't know.

Using an open-ended item, Market Strategies asked a national sample in September 1990 what things would have helped the most to make the confrontation with Iraq unnecessary [1035]. Three percent mentioned "continued the mandatory annual improvement in miles per gallon of U.S. autos, discontinued in 1984." (To put this in context, the most frequently selected item was $21 \%$ for supporting research and development (R\&D) for alternative energy sources to oil.)

Consistently, when samples were presented with the trade-off of higher cost for a more fuel-efficient car, they continued to favor fuel efficiency. For example, Opinion Dynamics Corporation asked a national sample in December 1989: "(Most solutions proposed for tackling environmental problems involve changes in the way we live and do business. These involve costs for people. I'm going to read you some programs that have been proposed and I'd like you to tell me whether you would strongly favor, somewhat favor, somewhat oppose, or strongly oppose each of these measures.) ... mandatory fuel efficiency and air pollution standards that would increase the cost of a new car by several hundred dollars but would reduce air pollution significantly" [1185]. Strongly favoring the standards were $40 \%$, somewhat favoring them were $30 \%$. Opposed were $12 \%$ "somewhat" and $15 \%$ "strongly."

The public perceives that automobile makers can make cars more fuel efficient. RSM asked a 1989 national sample: "U.S. automobile makers have the technology to make cars averaging $45 \mathrm{mpg}$ well before the year 2000" [1072]. Most agreed (83\%), 54\% "strongly" and 29\% "somewhat."

Roper's survey in December 1989 found opinion more divided. Roper asked two questions, one each to one-half of the national sample [1546]. The first question was: "A new standard has been proposed with respect to the emissions from cars. Rather than setting the maximum amount of pollution for any one car, a company would be told the total pollution it would be allowed for all the cars it makes. Do you think this is a good or a bad idea?" A plurality of $40 \%$ said it was a "good idea," while $32 \%$ said it was a "bad idea"; $16 \%$ volunteered they had "mixed feelings," while $12 \%$ didn't know. The second question was: "A somewhat similar approach has been taken with respect to the mileage on cars. Rather than setting the lowest miles per gallon allowable for any car, a company is told what the average miles per gallon for all the cars it makes must be. Do you think this is a good or a bad idea?" The idea of fleetwide efficiency standards caused more divided opinion; $36 \%$ for it and $33 \%$ against. 
Most items, however, elicited favorable response [1092 in October 1989; 1072 in October 1989; 1045 in April 1989; and 1431 in September 1988]. The League of Women Voters' study of public interest (100\%) and energy industry leaders (72\%) also favored "increasing automobile fuel-efficiency standards" [1534].

One item, used in October 1989, asked about an incentive rather than a standard: "(Suppose you could buy a new car today. Please tell me how important each of the following would be to your purchase decision.) Would ... a cash rebate or federal tax credit for the purchase of a fuel efficient car . . be extremely important, very important, only somewhat important, or not very important?" [1072]. Stating such a financial incentive would be "extremely important" were $15 \% ; 24 \%$ said "very important," $32 \%$ said "somewhat important," and $28 \%$ said "not very important."

With this single comparison data point, the evidence is not strong; however, it appears safe to conclude that the public strongly favors increasing CAFE standards.

Financial incentives for purchasing fuel-efficient vehicles. Providing financial incentives is one of the policy levers the federal government can use to encourage energy efficiency and the use of renewables. Data on financial incentives for transportation policy were slim. A few items addressed incentives for increasing fuel efficiency, toward which public opinion is favorable. And a few others focused on incentives for oil production; public preferences are more mixed on these incentives.

RSM's December 1990 study on national energy strategy options included two items on financial incentives [1025]. The first was "providing a cash benefit for scrapping older, less fuel-efficient cars," which evoked a favorable response from $72 \%$. The second was "providing a tax rebate for new cars that get better mileage than the federal standard," which evoked an even more favorable response, at $82 \%$. And, virtually everyone favored "providing incentives to use or develop alternative fuels such as fuels produced from grains."

RSM asked, in October 1989, "(Suppose you could buy a new car today. Please tell me how important each of the following would be to your purchase decision.) Would . . . a cash rebate or federal tax credit for the purchase of a fuel efficient car . . . be extremely important, very important, only somewhat important, or not very important?" [1072]. Fifteen percent responded "extremely important," 24\% "very important," and 32\% "somewhat important"; $28 \%$ said the incentive was "not very important."

Incentives are clearly a favored policy option for increasing fuel efficiency, at least based on these data. The question remains as to the actual number of fuel and automobile purchase decisions that would be affected by such incentives.

The earlier reviews reported that most of the public opposed special taxation for "gas guzzler" cars-those most fuel inefficient. In March 1979, opinion was divided on whether to "ban production of large cars that get less miles per gallon" [1149]. Almost half (49\%) said production should be banned, and a plurality of $45 \%$ said it should not. By April 1990, 51\% responded favorably to the item: "(Everyone wants a clean environment, but the question comes down to . . at what cost or inconvenience. I'm going to read some policy options and the problem associated with each. Tell me if you would favor or oppose each one) . . Limit the number of large cars that could be produced." A plurality of $44 \%$ opposed this idea, while $6 \%$ were unsure [1194].

Roper repeated an item verbatim in March 1979, March 1980, and March 1981 concerning placing "a penalty tax on large cars that get less miles per gallon" [1129]. In 1979, 50\% opposed this, in $198055 \%$ opposed it, and in $198158 \%$ opposed such a policy. However, in December 1990, a national sample was asked about policies that the government might try as part of a national energy strategy: "Adding a tax 
penalty on new cars getting fewer miles to the gallon than the federal standard." Sixty-two percent favored this and $35 \%$ opposed it.

Thus, public opinion has shifted over time toward favoring tax penalties on larger, fuel-inefficient automobiles.

Ridesharing/car pooling. The earlier reviews found that $5 \%$ to $14 \%$ of the driving population belonged to car pools. Surveys at that time asked about several possible government actions to encourage car pooling: reduced charges for bridges, toll roads, and parking spaces were preferred nationally by majorities, but special lanes on freeways and limiting available parking to people who car pool were approved by only about $10 \%$.

For the current analysis, only three items were located that addressed policy preferences under this category. In February 1990, Roper asked about a number of things to improve environmental quality, one of which was: "Require car pooling to and from work even though it means having to stick to the car pool schedule and not having a car at work in case of a personal emergency" [1453]. Opposing such an idea were $55 \% ; 34 \%$ were willing.

A 1984 Portland, Oregon, study asked about energy related areas that the city should be involved in. Seventy-eight percent selected "promoting car or van pooling" [1463]. Finally, in 1980, 48\% of a national sample opposed "mandatory ride-sharing on some roads" as a means of conserving energy [1511].

The data are so limited that it is not possible to draw conclusions; however, the evidence that does exist suggests that mandatory car pooling would be inconsistent with public preferences. However, encouraging the use of mass transit and car pooling would be more acceptable. In October 1989, RSM asked whether a national sample of registered voters agreed with the statement: "An important way to save energy is to make it easier for people to use mass transportation and car pooling" [1072]. A total of 87\% agreed with this statement, $56 \%$ strongly.

Gasoline rationing. The earlier reviews found that most of the public believed gasoline rationing would be effective in reducing gasoline consumption. Nevertheless, the public opposed gasoline rationing. However, gasoline rationing was preferred, at that time, to price increases. A significant amount of poll data was collected in the late seventies on this policy option, but probably because it has not been discussed seriously for several years, almost no information has been available on it since 1982 .

Two recent items were located. In August 1990, Penn and Schoen Associates (for Texaco) asked about "adopting programs of rationing to promote conservation" as an element of a new national energy policy [1206]. Sixty percent were moderately to strongly opposed; $38 \%$ were favorable.

Roper presented trend data on the rationing option, based on an item asked originally in 1975 and replicated in 1977 and again in 1990: "The situation in the Arab world has raised prices on imported oil, resulting in higher fuel costs to consumers. Some people say it would be good if the United States could be independent of these Arab oil producing countries, but there would be problems connected with this. We'd like to ask you how you feel about some of these means to becoming independent." 5

One of the five options presented was: "Becoming independent of Arab oil countries by reducing gas and oil consumption over the next 10 years, but this would mean restrictions on the amount of fuel people could use - including gas and oil rationing, more limited use of automobiles, etc. Would you be willing

\footnotetext{
${ }^{5}$ Appendix $\mathrm{H}$ presents the full set of responses to this item.
} 
to see this done or not?" [1554]. In January 1975, 51\% said they would be willing; in January 1977, 39\% responded the same; in September 1990, 52\% said they would be willing, and 38\% said they would not be willing.

Other items from 1982 and earlier continued to bear out the trend reported in the earlier reviews-that majorities opposed gasoline rationing as a transportation policy option.

Limited access to gas stations. In 1979, closing gasoline stations at certain hours or on certain days was seriously proposed as a means of conserving gasoline. Nine surveys taken in 1979 and 1980 asked specifically about limiting access to gasoline stations as a policy option; we located no data since 1980 on this topic.

By and large, the public did not favor limiting access to gasoline stations. A national poll taken in March 1979 found that $65 \%$ thought government regulations requiring gas station closings were very likely to occur within the next 6 to 12 months [1181], although this did not come to pass. At about the same time, another poll reported $57 \%$ in opposition to voluntary closings of gasoline stations on Sundays and evenings [1414]. Again in February 1979, a poll found 61\% responding that such closings were a "poor idea" [1312].

In January 1979 and January 1980, Roper repeated an item asking about ways to "reduce usage of oil and gasoline by $10 \% "$ " $1139 ; 1146]$. Among six options, $2 \%$ in 1979 and $15 \%$ in 1980 selected "closing gas stations during certain hours of the day so that gasoline wouldn't be so readily available." By comparison, $29 \%$ selected "gas rationing, with the number of coupons to be issued on the basis of demonstrated need" in 1980, and 48\% selected "an odd/even day purchase plan" in 1979 (not offered as a response option in 1980). Four other surveys reported a similar pattern of public disinterest or opposition to the concept of limiting access to gas stations $[1146 ; 1398 ; 1067 ; 1311]$.

In sum, limited access to gasoline stations appears to be an unproductive policy option to limit gasoline consumption.

No-drive days. Only two items on this were located since 1980. In October 1990, Roper asked two interrelated questions. First, they asked: "Here is a list of some different kinds of things some communities have placed restrictions on. (Card shown with 14 different items.) Would you go down that list and for each one tell me whether you have strict regulations and controls on it in this community or not?" Second, they asked: "Now would you quickly go down that list again, and for each one tell me whether you think there should be more restrictions on it around here, or less restrictions, or that restrictions on it are about right now?" [1555].

"Where and when automobiles may be used" was one of the options. Almost one-quarter (24\%) said their community had strict controls, while $65 \%$ said it did not, and $11 \%$ didn't know. Almost three-quarters (74\%) said restrictions were "about right now," 7\% said more were needed, and $8 \%$ said less were needed.

A 1980 national sample was asked: "If there was a temporary gasoline shortage this summer, as there was last year, would you prefer the government deal with it by ..." [1511]. The response category selected most often, by a plurality of $38 \%$, was "Restricting automobile use, including a vehicle sticker plan in which you would choose one day a week when the vehicles owned by your entire household would not be operated, except for emergency purposes." 
Roper asked a national sample in 1980 about some ways "to avoid dependence on imported oil in this country ..." Among 5 steps listed, including a ban on Sunday use of automobiles (selected by $3 \%$ ), $15 \%$ selected "One driverless day per week for all automobiles, with the choice of which day left to the individual owner and a sticker on the car to indicate which day it is banned from driving." [1139]. This preference ranked lower than closing gas stations, pollution control standards, and gasoline rationing (selected by 29\%).

Gallup asked in mid-1979: "Following are a number of proposals that have been made to deal with the energy situation. For each, do you favor or oppose . . . Requiring people to give up driving one day per week?" [1287]. Favoring were 48\%; opposing were $50 \%$.

This particular type of policy is unlikely to find widespread approval, if attitudes similar to those 10 years ago still hold. Apparently, polling organizations believe the idea is dead, since they are no longer asking about it.

55-mph speed limit. The earlier reviews found that most of the public favored the 55-mph speed limit, and they reported that they were driving slower because of it. Almost no data were located on the 55-mph speed limit after 1980.

A 1984 survey of Alabama residents asked whether the sample favored increased enforcement of the 55-mph speed limit; 73\% supported this idea [1448]. Yankelovich/Clancy/Shulman asked in 1989: "To conserve more energy, do you think we should lower the speed limit?" [1045]. Sixty-four percent opposed this idea, while $34 \%$ favored it, and $2 \%$ were unsure.

In April/May 1981, 35\% of respondents said they would drive 55-mph or less if they were on an all-day trip and wanted to make good time, on a four-lane divided highway during daylight hours, in good weather. The rest of the sample said they would drive faster. In August 1989, the proportion stating they would drive 55-mph or less under these conditions had decreased to $18 \%$ [1545].

The Roper Organization collected the most recent data on this topic. In March 1989, Roper asked a national sample: "Many things in our society have both good and bad effects. For example, aviation is good because it provides fast transportation. It is bad because it has caused a number of deaths. Here is a list of some different things that have resulted in both good and bad effects. (Card shown.) Would you read down the list, and for each one tell me whether, on balance, you think the good effects outweigh the bad, or whether the bad effects outweigh the good?" [1538]. The 55-mph speed limit was included in a list of items ranging from marriage and religion to genetic engineering. Responding that the good outweighs the bad were $72 \% ; 16 \%$ said the bad outweighs the good; $9 \%$ volunteered that the effects were equally bad and good. In March 1987, 68\% had responded that the 55-mph speed limit was, on balance, good; in March 1985, 83\% had said the same.

The available evidence, limited as it is, appears to show declining support for the 55 -mph speed limit as public policy and less willingness to observe it currently than in the late seventies.

\section{Mass Transit Policy}

The earlier reviews reported that $22 \%$ of respondents said they had public transportation available to them. Provision of special freeway lanes is a government action that could promote mass transit; however, the earlier reviews found that majorities wanted all travelers to be treated alike on highways during rush hour. However, majorities did favor increased federal spending to improve mass transit. 
A considerable number of items were located dealing with public preferences concerning mass transit policy options. Table 10-5 presents trend data on the question of level of government spending for mass transit. Approximately the same percentage, a large plurality of about $48 \%$ or $49 \%$, consistently stated that spending levels for mass transit were "about right" over the past 5 years. The proportions estimating such spending as "too little" increased 4 to 5 points beginning in 1990, and the proportions stating that "too much" is being spent declined, suggesting a slight shift in favor of more spending for mass transit. RSM, in their study on potential national energy strategy options, asked about "expanding federal spending on mass public transportation systems such as buses and subways" [1025]. Eighty percent indicated favorability.

When asked the "value added" of mass transit, 52\% of a February 1990 national sample said it was "average," 13\% said "good," and 35\% said "poor" [1485].

Favoring privatization of mass transit were $43 \%$ of a July 1991 national sample. Eighteen percent said service would be worse if provided by employees of private companies, while $28 \%$ said it would be about the same [1524].

Table 10-5. Trends in Preferences on Spending for Mass Transit, 1987-1991

"(We are faced with many problems in this country, none of which can be solved easily or inexpensively. I'm going to name some of these problems, and for each one l'd like you to tell me whether you think we're spending too much money on it, too little money, or about the right amount.) Are we spending too much, too little, or about the right amount on ... . mass transportation." (February each year)

\begin{tabular}{||l|c|c|c|c|c||}
\hline Response & 1987 & 1988 & 1989 & 1990 & 1991 \\
\hline Proportion responding (\%) & 29 & 28 & 29 & 34 & 33 \\
\hline \hline Too little & 47 & 49 & 49 & 47 & 48 \\
\hline About right & 13 & 10 & 8 & 8 & 9 \\
\hline Too much & 11 & 12 & 14 & 12 & 10 \\
\hline Don't know $^{\mid}$ & 100 & 99 & 100 & 101 & 100 \\
\hline \hline Total $^{\mathrm{a}}$ & $(1466)$ & $(1481)$ & $(1537)$ & $(1372)$ & $(1517)$ \\
\hline & {$[1520]$} & {$[1519]$} & {$[1518]$} & {$[1458]$} & {$[1458]$} \\
\hline Study number & & & & & \\
\hline
\end{tabular}

Source: Constructed by the author using data from the National Opinion Research Center.

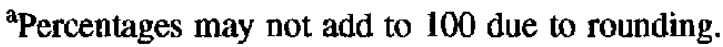


Widespread support exists for equipping mass transit for disabled and handicapped persons. Louis Harris and Associates found $91 \%$ favoring a policy requiring this [1525]. This same survey found, though, that $51 \%$ thought disabled people were not discriminated against in equal access to public transportation.

In April 1990, Hart-Teeter Research Companies asked about environmental policy options, one of which was " . . In major metropolitan areas, require people who drive to work to take public transportation one day a week" [1194]. Favoring this regulatory approach were 57\%; 41\% opposed it. In March 1990, Gordon S. Black Corp. asked about "regulations that require people to use mass transportation and place limits on how much they can use their motor vehicles for private use" [1283]. Opposing such policies were $65 \%$ of a national sample; favoring them were $31 \%$.

A majority favored "rules limiting parking in major cities and forcing commuters to take public transportation" in December 1989 [1185]. Thirty-six percent opposed such a regulation.

In general, majority support for mass transit has continued; however, no strong public mandate for intensive regulation of transportation has solidified.

\section{Alternative Fuels and Alternative Fuel Vehicle Policy}

Alternative fuels policy. Very few data were located on public preferences concerning the alternative fuels policies. One recent item located was employed in a 1990 Roper poll: "(Here is a list of some things that have been proposed to improve the quality of our environment. Would you please read down that list and for each one tell me if it is something you think would do enough good so you would be willing to see it happen in this community or you don't think it would do enough good to be worth the inconveniences or extra cost?) .. . Require all new cars to run on alternative fuel like ethanol or methanol even though they would get fewer miles to the gallon and require a larger fuel tank which means less trunk space" [1453]. Opinion was somewhat divided on this item: $47 \%$ were willing to have this requirement, while $39 \%$ said it was not worth the cost, and $14 \%$ didn't know. This same item was asked in 1989 (see Table 10-4). At that time, $42 \%$ were willing to have the requirement, and $45 \%$ were unwilling [1546].

RSM's December 1990 study on national energy strategy options included "providing incentives to use or develop alternative fuels such as fuels produced from grains" [1025]. Virtually everyone favored this policy option.

Harris and Associates asked a sequential item in 1979: "The government helps farmers with soil erosion problems. Growing more crops for gasohol will cause more soil erosion since more land will be used to grow the crops. Would you favor or would you oppose paying an extra $(\$ 100)(\$ 50)$ or $(\$ 25)$ per year in the price of gasohol at the pump to cover the cost of preventing this extra soil erosion?" [1254]. At that time, $88 \%$ opposed paying $\$ 100 ; 78 \%$ opposed paying $\$ 50$; and $53 \%$ opposed paying $\$ 25$ more to prevent this increased soil erosion attributed to growing gasohol feedstocks. However, the item appears to be misleading, because it did not examine other economic implications of growing feedstocks, such as reduced subsidies for Soil Bank lands.

A 1981 ORC item asked how much respondents had "read or heard about synthetic fuels, such as oil from coal and shale rock or gas from coal and alcohol fuels?" [1168]. The sample was not too knowledgeable. Nineteen percent said they'd heard or read "a great deal," one-third said "a fair amount," while the rest knew little or nothing at all.

In 1980, ABC News/Louis Harris and Associates asked respondents to compare gasohol with gasoline on three factors: price, mileage, and engine performance. The modal response for price and mileage was 
"just about the same" (42\% and $40 \%$, respectively), while $17 \%$ said the price of gasohol was better than gasoline and $33 \%$ said mileage was better. The modal response for engine performance was $37 \%$ stating that with gasohol it was better; one-third said it was "just about the same."

With so few data on alternative fuels policy, nothing can be concluded about the public's views. This is identified as a research gap.

Alternative fuel vehicle policy. In September 1990, one of the policy options Cambridge Reports presented in its list about one of the most important things that electric utilities could do to protect and improve the environment was "developing cars and trucks that run on electricity" [1457]. Almost half of the sample $(47 \%)$ rated this as one of the very most important things that should be done. ${ }^{6}$

Newsweek asked new car buyers in 1990 whether the government should require automakers to build alternative fuel vehicles (AFVs). Table 10-6 shows the results, by type of car purchased. A plurality of $48 \%$ of the car buyers said the government should impose such a requirement on automakers. Majorities of those purchasing imported vehicles (56\% of buyers of Asian cars; $54 \%$ of buyers of European cars) approved of requiring the manufacture of AFVs. More than a third of the sample didn't know. Newsweek also analyzed the responses by educational level, and found that the higher the educational level, the more approval of this requirement [1563].

In June 1989, ABC News/The Washington Post asked: "Do you approve or disapprove of requiring automakers to build and sell low-polluting methanol-powered cars in the urban areas with the greatest air pollution even if that means higher auto and gasoline prices?" [1371]. Most (76\%) approved of such a requirement; $23 \%$ disapproved, and $2 \%$ had no opinion.

Table 10-6. Preferences for Requiring the Manufacture of Alternative Fuel Vehicles (AFVs), 1990 "Should government require automakers to build cars that run on altemative fuels?" a

\begin{tabular}{||l|c|c|c|c||}
\hline & \multicolumn{4}{|c|}{ Percentages of new car buyers } \\
\hline Response & $\begin{array}{c}\text { All } \\
\text { car } \\
\text { buyers }\end{array}$ & $\begin{array}{c}\text { Domestic- } \\
\text { car } \\
\text { buyers }\end{array}$ & $\begin{array}{c}\text { Asian- } \\
\text { car } \\
\text { buyers }\end{array}$ & $\begin{array}{c}\text { European- } \\
\text { car } \\
\text { buyers }\end{array}$ \\
\hline \hline Yes & 48 & 45 & 56 & 54 \\
\hline No & 17 & 18 & 14 & 16 \\
\hline Don't know & 35 & 37 & 30 & 30 \\
\hline Totals & 100 & 100 & 100 & 100 \\
\hline
\end{tabular}

${ }^{a}$ Paraphrase; actual item wording was not provided [1563].

${ }^{b} 14,000+$ new car buyers.

${ }^{6}$ Appendix $H-3$ provides the balance of the response options and data. 
The Wirthlin Group conducted a 1990 survey of 900 adults in Baltimore, Chicago, Houston, Milwaukee, New York, and Philadelphia [1428]. This was a probability sample of randomly selected adults from residents in these six standard metropolitan statistical areas where air quality did not meet Environmental Protection Agency standards. It was a telephone survey of a sample of approximately 150 for each city. The study's sponsor was not identified.

The item asked was complex:

I'd like you to think about some legislation that is being considered on Capitol Hill. As you may know, Congress is working to pass a Clean Air Act which will set new emission requirements for cars and trucks. It will establish a program intended to improve air quality by introducing alternative fueled vehicles in the mid-1990s that run on a fuel such as ethanol, methanol, propane, or compressed natural gas.

Some people in Congress are also trying to go one step further to include a provision which would require the production and sale of millions of alternative fueled vehicles to the general public in a number of cities including yours.

The expected alternative fuels amendment is intended to further reduce smog and pollution in cities with the worst air pollution. In addition to reducing air pollution, proponents of alternative fuel vehicles also believe that alternative fuels will reduce American dependence on foreign fuels and avoid the potential threat of an oil embargo like we had in the 1970 s.

I'd like to read you a number of statements regarding alternative fuel vehicles and this proposed piece of legislation. You may agree with some of the statements and disagree with others. There are no right or wrong answers. After you hear each one please tell me whether you agree or disagree with the statement. [If agree/disagree, ask:] And would that be strongly (agree/disagree) or just somewhat (agree/disagree)? [1428].

The response items were as follows:

- "We should try to improve what we already have first. Different formulas for gasoline are being tested which may burn as cleanly as some of the alternative fuels under consideration. It makes better sense to use this cleaner burning gasoline, sometimes called "reformulated gasoline," until the problems with alternative-fuel vehicles are resolved." Agreeing with this statement were 87\%; $10 \%$ disagreed.

- $\quad$ "Some people feel that there has not been enough research yet on alternative fuels. Governments and large businesses should test these alternative fuel vehicles in their own vehicle fleets for a few years before we mandate something for the general public that has unknown consequences." The vast majority, $83 \%$, again agreed with this statement; $13 \%$ disagreed.

"Most people would be reluctant to buy an alternative fuel vehicle if they knew those vehicles may be difficult to start in cold weather, take longer to refuel at the pump, and may have lower resale value." Again, $83 \%$ agreed with the statement, while $14 \%$ disagreed.

"Most people would be reluctant to buy an alternative fuel vehicle if they knew they wouldn't be able to drive as far on a tank of an alternative fuel, the fuel may cost more, and not be available outside their city." Once again, $82 \%$ agreed; $15 \%$ disagreed. 
- II'm afraid that if alternative fuel vehicles are required to be sold to the general public before all the bugs are worked out, these kinds of cars will get a bad reputation and people will become more hesitant to buy them in the future." Agreeing were $78 \%$; disagreeing were $20 \%$.

The final item was:

- $\quad$ "Alternative fuel vehicles will cost more to buy than those powered by gasoline. Estimates run from 500 to 2000 dollars or more per vehicle, depending on the type of fuel used. Consumers will be reluctant to buy these vehicles because of their higher price." Seventy-two percent agreed with that statement; $24 \%$ disagreed.

This may be the most biased set of items in the current analysis. Usually, when "loaded" statements are used to elicit agree/disagree responses, the list includes statements on two or more sides of issues. In this instance, the polling organization used only negative statements about alternative fuels. Unless other positive statements were included, and these were not included in the data base, the results cannot be considered scientifically valid, and inferences regarding public opinion about alternative fuel vehicles cannot be drawn from them. 


\section{Chapter 11}

\section{Conclusions}

In a study of this breadth and depth, conclusions are of two types. The first type is a summary of empirical findings. The Executive Summary condenses the empirical findings of the analysis, which are also discussed in the Background and Summary sections at the beginning of each chapter.

The second type of conclusion attempts to go beyond those findings to interpret them and set them into a broader context. In a word, this type of conclusion answers the question, "What does it all mean?" This chapter presents interpretations of the meaning of the study's data taken together. It discusses broad inferences that are drawn from the data. Each statement made in this chapter is an interpretation of the data's meaning or an inference drawn from the data.

Environmental concerns are starting to drive energy choices. Problems such as global warming, stratospheric ozone depletion, acid rain, and air pollution in cities are primarily functions of energy production and consumption. As concern about the environment increases-itself driven by health and safety considerations-energy decisions are bound to be affected.

Because the public has exhibited strong and consistent preferences for energy efficiency, energy conservation, and renewable energy for the past 15 years, these energy alternatives are likely to become more important in public policy. These energy alternatives are widely perceived to be environmentally advantageous, particularly when compared with traditional energy sources, such as coal and nuclear power.

The evidence on conservation behavior suggests that such activity slowed during the $1980 \mathrm{~s}$. Yet, most people believe that the energy situation is serious and that it will remain serious in the future. Why, then, are people not engaging in lifestyle changes and more investment in efficiency that would reduce energy use? Similarly, although evidence shows a strong and growing concern for the environment, environmental activism is not nearly as widespread as the levels of expressed concern.

A hypothesis to account for this apparent discrepancy between what people say and what they do starts from the assumption that people generally report their perceptions, preferences, and behavior accurately in opinion polls. Under this hypothesis, the public wants U.S. energy institutions to change the way they do business when it comes to energy and the environment. The public is concerned about the environment and favors the use of efficiency and renewable energy. It wants recycling programs. The public wants to move forward with policies and programs that protect and improve the environment. It seems willing to do what it can up to a point, but wants and expects institutions to do a great deal more than they have in the past to promote efficiency, develop and adopt renewable energy technologies, and initiate policies and programs to protect and improve the environment. Institutions include, beyond government, such groups as automakers, builders, and lenders.

To raise the level of knowledge and sophistication on the energy and environmental policy debate among the public, policymakers, and private sector organizations, certain needs should be met. Conclusions are 
discussed in terms of three of these needs: (1) need to institutionalize the issue, (2) need for information and education, and (3) need for credibility.

\section{Need to Institutionalize the Issue}

Public preferences on energy and the environment can only be realized through institutions. The hypothesis is that the public wants efficiency and the use of renewable energy to become "institutionalized"-to become part of the routine way of doing business. Things need to be structured so that efficiency and reliance on sustainable energy sources are normal, not special. Systems need to be structured so that it is difficult and costly to be inefficient and to use nonrenewable, nonsustainable fuels. The burden of the change should fall on institutional, not just on family and individual, shoulders.

For example, if a couple are in the market for a newly built home, should they be able to depend on the fact that new homes on the market are already properly oriented at their sites to take maximum advantage of solar gain? Can the couple expect that natural shading was preserved during construction? That the house is well insulated and tight? That the windows and lighting are efficient? That the house is equipped with energy-efficient appliances and heating and cooling systems? Can they trust that the builder took into account the cost of operating the house-its future utility bills-in making construction choices? In short, can the couple trust that efficiency has been institutionalized in building practice, or do they have to take it upon themselves to retrofit the house after purchase with additional insulation, energy-efficient windows, and the latest high-efficiency lighting, appliances, and heating, ventilating, and air conditioning systems?

Industries working through their production processes, communities dealing with solid waste, universities managing their physical plants, utility companies designing energy services, manufacturers creating appliances and other consumer goods, builders constructing residential and commercial spaces, and many others - these institutions create the systems through which energy is produced, distributed, and consumed. With public preferences as a guide, these institutions will proactively seek ways to routinize energy efficiency and adopt renewables, while developing and testing new products and services for their benign influence on the environment. When this process is in fact institutionalized, all sectors of the economy will be able to pass the benefits on to the consumer, while themselves profiting from improved operations and markets.

\section{Need for Information and Education}

The evidence shows that people are just beginning to connect energy production and consumption practices with environmental damage. Also, the evidence shows a profound lack of "systems" thinking, in which one part of the energy system is seen as connected with other parts. These results show a deepseated need for public education about energy and the environment. Such education should begin in the elementary schools and extend through secondary education because lifestyle habits are engrained early. This education should also be central to college and university programs, thus establishing an ecological imperative in future leaders and decision makers. Continuing education and training for adults is also needed.

In addition, information and education are needed for an informed electorate that supports intelligent public policy. Information on the interconnectedness, first of the energy system itself and second of the energy system with the ecosphere, should be promulgated from multiple, credible sources. Basic energy facts-about the profitability of oil and utility companies, the actual level of gasoline taxes, and the percentage of imported oil, for example-need to be provided frequently and broadly. The media have a critical role and responsibility in this regard. 
Geared toward individual households, grassroots efforts, such as the Global Action Program, have already begun. These efforts are developing small group meetings in people's living rooms using group discussion on curriculum materials to involve community members in local solutions to global problems. These types of activities empower people to take action to help the environment. They address the part of the problem dealing with everyday living and its effects on the environment. These groups need to deal with the broader issues of institutionalizing solutions to energy and environmental problems, as well.

\section{$\underline{\text { Need for Credibility }}$}

The third major key is credibility. Public trust and confidence in energy institutions is not high. Business as usual is completely outmoded. Institutional support systems must be initiated that keep pace with the public desire for change.

Obviously, institutional changes involve costs. People appear to be willing to shoulder the costs of institutional change if they believe that the funds will actually be used to improve efficiency, employ renewables, increase sustainability, and protect and improve the environment. Consumers appear to be willing to pay the piper with "green pricing," higher gasoline taxes, and other proposals involving higher out-of-pocket costs. This will occur when institutional credibility is increased and credible leadership is established.

Credibility-building is crucial both for the public to believe factual information provided and for it to support effective policies. To the extent that corporations and agencies of government are straightforward with the public about the problems of environmental protection and cleanup-the difficulties and costs involved and the benefits that can be expected-they will gain new trust. To the degree that institutions, both public and private, share decision authotity with members of the public, and with stakeholders, they will earn credibility. To the degree that they trust the public, they themselves will be trusted.

The people are saying they care. They are looking for leadership, intelligent policies, and trustworthy behavior on the part of U.S. public and private institutions. 


\section{Bibliography}

ABC News. 1981. Public opinion survey. New York, NY: Capital Cities/ABC, Inc. September.

ABC News. 1983. Public opinion survey. New York, NY: Capital Cities/ABC, Inc. February.

ABC News. 1986. Public opinion survey. New York, NY: Capital Cities/ABC, Inc. April.

ABC News. 1990. Public opinion survey. New York, NY: Capital Cities/ABC, Inc. October.

ABC News. 1987. ABC News/Money survey. New York, NY: Capital Cities/ABC, Inc. August.

ABC News. 1988. ABC News/Money survey. New York, NY: Capital Cities/ABC, Inc. January.

ABC News and Louis Harris \& Associates. 1979. ABC News/Harris survey. New York, NY: Capital Cities/ABC, Inc.; Louis Harris \& Associates. February.

ABC News and Louis Harris \& Associates. 1979. ABC News/Harris survey. New York, NY: Capital Cities/ABC, Inc.; Louis Harris \& Associates. March a.

ABC News and Louis Harris \& Associates. 1979. ABC News/Harris survey. New York, NY: Capital Cities/ABC, Inc.; Louis Harris \& Associates. March b.

ABC News and Louis Harris \& Associates. 1979. ABC News/Harris survey. New York, NY: Capital Cities/ABC, Inc.; Louis Harris \& Associates. April 6.

ABC News and Louis Harris \& Associates. 1979. ABC News/Harris survey. New York, NY: Capital Cities/ABC, Inc.; Louis Harris \& Associates. April 9.

ABC News and Louis Harris \& Associates. 1979. ABC News/Harris survey. New York, NY: Capital Cities/ABC, Inc.; Louis Harris \& Associates. April 26.

ABC News and Louis Harris \& Associates. 1979. ABC News/Harris survey. New York, NY: Capital Cities/ABC, Inc.; Louis Harris \& Associates. April 30.

ABC News and Louis Harris \& Associates. 1979. ABC News/Harris survey. New York, NY: Capital Cities/ABC, Inc.; Louis Harris \& Associates. May 3.

ABC News and Louis Harris \& Associates. 1979. ABC News/Harris survey. New York, NY: Capital Cities/ABC, Inc.; Louis Harris \& Associates. May 9.

ABC News and Louis Harris \& Associates. 1979. ABC News/Harris survey. New York, NY: Capital Cities/ABC, Inc.; Louis Harris \& Associates. May 24.

ABC News and Louis Harris \& Associates. 1979. ABC News/Harris survey. New York, NY: Capital Cities/ABC, Inc.; Louis Harris \& Associates. May 26.

ABC News and Louis Harris \& Associates. 1979. ABC News/Harris survey. New York, NY: Capital Cities/ABC, Inc.; Louis Harris \& Associates. May 30. 
ABC News and Louis Harris \& Associates. 1979. ABC News/Harris survey. New York, NY: Capital Cities/ABC, Inc.; Louis Harris \& Associates. May 31.

ABC News and Louis Harris \& Associates. 1979. ABC News/Harris survey. New York, NY: Capital Cities/ABC, Inc.; Louis Harris \& Associates. June 11.

ABC News and Louis Harris \& Associates. 1979. ABC News/Harris survey. New York, NY: Capital Cities/ABC, Inc.; Louis Harris \& Associates. June 14.

ABC News and Louis Harris \& Associates. 1979. ABC News/Harris survey. New York, NY: Capital Cities/ABC, Inc.; Louis Harris \& Associates. June 21.

ABC News and Louis Harris \& Associates. 1979. ABC News/Harris survey. New York, NY: Capital Cities/ABC, Inc.; Louis Harris \& Associates. July 2.

ABC News and Louis Harris \& Associates. 1979. ABC News/Harris survey. New York, NY: Capital Cities/ABC, Inc.; Louis Harris \& Associates. July 11.

ABC News and Louis Harris \& Associates. 1979. ABC News/Harris survey. New York, NY: Capital Cities/ABC, Inc.; Louis Harris \& Associates. July 12.

ABC News and Louis Harris \& Associates. 1979. ABC News/Harris survey. New York, NY: Capital Cities/ABC, Inc.; Louis Harris \& Associates. July 23.

ABC News and Louis Harris \& Associates. 1979. ABC News/Harris survey. New York, NY: Capital Cities/ABC, Inc.; Louis Harris \& Associates. July 30.

ABC News and Louis Harris \& Associates. 1979. ABC News/Harris survey. New York, NY: Capital Cities/ABC, Inc.; Louis Harris \& Associates. August 13.

ABC News and Louis Harris \& Associates. 1979. ABC News/Harris survey. New York, NY: Capital Cities/ABC, Inc.; Louis Harris \& Associates. August 14.

ABC News and Louis Harris \& Associates. 1979. ABC News/Harris survey. New York, NY: Capital Cities/ABC, Inc.; Louis Harris \& Associates. September 4.

ABC News and Louis Harris \& Associates. 1979. ABC News/Harris survey. New York, NY: Capital Cities/ABC, Inc.; Louis Harris \& Associates. September 6.

ABC News and Louis Harris \& Associates. 1979. ABC News/Harris survey. New York, NY: Capital Cities/ABC, Inc.; Louis Harris \& Associates. November.

ABC News and Louis Harris \& Associates. 1979. ABC News/Harris survey. New York, NY: Capital Cities/ABC, Inc.; Louis Harris \& Associates. December.

ABC News and Louis Harris \& Associates. 1980. ABC News/Harris survey. New York, NY: Capital Cities/ABC, Inc.; Louis Harris \& Associates. January.

ABC News and Louis Harris \& Associates. 1980. ABC News/Harris survey. New York, NY: Capital Cities/ABC, Inc.; Louis Harris \& Associates. March. 
ABC News and Louis Harris \& Associates. 1980. ABC News/Harris survey. New York, NY: Capital Cities/ABC, Inc.; Louis Harris \& Associates. May.

ABC News and Louis Harris \& Associates. 1980. ABC News/Harris survey. New York, NY: Capital Cities/ABC, Inc.; Louis Harris \& Associates. June.

ABC News and Louis Harris \& Associates. 1980. ABC News/Harris survey. New York, NY: Capital Cities/ABC, Inc.; Louis Harris \& Associates. September.

ABC News and Louis Harris \& Associates. 1980. ABC News/Harris survey. New York, NY: Capital Cities/ABC, Inc.; Louis Harris \& Associates. October.

ABC News and Louis Harris \& Associates. 1980. ABC News/Harris survey. New York, NY: Capital Cities/ABC, Inc.; Louis Harris \& Associates. December 3.

ABC News and Louis Harris \& Associates. 1980. ABC News/Harris survey. New York, NY: Capital Cities/ABC, Inc.; Louis Harris \& Associates. December 8.

ABC News and Louis Harris \& Associates. 1980. ABC News/Harris survey. New York, NY: Capital Cities/ABC, Inc.; Louis Harris \& Associates. December 9.

ABC News and The Washington Post. 1981. ABC News/Washington Post survey. New York, NY: Capital Cities/ABC, Inc; The Washington Post. February.

ABC News and The Washington Post. 1981. ABC News/Washington Post survey. New York, NY: Capital Cities/ABC, Inc.; The Washington Post. April.

ABC News and The Washington Post. 1981. ABC News/Washington Post survey. New York, NY: Capital Cities/ABC, Inc; The Washington Post. September.

ABC News and The Washington Post. 1981. ABC News/Washington Post survey. New York, NY: Capital Cities/ABC, Inc.; The Washington Post. October.

ABC News and The Washington Post. 1981. ABC News/Washington Post survey. New York, NY: Capital Cities/ABC, Inc.; The Washington Post. November.

ABC News and The Washington Post. 1982. ABC News/Washington Post survey. New York, NY: Capital Cities/ABC, Inc.; The Washington Post. March.

$\mathrm{ABC}$ News and The Washington Post. 1983. ABC News/Washington Post survey. New York, NY: Capital Cities/ABC, Inc.; The Washington Post. April.

ABC News and The Washington Post. 1985. ABC News/Washington Post survey. New York, NY: Capital Cities/ABC, Inc.; The Washington Post. January.

ABC News and The Washington Post. 1986. ABC News/Washington Post survey. New York, NY: Capital Cities/ABC, Inc.; The Washington Post. April.

ABC News and The Washington Post. 1986. ABC News/Washington Post survey. New York, NY: Capital Cities/ABC, Inc.; The Washington Post. May. 
ABC News and The Washington Post. 1986. ABC News/Washington Post survey. New York, NY: Capital Cities/ABC, Inc.; The Washington Post. September.

ABC News and The Washington Post. 1987. ABC News/Washington Post survey. New York, NY: Capital Cities/ABC, Inc.; The Washington Post. June a.

ABC News and The Washington Post. 1987. ABC News/Washington Post survey. New York, NY: Capital Cities/ABC, Inc.; The Washington Post. June b.

ABC News and The Washington Post. 1988. ABC News/Washington Post survey. New York, NY: Capital Cities/ABC, Inc.; The Washington Post. July.

$\mathrm{ABC}$ News and The Washington Post. 1989. ABC News/Washington Post survey. New York, NY: Capital Cities/ABC, Inc.; The Washington Post. May.

$\mathrm{ABC}$ News and The Washington Post. 1989. ABC News/Washington Post survey. New York, NY: Capital Cities/ABC, Inc,; The Washington Post. June.

ABC News and The Washington Post. 1989. ABC News/Washington Post survey. New York, NY: Capital Cities/ABC, Inc.; The Washington Post. August.

ABC News and The Washington Post. 1990. ABC News/Washington Post survey. New York, NY: Capital Cities/ABC, Inc.; The Washington Post. July.

ABC News and The Washington Post. 1990. ABC News/Washington Post survey. New York, NY: Capital Cities/ABC, Inc.; The Washington Post. August.

$\mathrm{ABC}$ News and The Washington Post. 1990. ABC News/Washington Post survey. New York, NY: Capital Cities/ABC, Inc.; The Washington Post. September.

ABC News and The Washington Post. 1990. ABC News/Washington Post survey. New York, NY: Capital Cities/ABC, Inc.; The Washington Post. December.

ABC News and The Washington Post. 1991. ABC News/Washington Post survey. New York, NY: Capital Cities/ABC, Inc.; The Washington Post. January.

Analysis Group. 1988. Waste not, want not: a national opinion survey on energy policy. New Haven, CT: The Analysis Group.

Associated Press. 1990. Associated Press survey. New York, NY: Associated Press. August.

Associated Press. 1991. Associated Press survey. New York, NY: Associated Press. January.

Associated Press. 1991. Associated Press survey. New York, NY: Associated Press. July.

Associated Press. "Chernobyl Study Suggests Health Effects Exaggerated." AP News Data Base. May 21, 1991.

Associated Press. "Republics Still Feel Chernobyl's Effects," in The Sunday Capital (Annapolis, MD): April 26, 1992. p. A5. 
Associated Press and Media General. 1980. Associated Press/Media General survey. New York, NY: Associated Press; Media General. November.

Associated Press and Media General. 1986. Associated Press/Media General survey. New York, NY: Associated Press; Media General. June.

Associated Press and Media General. 1989. Associated Press/Media General survey. New York, NY: Associated Press; Media General. January.

Associated Press and Media General. 1989. Associated Press/Media General survey. New York, NY: Associated Press; Media General. May.

Associated Press and Media General. 1989. Associated Press/Media General survey. New York, NY: Associated Press; Media General. September.

Associated Press and Media General. 1990. Associated Press/Media General survey. New York, NY: Associated Press; Media General. May.

Audits \& Surveys. 1983. Merit report. Sponsored by Merit Corporation. New York, NY: Audits \& Surveys, Inc. July.

Behavior Research Center Inc. 1991. Solar energy survey. Sponsored by Arizona Department of Commerce, Energy Development and Utilization Division. Phoenix, AZ: Behavior Research Center, Inc. February.

Berenyi, Eileen and Robert Gould. 1991, 1991 Resource Recovery Yearbook. New York: Governmental Advisory Associates Inc.

Berkeley Solar Group and Xenergy. 1990. Occupancy patterns \& energy consumption in new California houses. Sponsored by California Energy Commission: Energy Efficiency \& Local Assistance Division; Demand Side Program Evaluation Office. Oakland, CA: Berkeley Solar Group; Xenergy. September.

Bradley, Richard A., Edward C. Watts, Edward R. Williams, eds. 1991. Limiting net greenhouse gas emissions in the United States: Report to the Congress of the United States. Washington, D.C.: U.S. Department of Energy.

Bunch, David S., et al. 1991. Demand for clean-fuel personal vehicles in Califormia: a discrete-choice stated preference survey. Sponsored by the California Energy Commission. Pacific Grove, CA: Conference on Transportation and Global Climate Change: Long Run Options. August 26.

Cambridge Energy Research Associates, Inc. and Opinion Dynamics. 1992. Fueling the Race for the Presidency. Cambridge, MA: Cambridge Energy Research Associates, Inc. and Opinion Dynamics. June.

Cambridge Reports. 1980. Cambridge report 23. Cambridge, MA: Cambridge Reports. May.

Cambridge Reports. 1980. Inflation, public policy and retail industry. Sponsored by American Retail Federation. Cambridge, MA: Cambridge Policy Research Corporation. April. 
Cambridge Reports. 1981. Electricity supply, cost and pricing policy. Sponsored by Union Carbide. Cambridge MA: Cambridge Policy Research Corporation. July.

Cambridge Reports. 1990. Sponsored by U.S. Council for Energy Awareness. Cambridge, MA: Cambridge Policy Research Corporation. February.

Cambridge Reports/Research International. 1990. Electric utilities and the environment: performance and expectations for the 1990's. Sponsored by Edison Electric Institute. Cambridge, MA: Cambridge Policy Research Corporation. October.

Cambridge Reports/Research International. 1991. The coal option: hope despite environmental concerns. Cambridge, MA: Cambridge Policy Research Corporation. April.

CBS News. 1986. CBS News survey. New York, NY: Columbia Broadcasting System. May.

CBS News. 1990. CBS News survey. New York, NY: Columbia Broadcasting System. August.

CBS News. 1990. CBS News survey. New York, NY: Columbia Broadcasting System. October.

CBS News. 1991. CBS News survey. New York, NY: Columbia Broadcasting System. January.

CBS News and The New York Times. 1979. CBS News/New York Times survey. New York, NY: Columbia Broadcasting System; The New York Times. March.

CBS News and The New York Times. 1979. CBS News/New York Times survey. New York, NY: Columbia Broadcasting System; The New York Times. April.

CBS News and The New York Times. 1979. CBS News/New York Times survey. New York, NY: Columbia Broadcasting System; The New York Times. June 9.

CBS News and The New York Times. 1979. CBS News/New York Times survey. New York, NY: Columbia Broadcasting System; The New York Times. June 11.

CBS News and The New York Times. 1979. CBS News/New York Times survey. New York, NY: Columbia Broadcasting System; The New York Times. July 12.

CBS News and The New York Times. 1979. CBS News/New York Times survey. New York, NY: Columbia Broadcasting System; The New York Times. July 17.

CBS News and The New York Times. 1979. CBS News/New York Times survey. New York, NY: Columbia Broadcasting System; The New York Times. October.

CBS News and The New York Times. 1979. CBS News/New York Times survey. New York, NY: Columbia Broadcasting System; The New York Times. November 5.

CBS News and The New York Times. 1979. CBS News/New York Times survey. New York, NY: Columbia Broadcasting System; The New York Times. November 7.

CBS News and The New York Times. 1980. CBS News/New York Times survey. New York, NY: Columbia Broadcasting System; The New York Times. February. 
CBS News and The New York Times. 1980. CBS News/New York Times survey. New York, NY: Columbia Broadcasting System; The New York Times. March.

CBS News and The New York Times. 1980. CBS News/New York Times survey. New York, NY: Columbia Broadcasting System; The New York Times. April.

CBS News and The New York Times. 1981. CBS News/New York Times survey. New York, NY: Columbia Broadcasting System; The New York Times. April.

CBS News and The New York Times. 1981. CBS News/New York Times survey. New York, NY: Columbia Broadcasting System; The New York Times. September.

CBS News and The New York Times. 1981. CBS News/New York Times survey. New York, NY: Columbia Broadcasting System; The New York Times. October.

CBS News and The New York Times. 1986. CBS News/New York Times survey. New York, NY: Columbia Broadcasting System; The New York Times. April.

CBS News and The New York Times. 1988. CBS News/New York Times survey. New York, NY: Columbia Broadcasting System; The New York Times. September.

CBS News and The New York Times. 1989. CBS News/New York Times survey. New York, NY: Columbia Broadcasting System; The New York Times. April.

CBS News and The New York Times. 1990. CBS News/New York Times survey. New York, NY: Columbia Broadcasting System; The New York Times. April.

CBS News and The New York Times. 1990. CBS News/New York Times survey. New York, NY: Columbia Broadcasting System; The New York Times. May.

CBS News and The New York Times. 1990. CBS News/New York Times survey. New York, NY: Columbia Broadcasting System; The New York Times. August 9.

CBS News and The New York Times. 1990. CBS News/New York Times survey. New York, NY: Columbia Broadcasting System; The New York Times. August 21.

CBS News and The New York Times. 1990. CBS News/New York Times survey. New York, NY: Columbia Broadcasting System; The New York Times. October.

CBS News and The New York Times. 1990. CBS News/New York Times survey. New York, NY: Columbia Broadcasting System; The New York Times. November.

CBS News and The New York Times. 1991. CBS News/New York Times survey. New York, NY: Columbia Broadcasting System; The New York Times. January 14.

CBS News and The New York Times. 1991. CBS News/New York Times survey. New York, NY: Columbia Broadcasting System; The New York Times. January 17.

CBS News and The New York Times. 1991. CBS News/New York Times survey. New York, NY; Columbia Broadcasting System; The New York Times. January 18. 
CBS News and The New York Times. 1991. CBS News/New York Times survey. New York, NY: Columbia Broadcasting System; The New York Times. January 21.

CBS News and The New York Times. 1991. CBS News/New York Times survey. New York, NY: Columbia Broadcasting System; The New York Times. June.

Center for Governmental Sciences. 1988. Evaluation of Alabama's energy conservation programs. Appendix only. Sponsored by Alabama Department of Economic and Community Affairs, Division of Science, Technology and Energy. Auburn, AL: Auburn University. June.

Chicago Tribune. "Chernobyl: A Cancerous Legacy in Belarus." February 2, 1992. p. C1.

Civic Service, Inc. 1980. Campaign financing and other national issues. St. Louis, MO: Civic Service, Inc. February.

Clinton, Charles J. et al. 1989. Survey of state energy officials. Sponsored by the National Association of State Energy Officials. Washington, D.C.: NASEO. October.

Craig Group, Inc. 1990. Commuter travel survey. Sponsored by Mid-Ohio Regional Planning Commission. Columbus, $\mathrm{OH}$ : The Craig Group, Inc. February.

Crites, Alice M. 1990. Energy education for low income home energy assistance recipients. Sponsored by the Nevada Cooperative Extension, University of Nevada. Reno, Nevada: University of Nevada. February.

Crites, Alice M. 1990. Energy saving practices of low income homes. Report of results for 1988 survey. Evaluation of the energy savings potential of LIHEA recipients, Markee et al., 1988. Research reporting session, National Association of Extension Home Economists, September 24.

Daniel Yankelovich Group. 1988. Americans Talk Security survey no. 10. New York, NY: Yankelovich Group. October.

Darnay, Arsen J,, ed, 1992. Statistical record of the environment. A Gale Environmental Library compilation. Detroit, MI: Gale Research, Inc.

Daugherty, David B. 1987. Utility customer segmentation: study results. Marion, IA: Frank N. Magid Associates. March.

Dunlap, Riley E. 1991a. "Public Opinion in the 1980s: Clear Consensus, Ambiguous Commitment." Environnment, 33: 10-37.

Dunlap, Riley E. 1991b. "Trends in Public Opinion toward Environmental Issues: 1965-1990." Society and Natural Resources, 4:285-312.

Dunlap, Riley E. and Angela G. Mertig. "The Evolution of the U.S. Environmental Movement from 1970 to 1990: An Overview." Society and Natural Resources, 4:209-218.

Dunlap, Riley E. and Rik Scarce. 1991. "Trends: Environmental Problems and Protection." Public Opinion Quarterly, 55:651-672. 
Dunlap, Riley E., George H. Gallup, and Alec M. Gallup. 1992. The Health of the Planet Survey. Sponsored by the government of Norway, the government of the United States, the Wislow Foundation, The World Wide Fund for Nature-International, Distribidora Chilectra Metropolitana, S.A., the Life Insurance Corporation of Indica (LIC), the East Asiatic Company, Ltd., Novo Nordsk A/S, Bacardi y Campañia S.A., Federal Office of Environment, Forest and Landscape (Switzerland), ASIC/Swiss Society of Consulting Engineers, Princeton, NJ: The George H. Gallup International Institute. May.

Eagleton Institute of Politics. 1978. New Jersey residents and energy conservation: a survey of citizens' attitudes. Sponsored by New Jersey Department of Energy. NJ: Rutgers University. October.

Eagleton Institute of Politics. 1982. HESP: an evaluation of the Home Energy Savings Program. Sponsored by New Jersey Department of Energy. NJ: Rutgers University. March.

Farhar, Barbara C. et al. 1979. Public opinion about energy: a literature review. Golden, CO: Solar Energy Research Institute. June.

Farhar, Barbara C., Charles T. Unseld, Rebecca Vories, and Robin Crews. 1980. "Public opinion about energy." Annual Review of Energy, 5:141-72.

Farhar-Pilgrim, Barbara and Charles T. Unseld. 1982. America's solar potential: a national consumer study. New York, NY: Praeger Publishers.

Frederick/Schneiders, Inc. 1992. Americans Speak Out on Energy Policy. Sponsored by the Safe Energy Communication Council. Washington, DC: Frederick/Schneiders, Inc. March.

Freudenberg, Nicholas and Carol Steinsapir. 1991. "Not in Our Backyards: The Grassroots Environmental Movement." Society and Natural Resources, 4:235-245.

Gallup Organization. 1977. The Gallup poll. Princeton, NJ: American Institute of Public Opinion. October.

Gallup Organization. 1979. The Gallup poll. Princeton, NJ: American Institute of Public Opinion. February.

Gallup Organization. 1979. The Gallup poll. Princeton, NJ: American Institute of Public Opinion. March.

Gallup Organization. 1979. The Gallup poll. Princeton, NJ: American Institute of Public Opinion. April.

Gallup Organization. 1979. The Gallup poll. Princeton, NJ: American Institute of Public Opinion. May a.

Gallup Organization. 1979. The Gallup poll. Princeton, NJ: American Institute of Public Opinion. May b

Gallup Organization. 1979. The Gallup poll. Princeton, NJ: American Institute of Public Opinion. June a. 
Gallup Organization. 1979. The Gallup poll. Princeton, NJ: American Institute of Public Opinion. June $b$.

Gallup Organization. 1979. The Gallup poll. Princeton, NJ: American Institute of Public Opinion. August a.

Gallup Organization. 1979. The Gallup poll. Princeton, NJ: American Institute of Public Opinion. August $b$.

Gallup Organization. 1979. The Gallup poll. Princeton, NJ: American Institute of Public Opinion. August c.

Gallup Organization. 1979. The Gallup poll. Princeton, NJ: American Institute of Public Opinion. September.

Gallup Organization. 1979. The Gallup poll. Princeton, NJ: American Institute of Public Opinion. December.

Gallup Organization. 1979. Gallup/Newsweek poll. Princeton, NJ: American Institute of Public Opinion. July.

Gallup Organization. 1980. Attitudes toward the presidency. Sponsored by Public Broadcasting System. Princeton, NJ: American Institute of Public Opinion. January.

Gallup Organization. 1980. The Gallup poll. Princeton, NJ: American Institute of Public Opinion. February.

Gallup Organization. 1980. The Gallup poll. Princeton, NJ: American Institute of Public Opinion. August.

Gallup Organization. 1980. Gallup/Newsweek poll. Princeton, NJ: American Institute of Public Opinion. March.

Gallup Organization. 1983. Attitudes of American public on foreign policy. Princeton, NJ: American Institute of Public Opinion. Sponsored by Chicago Council on Foreign Relations. January a.

Gallup Organization. 1983. Attitudes of opinion leaders on foreign policy. Princeton, NJ: American Institute of Public Opinion. Sponsored by Chicago Council on Foreign Relations. January b.

Gallup Organization. 1985. The Gallup poll. Princeton, NJ: American Institute of Public Opinion. April.

Gallup Organization. 1986. Attitudes towards public schools. Sponsored by Phi Delta Kappa. Princeton, NJ: American Institute of Public Opinion. April.

Gallup Organization. 1986. The Gallup poll. Princeton, NJ: American Institute of Public Opinion. June.

Gallup Organization. 1986. Gallup/Newsweek poll. Princeton, NJ: American Institute of Public Opinion. May. 
Gallup Organization. 1986. People and the press -- July 1986. Sponsored by Times Mirror. Princeton, NJ: American Institute of Public Opinion. July.

Gallup Organization. 1987. The Gallup poll. Princeton, NJ: American Institute of Public Opinion. July.

Gallup Organization. 1987. Public attitudes toward government and taxes. Sponsored by Advisory Commission on Intergovernmental Relations. Princeton, NJ: American Institute of Public Opinion. July.

Gallup Organization. 1987. U. S. foreign policy -- public. Princeton, NJ: American Institute of Public Opinion. Sponsored by Chicago Council on Foreign Relations. March.

Gallup Organization. 1988. Geography. Sponsored by National Geographic Society. Princeton, NJ: American Institute of Public Opinion. July.

Gallup Organization. 1988. People, the press, and politics. Sponsored by Times Mirror. Princeton, NJ: American Institute of Public Opinion. May.

Gallup Organization. 1988. People, the press, and politics. Sponsored by Times Mirror. Princeton, NJ: American Institute of Public Opinion. October.

Gallup Organization. 1988. Public attitudes on government and taxes. Sponsored by the Advisory Commission on Intergovernmental Relations. Princeton, NJ: American Institute of Public Opinion. July.

Gallup Organization. 1989. The Gallup poll. Princeton, NJ: American Institute of Public Opinion. March.

Gallup Organization. 1989. The Gallup poll. Princeton, NJ: American Institute of Public Opinion. May.

Gallup Organization. 1989. People, the press, and politics. Sponsored by Times Mirror. Princeton, NJ: American Institute of Public Opinion. March.

Gallup Organization. 1989. Times Mirror monthly newstrack. Princeton, NJ: American Institute of Public Opinion. May.

Gallup Organization. 1990. The Gallup poll. Princeton, NJ: American Institute of Public Opinion. January.

Gallup Organization. 1990. The Gallup poll. Princeton, NJ: American Institute of Public Opinion. April.

Gallup Organization. 1990. The Gallup poll. Princeton, NJ: American Institute of Public Opinion. August 5.

Gallup Organization. 1990. The Gallup poll. Princeton, NJ: American Institute of Public Opinion. August 15.

Gallup Organization. 1990. The Gallup poll. Princeton, NJ: American Institute of Public Opinion. August. 
Gallup Organization. 1990. The Gallup poll. Princeton, NJ: American Institute of Public Opinion. September a.

Gallup Organization. 1990. The Gallup poll. Princeton, NJ: American Institute of Public Opinion. September b.

Gallup Organization. 1990. The Gallup poll. Princeton, NJ: American Institute of Public Opinion. October a.

Gallup Organization. 1990. The Gallup poll. Princeton, NJ: American Institute of Public Opinion. October b.

Gallup Organization. 1990. The Gallup poll. Princeton, NJ: American Institute of Public Opinion. November.

Gallup Organization. 1990. The Gallup poll. Princeton, NJ: American Institute of Public Opinion. December a.

Gallup Organization. 1990. The Gallup poll. Princeton, NJ: American Institute of Public Opinion. December $b$.

Gallup Organization. 1990. Gallup/Newsweek poll. Princeton, NJ: American Institute of Public Opinion. August.

Gallup Organization. 1990. Gallup/Newsweek poll. Princeton, NJ: American Institute of Public Opinion. October.

Gallup Organization. 1990. Gallup/Newsweek poll. Princeton, NJ: American Institute of Public Opinion. November.

Gallup Organization. 1991. The Gallup poll. Princeton, NJ: American Institute of Public Opinion. January a.

Gallup Organization. 1991. The Gallup poll. Princeton, NJ: American Institute of Public Opinion. January b.

Gallup Organization. 1991. The Gallup poll. Princeton, NJ: American Institute of Public Opinion. February a.

Gallup Organization. 1991. The Gallup poll. Princeton, NJ: American Institute of Public Opinion. February b.

Gallup Organization. 1991. The Gallup poll. Princeton, NJ: American Institute of Public Opinion. April a.

Gallup Organization. 1991. The Gallup poll. Princeton, NJ: American Institute of Public Opinion. April b.

Gallup Organization. 1991. The Gallup poll. Princeton, NJ: American Institute of Public Opinion. July. 
Gallup Organization. 1991. Gallup/Newsweek poll. Princeton, NJ: American Institute of Public Opinion. January.

Genereux, John P. and M. Michele. 1982. A study conducted to confirm household survey data on energy-saving features in lowa homes: comparative findings from household surveys and independent home audit reports in a St. Paul neighborhood. Sponsored by Iowa Energy Policy Council. St. Paul, MN: J. P. Genereux. May.

Georgia Office of Energy Resources. 1985. Evaluation of the Public Information and Education Program. Atlanta, GA: Office of Energy Resources. October.

Gordon S. Black Corporation. 1984. Public opinion survey. Sponsored by U.S.A. Today. Rochester, NY: Gordon S. Black Corporation. March.

Gordon S. Black Corporation. 1984. Public opinion survey. Sponsored by U.S.A. Today. Rochester, NY: Gordon S. Black Corporation. November.

Gordon S. Black Corporation. 1990. Public opinion survey. Sponsored by U.S.A. Today. Rochester, NY: Gordon S. Black Corporation. March.

Gordon S. Black Corporation. 1990. Public opinion survey. Sponsored by U.S.A. Today. Rochester, NY: Gordon S. Black Corporation. August.

Gordon S. Black Corporation. 1990. Public opinion survey. Sponsored by U.S.A. Today. Rochester, NY: Gordon S. Black Corporation. November.

Gordon S. Black Corporation. 1990. Public opinion survey. Sponsored by U.S.A. Today. Rochester, NY: Gordon S. Black Corporation. December.

Grapentine Company. 1982. A home weatherization and ridesharing marketing study. Sponsored by Iowa Energy Policy Council. Des Moines, IA: Grapentine Co. August.

Hammel, Carol J., K. B. Livo, et al. 1987. The Colorado oxygenated fuels demonstration project: final report. Vol. I. Denver, CO: Air Pollution Control Division, Colorado Department of Health. January.

Hamilton, Frederick and Schneiders. 1988. Smoking. Sponsored by the Tobacco Institute. N.P.: Hamilton, Frederick and Schneiders. December.

Hart \& Teeter Research Companies. 1990. NBC News/Wall Street Journal survey. N.P.: Hart \& Teeter Research Companies. January.

Hart \& Teeter Research Companies. 1990. NBC News/Wall Street Joumal survey. N.P.: Hart \& Teeter Research Companies. April.

Hart \& Teeter Research Companies. 1990. NBC News/Wall Street Journal survey. N.P.: Hart \& Teeter Research Companies. May.

Hart \& Teeter Research Companies. 1990. NBC News/Wall Street Journal survey. N.P.: Hart \& Teeter Research Companies. July. 
Hart \& Teeter Research Companies. 1990. NBC News/Wall Street Journal survey. N.P.: Hart \& Teeter Research Companies. August.

Hart \& Teeter Research Companies. 1990. NBC News/Wall Street Journal survey. N.P.: Hart \& Teeter Research Companies. September a.

Hart \& Teeter Research Companies. 1990. NBC News/Wall Street Joumal survey. N.P.: Hart \& Teeter Research Companies. September b.

Hart \& Teeter Research Companies. 1990. NBC News/Wall Street Journal survey. N.P.: Hart \& Teeter Research Companies. October.

Hart \& Teeter Research Companies. 1990. NBC News/Wall Street Journal survey. N.P.: Hart \& Teeter Research Companies. December.

Hart \& Teeter Research Companies. 1991. NBC News/Wall Street Journal survey. N.P.: Hart \& Teeter Research Companies. January a.

Hart \& Teeter Research Companies. 1991. NBC News/Wall Street Journal survey. N.P.; Hart \& Teeter Research Companies. January b.

Hart \& Teeter Research Companies. 1991. NBC News/Wall Street Journal survey. N.P.; Hart \& Teeter Research Companies. March.

Hart \& Teeter Research Companies. 1991. NBC News/Wall Street Journal survey. N.P.: Hart \& Teeter Research Companies. August.

Hewitt, Myrna Livingston. 1992. Survey of league leaders on global climate change. Washington, DC: League of Women Voters Education Fund.

Indiana Department of Commerce. 1988. 1988 public awareness survey results. Indianapolis, IN: Division of Energy Policy, Dept. of Commerce.

Indiana Department of Commerce. 1989. Indiana citizens respond to acid rain question. Indianapolis, IN: Division of Energy Policy, Dept. of Commerce. January.

Institute for Policy Research. 1982. The Ohio poll. Cincinnati, OH: University of Cincinnati. Cincinnati, OH: University of Cincinnati. March.

Institute for Policy Research. 1983. The Ohio poll. Cincinnati, OH: University of Cincinnati. August. Institute for Policy Research. 1984. The Ohio poll. Cincinnati, OH: University of Cincinnati. April 3. Institute for Policy Research. 1985. The Ohio poll. Cincinnati, OH: University of Cincinnati. April. Institute for Policy Research. 1988. The Ohio poll. Sponsored by Cincinnati Post, Dayton Daily News, WKRC-TV, and the University of Cincinnati. Cincinnati, $\mathrm{OH}$ : University of Cincinnati. October.

Institute for Policy Research. 1989. The Ohio poll. Sponsored by Cincinnati Post, Dayton Daily News, WKRC-TV, and the University of Cincinnati. Cincinnati, OH: University of Cincinnati. April. 
Institute for Policy Research. 1989. The Ohio poll. Sponsored by Cincinnati Post, Dayton Daily News, WKRC-TV, and the University of Cincinnati. Cincinnati, OH: University of Cincinnati. July.

Institute for Policy Research. 1990. The Ohio poll. Sponsored by Cincinnati Post, Dayton Daily News, and the University of Cincinnati. Cincinnati, $\mathrm{OH}$ : University of Cincinnati. June.

Institute for Policy Research. 1991. The Ohio poll. Sponsored by the University of Cincinnati. Cincinnati, $\mathrm{OH}$ : University of Cincinnati. March.

Institute for Policy Research. 1991. The Ohio poll. Sponsored by the University of Cincinnati. Cincinnati, $\mathrm{OH}$ : University of Cincinnati. May.

Institute for Public Policy. 1990. Recycling in New Mexico: citizens' attitudes and behaviors. Sponsored by New Mexico State Energy, Minerals and Natural Resources Department. Albuquerque, NM: University of New Mexico. August.

Institute for Social Research. 1986. Residential energy conservation attitudes and practices in Connecticut. Sponsored by U.S. Department of Energy and Connecticut Office of Policy and Management, Energy Division. West Hartford, CT: University of Hartford. March.

Institute for Social Research. 1987. Connecticut residents' attitudes toward residential energy conservation and energy policies. Sponsored by U.S. Department of Energy and Connecticut Office of Policy and Management, Energy Division. West Hartford, CT: University of Hartford. February.

Institute for Survey Research. 1980. Attitudes toward science and technology. Sponsored by National Science Foundation. Philadelphia, PA: Temple University Institute for Survey Research. May.

International Solar Energy Intelligence Report. 1992. "National survey shows voters ready to elect solar advocates. June 1. p. 86.

Jones, Robert E. and Riley E. Dunlap. 1992. "The Social Bases of Environmental Concern: Have They Changed Over Time." Rural Sociology, 57:28-47.

Kentucky Division of Energy. 1990. Cost effective energy design workshop: final report. Frankfort, KY: Kentucky Division of Energy. November.

Leonard-Barton, D. 1978. The diffusion and adoption of solar equipment among California homeowners: report on a pretest study. Stanford, CA: Institute for Comunications Research, Stanford University.

Leonard-Barton, D., and E. H. Rogers. 1979. "Adoption of Energy Conservation among California Homeowners." Stanford: Stanford University, May, 1979.

Levi, Daniel. 1984. Public attitude survey on solar energy for Portland, Oregon. Sponsored by Solar Access Plan for Portland, Oregon and the City of Portland Energy Office. Portland, OR: Conservation Management Services, Inc. September.

Lieberman Research, Inc. 1986. Americans and their money. Sponsored by Money Magazine. Great Neck, NY: Lieberman Research, Inc. July.

Lindquist, Eric A. and Nicole L. Vautour. 1988. Residential windmill project. Sponsored by Central Maine Power Company. ME: Energy Management Planning. December. 
Los Angeles Times. 1979. Public opinion survey. Los Angeles: Times-Mirror, Inc. May.

Los Angeles Times. 1979. Public opinion survey. Los Angeles: Times-Mirror, Inc. December.

Los Angeles Times. 1981. Public opinion survey. Los Angeles: Times-Mirror, Inc. April.

Los Angeles Times. 1982. Public opinion survey. Los Angeles: Times-Mirror, Inc. August.

Los Angeles Times. 1983. Public opinion survey. Los Angeles: Times-Mirror, Inc. May.

Los Angeles Times. 1985. Public opinion survey. Los Angeles: Times-Mirror, Inc. January.

Los Angeles Times. 1986. Public opinion survey. Los Angeles: Times-Mirror, Inc. February.

Los Angeles Times. 1987. Public opinion survey. Los Angeles: Times-Mirror, Inc. June.

Los Angeles Times. 1989. Public opinion survey. Los Angeles: Times-Mirror, Inc. November.

Los Angeles Times. 1990. Public opinion survey. Los Angeles: Times-Mirror, Inc. November.

Los Angeles Times. 1990. Public opinion survey. Los Angeles: Times-Mirror, Inc. December.

Los Angeles Times. 1991. Public opinion survey. Los Angeles: Times-Mirror, Inc. January.

Los Angeles Times. 1991. Public opinion survey. Los Angeles: Times-Mirror, Inc. February.

Los Angeles Times. 1991. Public opinion survey. Los Angeles: Times-Mirror, Inc. April.

Louis Harris \& Associates. 1978. Harris survey. New York, NY: Louis Harris \& Associates. June 1.

Louis Harris \& Associates. 1980. Americans and the arts 1980. Sponsored by Philip Morris, Inc., \& National Endowment for the Arts; conducted for American Council for the Arts. New York, NY: Louis Harris \& Associates. July.

Louis Harris \& Associates. 1980. Attitudes of Americans and Jewish Americans toward Arab-Israeli conflict. Sponsored by World Jewish Congress. New York, NY: Louis Harris \& Associates. July.

Louis Harris \& Associates. 1980. Risk in a complex society. Sponsored by Marsh \& McLennan. New York, NY: Louis Harris \& Associates. January.

Louis Harris \& Associates. 1980. Soil, water, renewable resources conservation. Sponsored by U.S. Dept. of Agriculture. New York, NY: Louis Harris \& Associates. March.

Louis Harris \& Associates. 1981. Aging in the eighties. Sponsored by National Council on the Aging. New York, NY: Louis Harris \& Associates. October.

Louis Harris \& Associates. 1981. Harris survey. New York, NY: Louis Harris \& Associates. February. Louis Harris \& Associates. 1981. Harris survey. New York, NY: Louis Harris \& Associates. March. Louis Harris \& Associates. 1981. Harris survey. New York, NY: Louis Harris \& Associates. May. 
Louis Harris \& Associates. 1981. Harris survey. New York, NY: Louis Harris \& Associates. October 8.

Louis Harris \& Associates. 1981. Harris survey. New York, NY: Louis Harris \& Associates. October 15 .

Louis Harris \& Associates. 1981. Harris survey. New York, NY: Louis Harris \& Associates. November.

Louis Harris \& Associates. 1981. Harris survey. New York, NY: Louis Harris \& Associates. December.

Louis Harris \& Associates. 1982. American attitudes toward water pollution. Sponsored by Natural Resources Council of America. New York, NY: Louis Harris \& Associates. December.

Louis Harris \& Associates. 1982. Americans' attitudes toward Japan and the Japanese people. Sponsored by Asaiti Shimbun. New York, NY: Louis Harris \& Associates. March.

Louis Harris \& Associates. 1982. Consumer attitudes and the supermarket 1982. Sponsored by Food Marketing Institute. New York, NY: Louis Harris \& Associates. January.

Louis Harris \& Associates. 1982. Consumerism in the eighties. Sponsored by Atlantic Richfield Company. New York, NY: Louis Harris \& Associates. October.

Louis Harris \& Associates. 1982. Harris survey. New York, NY: Louis Harris \& Associates. May.

Louis Harris \& Associates. 1983. Business Week/Harris poll. New York, NY: Louis Harris \& Associates. April.

Louis Harris \& Associates. 1983. Consumer attitudes and the supermarket 1983. Sponsored by Food Marketing Institute. New York, NY: Louis Harris \& Associates. February.

Louis Harris \& Associates. 1983. Public attitudes toward risk 1983. Sponsored by Insurance Information Institute. New York, NY: Louis Harris \& Associates. August.

Louis Harris \& Associates. 1984. Consumer attitudes and the supermarket 1984. Sponsored by Food Marketing Institute. New York, NY: Louis Harris \& Associates. January.

Louis Harris \& Associates. 1985. Harris survey. New York, NY: Louis Harris \& Associates. April 1. Louis Harris \& Associates. 1985. Harris survey. New York, NY: Louis Harris \& Associates. April 4. Louis Harris \& Associates. 1986. Business Week/Harris poll. New York, NY: Louis Harris \& Associates. June.

Louis Harris \& Associates. 1986. Harris survey. New York, NY: Louis Harris \& Associates. January. Louis Harris \& Associates. 1986. Harris survey. New York, NY: Louis Harris \& Associates. April. Louis Harris \& Associates. 1986. Harris survey. New York, NY: Louis Harris \& Associates. May. 
Louis Harris \& Associates. 1987. Key issues in the country in 1987. Sponsored by Democratic Governors Association and Democrats for the Eighties. New York, NY: Louis Harris \& Associates. July.

Louis Harris \& Associates. 1987. Harris survey. New York, NY: Louis Harris \& Associates. May.

Louis Harris \& Associates. 1987. Harris survey. New York, NY: Louis Harris \& Associates. November.

Louis Harris \& Associates. 1987. Science, biotechnology, and genetic engineering. Sponsored by Office of Technology Assessment. New York, NY: Louis Harris \& Associates. January.

Louis Harris \& Associates. 1989. Harris poll. New York, NY: Louis Harris \& Associates. January 8.

Louis Harris \& Associates. 1989. Harris poll. New York, NY: Louis Harris \& Associates. January 15.

Louis Harris \& Associates. 1989. Harris poll. New York, NY: Louis Harris \& Associates. May.

Louis Harris \& Associates. 1989. Harris poll. New York, NY: Louis Harris \& Associates. July.

Louis Harris \& Associates. 1989. Harris poll. New York, NY: Louis Harris \& Associates. November.

Louis Harris \& Associates. 1990. Harris poll. New York, NY: Louis Harris \& Associates. April.

Louis Harris \& Associates. 1990. Harris poll. New York, NY: Louis Harris \& Associates. August.

Louis Harris \& Associates. 1990. Harris poll. New York, NY: Louis Harris \& Associates. September 9.

Louis Harris \& Associates. 1990. Harris poll. New York, NY: Louis Harris \& Associates. September 16.

Louis Harris \& Associates. 1990. Harris poll. New York, NY: Louis Harris \& Associates. December 2.

Louis Harris \& Associates. 1990. Harris poll. New York, NY: Louis Harris \& Associates. December 16.

Louis Harris and Associates. 1991. Business Week/Harris poll. New York, NY: Louis Harris \& Associates. December.

Louis Harris \& Associates. 1991. Harris poll. New York, NY: Louis Harris \& Associates. April.

Louis Harris and Associates. 1991. Public attitudes toward people with disabilities. Sponsored by the National Organization on Disability. New York, NY: Louis Harris \& Associates. June.

Louis Harris \& Associates. 1991. War Watch Poll \#3. Sponsored by National Public Radio. New York, NY: Louis Harris \& Associates. February.

Maples, John. 1991. Reasons for buying a new car and the factors associated with new car purchase, based on Newsweek's 1990 National Survey of New Car Buyers (Memorandum), February 5. 
Maritz Marketing Research. 1990. Maritz Ameripoll. St. Louis, MO: Maritz Marketing Research. July.

Maritz Marketing Research. 1990. Maritz Ameripoll. St. Louis, MO: Maritz Marketing Research. November.

Mark Clements Research. 1982. Women's attitudes 1982. Sponsored by Glamour Magazine. New York, NY: Mark Clements Research. September.

Mark Clements Research. 1983. Women's attitudes 1983. Sponsored by Glamour Magazine. New York, NY: Mark Clements Research. August.

Mark Clements Research. 1984. Women's attitudes 1984. Sponsored by Glamour Magazine. New York, NY: Mark Clements Research. August.

Mark Clements Research. 1986. Women's attitudes 1986. Sponsored by Glamour Magazine. New York, NY: Mark Clements Research. September.

Mark Clements Research. 1987. Women's attitudes 1987. Sponsored by Glamour Magazine. New York, NY: Mark Clements Research. September.

Markee, Nancy, Colleen Murray, Elaine Pedersen and Alice Crites. 1988. Evaluation of the energy savings potential of LIHEA recipients. Sponsored by the School of Home Economics, Nevada Cooperative Extension, University of Nevada. Reno, Nevada: University of Nevada. July.

Market Opinion Research. 1979. World hunger and U.S. role. Sponsored by Presidential Commission on World Hunger. Detroit, MI: Market Opinion Research. December.

Market Opinion Research. 1988. Americans talk security no. 9. Sponsored by Americans Talk Security. Detroit, MI: Market Opinion Research. October.

Market Strategies. 1990. Showdown in the Middle East 1990. Sponsored by Americans Talk Security. Boston, MA: Martilla \& Kiley, Inc. October.

Market Strategies. 1991. New World Order-What the Peace Should Be. Sponsored by American Talk Security. Boston, MA: Martilla \& Kiley, Inc. March.

Market Strategies and Greenberg-Lake. 1991. Americans Talk Issues \#16. Sponsored by Americans Talk Issues Foundation. Boston, MA: Martilla \& Kiley, Inc. July.

Market Strategies and Greenberg-Lake. 1991. Americans Talk Issues \#17. Sponsored by Americans Talk Issues Foundation. Boston, MA: Martilla \& Kiley, Inc. December.

Martilla \& Kiley. 1992. U.S./Japan public opinion survey. Sponsored by Detroit Free Press. Boston, MA: Martilla \& Kiley, Inc. January.

Martilla \& Kiley and Market Strategies. 1990. Survey of American voters: attitudes toward the environment. Sponsored by Environment Opinion Study, Inc. Boston, MA: Martilla \& Kiley, Inc. August.

Meridian Corporation. 1990. Virginia consumer needs assessment. Prepared for the Virginia Department of Mines, Minerals and Energy, Division of Energy. Alexandria, VA: Meridian Corp. April. 
McConnell, Beth. 1992. "House Energy Leader Not Impressed with DOE Strategic Reserve Buying Spree." The Energy Report, Vol. 20, No. 9, March 2: p. 163.

Miller, J. D. 1986. The attitudes of science policy, environmental, and utility leaders on U.S. energy issues and fusion. UCRL--15894. Livermore, CA: Lawrence Livermore National Laboratory. November.

Minnesota Energy Office. 1985. Renewable energy credit survey. MN: Minnesota Energy Office. February.

Missouri Department of Conservation, Forestry Division. 1982. Missouri residential fuelwood survey. Jefferson City, MO: Dept. of Conservation. October.

Missouri Department of Conservation, Planning Section. 1988. Four winters' worth of residential fuelwood use. Public Profile 9-88. Jefferson City, MO: Dept. of Conservation. December.

Mitchell, Robert Cameron, Angela Mertig, and Riley E. Dunlap, 1991. "Twenty Years of Environmental Mobilization: Trends Among National Environmental Organizations." Society and Natural. Resources, 4:219-234.

Monogahela Power Company. 1989. Customer opinion survey. OH: Monogahela Power Company. December.

Morrison, Bonnie Maas. 1992. Ninety years of U.S. household energy history: A quantitative update. (Draft), St. Paul: College of Ecology, University of Minnesota.

National Family Opinion Research. 1990. Special consumer survey report. Sponsored by the Conference Board. N.P.: National Family Opinion Research. February.

National Opinion Research Center. 1985. General social survey 1985. Chicago, IL: National Opinion Research Center. July.

National Opinion Research Center. 1987. General social survey 1987. Chicago, LL: National Opinion Research Center. July.

National Opinion Research Center. 1988. General social survey 1988. Chicago, IL: National Opinion Research Center. July.

National Opinion Research Center. 1989. General social survey 1989. Chicago, IL: National Opinion Research Center. July.

National Opinion Research Center. 1991. General social survey 1991. Chicago, IL: National Opinion Research Center. September.

NBC News and Associated Press. 1979. NBC News/Associated Press survey. New York, NY: National Broadcasting Company; Associated Press. February.

NBC News and Associated Press. 1979. NBC News/Associated Press survey. New York, NY: National Broadcasting Company; Associated Press. March. 
NBC News and Associated Press. 1979. NBC News/Associated Press survey. New York, NY: National Broadcasting Company; Associated Press. May.

NBC News and Associated Press. 1979. NBC News/Associated Press survey. New York, NY: National Broadcasting Company; Associated Press. June.

NBC News and Associated Press. 1979. NBC News/Associated Press survey. New York, NY: National Broadcasting Company; Associated Press. July a.

NBC News and Associated Press. 1979. NBC News/Associated Press survey. New York, NY: National Broadcasting Company; Associated Press. July b.

NBC News and Associated Press. 1979. NBC News/Associated Press survey. New York, NY: National Broadcasting Company; Associated Press. September.

NBC News and Associated Press. 1979. NBC News/Associated Press survey. New York, NY: National Broadcasting Company; Associated Press. December.

NBC News and Associated Press. 1980. NBC News/Associated Press survey. New York, NY: National Broadcasting Company; Associated Press. April.

NBC News and Associated Press. 1980. NBC News/Associated Press survey. New York, NY: National Broadcasting Company; Associated Press. May.

NBC News and Associated Press. 1981. NBC News/Associated Press survey. New York, NY: National Broadcasting Company; Associated Press. March.

NBC News and Associated Press. 1981. NBC News/Associated Press survey. New York, NY: National Broadcasting Company; Associated Press. April.

NBC News and Associated Press. 1981. NBC News/Associated Press survey. New York, NY: National Broadcasting Company; Associated Press. June.

NBC News and Associated Press. 1981. NBC News/Associated Press survey. New York, NY: National Broadcasting Company; Associated Press. October.

NBC News and Associated Press. 1981. NBC News/Associated Press survey. New York, NY: National Broadcasting Company; Associated Press. November a.

NBC News and Associated Press. 1981. NBC News/Associated Press survey. New York, NY: National Broadcasting Company; Associated Press. November b.

NBC News and Associated Press. 1982. NBC News/Associated Press survey. New York, NY: National Broadcasting Company; Associated Press. April.

NBC News and Associated Press. 1982. NBC News/Associated Press survey. New York, NY: National Broadcasting Company; Associated Press. November.

NBC News and The Wall Street Journal. 1986. NBC News/Wall Street Journal survey. New York, NY: National Broadcasting Company; The Wall Street Journal. February. 
NBC News and The Wall Street Journal. 1986. NBC News/Wall Street Journal survey. New York, NY: National Broadcasting Company; The Wall Street Journal. April.

NBC News and The Wall Street Journal. 1986. NBC News/Wall Street Journal survey. New York, NY: National Broadcasting Company; The Wall Street Journal. May.

NBC News and The Wall Street Journal. 1986. NBC News/Wall Street Journal survey. New York, NY: National Broadcasting Company; The Wall Street Journal. June.

NBC News and The Wall Street Journal. 1987. NBC News/Wall Street Journal survey. New York, NY: National Broadcasting Company; The Wall Street Journal. April.

NBC News and The Wall Street Journal. 1988. NBC News/Wall Street Journal survey. New York, NY: National Broadcasting Company; The Wall Street Journal. July.

NBC News and The Wall Street Journal. 1989. NBC News/Wall Street Joumal survey. New York, NY: National Broadcasting Company; The Wall Street Journal. April.

Nesbitt, Kevin A., Kenneth S. Kurani, and Mark A. DeLuchi, 1991. Home Recharging and the Household Vehicle Market; A Constraints Analysis. Davis, CA: University of California Institute for Transportation Studies. August.

New Hampshire Governor's Energy Office. 1991. 1990/91 New Hampshire fuel use telephone survey. Concord, NH: Governor's Energy Office. April.

New York Power Authority. 1989. Protecting the environment: energy strategies for the '90s and Beyond. The environment: summary. New York, NY: New York Power Authority, October.

New York Power Authority. 1989. Protecting the environment: energy strategies for the '90s and beyond. Global warming: summary. New York, NY: New York Power Authority, November.

New York Power Authority. 1989. Protecting the environment: energy strategies for the '90s and beyond. Press release only. New York, NY: New York Power Authority, November.

New York Power Authority. 1989. Protecting the environment: energy strategies for the '90s and Beyond. Report on the environment. New York, NY: New York Power Authority.

New York Times. 1990. New York Times survey. New York, NY: The New York Times. April.

New York Times. 1990. New York Times survey. New York, NY: The New York Times. August.

Newsweek. 1990. A special report on petroleum and alternative fuels: derived from 1990 buyer of new cars. New York, NY: Newsweek.

Newsweek. 1991. 1990 buyers of new cars. New York, NY: Newsweek, June.

Northeast Research. 1988. Fall 1987 WHIME workshop program evaluation: executive summary. Sponsored by Maine Office of Energy Resources. Orono, ME: Northeast Research. October. 
Office of Public Service and Research. 1985. Evaluation of Alabama's energy conservation programs; management reviews of state energy programs; statewide telephone survey results. Appendix only. Sponsored by Alabama Department of Economic and Community Affairs, Division of Energy. Auburn, AL: Auburn University. February.

Office of the Consumers' Counsel. 1981. Utility service rate comparison study. Columbus, OH: Office of the Consumers' Counsel. September.

Office of the Consumers' Counsel. 1987. Utility rate survey. Columbus, OH: Office of the Consumers' Counsel. October.

Office of the Consumers' Counsel. 1989. Utility rate survey. Columbus, OH: Office of the Consumers' Counsel. October.

Office of the Consumers' Counsel. 1991. OCC consumer survey 1990. Columbus, OH: Office of the Consumers' Counsel. January.

Olsen, M.E., E. Rosa, R.E. Dunlap, R.E. Howell, and D.A. Sillman, "Public Opinion Versus Governmental Policy on National Energy Issues," Research in Political Sociology, Volume 1, JAI Press, Inc. 1985: 189-210.

Opinion Dynamics Corporation. 1989. Sponsored by Cambridge Energy Research Associates. December.

Opinion Research Corporation. 1979. Public opinion index. Princeton, NJ: Opinion Research Corporation. April.

Opinion Research Corporation. 1979. Public opinion index. Princeton, NJ: Opinion Research Corporation. August.

Opinion Research Corporation. 1979. Public opinion index. Princeton, NJ: Opinion Research Corporation. October.

Opinion Research Corporation. 1980. Public opinion index. Princeton, NJ: Opinion Research Corporation. March.

Opinion Research Corporation. 1980. Public opinion index. Princeton, NJ: Opinion Research Corporation. April.

Opinion Research Corporation. 1980. Public opinion index. Princeton, NJ: Opinion Research Corporation. July.

Opinion Research Corporation. 1980. Public opinion index. Princeton, NJ: Opinion Research Corporation, August.

Opinion Research Corporation. 1980. Public opinion index. Princeton, NJ: Opinion Research Corporation. September.

Opinion Research Corporation. 1980. Public opinion index. Princeton, NJ: Opinion Research Corporation. December. 
Opinion Research Corporation. 1981. Public opinion index. Princeton, NJ: Opinion Research Corporation. February.

Opinion Research Corporation. 1981. Public opinion index. Princeton, NJ: Opinion Research Corporation. April.

Opinion Research Corporation. 1981. Public opinion index. Princeton, NJ: Opinion Research Corporation. May.

Opinion Research Corporation. 1981. Public opinion index. Princeton, NJ: Opinion Research Corporation. August.

Opinion Research Corporation. 1981. Public opinion index. Princeton, NJ: Opinion Research Corporation. September.

Opinion Research Corporation. 1981. Public opinion index. Princeton, NJ: Opinion Research Corporation. October.

Opinion Research Corporation. 1982. Public opinion index. Princeton, NJ: Opinion Research Corporation. January.

Opinion Research Corporation. 1982. Public opinion index. Princeton, NJ: Opinion Research Corporation. March.

Opinion Research Corporation. 1983. Public opinion index. Princeton, NJ: Opinion Research Corporation. January.

Opinion Research Corporation. 1983. Public opinion index. Princeton, NJ: Opinion Research Corporation. February.

Opinion Research Corporation. 1983. Public opinion index. Princeton, NJ: Opinion Research Corporation. July.

Opinion Research Corporation. 1983. Public opinion index. Princeton, NJ: Opinion Research Corporation. September.

Opinion Research Corporation. 1983. Public opinion index. Princeton, NJ: Opinion Research Corporation. October.

Opinion Research Corporation. 1984. Public opinion index. Princeton, NJ: Opinion Research Corporation. March.

Opinion Research Corporation. 1984. Public opinion index. Princeton, NJ: Opinion Research Corporation. May.

Opinion Research Corporation. 1984. Public opinion index. Princeton, NJ: Opinion Research Corporation. November.

Opinion Research Corporation. 1984. Public opinion index. Princeton, NJ: Opinion Research Corporation. December. 
Opinion Research Corporation. 1985. American attitudes toward higher education 1985. Sponsored by Council for Advancement \& Support of Education and New England Board of Higher Education. Princeton, NJ: Opinion Research Corporation. October.

Opinion Research Corporation. 1985. Public opinion index. Princeton, NJ: Opinion Research Corporation. January.

Opinion Research Corporation. 1985. Public opinion index. Princeton, NJ: Opinion Research Corporation. February.

Opinion Research Corporation. 1985. Public opinion index. Princeton, NJ: Opinion Research Corporation. April.

Opinion Research Corporation. 1986. ORC issue watch. Princeton, NJ: Opinion Research Corporation. June.

Opinion Research Corporation. 1987. ORC issue watch. Princeton, NJ: Opinion Research Corporation. June.

Opinion Research Corporation. 1990. ORC survey. Princeton, NJ: Opinion Research Corporation. April.

Opinion Research Corporation. 1990. O.R.C. issue watch. Princeton, NJ: Opinion Research Corporation. June.

Pasternack, Bruce A. 1991. Personal communication to J. Michael Davis, July 23.

Penn \& Schoen Associates. 1985. Tax issues. Sponsored by Committee for a Responsible Tax Policy. New York, NY: Penn \& Schoen Associates. January.

Penn \& Schoen Associates. 1990. Survey on the Iraqi crisis. Sponsored by Texaco, Inc., New York, NY: Penn \& Scheon Associates. August.

Peter D. Hart Research Associates. 1978. American attitudes toward transportation. Sponsored by U.S. Department of Transportation. Washington, D.C.: Peter D. Hart Research Associates. January.

Peter D. Hart Research Associates. 1979. Attitudes toward social security. Sponsored by National Commission on Social Security. Washington, D.C.: Peter D. Hart Research Associates. November.

Peter D. Hart Research Associates. 1991. Attitudes about cities. Sponsored by NBC News and Newsweek. Washington, D.C.: Peter D. Hart Research Associates. July.

Petersen, H. Craig. 1983. 1983 survey analysis of the federal residential conservation and solar tax credits. Sponsored by National Science Foundation and U.S. Department of Agriculture. Logan, UT: Utah State University. December.

Philadelphia Inquirer. "U.N. Study Casts Doubt on Chernobyl Health Toll." May 22, 1991. p. A9.

Power-Robertson \& Company. 1975. Electric vehicle owner survey. Los Angeles: Power-Robertson \& Company. November. 
Power-Robertson \& Company. 1977. Electric vehicle owner survey. Los Angeles: Power-Robertson \& Company. June.

Princeton Survey Research Associates. 1991. Times Mirror News Interest Index May 1991. Sponsored by Times Mirror. Princeton, NJ: Princeton Survey Research Associates. May.

Public Affairs Research Center. 1979. Drug regulation. Sponsored by Pfizer Pharmaceuticals. Houston, TX: University of Houston Public Affairs Research Center. April.

Public Agenda Foundation. 1980. Speaker and the listener. New York, NY: Public Agenda Foundation. January.

Public Policy Analysis Group. 1985. Public policy and economic growth, spring 1985. Sponsored by L.A. Times, N.Y. Stock Exchange, UCLA Graduate School of Management. Rochester, N.Y.: University of Rochester Public Policy Analysis Group. April.

Research \& Forecasts. 1981. American values in the eighties. Sponsored by Connecticut Mutual Life Insurance. New York, NY: Research \& Forecasts. January.

Research \& Forecasts, 1982. Continental Group report: toward responsible growth. Sponsored by Continental Group. New York, NY: Research \& Forecasts. December.

Research and Forecasts. 1990. Mitchum report on stress in the 90s. Sponsored by Mitchum AntiPerspirant and Deodorant. N.P.: Research and Forecasts. March.

Research/Strategy/Management. 1989. Global warming and energy priorities. Sponsored by Union of Concerned Scientists. N.P.: RSM, Inc. November.

Research/Strategy/Management and Greenberg/Lake-The Analysis Group. 1990. Energy, environment, and the public's priorities: a national perspective. Sponsored by Union of Concerned Scientists \& The Alliance to Save Energy. N.P.: RSM, Inc.; Greenberg-Lake-The Analysis Group. December.

Resources for the Future. 1980. Public opinion on environmental issues. Sponsored by Council on Environmental Quality. Washington, D.C.: Resources for the Future. April.

Rhode Island Governor's Office of Housing, Energy and Intergovernmental Relations. 1990. Non-profit institutions survey. Providence, RI: GOHEIR. April.

Ridley, Scott. 1987. The State of the States, 1987. Washington, DC: Fund for Renewable Energy and the Environment (Now Renew America).

Roper Organization. 1979. Roper report 79-2. New York, NY: Roper Organization. March.

Roper Organization. 1979. Roper report 79-3. New York, NY: Roper Organization. April a.

Roper Organization. 1979. Roper report 79-4. New York, NY: Roper Organization. April b.

Roper Organization. 1979. Roper report 79-5. New York, NY: Roper Organization. June.

Roper Organization. 1979. Roper report 79-6. New York, NY: Roper Organization. July. 
Roper Organization. 1979. Roper report 79-7. New York, NY: Roper Organization. August.

Roper Organization. 1979. Roper report 79-8. New York, NY: Roper Organization. October.

Roper Organization. 1979. Roper report 79-9. New York, NY: Roper Organization. November.

Roper Organization. 1979. Roper report 79-10. New York, NY: Roper Organization. December.

Roper Organization. 1979. Third annual tax study. Sponsored by H \& R Block. New York, NY: Roper Organization. May.

Roper Organization. 1979. Virginia Slims American women's poll. Sponsored by Virginia Slims. New York, NY: Roper Organization. October.

Roper Organization. 1980. Roper report 80-I. New York, NY: Roper Organization. January.

Roper Organization. 1980. Roper report 80-2. New York, NY: Roper Organization. February.

Roper Organization. 1980. Roper report 80-3. New York, NY: Roper Organization. April a.

Roper Organization. 1980. Roper report 80-4. New York, NY: Roper Organization. April b.

Roper Organization, 1980. Roper report 80-6. New York, NY: Roper Organization. July.

Roper Organization. 1980. Roper report 80-7. New York, NY: Roper Organization. August.

Roper Organization. 1980. Roper report 80-8. New York, NY: Roper Organization. October.

Roper Organization. 1980. Roper report 80-9. New York, NY: Roper Organization. November.

Roper Organization. 1980. Roper report 80-10. New York, NY: Roper Organization. December.

Roper Organization. 1981. Private initiatives and public values. Sponsored by American Enterprise Institute. New York, NY: Roper Organization. November.

Roper Organization. 1981. Roper report 81-1. New York, NY: Roper Organization. February.

Roper Organization. 1981. Roper report 81-2. New York, NY: Roper Organization. March.

Roper Organization. 1981. Roper report 81-3. New York, NY: Roper Organization. April a.

Roper Organization. 1981. Roper report 81-4. New York, NY: Roper Organization. April b.

Roper Organization. 1981. Roper report 81-5. New York, NY: Roper Organization. May.

Roper Organization. 1981. Roper report 81-6. New York, NY: Roper Organization. July.

Roper Organization, 1981. Roper report 81-7. New York, NY: Roper Organization. August.

Roper Organization. 1981. Roper report 81-8. New York, NY: Roper Organization. October. 
Roper Organization. 1981. Roper report 81-9. New York, NY: Roper Organization. November.

Roper Organization. 1982. Roper report 82-1. New York, NY: Roper Organization. January. Roper Organization. 1982. Roper report 82-3. New York, NY: Roper Organization. April. Roper Organization. 1982. Roper report 82-4. New York, NY: Roper Organization. May. Roper Organization. 1982. Roper report 82-6. New York, NY: Roper Organization. July. Roper Organization. 1982. Roper report 82-7. New York, NY: Roper Organization. August a. Roper Organization. 1982. Roper report 82-7-2. New York, NY: Roper Organization. August b. Roper Organization. 1982. Roper report 82-8. New York, NY: Roper Organization. October. Roper Organization. 1982. Roper report 82-9. New York, NY: Roper Organization. November. Roper Organization. 1982. Roper report 82-10. New York, NY: Roper Organization. December. Roper Organization. 1983. Roper report 83-1. New York, NY: Roper Organization. February. Roper Organization. 1983. Roper report 83-4. New York, NY: Roper Organization. May. Roper Organization. 1983. Roper report 83-5. New York, NY: Roper Organization. June. Roper Organization. 1983. Roper report 83-6. New York, NY: Roper Organization. August. Roper Organization. 1983. Roper report 83-7. New York, NY: Roper Organization. September. Roper Organization. 1983. Roper report 83-8. New York, NY: Roper Organization. October. Roper Organization. 1983. Roper report 83-9. New York, NY: Roper Organization. November. Roper Organization. 1983. Roper report 83-10. New York, NY: Roper Organization. December. Roper Organization. 1984. Roper report 84-1. New York, NY: Roper Organization. February. Roper Organization. 1984. Roper report 84-3. New York, NY: Roper Organization. April. Roper Organization. 1984. Roper report 84-4. New York, NY: Roper Organization. May. Roper Organization. 1984. Roper report 84-5. New York, NY: Roper Organization. June. Roper Organization. 1984. Roper report 84-6. New York, NY: Roper Organization. August. Roper Organization. 1984. Roper report 84-7. New York, NY: Roper Organization. September. Roper Organization. 1984. Roper report 84-8. New York, NY: Roper Organization. October. Roper Organization. 1984. Roper report 84-10. New York, NY: Roper Organization. December. 
Roper Organization. 1985. Roper report 85-1. New York, NY: Roper Organization. February.

Roper Organization. 1985. Roper report 85-2. New York, NY: Roper Organization. March.

Roper Organization. 1985. Roper report 85-4. New York, NY: Roper Organization. June.

Roper Organization. 1985. Roper report 85-5. New York, NY: Roper Organization. July.

Roper Organization. 1985. Roper report 85-6. New York, NY: Roper Organization. September.

Roper Organization. 1985. Roper report 85-7. New York, NY: Roper Organization. October.

Roper Organization. 1985. Roper report 85-8. New York, NY: Roper Organization. November.

Roper Organization. 1985. Roper report 85-9. New York, NY: Roper Organization. December.

Roper Organization. 1986. Roper report 85-10. New York, NY: Roper Organization. February.

Roper Organization. 1986. Roper report 86-1. New York, NY: Roper Organization. March.

Roper Organization. 1986. Roper report 86-3. New York, NY: Roper Organization. June.

Roper Organization. 1986. Roper report 86-4. New York, NY: Roper Organization. July.

Roper Organization. 1986. Roper report 86-5. New York, NY: Roper Organization. July.

Roper Organization. 1986. Roper report 86-6. New York, NY: Roper Organization. August.

Roper Organization. 1986. Roper report 86-7. New York, NY: Roper Organization. September.

Roper Organization. 1986. Roper report 86-8. New York, NY: Roper Organization. October.

Roper Organization. 1986. Roper report 86-9. New York, NY: Roper Organization. November.

Roper Organization. 1987. Roper report 87-1. New York, NY: Roper Organization. March.

Roper Organization. 1987. Roper report 87-2. New York, NY: Roper Organization. April.

Roper Organization. 1987. Roper report 87-3. New York, NY: Roper Organization. May.

Roper Organization. 1987. Roper report 87-4. New York, NY: Roper Organization. June.

Roper Organization. 1987. Roper report 87-5. New York, NY: Roper Organization. July a.

Roper Organization. 1987. Roper report 87-7. New York, NY: Roper Organization. July b.

Roper Organization, 1987. Roper report 87-6. New York, NY: Roper Organization. August.

Roper Organization. 1987. Roper report 87-8. New York, NY: Roper Organization. November.

Roper Organization. 1987. Roper report 87-9. New York, NY: Roper Organization. December. 
Roper Organization. 1989. Roper report 89-1. New York, NY: Roper Organization. February. Roper Organization. 1989. Roper report 89-2. New York, NY: Roper Organization. April. Roper Organization. 1989. Roper report 89-3. New York, NY: Roper Organization. May. Roper Organization. 1989. Roper report 89-4. New York, NY: Roper Organization. June. Roper Organization. 1989. Roper report 89-5. New York, NY: Roper Organization. July. Roper Organization. 1989. Roper report 89-6. New York, NY: Roper Organization. August. Roper Organization. 1989. Roper report 89-7. New York, NY: Roper Organization. October. Roper Organization. 1989. Roper report 89-8. New York, NY: Roper Organization. November. Roper Organization. 1989. Roper report 89-9. New York, NY: Roper Organization. December. Roper Organization. 1990. Roper report 90-1. New York, NY: Roper Organization. February. Roper Organization. 1990. Roper report 90-2. New York, NY: Roper Organization. March. Roper Organization. 1990. Roper report 90-4. New York, NY: Roper Organization. June a. Roper Organization. 1990. Roper report 90-5. New York, NY: Roper Organization. June b. Roper Organization. 1990. Roper report 90-7. New York, NY: Roper Organization. September. Roper Organization. 1990. Roper report 90-8. New York, NY: Roper Organization. October. Roper Organization. 1990. Roper report 90-9. New York, NY: Roper Organization. December. Roper Organization. 1991. Roper report 90-10. New York, NY: Roper Organization. January. Roper Organization. 1991. Roper report 91-1. New York, NY: Roper Organization. February. Roper Organization. 1991. Roper report 91-3. New York, NY: Roper Organization. May. Roper Organization. 1991. Roper report 91-4. New York, NY: Roper Organization. June. Roper Organization. 1991. Roper report 91-5. New York, NY: Roper Organization. July. Roper Organization. 1991. Roper report 91-6. New York, NY: Roper Organization. August. Roper Organization. 1990. Environment: public attitudes and individual behavior. Sponsored by S. C. Johnson and Son, Inc. New York, NY: Roper Organization. July.

Roper Organization. 1991. Sorting out the garbage: America looks at the consumer solid waste issue. Sponsored by Citizens for the Environment. New York, NY: Roper Organization. October. 
Roper Organization. 1986. Roper/U.S. News \& World Report/CNN survey. New York; Atlanta, GA: Roper Organization; U.S. News \& World Report; Cable News Network. May.

Roper Organization. 1986. Roper/U.S. News \& World Report/CNN survey. New York; Atlanta, GA: Roper Organization; U.S. News \& World Report; Cable News Network. December.

RPM Systems, Inc. 1989. 1989 survey of energy and conservation attitudes among Connecticut residents. Sponsored by Connecticut Office of Policy and Management, Energy Division. New Haven, CT: RPM Systems, Inc. April.

Sain Engineering Associates. 1990. Evaluation report of the Institutional Conservation Program. Prepared for the Alabama Department of Economic and Community Affairs, Science, Technology, and Energy Division. Birmingham, AL: Sain Engineering Associates. July.

Saurage-Thibodeaux Research, Inc. 1990. Needs analysis for energy information dissemination program. Sponsored by Louisiana Department of Natural Resources, Energy Division. Baton Rouge, LA: Saurage-Thibodeaux Research, Inc. October.

Schipper, Lee. 1991a. "Lifestyles and Energy: A New Perspective." Prepared for the Office of Technology Assessment, U.S. Congress. Berkeley, CA: Lawrence Berkeley Laboratory. Spring.

Schipper, Lee. 1991b. "Lifestyles and end-use: Energy for work or for pleasure," presented at the Interational Workshop on Social Behavior, Lifestyles and Energy Use for the International Institute of Applied Systems Analysis, Laxenburg, Austria: June 24-26.

Schwartz, Brad Alan. 1986. Ohio Energy Action loan program loan recipient survey: analysis of ECM costs and purchases. Sponsored by Office of Energy Conservation, Ohio Department of Development. Columbus, $\mathrm{OH}$ : Ohio Energy Action Corporation. March.

Sindlinger \& Co. 1979. Government and business. Sponsored by Fiscal Policy Council on Taxes \& Government. Swarthmore, PA: Sindlinger \& Co. July.

Smith, Kathleen, David Loveland. 1988. U.S. Energy Policy: the 1990 s and beyond. Sponsored by the League of Women Voters Educational Fund. Washington, D.C.: League of Women Voters Educational Fund.

Smith, Wil J., Frederick A. Zeller, Joyce A. Coombs and Paul J. Martin. 1987. A longitudinal study of the energy attitudes and behavior of members of West Virginia's households: 1987 survey results. Final Report VII. Sponsored by West Virginia Governor's Office of Community and Industrial Development, Fuel and Energy Office. Morgantown, WV: Applied Research, Evaluation and Planning, West Virginia University Extension Service, Center for Extension and Continuing Education. September.

Solar Industry Journal. 1990. "State Tax Credits and Oil Overcharge Funds Support Solar Industry: A State by Review of Projects and Programs." pp. 15-17.

Sperling, Daniel, Winardi Setiawan, and David Hungerford. 1991. The target market for methanol fuel. Davis, CA: Institute of Transportation Studies, University of California/Davis. August. 
Strategic Consumer Research. 1989. Energy consumption patterns study of Ohio residential customers. Sponsored by the Public Utilities Commission of Ohio. Cleveland, $\mathrm{OH}$ : Mid-America Consulting Group.

U.S. Congress, Office of Technology Assessment. 1992. Building energy efficiency, OTA-E-518, Washington, D.C.: U.S. Government Printing Office. May

U.S. Department of Commerce, Bureau of the Census. 1991. Statistical Abstract of the United States: 1991. (111th edition) p. 579. Washington, D.C.

U.S. Department of Energy. 1987. Residential and commercial conservation program strategic plan. Washington, D.C.: Residential and Commercial Conservation Program, Energy Management Programs Division, Office of State and Local Assistance Programs.

U.S. Department of Energy. 1991/1992. National energy strategy: powerful ideas for America. Washington, D.C.

U.S. Energy Information Administration. 1991. Annual Energy Review 1990. Washington, D.C.: U.S. Department of Energy.

U.S. Energy Information Administration, 1992. Annual Energy Review 1991. Washington, D.C.: U.S. Department of Energy.

U.S. Environmental Protection Agency, Office of Solid Waste and Emergency Response. 1990. Characterization of Municipal Solid Waste in the United States: 1990 update. 530-SW-90-042, Washington, DC.

Vories, Rebecca and Dennis L. White. 1990. "Life After RCS." Home Energy, 7:24-28.

Wall Street Journal. "Split Personality: Americans Are Loath to Curb Energy Use Despite War Concerns." January 30, 1991.

Wall Street Journal. "Technology \& Health: Child Cancers Found to Rise Near Chernobyl." September 3, 1992. p. B8.

The Washington Post. 1988. Washington Post survey. Washington, D.C.: The Washington Post. June.

The Washington Post. 1990. Washington Post survey. Washington, D.C.: The Washington Post. March.

The Washington Post. 1991. Washington Post survey. Washington, D.C.: The Washington Post. March.

Williams, Susan. 1991. Trash to cash. New business opportunities in the post-consumer waste stream. Washington, D.C.: Investor Responsibility Research Center.

The Wirthlin Group. 1990. Alternative fuels survey: American attitudes in non-attainment cities. McLean, VA: The Wirthlin Group. April.

Yankelovich/Clancy/Shulman. 1986. Time/Yankelovich, Clancy, Shulman survey. New York, NY: TimeWarner, Inc.; Yankelovich/Clancy/Shulman. May. 
Yankelovich/Clancy/Shulman. 1987. Time/Yankelovich, Clancy, Shulman survey. New York, NY: TimeWarner, Inc.; Yankelovich/Clancy/Shulman. February.

Yankelovich/Clancy/Shulman. 1988. Time/Yankelovich, Clancy, Shulman survey. New York, NY: TimeWarner, Inc.; Yankelovich/Clancy/Shulman. February.

Yankelovich/Clancy/Shulman. 1989. Time/CNN/Yankelovich, Clancy, Shulman survey. New York; Atlanta, GA: Time-Warner, Inc.; Cable News Network; Yankelovich/Clancy/Shulman. January.

Yankelovich/Clancy/Shulman. 1989. Time/CNN/Yankelovich, Clancy, Shulman survey. New York; Atlanta, GA: Time-Warner, Inc.; Cable News Network; Yankelovich/Clancy/Shulman. April.

Yankelovich/Clancy/Shulman. 1989. Time/CNN/Yankelovich, Clancy, Shulman survey. New York; Atlanta, GA: Time-Warner, Inc.; Cable News Network; Yankelovich/Clancy/Shulman. May.

Yankelovich/Clancy/Shulman. 1990. Time/CNN/Yankelovich, Clancy, Shulman survey. New York; Atlanta, GA: Time-Warner, Inc.; Cable News Network; Yankelovich/Clancy/Shulman. March.

Yankelovich/Clancy/Shulman. 1990. Time/CNN/Yankelovich, Clancy, Shulman survey. New York; Atlanta, GA: Time-Warner, Inc.; Cable News Network; Yankelovich/Clancy/Shulman. August.

Yankelovich/Clancy/Shulman. 1990. Time/CNN/Yankelovich, Clancy, Shulman survey. New York; Atlanta, GA: Time-Warner, Inc.; Cable News Network; Yankelovich/Clancy/Shulman. September 10.

Yankelovich/Clancy/Shulman. 1990. Time/CNN/Yankelovich, Clancy, Shulman survey. New York; Atlanta, GA: Time-Warner, Inc.; Cable News Network; Yankelovich/Clancy/Shulman. September 20.

Yankelovich/Clancy/Shulman. 1990. Time/CNN/Yankelovich, Clancy, Shulman survey. New York; Atlanta, GA: Time-Warner, Inc;; Cable News Network; Yankelovich/Clancy/Shulman. November 21.

Yankelovich/Clancy/Shulman. 1990. Time/CNN/Yankelovich, Clancy, Shulman survey. New York; Atlanta, GA: Time-Warner, Inc.; Cable News Network; Yankelovich/Clancy/Shulman. November 28 .

Yankelovich/Clancy/Shulman. 1990. Time/CNN/Yankelovich, Clancy, Shulman survey. New York; Atlanta, GA: Time-Warner, Inc.; Cable News Network; Yankelovich/Clancy/Shulman. December

Yankelovich/Clancy/Shulman. 1991. Time/CNN/Yankelovich, Clancy, Shulman survey. New York; Atlanta, GA: Time-Warner, Inc; Cable News Network; Yankelovich/Clancy/Shulman. January a.

Yankelovich/Clancy/Shulman. 1991. Time/CNN/Yankelovich, Clancy, Shulman survey. New York; Atlanta, GA: Time-Warner, Inc.; Cable News Network; Yankelovich/Clancy/Shulman. January b.

Yankelovich/Clancy/Shulman. 1991. Time/CNN/Yankelovich, Clancy, Shulman survey. New York; Atlanta, GA: Time-Warner, Inc.; Cable News Network; Yankelovich/Clancy/Shulman. April. 
Yankelovich/Clancy/Shulman. 1991. Time/CNN/Yankelovich/Clancy/Shulman survey. New York; Atlanta, GA: Time-Warner, Inc.; Cable News Network; Yankelovich/Clancy/Shulman. May.

Yankelovich/Clancy/Shulman. 1992. Time/CNN/Yankelovich/Clancy/Shulman survey. New York, NY; Atlanta, GA: Time-Warner, Inc.; Cable News Network; Yankelovich/Clancy/Shulman. January.

Yankelovich, Skelly and White. 1979. Time/Yankelovich, Skelly and White survey. New York, NY: Time-Warner, Inc.; Yankelovich, Skelly and White. April.

Yankelovich, Skelly and White. 1979. Monitoring attitudes of the public 1979. Sponsored by American Council of Life Insurance. New York, NY: Yankelovich, Skelly and White. June.

Yankelovich, Skelly and White. 1979. Time/Yankelovich, Skelly and White survey. New York, NY: Time-Warner, Inc.; Yankelovich, Skelly and White. August.

Yankelovich, Skelly and White. 1979. Time/Yankelovich, Skelly and White survey. New York, NY: Time-Warner, Inc.; Yankelovich, Skelly and White. October.

Yankelovich, Skelly and White. 1979. Time/Yankelovich, Skelly and White survey. New York, NY: Time-Warner, Inc; Yankelovich, Skelly and White. December.

Yankelovich, Skelly and White. 1980. Time/Yankelovich, Skelly and White survey. New York, NY: Time-Warner, Inc.; Yankelovich, Skelly and White. January.

Yankelovich, Skelly and White. 1980. TimerYankelovich, Skelly and White survey. New York, NY: Time-Warner, Inc.; Yankelovich, Skelly and White. March a.

Yankelovich, Skelly and White. 1980. Time/Yankelovich, Skelly and White survey. New York, NY: Time-Warner, Inc.; Yankelovich, Skelly and White. March b.

Yankelovich, Skelly and White. 1980. Monitoring attitudes of the public 1980. Sponsored by American Council of Life Insurance. New York, NY: Yankelovich, Skelly and White. May.

Yankelovich, Skelly and White. 1980. Time/Yankelovich, Skelly and White survey. New York, NY: Time-Warner, Inc.; Yankelovich, Skelly and White. May.

Yankelovich, Skelly and White. 1980. Time/Yankelovich, Skelly and White survey. New York, NY: Time-Warner, Inc.; Yankelovich, Skelly and White. August.

Yankelovich, Skelly and White. 1980. Time/Yankelovich, Skelly and White survey. New York, NY: Time-Warner, Inc.; Yankelovich, Skelly and White. October.

Yankelovich, Skelly and White. 1981. Anti-Semitism in the United States. Sponsored by American Jewish Committee. New York, NY: Yankelovich, Skelly and White. July.

Yankelovich, Skelly and White. 1981. Time/Yankelovich, Skelly and White survey. New York, NY: Time-Warner, Inc.; Yankelovich, Skelly and White. January.

Yankelovich, Skelly and White. 1983. Time/Yankelovich, Skelly and White survey. New York, NY: Time-Warner, Inc.; Yankelovich, Skelly and White. June. 
Yankelovich, Skelly and White. 1983. Time/Yankelovich, Skelly and White survey. New York, NY: Time-Warner, Inc.; Yankelovich, Skelly and White. September.

Yankelovich, Skelly and White. 1984. Time/Yankelovich, Skelly and White survey. New York, NY: Time-Warner, Inc.; Yankelovich, Skelly and White. February.

Yankelovich, Skelly and White. 1984. Time/Yankelovich, Skelly and White survey. New York, NY: Time-Warner, Inc.; Yankelovich, Skelly and White. December.

Yankelovich, Skelly and White. 1985. Time/Yankelovich, Skelly and White survey. New York, NY: Time-Warner, Inc.; Yankelovich, Skelly and White. September. 
Appendixes 


\title{
Appendix A
}

\author{
Methodology
}

\section{Introduction}

Literature search. This updated review of public opinion on energy was planned to cover the 12 years since the publication of the first literature review in 1979. Researchers found a great deal more data than were available for the earlier review, necessitating some differences in literature search strategy. On-line search capabilities became available since the last review, simplifying the basic procedure. Researchers took several steps to approach the task of organizing and presenting the data.

- A basic group of general national adult studies was selected for comparison, and a secondary group of regional general public and regional special group studies was added to the data base during the project. Coders assigned each study an arbitrary identification number, which serves as its reference number in this report.

- $\quad$ Researchers developed a comprehensive set of categories by which to sort findings similar in content but not identical in wording. They developed these categories from a similar set used for the 1979 report, but made modifications necessitated by changing trends in public opinion and recent historical developments. As the project proceeded, it was necessary to expand some of these categories and create or rearrange others.

- Individual items from each of the surveys used were photocopied, sorted, and labeled by categories. Where patterns or trends were identified, items were grouped separately to facilitate description of the patterns in tables and narrative reviews.

Described in this chapter are the search procedures used, the resulting surveys, survey funding sources, a discussion of the categories used to sort the data, and the coding procedures used for each item.

Coding procedure. Researchers developed a set of categories to sort items by content. Taken as a whole, these categories represent a theoretical approach to public preferences and actions on energy questions. Each of the survey items was sorted separately by hand and labeled by category.

Trends of findings were located by physically examining individual items in each category and looking for identically worded questions repeated by the same pollster over months or years. Such items were clipped together and, subsequently, described separately in tables. Research gaps were noted where expected categories failed to contain any data or contained only a few items.

\section{Search Procedures}

National-level public opinion data. In 1990, the Roper Organization developed an on-line data base, Public Opinion On-Line, to include data from public opinion polls back to 1940. This data base is indexed by search descriptors and is available through the DIALOG on-line data base service. The first step, therefore, was to request the technical library staff at the National Renewable Energy Laboratory to search on-line for survey items. The search dates were 1979 through January 1992. All of the items resulting from these searches came from national probability samples of the adult population rather than from regional or special samples. Some national surveys oversampled special groups. 
The keywords used in these searches were as follows:

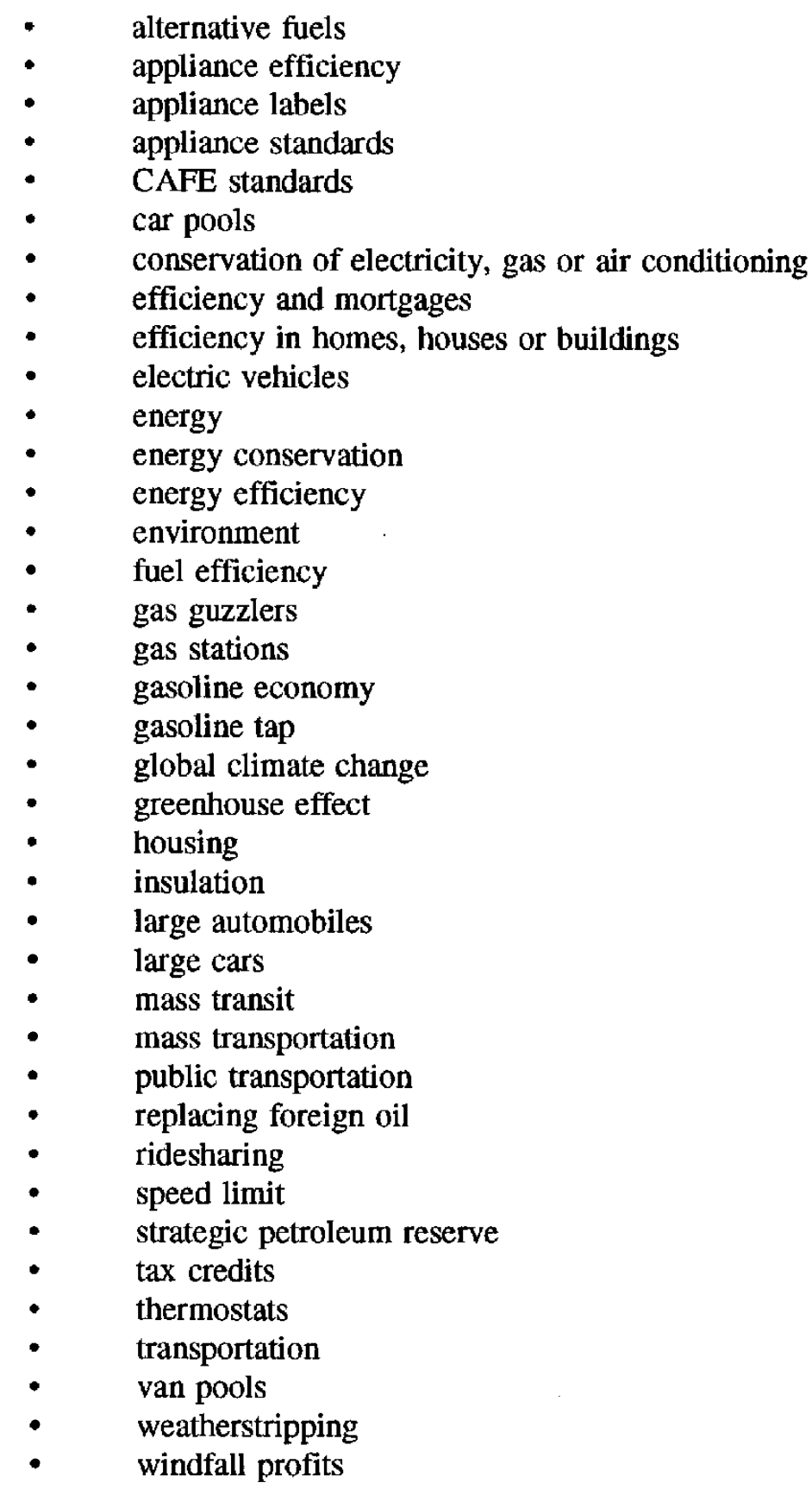

The DIALOG data base does not contain complete information on the most recent surveys, say, those completed within 5 years of any given on-line search. The reason is that polling organizations wish to continue marketing those results. When researchers discovered this, they performed bibliographic searches to locate other national poll data and visited federal libraries to obtain the more recent data. In this manner, the national data set included was brought up through 1991; a few items from early 1992 were also included.

Other public opinion data. Researchers collected data three other ways: (1) accessing data in fede4ral government libraries, (2) searching the literature, and (3) contacting state energy offices. The libraries of several federal government agencies in Washington, D.C., were visited to locate their collections of recent 
poll data. Journal literature was identified by searching the DIALOG Information Retrieval for records containing information on public opinion surveys or attitudes about energy. Report literature was identified by searching the Energy Science and Technology data base and the NTIS data base on the DIALOG Information Retrieval Service. The keywords listed earlier were used in this search.

Researchers contacted energy offices in each of the 50 states and asked them to identify and supply a copy of any studies done for their states or populations within their areas over the past decade. Other studies were collected by contacting local leaders in the fields of transportation and alternative fuels. These contacts produced 43 studies from 20 states, 4 of them national in scope.

\section{Surveys Included in This Report}

Definition of survey. A survey is a systematic collection of data from a specified population using a structured data collection instrument (interview schedule or questionnaire) at a specific time. Surveys are therefore identified by data collection efforts rather than by final reports or summaries of more than one study. Each data collection period represents a separate survey. The criterion for inclusion of a survey in the report was a sampling technique designed to provide results representative of the entire population studied. Each survey included contained items relevant to energy, but it may not have been limited to energy topics.

Survey numbering. Each survey was assigned an arbitrary number as part of a coding process. Appendix B contains a list of the surveys and includes survey number, author or polling organization, population sampled, sample size, and date of data collection. Because the citation system in this report uses these numbers, the reader should refer to this list and subsequently to the bibliography to locate references.

Inclusive dates of surveys. All surveys in this report were conducted between October 1978 and February 1992. As discussed in the section on descriptive survey findings, the location of a survey sometimes affected its results. Thus the survey findings are presented in their context of time and space for interpretive purposes.

\section{Survey Funding Sources}

Possibility of bias. Public opinion surveys are expensive to conduct. Knowing survey sponsors is useful in assessing whether bias may be present through agendas of sponsoring organizations. Bias may be seen in the kinds of questions asked and omitted, response categories given in forced-choice items, arrangement of items in the survey or within question series, and item wording. Ordinarily, bias is not purposefully introduced by researchers, but it can creep in unintentionally. Certain important questions may never be asked because no one is interested in paying to have them explored, or questions may be asked for a more narrow purpose than gaining a broad understanding of public opinion (which is the purpose of this report).

Sponsors for surveys included in this report. The types of funding sources for the surveys in this report are listed in Table A-1. Professional polling organizations sponsored $42 \%$ of the surveys included, either solely or in cooperation with private industry or media. These organizations are maintained through user subscription and special contracts to conduct surveys by government and private industry. They are more influenced, therefore, by what government and industry want to know than by what researchers need or what the general public would like to know about itself. State and local agencies and universities financed $10.5 \%$ of the surveys, the federal government paid for 11 studies $(2.5 \%)$, and environmental or energy conservation groups sponsored seven studies. The remainder were funded by private sources $(43.6 \%)$, including utilities and news agencies. 
Table A-1. Funding Sources for Public Opinion Polls

\begin{tabular}{lrc}
\hline \multicolumn{1}{c}{ Funding Organization } & $\begin{array}{c}\text { Number of }_{\text {Studies }^{\mathrm{a}}} \\
\text { Solling organizations }^{\mathrm{b}}\end{array}$ & $\begin{array}{c}\% \text { of } \\
\text { Surveys }\end{array}$ \\
Private organizations & 224 & 42.0 \\
State/local agencies and universities & 232 & 43.6 \\
Federal agencies & 58 & 10.5 \\
Environmental/energy agencies & 11 & 2.5 \\
$\quad$ Total & 7 & 1.4 \\
\hline
\end{tabular}

${ }^{\text {a }}$ Sponsorship was analyzed for 532 of the nearly 600 studies included in the report.

${ }^{b}$ Sponsorship of omnibus types of surveys usually comes from a number of organizations; items of interest to these sponsoring organizations are included in the surveys.

\section{Categories}

A set of categories was employed to organize the survey findings.

FIRST LEVEL: Include any item that contains any of the following topics as one of its elements:

a. Definitions of the energy situation (e.g., energy problem severity, how important is it [salience-often asked in conjunction with other national problems], how caused, perceived impacts, prices, etc.)

b. Preferences for energy supply alternatives (i.e., comparisons among supply/demand sources of energy, such as nuclear power, coal, oil, natural gas, solar, and energy conservation)

d. Energy conservation/energy efficiency

e. Renewable energy technologies

f. Policy preferences (e.g., rationing, taxes, corporate average fuel efficiency (CAFE) standards, energy-efficient mortgages, etc.)

g. Electricity/utilities

h. Environmental trade-offs

i. Environmental material that does not fall into category (h) 
SECOND LEVEL: Divide categories (a), (d), and (f) into the following subcategories:

Definitions

1. Perceived seriousness of the energy situation

2. Energy crisis: real or contrived?

3. Attribution of causes and responsibility

4. Salience

5. Perceived impacts of the energy problem

6. Perceived future energy situation

7. Organizational roles

8. Policies under President Carter

9. Policies under President Reagan

10. Policies under President Bush

Energy conservation/efficiency

1. Transportation

2. Buildings

3. Industry

4. Information

Policy preferences

1. Transportation

2. Buildings

3. Industry

4. Policies under President Carter

5. Policies under President Reagan

6. Information

7. Policies under President Bush

THIRD LEVEL: Take the following categories:

a. Coal

b. Energy conservation/efficiency

c. Natural gas

d. Nuclear energy

e. Oil

f. Renewable energy technologies

Sort them as follows:

1. Perceived effectiveness of the alternative

2. Perceived relative advantage of the alternative

3. Perceived risk of using the alternative

4. Knowledgeability

5. Information sources

6. Behavioral intention and action

7. Evaluation (favorability/opposition)

8. Perceived and preferred decision making (who should decide, how should decisions be made) 
Subsequently, data that had been organized into these categories was sorted again to reflect the general divisions of transportation, buildings, and utilities. Categories for waste management and recycling were also added, while the industrial category was deleted owing to lack of data.

\section{Coding Procedures}

Survey data were available in one of two forms: single item sheets resulting from the DIALOG search, or item-by-item presentations accompanied by an interpretive text for those studies sent directly to the project.

Bibliographic coding procedures. The coder assigned a number to each survey represented and produced a numerical list of surveys. For each survey, the list named the author or pollster, the sponsor or funding source, population sampled, date of data collection, and sample size. A separate list showed the survey release dates as well as the item numbers and the DIALOG data base identification number for each survey. This enabled the coder to cross-check the lists with the actual items to avoid any possibility of omitting a survey or mislabeling an item. When additional studies were received, they were numbered and added to the list.

Data sorting procedures. The coder photocopied pages of survey data and sorted and labeled each page of data, using the categories described above. At the end of the sorting process, which took several months, the entire body of data was sorted into usable categories, ready to be analyzed. As the analysis began to take account of the available data, re-sorting into the categories found in the report took place. 


\section{Appendix B}

Public Opinion Surveys Included in the Study

\begin{tabular}{|c|c|c|c|c|c|}
\hline $\begin{array}{l}\text { Survey } \\
\text { Number }\end{array}$ & $\begin{array}{l}\text { Author or } \\
\text { Polling Organization }\end{array}$ & $\begin{array}{l}\text { Population or } \\
\text { Area Sampled }\end{array}$ & $\begin{array}{l}\text { Ending Date of } \\
\text { Data Collection }\end{array}$ & $\begin{array}{l}\text { Sample } \\
\text { Size }\end{array}$ & $\begin{array}{l}\text { Release } \\
\text { Date }\end{array}$ \\
\hline 1001 & $\begin{array}{l}\text { Yankelovich, Clancy, Shulman } \\
\text { (Sponsor: Time, CNN) }\end{array}$ & National adult & $1 / 10 / 91$ & 1000 & $1 / 14 / 91$ \\
\hline 1002 & $\begin{array}{l}\text { Hart \& Teeter Research Companies } \\
\text { (Sponsor: NBC News, The Wall Street Journal) }\end{array}$ & Registered voters & $1 / 23 / 91$ & 808 & $1 / 23 / 91$ \\
\hline 1003 & $\begin{array}{l}\text { Gordon S. Black Corporation } \\
\text { (Sponsor: U.S.A. Today) }\end{array}$ & National adult & $11 / 12 / 90$ & 615 & $11 / 90$ \\
\hline 1004 & $\begin{array}{l}\text { Gordon S. Black Corporation } \\
\text { (Sponsor: U.S.A. Today) }\end{array}$ & National adult & $8 / 8 / 90$ & 610 & $8 / 90$ \\
\hline 1005 & $\begin{array}{l}\text { Gordon S. Black Corporation } \\
\text { (Sponsor: U.S.A. Today) }\end{array}$ & National adult & $12 / 30 / 90$ & 1008 & $12 / 90$ \\
\hline 1006 & $\begin{array}{l}\text { Gallup Organization } \\
\text { (Sponsor: Newsweek) }\end{array}$ & National adult & $1 / 11 / 91$ & 751 & $1 / 14 / 90$ \\
\hline 1007 & Gallup Organization & National adult & $12 / 2 / 90$ & 1013 & $12 / 90$ \\
\hline 1008 & CBS News/The New York Times & National adult & $1 / 20 / 91$ & 867 & $1 / 21 / 91$ \\
\hline 1009 & CBS News/The New York Times & National adult & $1 / 17 / 91$ & 544 & $1 / 18 / 91$ \\
\hline 1010 & CBS News/The New York Times & National adult & $1 / 17 / 91$ & 412 & $1 / 17 / 91$ \\
\hline 1011 & CBS News/The New York Times & National adult & $1 / 13 / 91$ & 1512 & $1 / 14 / 91$ \\
\hline 1012 & CBS News & National adult & $10 / 7 / 90$ & 775 & $10 / 8 / 90$ \\
\hline 1013 & CBS News & National adult & $1 / 28 / 91$ & 1173 & $1 / 29 / 91$ \\
\hline 1014 & Associated Press & National adult & $1 / 8 / 91$ & 1004 & $1 / 9 / 91$ \\
\hline 1015 & $\mathrm{ABC}$ News/The Washington Post & National adult & $1 / 20 / 91$ & 532 & $1 / 21 / 91$ \\
\hline 1016 & $\begin{array}{l}\text { Yankelovich, Clancy, Shulman } \\
\text { (Sponsor: Time, CNN) }\end{array}$ & National adult & $11 / 28 / 90$ & 1000 & $12 / 17 / 90$ \\
\hline 1017 & $\begin{array}{l}\text { Yankelovich/Clancy/Shulman } \\
\text { (Sponsor: Time, CNN) }\end{array}$ & National adult & $11 / 14 / 90$ & 500 & $11 / 28 / 90$ \\
\hline 1018 & $\begin{array}{l}\text { Hart \& Teeter Research Companies } \\
\text { (Sponsor: NBC News, The Wall Street Journal) }\end{array}$ & Registered voters & $12 / 11 / 90$ & 1002 & $12 / 14 / 90$ \\
\hline 1019 & The Los Angeles Times & National adult & $12 / 12 / 90$ & 2205 & $12 / 14 / 90$ \\
\hline 1020 & Louis Harris \& Associates & National adult & $11 / 13 / 90$ & 1255 & $12 / 16 / 90$ \\
\hline
\end{tabular}


Public Opinion Surveys Included in the Study

\begin{tabular}{|c|c|c|c|c|c|}
\hline $\begin{array}{l}\text { Survey } \\
\text { Number }\end{array}$ & $\begin{array}{l}\text { Author or } \\
\text { Polling Organization }\end{array}$ & $\begin{array}{l}\text { Population or } \\
\text { Area Sampled }\end{array}$ & $\begin{array}{l}\text { Ending Date of } \\
\text { Data Collection }\end{array}$ & $\begin{array}{l}\text { Sample } \\
\text { Size }\end{array}$ & $\begin{array}{l}\text { Release } \\
\text { Date }\end{array}$ \\
\hline 1021 & Louis Harris \& Associates & National adult & $11 / 13 / 90$ & 1255 & $12 / 2 / 90$ \\
\hline 1022 & $\begin{array}{l}\text { Gallup Organization } \\
\text { (Sponsor: Newsweek) }\end{array}$ & National adult & $12 / 7 / 90$ & 769 & $12 / 10 / 90$ \\
\hline 1023 & Gallup Organization & National adult & $11 / 11 / 90$ & 1008 & $11 / 90$ \\
\hline 1024 & CBS News/The New York Times & National adult & $10 / 10 / 90$ & 960 & $10 / 13 / 90$ \\
\hline 1025 & $\begin{array}{l}\text { Research/Strategy/Management and } \\
\text { Greenberg/Lake-The Analysis Group } \\
\text { (Sponsor: Union of Concerned Scientists } \\
\text { \& The Alliance to Save Energy) }\end{array}$ & Registered voters & $12 / 11 / 90$ & 1200 & $12 / 90$ \\
\hline 1026 & ABC News/The Washington Post & National adult & $12 / 2 / 90$ & 758 & $12 / 3 / 90$ \\
\hline 1027 & $\begin{array}{l}\text { Yankelovich, Clancy, Shulman } \\
\text { (Sponsor: Time, CNN) }\end{array}$ & National adult & $11 / 14 / 90$ & 500 & $11 / 21 / 90$ \\
\hline 1028 & Maritz Marketing Research & National adult & $10 / 24 / 90$ & 1000 & $11 / 9 / 90$ \\
\hline 1029 & $\begin{array}{l}\text { Gallup Organization } \\
\text { (Sponsor: Newsweek) }\end{array}$ & National adult & $11 / 16 / 90$ & 754 & $11 / 90$ \\
\hline 1030 & CBS News/The New York Times & National adult & $11 / 15 / 90$ & 1370 & $11 / 19 / 90$ \\
\hline 1031 & CBS News/The New York Times & National adult & $8 / 19 / 90$ & 1422 & $8 / 21 / 90$ \\
\hline 1032 & $\begin{array}{l}\text { Yankelovich, Clancy, Shulman } \\
\text { (Sponsor: Time, CNN) }\end{array}$ & National adult & $9 / 13 / 90$ & 500 & $9 / 20 / 90$ \\
\hline 1033 & The New York Times & National adult & $4 / 22 / 90$ & 1462 & $4 / 90$ \\
\hline 1034 & $\begin{array}{l}\text { Hart \& Teeter Research Companies } \\
((\text { Sponsor: NBC News, The Wall Street Journal) }\end{array}$ & Registered voters & $10 / 31 / 90$ & 507 & $10 / 90$ \\
\hline 1035 & $\begin{array}{l}\text { Market Strategies } \\
\text { (Sponsor: Americans Talk Security) }\end{array}$ & National adult & $9 / 26 / 90$ & 1000 & $10 / 1 / 90$ \\
\hline 1036 & $\begin{array}{l}\text { Gallup Organization } \\
\text { (Sponsor: Newsweek) }\end{array}$ & National adult & $10 / 19 / 90$ & 755 & $10 / 90$ \\
\hline 1037 & Gallup Organization & National adult & $10 / 4 / 90$ & 1010 & $10 / 90$ \\
\hline 1038 & Gallup Organization & National adult & $9 / 11 / 90$ & 1031 & $9 / 90$ \\
\hline 1039 & Gallup Organization & National adult & $9 / 30 / 90$ & 1000 & $9 / 90$ \\
\hline 1040 & Gallup Organization & National adult & $8 / 4 / 90$ & 810 & $8 / 90$ \\
\hline
\end{tabular}


Public Opinion Surveys Included in the Study

\begin{tabular}{|c|c|c|c|c|c|}
\hline $\begin{array}{l}\text { Survey } \\
\text { Number }\end{array}$ & $\begin{array}{l}\text { Author or } \\
\text { Polling Organization }\end{array}$ & $\begin{array}{l}\text { Population or } \\
\text { Area Sampled }\end{array}$ & $\begin{array}{l}\text { Ending Date of } \\
\text { Data Collection }\end{array}$ & $\begin{array}{l}\text { Sample } \\
\text { Size }\end{array}$ & $\begin{array}{l}\text { Release } \\
\text { Date }\end{array}$ \\
\hline 1041 & ABC News/The Washington Post & National adult & $9 / 9 / 90$ & 1011 & $9 / 90$ \\
\hline 1042 & $\mathrm{ABC}$ News/The Washington Post & National adult & $8 / 8 / 90$ & 769 & $8 / 90$ \\
\hline 1043 & $\mathrm{ABC}$ News/The Washington Post & National adult & $7 / 23 / 90$ & 1500 & $7 / 90$ \\
\hline 1044 & $\begin{array}{l}\text { Yankelovich, Clancy, Shulman } \\
\text { (Sponsor: Time, CNN) }\end{array}$ & National adult & $5 / 4 / 89$ & 504 & $5 / 89$ \\
\hline 1045 & $\begin{array}{l}\text { Yankelovich, Clancy, Shulman } \\
\text { (Sponsor: Time, CNN) }\end{array}$ & National adult & $4 / 5 / 89$ & 1012 & $4 / 20 / 89$ \\
\hline 1046 & $\begin{array}{l}\text { Yankelovich, Clancy, Shulman } \\
\text { (Sponsor: Time) }\end{array}$ & National adult & $2 / 18 / 88$ & 1824 & $2 / 18 / 88$ \\
\hline 1047 & $\begin{array}{l}\text { Yankelovich, Clancy, Shulman } \\
\text { (Sponsor: Time) }\end{array}$ & National adult & $5 / 22 / 86$ & 1013 & $5 / 22 / 86$ \\
\hline 1048 & $\begin{array}{l}\text { Yankelovich, Clancy, Shulman } \\
\text { (Sponsor: Time, CNN) }\end{array}$ & National adult & $8 / 23 / 90$ & 500 & $9 / 10 / 90$ \\
\hline 1049 & $\begin{array}{l}\text { Yankelovich, Clancy, Shulman } \\
\text { (Sponsor: Time, CNN) }\end{array}$ & National adult & $8 / 9 / 90$ & 500 & $8 / 14 / 90$ \\
\hline 1050 & $\begin{array}{l}\text { Yankelovich, Clancy, Shulman } \\
\text { (Sponsor: Time, CNN) }\end{array}$ & National adult & $3 / 14 / 90$ & 500 & $3 / 19 / 90$ \\
\hline 1051 & $\begin{array}{l}\text { Yankelovich, Skelly, White } \\
\text { (Sponsor: Time) }\end{array}$ & Registered voters & 9/19/85 & 1014 & $9 / 19 / 85$ \\
\hline 1052 & $\begin{array}{l}\text { Yankelovich, Skelly, White } \\
\text { (Sponsor: Time) }\end{array}$ & Registered voters & $12 / 12 / 84$ & 1024 & $12 / 12 / 84$ \\
\hline 1053 & $\begin{array}{l}\text { Yankelovich, Skelly, White } \\
\text { (Sponsor: Time) }\end{array}$ & Registered voters & $2 / 2 / 84$ & 1021 & $2 / 2 / 84$ \\
\hline 1054 & $\begin{array}{l}\text { Yankelovich, Skelly, White } \\
\text { (Sponsor: Time) }\end{array}$ & Registered voters & $6 / 29 / 83$ & 1007 & $6 / 83$ \\
\hline 1055 & $\begin{array}{l}\text { Yankelovich, Skelly, White } \\
\text { (Sponsor: Time) }\end{array}$ & Registered voters & $1 / 7 / 81$ & 1219 & $1 / 7 / 81$ \\
\hline 1056 & $\begin{array}{l}\text { Yankelovich, Skelly, White (Sponsor: } \\
\text { American Jewish Committee) }\end{array}$ & $\begin{array}{l}\text { National adult + } \\
\text { oversamples of Jews } \\
\text { and blacks }\end{array}$ & $3 / 6 / 81$ & 1215 & $7 / 81$ \\
\hline 1057 & $\begin{array}{l}\text { Yankelovich, Skelly, White } \\
\text { (Sponsor: Time) }\end{array}$ & Registered voters & $10 / 16 / 80$ & 1622 & $10 / 16 / 80$ \\
\hline
\end{tabular}


Public Opinion Surveys Included in the Study

\begin{tabular}{|c|c|c|c|c|c|}
\hline $\begin{array}{l}\text { Survey } \\
\text { Number }\end{array}$ & $\begin{array}{l}\text { Author or } \\
\text { Polling Organization }\end{array}$ & $\begin{array}{l}\text { Population or } \\
\text { Area Sampled }\end{array}$ & $\begin{array}{l}\text { Ending Date of } \\
\text { Data Collection }\end{array}$ & $\begin{array}{l}\text { Sample } \\
\text { Size }\end{array}$ & $\begin{array}{l}\text { Release } \\
\text { Date }\end{array}$ \\
\hline 1058 & $\begin{array}{l}\text { Yankelovich, Skelly, White } \\
\text { (Sponsor: Time) }\end{array}$ & Registered voters & $8 / 28 / 80$ & 1644 & $8 / 28 / 80$ \\
\hline 1059 & $\begin{array}{l}\text { Yankelovich, Skelly, White } \\
\text { (Sponsor: Time) }\end{array}$ & Registered voters & $5 / 16 / 80$ & 1221 & $5 / 16 / 80$ \\
\hline 1060 & $\begin{array}{l}\text { Yankelovich, Skelly, White } \\
\text { (Sponsor: Time) }\end{array}$ & Registered voters & $3 / 30 / 80$ & 917 & $3 / 30 / 80$ \\
\hline 1061 & $\begin{array}{l}\text { Yankelovich, Skelly, White } \\
\text { (Sponsor: Time) }\end{array}$ & Registered voters & $3 / 20 / 80$ & 1221 & $3 / 20 / 80$ \\
\hline 1062 & $\begin{array}{l}\text { Yankelovich, Skelly, White } \\
\text { (Sponsor: Time) }\end{array}$ & Registered voters & $1 / 24 / 80$ & 1227 & $1 / 24 / 80$ \\
\hline 1063 & $\begin{array}{l}\text { Yankelovich, Skelly, White (Sponsor: } \\
\text { American Council of Life Insurance) }\end{array}$ & National adult & $5 / 28 / 80$ & 1549 & $5 / 80$ \\
\hline 1064 & $\begin{array}{l}\text { Yankelovich, Skelly, White } \\
\text { (Sponsor: Time) }\end{array}$ & Registered voters & $12 / 12 / 79$ & 1041 & $12 / 12 / 79$ \\
\hline 1065 & $\begin{array}{l}\text { Yankelovich, Skelly, White } \\
\text { (Sponsor: Time) }\end{array}$ & Registered voters & $10 / 25 / 79$ & 1027 & $10 / 25 / 79$ \\
\hline 1066 & $\begin{array}{l}\text { Yankelovich, Skelly, White } \\
\text { (Sponsor: Time) }\end{array}$ & Registered voters & $8 / 23 / 79$ & 1049 & $8 / 23 / 79$ \\
\hline 1067 & $\begin{array}{l}\text { Yankelovich, Skelly, White } \\
\text { (Sponsor: Time) }\end{array}$ & Registered voters & $4 / 79$ & 1024 & $4 / 79$ \\
\hline 1068 & $\begin{array}{l}\text { Yankelovich, Skelly, White (Sponsor: } \\
\text { American Council of Life Insurance) }\end{array}$ & National adult & $6 / 22 / 79$ & 1554 & $6 / 79$ \\
\hline 1069 & $\begin{array}{l}\text { Yankelovich, Skelly, White } \\
\text { (Sponsor: Time) }\end{array}$ & Registered voters & $9 / 22 / 83$ & 1016 & $9 / 83$ \\
\hline 1070 & $\begin{array}{l}\text { Institute for Survey Research } \\
\text { (Sponsor: National Science Foundation) }\end{array}$ & National adult & $12 / 21 / 79$ & 1635 & $5 / 10 / 80$ \\
\hline 1071 & $\begin{array}{l}\text { Sindlinger \& Co. (Sponsor: Fiscal } \\
\text { Policy Council on Taxes \& Government) }\end{array}$ & National adult & $7 / 4 / 79$ & 1500 & $7 / 79$ \\
\hline 1072 & $\begin{array}{l}\text { Research/Strategy/Management } \\
\text { (Sponsor: Union of Concerned Scientists) }\end{array}$ & Registered voters & $11 / 4 / 89$ & 1200 & $11 / 89$ \\
\hline 1073 & Roper Organization & National adult & $9 / 26 / 87$ & 1990 & $12 / 87$ \\
\hline 1074 & Roper Organization & National adult & $8 / 29 / 87$ & 1987 & $11 / 87$ \\
\hline
\end{tabular}


Public Opinion Surveys Included in the Study

\begin{tabular}{|c|c|c|c|c|c|}
\hline $\begin{array}{l}\text { Survey } \\
\text { Number }\end{array}$ & $\begin{array}{c}\text { Author or } \\
\text { Polling Organization }\end{array}$ & $\begin{array}{l}\text { Population or } \\
\text { Area Sampled }\end{array}$ & $\begin{array}{l}\text { Ending Date of } \\
\text { Data Collection }\end{array}$ & $\begin{array}{l}\text { Sample } \\
\text { Size }\end{array}$ & $\begin{array}{c}\text { Release } \\
\text { Date }\end{array}$ \\
\hline 1075 & Roper Organization & National adult & $7 / 25 / 87$ & 1997 & $7 / 87$ \\
\hline 1076 & Roper Organization & National adult & $5 / 30 / 87$ & 1998 & $8 / 87$ \\
\hline 1077 & Roper Organization & National adult & $5 / 2 / 87$ & 2000 & $7 / 87$ \\
\hline 1078 & Roper Organization & National adult & $3 / 28 / 87$ & 1980 & $6 / 87$ \\
\hline 1079 & Roper Organization & National adult & $1 / 24 / 87$ & 1997 & $4 / 87$ \\
\hline 1080 & Roper Organization & National adult & $12 / 31 / 86$ & 1997 & $3 / 87$ \\
\hline 1081 & Roper Organization & National adult & $9 / 27 / 86$ & 1997 & $11 / 86$ \\
\hline 1082 & Roper Organization & National adult & $8 / 23 / 86$ & 1992 & $10 / 86$ \\
\hline 1083 & Roper Organization & National adult & $7 / 19 / 86$ & 1991 & $9 / 86$ \\
\hline 1084 & Roper Organization & National adult & $6 / 7 / 86$ & 1994 & $8 / 86$ \\
\hline 1085 & Roper Organization & National adult & $5 / 3 / 86$ & 1998 & $7 / 31 / 86$ \\
\hline 1086 & Roper Organization & National adult & $3 / 22 / 86$ & 1993 & $7 / 86$ \\
\hline 1087 & Roper Organization & National adult & $12 / 14 / 85$ & 1980 & $3 / 86$ \\
\hline 1088 & Roper Organization & National adult & $2 / 22 / 86$ & 1993 & $6 / 86$ \\
\hline 1089 & Roper Organization & National adult & $9 / 28 / 85$ & 1996 & $12 / 85$ \\
\hline 1090 & Roper Organization & National adult & $8 / 24 / 85$ & 1996 & $11 / 85$ \\
\hline 1091 & Roper Organization & National adult & $7 / 20 / 85$ & 1997 & $10 / 85$ \\
\hline 1092 & Roper Organization & National adult & $6 / 22 / 85$ & 2000 & $9 / 85$ \\
\hline 1093 & Roper Organization & National adult & $5 / 4 / 85$ & 1988 & $7 / 85$ \\
\hline 1094 & Roper Organization & National adult & $3 / 30 / 85$ & 2000 & $6 / 85$ \\
\hline 1095 & Roper Organization & National adult & $1 / 19 / 85$ & 1989 & $3 / 85$ \\
\hline 1096 & Roper Organization & National adult & $11 / 2 / 85$ & 1998 & $2 / 86$ \\
\hline 1097 & Roper Organization & National adult & $12 / 8 / 84$ & 1977 & $2 / 8 / 85$ \\
\hline 1098 & Roper Organization & National adult & $8 / 18 / 84$ & 2000 & $10 / 84$ \\
\hline 1099 & Roper Organization & National adult & $7 / 14 / 84$ & 2000 & $9 / 84$ \\
\hline
\end{tabular}


Public Opinion Surveys Included in the Study

\begin{tabular}{|c|c|c|c|c|c|}
\hline $\begin{array}{l}\text { Survey } \\
\text { Number }\end{array}$ & $\begin{array}{c}\text { Author or } \\
\text { Polling Organization }\end{array}$ & $\begin{array}{l}\text { Population or } \\
\text { Area Sampled }\end{array}$ & $\begin{array}{l}\text { Ending Date of } \\
\text { Data Collection }\end{array}$ & $\begin{array}{l}\text { Sample } \\
\text { Size }\end{array}$ & $\begin{array}{c}\text { Release } \\
\text { Date }\end{array}$ \\
\hline 1100 & Roper Organization & National adult & $6 / 3 / 84$ & 2000 & $8 / 84$ \\
\hline 1101 & Roper Organization & National adult & $4 / 28 / 84$ & 2000 & $6 / 84$ \\
\hline 1102 & Roper Organization & National adult & $3 / 24 / 84$ & 2000 & $5 / 84$ \\
\hline 1103 & Roper Organization & National adult & $2 / 25 / 84$ & 2000 & $4 / 84$ \\
\hline 1104 & Roper Organization & National adult & $11 / 3 / 84$ & 2000 & $12 / 84$ \\
\hline 1105 & Roper Organization & National adult & $12 / 10 / 83$ & 2000 & $2 / 84$ \\
\hline 1106 & Roper Organization & National adult & $11 / 5 / 83$ & 2000 & $12 / 83$ \\
\hline 1107 & Roper Organization & National adult & $10 / 1 / 83$ & 2000 & $11 / 83$ \\
\hline 1108 & Roper Organization & National adult & $8 / 20 / 83$ & 2000 & $10 / 83$ \\
\hline 1109 & Roper Organization & National adult & $7 / 16 / 83$ & 2000 & $9 / 83$ \\
\hline 1110 & Roper Organization & National adult & $6 / 11 / 83$ & 2000 & $8 / 83$ \\
\hline 1111 & Roper Organization & National adult & $4 / 30 / 83$ & 2000 & $6 / 83$ \\
\hline 1112 & Roper Organization & National adult & $3 / 26 / 83$ & 2000 & $5 / 83$ \\
\hline 1113 & Roper Organization & National adult & $12 / 11 / 82$ & 2000 & $2 / 83$ \\
\hline 1114 & Roper Organization & National adult & 9/18/82 & 2000 & $11 / 82$ \\
\hline 1115 & Roper Organization & National adult & $8 / 21 / 82$ & 2000 & $10 / 82$ \\
\hline 1116 & Roper Organization & National adult & $6 / 12 / 82$ & 2000 & $8 / 82$ \\
\hline 1117 & Roper Organization & National adult & $7 / 17 / 82$ & 2000 & $8 / 82$ \\
\hline 1118 & Roper Organization & National adult & $6 / 12 / 82$ & 2000 & $7 / 82$ \\
\hline 1119 & Roper Organization & National adult & $3 / 27 / 82$ & 2000 & $5 / 82$ \\
\hline 1120 & Roper Organization & National adult & $2 / 27 / 82$ & 2000 & $4 / 82$ \\
\hline 1121 & Roper Organization & National adult & $10 / 30 / 82$ & 2000 & $12 / 82$ \\
\hline 1122 & Roper Organization & National adult & $12 / 12 / 81$ & 2000 & $1 / 82$ \\
\hline 1123 & $\begin{array}{l}\text { Roper Organization (Sponsor: } \\
\text { American Enterprise Institue) }\end{array}$ & National adult & $11 / 21 / 81$ & 1500 & $11 / 81$ \\
\hline
\end{tabular}


Public Opinion Surveys Included in the Study

\begin{tabular}{|c|c|c|c|c|c|}
\hline $\begin{array}{l}\text { Survey } \\
\text { Number }\end{array}$ & $\begin{array}{c}\text { Author or } \\
\text { Polling Organization }\end{array}$ & $\begin{array}{l}\text { Population or } \\
\text { Area Sampled }\end{array}$ & $\begin{array}{l}\text { Ending Date of } \\
\text { Data Collection }\end{array}$ & $\begin{array}{l}\text { Sample } \\
\text { Size }\end{array}$ & $\begin{array}{l}\text { Release } \\
\text { Date }\end{array}$ \\
\hline 1124 & Roper Organization & National adult & $9 / 26 / 81$ & 2000 & $11 / 81$ \\
\hline 1125 & Roper Organization & National adult & $8 / 22 / 81$ & 2000 & $10 / 81$ \\
\hline 1126 & Roper Organization & National adult & $7 / 18 / 81$ & 2000 & $8 / 81$ \\
\hline 1127 & Roper Organization & National adult & $6 / 6 / 81$ & 2003 & $7 / 81$ \\
\hline 1128 & Roper Organization & National adult & $5 / 2 / 81$ & 1999 & $5 / 81$ \\
\hline 1129 & Roper Organization & National adult & $3 / 28 / 81$ & 2000 & $4 / 81$ \\
\hline 1130 & Roper Organization & National adult & $2 / 28 / 81$ & 2005 & $4 / 81$ \\
\hline 1131 & Roper Organization & National adult & $1 / 24 / 81$ & 2000 & $3 / 81$ \\
\hline 1132 & Roper Organization & National adult & $12 / 13 / 80$ & 2000 & $2 / 81$ \\
\hline 1133 & Roper Organization & National adult & $10 / 4 / 80$ & 2005 & $11 / 80$ \\
\hline 1134 & Roper Organization & National adult & $8 / 23 / 80$ & 2001 & $10 / 80$ \\
\hline 1135 & Roper Organization & National adult & $7 / 13 / 80$ & 2005 & $8 / 80$ \\
\hline 1136 & Roper Organization & National adult & $6 / 12 / 80$ & 2006 & $7 / 80$ \\
\hline 1137 & Roper Organization & National adult & $4 / 5 / 80$ & 2002 & $4 / 80$ \\
\hline 1138 & Roper Organization & National adult & $2 / 23 / 80$ & 2001 & $4 / 80$ \\
\hline 1139 & Roper Organization & National adult & $1 / 19 / 80$ & 2005 & $2 / 1 / 80$ \\
\hline 1140 & Roper Organization & National adult & $11 / 15 / 80$ & 2004 & $12 / 80$ \\
\hline 1141 & Roper Organization & National adult & $12 / 8 / 79$ & 2003 & $1 / 80$ \\
\hline 1142 & $\begin{array}{l}\text { Roper Organization } \\
\text { (Sponsor: H \& R Block) }\end{array}$ & National adult & $5 / 12 / 79$ & 1459 & $5 / 79$ \\
\hline 1143 & $\begin{array}{l}\text { Roper Organizaion } \\
\text { (Sponsor: Virginia Slims) }\end{array}$ & National adult & $10 / 20 / 79$ & 3944 & $10 / 79$ \\
\hline 1144 & Roper Organization & National adult & $9 / 29 / 79$ & 2009 & $11 / 79$ \\
\hline 1145 & Roper Organization & National adult & $8 / 25 / 79$ & 2005 & $10 / 15 / 79$ \\
\hline 1146 & Roper Organization & National adult & $6 / 14 / 79$ & 2000 & $8 / 25 / 79$ \\
\hline 1147 & Roper Organization & National adult & $6 / 9 / 79$ & 2006 & $7 / 79$ \\
\hline
\end{tabular}


Public Opinion Surveys Included in the Study

\begin{tabular}{|c|c|c|c|c|c|}
\hline $\begin{array}{l}\text { Survey } \\
\text { Number }\end{array}$ & $\begin{array}{c}\text { Author or } \\
\text { Polling Organization }\end{array}$ & $\begin{array}{l}\text { Population or } \\
\text { Area Sampled }\end{array}$ & $\begin{array}{l}\text { Ending Date of } \\
\text { Data Collection }\end{array}$ & $\begin{array}{l}\text { Sample } \\
\text { Size }\end{array}$ & $\begin{array}{l}\text { Release } \\
\text { Date }\end{array}$ \\
\hline 1148 & Roper Organization & National adult & $5 / 5 / 79$ & 2007 & $6 / 79$ \\
\hline 1149 & Roper Organization & National adult & $3 / 31 / 79$ & 2004 & $4 / 79$ \\
\hline 1150 & Roper Organization & National adult & $2 / 24 / 79$ & 2004 & $4 / 79$ \\
\hline 1151 & Roper Organization & National adult & $1 / 20 / 79$ & 2003 & $3 / 79$ \\
\hline 1152 & Roper Organization & National adult & $11 / 3 / 79$ & 2008 & $12 / 79$ \\
\hline 1153 & Opinion Research Corporation & National adult & $5 / 14 / 86$ & 1007 & $6 / 86$ \\
\hline 1154 & Opinion Research Corporation & National adult & $11 / 12 / 84$ & 1009 & $1 / 85$ \\
\hline 1155 & Opinion Research Corporation & National adult & $12 / 7 / 84$ & 1006 & $2 / 85$ \\
\hline 1156 & $\begin{array}{l}\text { Opinion Research Corporation } \\
\text { (Sponsor: Council for Advancement \& } \\
\text { Support of Higher Education/New England } \\
\text { Board of Higher Education) }\end{array}$ & National adult & $10 / 7 / 85$ & 1004 & $10 / 85$ \\
\hline 1157 & Opinion Research Corporation & National adult & $2 / 26 / 85$ & 1003 & $4 / 85$ \\
\hline 1158 & Opinion Research Corporation & National adult & $4 / 19 / 84$ & 1004 & $5 / 84$ \\
\hline 1159 & Opinion Research Corporation & National adult & $7 / 83$ & 2012 & $3 / 84$ \\
\hline 1160 & Opinion Research Corporation & National adult & $8 / 15 / 83$ & 1000 & $9 / 83$ \\
\hline 1161 & Opinion Research Corporation & National adult & $8 / 15 / 83$ & 1000 & $10 / 83$ \\
\hline 1162 & Opinion Research Corporation & National adult & $6 / 5 / 83$ & 1001 & $7 / 83$ \\
\hline 1163 & Opinion Research Corporation & National adult & $12 / 14 / 82$ & 1005 & $1 / 83$ \\
\hline 1164 & Opinion Research Corporation & National adult & $1 / 8 / 83$ & 1003 & $2 / 83$ \\
\hline 1165 & Opinion Research Corporation & National adult & $7 / 15 / 81$ & 2061 & $3 / 82$ \\
\hline 1166 & Opinion Research Corporation & National adult & $11 / 2 / 81$ & 1005 & $1 / 82$ \\
\hline 1167 & Opinion Research Corporation & National adult & $8 / 16 / 81$ & 1001 & $9 / 81$ \\
\hline 1168 & Opinion Research Corporation & National adult & $9 / 20 / 81$ & 1004 & $10 / 31 / 81$ \\
\hline 1169 & Opinion Research Corporation & National adult & $3 / 31 / 81$ & 1000 & $5 / 81$ \\
\hline 1170 & Opinion Research Corporation & National adult & $12 / 17 / 80$ & 1011 & $2 / 81$ \\
\hline
\end{tabular}


Public Opinion Surveys Included in the Study

\begin{tabular}{|c|c|c|c|c|c|}
\hline $\begin{array}{l}\text { Survey } \\
\text { Number }\end{array}$ & $\begin{array}{l}\text { Author or } \\
\text { Polling Organization }\end{array}$ & $\begin{array}{l}\text { Population or } \\
\text { Area Sampled }\end{array}$ & $\begin{array}{l}\text { Ending Date of } \\
\text { Data Collection }\end{array}$ & $\begin{array}{l}\text { Sample } \\
\text { Size }\end{array}$ & $\begin{array}{l}\text { Release } \\
\text { Date }\end{array}$ \\
\hline 1171 & Opinion Research Corporation & National adult & $7 / 20 / 81$ & 1004 & $8 / 81$ \\
\hline 1172 & Opinion Research Corporation & National adult & $3 / 15 / 81$ & 1010 & $4 / 81$ \\
\hline 1173 & Opinion Research Corporation & National adult & $7 / 31 / 80$ & 1010 & $9 / 15 / 80$ \\
\hline 1174 & Opinion Research Corporation & National adult & $8 / 16 / 79$ & 1054 & $3 / 80$ \\
\hline 1175 & Opinion Research Corporation & National adult & $3 / 3 / 80$ & 1004 & $7 / 80$ \\
\hline 1176 & Opinion Research Corporation & National adult & $11 / 16 / 80$ & 1013 & $12 / 80$ \\
\hline 1177 & Opinion Research Corporation & National adult & $7 / 31 / 80$ & 1010 & $8 / 80$ \\
\hline 1178 & Opinion Research Corporation & National adult & $3 / 3 / 80$ & 1004 & $4 / 15 / 80$ \\
\hline 1179 & Opinion Research Corporation & National adult & $8 / 26 / 79$ & 1004 & $10 / 79$ \\
\hline 1180 & Opinion Research Corporation & National adult & $8 / 5 / 79$ & 1010 & $8 / 79$ \\
\hline 1181 & Opinion Research Corporation & National adult & $3 / 18 / 79$ & 1015 & $4 / 79$ \\
\hline 1182 & Opinion Research Corporation & National adult & $11 / 12 / 84$ & 1009 & $12 / 84$ \\
\hline 1183 & Opinion Research Corporation & National adult & $9 / 26 / 84$ & 1019 & $11 / 84$ \\
\hline 1184 & Opinion Research Corporation & National adult & $3 / 11 / 90$ & 1046 & $4 / 19 / 90$ \\
\hline 1185 & $\begin{array}{l}\text { Opinion Dynamics Corporation (Sponsor: } \\
\text { Cambridge Energy Research Associaes) }\end{array}$ & National adult & $12 / 18 / 89$ & 1250 & $12 / 89$ \\
\hline 1186 & The New York Times & National adult & $8 / 10 / 90$ & 670 & $8 / 90$ \\
\hline 1187 & National Opinion Research Center & National adult & $4 / 85$ & 1534 & $7 / 86$ \\
\hline 1188 & $\begin{array}{l}\text { Hart \& Teeter Research Companies } \\
\text { (Sponsor: NBC News, The Wall Street Journat) }\end{array}$ & Registered voters & $9 / 18 / 90$ & 1508 & $9 / 90$ \\
\hline 1189 & $\begin{array}{l}\text { Hart \& Teeter Research Companies } \\
\text { (Sponsor: NBC News, The Wall Street Journal) }\end{array}$ & Registered voters & $9 / 5 / 90$ & 800 & $9 / 90$ \\
\hline 1190 & $\begin{array}{l}\text { Hart \& Teeter Research Companies } \\
\text { (Sponsor: NBC News, The Wall Street Journal) }\end{array}$ & Registered voters & $5 / 22 / 90$ & 1007 & $5 / 90$ \\
\hline 1191 & $\begin{array}{l}\text { Hart \& Teeter Research Companies } \\
\text { (Sponsor: NBC News, The Wall Street Journal) }\end{array}$ & Registered voters & $7 / 10 / 90$ & 1555 & $7 / 90$ \\
\hline 1192 & $\begin{array}{l}\text { Hart \& Teeter Research Companies } \\
\text { (Sponsor: NBC News, The Wall Street Journal) }\end{array}$ & Registered voters & $1 / 16 / 90$ & 1510 & $1 / 16 / 90$ \\
\hline
\end{tabular}


Public Opinion Surveys Included in the Study

\begin{tabular}{|c|c|c|c|c|c|}
\hline $\begin{array}{l}\text { Survey } \\
\text { Number }\end{array}$ & $\begin{array}{l}\text { Author or } \\
\text { Polling Organization }\end{array}$ & $\begin{array}{l}\text { Population or } \\
\text { Area Sampled }\end{array}$ & $\begin{array}{l}\text { Ending Date of } \\
\text { Data Collection }\end{array}$ & $\begin{array}{l}\text { Sample } \\
\text { Size }\end{array}$ & $\begin{array}{l}\text { Release } \\
\text { Date }\end{array}$ \\
\hline 1193 & $\begin{array}{l}\text { Hart \& Teeter Research Companies } \\
\text { (Sponsor: NBC News, The Wall Street Journal) }\end{array}$ & Registered voters & $8 / 19 / 90$ & 805 & $8 / 90$ \\
\hline 1194 & $\begin{array}{l}\text { Hart \& Teeter Research Companies } \\
\text { (Sponsor: NBC News, The Wall Street Journal) }\end{array}$ & Registered voters & $4 / 16 / 90$ & 1001 & $4 / 90$ \\
\hline 1195 & NBC News/The Wall Street Journal & Registered voters & $1 / 22 / 88$ & 2392 & $7 / 1 / 88$ \\
\hline 1196 & NBC News/The Wall Street Journal & Registered voters & $2 / 7 / 86$ & 1597 & $2 / 25 / 86$ \\
\hline 1197 & NBC News/The Wall Street Journal & Registered voters & $6 / 3 / 86$ & 1599 & $6 / 11 / 86$ \\
\hline 1198 & NBC News/The Wall Street Joumal & Registered voters & $4 / 29 / 86$ & 1599 & $5 / 12 / 86$ \\
\hline 1199 & NBC News/The Wall Street Journal & Registered voters & $4 / 15 / 86$ & 2239 & $4 / 23 / 86$ \\
\hline 1200 & NBC News/The Wall Street Journal & Registered voters & $4 / 18 / 89$ & 1447 & a \\
\hline 1201 & $\begin{array}{l}\text { Roper Organization (Sponsor: } \\
\text { U.S. News \& World Report, CNN) }\end{array}$ & National adult & $12 / 11 / 86$ & 1003 & $12 / 86$ \\
\hline 1202 & $\begin{array}{l}\text { Roper Organization (Sponsor: } \\
\text { U.S. News \& World Report, CNN) }\end{array}$ & National adult & $5 / 8 / 86$ & 1003 & $5 / 8 / 86$ \\
\hline 1203 & $\begin{array}{l}\text { Resources for the Future (Sponsor: } \\
\text { Council for Environmental Quality) }\end{array}$ & National adult & $4 / 5 / 80$ & 1576 & $4 / 80$ \\
\hline 1204 & $\begin{array}{l}\text { Research \& Forecasts } \\
\text { (Sponsor: Continental Group) }\end{array}$ & National adult & $4 / 13 / 82$ & 1310 & $12 / 82$ \\
\hline 1205 & $\begin{array}{l}\text { Research \& Forecasts (Sponsor: } \\
\text { Connecticut Mutual Life Insurance) }\end{array}$ & $\begin{array}{l}\text { National adult }+ \\
\text { oversamples of blacks, } \\
\text { senior citizens } 65+\text {, } \\
\text { and youths }\end{array}$ & $11 / 15 / 80$ & 2018 & $1 / 81$ \\
\hline 1206 & $\begin{array}{l}\text { Penn \& Schoen Associates } \\
\text { (Sponsor: Texaco, Inc.) }\end{array}$ & National adult & $8 / 19 / 90$ & 677 & $8 / 23 / 90$ \\
\hline 1207 & $\begin{array}{l}\text { Penn \& Schoen Associates (Sponsor: } \\
\text { Committee for a Responsible Tax Policy) }\end{array}$ & National adult & $1 / 85$ & 1000 & $1 / 30 / 85$ \\
\hline 1208 & $\begin{array}{l}\text { Public Affairs Research Center } \\
\text { (Sponsor: Pfizer Pharmaceuticals) }\end{array}$ & National adult & $2 / 11 / 79$ & 1514 & $4 / 79$ \\
\hline 1209 & Public Agenda Foundation & National adult & $12 / 23 / 79$ & 1000 & $1 / 80$ \\
\hline
\end{tabular}

aInformation not provided. 


\section{Public Opinion Surveys Included in the Study}

\begin{tabular}{|c|c|c|c|c|c|}
\hline $\begin{array}{l}\text { Survey } \\
\text { Number }\end{array}$ & $\begin{array}{c}\text { Author or } \\
\text { Polling Organization }\end{array}$ & $\begin{array}{l}\text { Population or } \\
\text { Area Sampled }\end{array}$ & $\begin{array}{l}\text { Ending Date of } \\
\text { Data Collection }\end{array}$ & $\begin{array}{l}\text { Sample } \\
\text { Size }\end{array}$ & $\begin{array}{l}\text { Release } \\
\text { Date }\end{array}$ \\
\hline 1210 & Opinion Research Corporation & National adult & $5 / 11 / 87$ & 1011 & $6 / 87$ \\
\hline 1211 & NBC News/Associated Press & National adult & $11 / 16 / 82$ & 1583 & $11 / 82$ \\
\hline 1212 & NBC News/Associated Press & National adult & $10 / 26 / 81$ & 1598 & $10 / 81$ \\
\hline 1213 & NBC News/Associated Press & National adult & $11 / 17 / 81$ & 1602 & $11 / 81$ \\
\hline 1214 & NBC News/Associated Press & National adult & $1 / 28 / 82$ & 1599 & $4 / 13 / 82$ \\
\hline 1215 & NBC News/Associated Press & National adult & $11 / 17 / 81$ & 1602 & $11 / 24 / 81$ \\
\hline 1216 & NBC News/Associated Press & National adult & $5 / 19 / 81$ & 1599 & $6 / 4 / 81$ \\
\hline 1217 & NBC News/Associated Press & National adult & $4 / 26 / 80$ & 1603 & $5 / 1 / 80$ \\
\hline 1218 & NBC News/Associated Press & National adult & $3 / 21 / 80$ & 1600 & $4 / 4 / 80$ \\
\hline 1219 & NBC News/Associated Press & National adult & $12 / 12 / 79$ & 1595 & $12 / 18 / 79$ \\
\hline 1220 & NBC News/Associated Press & National adult & $9 / 11 / 79$ & 1599 & $9 / 14 / 79$ \\
\hline 1221 & NBC News/Associated Press & National adult & $7 / 24 / 79$ & 803 & $7 / 27 / 79$ \\
\hline 1222 & NBC News/Associated Press & National adult & $7 / 17 / 79$ & 1599 & $7 / 20 / 79$ \\
\hline 1223 & $\begin{array}{l}\text { Alice M. Crites et al. (Sponsor: } \\
\text { Nevada Cooperative Extension) }\end{array}$ & $\begin{array}{l}\text { Nevada LIHEAP } \\
\text { participant bouseholds }\end{array}$ & $6 / 88$ & 293 & $9 / 24 / 90$ \\
\hline 1224 & NBC News/Associated Press & National adult & $5 / 29 / 79$ & 800 & $6 / 4 / 79$ \\
\hline 1225 & NBC News/Associated Press & National adult & $5 / 1 / 79$ & 1600 & $5 / 3 / 79$ \\
\hline 1226 & NBC News/Associated Press & National adult & $3 / 20 / 79$ & 1600 & $3 / 21 / 79$ \\
\hline 1227 & NBC News/Associated Press & National adult & $2 / 6 / 79$ & 1600 & $2 / 879$ \\
\hline 1228 & NBC News/Associated Press & National adult & $4 / 14 / 81$ & 1604 & $4 / 28 / 81$ \\
\hline 1229 & NBC News/Associated Press & National adult & $2 / 24 / 81$ & 1597 & $3 / 3 / 81$ \\
\hline 1230 & $\begin{array}{l}\text { Market Opinion Research (Sponsor: } \\
\text { Presidential Commission on World Hunger) }\end{array}$ & National adult & $12 / 14 / 79$ & 1200 & $12 / 79$ \\
\hline 1231 & $\begin{array}{l}\text { Market Opinion Research } \\
\text { (Sponsor: Americans Talk Security) }\end{array}$ & Registered voters & $9 / 18 / 88$ & 1005 & $10 / 88$ \\
\hline 1232 & Maritz Marketing Research & National adult & $7 / 90$ & 1000 & $7 / 11 / 90$ \\
\hline
\end{tabular}


Public Opinion Surveys Included in the Study

\begin{tabular}{|c|c|c|c|c|c|}
\hline $\begin{array}{l}\text { Survey } \\
\text { Number }\end{array}$ & $\begin{array}{c}\text { Author or } \\
\text { Polling Organization }\end{array}$ & $\begin{array}{l}\text { Population or } \\
\text { Area Sampled }\end{array}$ & $\begin{array}{l}\text { Ending Date of } \\
\text { Data Collection }\end{array}$ & $\begin{array}{l}\text { Sample } \\
\text { Size }\end{array}$ & $\begin{array}{l}\text { Release } \\
\text { Date }\end{array}$ \\
\hline 1233 & $\begin{array}{l}\text { Lieberman Research, Inc. } \\
\text { (Sponsor: Money Magazine) }\end{array}$ & $\begin{array}{l}\text { National-household } \\
\text { financial decision makers }\end{array}$ & $7 / 2 / 86$ & 2555 & $7 / 86$ \\
\hline 1234 & The Los Angeles Times & National adult & $11 / 24 / 85$ & 1454 & $11 / 85$ \\
\hline 1235 & The Los Angeles Times & National adult & $5 / 12 / 83$ & 1395 & $5 / 83$ \\
\hline 1236 & The Los Angeles Times & National adult & $8 / 26 / 82$ & 1592 & $8 / 82$ \\
\hline 1237 & The Los Angeles Times & National adult & $4 / 16 / 81$ & 1406 & $4 / 81$ \\
\hline 1238 & The Los Angeles Times & National adult & $12 / 18 / 79$ & 1047 & $12 / 31 / 79$ \\
\hline 1239 & The Los Angeles Times & National adult & $5 / 25 / 79$ & 1304 & $5 / 79$ \\
\hline 1240 & The Los Angeles Times & National adult & $6 / 1 / 87$ & 2317 & $6 / 87$ \\
\hline 1241 & The Los Angeles Times & National adult & $2 / 25 / 86$ & 2241 & $2 / 86$ \\
\hline 1242 & $\begin{array}{l}\text { Peter D. Hart Research Associates } \\
\text { (Sponsor: National Commission on } \\
\text { Social Security) }\end{array}$ & National adult & $11 / 26 / 79$ & 1549 & $11 / 79$ \\
\hline 1243 & $\begin{array}{l}\text { Louis Harris \& Associates } \\
\text { (Sponsor: Democratic Governors } \\
\text { Association/Democrats for the } 80^{\prime} \text { s) }\end{array}$ & Likely voters & $7 / 22 / 87$ & 1261 & $7 / 87$ \\
\hline 1244 & $\begin{array}{l}\text { Louis Harris \& Associates } \\
\text { (Sponsor: Office of Technology } \\
\text { Assessment) }\end{array}$ & National adult & $11 / 17 / 86$ & 1273 & $1 / 87$ \\
\hline 1245 & $\begin{array}{l}\text { Louis Harris \& Associates } \\
\text { (Sponsor: Food Marketing Institute) }\end{array}$ & Shoppers & $3 / 30 / 84$ & 1008 & $3 / 84$ \\
\hline 1246 & $\begin{array}{l}\text { Louis Harris \& Associates } \\
\text { (Sponsor: Insurance Information } \\
\text { Institute) }\end{array}$ & National adult & $8 / 21 / 83$ & 1255 & $8 / 83$ \\
\hline 1247 & $\begin{array}{l}\text { Louis Harris \& Associates } \\
\text { (Sponsor: Food Marketing Institute) }\end{array}$ & Shoppers & $1 / 24 / 83$ & 1001 & $2 / 83$ \\
\hline 1248 & $\begin{array}{l}\text { Louis Harris \& Associates } \\
\text { (Sponsor: Atlantic Richfield Company) }\end{array}$ & National adult & $10 / 26 / 82$ & 1252 & $10 / 82$ \\
\hline 1249 & $\begin{array}{l}\text { Louis Harris \& Associates } \\
\text { (Sponsor: Food Marketing Institute) }\end{array}$ & Shoppers & $1 / 26 / 82$ & 1003 & $10 / 83$ \\
\hline
\end{tabular}


Public Opinion Surveys Included in the Study

\begin{tabular}{|c|c|c|c|c|c|}
\hline $\begin{array}{l}\text { Survey } \\
\text { Number }\end{array}$ & $\begin{array}{c}\text { Author or } \\
\text { Polling Organization }\end{array}$ & $\begin{array}{l}\text { Population or } \\
\text { Area Sampled }\end{array}$ & $\begin{array}{l}\text { Ending Date of } \\
\text { Data Collection }\end{array}$ & $\begin{array}{l}\text { Sample } \\
\text { Size }\end{array}$ & $\begin{array}{l}\text { Release } \\
\text { Date }\end{array}$ \\
\hline 1250 & $\begin{array}{l}\text { Louis Harris \& Associates } \\
\text { (Sponsor: National Council on the Aging) }\end{array}$ & $\begin{array}{c}\text { National adult plus } \\
\text { oversamples of adults } \\
55+\text {, blacks, and Hispanics }\end{array}$ & $7 / 31 / 81$ & 3427 & $10 / 81$ \\
\hline 1251 & $\begin{array}{l}\text { Louis Harris \& Associates } \\
\text { (Sponsor: Marsh \& McLemnan) }\end{array}$ & National adult & $1 / 2 / 80$ & 1488 & $1 / 80$ \\
\hline 1252 & $\begin{array}{l}\text { Louis Harris \& Associates } \\
\text { (Sponsor: World Jewish Congress) }\end{array}$ & National adult & $7 / 23 / 80$ & 1506 & $9 / 80$ \\
\hline 1253 & $\begin{array}{l}\text { Louis Harris \& Associates (Sponsor: } \\
\text { Philip Morris, lnc., \& National Endowment } \\
\text { for the Arts; conducted for American } \\
\text { Council for the Arts) }\end{array}$ & National adult & $7 / 28 / 80$ & 1501 & $7 / 80$ \\
\hline 1254 & $\begin{array}{l}\text { Louis Harris \& Associates } \\
\text { (Sponsor: U.S. Dept. of Agriculture) }\end{array}$ & National adult & $11 / 21 / 79$ & 7010 & $3 / 80$ \\
\hline 1255 & Louis Harris \& Associates & National adult & $12 / 13 / 81$ & 1249 & $12 / 28 / 81$ \\
\hline 1256 & Louis Harris \& Associates & National adult & $11 / 1 / 89$ & 1249 & $11 / 19 / 89$ \\
\hline 1257 & Louis Harris \& Associates & National adult & $11 / 3 / 81$ & 1249 & $11 / 12 / 81$ \\
\hline 1258 & Louis Harris \& Associates & National adult & $11 / 4 / 87$ & 1251 & $11 / 9 / 87$ \\
\hline 1259 & Louis Harris \& Associates & National adult & $9 / 24 / 81$ & 1249 & $10 / 15 / 81$ \\
\hline 1260 & Louis Harris \& Associates & National adult & $9 / 24 / 81$ & 1249 & $10 / 8 / 81$ \\
\hline 1261 & Louis Harris \& Associates & National adult & $8 / 21 / 90$ & 1255 & $9 / 16 / 90$ \\
\hline 1262 & Louis Harris \& Associates & National adult & $8 / 21 / 90$ & 1255 & $9 / 9 / 90$ \\
\hline 1263 & Louis Harris \& Associates & National adult & $8 / 21 / 90$ & 1255 & $8 / 26 / 90$ \\
\hline 1264 & Louis Harris \& Associates & National adult & $7 / 6 / 89$ & 1249 & $7 / 9 / 89$ \\
\hline 1265 & Louis Harris \& Associates & National adult & $5 / 16 / 89$ & 1247 & $5 / 28 / 89$ \\
\hline 1266 & Louis Harris \& Associates & National adult & $5 / 10 / 81$ & 1250 & $5 / 28 / 89$ \\
\hline 1267 & Louis Hatris \& Associates & National adult & $4 / 8 / 86$ & 1254 & $5 / 19 / 86$ \\
\hline 1268 & Louis Harris \& Associates & National adult & $4 / 15 / 87$ & 1251 & $5 / 11 / 87$ \\
\hline 1269 & Louis Harris \& Associates & National adult & $4 / 22 / 82$ & 1258 & $5 / 10 / 82$ \\
\hline 1270 & Louis Harris \& Associates & National adult & $4 / 8 / 86$ & 1254 & $4 / 21 / 86$ \\
\hline
\end{tabular}


Public Opinion Surveys Included in the Study

\begin{tabular}{|c|c|c|c|c|c|}
\hline $\begin{array}{l}\text { Survey } \\
\text { Number }\end{array}$ & $\begin{array}{l}\text { Author or } \\
\text { Polling Organization }\end{array}$ & $\begin{array}{l}\text { Population or } \\
\text { Area Sampled }\end{array}$ & $\begin{array}{l}\text { Ending Date of } \\
\text { Data Collection }\end{array}$ & $\begin{array}{l}\text { Sample } \\
\text { Size }\end{array}$ & $\begin{array}{l}\text { Release } \\
\text { Date }\end{array}$ \\
\hline 1271 & Louis Harris \& Associates & National adult & $3 / 11 / 85$ & 1254 & $4 / 4 / 85$ \\
\hline 1272 & Louis Harris \& Associates & National adult & $3 / 13 / 90$ & 1254 & $4 / 1 / 90$ \\
\hline 1273 & Louis Harris \& Associates & National adult & $3 / 11 / 85$ & 1254 & $4 / 1 / 85$ \\
\hline 1274 & Louis Harris \& Associates & National adult & $2 / 22 / 81$ & 1254 & $3 / 2 / 81$ \\
\hline 1275 & Louis Harris \& Associates & National adult & $1 / 25 / 81$ & 1250 & $2 / 9 / 81$ \\
\hline 1276 & Louis Harris \& Associates & National adult & $1 / 7 / 86$ & 1254 & $1 / 16 / 86$ \\
\hline 1277 & Louis Harris \& Associates & National adult & $12 / 6 / 88$ & 1248 & $1 / 15 / 89$ \\
\hline 1278 & Louis Harris \& Associates & National adult & $12 / 6 / 88$ & 1248 & $1 / 8 / 89$ \\
\hline 1279 & $\begin{array}{l}\text { Louis Harris \& Associates (Sponsor: } \\
\text { Natural Resources Council of Ameria) }\end{array}$ & National adult & $11 / 30 / 82$ & 2503 & $12 / 82$ \\
\hline 1280 & $\begin{array}{l}\text { Louis Harris \& Associates } \\
\text { (Sponsor: Asaiti Shimbun) }\end{array}$ & National adult & $3 / 21 / 82$ & 1599 & $3 / 82$ \\
\hline 1281 & $\begin{array}{l}\text { Louis Harris \& Associates } \\
\text { (Sponsor: Business Week) }\end{array}$ & National adult & $4 / 22 / 86$ & 1877 & $6 / 9 / 86$ \\
\hline 1282 & $\begin{array}{l}\text { Louis Harris \& Associates } \\
\text { (Sponsor: Business Week) }\end{array}$ & National adult & $2 / 27 / 83$ & 1253 & $4 / 4 / 83$ \\
\hline 1283 & $\begin{array}{l}\text { Gordon S. Black Corporation } \\
\text { (Sponsor: U.S.A. Today) }\end{array}$ & National adult & $3 / 28 / 90$ & 850 & $3 / 28 / 90$ \\
\hline 1284 & $\begin{array}{l}\text { Gordon S. Black Corporation } \\
\text { (Sponsor: U.S.A. Today) }\end{array}$ & National adult & $11 / 13 / 84$ & 760 & $11 / 13 / 84$ \\
\hline 1285 & $\begin{array}{l}\text { Gordon S. Black Corporation } \\
\text { (Sponsor: U.S.A. Today) }\end{array}$ & Registered voters & $3 / 16 / 84$ & 1312 & $3 / 16 / 84$ \\
\hline 1286 & $\begin{array}{l}\text { Gallup Organization } \\
\text { (Sponsor: Newsweek) }\end{array}$ & National adult & $8 / 10 / 90$ & 770 & $8 / 20 / 90$ \\
\hline 1287 & $\begin{array}{l}\text { Gallup Organization } \\
\text { (Sponsor: Newsweek) }\end{array}$ & National adult & $7 / 19 / 79$ & 539 & $7 / 30 / 79$ \\
\hline 1288 & $\begin{array}{l}\text { Gallup Organization } \\
\text { (Sponsor: Newsweek) }\end{array}$ & National adult & $5 / 1 / 86$ & 762 & $5 / 12 / 86$ \\
\hline 1289 & $\begin{array}{l}\text { Gallup Organization } \\
\text { (Sponsor: Newsweek) }\end{array}$ & National adult & $2 / 11 / 80$ & 1111 & $3 / 3 / 80$ \\
\hline
\end{tabular}


Public Opinion Surveys Included in the Study

\begin{tabular}{|c|c|c|c|c|c|}
\hline $\begin{array}{l}\text { Survey } \\
\text { Number }\end{array}$ & $\begin{array}{c}\text { Author or } \\
\text { Polling Organization }\end{array}$ & $\begin{array}{l}\text { Population or } \\
\text { Area Sampled }\end{array}$ & $\begin{array}{l}\text { Ending Date of } \\
\text { Data Collection }\end{array}$ & $\begin{array}{l}\text { Sample } \\
\text { Size }\end{array}$ & $\begin{array}{l}\text { Release } \\
\text { Date }\end{array}$ \\
\hline 1290 & $\begin{array}{l}\text { Gallup Organization } \\
\text { (Sponsor: National Geographic Society) }\end{array}$ & National adult & $5 / 8 / 88$ & 1611 & $7 / 88$ \\
\hline 1291 & $\begin{array}{l}\text { Gallup Organization } \\
\text { (Sponsor: Phi Delta Kappa) }\end{array}$ & National adult & $4 / 20 / 86$ & 1552 & $4 / 20 / 86$ \\
\hline 1292 & $\begin{array}{l}\text { Gallup Organization (Sponsor: } \\
\text { Chicago Council on Foreign Relations) }\end{array}$ & National adult & $11 / 12 / 86$ & 1585 & $3 / 87$ \\
\hline 1293 & Gallup Organization & National adult & $6 / 16 / 86$ & 1004 & $6 / 16 / 86$ \\
\hline 1294 & $\begin{array}{l}\text { Gallup Organization } \\
\text { (Sponsor: Public Broadcasting Sysem) }\end{array}$ & National adult & $10 / 1 / 79$ & 1520 & $1 / 80$ \\
\hline 1295 & $\begin{array}{l}\text { Gallup Organization } \\
\text { (Sponsor: Times Mirror) }\end{array}$ & National adult & $7 / 24 / 86$ & 1504 & $7 / 86$ \\
\hline 1296 & $\begin{array}{l}\text { Gallup Organization } \\
\text { (Sponsor: Times Mirror) }\end{array}$ & National adult & $5 / 7 / 89$ & 1239 & $5 / 89$ \\
\hline 1297 & $\begin{array}{l}\text { Gallup Organization } \\
\text { (Sponsor: Times Mirror) }\end{array}$ & National adult & $5 / 22 / 88$ & 3021 & $5 / 88$ \\
\hline 1298 & Gallup Organization & National adult & $8 / 4 / 90$ & 810 & $8 / 5 / 90$ \\
\hline 1299 & Gallup Organization & National adult & $2 / 18 / 85$ & 1557 & $4 / 85$ \\
\hline 1300 & Gallup Organization & National adult & $7 / 13 / 87$ & 1607 & $7 / 13 / 87$ \\
\hline 1301 & Gallup Organization & National adult & $8 / 4 / 80$ & 1538 & $8 / 4 / 80$ \\
\hline 1302 & Gallup Organization & National adult & $2 / 4 / 80$ & 1584 & $2 / 4 / 80$ \\
\hline 1303 & Gallup Organization & National adult & $11 / 5 / 79$ & 1541 & $12 / 5 / 79$ \\
\hline 1304 & Gallup Organization & National adult & $9 / 10 / 79$ & 1538 & $9 / 10 / 79$ \\
\hline 1305 & Gallup Organization & National adult & $8 / 20 / 79$ & 1554 & $8 / 20 / 79$ \\
\hline 1306 & Gallup Organization & National adult & $8 / 6 / 79$ & 1571 & $8 / 6 / 79$ \\
\hline 1307 & Gallup Organization & National adult & $8 / 6 / 79$ & 1562 & $8 / 6 / 79$ \\
\hline 1308 & Gallup Organization & National adult & $6 / 4 / 79$ & 1511 & $6 / 4 / 79$ \\
\hline 1309 & Gallup Organization & National adult & $5 / 21 / 79$ & 1514 & $5 / 21 / 79$ \\
\hline 1310 & Gallup Organization & National adult & $4 / 6 / 79$ & 1509 & $4 / 9 / 79$ \\
\hline
\end{tabular}


Public Opinion Surveys Included in the Study

\begin{tabular}{|c|c|c|c|c|c|}
\hline $\begin{array}{l}\text { Survey } \\
\text { Number }\end{array}$ & $\begin{array}{l}\text { Author or } \\
\text { Polling Organization }\end{array}$ & $\begin{array}{l}\text { Population or } \\
\text { Area Sampled }\end{array}$ & $\begin{array}{l}\text { Ending Date of } \\
\text { Data Collection }\end{array}$ & $\begin{array}{l}\text { Sample } \\
\text { Size }\end{array}$ & $\begin{array}{l}\text { Release } \\
\text { Date }\end{array}$ \\
\hline 1311 & Gallup Organization & National adult & $3 / 19 / 79$ & 1563 & $3 / 19 / 79$ \\
\hline 1312 & Gallup Organization & National adult & $2 / 26 / 79$ & 1534 & $2 / 26 / 79$ \\
\hline 1313 & Gallup Organization & National adult & $8 / 12 / 90$ & 1227 & $8 / 15 / 90$ \\
\hline 1314 & Gallup Organization & National adult & $5 / 27 / 79$ & 510 & $6 / 1 / 79$ \\
\hline 1315 & Gallup Organization & National adult & $5 / 4 / 79$ & 511 & $5 / 20 / 79$ \\
\hline 1316 & Gallup Organization & National aduit & $5 / 7 / 89$ & 1239 & $5 / 15 / 89$ \\
\hline 1317 & Gallup Organization & National adult & $3 / 2 / 89$ & 1000 & $3 / 30 / 89$ \\
\hline 1318 & Gallup Organization & National adult & $11 / 19 / 89$ & 1234 & $1 / 1 / 90$ \\
\hline 1319 & $\begin{array}{l}\text { Gallup Organization } \\
\text { (Sponsor: Times Mirror) }\end{array}$ & Registered voters & $10 / 26 / 88$ & 2006 & $10 / 88$ \\
\hline 1320 & $\begin{array}{l}\text { Gallup Organization } \\
\text { (Sponsor: Times Mirror) }\end{array}$ & National adult & $2 / 5 / 89$ & 2048 & $3 / 89$ \\
\hline 1321 & $\begin{array}{l}\text { Gallup Organization (Sponsor: } \\
\text { Chicago Council on Foreign Relations) }\end{array}$ & Opinion leaders & $12 / 17 / 82$ & 341 & $1 / 83$ \\
\hline 1322 & $\begin{array}{l}\text { Gallup Organization (Sponsor: } \\
\text { Chicago Council on Foreign Relations) }\end{array}$ & National adult & $11 / 6 / 82$ & 1547 & $1 / 83$ \\
\hline 1323 & $\begin{array}{l}\text { Daniel Yankelovich Group } \\
\text { (Sponsor: Americans Talk Security) }\end{array}$ & Registered voters & $10 / 4 / 88$ & 1008 & $10 / 88$ \\
\hline 1324 & $\begin{array}{l}\text { Mark Clements Research } \\
\text { (Sponsor: Glamour Magazine) }\end{array}$ & Women aged 18-65 & $8 / 8 / 84$ & 1000 & $8 / 84$ \\
\hline 1325 & $\begin{array}{l}\text { Mark Clements Research } \\
\text { (Sponsor: Glamour Magazine) }\end{array}$ & Women aged 18-65 & $8 / 31 / 83$ & 1000 & $8 / 83$ \\
\hline 1326 & $\begin{array}{l}\text { Mark Clements Research } \\
\text { (Sponsor: Glamour Magazine) }\end{array}$ & Women aged 18-65 & $9 / 16 / 82$ & 1000 & $9 / 82$ \\
\hline 1327 & Civic Service, Inc. & National adult & $2 / 15 / 80$ & 1611 & $2 / 80$ \\
\hline 1328 & CBS News/The New York Times & National adult & $9 / 11 / 88$ & 1606 & $9 / 88$ \\
\hline 1329 & CBS News/The New York Times & National adult & $7 / 16 / 79$ & 895 & $7 / 18 / 79$ \\
\hline 1330 & CBS News/The New York Times & National adult & $11 / 3 / 79$ & 1385 & $11 / 79$ \\
\hline 1331 & CBS News/The New York Times & National adult & $11 / 3 / 79$ & 1385 & $11 / 79$ \\
\hline
\end{tabular}


Public Opinion Surveys Included in the Study

\begin{tabular}{|c|c|c|c|c|c|}
\hline $\begin{array}{l}\text { Survey } \\
\text { Number }\end{array}$ & $\begin{array}{c}\text { Author or } \\
\text { Polling Organization }\end{array}$ & $\begin{array}{l}\text { Population or } \\
\text { Area Sampled }\end{array}$ & $\begin{array}{l}\text { Ending Date of } \\
\text { Data Collection }\end{array}$ & $\begin{array}{l}\text { Sample } \\
\text { Size }\end{array}$ & $\begin{array}{l}\text { Release } \\
\text { Date }\end{array}$ \\
\hline 1332 & CBS News/The New York Times & National adult & $10 / 13 / 79$ & 1514 & $10 / 19 / 79$ \\
\hline 1333 & CBS News/The New York Times & National adult & $9 / 27 / 81$ & 1479 & $10 / 3 / 81$ \\
\hline 1334 & CBS News/The New York Times & National adult & 9/27/81 & 1479 & $9 / 28 / 81$ \\
\hline 1335 & CBS News/The New York Times & National adult & $8 / 7 / 80$ & 1769 & $8 / 9 / 80$ \\
\hline 1336 & CBS News/The New York Times & National adult & $7 / 11 / 79$ & 1192 & $7 / 12 / 79$ \\
\hline 1337 & CBS News/The New York Times & National adult & $6 / 6 / 79$ & 1422 & $6 / 11 / 79$ \\
\hline 1338 & CBS News/The New York Times & National adult & $6 / 6 / 79$ & 1422 & $6 / 9 / 79$ \\
\hline 1339 & CBS News/The New York Times & National adult & $5 / 24 / 90$ & 1140 & $5 / 26 / 90$ \\
\hline 1340 & CBS News/The New York Times & National adult & $4 / 26 / 81$ & 1439 & $4 / 29 / 81$ \\
\hline 1341 & CBS News/The New York Times & National adult & $4 / 14 / 80$ & 1605 & $4 / 27 / 80$ \\
\hline 1342 & CBS News/The New York Times & National adult & $4 / 16 / 89$ & 1412 & $4 / 19 / 89$ \\
\hline 1343 & CBS News/The New York Times & National adult & $4 / 2 / 90$ & 1515 & $4 / 16 / 90$ \\
\hline 1344 & CBS News/The New York Times & National adult & $4 / 10 / 86$ & 1601 & $4 / 14 / 86$ \\
\hline 1345 & CBS News/The New York Times & National adult & $4 / 7 / 79$ & 1158 & $4 / 9 / 79$ \\
\hline 1346 & The Los Angeles Times & National adult & $11 / 14 / 90$ & 1031 & 1990 \\
\hline 1347 & CBS News/The New York Times & National adult & $3 / 27 / 79$ & 1221 & $3 / 28 / 79$ \\
\hline 1348 & CBS News/The New York Times & National adult & $3 / 15 / 80$ & 1468 & $3 / 17 / 80$ \\
\hline 1349 & CBS News/The New York Times & National adult & $2 / 17 / 80$ & 1536 & $2 / 19 / 80$ \\
\hline 1350 & CBS News & National adult & $8 / 8 / 90$ & 773 & $8 / 9 / 90$ \\
\hline 1351 & CBS News & National adult & $5 / 1 / 86$ & 695 & $5 / 2 / 86$ \\
\hline 1352 & $\begin{array}{l}\text { Cambridge Reports } \\
\text { (Sponsor: Union Carbide) }\end{array}$ & National adult & $7 / 29 / 81$ & 1001 & $7 / 81$ \\
\hline 1353 & $\begin{array}{l}\text { Cambridge Reports } \\
\text { (Sponsor: American Retail Federation }\end{array}$ & National adult & $5 / 5 / 80$ & 1503 & $5 / 80$ \\
\hline 1354 & $\begin{array}{l}\text { Audits \& Surveys } \\
\text { (Sponsor: Merit) }\end{array}$ & National adult & $6 / 30 / 83$ & 1221 & $7 / 1 / 83$ \\
\hline
\end{tabular}


Public Opinion Surveys Included in the Study

\begin{tabular}{|c|c|c|c|c|c|}
\hline $\begin{array}{l}\text { Survey } \\
\text { Number }\end{array}$ & $\begin{array}{c}\text { Author or } \\
\text { Polling Organization }\end{array}$ & $\begin{array}{l}\text { Population or } \\
\text { Area Sampled }\end{array}$ & $\begin{array}{l}\text { Ending Date of } \\
\text { Data Collection }\end{array}$ & $\begin{array}{l}\text { Sample } \\
\text { Size }\end{array}$ & $\begin{array}{l}\text { Release } \\
\text { Date }\end{array}$ \\
\hline 1355 & Associated Press/Media General & National adult & $5 / 20 / 90$ & 1143 & $5 / 90$ \\
\hline 1356 & Associated Press/Media General & National adult & $9 / 24 / 89$ & 1071 & $9 / 89$ \\
\hline 1357 & Associated Press/Media General & National adult & $5 / 13 / 89$ & 1084 & $5 / 89$ \\
\hline 1358 & Associated Press/Media General & National adult & $1 / 12 / 89$ & 1162 & $1 / 89$ \\
\hline 1359 & Associated Press/Media General & National adult & $11 / 20 / 88$ & 1084 & $11 / 88$ \\
\hline 1360 & Associated Press/Media General & National adult & $6 / 28 / 86$ & 1365 & $6 / 86$ \\
\hline 1361 & Associated Press & National adult & $8 / 12 / 90$ & 1004 & $8 / 16 / 90$ \\
\hline 1362 & $\begin{array}{l}\text { The Analysis Group (Sponsor: The L.A. } \\
\text { Times, N.Y. Stock Exchange, UCLA Graduate } \\
\text { School of Management) }\end{array}$ & National adult & $1 / 14 / 85$ & 1017 & $4 / 85$ \\
\hline 1363 & ABC News/The Washington Post & National adult & $9 / 8 / 86$ & 1507 & $9 / 8 / 86$ \\
\hline 1364 & $\mathrm{ABC}$ News/The Washington Post & National adult & $5 / 19 / 86$ & 1506 & $5 / 86$ \\
\hline 1365 & ABC News/The Washington Post & National adult & $4 / 28 / 86$ & 1505 & $4 / 28 / 86$ \\
\hline 1366 & $\mathrm{ABC}$ News/The Washington Post & National adult & $4 / 12 / 83$ & 1516 & $4 / 83$ \\
\hline 1367 & $\mathrm{ABC}$ News/The Washington Post & National adult & $11 / 22 / 81$ & 1512 & $11 / 24 / 81$ \\
\hline 1368 & $\mathrm{ABC}$ News/The Washington Post & National adult & $10 / 18 / 81$ & 1505 & $10 / 20 / 81$ \\
\hline 1369 & ABC News/The Washington Post & National adult & 9/20/81 & 1501 & $9 / 20 / 81$ \\
\hline 1370 & ABC News/The Washington Post & National adult & $8 / 21 / 89$ & 1509 & $8 / 89$ \\
\hline 1371 & ABC News/The Washington Post & National adult & $6 / 19 / 89$ & 1546 & $6 / 89$ \\
\hline 1372 & ABC News/The Washington Post & National adult & $5 / 23 / 89$ & 1513 & $5 / 89$ \\
\hline 1373 & $\mathrm{ABC}$ News/The Washington Post & National adult & $3 / 29 / 81$ & 1206 & $4 / 8 / 81$ \\
\hline 1374 & $\mathrm{ABC}$ News/The Washington Post & National adult & $7 / 13 / 88$ & 1500 & $7 / 88$ \\
\hline 1375 & ABC News/The Washington Post & National adult & $2 / 20 / 81$ & 1205 & $2 / 81$ \\
\hline 1376 & $\mathrm{ABC}$ News/The Washington Post & National adult & $6 / 29 / 87$ & 1506 & $6 / 29 / 87$ \\
\hline 1377 & ABC News/The Washington Post & National adult & $6 / 1 / 87$ & 1509 & $6 / 87$ \\
\hline 1378 & $\mathrm{ABC}$ News/The Washington Post & National adult & $1 / 16 / 85$ & 1505 & $1 / 85$ \\
\hline
\end{tabular}


Public Opinion Surveys Included in the Study

\begin{tabular}{|c|c|c|c|c|c|}
\hline $\begin{array}{l}\text { Survey } \\
\text { Number }\end{array}$ & $\begin{array}{l}\text { Author or } \\
\text { Polling Organization }\end{array}$ & $\begin{array}{l}\text { Population or } \\
\text { Area Sampled }\end{array}$ & $\begin{array}{l}\text { Ending Date of } \\
\text { Data Collection }\end{array}$ & $\begin{array}{c}\text { Sample } \\
\text { Size }\end{array}$ & $\begin{array}{c}\text { Release } \\
\text { Date }\end{array}$ \\
\hline 1379 & ABC News/The Washington Post & National adult & $3 / 8 / 82$ & 1672 & $3 / 10 / 82$ \\
\hline 1380 & ABC News/Louis Harris \& Associates & National adult & $2 / 12 / 79$ & 1199 & $3 / 20 / 79$ \\
\hline 1381 & ABC News/Louis Harris \& Associates & National adult & $11 / 29 / 79$ & 1496 & $12 / 10 / 79$ \\
\hline 1382 & ABC News/Louis Harris \& Associates & National adult & $11 / 10 / 80$ & 1199 & $12 / 9 / 80$ \\
\hline 1383 & ABC News/Louis Harris \& Associates & National adult & $11 / 10 / 80$ & 1199 & $12 / 8 / 80$ \\
\hline 1384 & ABC News/Louis Harris \& Associates & National adult & $11 / 10 / 80$ & 1199 & $12 / 3 / 80$ \\
\hline 1385 & ABC News/Louis Harris \& Associates & National adult & $10 / 29 / 79$ & 1500 & $11 / 6 / 79$ \\
\hline 1386 & ABC News/Louis Harris \& Associates & Likely voters & $10 / 6 / 80$ & 1503 & $10 / 16 / 80$ \\
\hline 1387 & ABC News/Louis Harris \& Associates & Likely voters & $9 / 7 / 80$ & 1492 & $9 / 22 / 80$ \\
\hline 1388 & ABC News/Louis Harris \& Associates & National adult & $7 / 15 / 79$ & 1508 & $9 / 6 / 79$ \\
\hline 1389 & ABC News/Louis Harris \& Associates & National adult & $7 / 15 / 79$ & 1508 & $9 / 4 / 79$ \\
\hline 1390 & ABC News/Louis Harris \& Associates & National adult & $7 / 21 / 79$ & 1496 & $8 / 14 / 79$ \\
\hline 1391 & ABC News/Louis Harris \& Associates & National adult & $7 / 21 / 79$ & 1496 & $8 / 13 / 79$ \\
\hline 1392 & ABC News/Louis Harris \& Associates & National adult & $7 / 21 / 79$ & 1496 & $7 / 30 / 79$ \\
\hline 1393 & ABC News/Louis Harris \& Associates & National adult & $6 / 17 / 79$ & 1496 & $7 / 23 / 79$ \\
\hline 1394 & ABC News/Louis Harris \& Associates & National adult & $6 / 17 / 79$ & 1496 & $7 / 12 / 79$ \\
\hline 1395 & ABC News/Louis Harris \& Associates & National adult & $6 / 17 / 79$ & 1496 & $7 / 11 / 79$ \\
\hline 1396 & ABC News/Louis Harris \& Associates & National adult & $6 / 17 / 79$ & 1496 & $7 / 2 / 79$ \\
\hline 1397 & ABC News/Louis Harris \& Associates & National adult & $5 / 22 / 79$ & 1498 & $6 / 21 / 79$ \\
\hline 1398 & ABC News/Louis Harris \& Associates & National adult & $5 / 29 / 79$ & 1200 & $6 / 14 / 79$ \\
\hline 1399 & ABC News/Louis Harris \& Associates & National adult & $5 / 29 / 79$ & 1200 & $6 / 11 / 79$ \\
\hline 1400 & ABC News/Louis Harris \& Associates & National adult & $5 / 11 / 80$ & 1400 & $6 / 8 / 79$ \\
\hline 1401 & ABC News/Louis Harris \& Associates & National adult & $4 / 15 / 79$ & 1510 & $5 / 31 / 79$ \\
\hline 1402 & ABC News/Louis Harris \& Associates & National adult & $4 / 15 / 79$ & 1510 & $5 / 30 / 79$ \\
\hline 1403 & ABC News/Louis Harris \& Associates & National adult & $5 / 1 / 79$ & 1186 & $5 / 26 / 79$ \\
\hline
\end{tabular}


Public Opinion Surveys Included in the Study

\begin{tabular}{|c|c|c|c|c|c|}
\hline $\begin{array}{l}\text { Survey } \\
\text { Number }\end{array}$ & $\begin{array}{c}\text { Author or } \\
\text { Polling Organization }\end{array}$ & $\begin{array}{l}\text { Population or } \\
\text { Area Sampled }\end{array}$ & $\begin{array}{l}\text { Ending Date of } \\
\text { Data Collection }\end{array}$ & $\begin{array}{l}\text { Sample } \\
\text { Size }\end{array}$ & $\begin{array}{l}\text { Release } \\
\text { Date }\end{array}$ \\
\hline 1404 & ABC News/Louis Harris \& Associates & National adult & $4 / 15 / 79$ & 1510 & $5 / 24 / 79$ \\
\hline 1405 & ABC News/Louis Harris \& Associates & National adult & $5 / 18 / 80$ & 1197 & $5 / 22 / 80$ \\
\hline 1406 & ABC News/Louis Harris \& Associates & National adult & $5 / 1 / 79$ & 1186 & $5 / 9 / 79$ \\
\hline 1407 & ABC News/Louis Harris \& Associates & National adult & $4 / 9 / 79$ & 1200 & $5 / 3 / 79$ \\
\hline 1408 & ABC News/Louis Harris \& Associates & National adult & $4 / 9 / 79$ & 1200 & $4 / 30 / 79$ \\
\hline 1409 & ABC News/Louis Harris \& Associates & National adult & $4 / 9 / 79$ & 1200 & $4 / 26 / 79$ \\
\hline 1410 & ABC News/Louis Harris \& Associates & National adult & $3 / 27 / 79$ & 1596 & $4 / 9 / 79$ \\
\hline 1411 & ABC News/Louis Harris \& Associates & National adult & $4 / 5 / 79$ & 1200 & $4 / 6 / 79$ \\
\hline 1412 & ABC News/Louis Harris \& Associates & National adult & $3 / 12 / 79$ & 1500 & $3 / 20 / 79$ \\
\hline 1413 & ABC News/Louis Harris \& Associates & National adult & $9 / 28 / 79$ & 1514 & $3 / 3 / 80$ \\
\hline 1414 & ABC News/Louis Harris \& Associates & National adult & $2 / 12 / 79$ & 1199 & $2 / 22 / 79$ \\
\hline 1415 & ABC News/Louis Harris \& Associates & National adult & $12 / 16 / 79$ & 1500 & $1 / 7 / 80$ \\
\hline 1416 & ABC News (Sponsor: Money Magazine) & National adult & $1 / 10 / 88$ & 513 & $1 / 10 / 88$ \\
\hline 1417 & ABC News (Sponsor: Money Magazine) & National adult & $8 / 23 / 87$ & 522 & $8 / 23 / 87$ \\
\hline 1418 & $A B C$ News & National adult & $4 / 17 / 86$ & 505 & $4 / 17 / 86$ \\
\hline 1419 & $A B C$ News & National adult & $12 / 18 / 82$ & 2464 & $2 / 13 / 83$ \\
\hline 1420 & ABC News & National adult & $9 / 26 / 81$ & 501 & $9 / 27 / 81$ \\
\hline 1421 & ABC News & National adult & $9 / 30 / 90$ & 50 & $10 / 1 / 90$ \\
\hline 1422 & $\begin{array}{l}\text { Mark Clements Research } \\
\text { (Sponsor: Glamour Magazine) }\end{array}$ & Women aged 18-65 & $9 / 29 / 87$ & 800 & 1987 \\
\hline 1423 & $\begin{array}{l}\text { Mark Clements Research } \\
\text { (Sponsor: Glamour Magazine) }\end{array}$ & Women aged $18-65$ & $9 / 1 / 86$ & 800 & 1986 \\
\hline 1424 & $\begin{array}{l}\text { Alice M. Crites (Sponsor: } \\
\text { Nevada Cooperative Extension) }\end{array}$ & $\begin{array}{l}\text { Southern Nevada } \\
\text { LIHEAP participant }\end{array}$ & $7 / 89$ & 711 & $2 / 15 / 90$ \\
\hline 1425 & Cambridge Reports/Research International & National adult & $1 / 7 / 91$ & 1250 & $4 / 91$ \\
\hline 1426 & Purposely not used. & & & & \\
\hline
\end{tabular}


Public Opinion Surveys Included in the Study

\begin{tabular}{cccccc}
\hline $\begin{array}{c}\text { Survey } \\
\text { Number }\end{array}$ & Author or & Population or & Ending Date of & Sample & Release \\
& Polling Organization & Area Sampled & Data Collection & Size & Date \\
\hline
\end{tabular}

1427 Miller, J. D.

Nat'l science, environmental,
and utility leaders

747

$11 / 1 / 86$

1428 The Wirthlin Group

Adults in Baltimore, Chicago, $\quad 4 / 26 / 90$

900

$4 / 90$ Houston, Milwaukee, New York,
and Philadelphia

1429 RPM Systems, Inc. (Sponsor: Connecticut

Connecticut residents

$1 / 23 / 89$

406

$4 / 89$

Office of Policy and Management, Energy

Division)

1430 Saurage-Thibodeaux Research, Inc. (Sponsor

Louisiana adult residents

$6 / 90$

1007

$10 / 90$

Louisiana Department of Natural Resources,

Energy Division)

1431 The Analysis Group

Registered voters

$9 / 14 / 88$

1001

$9 / 88$

1432 Behavior Research Center, Inc.

(Sponsor: Arizona Department of Commerce,

Phoenix, AZ heads of

$2 / 91$

600

$2 / 91$

Energy Development and Utilization Division) households

1433

Berkeley Solar Group and Xenergy. (Sponsor

California Energy Commission: Energy

Efficiency \& Local Assistance Division;

Demand Side Program Evaluation Office)

1434

Center for Governmental Sciences (Sponsor:

Alabama residents

ingle-family bouse

1987

2845

$9 / 90$

Alabama Department of Economic and Community

occupants

Affairs, Division of Science, Technology

and Energy)

1435 Saurage-Thibodeaux Research, Inc. (Sponsor: Louisiana opinion leaders

$7 / 90$

98

$10 / 90$

Louisiana Department of Natural Resources,

Energy Division)

1436 Craig Group, Inc. (Sponsor:

Mid-Ohio Regional Planning Commission)
Columbus, $\mathrm{OH}$ metro residents

$1 / 90$

454

$2 / 90$

National adult

$8 / 24 / 91$

1004

$10 / 19 / 91$

the Environment)

1438 Eagleton Institute of Politics (Sponsor:

New Jersey households

$11 / 81$

1216

$3 / 82$

New Jersey Department of Energy)

1439 Purposely not used.

1440

Genereux, John P. and M. Michele (Sponsor:

St. Paul, MN residents

$3 / 82$

50

$5 / 20 / 82$ 
Public Opinion Surveys Included in the Study

\begin{tabular}{|c|c|c|c|c|c|}
\hline $\begin{array}{l}\text { Survey } \\
\text { Number }\end{array}$ & $\begin{array}{l}\text { Author or } \\
\text { Polling Organization }\end{array}$ & $\begin{array}{l}\text { Population or } \\
\text { Area Sampled }\end{array}$ & $\begin{array}{l}\text { Ending Date of } \\
\text { Data Collection }\end{array}$ & $\begin{array}{l}\text { Sample } \\
\text { Size }\end{array}$ & $\begin{array}{l}\text { Release } \\
\text { Date }\end{array}$ \\
\hline 1441 & $\begin{array}{l}\text { Louis Harris and Associates } \\
\text { (Sponsor: Business Week) }\end{array}$ & National adult & $12 / 2 / 91$ & 1258 & $12 / 2 / 91$ \\
\hline 1442 & Georgia Office of Energy Resources & $\begin{array}{l}\text { Jeorgia residents requesting } \\
\text { informational materials }\end{array}$ & $10 / 85$ & 228 & $10 / 85$ \\
\hline 1443 & $\begin{array}{l}\text { Grapentine Company (Sponsor: Iowa } \\
\text { Energy Policy Counil) }\end{array}$ & Iowa households & $12 / 81$ & 605 & $8 / 82$ \\
\hline 1444 & Indiana Department of Commerce & Indiana residents & $12 / 88$ & 1089 & 1988 \\
\hline 1445 & Indiana Department of Commerce & Indiana residents & $12 / 88$ & 777 & $1 / 89$ \\
\hline 1446 & $\begin{array}{l}\text { Grapentine Company (Sponsor: Iowa } \\
\text { Energy Policy Council) }\end{array}$ & $\begin{array}{l}\text { lowa employers with more } \\
\text { than } 100 \text { employees }\end{array}$ & $2 / 82$ & 100 & $8 / 82$ \\
\hline 1447 & Institute for Policy Research & Ohio residents & $2 / 82$ & 1024 & $3 / 23 / 82$ \\
\hline 1448 & $\begin{array}{l}\text { Office of Public Service and Research (Sponsor: } \\
\text { Alabama Department of Economic and } \\
\text { Community Affairs, Division of Energy) }\end{array}$ & Alabama residents & 1984 & 414 & $2 / 85$ \\
\hline 1449 & Institute for Policy Research & Ohio residents & $7 / 83$ & 1002 & $9 / 83$ \\
\hline 1450 & Arsen J. Darnay, ed. & $\begin{array}{l}\text { National adult } \\
\text { compilation of various } \\
\text { survey results, compilation }\end{array}$ & 1992 & - & 1992 \\
\hline 1451 & $\begin{array}{l}\text { Martilla \& Kiley (Sponsor: } \\
\text { Detroit Free Press) }\end{array}$ & $\begin{array}{l}\text { National auto owners who } \\
\text { are active drivers }\end{array}$ & $1 / 20 / 92$ & 607 & $1 / 24 / 92$ \\
\hline 1452 & Institute for Policy Research & Ohio residents & $2 / 85$ & 826 & $4 / 23 / 85$ \\
\hline 1453 & $\begin{array}{l}\text { Roper Organization (Sponsor: } \\
\text { S. C. Johnson and Son, Inc.) }\end{array}$ & National adult & $3 / 3 / 90$ & 1413 & $7 / 90$ \\
\hline 1454 & Institute for Policy Research & Ohio residents & $2 / 89$ & 811 & $7 / 10 / 89$ \\
\hline 1455 & Yankelovich, Clancy, Shulman (Sponsor: Time) & National adult & $2 / 18 / 87$ & 1014 & $2 / 18 / 87$ \\
\hline 1456 & $\begin{array}{l}\text { Gallup Organization (Sponsor: Advisory } \\
\text { Commission on Intergovernmental Relations) }\end{array}$ & National adult & $6 / 14 / 87$ & 1044 & $7 / 87$ \\
\hline 1457 & $\begin{array}{l}\text { Cambridge Reports/Research } \\
\text { International }\end{array}$ & $\begin{array}{l}\text { National residential } \\
\text { electricity customers }\end{array}$ & $9 / 17 / 90$ & 1250 & 1990 \\
\hline 1458 & National Opinion Research Center & National adult & $4 / 91$ & 1517 & 9/91 \\
\hline
\end{tabular}


Public Opinion Surveys Included in the Study

\begin{tabular}{ll}
$\begin{array}{c}\text { Survey } \\
\text { Number }\end{array}$ & \multicolumn{1}{c}{$\begin{array}{c}\text { Author or } \\
\text { Polling Organization }\end{array}$} \\
\hline 1459 & $\begin{array}{l}\text { Institute for Public Policy (Sponsor: } \\
\text { New Mexico State Energy, Minerals and } \\
\text { Natural Resources Department) }\end{array}$ \\
1460 & $\begin{array}{l}\text { Institute for Social Research (Sponsor: } \\
\text { U.S. Department of Energy; Connecticut Office } \\
\text { of Policy and Management, Energy Division) }\end{array}$ \\
1461 & $\begin{array}{l}\text { Purposely not used. } \\
1462\end{array}$ \\
& $\begin{array}{l}\text { Market Strategies and Greenberg-Lake } \\
\text { (Sponsor: Americans Talk Issues Foundation) }\end{array}$
\end{tabular}

New Mexico residents

$7 / 90$

785

$8 / 90$

Connecticut residents

$11 / 85$

519

$3 / 86$

(Sponsor: Americans Talk Issues Foundation)

National adult

$12 / 2 / 91$

1000

$12 / 91$

1463 Purposely not used.

1464 Lindquist, Eric A. and Nicole L. Vautour (Sponsor: Central Maine Power Company)

$$
\begin{aligned}
& \text { Maine residential wind } \\
& \text { generator owners }
\end{aligned}
$$

1465 Purposely not used.

1466 Schwartz, Brad Alan (Sponsor: Office of Energy Conservation, Ohio Department of Development)

Ohio Energy Action Loan recipient households

$8 / 85$

2000 $3 / 86$

National voters

$7 / 1 / 90$

1004

$8 / 90$

(Sponsor: Environment Opinion Study, Inc.)

1469 Purposely not used.

1470 Minnesota Energy Office

Minnesota residents claiming

1985 renewable energy tax credits

1471 Purposely not used.

1472 Purposely not used.

Ohio utility customers

National adult

1474 Gallup Organization

1475

Smith, Wil J., Frederick A. Zeller, Joyce A. West Virginia households Coombs and Paul J. Martin (Sponsor: West $10 / 89$ 1732 Virginia Governor's Office of Community and Industrial Development, Fuel and Energy Office) 


\section{Public Opinion Surveys Included in the Study}

\begin{tabular}{|c|c|c|c|c|c|}
\hline $\begin{array}{l}\text { Survey } \\
\text { Number }\end{array}$ & $\begin{array}{l}\text { Author or } \\
\text { Polling Organization }\end{array}$ & $\begin{array}{l}\text { Population or } \\
\text { Area Sampled }\end{array}$ & $\begin{array}{l}\text { Ending Date of } \\
\text { Data Collection }\end{array}$ & $\begin{array}{l}\text { Sample } \\
\text { Size }\end{array}$ & $\begin{array}{l}\text { Release } \\
\text { Date }\end{array}$ \\
\hline 1476 & $\begin{array}{l}\text { Strategic Consumer Research (Sponsor: Public } \\
\text { Utilities Commission of Ohio) }\end{array}$ & Ohio utility customers & $5 / 89$ & 3600 & 1989 \\
\hline 1477 & $\begin{array}{l}\text { Yankelovich, Clancy, Shulman } \\
\text { (Sponsor: Time, Cable News Network) }\end{array}$ & National adult & $1 / 8 / 92$ & 500 & $1 / 8 / 92$ \\
\hline 1478 & Purposely not used. & & & & \\
\hline 1479 & Office of the Consumers' Council & Ohio utility customers & $8 / 81$ & 1891 & $9 / 81$ \\
\hline 1480 & Office of the Consumers' Council & Ohio utility customers & $8 / 87$ & 812 & $10 / 87$ \\
\hline 1481 & Office of the Consumers' Council & Ohio utility customers & $8 / 89$ & 69 & $10 / 89$ \\
\hline 1482 & Office of the Consumers' Council & Ohio utility customers & $10 / 90$ & 373 & $1 / 91$ \\
\hline 1483 & $\begin{array}{l}\text { Office of Public Service and Research (Sponsor: } \\
\text { Alabama Department of Economic and } \\
\text { Community Affairs, Division of Energy) }\end{array}$ & Alabama residents & 1984 & 36 & $2 / 85$ \\
\hline 1484 & Purposely not used. & & & & \\
\hline 1485 & National Family Opinion Research & National adult & $2 / 90$ & 7000 & $2 / 90$ \\
\hline 1486 & $\begin{array}{l}\text { Hart and Teeter Research Companies } \\
\text { (Sponsor: NBC News, The Wall Street Journal) }\end{array}$ & Registered voters & $7 / 29 / 91$ & 1004 & $8 / 5 / 91$ \\
\hline 1487 & The Los Angeles Times & National adult & $4 / 9 / 91$ & 1761 & $4 / 91$ \\
\hline 1488 & $\begin{array}{l}\text { Market Strategies and Greenberg-Lake } \\
\text { (Sponsor: Americans Talk Issues Foundaton) }\end{array}$ & National adult & $7 / 1 / 91$ & 1000 & $7 / 91$ \\
\hline 1489 & Gallup Organization & National adult & $7 / 21 / 91$ & 1002 & $7 / 31 / 91$ \\
\hline 1490 & The Washington Post & National adult & $3 / 19 / 91$ & 1015 & $3 / 91$ \\
\hline 1491 & CBS News/The New York Times & National adult & $6 / 6 / 91$ & 1424 & $6 / 91$ \\
\hline 1492 & Associated Press & National adult & $7 / 21 / 91$ & 1002 & $7 / 91$ \\
\hline 1493 & Gallup Organization & National adult & $4 / 14 / 91$ & 1007 & $4 / 91$ \\
\hline 1494 & $\begin{array}{l}\text { Yankelovich, Clancy, Shulman } \\
\text { (Sponsor: Time, Cable News Network) }\end{array}$ & National adult & $5 / 8 / 91$ & 500 & $6 / 91$ \\
\hline 1495 & $\begin{array}{l}\text { Princeton Survey Research Associates } \\
\text { (Sponsor: Times Mirror) }\end{array}$ & National adult & $5 / 19 / 91$ & 1206 & $5 / 23 / 91$ \\
\hline
\end{tabular}


Public Opinion Surveys Included in the Study

\begin{tabular}{|c|c|c|c|c|c|}
\hline $\begin{array}{c}\text { Survey } \\
\text { Number }\end{array}$ & $\begin{array}{l}\text { Author or } \\
\text { Polling Organization }\end{array}$ & $\begin{array}{l}\text { Population or } \\
\text { Area Sampled }\end{array}$ & $\begin{array}{l}\text { Ending Date of } \\
\text { Data Collection }\end{array}$ & $\begin{array}{l}\text { Sample } \\
\text { Size }\end{array}$ & $\begin{array}{l}\text { Release } \\
\text { Date }\end{array}$ \\
\hline 1496 & $\begin{array}{l}\text { Yankelovich, Clancy, Shulman } \\
\text { (Sponsor: Time, Cable News Network) }\end{array}$ & National adult & $4 / 11 / 91$ & 1000 & $5 / 16 / 91$ \\
\hline 1497 & Gallup Organization & National adult & $4 / 28 / 91$ & 1005 & $5 / 3 / 91$ \\
\hline 1498 & $\begin{array}{l}\text { Market Strategies (Sponsor: } \\
\text { Americans Talk Security) }\end{array}$ & National adult & $3 / 24 / 91$ & 1000 & $3 / 91$ \\
\hline 1499 & Louis Harris and Associates & National adult & $4 / 2 / 91$ & 1255 & $5 / 5 / 91$ \\
\hline 1500 & $\begin{array}{l}\text { Hart and Teeter Research Companies } \\
\text { (Sponsor: NBC News, The Wall Street Journal) }\end{array}$ & Registered voters & $3 / 19 / 91$ & 1505 & $3 / 29 / 91$ \\
\hline 1501 & Gallup Organization & National adult & $2 / 10 / 91$ & 1013 & $2 / 20 / 91$ \\
\hline 1502 & Gallup Organization & National adult & $2 / 2 / 91$ & 1005 & $2 / 30 / 91$ \\
\hline 1503 & Gallup Organization & National adult & $1 / 26 / 91$ & 1011 & $1 / 27 / 91$ \\
\hline 1504 & ABC News/The Washington Post & National adult & $3 / 4 / 91$ & 1215 & $3 / 6 / 91$ \\
\hline 1505 & $\begin{array}{l}\text { Yankelovich, Clancy, Shulman } \\
\text { (Sponsor: Time, Cable News Network) }\end{array}$ & National adult & $1 / 24 / 91$ & 1000 & $1 / 29 / 91$ \\
\hline 1506 & $\begin{array}{l}\text { Hart and Teeter Research Companies } \\
\text { (Sponsor: NBC News, The Wall Street Journal) }\end{array}$ & Registered voters & $1 / 23 / 91$ & 808 & $1 / 30 / 91$ \\
\hline 1507 & The Los Angeles Times & National adult & $2 / 17 / 91$ & 1822 & $2 / 22 / 91$ \\
\hline 1508 & The Los Angeles Times & National adult & $1 / 18 / 91$ & 1406 & $1 / 31 / 91$ \\
\hline 1509 & $\begin{array}{l}\text { Louis Harris and Associates } \\
\text { (Sponsor: National Public Radio) }\end{array}$ & National adult & $2 / 24 / 91$ & 1253 & $2 / 25 / 91$ \\
\hline 1510 & Gallup Organization & National adult & $1 / 13 / 91$ & 1004 & $1 / 15 / 91$ \\
\hline 1511 & Cambridge Reports & National adult & $5 / 80$ & b & $5 / 80$ \\
\hline 1512 & Power-Robertson \& Company & $\begin{array}{l}\text { National owners of electric } \\
\text { vehicles }\end{array}$ & $11 / 20 / 75$ & 116 & $11 / 20 / 75$ \\
\hline 1513 & Power-Robertson \& Company & $\begin{array}{l}\text { National owners of electric } \\
\text { vehicles }\end{array}$ & $6 / 15 / 77$ & 195 & $6 / 25 / 77$ \\
\hline 1514 & David S. Bunch et al. & outhern California residents & $8 / 26 / 91$ & 700 & $8 / 26 / 91$ \\
\hline
\end{tabular}

\footnotetext{
bInformation not available.
} 
Public Opinion Surveys Included in the Study

\begin{tabular}{|c|c|c|c|c|c|}
\hline $\begin{array}{l}\text { Survey } \\
\text { Number }\end{array}$ & $\begin{array}{c}\text { Author or } \\
\text { Polling Organization }\end{array}$ & $\begin{array}{l}\text { Population or } \\
\text { Area Sampled }\end{array}$ & $\begin{array}{l}\text { Ending Date of } \\
\text { Data Collection }\end{array}$ & $\begin{array}{l}\text { Sample } \\
\text { Size }\end{array}$ & $\begin{array}{c}\text { Release } \\
\text { Date }\end{array}$ \\
\hline 1515 & Daniel Sperling et al. & $\begin{array}{l}\text { California and New York } \\
\text { registered vehicle owners }\end{array}$ & $8 / 91$ & 1876 & $8 / 91$ \\
\hline 1516 & $\begin{array}{l}\text { Yankelovich, Clancy, Shulman } \\
\text { (Sponsor: Time, CNN) }\end{array}$ & National adult & $1 / 10 / 89$ & 1012 & $1 / 17 / 89$ \\
\hline 1517 & Roper Organization & National adult & $2 / 28 / 87$ & 1996 & $5 / 87$ \\
\hline 1518 & National Opinion Research Center & National adult & $4 / 89$ & 1537 & $7 / 89$ \\
\hline 1519 & National Opinion Research Center & National adult & $4 / 88$ & 1481 & $7 / 88$ \\
\hline 1520 & National Opinion Research Center & National adult & $4 / 87$ & 1466 & $7 / 87$ \\
\hline 1521 & NBC News and The Wall Street Journal & National adult & $4 / 14 / 87$ & 2304 & $4 / 24 / 87$ \\
\hline 1522 & The Los Angeles Times & National adult & $11 / 21 / 89$ & 1623 & $11 / 89$ \\
\hline 1523 & $\begin{array}{l}\text { Gallup Organization (Sponsor: Advisory } \\
\text { Commission on Intergovernmental Relations) }\end{array}$ & National adult & $6 / 19 / 88$ & 1013 & 7/88 \\
\hline 1524 & $\begin{array}{l}\text { Peter D. Hart Research Associates } \\
\text { (Sponsor: NBC News, Newsweek) }\end{array}$ & $\begin{array}{l}\text { Nat'l adult with oversamples } \\
\text { of residents in cities of } \\
200,000 \text { or more, and of blacks }\end{array}$ & $7 / 18 / 91$ & 1218 & 7/91 \\
\hline 1525 & $\begin{array}{l}\text { Louis Harris and Associates (Sponsor: } \\
\text { National Organization on Disability) }\end{array}$ & National adult & $6 / 18 / 91$ & 1257 & $6 / 91$ \\
\hline 1526 & The Washington Post & National adult & $6 / 19 / 88$ & 1012 & $6 / 88$ \\
\hline 1527 & $\begin{array}{l}\text { Research and Forecasts (Sponsor: } \\
\text { Mitchum Anti-Perspirant and Deododrant) }\end{array}$ & National adult & $1 / 7 / 90$ & 501 & $3 / 90$ \\
\hline 1528 & Opinion Research Corporation & National adult & $4 / 16 / 90$ & 1046 & $6 / 28 / 90$ \\
\hline 1529 & $\begin{array}{l}\text { Hamilton, Frederick and Schneiders } \\
\text { (Sponsor: Tobacco Institute) }\end{array}$ & National adult & $12 / 6 / 88$ & 1500 & $12 / 88$ \\
\hline 1530 & Purposely not used. & & & & \\
\hline 1531 & The Washington Post & National adult & $3 / 26 / 90$ & 1016 & $3 / 90$ \\
\hline 1532 & Gallup Organization & National adult & $4 / 8 / 90$ & 1223 & $4 / 11 / 90$ \\
\hline 1533 & $\begin{array}{l}\text { SERI/Gallup } \\
\text { (Farhar-Pilgrim and Unseld) }\end{array}$ & National homeowners & $11 / 24 / 80$ & 2023 & 1982 \\
\hline 1534 & $\begin{array}{l}\text { Smith and Loveland } \\
\text { (League of Women Voters) }\end{array}$ & $\begin{array}{l}\text { Energy leaders and } \\
\text { Gallup onmibus survey }\end{array}$ & $4 / 30 / 88$ & $\begin{array}{r}271 \\
1013\end{array}$ & 1988 \\
\hline
\end{tabular}


Public Opinion Surveys Included in the Study

\begin{tabular}{|c|c|c|c|c|c|}
\hline $\begin{array}{l}\text { Survey } \\
\text { Number }\end{array}$ & $\begin{array}{c}\text { Author or } \\
\text { Polling Organization }\end{array}$ & $\begin{array}{l}\text { Population or } \\
\text { Area Sampled }\end{array}$ & $\begin{array}{l}\text { Ending Date of } \\
\text { Data Collection }\end{array}$ & $\begin{array}{l}\text { Sample } \\
\text { Size }\end{array}$ & $\begin{array}{l}\text { Release } \\
\text { Date }\end{array}$ \\
\hline 1535 & $\begin{array}{l}\text { New York Power Authority \& } \\
\text { Century Opinion Polls }\end{array}$ & New York state adult & $5 / 22 / 89$ & 1003 & $11 / 89$ \\
\hline 1536 & $\begin{array}{l}\text { New York Power Authority \& } \\
\text { Century Opinion Polls }\end{array}$ & New York state adult & $5 / 22 / 89$ & 1003 & $10 / 89$ \\
\hline 1537 & New York Power Authority & New York state adult & $5 / 22 / 89$ & 1003 & $10 / 89$ \\
\hline 1538 & Roper Organization & National adult & $3 / 18 / 89$ & 1977 & $6 / 89$ \\
\hline 1539 & Roper Organization & National adult & $12 / 10 / 88$ & 1974 & $2 / 89$ \\
\hline 1540 & Roper Organization & National adult & $1 / 21 / 89$ & 1968 & $4 / 89$ \\
\hline 1541 & Roper Organization & National adult & $2 / 25 / 89$ & 1992 & $5 / 89$ \\
\hline 1542 & Roper Organization & National aduIt & $4 / 22 / 89$ & 1986 & $7 / 89$ \\
\hline 1543 & Roper Organization & National adult & $5 / 20 / 89$ & 1986 & $8 / 89$ \\
\hline 1544 & Roper Organization & National adult & $7 / 22 / 89$ & 1979 & $10 / 89$ \\
\hline 1545 & Roper Organization & National adult & $8 / 19 / 89$ & 1991 & $11 / 89$ \\
\hline 1546 & Roper Organization & National adult & $9 / 23 / 89$ & 1972 & $12 / 89$ \\
\hline 1547 & Roper Organization & National adult & $12 / 9 / 89$ & 1960 & $2 / 90$ \\
\hline 1548 & Roper Organization & National adult & $1 / 20 / 90$ & 1994 & $3 / 90$ \\
\hline 1549 & Roper Organization & National adult & $3 / 17 / 90$ & 1975 & $6 / 90$ \\
\hline 1550 & Roper Organization & National adult & $4 / 90$ & c & $6 / 90$ \\
\hline $155 !$ & Roper Organization & National audult & $7 / 21 / 90$ & 1995 & $9 / 90$ \\
\hline 1552 & Roper Organization & National adult & $8 / 11 / 90$ & 1997 & $10 / 90$ \\
\hline 1553 & Roper Organization & National adult & $5 / 18 / 91$ & 1987 & $8 / 91$ \\
\hline 1554 & Roper Organization & National adult & $9 / 15 / 90$ & 1988 & $12 / 90$ \\
\hline 1555 & Roper Organization & National adult & $10 / 27 / 90$ & 1990 & $1 / 91$ \\
\hline 1556 & Roper Organization & National adult & $12 / 8 / 90$ & 1993 & 2/91 \\
\hline
\end{tabular}

\footnotetext{
${ }^{\mathrm{C}}$ Information not available.
} 
Public Opinion Surveys Included in the Study

\begin{tabular}{|c|c|c|c|c|c|}
\hline $\begin{array}{l}\text { Survey } \\
\text { Number }\end{array}$ & $\begin{array}{c}\text { Author or } \\
\text { Polling Organization }\end{array}$ & $\begin{array}{l}\text { Population or } \\
\text { Area Sampled }\end{array}$ & $\begin{array}{l}\text { Ending Date of } \\
\text { Data Collection }\end{array}$ & $\begin{array}{l}\text { Sample } \\
\text { Size }\end{array}$ & $\begin{array}{l}\text { Release } \\
\text { Date }\end{array}$ \\
\hline 1557 & Roper Organization & National adult & $2 / 23 / 91$ & 1970 & $5 / 92$ \\
\hline 1558 & Roper Organization & National adult & $4 / 20 / 91$ & 1972 & $6 / 91$ \\
\hline 1559 & Roper Organization & National adult & $2 / 23 / 91$ & 1984 & $7 / 91$ \\
\hline 1560 & $\begin{array}{l}\text { Riley E. Dunlap, George H. } \\
\text { Gallup, Jr. and Alec M. Gallup } \\
\text { (Sponsors: Varied inter- } \\
\text { national organizations and } \\
\text { governments, including the } \\
\text { United States) }\end{array}$ & $\begin{array}{l}22 \text { nations including } \\
\text { the United States }\end{array}$ & $3 / 21 / 92$ & $\begin{array}{r}25,000+ \\
(1032 \text { U.S.) }\end{array}$ & $5 / 92$ \\
\hline 1561 & $\begin{array}{l}\text { Frederick/Schneiders, Inc. } \\
\text { (Safe Energy Communication Council) }\end{array}$ & National adult & $3 / 92$ & 750 & $3 / 92$ \\
\hline 1562 & $\begin{array}{l}\text { Cambridge Energy Research Associates, } \\
\text { Inc. and Opinion Dynamics }\end{array}$ & National adult & $1 / 92$ & 1,200 & $6 / 92$ \\
\hline 1563 & Newsweek Survey & New car buyers & 1990 & $14,000+$ & $6 / 91$ \\
\hline 1564 & Gallup Organization & National adult & $10 / 3 / 77$ & 1509 & $10 / 3 / 77$ \\
\hline 1565 & $\begin{array}{l}\text { Peter D. Hart Research Associates } \\
\text { (U.S. Department of Transportation) }\end{array}$ & National adult & $12 / 20 / 77$ & 1538 & $1 / 78$ \\
\hline 1566 & Louis Harris and Associates & National adult & $4 / 3 / 78$ & 1529 & $6 / 1 / 78$ \\
\hline 1567 & ABC News/Louis Harris and Associates & National adult & $5 / 18 / 80$ & 1197 & $6 / 3 / 80$ \\
\hline 1568 & $\begin{array}{l}\text { Cambridge Reports } \\
\text { (U.S. Council for Energy Awareness) }\end{array}$ & National adult & $2 / 14 / 90$ & 1250 & $2 / 90$ \\
\hline 1569 & $\begin{array}{l}\text { League of Women Voters (LWV) } \\
\text { Education Fund (M. Hewitt) }\end{array}$ & LWV & $\begin{array}{l}\text { Summer } \\
1992\end{array}$ & 1150 & $12 / 92$ \\
\hline
\end{tabular}




\section{Appendix C}

\section{State Financial Incentives for Renewable Energy Systems*}

\begin{tabular}{|l|l|l||}
\hline \multicolumn{1}{|c|}{ State } & \multicolumn{1}{|c|}{$\begin{array}{c}\text { Income Tax Credits for Solar } \\
\text { and Renewable Energy Systems }\end{array}$} & \multicolumn{1}{|c|}{$\begin{array}{c}\text { Tax Credit } \\
\text { Expiration Date }\end{array}$} \\
\hline \hline AL & None & N/A \\
\hline AK & None & N/A \\
\hline AZ & $\begin{array}{l}\text { Solar home program to provide home } \\
\text { builders with market incentives to } \\
\text { incorporate solar energy features in new } \\
\text { homes. }\end{array}$ & Unavailable \\
\hline AR & None & N/A \\
\hline CA & $\begin{array}{l}\text { Tax credit equal to 10\% of the installed cost } \\
\text { of solar energy systems used for commercial } \\
\text { purposes. }\end{array}$ & $12 / 93$ \\
\hline CO & $\begin{array}{l}\text { Tax credits for commercial applications are } \\
30 \% .\end{array}$ & $12 / 86$ \\
\hline CT & $\begin{array}{l}\text { Solar equipment exempt from sales and use } \\
\text { tax; property tax exemptions are available in } \\
\text { many towns in the state. }\end{array}$ & $12 / 86$ \\
\hline DE & None & N/A \\
\hline FL & $\begin{array}{l}\text { Renewable energy source exemptions } \\
\text { offered for improved real property upon } \\
\text { which a solar system has been installed. } \\
\text { Exemption cannot exceed 8\% of the } \\
\text { assessed value of the property. }\end{array}$ & N/A \\
\hline IL & $\begin{array}{l}\text { Tax credits for residential and commercial } \\
\text { applications are 10\% and 20\%, respectively. }\end{array}$ & $12 / 89$ \\
\hline IN & $\begin{array}{l}\text { 20\% state tax credit } \\
\text { Tax deduction of 40\% of the cost of a } \\
\text { system for the first year, 20\% for up to } \\
3 \text { years, or a maximum of \$5,000. }\end{array}$ & Open-ended \\
\hline HI & $\begin{array}{l}\text { None } \\
\text { Property tax deductions are administered } \\
\text { locally, with the value of the solar system } \\
\text { deducted from the appraised value of the } \\
\text { home. }\end{array}$ & N/A \\
\hline ID & N/A \\
\hline
\end{tabular}

\footnotetext{
*Sources: Ridley (1987) and Solar Industry Journal (1990)
} 


\begin{tabular}{|c|c|c|}
\hline State & $\begin{array}{l}\text { Income Tax Credits for Solar } \\
\text { and Renewable Energy Systems }\end{array}$ & $\begin{array}{c}\text { Tax Credit } \\
\text { Expiration Date }\end{array}$ \\
\hline A & $\begin{array}{l}\text { Property tax exemption to solar system } \\
\text { purchasers. }\end{array}$ & N/A \\
\hline KS & None & N/A \\
\hline KY & None & N/A \\
\hline LA & None & N/A \\
\hline ME & None & N/A \\
\hline MD & $\begin{array}{l}\text { Counties have option to offer property tax } \\
\text { exemption. }\end{array}$ & N/A \\
\hline MA & State tax credit is $25 \%$ this year. & N/A \\
\hline MI & Tax credit is $30 \%$ of the first $\$ 2,000$. & N/A \\
\hline MN & $\begin{array}{l}\text { Offers double-declining balance } 5 \text {-year- } \\
\text { depreciation schedule for qualifying } \\
\text { renewable energy equipment. }\end{array}$ & N/A \\
\hline MS & None & N/A \\
\hline MO & $\begin{array}{l}\text { Income tax credit for systems using } \\
\text { nonfossil fuel sources; maximum credit is } \\
\$ 125 \text {, or } 5 \% \text { of the first } \$ 1,000 \text { of system } \\
\text { cost, and } 2.5 \% \text { of the next } \$ 3,000 \text {. Also, } \\
\text { there is a } 10 \text {-year property-tax exemption } \\
\text { based on the value of the system. Passive } \\
\text { solar-energy systems are eligible for both the } \\
\text { income tax credit and the property tax } \\
\text { exemption. Other income tox credits are } \\
\text { available for energy conservation } \\
\text { improvements in residences and commercial, } \\
\text { industrial, and agricultural buildings. }\end{array}$ & N/A \\
\hline $\mathrm{NE}$ & None & $\mathrm{N} / \mathrm{A}$ \\
\hline NV & $\begin{array}{l}\text { Tax credits for commercial and residential } \\
\text { applications are } 35 \% \text {. }\end{array}$ & $\mathrm{N} / \mathrm{A}$ \\
\hline NH & $\begin{array}{l}\text { Towns in the state may give property tax } \\
\text { exemptions at their option. }\end{array}$ & N/A \\
\hline NJ & $\begin{array}{l}\text { Solar systems are exempt from state sales } \\
\text { and use taxes. The installation of solar } \\
\text { equipment is exempt from construction } \\
\text { permit fees. }\end{array}$ & N/A \\
\hline NM & $\begin{array}{l}\text { Tax credits for commercial and residential } \\
\text { applications: } 25 \% \text {. }\end{array}$ & $12 / 89$ \\
\hline
\end{tabular}




\begin{tabular}{|c|c|c|}
\hline State & $\begin{array}{l}\text { Income Tax Credits for Solar } \\
\text { and Renewable Energy Systems }\end{array}$ & $\begin{array}{c}\text { Tax Credit } \\
\text { Expiration Date }\end{array}$ \\
\hline NY & $\begin{array}{l}\text { A real property tax exemption is offered for } \\
\text { solar and wind systems, exempting property } \\
\text { owners from paying increased property taxes } \\
\text { for } 15 \text { years after the facility has been } \\
\text { installed. }\end{array}$ & $\mathrm{N} / \mathrm{A}$ \\
\hline $\mathrm{NC}$ & $\begin{array}{l}\text { Tax credits of } 25 \% \text { have been in effect for } \\
\text { solar heating, cooling, and water systems, } \\
\text { and photovoltaics. }\end{array}$ & N/A \\
\hline ND & $\begin{array}{l}\text { The tax credit is } 5 \% \text { per year for } 3 \text { years, } \\
\text { based on the cost and installation of the } \\
\text { system. Property tax exemptions are valid } \\
\text { for } 5 \text { years following the date of system } \\
\text { installation. }\end{array}$ & $\mathrm{N} / \mathrm{A}$ \\
\hline $\mathrm{OH}$ & $\begin{array}{l}\text { Solar systems are exempt from real property } \\
\text { taxes. }\end{array}$ & N/A \\
\hline OK & $\begin{array}{l}\text { Residential tax credits of } 35 \% \text {, up to } \\
\$ 10,000 \text {; commercial credits of } 30 \% \text {. }\end{array}$ & $12 / 90$ \\
\hline OR & $\begin{array}{l}\text { Residential tax credit program covers solar, } \\
\text { geothermal, hydro, and wind energy } \\
\text { systems. Tax credits are based on energy } \\
\text { savings. 35\% credit for commercial } \\
\text { business on the cost of energy projects, } \\
\text { taken over } 5 \text { years. }\end{array}$ & $12 / 95$ \\
\hline PA & None & N/A \\
\hline RI & $\begin{array}{l}\text { Tax credits for commercial and residential } \\
\text { applications are } 10 \% \text {. }\end{array}$ & N/A \\
\hline SC & $\begin{array}{l}\text { Tax credits for commercial and residential } \\
\text { applications are } 25 \% \text {. }\end{array}$ & Open-ended \\
\hline SD & None & $\mathrm{N} / \mathrm{A}$ \\
\hline TN & $\begin{array}{l}\text { Loan program for energy conservation in } \\
\text { small business. Rates are } 5 \% \text { interest up to } \\
\$ 100,000 \text {. }\end{array}$ & N/A \\
\hline TX & Property tax exemption is in effect. & $\mathrm{N} / \mathrm{A}$ \\
\hline UT & $\begin{array}{l}\text { An energy saving systems tax credit allows } \\
\text { owners of residential systems a credit of } \\
25 \% \text { of the system cost, up to } \$ 1,500 \text {. }\end{array}$ & $12 / 90$ \\
\hline vT & None & N/A \\
\hline
\end{tabular}




\begin{tabular}{||l|l|l||}
\hline \multicolumn{1}{|c|}{ State } & \multicolumn{1}{|c|}{$\begin{array}{c}\text { Income Tax Credits for Solar } \\
\text { and Renewable Energy Systems }\end{array}$} & \multicolumn{1}{|c|}{$\begin{array}{c}\text { Tax Credit } \\
\text { Expiration Date }\end{array}$} \\
\hline \hline VA & $\begin{array}{l}\text { Some localities offer property tax } \\
\text { exemptions. }\end{array}$ & N/A \\
\hline WA & None & N/A \\
\hline WV & None & N/A \\
\hline WI & None & N/A \\
\hline WY & None & N/A \\
\hline PR & $\begin{array}{l}\text { Tax deduction for residential applications is } \\
30 \%, \text { up to \$500. Agricultural solar water is } \\
\text { exempt from excise tax. }\end{array}$ & \\
\hline
\end{tabular}




\section{Appendix D}

\section{Wording for Items That Asked about Increasing the Gasoline Tax \\ (Table 10-1)}

Study No.

1012

1037

1045

1046

1050

1160

1160

1185

$1190,1191,1192$

1196

1206

\section{Item Wording}

"In order to reduce the federal budget deficit, would you be willing or not willing to raise the tax on gasoline?"

"(Here are some of the proposals that are currently included in the proposed federal budget plan. Please tell me if you favor or oppose each as I read them.) Raising the federal gasoline tax by 12 cents per gallon."

"(To conserve more energy, do you think we should) raise the tax on gasoline?"

"(Do you favor or oppose the following proposals to reduce the federal budget deficit?) Raising taxes on gasoline."

"(Here are some specific measures for reducing the deficit. Please tell me if you favor or oppose each.) Raise the excise tax on gasoline."

"Do you think the federal government should increase the tax on oil produced in the United States as a means of reducing the federal deficit, even if it might mean higher prices to the consumer for oil and gasoline?"

"Do you think that the federal government should gradually increase the tax on each barrel of crude oil to encourage continued energy conservation, even though it might mean higher prices to the consumer for oil and gasoline?"

"(Most solutions proposed for tackling environmental problems involve changes in the way we live and do business. These involve costs for people. I' $\mathrm{m}$ going to read you some programs that have been proposed and I'd like you to tell me whether you would strongly favor, somewhat favor, somewhat oppose, or strongly oppose each of these measures.) A 25 cent per gallon gasoline tax that would be used to control pollution."

"(Let us suppose the government needed to raise taxes. For each of the following, please tell me if you would favor or oppose raising that tax.) Raising the tax on gasoline."

"To help reduce the federal budget deficit, would you be willing to have the tax on gasoline raised, or not?"

"(Here are some possible elements of a new national energy policy to promote conservation and reduce our dependence on foreign oil. For each element, please tell me if you would strongly favor it, moderately favor it, moderately oppose it or strongly oppose it.) Putting high consumption taxes on gasoline to promote conservation." 
Study No.

1210

1241

1258

1268

1270

1270

1278
Item Wording

"One of the economic problems facing our country today is the federal budget deficit. Would you be for or against an increase in the federal gasoline tax as a way of reducing the budget deficit?"

"Another way to reduce the federal budget deficit would be to increase revenues. Of course, nobody wants to pay more to the government, but if money has to be raised, would you favor higher gasoline taxes or would you rather consider some other way to raise money for the government, instead?"

"(Negotiators from the White House and Congress are trying to come up with an agreement on both spending cuts and tax increases in order to cut the federal budget deficit by $\$ 23$ billion. Tell me if you favor or oppose each of these provisions.) Raising energy taxes?"

"(Now let me ask you about some of the possible federal taxes that have been proposed as a way to reduce the federal deficit. In answering, please assume that there would be a guarantee that the money collected from the taxes would have to go toward reducing the deficit and would not be used for new spending programs. How much would you object to) a 20 cent a gallon tax on gasoline-a great deal, some but not a lot, only a little, or not at all?"

"Now let me ask you about a tax on gasoline, which would be used only to reduce the federal deficit, not for additional federal spending. Keep in mind that each one cent increase in the gasoline tax means one billion dollars more toward reducing the federal deficit. As you know, the price of gasoline has recently gone down to roughly 80 cents a gallon.

Would you favor or oppose a 20 cent a gallon federal tax on gasoline, the proceeds from which could be used only for reducing the federal deficit and not for additional federal spending in order to end deficit spending in three years?"

"Now let me ask you about a tax on gasoline, which would be used only to reduce the federal deficit, not for additional federal spending. Keep in mind that each one cent increase in the gasoline tax means one billion dollars more toward reducing the federal deficit. As you know, the price of gasoline has recently gone down to roughly 80 cents a gallon. Would you favor or oppose a 20 cent a gallon federal tax on gasoline the proceeds from which could be used only for reducing the federal deficit and not for additional federal spending in order to end deficit spending in three years?"

"(Now let me ask you about some specific tax increases that some people feel are necessary to balance the federal budget and end deficit spending. In each case, the Congress would pass a tax increase that would make sure none of the money raised from added taxes would be used for additional spending. Instead, all of the new tax money would have to be used to reduce the federal deficit. This tax would be in effect for only three years.) If a tax on each gallon of gasoline combined with spending reductions would eliminate the federal deficit in 3 years, would you favor or oppose that tax?" 
Study No.

1286

1291

1320

1339

1359

1421

1477

1486

1487

\section{Item Wording}

"Some people say this is the time to raise federal taxes on gasoline to help lower consumption, make the U.S. less dependent on Mideast oil and generated needed federal revenue. Others say the Mideast situation has already raised gasoline prices too much to make additional federal taxes a good idea. Which comes closer to your view?"

"Many states have recently passed school improvements legislation that requires additional financial expenditures. If your state needed to raise more money for the public schools, would you vote for or against the following proposals? Increased gasoline taxes?"

"(I am going to read you a number of ways in which government revenues could be increased or government expenses could be cut in order to reduce the federal budget deficit. For each one, tell me if you would strongly favor it, favor it, accept it only as a last resort, or strongly oppose it?) Increasing taxes on gasoline.

"If taxes had to be raised, would it be acceptable or not acceptable to you to...raise the tax on gasoline?"

"(Here are some possible ways for the government to raise money to reduce the federal budget deficit. For each, please tell me whether you support or oppose it.) higher federal taxes on gasoline."

"(The budget deficit reduction plan (negotiated by the Bush administration and Congress) includes some higher taxes and some spending cuts in order to reduce the federal budget deficit. I'm going to mention some of them and, after each, please tell me if you approve or disapprove of it. How about) raising taxes on gasoline and all forms of energy?"

"(Do you favor or oppose each of the following to finance measures to spur on the economy?) An increase in gasoline taxes."

"Some people believe that the most efficient way to reduce our dependence on foreign oil and encourage conservation would be to increase the tax on gasoline because people would drive less. Would you favor or oppose increasing the tax on gasoline by 25 cents over the next five years to reduce our dependence on foreign oil and encourage conservation?"

"As you may know, last fall Congress and the President agreed to change the tax code by increasing the tax on luxury items such as expensive cars and fur coats to ten percent, and by doubling the federal gasoline taxes. Specifically, because of these new taxes, have you put off buying a luxury item such as an expensive car or fur coat, or not?" 
Study No.

1499

1516

\section{Item Wording}

"As you know, the roads, highways, bridges, and other public structures in the country have not been repaired for some time in places. If the money collected could be used only for the purpose of repairing neglected roads, highways, bridges and other structures, would you favor or oppose raising the tax at the pump on gasoline by 5 cents a gallon?"

"If taxes had to be raised to reduce the budget deficit, which of these taxes would you most prefer?" 


\section{Appendix E}

\section{Item Wording for Table 7-2}

Study No.

1025

1072

1194

1198

1202

1214

1232

1282

1283

1351

1358

$\underline{\text { Item }}$

"Do you favor or oppose a proposal to build more nuclear power plants in the United States?"

"Would you favor or oppose a proposal to build more nuclear power plants in the United States? (If favor/oppose, ask:) Would that be strongly (favor/oppose) or just somewhat (favor/oppose)?

"Some people think we should build more nuclear power plants because they don't burn coal or oil which create air pollution. Others think that we should not build any more nuclear plants because of the threat of an accident or radiation. Which do you agree with?"

"Do you think that more nuclear power plants should be built in the United States or do you think they should not be built?"

"Generally speaking, do you approve or disapprove of using nuclear energy to produce electric power?"

"Do you think that more nuclear power plants should be built in the United States, or do you think they should not be built?"

"Do you think that more nuclear power plants should be built in the United States, or do you think they should not be built?"

"Which of the following statements best represents your opinion about the construction of more nuclear power plants to meet our increasing energy needs? Strongly in favor of, in favor of, opposed to, strongly opposed to, don't know."

"On the question of nuclear power, in general, do you favor or oppose the building of more nuclear power plants in the United States?"

"In general, do you favor or oppose the building of more nuclear power plants in the United States?"

"(For each of the following items, please tell me whether you strongly favor, somewhat favor, somewhat oppose, or strongly oppose each one.)... What about the use of nuclear power? Do you ...?"

"I have some questions about nuclear energy. Would you approve or disapprove of building more nuclear power plants to generate electricity?"

"Do you think more nuclear power plants should be built in the United States, or not?" 
"In general, would you favor or oppose building more nuclear power plants at this time?"

"(I am going to read a few statements. After each, please tell me if you agree with that statement or disagree with it, or if, perhaps, you have no opinion about that statement.) ... We should stop building nuclear power plants because of the safety and waste problems."

"Well, in general, would you favor or oppose building more nuclear power plants at this time?"

"In general, do you favor or oppose the building of more nuclear power plants in the United States?"

1401

1409

"In general, do you favor or oppose the building of more nuclear power plants in the United States?"

"In general, do you favor or oppose the building of more nuclear power plants in the United States?"

"In general, do you favor or oppose the building of more nuclear power plants in the United States?"

"In general, do you favor or oppose the building of more nuclear power plants in the United States?"

"In general, do you favor or oppose building more nuclear power plants in this country?"

"Do you favor or oppose for the national energy strategy a proposal to build more nuclear power plants in the United States?"

"Would you approve or disapprove of building more nuclear power plants to generate electricity?"

"Would building a new nuclear power plant in your community be acceptable or unacceptable to you?"

"Do you favor or oppose building more nuclear power plants in this country?" 


\section{Appendix F}

\section{Chronology of Energy Events}

This appendix provides a chronological listing of major energy-related events classified into three categories: (1) major oil market developments, 1971-1986; (2) other events, 1979-1991; and (3) public announcements on ozone depletion and the greenhouse effect.

\section{Major Oil Market Developments, 1971-1986}

January 1972 Persian Gulf members of the Organization of Petroleum Exporting Countries (OPEC) cartel agree with western oil companies to raise average prices $8.49 \%$ to $\$ 2.41$ per barrel from $\$ 2.23$.

December 1972

U.S. 1972 consumer prices rise $3.2 \%$.

October 1973

Persian Gulf OPEC states hike prices and taxes to bring crude prices to $\$ 5.00$ range: Arab nations begin total oil embargo against the United States and the Netherlands for their support of Israel. OPEC exports to other European nations are cut.

December 1973 Persian Gulf states, other OPEC members double prices; Persian Gulf benchmark price goes to $\$ 11.65$ per barrel from $\$ 5.11$; premium crudes rise to as high as \$18.77: United States sets 55-mile-per-hour speed limit for conservation: OPEC's 1973 annual output is about 31 million barrels per day, the cartel's peak level. World output is 55 million barrels: U.S. gasoline prices average 38 cents per gallon during 1973.

March 1974

Most Arab nations end oil embargo against United States.

May 1974

U.S. gasoline prices rise to an average of 55 cents.

December $1974 \quad$ U.S. petroleum consumption declines in 1974 owing to the oil embargo and an economic recession: Soviet Union displaces the United States as number one oil producer during 1974, pumping some 9.4 million barrels per day: U.S. consumer price inflation hits $12.2 \%$.

January $1975 \quad$ OPEC sets nine-month price freeze.

June 1975 First North Sea crude oil is pumped.

March 1977 Mexico sets six-year plan to double output to 2.2 million barrels per day and boost exports to 1.1 millon barrels per day from 130,000 .

January 1979

Shah flees Iran.

May 1979

Parts of the United States are plagued by long lines to buy gasoline. Lines persist for several months. California and other states set gas rationing by odd-even license plate formula. 
June 1979

July 1979

September 1980

December 1980

April 1981

December 1981

January 1983

October 1984

December 1985

January 1986

February 1986

April 1986

\section{Other Events}

Jan. - July 1979

April 1986

July 1987

June 1988

March 1989
OPEC benchmark price rises to $\$ 18$ per barrel. Premium crude rises to $\$ 23.50$.

President Carter addresses United States on energy. Says country is suffering from a "malaise."

Saudi light price increases to $\$ 30$ per barrel: Iran-Iraq War breaks out.

Saudi light price rises to $\$ 32$; some premium crudes go over $\$ 40$.

Saudi Oil Minister Sheik Ahmed Zaki Yamani says the Saudis have helped engineer an oil glut to stabilize world prices.

United States gasoline prices peak at an average of $\$ 1.35$ per gallon for 1981 .

Another OPEC meeting fails to reach price or output accords.

Britain, Nigeria and Norway cut their crude prices to about $\$ 28$, the first major price cuts in 19 months.

OPEC abandons official pricing policy; says it will fight to regain "fair" market share: U.S. Consumer Price Index rises $3.8 \%$ in 1985, the fourth year at or below $4 \%$.

Prices plunge to six-year lows on world spot markets. N.Y. Merc futures fall below $\$ 20$.

Prices continue plunge with N.Y. Merc futures falling below $\$ 15$. Great Britain refuses OPEC's call to force cuts in North Sea production.

Brent crude, World Trade Institute prices dip briefly below $\$ 10$, the lowest levels in nine and 12 years, respectively.

Oil spills pollute ocean waters in Atlantic and Gulf of Mexico (Jan. 1, June 8, July 21).

Major nuclear accident at Soviet Union's Chernobyl power station alarms world.

Soviet sentences three Chernobyl officials for safety violations in nuclear disaster.

Much of the United States suffers the worst drought in more than 50 years. Half of the nation's agricultural counties are designated disaster areas.

The largest oil spill in United States history occurs after the Exxon Valdez strikes Bligh Reef in Alaska's Prince William Sound. The off-course tanker was being piloted by the third mate instead of by the captain. Exxon Corp. announces that it accepts full financial responsibility for the spill, initially estimated at 240,000 barrels; then announces that the spill could not be contained. 
August 1990

December 1991

October 1985

August 1986

October 1986

November 1986

July 1988

October 1983

August 1986

October 1986

July 1988

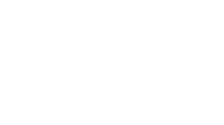

Operation Desert Shield forces leave for Saudi Arabia to defend that country following the invasion of its neighbor Kuwait by Iraq. The American Auto Assn. reports that the retail price for gas has risen 18 cents per gallon.

After a sweeping probe of the Chernobyl disaster, a Ukrainian parliamentary commission accuses Communist leaders at the time, including Soviet President Mikhail S. Gorbachev, of a massive cover-up that led to thousands of deaths.

\section{Public Announcements on Ozone Depletion and the Greenhouse Effect}

February 1989

(1989

The U.S. Environmental Protection Agency and the National Research Council issue reports stating a buildup of carbon dioxide in the atmosphere would warm the global climate in the coming decades, with possible severe consequences. This warming is known as the "greenhouse effect." Many of the 100 scientists who reviewed the report call the warming predictions "too conservative."

Scientists from 29 nations at a conference warn that the world must develop economic and social plans on the assumption that the world's climate would be warmer and sea levels higher in the next century.

Scientists struggle to explain growing seasonal depletion of the ozone layer in the atmosphere above Antarctica. The thinning reaches its peak each year around October. It was not yet known whether the ozone hole was a transitory climatic phenomenon that would go away by itself, or whether it was a spreading and potentially dangerous problem caused by man-made pollution.

A scientific team reports by satellite from Antarctica that a sharp seasonal drop in the atmosphere's protective ozone layer over Antarctica appears to be caused by a chemical mechanism. Measurements over the South Pole reveal "highly elevated" levels of chlorine dioxide, a breakdown product of chlorofluorocarbons, the class of chemicals that destroy stratospheric ozone.

British scientists confirm for the first time that the Earth is getting warmer because of the "greenhouse effect."

It is thought that the Earth's warming is due to man-made pollutants in the atmosphere. 1988 goes down as the hottest year in history.

Drought affects $50 \%$ of the U.S. farm counties. The drought desiccates pastures and crops, sending commodity prices and Chicago futures soaring while threatening the recovery of a U.S. agriculture sector emerging from a seven-yearlong depression. Also affected by the drought are forests across the Southeast and upper Midwest and West.

Average global temperature is highest in the 130 years since reliable records were first kept. Some researchers view the result as confirmation of the so-called "greenhouse effect"; however, U.S. scientists studying weather data stretching back to 1895 conclude that there has been no significant change in average U.S. temperatures or rainfall over the entire 93-year period. 
November 1989

March 1991
An international conference on climate adopts a compromise resolution to stabilize carbon dioxide emissions that were believed to be contributing to the "greenhouse effect." The resolution was passed unanimously. The meeting was the first ministerial-level meeting on world climate change.

California drought is relieved by rainstorms, which occurred at the rate of about one every two days; however, rainfall for all of 1991 will still be below average. 


\section{Appendix G}

\section{Item Wording for Table 2-4 Response Categories}

Hazardous waste sites in active use

Abandoned hazardous waste sites that have not been cleaned up of the type commonly addressed by Superfund

Water pollution from industrial wastes

Worker exposure to toxic chemicals

Accidental oil spills from tankers, drilling rigs, etc.

Destruction of the ozone layer over the earth, permitting strong sun's rays to get through, causing skin cancer and other problems

Radiation from a nuclear power plant accident

Industrial accidents releasing pollutants into air, water, or soil

Radiation from radioactive wastes

Outdoor air pollution from factories, mills, processing plants, etc.

Underground storage tanks leaking gasoline and other substances

Contamination of oceans, coastal waters, and estuaries from all sources except oil spills

Solid waste problems created by litter and the garbage and trash that people throw away

Pesticides harming farmers, farm workers, and consumers who work with them

Water pollution from run-off of pesticides, herbicides, fertilizers, etc. from farms

Water pollution from municipal sewage treatment plants

Outdoor air pollution from auto, bus, and truck exhaust

Pesticide residue on foods eaten by humans

The "greenhouse" effect-an accumulation of certain gases in the atmosphere that will cause the temperature on earth to rise

Contamination of drinking water as it comes from the tap (from chemicals, lead from pipes, biological contaminants, radiation, etc.)

Contamination and physical destruction of coastal and inland wetlands, from all sources except oil spills 
Environmental damage due to acid rain

Water pollution from run-off from city streets, parking lots, construction sites, etc., containing oil, salt, chemicals

Non-hazardous waste sites such as trash disposal from households and industry

Problems caused by biotechnology (contamination of environment by release of genetically altered materials)

Indoor air pollution (from household and industrial cleaners and other chemicals used in home or office, tobacco smoke, aerosol sprays, asbestos, etc.)

Radiation from X-rays

Indoor air pollution from radon in homes and other buildings

Radiation from microwave ovens 


\section{Appendix H}

\section{Miscellaneous Policy Preference Items}

\section{Table H-1. Trends in National Security Policy Preferences}

"The situation in the Arab world has raised prices on imported oil resulting in higher fuel costs to consumers. Some people say it would be good if the United States could be independent of these Arab oil producing countries, but there would be problems connected with this. We'd like to ask you how you feel about some of these means to becoming independent." (September 1990) [1554].

Percent willing to do

The government could impose an excess profits tax on oil companies to encourage their putting more money into exploration.

Becoming independent of Arab oil countries by reducing gas and oil consumption over the next ten years, but this would mean restrictions on the amount of fuel people could use--including gas and oil rationing, more limited use of automobiles, etc.

The federal government could invest in new energy exploration and technology, but this would require a higher tax on gasoline to pay for it. Would you be willing to see this happen or not?

The federal government could give U.S. oil companies low interest loans to do further oil exploration, but this would take money out of the treasury. Would you be willing to see us do this or not?

All electric utility companies could be required to switch from oil to coal in producing electricity, but this would add to pollution problems somewhat.

Source: Roper Organization

${ }^{*}$ Not asked 


\section{Table H-2. Trends in Economic/Environment Trade-ofis}

"As you know, our economy is not in the best of shape. At the same time, the government is scheduled to put many new safety and environmental standards on business. Some people say these new safety and environmental rules must be lifted or postponed because they raise both costs and prices and therefore will depress the economy. Others disagree, and say these new standards must be put into effect to protect workers, the public, and the environment regardless of their effect on the economy. Here's a list of steps that could be taken to lift regulations on business. (Card shown) For each one would you tell me if you would be in favor of such a step or opposed to it?" (February 1991) [1557].

$\frac{\text { Percent }}{\underline{1981}} \underline{\underline{1991}}$

Postpone new and stricter rules about the use of computers and video display terminals in workplaces

$\begin{array}{llll}- & - & 24 & 54 \\ 34 & 52 & 24 & 61\end{array}$

Change or put off new and stricter standards on things such as scaffolding, asbestos, and chemical exposure, and grain elevator and dust control

Postpone stronger exhaust emission standards for cars and trucks

Eliminate the requirement that future model cars have air bags that inflate automatically in the event of a collision

Postpone stronger requirements for industry to clean up its waste water before it dumps it

Postpone stronger air pollution standards for factories and utilities

$\begin{array}{llll}- & - & 16 & 75 \\ 36 & 44 & 16 & 65\end{array}$

Allow utility companies to burn cheaper high sulphur fuels

Source: Roper Organization 


\section{Table H-3. Preferences for Utility Actions in Protecting the Environment}

"I am going to read you a list of several things electric companies could do to protect and improve the environment. While all of these things may be important, l'd like you to tell me exactly how important each is to you personally. Please use any number from 1 to 7 where 1 means 'one of the less important and 7 means 'one of the very most important things' electric companies could do to protect and improve the environment?" (September 1990) [1457]

Mean

(Scale: 1-7)

\begin{tabular}{cc}
\multicolumn{2}{c}{ Percent } \\
\hline Most & Least \\
$\underline{\text { Important }}$ & $\underline{\text { Important }}$
\end{tabular}

Planting trees to help reduce carbon dioxide in the atmosphere

78

4

Phasing out use of CFCs and other chemicals that can harm the ozone layer

73 5

Promoting building codes that require proper insulation and other energyefficient measures

72 4

Protecting wildlife habitats from development 71 5

Developing clean coal technologies that will reduce emissions from coalburning power plants

Funding environmental research

Recycling paper and other materials at its own facilities

Providing free information on environmental issues

Promoting use of energy-efficient lighting 
Table H-3. (Continued)

\begin{tabular}{|c|c|c|}
\hline \multirow[b]{2}{*}{$\begin{array}{c}\text { Mean } \\
\text { (Scale: 1.7) }\end{array}$} & \multicolumn{2}{|c|}{ Percent } \\
\hline & $\begin{array}{c}\text { Most } \\
\text { Important }\end{array}$ & $\begin{array}{c}\text { Least } \\
\text { Important }\end{array}$ \\
\hline
\end{tabular}

Offering rebates or loans to help customers buy energy-efficient heating and cooling systems or other major appliances

62

5

Reclaiming land from mining and other utility operations for agricultural, recreational, or other uses

60

Using waste from coal-burning plants in concrete and other building materials, reducing the need to dispose of it in landfills

60

Informing the public about the strength of electric and magnetic fields from electric transmission lines near populated areas

58

7

Developing electric "smart" houses that allow customers to monitor and automatically regulate their use of household appliances

Promoting electric heat pumps to replace less efficient heating and cooling systems

Taking steps to reduce the strength of electric and magnetic fields from electric transmission lines

Allowing recreational use of utilityowned lakes and other properties

Developing cars and trucks that run on electricity

Using electricity to replace other energy sources 
Table H-3. (Continued)

\begin{tabular}{|c|c|c|}
\hline \multirow[b]{2}{*}{$\begin{array}{c}\text { Mean } \\
\text { (Scale: 1-7) }\end{array}$} & \multicolumn{2}{|c|}{ Percent } \\
\hline & $\begin{array}{c}\text { Most } \\
\text { Important }\end{array}$ & $\begin{array}{c}\text { Least } \\
\text { Important }\end{array}$ \\
\hline
\end{tabular}

Directly controlling customers' major appliances to reduce demand for electricity at certain times

28

26

Allowing recreational use of utilityowned land under electric transmission lines

Source: Constructed by author using data from Cambridge Reports/Research International. 
Table H-4. Preferences for a Variety of Environmental Protection Trade-offs

"We're hearing more these days about trade-offs-in other words, sacrificing one thing for the sake of another. For example, some people have given up things they enjoy eating-such as fried or fatty foods-because they feel it is a healthy thing to do. But others feel the possible health benefit is really too small considering the sacrifice of giving up one's favorite foods. (Card shown) Now here is a list of some trade-offs having to do with protecting the environment. Considering both the advantages and disadvantages of each one, please tell me whether you think the sacrifice would be worth making or not." (May 1991) [1553]."

\section{Percent responding}

sacrifice is worth making

Every household could be required to recycle newspapers, plastics, tin cans, and glass containers, but this would inconvenience consumers and require higher local taxes to pay for recycling programs

The federal government could require all states to enact bottle bills for all beverage containers, but this would inconvenience consumers by making them return bottles and cans if they want their deposits back

We could reduce air pollution caused by automobile exhausts, but this would mean adding several hundred dollars to the price people pay for a new car

Supermarket customers could be required to bring their own bags when they shop to cut down on solid waste, but this might be an inconvenience for many people

Oil companies could change the ingredients and methods used in refining gasoline to reduce air pollution from automobiles, but this would mean that consumers would have to pay 10 cents more per gallon for gas

In refrigerators we could stop using chemicals that are harmful to the earth's ozone layer, but more energy would have to be generated to run the new refrigerators

\footnotetext{
${ }^{* *}$ Each item asked of a half-sample.
} 
Table H-4. (Continued)

\section{Percent responding sacrifice is worth making}

We could reduce landfill problems by banning disposable diapers, but this might inconvenience parents, and the laundering of more cloth diapers could increase water pollution

Oil companies could change ingredients and methods used in refining gasoline to reduce air pollution from automobiles, but this would mean that consumers would have to pay 30 cents more per gallon for gas

We could help save South American rain forests from being destroyed, but to do this countries like Brazil would need financial help from the United States

We could cut way down on smog by reserving one lane just for cars containing three passengers or more, but this would worsen traffic for other drivers

We could use more nuclear power to generate electricity since it creates much less air pollution than other fuels, but this would create more nuclear waste to dispose of

In forests of the Northwestern United States we could protect the spotted owl from extinction, but this could put a large number of loggers out of work

Source: Roper Organization 
Table H-5. Preferred Trade-offs to Protect and Improve Air Quality

"There is a great deal of discussion these days about the quality of the air we breathe and what we can do to improve it. Here is a list of some things that have been proposed. (Card shown) Would you please read down that list and for each one tell me if it is something you think would do enough good so you would be willing to see it happen in this community or you don't think it would do enough good to be worth the inconveniences or extra cost?" (September 1989) [1546]

\section{Percent \\ willing to \\ see happen}

Require spray pumps only instead of aerosols even though some things work better in aerosol cans and other things like paint might not work at all in a pump spray

Force all utilities to install scrubbers to clean their emissions even though it would mean an increase in your utility bills due to the high expense of the equipment

Force all companies, even small businesses, to comply with very strict air pollution standards, even though it might put some of them out of business, thereby causing a loss of jobs

Ban the use of high sulfur coal to reduce acid rain even though this might make the U.S. more dependent on other countries for its energy supplies

Allow only water-based paints, varnishes, and finishes even though they don't look as good as the oil-based ones

Require dry cleaners to install a lot of new equipment to control the fumes from the chemicals they use, which would mean fewer dry cleaners and higher costs because the equipment is so expensive

Require all new cars to run on alternative fuel like ethanol or methanol even though they would get fewer miles to the gallon and require a larger fuel tank which means less trunk space

Require charcoal barbecues to be started with an electric starter rather than lighter fluid even though it takes longer and you need to run an electrical cord to the barbecue 
Table H-5. (Continued)

\section{Percent willing to \\ see happen}

Require car pooling to and from work even though it means having to stick to the car pool schedule and not having a car at work in case of a personal emergency

Require all new cars to run on natural gas rather than gasoline even though the U.S. would be dependent on other countries to supply the natural gas

Set up odd-even driving days so that if your car's license plate ended with an odd number you could only drive it on odd numbered days

Source: Roper Organization 


\section{Index}

$\underline{\text { Page }}$

$\underline{\mathrm{A}}$

Acceptable $\ldots \ldots \ldots \ldots \ldots \ldots \ldots \ldots 11,28,35,71,153,156,158,165,178,231,248,335,338$ Accident(s) . . . . . . . 1, 5, 9, 18-20, 133, 152-153, 156, 166-173, 175-180, 208, 226, 337, 340,343

Accidental 156,343

Acid rain $\ldots \ldots \ldots \ldots \ldots \ldots \ldots \ldots 1,9-10,18-22,24,32,35-36,43-44,47-48,163,165,244$, 344,352

Action(s) (See also activism, behavioral intention) $\ldots \ldots \ldots \ldots \ldots \ldots$ 1-2, 4, 7, 11-12, 28-30, $32-34,42-43,53,55,57-58,60-61,69-70,73-74,78-80,82,84,89,113,115-117,138,143,157$, $161,166,181-182,196-197,201,213-214,216,218,230,234,236,242-243,248,250,258,295$, 299,347

Activism (See also actions, anti-nuclear activism, behavioral intention) $\ldots \ldots .4,9,11,52-53,57-58$, 167,256

Administration $\ldots \ldots \ldots \ldots \ldots \ldots .483,85,113-117,124,134,143,157,204,234-235,238,335$

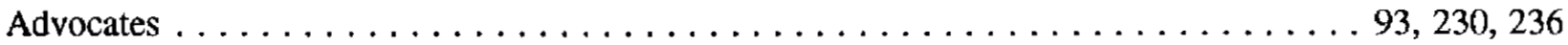

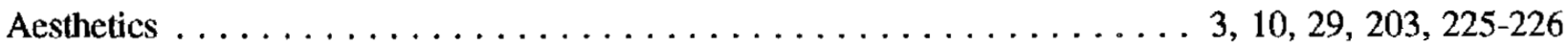

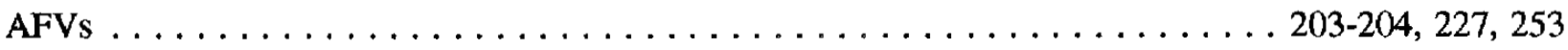

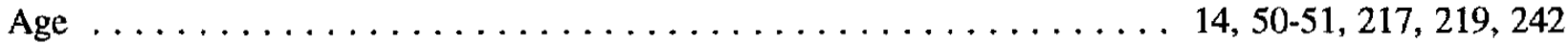

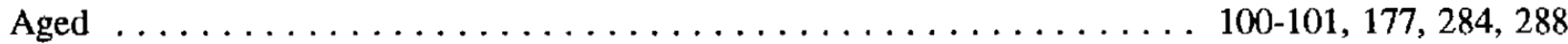

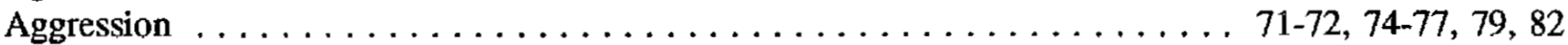

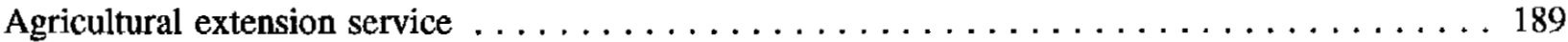

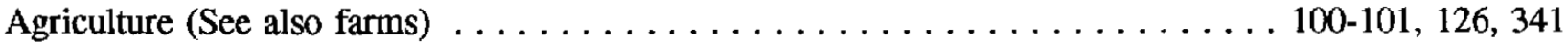

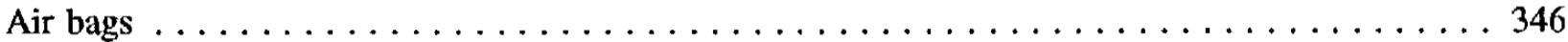

Air pollution ..........9, 11, 17-24, 29, 31-32, 35, 43-44, 46-47, 49-50, 58, 62, 65, $68,94,160,163,172,176,203,219,222,225,234,244,246,253,255-256,337,343-344,346$, $350-352$

Air quality $11,17,24-25,47,53,65,129,157,163$, $220,243-245,255,346,352$

Alaska National Wildlife Refuge (See also ANWR) . . . . . . . 12, 39, 135, 137, 203, 210-211 Alternative(s) $\ldots \ldots \ldots \ldots \ldots \ldots 2-6,45,65,68,70,76,82,93,113-114,116,127,133,135$, $138-139,142-146,148-153,157,161,168,180,188,191,199,202-203,218-222,227-228$, $230-232,239,243-244,246-247,252-253,255-256,296-297,299$

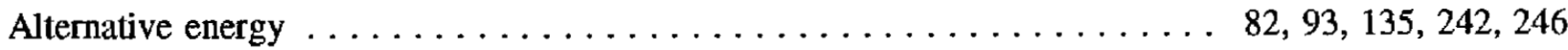
Alternative fuel vehicles (See also AFVs) . . . . . . . 202, 220, 227, 230-232, 252-253, 255-256 Alternative fuels . . . . . . . . . 4, 6, 45, 65, 113-114, 116, 127, 133, 150-151, 202-203, $219-222,230-232,243,247,252-253,255-256,296-297$

Aluminum

$11,59-60,66$

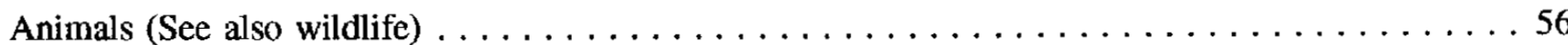

Anomalous $2,3,14$

Anomaly 146,170

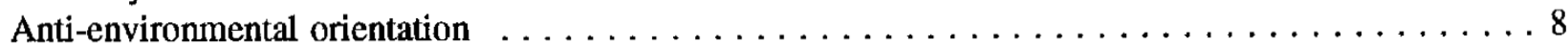

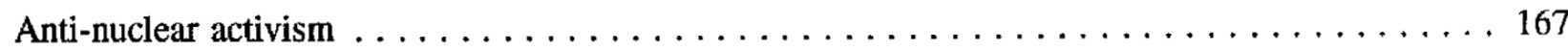

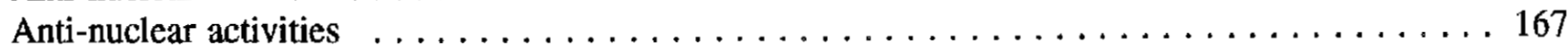

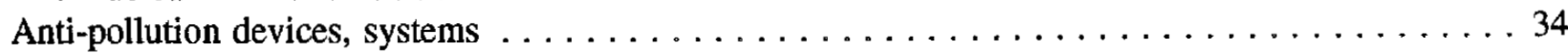

ANWR 


\section{Index (Continued)}

Appliances $22,26,57,69-70,104,129,160-161,182-184,192,197,200$, $257,346,348-349$

Arab(s) $1,4,71-73,84,113,115-117,124,127,132,159,205,232$, $241,243,248,339,345$

Arab oil embargo . $1,4,72,113,124,127,132,205,243$ Architects

Audit $184,186-192$

Automakers

$5,35,50,114,121,232,253,256$

Automobile(s) [See also car(s), vehicle(s)]

$1,5,8,10,12,29,34-35,39-40,42$, $50,58,62,103,105,113-114,118,121-122,132,157,163,165,177,180,202-203,210$, $212-214,218-219,221-222,229,231,245-250,296,345,350-351$

Automobile exhaust 163,165 Awareness (See also knowledge) $4,8,10,29,30,35,59,72,163,168,202,204,219-220$

$\underline{B}$

Balance of trade (See also trade deficit) 165

Bank(s) $109,130,252$

Banning CFCs (See also CFCs) $68,199-200$

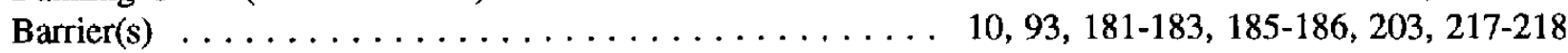
Behavioral intention (See also activism, actions, anti-nuclear activism) $\ldots \ldots \ldots \ldots \ldots, 6$, $192,213,299$

Benefit(s) $11,29,43,48-50,64,85,140,161,166-168,172,185-187$ $236,247,257-258,350$

Benefit/cost ratio(s) $46-47,49,67,130,167,184,189,197$

Bias $2,3,29,146,297$

Bicycling $57,203,212,218$

Bill(s) . $1,5,8,47-48,65,127,131,166-167,181,184-187,244,257,350-352$

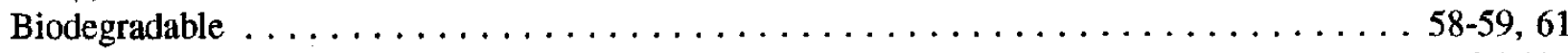

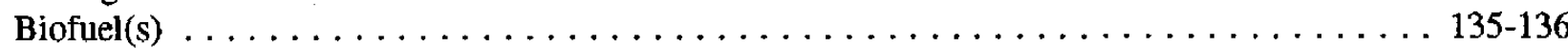

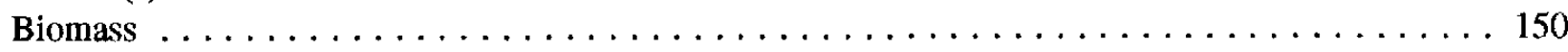

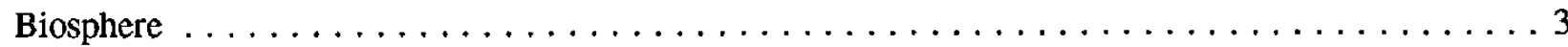

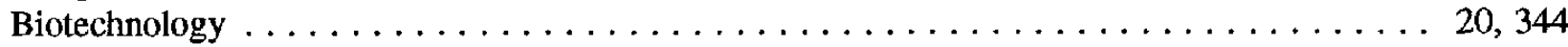

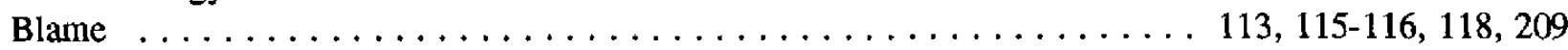

Bonus . . . . . . . . . . . . . . . . . . . . . . . . . . . . . . . . . 134

Bottles ........................ 10, 26, 59-61, 66-67, 350

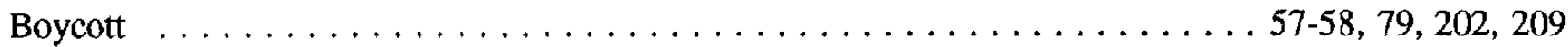

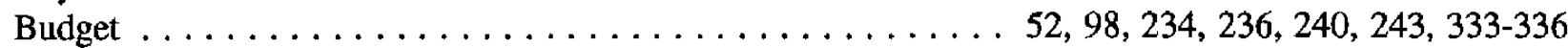

Building codes $\ldots \ldots \ldots \ldots \ldots \ldots \ldots \ldots \ldots \ldots \ldots$ 161, 197, 199-200, 347

Building(s) . . . . .

$181-183,188-189,191,197-203,218,296,299-300,344$

Burn $\ldots \ldots \ldots \ldots \ldots \ldots \ldots \ldots \ldots \ldots \ldots$ 48, 62, 66-67, 159, 163, 172, 176, 254, 337, 346 Burning $\ldots \ldots \ldots \ldots \ldots \ldots \ldots \ldots \ldots \ldots \ldots, 16 \ldots \ldots, 28,30,32-36,43,45,47,65-66,69-70$, $158-166,180,203,222,246,255,346,352$ 


\section{Index (Continued)}

Bush, President George (See also President Bush) $\ldots \ldots \ldots$ 32-33, 68, 70, 79, 103, 114, $120,125,134,139,299,335$

Business(es) $\ldots \ldots \ldots \ldots \ldots \ldots \ldots \ldots, 9,11,14,38,44,52-54,56-57,68-70,85,93,116,127$, $134-135,159,177,181-182,184,191,199,201,238,244,246,254,256-258,331,333,346,352$

$\underline{\mathrm{C}}$

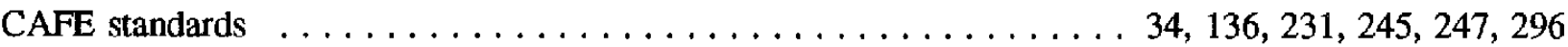

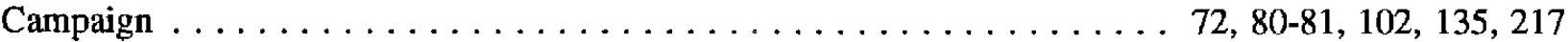

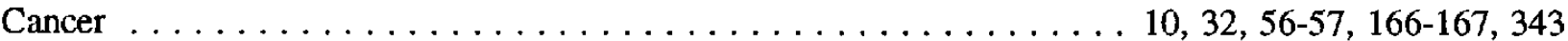

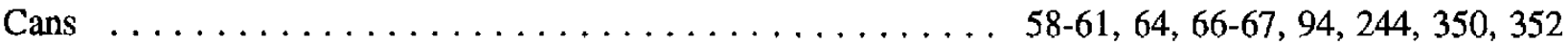

Car(s) [See also automobile(s), vehicle(s)] . . . . . . $48,50-51,57-58,62,65,129,132-140,142,146,149-150,153,156-157,203,205,210,212-222$, $225-229,231-232,234,243-248,250,252-253,255-256,296,335,346,348,350-353$

Car buyers $46,50-51,203,219-222,225-228,232,253-254$

Car pool(s) (See also ridesharing) $\ldots \ldots \ldots \ldots \ldots \ldots \ldots \ldots$ 203, 212, 214-218, 245, 248, 353

Car pooling (See also ridesharing) $\ldots \ldots \ldots \ldots \ldots \ldots, 136,138,203,212-214,216-218,229$, $231,243,245,248,353$

Carbon dioxide $8,12,30-31,33-34,69,140,149,341-342,347$

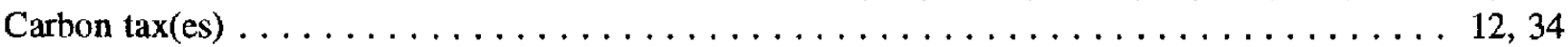

Carter, President Jimmy (See also President Carter) . . . . . . . . . . 85, 143, 299, 340

Caulking . . . . . . . . . . . . . . . . . . . . . . . . . . . . . . . . . 182, 192, 196

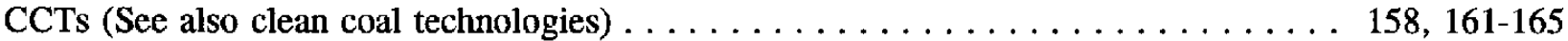

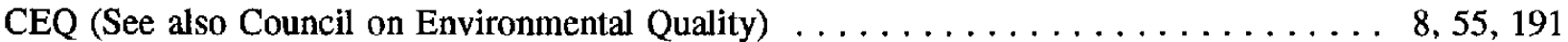

CFCs (See also chlorofluorocarbons) $\ldots \ldots \ldots \ldots \ldots \ldots \ldots \ldots \ldots \ldots \ldots$ 10,68-69, 199-200, 347

Chemical(s) . . . . . . . . . . . 9, 14, 17, 19-20, 22, 24, 30, 56-57, 60, 62, 69, 71, 74-76, $102,118,122,177,200,244,341,343-344,346-347,352$

Chemical weapons 14

Chernobyl $176-178,180,340,341$

Children $1,5,89,145,150,152,156,166-167,169-171,173-174$ Chlorofluorocarbons (See also CFCs) $161-163,165-166,202,208-209,214,244,247,255,346-347,352$

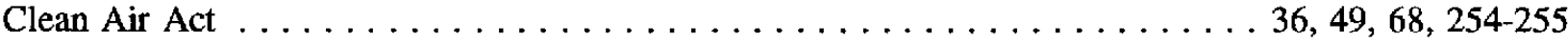
Clean coal technologies (See also CCTs) $\ldots \ldots \ldots \ldots \ldots \ldots \ldots \ldots, 158,161-163,165,347$

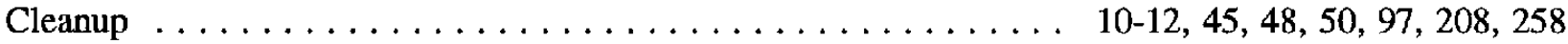
Climate change (See also global warming) $\ldots \ldots \ldots \ldots .4,9,30,89,159,165,180,296,342$

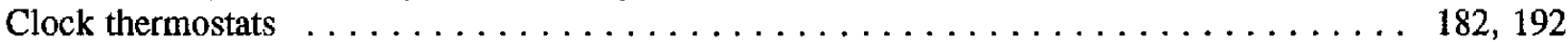

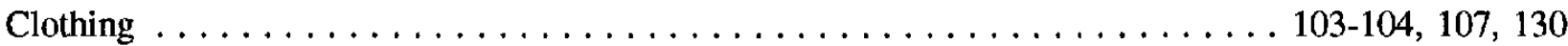
Coal $\ldots \ldots \ldots \ldots \ldots \ldots \ldots \ldots 4-5,9,16,25,30,33-36,43,45,47-48,69-70,133,137,140$, $143-153,157-165,170,172,176,180,193,209,230,239,242,244,252,256,298-299,337,345$, $347-348,352$

Coastal flooding 


\section{Index (Continued)}

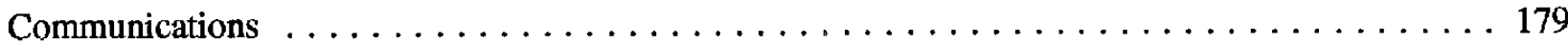

Community(-ies) $\ldots \ldots \ldots \ldots \ldots \ldots, 17,26,29,32,54,59,64,66-67,69,95,97,103,114$,

$129,131,165-166,168,170-171,190,244,249,252,257-258,288-289,291,338,352$

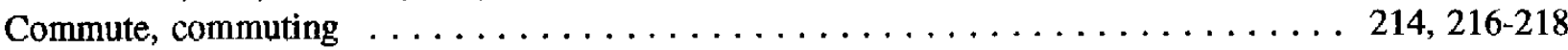

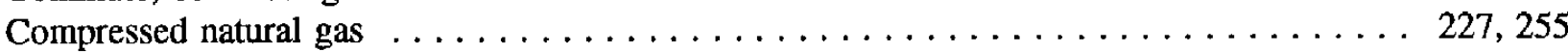

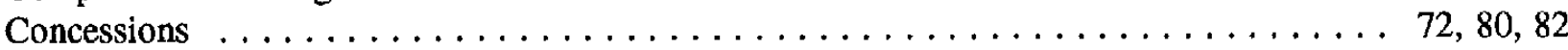

Confidence . . . . . . . . . . . . . 85, 88-89, 114, 120, 123, 127, 180, 189, 258

Conflict (See also hostilities, combat, war) $\ldots \ldots \ldots \ldots \ldots \ldots \ldots \ldots \ldots \ldots \ldots \ldots \ldots$ 74, 78, 95

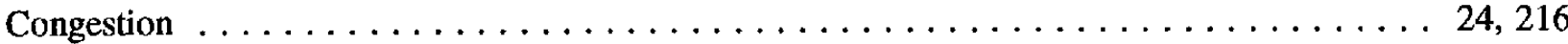

Congress . . . . . . . $212,234,243,255,280,334-335$

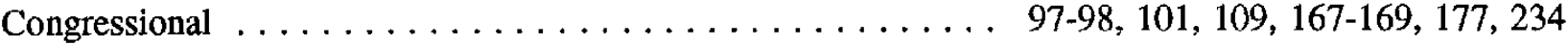

Conservation (See also energy conservation) $\ldots \ldots \ldots \ldots \ldots \ldots \ldots, 4,24,32,43-45,48,50,52$, 57-58, 72, 80-82, 91, 127, 133-135, 137-139, 142, 146-147, 150-151, 181-186, 188-189, 191-192, $196-199,201-203,209-210,212-214,217-219,229-232,236-237,239-240,245,248,256$, $296-299,330-331,333,335,339$

Conservative $138,172,341$

Conserve (See also energy conservation) $\ldots \ldots \ldots \ldots \ldots \ldots \ldots \ldots \ldots \ldots \ldots \ldots, 11,32,59,73,86$, $160,182-185,188,191,196-197,203,212-215,217-218,236,250,333$

Construction ............... 3, 39, 169, 170, 174, 177, 199, 257, 330, 337, 344

Consumer(s) $\ldots \ldots \ldots \ldots \ldots \ldots \ldots \ldots \ldots$ 1-2, 14, 26, 40, 47-49, 54, 57-59, 60, 64, 66, 86, 93, 103 , $105-106,113,115-117,121,124,129-130,132,159-160,178,183-186,191,198-199,219,229$, $232,234,236-237,241-242,248,256-258,291,333,339-340,343,345,350-351$

Consumption . . . . . . $181-183,202,204,212,229-231,236-237,248-249,256-257,335,339,345,353$

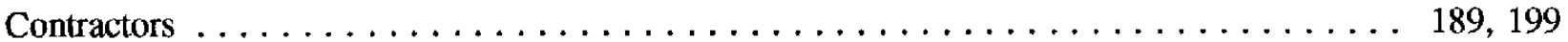

Controls . . . . . . . . . . 12, 39-41, 47, 50, 67, 74, 158-160, 229-230, 237-238, 241, 249

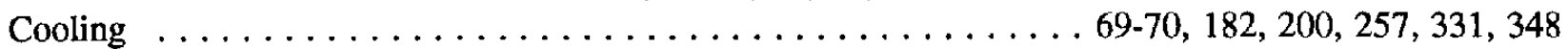

Corporate average fuel economy (See also CAFE standards) . . . . . . . . . . . . 8 80, 229

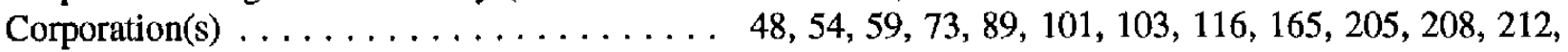
$231,236,243,246,258$

Cost(s) . . . . . . . . . 1, 12, 14-15, 28, 33-34, 39-40, 42, 45-48, 50, 62, 65, 68-69, 79-80, $83,85-86,89,95,104-105,107-110,113-114,127,129-130,132-133,157,159-160,163,167$, $172-173,179,181-187,190-192,197,199-200,203,208,210,212,217-222,225,227,230,232$, $236-238,240-242,244-248,252,255-258,329-331,333,345-346,352$

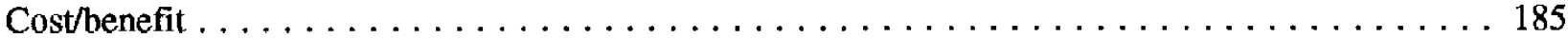

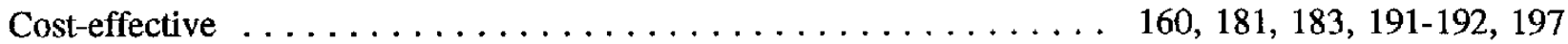

Council on Environmental Quality (See also CEQ) $\ldots \ldots \ldots \ldots \ldots \ldots \ldots \ldots \ldots$ 8, 55, 188, 191

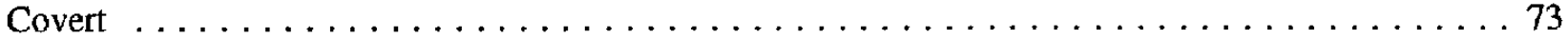

Credibility $\ldots \ldots \ldots \ldots \ldots \ldots \ldots \ldots \ldots \ldots \ldots \ldots \ldots \ldots \ldots \ldots \ldots \ldots, 32,52,169,188-190,257-258$

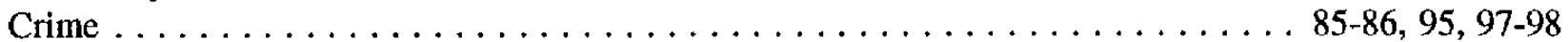

Crisis (See also energy crisis) $\ldots \ldots \ldots \ldots \ldots \ldots \ldots \ldots \ldots \ldots, 4,74-76,78-80,85,93,95-96$,

$98,113-117,124,127,166,184-185,227,237,243,299$

$\underline{\mathbf{D}}$

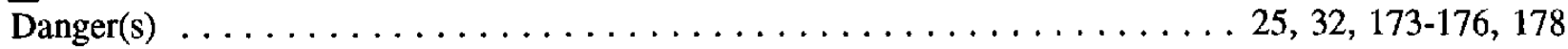

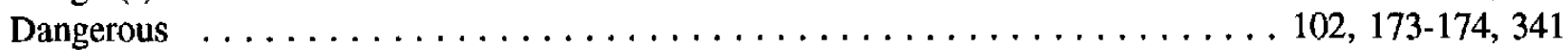

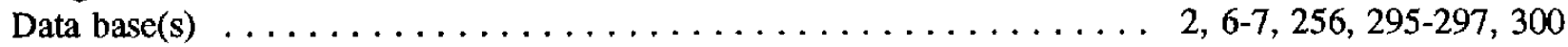




\section{Index (Continued)}

Death(s)

$156,166,250,341$

Debate

3,256

Debt(s) 98,185

Decision(s) $\ldots \ldots \ldots \ldots \ldots \ldots \ldots \ldots \ldots \ldots$ 1-2, 4, 6, 29, 55, 82, 89, 169, 179, 182-187, 202-203, 212 , 219-222, 225, 227, 247, 256-258, 279, 299

Decision factors (See also reasons)

$2,4,6,55,183,185-187$ $203,212,216-218,222,225,227-228$

Decision making

Decommissioning

Decrease demand (See also demand reduction)

$136-137,139$

Default

Defense $52,100,126,236$

Deficit $14,86,94,96-97,230,234,236,240-241,243,333-336$

Deforestation $21,24,30,32$

Delay 43,189

Demand . . . . . . . .

$205-206,230,236,288,349$

Demand reduction (See also decrease demand) $133,135,137,139-140$

Demand-side management (See also DSM programs) . . . . . . . . . . . . . . . 159, 191-192

Democrats 8,280

Demonstration 189,227

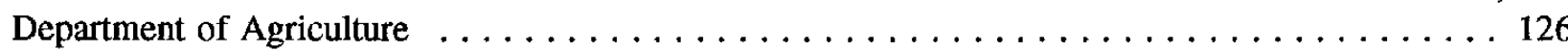

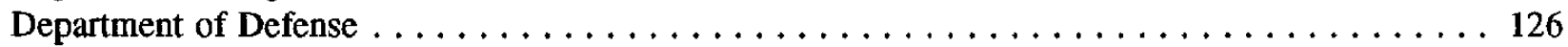

Department of Energy (See also DOE) . . . . . . . . . 28, 114, 124, 126, 146-147, $197,243,289,290$

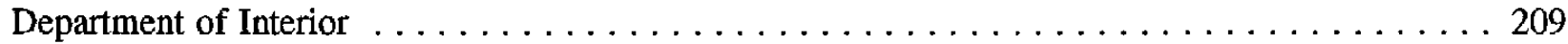

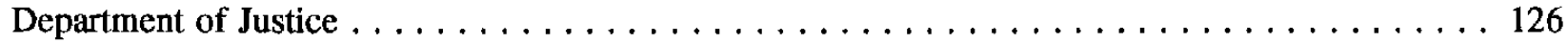

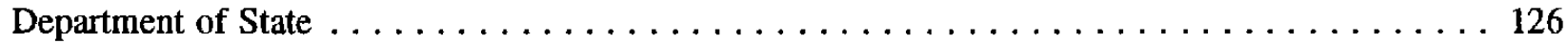

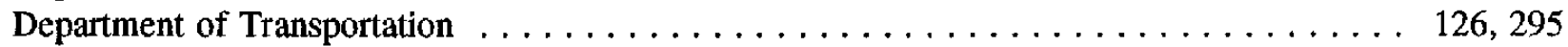

Dependence $\ldots \ldots \ldots \ldots \ldots \ldots \ldots \ldots 10,14-15,36,39,42-43,50,72,86-87,92,124,157-158$, $161-162,164-165,202,204-206,209-210,219,239-241,250,255,333,335$

Dependent $\ldots \ldots \ldots \ldots \ldots \ldots \ldots$ 15, 36, 39, 42, 86, 126, 203, 205, 237, 244-45, 335, 352-353

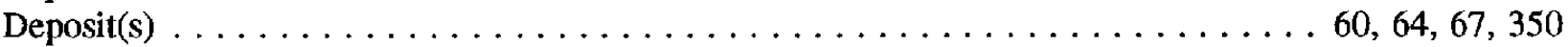

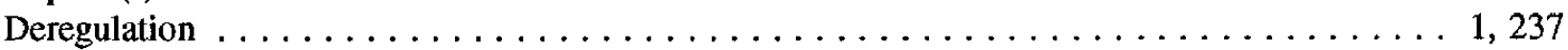

Desert Shield $\ldots \ldots \ldots \ldots \ldots \ldots \ldots \ldots \ldots \ldots \ldots \ldots \ldots \ldots \ldots \ldots \ldots$ 1,71,74, 82, 89, 341

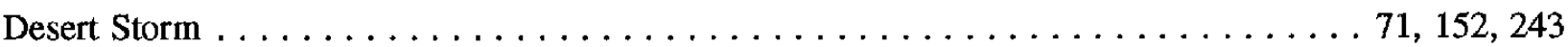

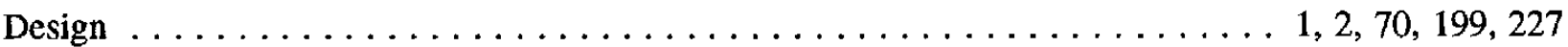

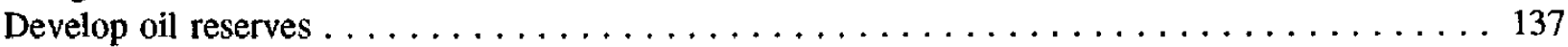

Developing countries (See also Third World) $\ldots \ldots \ldots \ldots \ldots \ldots \ldots \ldots \ldots \ldots \ldots, 98$

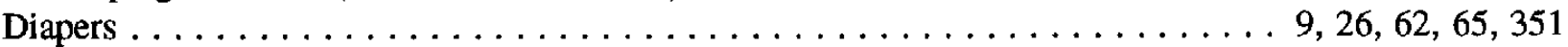

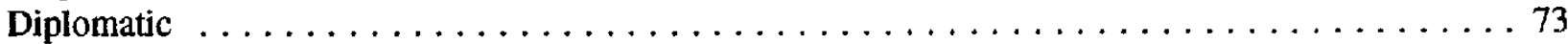

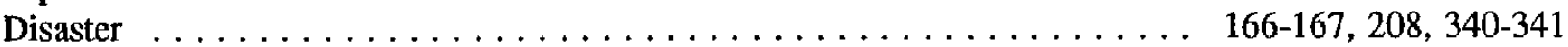

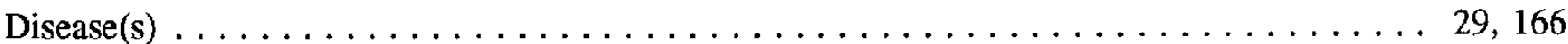

Disposal . . . . . . . . . . . . 9-11, 17, 21-22, 24, 26, 28, 43, 66-67, 97, 173, 175, 344

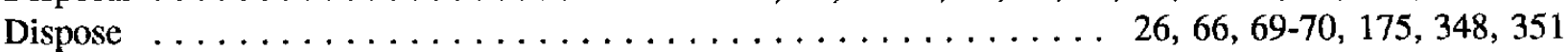

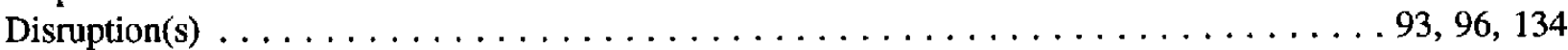

DOE (See also Department of Energy) $\ldots \ldots \ldots \ldots \ldots \ldots \ldots \ldots \ldots \ldots, 28,34,114,124,243$ 


\section{Index (Continued)}

Dollars (See also money) $\ldots \ldots \ldots \ldots \ldots \ldots \ldots \ldots \ldots \ldots \ldots \ldots$ 34, 72, 80, 109, 246, 256, 334, 350 Domestic oil (See also oil, domestic) $\ldots \ldots \ldots \ldots \ldots \ldots \ldots \ldots, 80,115-116,126,136,138,149$, 151,239

Domestic production . . . . . . . . . . . . . . . 229-230, 239-240, 242, 345

Drilling $\ldots \ldots \ldots \ldots \ldots \ldots \ldots \ldots \ldots \ldots$ 12, 39-40, 42-43, 50, 72, 80, 126, 202-203, 208-211, 343

Drinking water (See also water supply) $\ldots \ldots \ldots \ldots \ldots \ldots \ldots \ldots \ldots \ldots \ldots \ldots \ldots \ldots, 19,21,24-25,343$

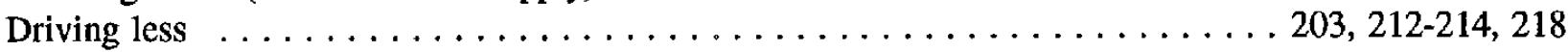

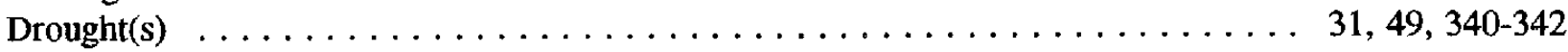

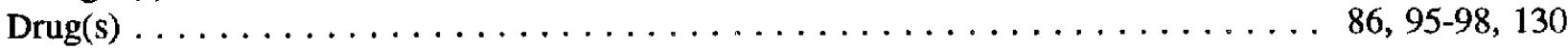

DSM programs (See also demand-side management programs) $\ldots \ldots \ldots \ldots \ldots 136,158,160,170$

$\underline{E}$

Earlier review(s) (of public opinion) $\ldots \ldots \ldots \ldots \ldots \ldots \ldots, 36,85,103,113-114,133,161$, $166,182,184,188,191-192,204,212,214,229,237,245,247-248,250,295$

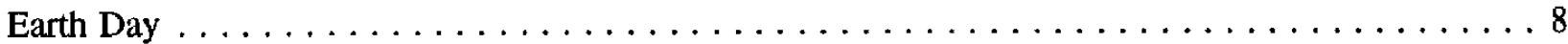

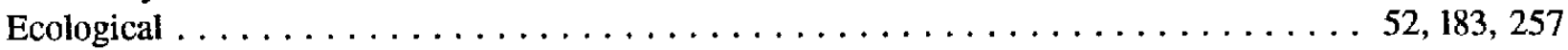

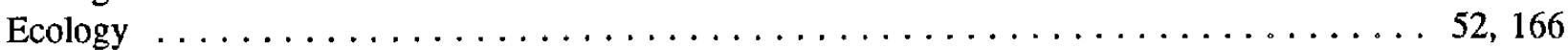

Economic development (See also sustainable development) $\ldots \ldots \ldots \ldots \ldots \ldots \ldots$. $\ldots \ldots, 36$

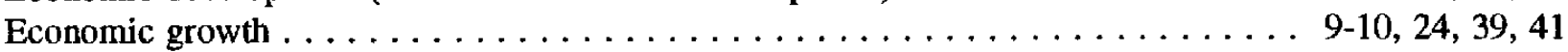

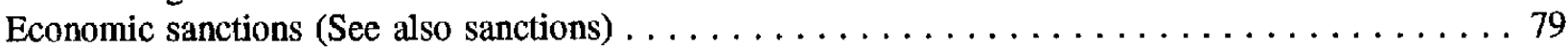

Economical . . . . . . . . . . . . . . . . . . . . . . . . . . . 225-226

Economy(-ies) $\ldots \ldots \ldots \ldots \ldots \ldots$ 8, 11, 14, 39, 50, 55, 74, 77, 79-80, 86, 95, 97, 104-106, $121,159,203,219,221,225-228,229,231,243-246,257,296,335,346$

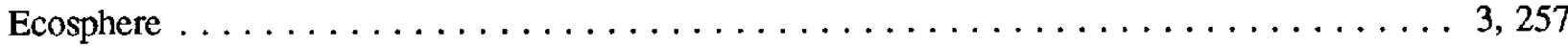

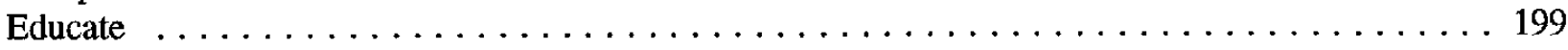

Education $\ldots \ldots \ldots \ldots \ldots \ldots \ldots \ldots \ldots \ldots \ldots \ldots \ldots \ldots, 38,50-51,59,86,95,97-98,101,189$,

$201,219,257,276,295$

Efficiency (See also energy efficiency) . . . . . . . $129,132-133,135-136,138,140-141,143,146,149-150,152,158,160,165,181-186,188-189$, $191-192,196-203,212,218,229-231,236,245-247,256-258,296,298-299,346$

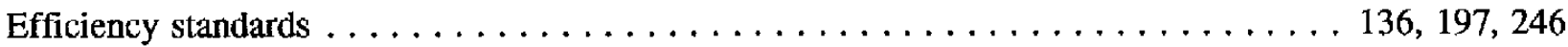

EIA (See also Energy Information Administration) $\ldots \ldots \ldots \ldots \ldots \ldots \ldots \ldots \ldots \ldots \ldots \ldots \ldots \ldots$ 157, 238

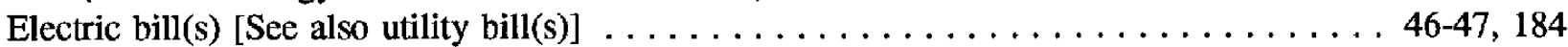

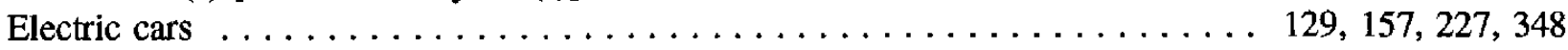

Electric company(-ies) [See also electric utility(-ies)] . . . . . 47, 69, 129-131, 189, 199-200, 347

Electric rates . . . . . . . . . . . . . . . . . . . . . . . . . . . . . . . . . . 129

Electric utility(-ies) $[$ See also electric company(-ies)] $\ldots \ldots \ldots \ldots \ldots 28,48,64,114,122,127$, $129-131,159-161,163,177,253$

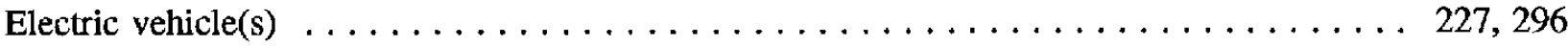

Electrical companies $[$ See also electric utility(-ies)] $\ldots \ldots \ldots \ldots \ldots \ldots \ldots \ldots \ldots$

Electricity . . . . . $70,89,93,97,103,106-107,114,127,129-130,137-138,140,147,150,153,157-163,165-170$, $176,178,180,182-183,186,196,200,203,219,221,253,296,298,337-338,345,348,351$

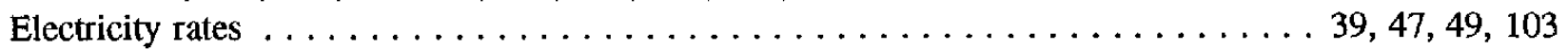

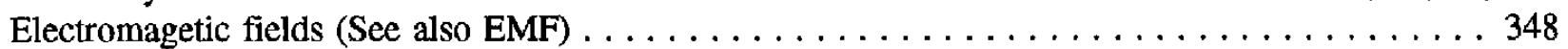

Embargo . . . . . . . . . . 1, 4, 72, 74, 79-80, 85, 113, 124, 127, 132, 205, 243, 255, 339

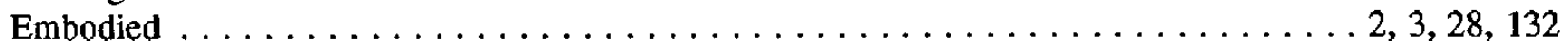

Embodied energy $\ldots \ldots \ldots \ldots \ldots \ldots \ldots \ldots \ldots \ldots \ldots \ldots \ldots \ldots \ldots \ldots \ldots \ldots \ldots \ldots, 28,132$ 


\section{Index (Continued)}

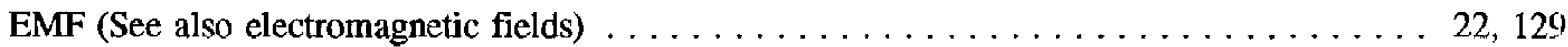

Emission controls . . . . . . . . . . . . . . . . . . . . . . . . . 47, 229

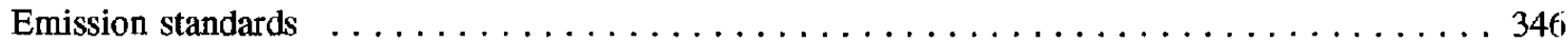

Emissions . . . . $\ldots \ldots \ldots \ldots \ldots \ldots \ldots \ldots \ldots \ldots, 8,11-12,28,32-35,39,45,47-48,62,65$, $68-69,132,157,160-161,163,203,227,244,246,342,347,352$

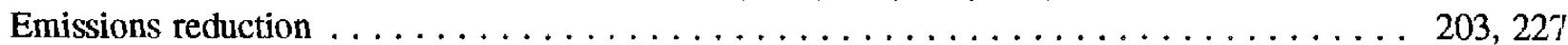

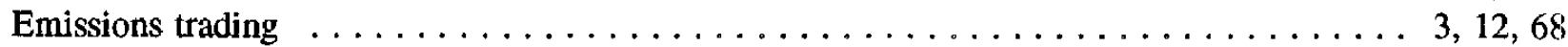

Employee(s) . . . . . . . . . . . . . . . . . . . . . 130-131, 218, 251, 289

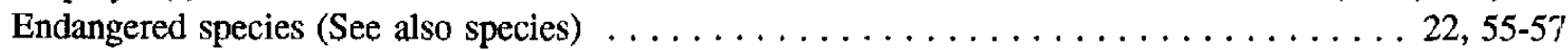

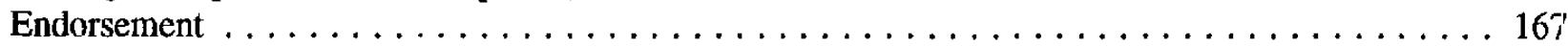

Energy . . . . . . . . . . $1-6,8-12,14-17,20,22,25,28-30,32,34,36,38-39,41-45$, $47-48,50,53,57-59,62,66-67,69-70,72-73,80-82,85-86,88-90,93-98,101-104,106,108-109$, $113-117,124,126-127,129,131-153,156-172,174-175,178-180,181-192,196-202,204-205$, $209-210,212,214,216-218,221,227,230,232,234,236-244,246-248,250-252,256-258$, $295-299,329-331,333-335,337-340,345-348,350,352$

Energy conservation (See also conserve, conservation) $\ldots \ldots \ldots \ldots \ldots$, 4, 32, 43-45, 48, 58, 109 , $142,146-147,182-185,188-189,191-192,196-199,214,248,256,296-299,330-331,333$

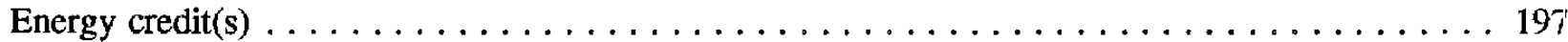

Energy crisis (See also energy problem, energy situation) $\ldots \ldots \ldots \ldots \ldots 1,4,93,95-96,114-117$, $124,184-185,227,243,299$

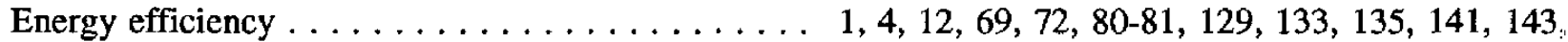
$146-147,149-150,160,165,181-184,186,188-189,191-192,197,201,212,218,236,247,256$ $257,296,298,346$

Energy-efficient mortgages (EEMs) (See also mortgage financing incentives) . . . . . . . 6 197-198, 201, 298

Energy from ocean tides $\ldots \ldots \ldots \ldots \ldots \ldots \ldots \ldots \ldots \ldots \ldots \ldots \ldots \ldots$ 143-146

Energy industry $\ldots \ldots \ldots \ldots \ldots \ldots \ldots 12,41,93,141-142,149,151,175,199,230,236,239$. 241,246

Energy Information Administration (See also EIA) $\ldots \ldots \ldots \ldots \ldots \ldots \ldots \ldots$ 157, 204, 238

Energy needs $\ldots \ldots \ldots \ldots \ldots \ldots \ldots \ldots \ldots \ldots \ldots \ldots \ldots \ldots 114-15,127,129,131,140-141,147,150$, $151-152,165,204-205,337$

Energy policy (See also policy, policy preferences) $\ldots \ldots \ldots \ldots \ldots \ldots \ldots$ 2, 4-6, 20, 36, 47, 50, $80,82,93,102,113-115,127,135,139,141-142,165,175,181,198-199,209,217,237-239$, 248,333

Energy problem(s) (See also energy crisis, energy situation) $\ldots \ldots \ldots \ldots \ldots \ldots \ldots \ldots$. $\ldots$. $\ldots$-86. 92, 94-95, 97-98, 102, 113-115, 124, 127, 184, 191, 298, 299

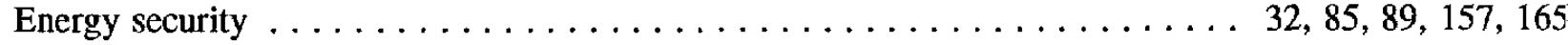
Energy shortage(s) . . . . . . . 16, 85-86, 89-90, 93, 95, 135, 183-184, 186-187, 197, 216, 218

Energy situation (See also energy crisis, energy problem) . . . . . . . . . 1, 4-5, 85-89, $103,113,115,157,165,183,190,197,210,250,256,298-299$

Energy source(s) $\ldots \ldots \ldots \ldots \ldots \ldots \ldots \ldots \ldots \ldots \ldots \ldots \ldots$ 42-45, 70, 72-73, 80-81, $135,140,142-144,146-153,160-161,188,198,239,242,246,256-257,329,348$

Energy supply(-ies) $\ldots \ldots \ldots \ldots \ldots \ldots \ldots$ 4-5, 9-10, 16, 36, 38-39, 73, 85, 89, 93-94, 98, $113-114,116,127,133-135,141-144,146,150,152-153,161,164,186,199,244,298,352$

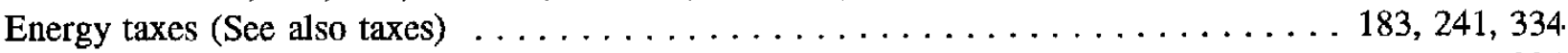

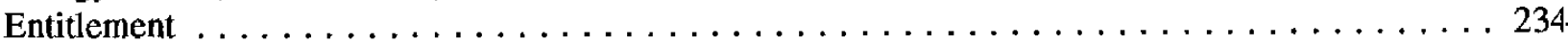




\section{Index (Continued)}

Environment (See also environmental protection)

$2-7,8-17,20,22,24,28$, $34-36,38-43,45-47,49-50,52-62,64-65,71,80,84,86,88,97-98,101-102,114,123,129,131$, $134,140,147,152-153,157-163,170,172,175,177-178,180,187,199-200,202,208-210$, $213-214,216,218-219,225,230,247,252-253,256-258,296,289,290,344,346-347,350$

Environmental concern(s) $\ldots \ldots \ldots \ldots \ldots \ldots \ldots \ldots \ldots \ldots$, 8-9, 12, 14, 17, 19-21, 23-25, 58, 80, $86,133,158,161,163-164,184,202,256$

Environmental controls

$12,39,50$

Environmental degradation $1,4,11,14-15,57,157,163$

Environmental issues $9-10,17-18,32-33,57-58,69$

Environmental laws $8-9,11,53$

Environmental movement . $1,52-53,92$

Environmental organizations

Environmental protection (See also environment) $49-50,54,56-60,65,114,131,159,161,186,210,243,255,258,341,350$

Environmental Protection Agency (See also EPA) $\ldots \ldots \ldots \ldots \ldots \ldots \ldots \ldots, 26,255,341$ Environmental quality $8,11-14,22,52,55,162,188,191,248$ Environmental regulation(s) $\ldots \ldots \ldots 60,64,130,239$ Environmental threat(s) $10,29,33,70,147,150,152-153,161$

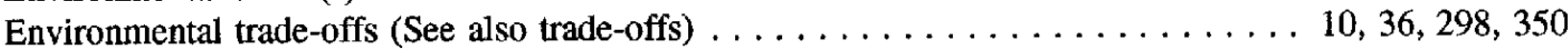
Environmental trust fund $9,11,52-53,57,59,161,213$

Environmentalism (See also activism) Environmentalist(s) $\ldots \ldots \ldots \ldots \ldots \ldots \ldots \ldots \ldots$ 3, 19, 53, 58, 85, 113, 115-117, 124, 208-209 EPA (See also Environmental Protection Agency) $\ldots \ldots \ldots \ldots \ldots \ldots \ldots \ldots \ldots \ldots \ldots$. $\ldots \ldots \ldots$

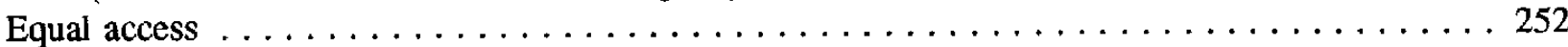
Equipment $\ldots \ldots \ldots \ldots \ldots \ldots \ldots \ldots, 47,59,62,65,68,121,160,197,244,329-330,352$ Ethanol ......................... 203, 227, 244, 252, 255, 352

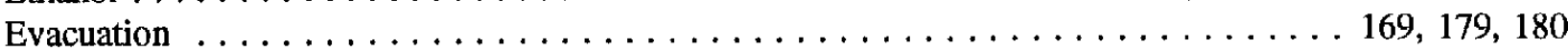

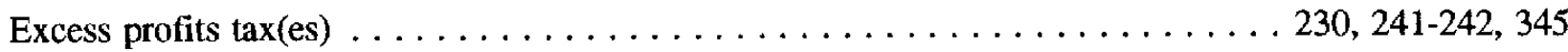

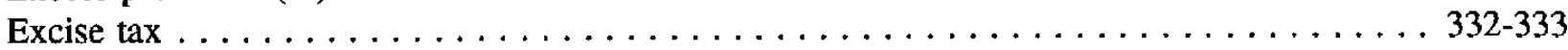

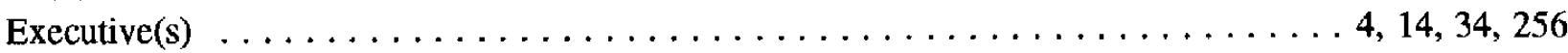

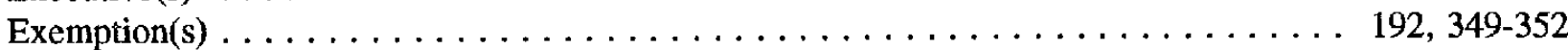

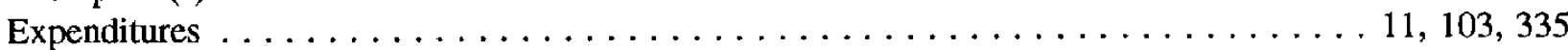

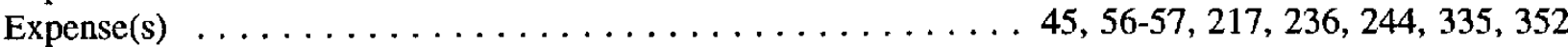
Exploration $\ldots \ldots \ldots \ldots \ldots \ldots 38,43-44,50,81,116,135,138,205,209-210,230,232,237$, $239,241-242,345$

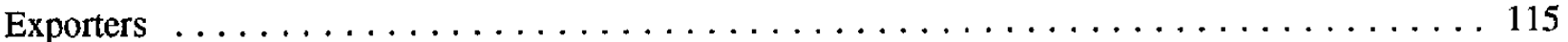

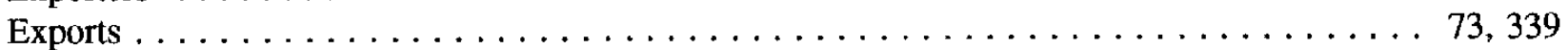

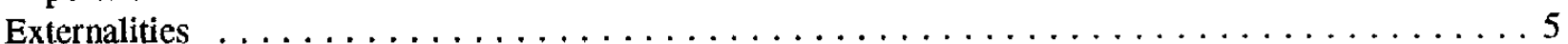

Exxon $\ldots \ldots \ldots \ldots \ldots \ldots \ldots \ldots \ldots \ldots \ldots \ldots \ldots \ldots \ldots$ 52, 84, 122-123, 202, 208-209, 340

$\underline{F}$ Facility siting $[$ See also siting decision(s) $] \ldots \ldots \ldots \ldots \ldots \ldots \ldots \ldots \ldots \ldots$ 28-29, 174 Factories . . . . . $\ldots \ldots \ldots .8,12,17,19-20,30,34-35,62,65,72,78,80-81,114,124,127$, $131,129,135,163,343,346$

Farm(s) (See also agriculture) $\ldots \ldots \ldots \ldots \ldots \ldots \ldots \ldots \ldots \ldots \ldots \ldots \ldots 19,25,32,191,198,343$

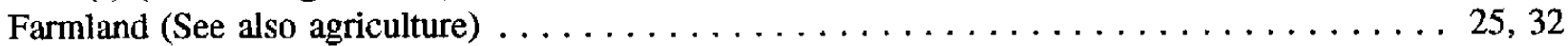




\section{Index (Continued)}

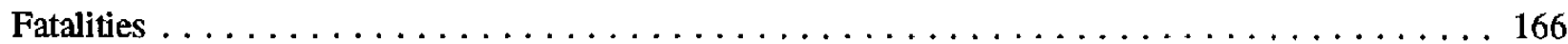
Favor $\ldots \ldots \ldots \ldots \ldots .9-12,32-34,36,39-40,45,47-48,50,62,65-68,74,79-80,83-84,98$, $133-134,136-137,139-140,146,150-151,158-159,164,170-172,178,198,203,209-210,217$, $230,232-234,236-237,240-243,246-247,249-252,333-338,346$

Favorability . . . . . . . . $135,146,149,158,161,164-166,170-172,180,209,231,239,241-242,251,299$

Favorable $\ldots \ldots \ldots \ldots \ldots \ldots \ldots \ldots 12,59-60,71,113-114,118,121-122,124,126,129,132$, $140,159,162,164-165,170,172,209,231,240,246-248$

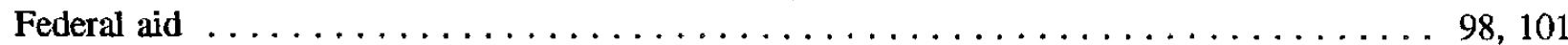

Federal gasoline tax (See also gasoline tax) $\ldots \ldots \ldots \ldots \ldots \ldots \ldots \ldots \ldots$ 137, 230, 232, 234, $236,241,333-334$

Feedstocks 252

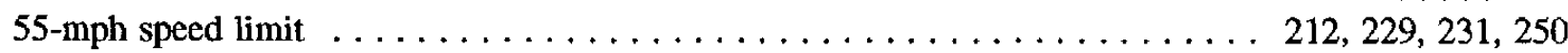

Film . . . . . . . . . . . . . . . . . . . . . . . . . . 196

Financial incentive(s) $[$ See also incentive(s) $] \ldots \ldots \ldots \ldots \ldots \ldots \ldots$ 134, 160, 199, 201, 226, $229,231,247,349$

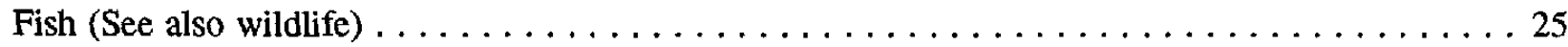

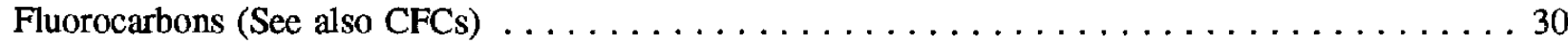

Food(s) . . . . . . . . . 19, 22, 56-57, 61-62, 64-65, 67, 73, 93-94, 102-103, 110-112, 118, $121-122,130,178,196,236,343,350$

Foreign aid $38,96-97,241,351$

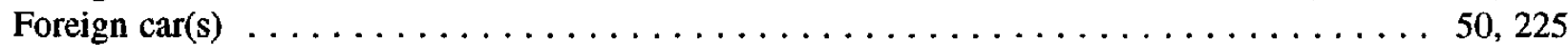

Foreign oil (See also imported oil) . . . . . . . $86,89,91-92,115,124,126,135,139,143-144,146,157-158,161-162,164-165,202,204-205$, $209-210,237,239-240,243,296,299,335$

Foreign policy $\ldots \ldots \ldots \ldots \ldots \ldots \ldots \ldots \ldots \ldots \ldots \ldots \ldots \ldots \ldots \ldots$ 72, 74-76, 80, 142

Fossil fuel(s) $\ldots \ldots \ldots \ldots \ldots \ldots \ldots \ldots \ldots \ldots \ldots \ldots \ldots, 2,6 \ldots, 11-12,28,30,32-34,45,85-86,133$, $139,142,146,149,160-161,165,166,170,184$

Free access . . . . . . . . . . . . . . . . . . . . . . . . . . 74

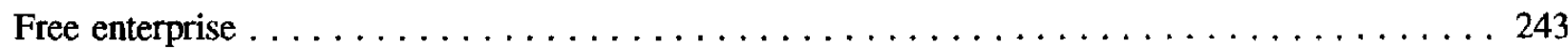

Fuel(s) $\ldots \ldots \ldots \ldots \ldots \ldots \ldots \ldots 1,4-6,8,11-12,28,30,32-35,43-46,57-58,65,80,85-86$,

$89,93,105,113-114,116,127,132-136,138-139,142,146,149-151,157-161,165-166,170$, $183-185,189-190,192,196-197,202-203,212-215,218-222,225,227-232,234,236,241$, $243-248,252-253,255-256,296-298,330,332,345-346,351$

Fuel economy (See also CAFE standards) $\ldots \ldots \ldots \ldots \ldots \ldots, 225,227,229,231,245-246$

Fuel-efficient automobile(s) $\ldots \ldots \ldots \ldots \ldots \ldots \ldots \ldots \ldots \ldots \ldots \ldots \ldots \ldots \ldots \ldots \ldots \ldots \ldots, 212,214$

Fuel-efficient $\operatorname{car}(\mathrm{s}) \ldots \ldots \ldots \ldots \ldots \ldots \ldots$ 57, 134, 138, 203, 213-214, 218, 225, 234, 246-247

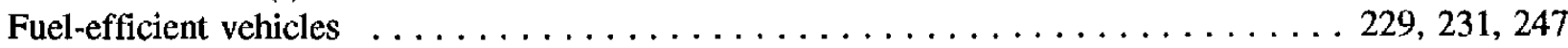

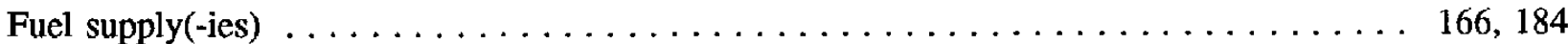

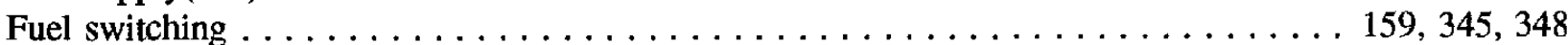

Fund(s) . . . . . . . . . . . . . 45, 52, 69, 98, 101, 114, 126, 136-137, 146-148, 242

Funding $\ldots \ldots \ldots \ldots \ldots 98,101,126,146-148,159,161,163,165,199,295,297-298,300,347$

Future $\ldots \ldots \ldots \ldots \ldots \ldots \ldots \ldots \ldots \ldots \ldots$ 11, 14-15, 33, 36, 55-57, 66, 85-86, 89, 93, 95-96, $106,108-109,114,116,118,127,129,131,139-140,146-152,157,160-162,165,167,178-180$, $185-186,198,256-257,299,346$ 


\section{Index (Continued)}

$\underline{\mathrm{G}}$

Gap(s)

$1,5,7,36,184,191,204,231-232,253,295$

Garbage $17,23-24,26,44,58-59,61,64-65,67,97,130,343$

Gas company(-ies) $129,189,238$

Gas guzzler cars 65

Gas mileage $215,225-226,229,234$

Gas station(s)

Gas tax (See also gasoline taxes)

$79,106,122,209,229,231,249-250,296$

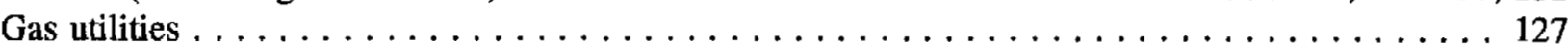

Gasohol . . . . . . . . . . . . . . . . . . . . . . . . . . . . . 252-253

Gasoline . . . . . . $89,93,96,98,103-109,113,115,118,120,122-125,130,133,135,137,165,180,182,196$, 202-203, 205, 209-210, 212-214, 217-222, 225, 227-234, 236-241, 243, 245, 248-250, 252-253, $255-258,296,333-336,339-340,343,345,350-351,353$

Gasoline policy $229-230,232$

Gasoline price(s) $\ldots \ldots \ldots \ldots \ldots \ldots 1,3-5,12,40,50,62,72,79,83,98,102-109,118,120$, $124-125,212,225,229-230,237-238,253,335,339-340$

Gasoline rationing $229,231,248,250,345$

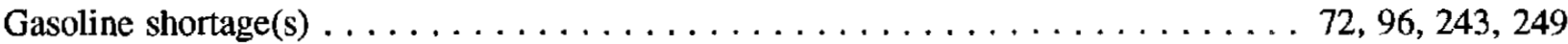

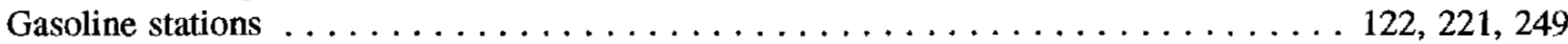

Gasoline tax(es) [See also gas tax(es)] $\ldots \ldots \ldots \ldots \ldots \ldots 12,32,34,45,73,83,106 ; 136-137$, $212,229-230,232-234,236-237,240-241,257-258,334-335,345,353$

Gender $219,221-222$

Geothermal $151,157,351$

Glass $11,59-61,64,66,196,350$

Global $4,8-12,14,16-18,22-24,29-36,39,45,52-54,57,60,68,89,146$, $159,161,165-166,175,180,246,256,258,296,341$

Global climate change (See also global warming) $3-4,9,30,159,165,180,296$

Global warming (See also greenhouse effect, climate change) . . . . . . . 1-3, 5, 8-11, 16-18, $22-24,29-36,45,52-54,57,60,68,146,159,161,165-166,175,180,246,256$

Globally

GM

Goal(s)

Government $\ldots \ldots \ldots \ldots \ldots \ldots 1,4-5,7-9,11,14,32-33,45,53-54,68-70,74-76,81,85-86$, $94-95,97-98,101,113-115,123-124,126-127,130-132,134,136,139,142-143,147,159$, $162-163,165-166,168-170,175-176,178-180,182$, 184, 187-190, 192, 197-199, 201, 208-211, $229-232,236-238,240-243,245,247-253,256,258,296-297,353-335,345-346,350$

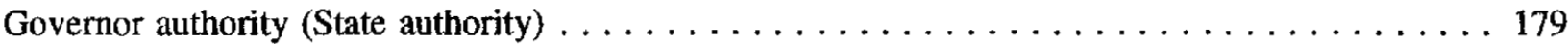
Grain(s) $230,236,247,252$

Grandchildren 93-94

Grants 199

Grassroots $11,53,59,93,258$

Green pricing $158-159,161,258$

Green products 11,59

Greenhouse effect (See also global warming, climate change)

$9,16-22,24$, $29-34,43-44,49,93-95,133,166,180,296,339,341-342$ 


\section{Index (Continued)}

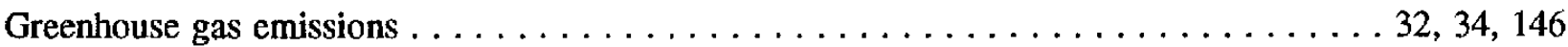

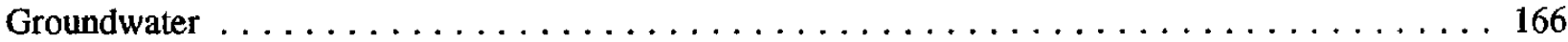

Gulf $w a r \ldots \ldots \ldots \ldots \ldots \ldots \ldots \ldots \ldots \ldots \ldots, 4-5,71,74,81-83,85-86,93,125,133,240$

$\underline{\mathbf{H}}$

Habit(s) (See also lifestyle) . . . . . . . . . . . . . . . . . . . 4, 181, 184-185, 226, 257

Hazardous waste $\ldots \ldots \ldots \ldots \ldots \ldots \ldots \ldots \ldots \ldots \ldots \ldots \ldots \ldots \ldots \ldots \ldots \ldots \ldots \ldots \ldots, 17,19,23,343,344$

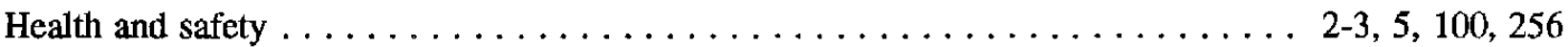

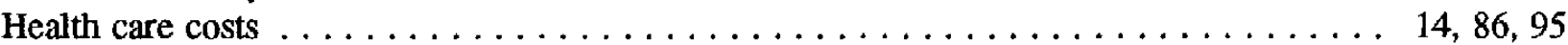

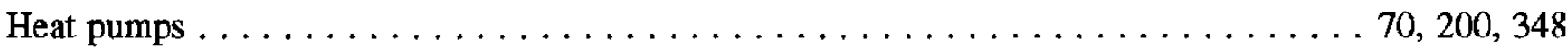

Heating $\ldots \ldots \ldots \ldots \ldots \ldots \ldots \ldots \ldots \ldots \ldots \ldots \ldots \ldots, 58,69-70,93,130,151,157,182-183$,

$189,196-197,200,230,237,257,331,348$

Heating, ventilating, and air conditioning (HVAC) systems $\ldots \ldots \ldots \ldots \ldots \ldots \ldots \ldots$

High bill complaints . . . . . . . . . . . . . . . . . . . . . . . . . . . . . 189

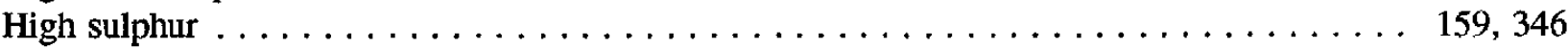

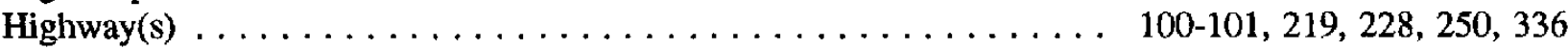

Homebuilders . . . . . . . . . . . . . . . . . . . . . . . . . . . . . . . 189

Homeowners . . . . . . . . . . . . . . . . . . . . . 186-188, 190-191, 293

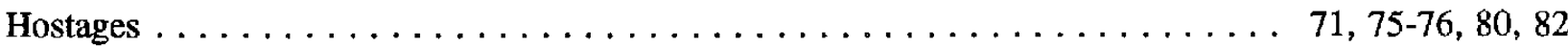

Hostilities (See also combat, conflict, war) $\ldots \ldots \ldots \ldots \ldots \ldots \ldots \ldots \ldots \ldots \ldots$ 71-72, 75, 82, 89

Household $\ldots \ldots \ldots \ldots \ldots \ldots \ldots \ldots \ldots \ldots \ldots \ldots \ldots \ldots \ldots \ldots \ldots, 22,26,51,58-62,64,67,70,181-189$, $196-197,200,213,218,228,249,279,344,348,350$

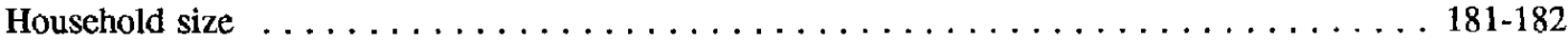

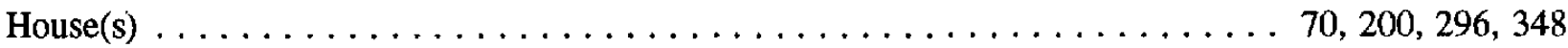

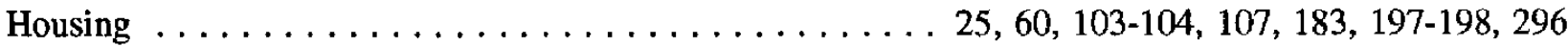

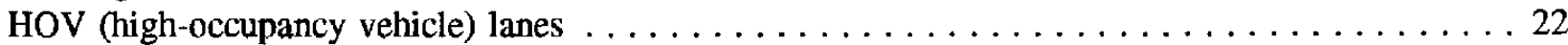

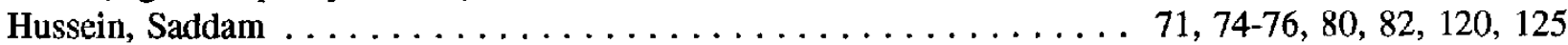

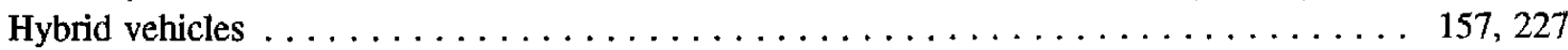

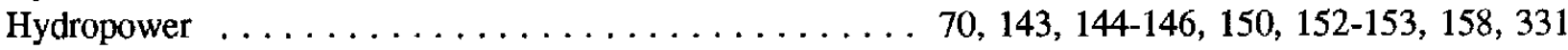

$\underline{\mathbf{I}}$

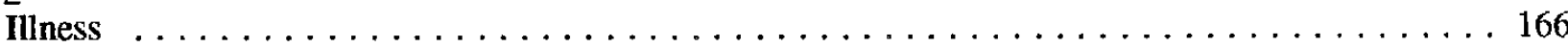

Impact(s) $\ldots \ldots \ldots \ldots \ldots \ldots \ldots \ldots \ldots \ldots \ldots \ldots \ldots, 16,28-31,48,57-59,71-72,83,85-86$,

$102-103,105-107,109,157,161-165,167,169,184-186,204,208,298-299$

Imported oil (See also foreign oil) $\ldots \ldots \ldots \ldots \ldots \ldots \ldots \ldots \ldots \ldots \ldots \ldots \ldots, 36,83,85,89,133$, $135,150-151,159,204-206,212,230,232,240-241,248,250,257,345$

Incentive(s) $\ldots \ldots \ldots \ldots \ldots \ldots \ldots 68,81,114,124,126-127,134-138,142,158-160,197-199$, $201,216-217,226,229-231,237,239,242,247,252,329$

Income $43,50-51,85,104,106,185,187-188,192$, $197,201,206,217,222,234,236,238,329-330$

Income $\operatorname{tax}($ See also tax credits) $\ldots \ldots \ldots \ldots \ldots \ldots \ldots \ldots \ldots \ldots \ldots \ldots$ 187, 192, 234, 329-330

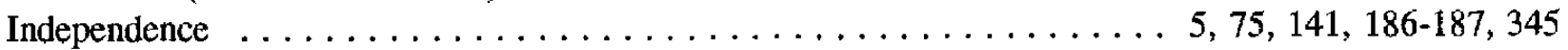
Independent $\ldots \ldots \ldots \ldots \ldots \ldots \ldots \ldots \ldots \ldots \ldots \ldots \ldots \ldots \ldots \ldots \ldots \ldots \ldots \ldots \ldots \ldots \ldots, 135,159,232,241,248,345$

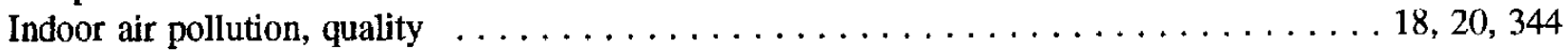

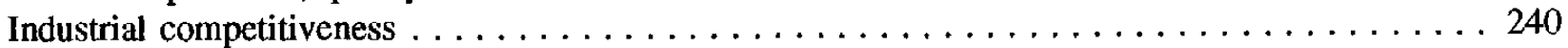
Industrial plant(s) $\ldots \ldots \ldots \ldots \ldots \ldots \ldots \ldots \ldots \ldots \ldots \ldots \ldots \ldots \ldots \ldots \ldots \ldots \ldots \ldots, 39,40$ 


\section{Index (Continued)}

Industry(-ies) $\ldots \ldots \ldots \ldots \ldots \ldots \ldots \ldots \ldots \ldots \ldots \ldots \ldots, 5-6,9,11-12,14,32,39,41,52-54,57$, $59,68,85,93,104,113-114,116,118,120-125,127,129-132,141-143,149-151,160,162-163$, $165-168,175,177,179-180,182,184,189-190,199,203,206-207,209,219,225,230-232$, $236-237,239-243,246,257,297,299,344,346$

Inexpensive $166-167,203,221$ Inflation $72,79,85-86,97-98,106,109,218,242,339$ Information $\ldots \ldots \ldots \ldots \ldots \ldots \ldots \ldots \ldots \ldots \ldots \ldots \ldots \ldots$ 1-2, 4, 6-7, 9, 12, 29, 55, 68-69, 114, 116, $118,121,124,127,130-131,133,135,152,157-160,163,166,168-169,174,180-181,183-186$, $188-192,199-202,204,216,220-221,229,238,248,257-258,296-297,299,347$

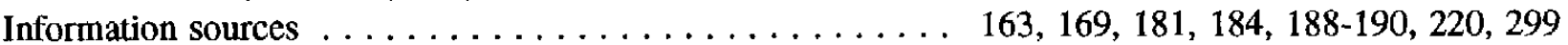

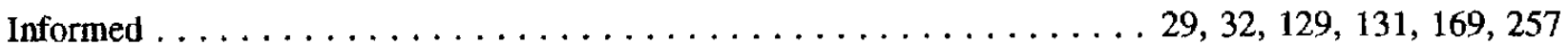

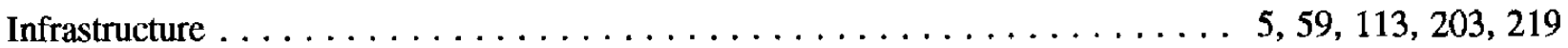

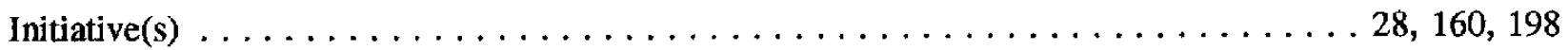

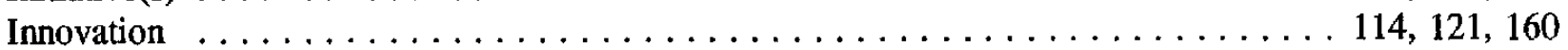
Inspect . . . . . . . . . . . . . . . . . . . . . . . . . . . . . . . . 199

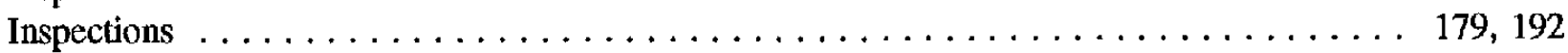
Institutional $\ldots \ldots \ldots \ldots \ldots \ldots \ldots \ldots \ldots \ldots \ldots \ldots \ldots \ldots \ldots \ldots \ldots \ldots \ldots .113,182-183,186,219,257-258$ Institutionalized inefficiency $\ldots \ldots \ldots \ldots \ldots \ldots \ldots \ldots \ldots \ldots \ldots \ldots \ldots \ldots, 186,197,203,219$ Institutions $\ldots \ldots \ldots \ldots \ldots \ldots \ldots 2,4-5,10,54,58,98,113-115,132,184,188,219,256-258$

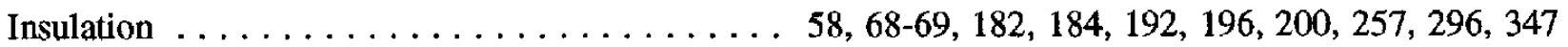
Integrated resource planning (IRP) $($ See also IRP) $\ldots \ldots \ldots \ldots \ldots \ldots \ldots \ldots \ldots \ldots \ldots$

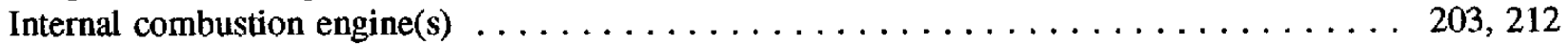
Internal Revenue Service (IRS) $\ldots \ldots \ldots \ldots \ldots \ldots \ldots \ldots \ldots \ldots \ldots \ldots \ldots$

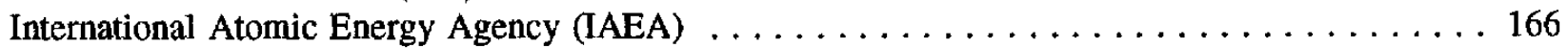

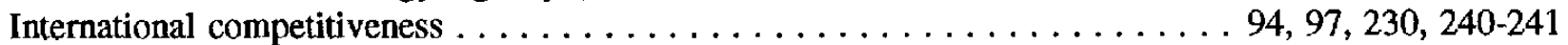

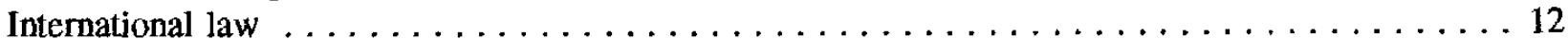
Invade . . . . . . . . . . . . . . . . . . . . . . . . . . . . . 82-83

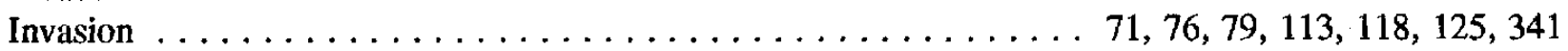

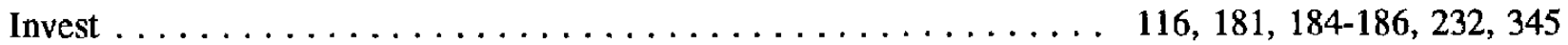
Investment(s) $\ldots \ldots \ldots \ldots \ldots \ldots 95,114,116,126,136,160,181-183,185-186,192,196-197,256$ Investor-owned utilities $\ldots \ldots \ldots \ldots \ldots \ldots \ldots \ldots \ldots \ldots \ldots \ldots \ldots \ldots \ldots$. $\ldots \ldots, 160$ IRP (See also integrated resource planning) $\ldots \ldots \ldots \ldots \ldots \ldots \ldots \ldots \ldots \ldots \ldots$ 114, 157-160

$\underline{\mathbf{J}}$

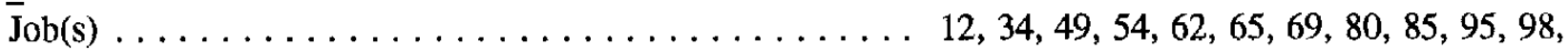
$102,121,127,169,178,189,208,244,351$

$\underline{\mathrm{K}}$

Knowledge (See also awareness) $\ldots \ldots \ldots \ldots \ldots \ldots \ldots 1-3,6,29-30,59,93,134,163,165,181$, $184,188,191-192,202-204,217,219-220,256$

Knowledgeable (See also awareness) $29,168,202,204,220,252$

$\underline{\mathbf{L}}$

Labeling . . . . . . . . . . . . . . . . . . . . . . . . . . . . . . . . . . . . . . . 101-102, 198

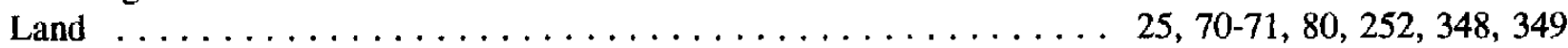
Landfill(s) . . . . . . . . . . . . . . . 11, 20-22, 28, 59-60, 62, 65-66, 70, 348, 351

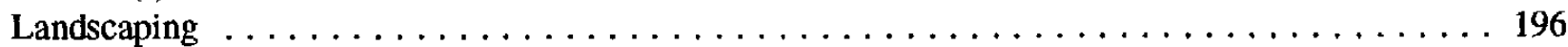
$\operatorname{Law}(\mathrm{s}) \ldots \ldots \ldots \ldots \ldots \ldots$ 12, 34-35, 48, 60, 64, 70, 97, 139, 176-177, 199, 237, 240, 246 
Leaders $\ldots \ldots \ldots \ldots \ldots \ldots \ldots \ldots \ldots \ldots \ldots \ldots \ldots \ldots \ldots 12,29,32,39,41,45,54,57,93-94,98,102$, $141-143,149-151,160,165,167-169,175,177,188,199,201,230,234,236,239,241,243,246$, $257,297,341$

Leadership

$41,57,94-95,258$

League of Women Voters (LWV)

$11,29,32,39,45,53-54,57$

Leasing

Least-cost utility planning (See also integrated resource planning) $\ldots \ldots \ldots \ldots \ldots \ldots$ 157, 160

Legal

Legislation

$8,134-135,179,255,335$

Legislator(s)

$47,168,177$

Lenders

256

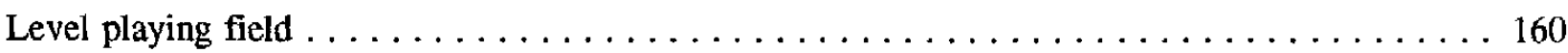

Level(s) of concern

$9,23,29-30,32,36$

Liberal(s)

8,138

License

$245,339,353$

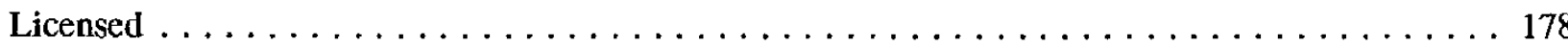

Lifestyle (See also habits) $\ldots \ldots \ldots \ldots \ldots \ldots \ldots \ldots \ldots, 20,57-59,182,192,212,218,256,257$

Light bulbs

$69,200,257,347$

Lighting

LIHEAP (Low-Income Home Energy Assistance Program)

$229,231,249$

Limited access to gas stations

Litter(-ing)

$3,19,21,59,67,343$

Load control

200,349

Load shifting

Loan(s)

$69,109,192,199-200,331,345,348$

Low-cost

$69,199-200$

Low-Income Home Energy Assistance Program $\ldots \ldots \ldots \ldots \ldots \ldots \ldots \ldots \ldots$

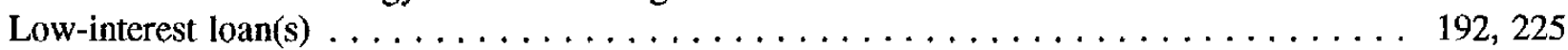

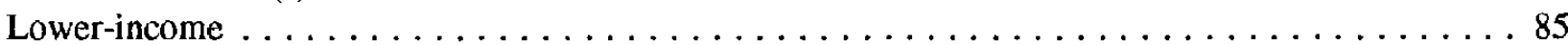

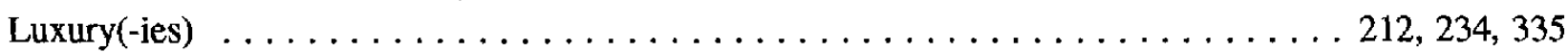

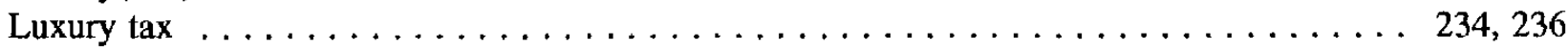

$\underline{\mathrm{M}}$

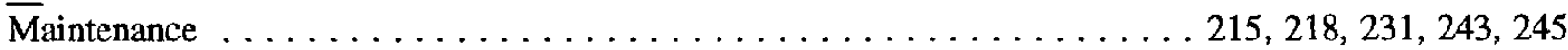

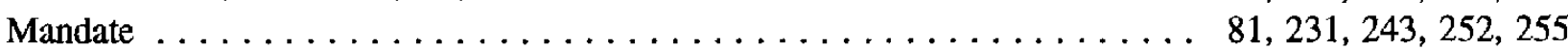

Mandatory $\ldots \ldots \ldots \ldots \ldots \ldots \ldots \ldots \ldots \ldots \ldots \ldots \ldots \ldots \ldots \ldots \ldots \ldots, 11,64,67,81,135,138,243,246,248$

Market(s) . . . . . . . . . . 33-34, 68, 80-81, 83, 86, 89, 118, 135, 181, 186, 199, 203, $205-206,214,222,225,234,237,240,245-246,257,329,339-340$

Marketplace

57, 142-143, 199

Mass transit (See also public transportation)

$36,138,203,212-214,217-218$, $229,231-232,242,248,250-252,296$

Media $20,33,169,177,180,183,189,211,221,257,297$

Medicare 234,236

Medicine ... 178

Meltdown 166,176

Membership(s)

$11,52-53,59$

Men 219, 228

$\operatorname{Metal}(s)$ 59, 196 
Methanol $50,58,203,219,221-222,244,252-253,255,352$

Middle East $71-76,78-84,86,97,113,118,124-125,135$

Midwest $15,138,140,148,161,341$

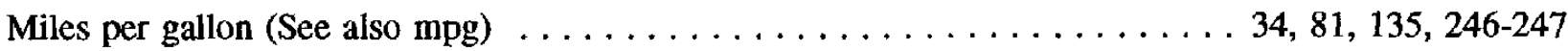

Military $38,71-74,76-80,82,84,95,98$

Mines $28,70,348$

Mining $11,36,43,53,163$

Minorities $10,30,53$

Minority

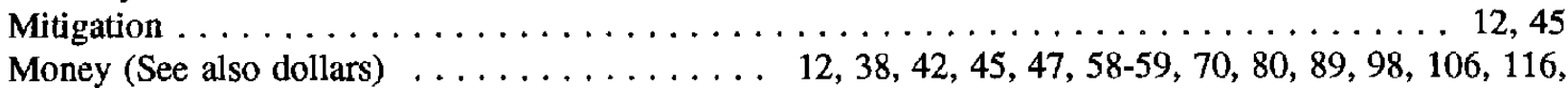
$118,125,131,140,146-147,163,184-187,217,232,236,241,251,334-336,345$

Montreal Protocol 33

Moratorium . . . . . . . . . . . . . . . . . . . . . . . . . . . . . . . . . . . . . . 209

Mortgage financing incentives (See also energy-efficient mortgages) $\ldots \ldots \ldots \ldots \ldots \ldots \ldots$. . . 198

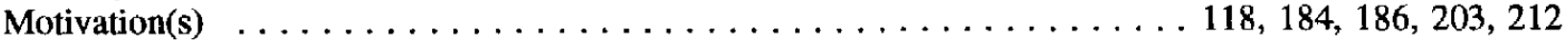

$\operatorname{mpg}($ See also miles per gallon) $\ldots \ldots \ldots \ldots \ldots \ldots \ldots \ldots \ldots \ldots \ldots \ldots \ldots \ldots \ldots \ldots \ldots, 217,246$

MSW (See also municipal solid waste) $\ldots \ldots \ldots \ldots \ldots \ldots \ldots \ldots \ldots \ldots \ldots \ldots, 11,26$

Municipal solid waste (See also waste) $\ldots \ldots \ldots \ldots \ldots \ldots \ldots \ldots \ldots \ldots \ldots \ldots \ldots \ldots \ldots .2,5,9,26-28,66$

$\underline{N}$

Nation $\ldots \ldots \ldots \ldots \ldots \ldots \ldots \ldots \ldots \ldots .1-2,8,14-15,25,36,38,53,69,72,80,84-86,89,95$, $98,102-103,113,115,140,148-150,157,165,167,204,212,219,340$

National energy policy (See also National Energy Strategy) . . . . . . . 4, 36, 50, 93, 102, $133,139,198,209,237,239,248,333$

National Energy Strategy (See also national energy policy) . . . . . . . . 1, 28, 36, 45, 134, $136,150,197-198,210,240,247,251-252,338$

National Environmental Policy Act (See also NEPA) $\ldots \ldots \ldots \ldots \ldots \ldots \ldots \ldots \ldots$ National health insurance . . . . . . . . . . . . . . . . . . . . . . . . 101-102 National Renewable Energy Laboratory (See also NREL) . . . . . . . . . . . 6, 186-187, 295

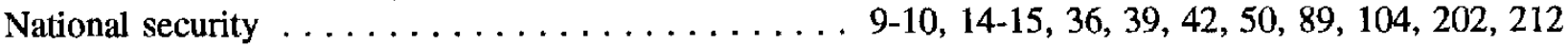

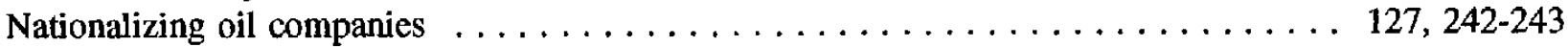

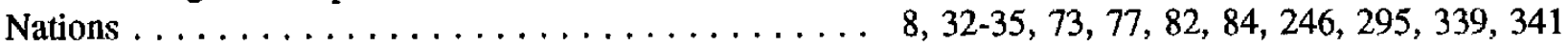
Natural gas . . . . . $149-153,157-158,165,182,196,206,210,221,238-239,243,245,255,298,349,353$

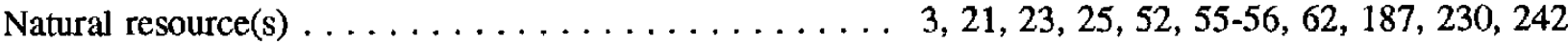

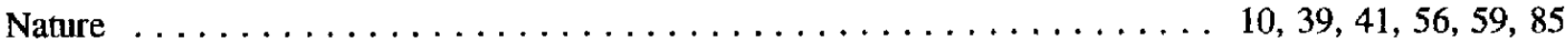

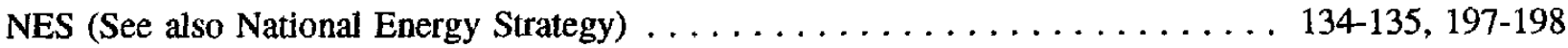
Newspapers . . . . . . . . . . . . . . . . . 59-61, 64, 67-68, 183, 188-189, 350

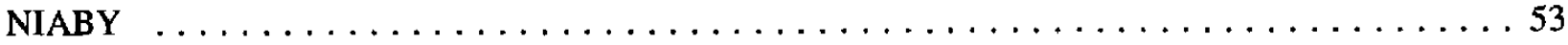

NIMBY syndrome . . . . . . . . . . . . . . . . . . . . . . . . . . . 28 28 29

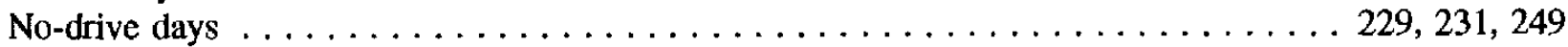

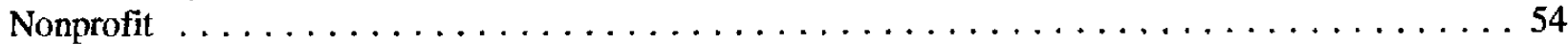

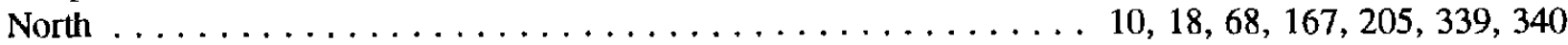

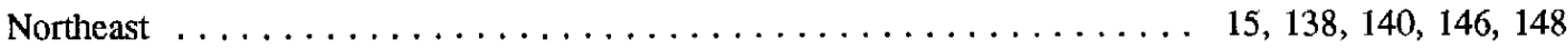

NEPA (See also National Environmental Policy Act) $\ldots \ldots \ldots \ldots \ldots \ldots \ldots \ldots \ldots$

NREL (See also National Renewable Energy Laboratory) . . . . . . . . . . . . . . . . 6, 187

Nuclear accident(s) $\ldots \ldots \ldots \ldots \ldots \ldots \ldots 1,5,133,152,166,168-169,172,176,179-180,340$ 


\section{Index (Continued)}

Nuclear energy (See also nuclear power) $\ldots \ldots \ldots \ldots \ldots \ldots$.5 . 48, 70, 133-135, 142-147, $149,151,153,156-160,165-172,174,178-180,299,337$

Nuclear industry . . . . . . . . . . . . . . . . . . . . 166-167, 179-180

Nuclear power (See also nuclear energy) $\ldots \ldots \ldots \ldots \ldots \ldots .12,16,19,34,39-40,89,93$, $120,127,135,137-139,147,150-152,156-157,159-161,166-180,256,298,337-338,343,351$

Nuclear power industry $\ldots \ldots \ldots \ldots \ldots \ldots \ldots \ldots \ldots \ldots \ldots \ldots \ldots$. 120, 167, 177

Nuclear power plant(s) . . . . . . . . . . . 19, 34, 39-40, 88, 135, 137, 159, 161, 166-180, $337-338,343$,

Nuclear proliferation . . . . . . . . . . . . . . . . . . . . . . . . . . . . . . . . 179

Nuclear regulation . . . . . . . . . . . . . . . . . . . . . . . . . 40, 179

Nuclear safety . . . . . . . . . . . . . . . . . . . . . . . 172, 177-178

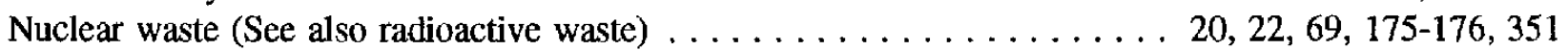

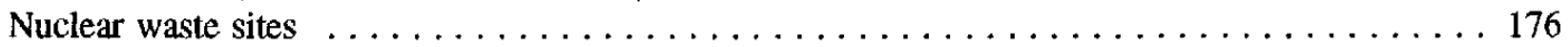

Nuclear weapon(s) $\ldots \ldots \ldots \ldots \ldots \ldots \ldots \ldots \ldots \ldots \ldots \ldots \ldots \ldots \ldots \ldots$ 14, 71, 74-76, 170, 178

$\underline{\underline{O}}$

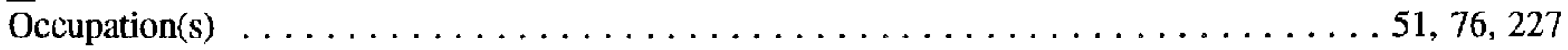

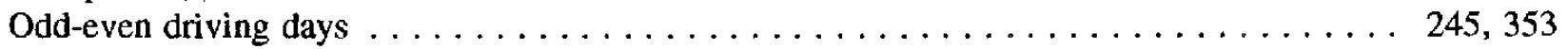

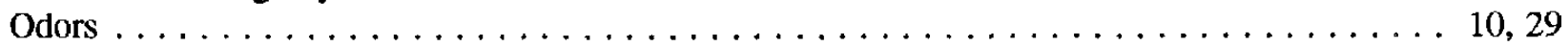

Office(s) . . . . . . 1, 4-6, 70, 72, 80-81, 129, 135, 150, 188-192, 280, 288-291, 296-297, 344

Offshore oil $\ldots \ldots \ldots \ldots \ldots \ldots \ldots \ldots \ldots \ldots \ldots \ldots \ldots \ldots \ldots$ 42-43, 137, 143-146, 202, 208-211

Oil (See also petroleum) . . . . . . . . . 9-12, 14-22, 24-25, 34, 36, 39-40, 42-45, 47-48, $50,52,59-60,62,70-84,85-87,89,92-93,96,103-109,113-118,120-127,130,132-133$, $135-140,143-144,146-153,157-162,164-165,170,172,177,180,184,202-212,219,229-232$, $237-250,252,255,257,296,298-299,333,335,337,339-340,343-345,350-352$

Oil company(-ies) (See also oil industry) $\ldots \ldots \ldots \ldots \ldots \ldots, 45,72,74,81,85,105$, $106,108-109,113-118,120-125,127,130,135-136,184,202,205,208-209,230,237,239-243$, $339,345,350-351$

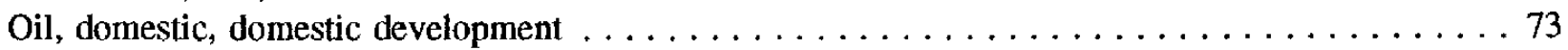

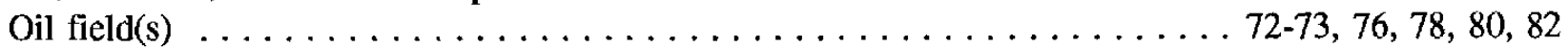

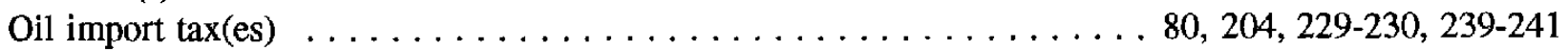

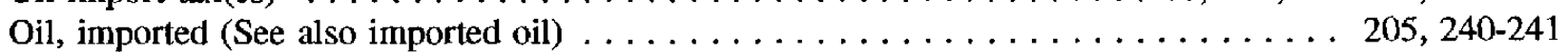

Oil imports (See also imported oil) $\ldots \ldots \ldots \ldots \ldots \ldots \ldots \ldots \ldots \ldots, 4,6,72,79,87,93,136$,

$158,162,202,204-207,240-241$

Oil industry (See also oil companies) . . . . . . . . 1, 104, 113, 116, 118, 120-125, 127, $130,230-231,237,240,243$

Oil price(s) $\ldots \ldots \ldots \ldots \ldots \ldots \ldots \ldots \ldots \ldots \ldots \ldots \ldots \ldots \ldots \ldots$, 72-74, 77, 79, 85, 89, 103-104, $106-109,113,115,125,237-238,242$

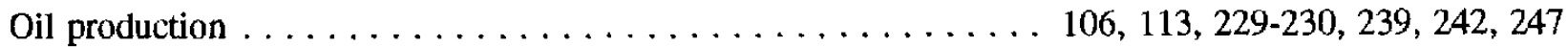
Oil spill(s) $\ldots \ldots \ldots \ldots \ldots \ldots 9,17-19,21-22,24,52,72,123,133,144,202,208-210,340,343$

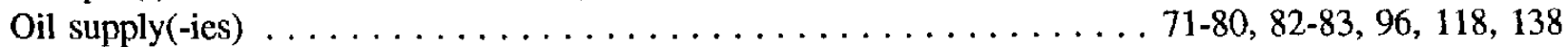

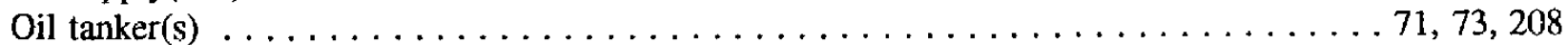

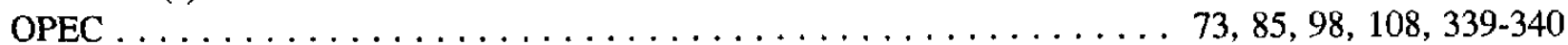
Opinion leaders $\ldots \ldots \ldots \ldots \ldots \ldots \ldots \ldots \ldots \ldots \ldots \ldots$ 141-142, 177, 188, 201, 230 Option(s) $\ldots \ldots \ldots \ldots \ldots \ldots \ldots \ldots \ldots \ldots \ldots \ldots, 10 \ldots \ldots \ldots$ 12, 16-17, 24, 28, 39, 42, 45-49, $60,62,65,68,133,135-137,139-141,143,146-148,150-153,157,159,161,164-165,167,191$, $198-200,209-210,214,221,229-232,234,236,239-243,245,247-249,251-253,330$ 


\section{Index (Continued)}

Organization(s) $\ldots \ldots \ldots \ldots \ldots \ldots \ldots 1-3,6-8,11,17,20,25-26,31,38,52-57,59,61,66-67$, $73,85,94,102-103,107-109,113,115,117,121,123,126,131,143-144,168,175,180-181$, $189,192,196,202,207,231,238,245,250,256,295,297-298,339,345-346,351,353$

Organization of Petroleum Exporting Countries (See also OPEC) $\ldots \ldots \ldots \ldots \ldots \ldots$. . . . 85, 339 Overpopulation . . . . . . . . . . . . . . . . . . . . . . . . . . 92-94 Ozone $\ldots \ldots \ldots \ldots \ldots \ldots \ldots$ 9-10, 17-20, 22, 24, 29-30, 32-33, 35, 43-44, 52-53, 68-69, $94,169,200,256,339,341,343,347,350$

Ozone depletion $\ldots \ldots \ldots \ldots \ldots \ldots \ldots \ldots \ldots \ldots \ldots \ldots \ldots \ldots \ldots \ldots, 7,9,18,20,24,29,30,32-33,53$, $68,256,339,341$

Ozone hole (See also ozone depletion) $10,68,341$

Ozone layer (See also ozone depletion) $17,19,24,30,32,35,43-44$ $68-69,169,200,341,343,347,350$

$\underline{\mathbf{P}}$

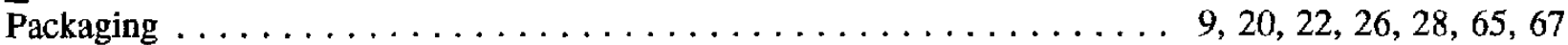

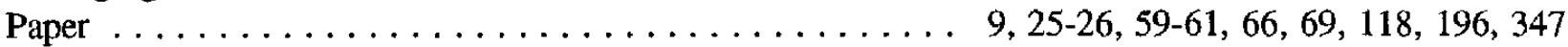

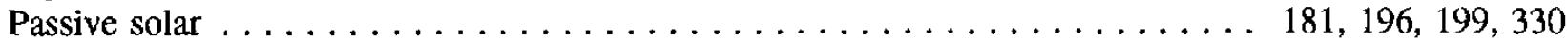

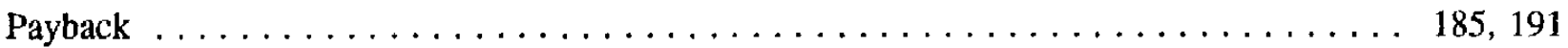

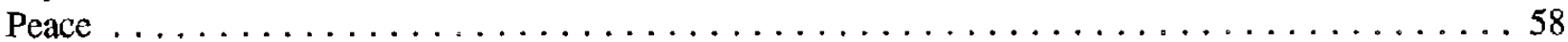

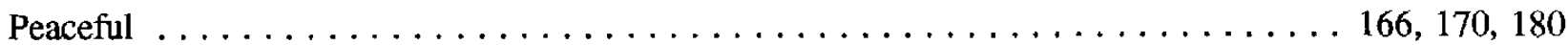
Performance ................ 114, 129-131, 178, 203, 220, 226-227, 252-253

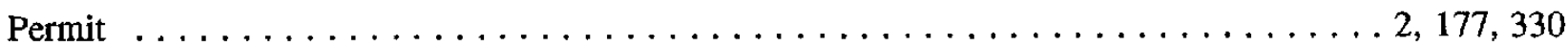

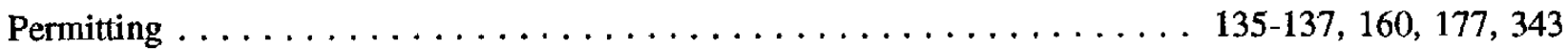
Persian Gulf war (See also Gulf war) $\ldots \ldots \ldots \ldots \ldots \ldots 1-5,7,71,81,83,125,133,237,240$

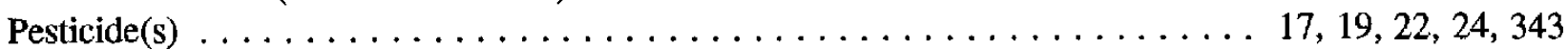
Petroleum (See also oil) $66,73,80,85,93,157,202,205-207,229$, $231,243,296,339$

Photovoltaic(s) $151,157,331$

Plants $135,137-138,140,157,159-161,163,167,169-173,175-180,186-187,257,337-338,343$, $347-348$

Plastic(s) .

$9-11,26,58,60-61,64,66-67,196,350$

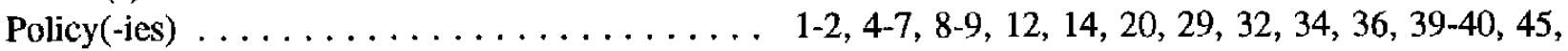
$47,50,53,58-60,62,64,72,74,80,82,89,93,98,102,114,116-117,124,127,131,133-139$, $141-142,157-160,165,167-169,175,181,183-184,186-187,197-201,204,209-210,217$, 229-232, 236-243, 245, 247-253, 256-257, 298-299, 333, 340, 345

Policy preference(s) [See also specific policies or policy options (e.g., carbon taxes)] . . 4-5, 7, 9, 32, 34, $60,64,93,114,127,139,158-159,165,181,197-199,201,229-230,243,248,298-299,345$

Policymakers $1-3,6,168,256$

Political $9,57-58,115,164,243$

Pollutants (See also air pollution, water pollution) $\ldots \ldots \ldots \ldots \ldots \ldots$ 19-20, 40, 341, 343

Pollution (See also air pollution, water pollution) $\ldots \ldots \ldots \ldots \ldots \ldots \ldots \ldots$ 8-9, 11-12, 14, $16-24,29-32,35-36,39-40,43-47,49-51,55,58,62,65,68-70,93-94,97,158-161,163,172$, $176,203,219,222,225,234,244,246,250,253,255-256,353,337,341,343-346,350-352$

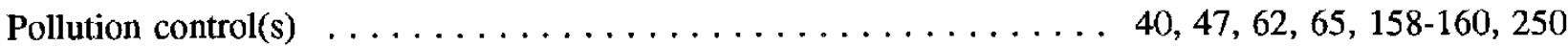

Pollution regulation $\ldots \ldots \ldots \ldots \ldots \ldots \ldots \ldots \ldots \ldots \ldots \ldots \ldots \ldots \ldots \ldots \ldots \ldots$. $\ldots \ldots \ldots$. $4 \ldots \ldots$

Population, overpopulation ........... $212,214-215,248,295,297,300$ 


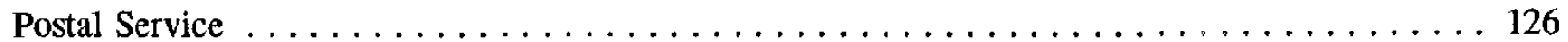
Poverty $\ldots \ldots \ldots \ldots \ldots \ldots \ldots \ldots \ldots \ldots \ldots \ldots \ldots \ldots \ldots \ldots \ldots \ldots \ldots \ldots \ldots \ldots \ldots \ldots, 86,94$

Power $\ldots \ldots \ldots \ldots \ldots \ldots \ldots \ldots \ldots$ 8-9, 12, 16, 18-19, 28, 30, 34-35, 39-40, 43-45, 47-48, $69,80,82,89,93,114-117,120,124,127,129-131,133,135,137-140,144,146-147,149-152$, 156-157, 159-161, 163, 165-180, 186-187, 191, 198, 203, 219, 221-222, 227-228, 230, 256, 298, $337-338,340,343,347,351$

Power plant(s) $\ldots \ldots \ldots \ldots \ldots \ldots \ldots \ldots \ldots$ 8, 12, 18-19, 22, 28, 34-35, 39-40, 43, 47-48, $69,88,133,135,137-138,140,157,159-161,163,165-180,186-187,337-338,343,347$

Practice $10,179,183,189,197,257$

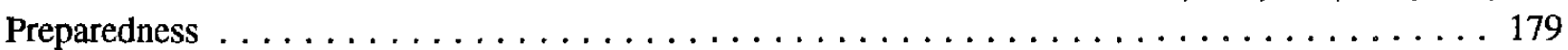

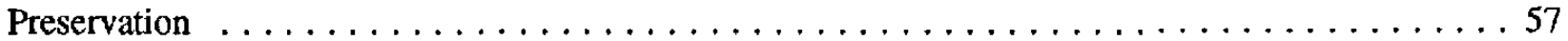
Preserve $\ldots \ldots \ldots \ldots \ldots \ldots \ldots \ldots \ldots \ldots \ldots \ldots \ldots \ldots 41,55-56,58,184,214$ President Bush (See also Bush, President George) . . . . 32, 68, 70, 79, 103, 120, 125, 134, 139, 349 President Carter (See also Carter, President Jimmy) . . . . . . . . . . . . . . . . 299, 340 President Reagan (See also Reagan) $\ldots \ldots \ldots \ldots \ldots \ldots \ldots \ldots \ldots \ldots \ldots$ 114, 124, 143, 349 Price(s) $\ldots \ldots \ldots \ldots \ldots \ldots \ldots \ldots \ldots 10-12,34,39-40,42,45,47,50,52,62,65,72-80$, $82-83,85-86,89,96,98,103-109,113-115,118,120,123-125,127,130-133,157,159-160,163$, $183,185,197,203,212,221-222,225,227,229-230,232,236-238,240-242,245,248,252-253$, $256,298,333-335,339-341,345,346,350$

Price control(s) . . . . . . . . . . . . . . . . . . . . . . . 229-230, 237-238 Price increases . . . . . . . . 1, 72, 79, 103-104, 107, 118, 125, 163, 229, 238, 248, 340

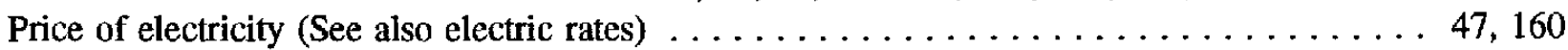
Price of gasoline (See also oil prices) $\ldots \ldots \ldots \ldots \ldots \ldots \ldots \ldots \ldots \ldots \ldots \ldots \ldots, 45,65,78-80,103,109$, $113,123-125,230,237-238,240-241,334$

Price of oil (See also oil prices) $1,4-5,45,76-78,82$, $105,108,118,125,238$

Price supports 236

Priority(-ies) $14,33,39,98,114,126,146-148,182,184,201$

Private sector $53-54,256$

Procedure(s) $1-2,5-6,180,295,300$

Product(s) . . . . . . . . . . 11, 15, 28, 34, 39-40, 54, 57-59, 61, 66, 68, 95, 102, 113-114, $116,121,132,157,165,178,202,209,221,237-238,241,257,341$

Production $\ldots \ldots \ldots \ldots \ldots \ldots \ldots \ldots \ldots \ldots \ldots$ 1-2, 5, 8-9, 12, 14-15, 20, 22, 35, 39, 69, 73, 86, $102,106,113-114,124,130,133-141,149,157,161-162,178,205,229-230,239-240,242,247$, $255-257,340$

Profit(s) $72,74,80-81,106,109,113-114,116,123$, $130-132,134,158-160,184,229-230,241-242,296,345$

Program(s) $\ldots \ldots \ldots \ldots \ldots 1,11,28,32,59-60,64,97,100-102,114,126-127,129,131,136$, $142,158-160,165,170,188-189,191-192,198,201,209-210,215-217,234,236,240,246,248$, $255-258,329,331,333-334$

Propane 227,255

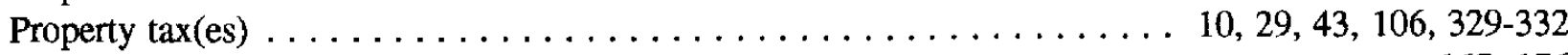

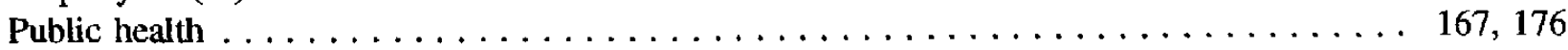

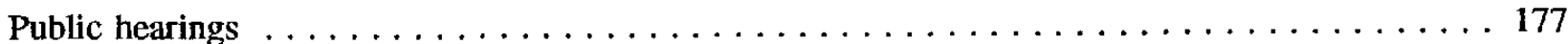

Public interest . . . . . . $199,230,236-237,239,241,243,246$

Public sector 


\section{Index (Continued)}

Public transportation (See also mass transit)

$58,65,106,212-215,217-218$, $234,250-252,296$

Purchase(s)

$11,192,202-203,214,221-222,225,227,243,247,249,257$

Q

Quality . . . . . . . . . . 2, 4, 6, 8, 11-14, 17, 20, 22, 24, 29, 47, 52-53, 55, 58-59, 65, $94-98,114,121,129-132,157,162-163,177,188,191,203,213,218,220-221,225-226$, $243-245,248,252,254-255,352$

Quality of life [See also standard(s) of living]

$\underline{\mathbf{R}}$

R\&D

$98,101,114,127,134-135,146,159,165,170,199,246,345$

Radiation $17,19-20,166,169,172,176,178,337,343-344$

Radio $188-189,292$

Radioactive $19,69,159,161,166,169,172-173,175-176,178,180,343$

Radioactive waste(s) (See also facility siting, nuclear waste)

$19,159,161$, $172-173,175-176,180,343$

Radioactivity $159,166,180$

Radon $17,20,344$

Rain forest(s)

Range . 16-18

Rate(s) $18,32,47,53,86,89,95,106,124,203,218,227-228,339$

$166-167,182,191,208,226,234,236,331,342$

Reagan (See also President Reagan) $8,114,124,143,145,349$

Reason(s) (See also decision factors)

$113-115,121,125,132,165,174,181,185-186,189,203,212-213,216,218,222,225-226,296$

Rebate(s) $69,136,160,200,225-227,247,348$

Recession $72,78,339$

Recreation

Recreational

Recycle $55,70,214-215,348-349$

Recycling $1,32,59-62,64,66,69,350$ 347,350

Reducing dernand $5,133,138,160$

Reforestation 12,34

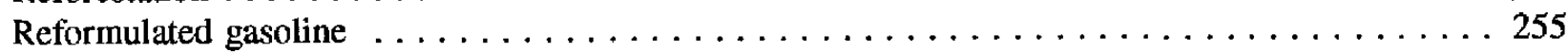

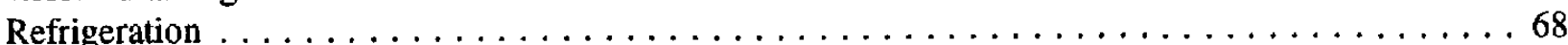

Region(s) $14-15,59,74,83,139-140,146-148$

Regulate(d) $40,70,88,113,124,131,200,243,348$

Regulating $40,113-114,131,160,178-180,237-239,242$

Regulation(s) . . . . . . . 11, 35, 39-40, 47, 49-50, 60, 64-65, 67, 70, 102, 113-114, 123-124, $130-132,135-138,142,159-160,178-179,205,208,229-232,237-239,242-245,252,346$

Regulators $136,160,178$

Relative advantage $5,9-12,21,24,26,28,53,57-62,64,66-69,218,256,300$,

Reliability

Reliance $\ldots \ldots \ldots 114,129,186,203,225-226$

Renewable energy technologies $85,89,133,152,163,187,208,212,257$ Republicans $1,143,147,149,151,201,256,298-299$ 


\section{Index (Continued)}

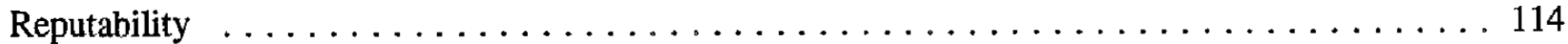

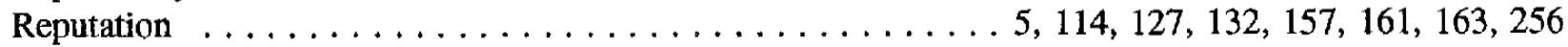
Require $\ldots \ldots \ldots \ldots \ldots 11,28,33,43,45,64-65,69,136,139,199-200,232,244-246,248$, $252-253,255,347,350,352-353$

Requirements $34-36,43,68,188,246,255,346$

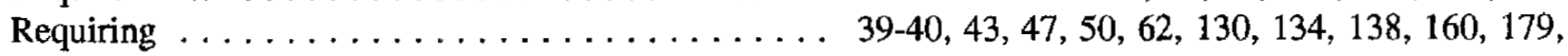
$198,231-232,242-243,246,249-250,252-253$

Research and development (See also R\&D) $72,98,101,114,134,146-147,159$ $163,197,246$

Research gap(s) (See also gaps) . . . . . . . . . . . . . . . 184, 204, 231-232, 253, 295

Residential . . . . . . . . . . . . . . 3, 5, 133, 160, 181-183, 186-187, 189, 192, $196-197,201,257,290,329-332$

Residential Conservation Service Program (RCS) $\ldots \ldots \ldots \ldots \ldots \ldots \ldots \ldots \ldots \ldots$

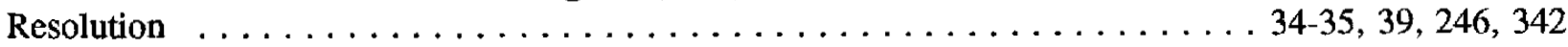

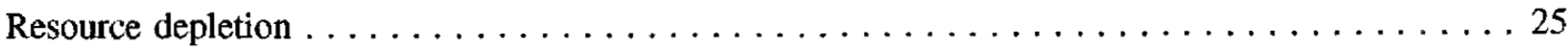

Resource recovery . . . . . . . . . . . . . . . . . . . . . . . . . 66-67

Resources . . . . . . . . 12, 21, 23, 25, 39, 52, 55-56, 62, 72, 85, 114, 126-127, 147-148, $165,172,185,187,191,196,199,214,230,242$

Responsibility(-ies) . . . . . . . . . 4, 53, 113-116, 127, 175, 179, 192, 257, 299, 340 Restrictions . . . . . . . . . . . . . . 8, 42-43, 48, 64, 94, 209-210, 231, 248-249, 345

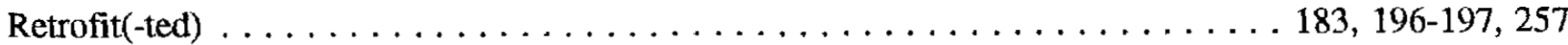
Revenue(s) . . . . . . . . . . . . . . . . . . 197, 230, 234, 236, 243, 334-335 Review (of public opinion) (See also earlier reviews) $\ldots \ldots \ldots \ldots \ldots \ldots$ 6 182, 238, 295

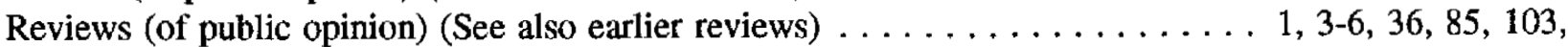
$113-114,133,161,166,184,188,191-192,204,212,214,229,237,245,247-248,250,295$

Ridesharing (See also car pooling) . . . . . . . . . . 214, 216-217, 229, 231, 248, 296 $\operatorname{Risk}(\mathrm{s})$ (See also environmental threat; threat) $\ldots \ldots \ldots \ldots \ldots 17,19,39,72,80,146,152,156$, $159,163,167-169,172,174-175,178,180,184,209-210,299$

Role(s) . . . . . . . . . . . . 34, 93, 113-114, 124, 126-127, 129, 131, 142-143, 151, $157,165,189,199,209,225,257,299$

Rule(s) $12,34,45,70,159,178,252,346$

$\underline{S}$

Sacrifice(s) $40,47,64,80,146,214,350-351$ Safe . . . . . . . . . . . . . 43, 68-69, 153, 174-175, 177-179, 203, 209, 220, 247 Safeguard(s) Safety $338,340,346$

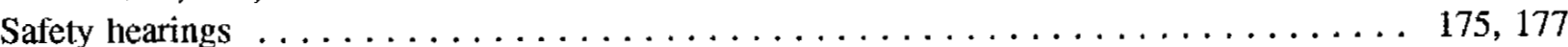
Salience . . . . . . . . . . . . . . . . . . . 4-5, 86, 94-95, 97-98, 102, 349 Sample . . . . . . . 7, 14, 17, 20, 24, 26, 28-30, 33-36, 39, 42-43, 45, 47-50, 53, 55-60, 62, $67-70,72-73,83,86-87,93,95,97,104,106,115-117,124,126-127,129-132,134-135,138-140$, $142-143,147,152,160,163,165,167,170,177-180,182-191,197-199,204-206,209-210$, $212-213,216-222,225,227-228,232,234,236-238,240-243,245-253,255,297,300,350$

Sampling $12,45,130,153,159,169,172-175,177-180,203,227,256$, $1-2,6,98,143,210,297$

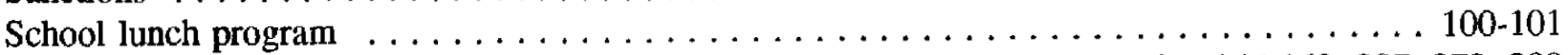
Science $11,95,98,127,167-169,297,272,288$ 


\section{Index (Continued)}

Scientists

$11,31-33,68,165-166,180,270,272,341$

Scrap

59,136

Scrubbers

$161,244,352$

Sea levels

. . 341

Search

$2,6,9,113,116,295-297,300$

Service

$160,167,189-190,197,220,251,295,297$

Severance tax(es)

229-230, 242

Severity

$3,5,17-18,23,26,35,57,83,85-86,88-89,93,197,298$

Sewage

$17,19,24,28,343$

Shale oil (See also oil shale)

$144-146$

Shareholders

$47-48$

Shipping 208

Shortage(s) (See also energy shortage, gasoline shortage)

$16,24,36,56,71-72$, $78-80,85-86,89-90,93-96,98,115,135,140,161,183-184,186-187,197,216,218,227,237$, $243,245,249$

Site energy

Siting decision(s) (See also facility siting)

. 181

"Smart" houses

29,176

Social

$70,200,348$

Social movement

$9,11,14,29,53,101,160,219,236,240,280,290,341$

Social Security

$236,240,280$

Society

$9,11,52,54,58,113-114,169,250,282$

Soil

$17-18,24,166,252,343$

Soil quality

$17,24,166$

Solar domestic hot water . . . . . . . . . . . . . . . . . . . . . . . . . . . . 181, 199

Solar energy

$6,70,127,142-147,149$ 150-152, 181-184, 186-189,

$191-192,197,199,329$

Solar energy systems

Solar heating 151,351

Solar homeowners

$186-187$

Solar screens 196

Solar tax credits

$136,197-198,329-330$

Soldiers (See also troops)

Solid waste (See also municipal solid waste)

$43-44,62,65-67,147,150,152-153,257,343,350$

Source electricity

Source energy

181-182

South

$14-15,138,140,146,148,341,351$

Space

$5,38,59,101,178,182,244,252,297,352$

Species

$18,22,55-57,351$

Spending

240-241, 250-251, 334-335

SPR (See also Strategic Petroleum Reserve)

$229,231,243,245$

Stability

$98,114,127$

Stabilization

107,114

Stabilize

$114,340,342$

Stable

$85,89,197$ 


\section{Index (Continued)}

Standard of living $\ldots \ldots \ldots \ldots \ldots \ldots \ldots \ldots \ldots \ldots \ldots \ldots \ldots \ldots \ldots \ldots \ldots \ldots, 42,50$

Standards (See also type of standards; e.g., efficiency standards, CAFE standards) . . . 80, 134, 136, $138-139,159,163,180,197-198,220,229,231,244-247,250,255,296,298,346,352$

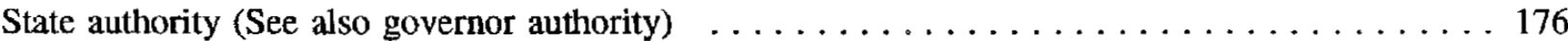

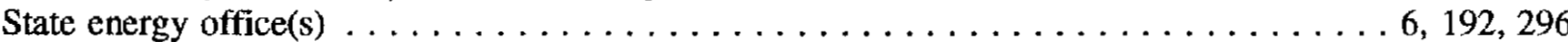

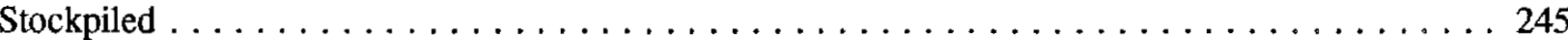

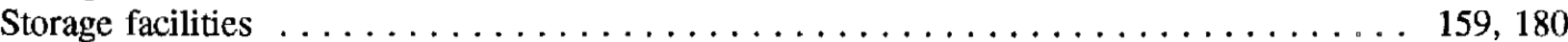

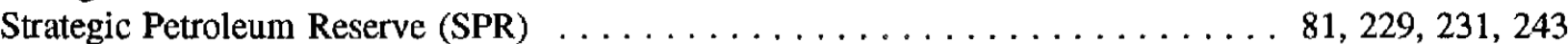

Stratospheric ozone depletion (See also ozone depletion) $\ldots \ldots \ldots \ldots \ldots \ldots \ldots$ 1-5, 9, 29-30, 256

Styrofoam . . . . . . . . . . . . . . . . . . . . . . . 9, 26, 61-62, 65-67

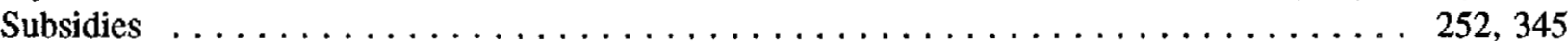

Sulfur dioxide $\ldots \ldots \ldots \ldots \ldots \ldots \ldots \ldots \ldots \ldots \ldots \ldots \ldots \ldots \ldots \ldots \ldots \ldots$

Summit $\ldots \ldots \ldots \ldots \ldots \ldots \ldots \ldots \ldots \ldots \ldots \ldots \ldots \ldots \ldots \ldots \ldots \ldots \ldots \ldots, 33,80 \ldots \ldots$

Suppliers $\ldots \ldots \ldots \ldots \ldots \ldots \ldots \ldots \ldots \ldots \ldots \ldots \ldots \ldots \ldots \ldots \ldots \ldots \ldots \ldots, 125$

Supply(-ies) $\ldots \ldots \ldots \ldots \ldots \ldots \ldots \ldots 9-10,14,16,24,36,38-39,71-76,78-80,82-83,85,89$, $93-94,96,98,113-114,116,118,127,133-135,137-139,141-144,146,150,152-153,160-162$, $164-168,184,186-187,199,205,238,244-245,297-298,352-353$

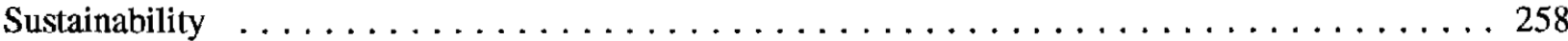

Sustainable development (See also economic development) $\ldots \ldots \ldots \ldots \ldots \ldots \ldots \ldots$

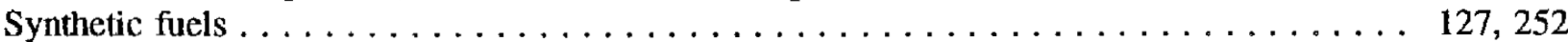

System(s) $\ldots \ldots \ldots \ldots \ldots \ldots \ldots 4,7,28,32,34,58,69-70,93,102,118,158,162,165,178$, $181-183,189,191-192,197,199-201,203,219,251,257-258,297,329-331,348$

$\underline{T}$

Tax(es) (See also type of tax, e.g., carbon tax, gasoline tax) $\ldots \ldots \ldots \ldots \ldots 10,12,16,29,32$, $34,39-40,42-45,48,64,73,81,83,97,102-104,106,126,130,135-137,183,186-187,192$, $197-198,201,205,212,227,229-234,236-242,247,257-258,296,298,329-336,339,345,350$

Tax break(s) $136,186,239$

Tax credit(s) ............. 136, 183, 187, 192, 197-198, 201, 227, 247, 329-331

Tax on imported oil (See also oil import taxes) . . . . . . . . . . . . . 81, 135, 240-241

Technology(-ies) . ........... 1-2, 6, 11, 28, 39, 56-57, 68-69, 95, 98, 127, 134, 143, $146,148,151,161-163,165,168,180-181,184,199,201,232,246,256,297-299,345$

Television

$118,121,130,188-189$

Territory

Terrorism

Thermostat $182,184,192,196$

Third World (See also developing countries) $\ldots \ldots \ldots \ldots \ldots \ldots \ldots \ldots \ldots \ldots \ldots$ 14, 98 Threat (See also environmental threat) $\ldots \ldots \ldots \ldots \ldots \ldots \ldots \ldots \ldots \ldots \ldots \ldots \ldots, 14,20,22,29,33,68$, $70,72,74,79-80,83,89,147,150,152-153,161,163,172,255,337$

Three Mile Island (TMI) (See also TMI) . . . . . . . . . . . . . . . . . 1, 89, 145, 166, 173-174

Tires 26,184

TMI $166,170,174,178$

Total fuel cycle $\ldots \ldots \ldots \ldots \ldots \ldots \ldots \ldots \ldots \ldots \ldots \ldots \ldots \ldots \ldots \ldots \ldots$

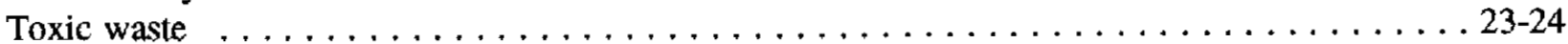

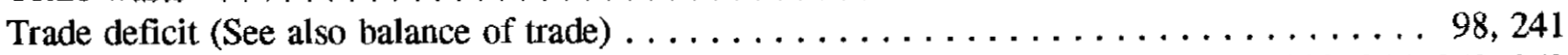
Trade-offs . . . . . . . . . 9-11, 16, 36, 39, 41-43, 49-50, 55, 62, 64-65, 298, 346, 350, 352

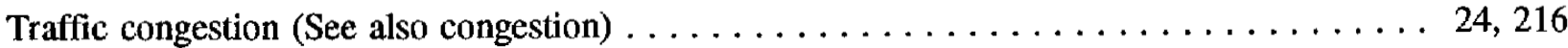
Transmission lines 


\section{Index (Continued)}

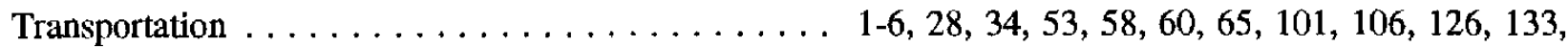
$157,166,201-204,210,212-219,225,229,231-232,234,241-242,247-248,250-252,296-297$, 299-300

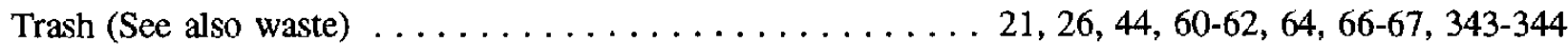

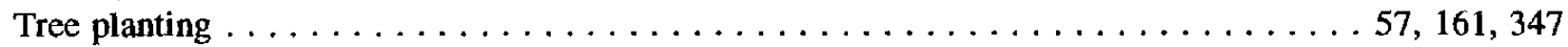

Trees (See also deforestation, rain forest, reforestation) $\ldots \ldots \ldots \ldots \ldots \ldots 25,34,69,347$

Trend(s) $\ldots \ldots \ldots \ldots \ldots \ldots \ldots \ldots, 7,13,17,25-26,30-31,36,38,40,43,49,60-61,64,67$, $85-86,88,94,96-97,101,115-116,118,120,122,124,126,132-133,141,143,146,152,156$, $159,161-162,163-164,170-175,181,185,188-190,192,202,204,214-215,222,237,239,248$, $251,295,345,346$

Troops $71,73-74,76,78,80,82-84,95$

Trust $45,96-97,113,127,159,169,180,232,257-258$

$\underline{U}$

Unemployment $85-86,95,97-98,109,351$

United Nations $34-35,246$

University(-ies) $8,190,257,297-298$

Uranium 242

Utility (See also electric utility, electric company, gas company) . . . . . . . . . . . 1-2, 4-6, $12,28,47-48,60,64-65,69-70,85-86,89,92,98,107,109,113-114,122,124,127,129-131$, $136,146,150,157-161,163,166-170,175,177,179-192,197-199,209,222,244,253,257$, $297-298,300,345-349,352$

Utility bills (See also electric bill) . . . . . . $187,244,257$

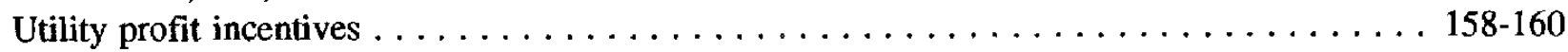

$\frac{\mathrm{V}}{\text { Valdez }}$ $18,52,84,89,123,144-145,202,208-210,340$

Value $105-107,114,121,130-132,187,222,251,255,329-330$

Vehicle(s) (See also automobiles, cars) . . . . . . . . . $212,214-215,217,219-220,222,225,227-232,247,249,252-253,255-256,296$

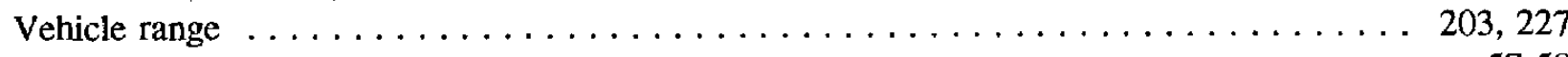

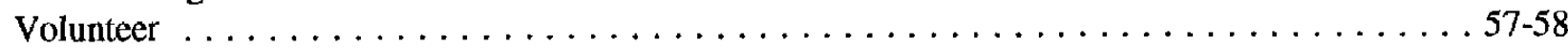

Voter(s) $\ldots \ldots \ldots \ldots \ldots \ldots 1,4-8,11,29,36,47,57,93,124,141-143,146,149,151,160$, $165,170,175,199,214,225,234,236,239,241,243,246,248$

$\underline{W}$

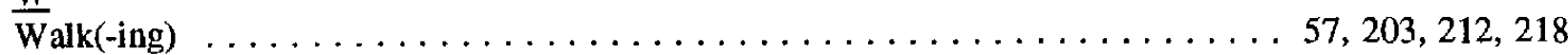

War (See also conflict, combat, hostilities) $\ldots \ldots \ldots \ldots \ldots \ldots \ldots, 71-74,76-86,93,98$, $118,124-125,133,240,245,340$

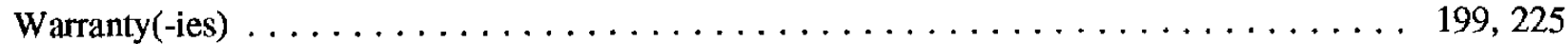

Waste (See also municipal solid waste) $\ldots \ldots \ldots \ldots \ldots \ldots 5-6,9-11,17,19-24,26-29,43-44$, $59-60,62,65-67,69-70,97,147,152-153,157,159,172-173,175-176,180,196,257,300,338$, $343-344,346,348,350-351$

Waste disposal $9,11,21,24,26,28,43,66-67,76,175-176$

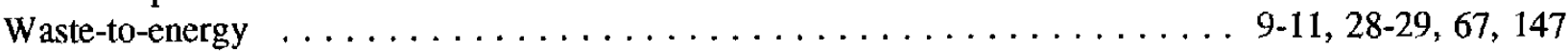

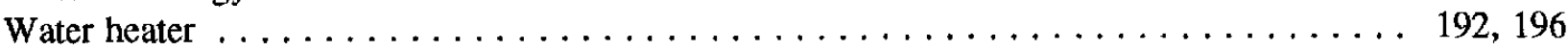

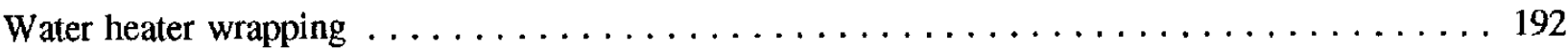




\section{Index (Continued)}

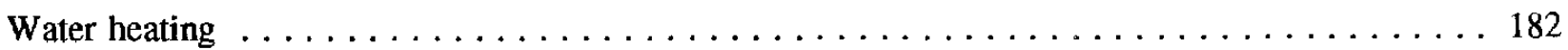

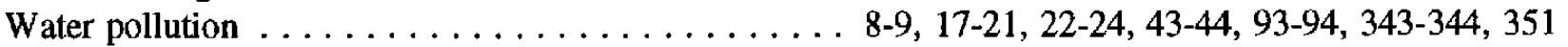

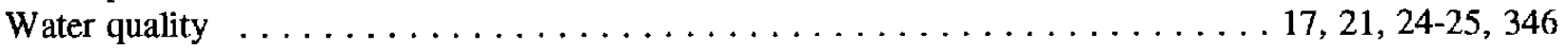

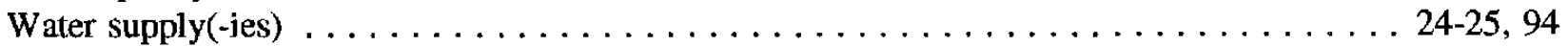

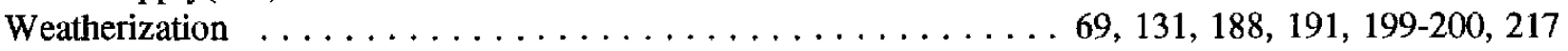

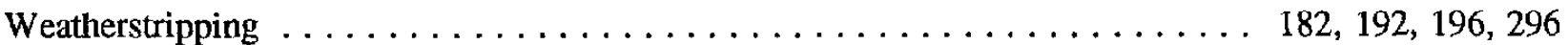

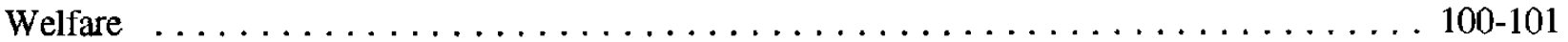

West $\ldots \ldots \ldots 14-15,18,80,138,140,146,148,161,170,185,188-191,210,214-215,291,341$

Wetlands . . . . . . . . . . . . . . . . . . . . . . . . 19-20, 343

Wilderness ................ 11, 20, 22, 24-25, 43-44, 50, 52, 72, 137-138

Wilderness areas $\ldots \ldots \ldots \ldots \ldots \ldots \ldots \ldots \ldots \ldots \ldots \ldots \ldots \ldots \ldots, 22,24-25,43,50,72,137-138$

Wildlife $\ldots \ldots \ldots \ldots \ldots \ldots \ldots \ldots \ldots \ldots \ldots \ldots 11-12,24-25,39,50,52,55,57,69,135,137,161$, $203,208,210-211,347$

Willingness to pay $\ldots \ldots \ldots \ldots \ldots \ldots \ldots \ldots \ldots \ldots \ldots \ldots \ldots 12-47,50,157,191,222,350$

Wind $\ldots \ldots \ldots \ldots \ldots \ldots \ldots \ldots$ 12,44-45, 79, 140, 143-151, 157, 160, 169, 181, 186, 198, 331

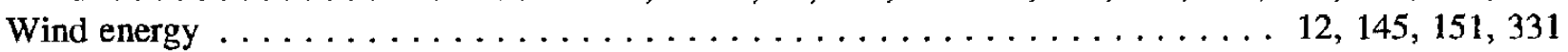

Wind power $\ldots \ldots \ldots \ldots \ldots \ldots \ldots \ldots \ldots \ldots \ldots \ldots 44-45,140,144-147,149,198$

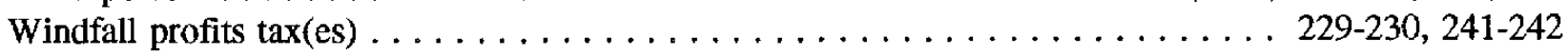

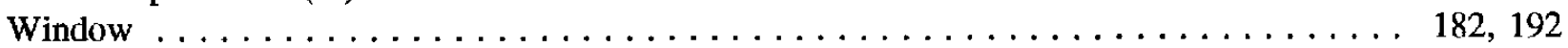

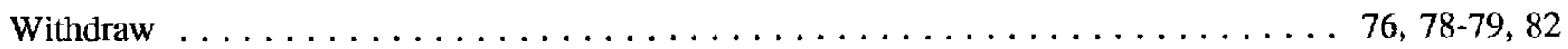

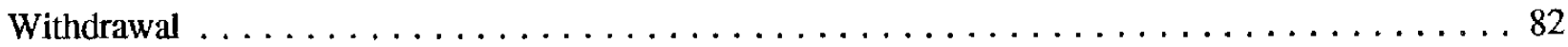

Women . . . . . . . $199,219,236,239,241,243,246$

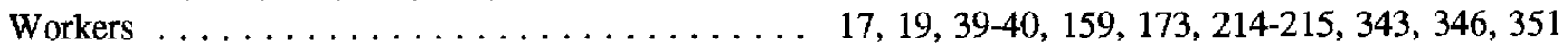

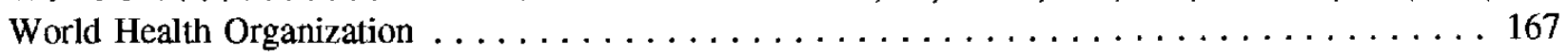

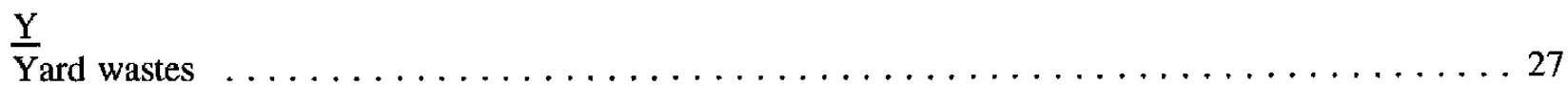




\begin{tabular}{|c|c|c|c|}
\hline $\begin{array}{c}\text { Document Control } \\
\text { Page }\end{array}$ & $\begin{array}{l}\text { 1. NREL Report No. } \\
\text { NREL-TP-461-4857 }\end{array}$ & $\begin{array}{l}\text { 2. NTIS Accession No. } \\
\text { DE93000069 }\end{array}$ & 3. Reciplent's Accession No. \\
\hline \multirow{2}{*}{\multicolumn{3}{|c|}{$\begin{array}{l}\text { 4. Title and Subtitle } \\
\text { Trends in Public Perceptions and Preferences on Energy and } \\
\text { Environmental Policy }\end{array}$}} & $\begin{array}{l}\text { 5. Publication Date } \\
\text { February } 1993\end{array}$ \\
\hline & & & 6. \\
\hline \multicolumn{3}{|l|}{$\begin{array}{l}\text { 7. Author(s) } \\
\text { B.C. Farhar }\end{array}$} & 8. Performing Organization Rept. No. \\
\hline \multirow{2}{*}{\multicolumn{3}{|c|}{$\begin{array}{l}\text { 9. Performing Organization Name and Address } \\
\text { National Renewable Energy Laboratory } \\
1617 \text { Cole Boulevard } \\
\text { Golden, Colorado } 80401-3393\end{array}$}} & $\begin{array}{l}\text { 10. Project/Task/Work Unit No. } \\
\text { AS } 026105\end{array}$ \\
\hline & & & $\begin{array}{l}\text { 11. Contract (C) or Grant (G) No. } \\
\text { (C) } \\
\text { (G) }\end{array}$ \\
\hline \multirow{2}{*}{\multicolumn{3}{|c|}{ 12. Sponsoring Organization Name and Address }} & $\begin{array}{l}\text { 13. Type of Report \& Period Covered } \\
\text { Technical Report }\end{array}$ \\
\hline & & & 14. \\
\hline \multicolumn{4}{|c|}{ 15. Supplementary Notes } \\
\hline \multicolumn{4}{|c|}{$\begin{array}{l}\text { 16. Abstract (Limit: } 200 \text { words) } \\
\text { This report presents selected results from a secondary analysis of public opinion surveys, taken at the national } \\
\text { and state/local levels, relevant to energy and environmental policy choices. The data base used in the analysis } \\
\text { includes about } 2000 \text { items from nearly } 600 \text { separate surveys conducted between } 1979 \text { and } 1992 \text {. Answers to } \\
\text { word-for-word questions were traced over time, permitting trend analysis. Patterns of response were also } \\
\text { identified for findings from similarly worded survey items. The analysis identifies changes in public opinion } \\
\text { concerning energy during the past } 10 \text { to } 15 \text { years. }\end{array}$} \\
\hline \multirow{2}{*}{\multicolumn{4}{|c|}{$\begin{array}{l}\text { 17. Document Analysis } \\
\text { a. Descriptors } \\
\text { energy policy; environmental policy; opinion surveys; policy preferences; public opinion; trends } \\
\text { b. Identifiers/Open-Ended Terms }\end{array}$}} \\
\hline & & & \\
\hline \multirow{2}{*}{\multicolumn{3}{|c|}{$\begin{array}{l}\text { 18. Availabllity Statement } \\
\text { National Technical Information Service } \\
\text { U.S. Department of Commerce } \\
5285 \text { Port Royal Road } \\
\text { Springfield, VA } 22161\end{array}$}} & $\begin{array}{l}\text { 19. No. of Pages } \\
419\end{array}$ \\
\hline & & & $\begin{array}{l}\text { 20. Price } \\
\text { A18 }\end{array}$ \\
\hline
\end{tabular}

